\title{
Cost and Quality of Fuels for Electric Utility Plants 1992
}

\section{August 1993}

\section{Energy Information Administration \\ Office of Coal, Nuclear, \\ Electric and Alternate Fuels \\ U.S. Department of Energy \\ Washington DC 20585}

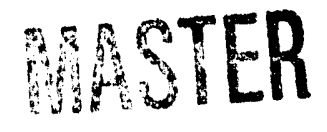

DISTRIBUTION OF THIS DOCUMENT IS UNLIMITED

This report was prepared by the Energy Informat.n: Administration, the independent statistical and analytical agency within the Department of Energy. The information contained herein should not be construed as advocating or reflecting any policy position of the Department of Energy or any other organization. 


\section{Contacts}

The Cost and Quality of Fuels for Electric Utility Plants is prepared by the Energy Information Administration (EIA), Office of Coal, Nuclear, Electric and Alternate Fuels. General questions concerninr, the contents of the report may be referred to Howard Walton
(202/254-5500), Director of the Survey Management Division; Neal Moerschel (202/254-5640), Chief of the Electric Data Systems Branch; and Kenneth McClevey (202/254-5655), survey statistician, Electric Data Systems Branch. 


\section{Preface}

The Cost and Quality of Fuels for Electric Utility Plants $(C \& Q)$ presents an annual summary of statistics at the national, Census division, State, electric utility, and plant levels regarding the quantity, quality, and cost of fossil fuels used to produce electricity. The purpose of this publication is to provide energy decision-makers with accurate and timely information that may be used in forming various perspectives on issues regarding electric power.

\section{Background}

The $C \& Q$ is prepared by the Survey Management Division; Office of Coal, Nuclear, Electric and Alternate Fuels; Energy Information Administration (EIA); Department of Energy. This publication provides comprehensive information concerning the quality, quantity, and cost of fossil fuels used to produce electricity in the United States.

The summarized data in this report are presented for the use of a wide audience including Congress, Federal and State agencies, the electric utility industry, and the general public. The data in this report,collected by the FERC, and published by the EIA to fulfill its data dissemination responsibilities as specified in the Federal Energy Administration Act of 1974 (Public Law 93-275), as amended.

\section{Coverage of Sources}

Data published in the $C \& Q$ are compiled from the Federal Energy Regulatory Commission (FERC) Form 423, "Monthly Report of Cost and Quality of Fuels for Electric Plants." This survey is described in Appendix C, "Technical Notes." A brief summary of the survey follows.

The FERC Form 423 survey is a restricted census which collects monthly data from steam-electric and combined-cycle plantr: with a total generator nameplate capacity of 50 or more megawatts (approximately 230 electric utilities). The 50-megawatt threshold was established by the FERC. The geographic coverage includes the contiguous United States, Alaska, Hawaii, and the District of Columbia. Electric utilities that report on the FERC Form 423 represent approximately 90 percent of all fossil-fuel generating capacity in the United States. 


\section{Contents}

Executive Summary $\ldots \ldots \ldots \ldots \ldots \ldots \ldots \ldots \ldots \ldots \ldots \ldots \ldots \ldots \ldots \ldots \ldots \ldots$

Fossil-Fuel Data at the Census Division and State Level $\ldots \ldots \ldots \ldots \ldots \ldots \ldots \ldots \ldots \ldots \ldots$

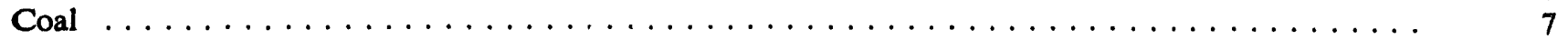

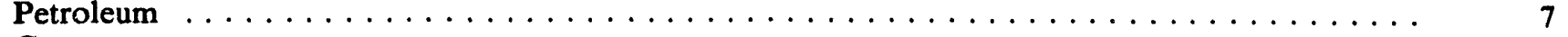

Gas $\ldots \ldots \ldots \ldots \ldots \ldots \ldots \ldots \ldots \ldots \ldots \ldots \ldots \ldots \ldots \ldots \ldots$

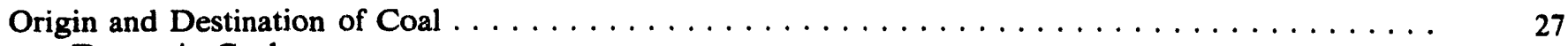

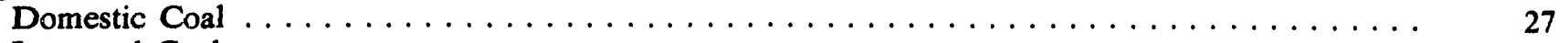

Imported Coal $\ldots \ldots \ldots \ldots \ldots \ldots \ldots \ldots \ldots \ldots \ldots \ldots \ldots \ldots \ldots \ldots$

Fossil-Fuel Data at the Electric Utility and Plant Level $\ldots \ldots \ldots \ldots \ldots \ldots \ldots \ldots \ldots \ldots$

Appendices

A. Electric Utilities Reporting on the FERC Form $423 \ldots \ldots \ldots \ldots \ldots \ldots \ldots \ldots$

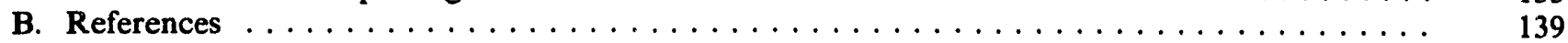

C. Technical Notes $\ldots \ldots \ldots \ldots \ldots \ldots \ldots \ldots \ldots \ldots \ldots \ldots \ldots \ldots \ldots \ldots 143$

Glossary $\ldots \ldots \ldots \ldots \ldots \ldots \ldots \ldots \ldots \ldots \ldots \ldots \ldots \ldots \ldots \ldots \ldots \ldots \ldots \ldots \ldots \ldots \ldots$ 


\section{Tables}

Receipts of Coal by Census Division and State, 1988-1992 . . . . . . . . . . . . . .

2. Average Delivered Cost of Coal by Census Division and State, 1988-1992 . . . . . . . . . Receipts and Average Delivered Cost of Coal by Census Division and State, $1992 \ldots \ldots$ Receipts of Coal by Rank, Census Division, and State, $1992 \ldots \ldots \ldots \ldots$ Receipts and Average Delivered Cost of Coal by Sulfur Content, Census Division and State,

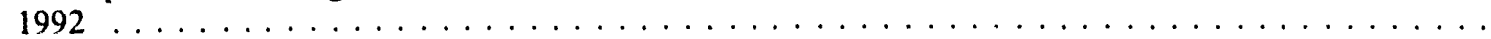
Receipts of Petroleum by Census Division and State, 1988-1992 . . . . . . . . . . . . . . . Average Delivered Cost of Petroleum by Census Division and State, 1988-1992 . . . . . . . Receipts and Average Delivered Cost of Petroleum by Census Division and State, 1992 . . Receipts of Petroleum by Type, Census Division, and State, $1992 \ldots \ldots \ldots$

10. Receipts and Average Delivered Cost of Petroleum by Sulfur Content, Census Division and

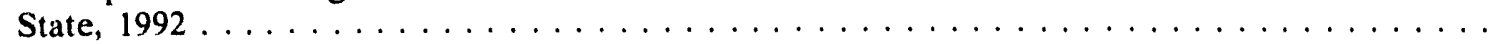

11. Receipts of Gas by Census Division and State, $1988-1992 \ldots \ldots \ldots \ldots$

12. Average Delivered Cost of Gas by Census Division and State, 1988-1992 . . . . . . . . . Receipts and Average Delivered Cost of Gas by Census Division and State, $1992 \ldots \ldots$ Receipts of Gas by Type, Census Division, and State, $1992 \ldots \ldots \ldots \ldots \ldots$ Total Heating Value and Cost of Fossil-Fuels by Census Division and State, $1992 \ldots \ldots$

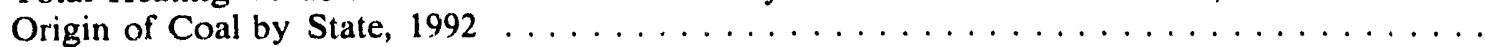
Receipts of Lignite by Electric Utility, $1992 \ldots \ldots \ldots \ldots \ldots \ldots \ldots$ Receipts, Quality, and Average Delivered Cost of Imported Coal, 1988-1992 . . . . . . . . Receipts of Appalachian Region Coal by Electric Utility, $1992 \ldots \ldots \ldots \ldots$ Receipts of Interior Region Coal by Electric Utility, $1992 \ldots \ldots \ldots \ldots$ Receipts of Western Region Coal by Electric Utility, $1992 \ldots \ldots \ldots \ldots$ Destination and Origin of Coal by State, $1992 \ldots \ldots \ldots \ldots \ldots \ldots$ Origin and Destination of Coal by State, $1992 \ldots \ldots \ldots \ldots \ldots \ldots$ Origin of Coal Received by Electric Utility and Plant, $1992 \ldots \ldots \ldots \ldots$ The Top 20 Electric Utilities Ranked by Receipts of Coal, $1992 \ldots \ldots \ldots \ldots$ The Top 20 Electric Utilities Ranked by Receipts of Petroleum, $1992 \ldots \ldots \ldots$ The Top 20 Electric Utilities Ranked by Receipts of Gas, $1992 \ldots \ldots \ldots$ Receipts of Petroleum Coke by Electric Utility, $1992 \ldots \ldots \ldots \ldots$ Receipts of No. 6 Fuel Oil by Electric Utility, $1992 \ldots \ldots \ldots \ldots \ldots$ 29. Receipts and Average Delivered Cost of Coal by Type of Purchase, Electric Utility, and

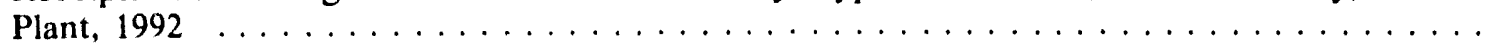

31. Receipts, Average Delivered Cost, and Quality of Fossil-Fuels by Electric Utility and Plant,

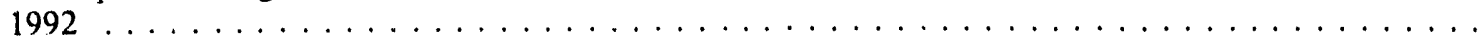

A1. Electric Utilities Reporting on the FERC Form 423 by State $\ldots \ldots \ldots$ 


\section{Executive Summary}

A number of factors appear to have had a notable effect on the volume of receipts and the cost of fossil fuels delivered to electric utilities during 1992 . Variations in annual weather conditions had substantial effects on electric utility fuel purchases. In 1992, a drought in the western United States, Hurricane Andrew in the South, and mild winter and summer temperatures throughout much of the Nation played a major role in determining electric utility fuel requirements for 1992.

The average cost of all fossil-fuels delivared to electric utilities in 1992 was $\$ 1.59$ per million Btu, the lowest average annual cost since $1978 .{ }^{\prime}$ Fuel oil was the most expensive at $\$ 2.55$ per million Btu, natural gas was second at $\$ 2.33$ per million $B t u$, and coal was the least expensive at $\$ 1.41$ per million Btu. The average cost of coal decreased $\$ 0.04$ per million Btu in 1992, fuel oil was unchanged, and natural gas increased $\$ 0.18$ per million Btu. However, since coal accounted for 82 percent of the total Btu content of fossil fuels delivered to electric utilities in 1992, the overall average cost decreased \$0.01 per million Btu.

In 1992, sales of electricity to ultimate consumers posted a decrease, the first since 1982 . Sales to residential, commercial, and other customers decreased while sales to industrial customers increased. ${ }^{2}$ Mild winter and summer weather throughout most of the Nation probably had the largest effect on sales of electricity. A reduction in sales by electric utilities can have the effect of reducing electric utility fossil-fuel requirements.

Coal. Abundant supplies of coal were available to electric utilities in 1992, contributed to depressed coal prices. The average delivered cost of coal to electric utilities in 1992 was $\$ 29.36$ per short ton (Table ES2). ${ }^{3}$ This was a 2-percent decrease from the $\$ 30.02$ per short ton reported in 1991 and the lowest average cost of coal delivered to electric utilities since 1980.4 The average cost of both contract and spot-market coal delivered to electric utilities decreased in 1992. The average cost of contract coal decreased $\$ 0.66$ per short ton to a level of $\$ 29.89$ per short ton based on receipts of 649 million short tons, a decrease of 6 million short tons from 1991 (Table ES2). Receipts of spot-market coal totaled 127 million short tons, an increase of 12 million short tons from 1991. The average cost of spotmarket coal decreased $\$ 0.38$ per short ton to a level of $\$ 26.64$ per short ton. This is the lowest average annual cost for coal purchased in the spot-market and delivered to electric utilities since 1977.' As has been the case since 1985, the average delivered cost of coal purchased under contract was higher than that for coal purchased in the spot-market $(\$ 29.89$ versus $\$ 26.64$ per short ton). This indicates an excess supply of coal and an expectation of a continued decline in the cost of coal. Aiding a decline in the average cost of coal is the fact that electric utilities follow strategies that will reduce their fuel costs. With spot-market costs $\$ 3.25$ per short ton less, on average, than the average cost of contract coal, electric utilities will oitten minimize their contract receipts and opt for spot-narket purchases. Some electric utilities have found it economical to pay a fee to "buy out" older contracts and increase purchases under newer less expensive contracts. Also, the cost of coal under some contracts is adjusted annually according to changes in coal related indices, while some contracts are periodically open for renegotiation. Since the overall cost of coal has been decreasing for the past several years, renegotiation of contracts or index-related adjustments usually result in a reduction in the cost of coal. In addition, several electric utilities have been able to reduce the cost of transporting the coal to the plant either by renegotiation of contracts or by increasing competition among the carriers.

In the western United States a continuing drought reduced hydroelectric generation. An increase in coalfired generation in the region appears to have made up for the shortfall. This was most significant in contributing to an annual increase in coal receipts, colsumption, and generation. Receipts of coal to electric utilities totaled 776 million short tons, an increase of 6 million short tons from 1991 (Table ES1). Coal consumption totaled 780 million short tons, an increase of 8 million short tons ( 1 percent), while net generation from coal

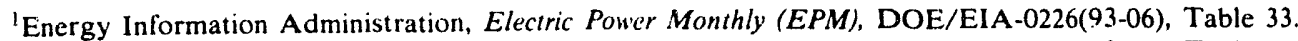

2Energy Information Administration, Electric Power Monthly (EPM), DOE/EIA-0226(93-06), Table 51.

${ }^{3}$ The delivered cost of fossil fuels includes all costs (including transportation, taxes, etc.) incurred by the electric utility for delivery of the fuel to the plant.

${ }^{4}$ Energy Information Administration, Historical Monthly Energy Review (HMER), DOE/EIA-C035(73-88), Table 9.10.

${ }^{5}$ Energy Information Administration, Cost and Quality of Fueis for Electric Utility Plants 1991, DOE/EIA-0191(91) and prior issues.
} 
increased 2 percent. "End-of-year stocks of coal at electric utilities totaled 154 million short tons, a decrease of 4 million short tons from 1991.' The average end-of-year stocks of coal over the last 5 years were 150 million short tons. ${ }^{8}$

As in previous years, electric utilities continue to increase their use of subbituminous and lignite coal. Subbituminous coal is mined in the western United States, with the majority of the coal originating in the Powder River Basin of Wyoming and Montana. Its low-sulfur content is excellent for allowing electric utilities to meet stringent air quality emission standards. In 1992 receipts of subbituminous coal totaled 241 million short tons, an increase of just over 1 million short tons (Table ES1). Several electric utilities are expected to switch to subbituminous coal during 1993 and 1994 in order to meet the emission requirements of Phase 1 of the Clean Air Act Amendments (CAAA) of 1990 which takes effect on January 1, 1995. Receipts of lignite at electric utilities in 1992 totaled 80 million short tons, an increase of 2 million short tons from 1991. Most of this low-Btu, low-cost coal is consumed by electric plants located in Texas, North Dakota, and Louisiana.

Electric utilities used 1992 as a year to test new types and various blends of coal as they worked toward developing a strategy to comply with the CAAA. Many electric plants, especially those built several years ago, were designed to burn a particular type or blend of coal containing certain quality and physical characteristics. In changing the type or blend of coal, the boilers in which the coal is burned may loose efficiency, encounter maintenance or operational problems, or simply not meet the flue-gas emission limits that the electric plant mist meet. Problesis may be encountered in the logistics of transporting the coal to the plant. Testburning various coals well in advance of the start of Phase 1 of the CAAA ensures adequate time to resolve any problems that are encountered or to switch to a different blend or type of coal. Some of the electric utilities that received test shipments of coal during 1992 (and the origin of that coal) include Tampa Electric (Colorado, Utah, imports from Indonesia); Ohio Edison (Wyoming and Indonesia); Tennessee Valley Authority ( Wyoming); Minnesota Power \& Light (Wyoming); Mississippi Power (Wyoming); Missouri Public Service (Utah and Colorado); Nebraska Public Power District (various Powder River basin coals); and PSI Energy Inc., (West Virginia).
The coal requirements for some electric utilities are so large that they have a noticeable effect on the coal markets. Decisions by several electric utilities on major long-term coal supply contracts that are to be put in place before Phase 1 compliance with the CAAA starts in 1995 were anxiously awaited by the coal and electric power industries during 1992. Most notable were coal procurement strategies for the Georgia Power Company (Sherrer plant), Tennessee Valley Authority (Paradise), and the Ohio Power Company (Gavin). Each of these electric utilities proposed at least a partial shift from eastern coal to western coal ir order to comply with the CAAA. However, as of the end of 1992, no firm decisions had been made concerning future longterm coal deliveries to these three plants.

Petroleum. The petroleum market was relatively stable during 1992. The average monthly refiner acquisition cost of crude oil ranged from $\$ 16.28$ per barrel in February to $\$ 20.10$ per barrel in July. ${ }^{9}$ No after-effects of the Persian Gulf Conflict of 1991 are readily apparent in the data submitted for electric utility fuel purchases during 1992. The average cost of petroleum products (fuel oil) delivered to electric utilities in 1992 was $\$ 16.15$ per barrel $(\$ 2.55$ per million Btu), an increase of only $\$ 0.06$ per barrel from 1991 (Table ES2). The average monthly cost of fuel oil delivered to electric utilities ranged between $\$ 13.52$ per barrel reported in March and $\$ 18.89$ per barrel reported in October. ${ }^{10}$ The cost of fuel oil delivered to electric utilities did increase rather sharply during mid-year, in tandem with the cost of natural gas. Receipts of fuel oil at electric utilities totaled 144 million barrels, a decrease of 25 million barrels from 1991 (Table ES1). This is the lowest annual total reported since data collection was begun in 1972. Fuel oil accounted for only 5 percent of the total Btu content of fossil fuels delivered in 1992 Consumption of petroleum products at steamelectric plants totaled 141 million barrels, a decrease of 36 million barrels ( 20 percent) from 1991." Steam net-generation from petroleum also decreased 21 percent. End-of-year stocks of fuel oil at steam-electric plants totaled 62 million barrels, a decrease of nearly 3 million barrels from 1992. The average end-of-year stocks of fuel oil over the last 5 years were 63 million barrels. ${ }^{12}$ Receipts of fuel oil to electric utilities peaked at 636 million barrels in 1977 , and have since decreased to a point that only a few electric utilities, located primarily in Florida, New York, and Massachusetts, are heavily dependent on the fuel for electric generation.

\footnotetext{
'Energy Information Administration, Electric Power Monthly (EPM), DOE/EIA-(226(93-06), Tables 4 and 17

${ }^{7}$ Data on generation, consumption, and stocks of fossil fuels at electric utilities are based on data collected on the Energy Information Administration, Form EIA-759, "Monthly Power Plant Report." These data cover all electric generating plants.

${ }^{8}$ Energy Information Administration, Electric Power Monthly (EPM). DOE/EIA-0226(93-06), Table 28.

"Energy Information Administration, Monthly Encrgy Review' (MER), DOE/EIA-0035(93/03), Table 9.1

${ }^{10}$ Energy Information Administration, Electric Power Monthly (EPM). DOE/EIA-0226(93-06), Table 33; and Energy Information Administration, Electric Power Monthly (EPM). DOE/EIA-0226(92-12) and prior issues, Table C1. The formula used to produce average dollars per barrel is found in the Technical Notes section of Appendix $C$ in the EPM.

"Energy Information Administration, Monthly Lin'rgy Review' (MER), DOE/EIA-0035(93/03), Table 7.3.

"Energy Information Administration, Momtinly En'rgy Revi'w' (MER), DOE/EIA-0035(93/03), Table 7.4.
} 
Gas. The natural gas markets appeared to be somewhat less stable than the petroleum markets during 1992. The wellhead cost of natural gas decreased from $\$ 2.00$ per thousand cubic feet (Mcf) in December 1991 to $\$ 1.37$ per Mcf in February 1992 before increasing to $\$ 2.56$ per Mcf in October 1992. ${ }^{13}$ The average cost of natural gas delivered to electric utilities was $\$ 2.38$ per thousand cubic feet ( $\$ 2.33$ per million $B t u)$, an increase of 8 percent from 1991 (Table ES2). The lowest average monthly cost of natural gas delivered to electric utilities was $\$ 2.01$ per Mcfreported in March. However, by October the average cost of natural gas had increased to $\$ 3.05$ per Mcf..$^{14}$ Several factors have been noted as contributing to this price increase including "shut-in" wells (wells where production has been stopped) due to low prices, OPEC'S reduction in production of heavier crudes, which compete with natural gas, and Hurricane Andrew, which destroyed an estimated 5 percent of the gas-producing wells in the Gulf of Mexico. ${ }^{15}$

Receipts oî natural gas at electric utilities totaled 2,638 billion cubic feet (Bcf), nearly unchanged from the 2,631 Bcf reported in 1991 (Table ES1). Monthly receipts of natural gas peaked in July at $316 \mathrm{Bcf}$ as elec- tric utilities increased purchases of natural gas under interruptible contracts. Receipts were lowest in January and February, $160 \mathrm{Bcf}$ each. ${ }^{16}$ Typically, receipts of natural gas are lowest in the winter months because residential and commercial users of natural gas are given priority (for heating purposes) over electric utilities in the distribution of gas. Pipeline capacity is the limiting factor in the distribution of natural gas. During warmer months, more natural gas is available to electric utilities since residential and commercial users require less natural gas.

The average cost of natural gas delivered to electric utilities usually is highest in the winter months when most receipts are delivered under firm contracts (that is, delivery is guaranteed). In the warmer months a high vo'ame of natural gas is delivered under interruptible contract (that is, delivery may be interrupted--often in exchange tor a reduction in cost to the utility). This usually results in a higher volume of gas receipts at lower costs during the warmer months of the year, compared with the colder months. This pattern did not hold in 1992 due to the previously mentioned factors affecting the cost of natural gas during 1992.

Table ES1. Receipts of Fossil Fuels by Type of Fuel, 1991-1992

\begin{tabular}{|c|c|c|c|c|}
\hline Type of Fuel & 1992 & 1991 & Dlfference & $\begin{array}{l}\text { Percent } \\
\text { Difference }\end{array}$ \\
\hline 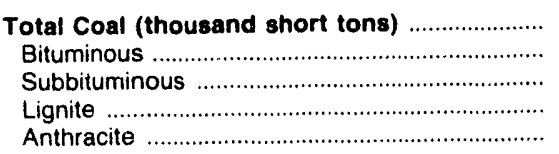 & $\begin{array}{r}775,963 \\
453,732 \\
241,291 \\
80,433 \\
503\end{array}$ & $\begin{array}{r}769,923 \\
450,462 \\
239,929 \\
78,810 \\
723\end{array}$ & $\begin{array}{r}6,040 \\
3,270 \\
1,362 \\
1.628 \\
-220\end{array}$ & $\begin{array}{r}0.8 \\
.7 \\
.6 \\
2.1 \\
-30.4\end{array}$ \\
\hline 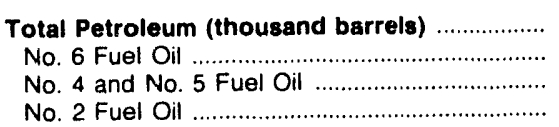 & $\begin{array}{r}144,390 \\
138,261 \\
276 \\
5,853\end{array}$ & $\begin{array}{r}169,625 \\
162,623 \\
483 \\
6,518\end{array}$ & $\begin{array}{r}-25,235 \\
-24,362 \\
-207 \\
-665\end{array}$ & $\begin{array}{l}-14.9 \\
-15.0 \\
-42.6 \\
-10.2\end{array}$ \\
\hline 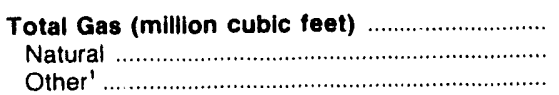 & $\begin{array}{r}2,637,678 \\
2,623,146 \\
14,533\end{array}$ & $\begin{array}{r}2,630,818 \\
2,616,145 \\
14,673\end{array}$ & $\begin{array}{r}6,860 \\
7,001 \\
-140\end{array}$ & $\begin{array}{r}.3 \\
.3 \\
-1.0\end{array}$ \\
\hline
\end{tabular}

- Includes small quantities of coke-oven gas, refinery and blast-furnace gas.

Notes: - Totals may not equal sum of components because of independent rounding. - Data are for electric generating plants with a total steamelectric and combined-cycle nameplate capacity of 50 or more megawatts.

Source: Federal Energy Regulatory Commission, FERC Form 423, "Monthly Report of Cost and Quality of Fueis for Electric Plants."

\footnotetext{
${ }^{13}$ Energy Information Administration, Monthly Energy Review (MER), DOE/EIA-0035(93/03), Table 9.11.

${ }^{14}$ Energy Information Administration, Electric Power Monthly (EPM). DOE/EIA-0226(93-06). Table 33.

${ }^{15}$ Standard \& Poor's Industry Survey, Natural Gas, Vol. 160, No. 47, November 19, 1992

${ }^{16}$ Energy Information Administration, Electric Power Monthly (EPM), DOE/EIA-0226(93-06), Table 33; and Energy Information Administration, Electric Power Monthly (EPM), DOE/EIA-0226(92-12) and prior issues, Table C1. The formula used to produce average dollars per Mcf is found in the Technical Notes section of Appendix $C$ in the EPM.
} 
Table ES2. Average Dellvered Cost of Fossil Fuels, 1991-1992

\begin{tabular}{|c|c|c|c|c|}
\hline Type of Purchase & 1992 & 1991 & Difference & $\begin{array}{c}\text { Percent } \\
\text { Difference }\end{array}$ \\
\hline 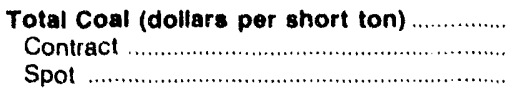 & $\begin{array}{l}29.36 \\
29.89 \\
26.64\end{array}$ & $\begin{array}{l}30.02 \\
30.55 \\
27.02\end{array}$ & $\begin{array}{r}-0.66 \\
-.66 \\
-.38\end{array}$ & $\begin{array}{l}-2.2 \\
-2.2 \\
-1.4\end{array}$ \\
\hline 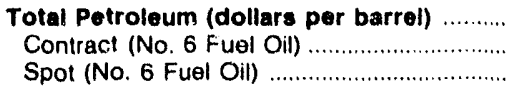 & $\begin{array}{l}16.15 \\
15.83 \\
15.36\end{array}$ & $\begin{array}{l}16.09 \\
15.69 \\
15.42\end{array}$ & $\begin{array}{l}.06 \\
.14 \\
.06\end{array}$ & $\begin{array}{l}.4 \\
.9 \\
.4\end{array}$ \\
\hline 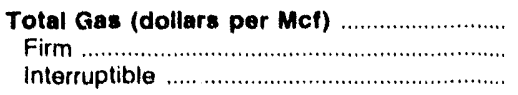 & $\begin{array}{l}2.38 \\
2.37 \\
2.40\end{array}$ & $\begin{array}{l}2.20 \\
2.19 \\
2.22\end{array}$ & $\begin{array}{l}.18 \\
.18 \\
.18\end{array}$ & $\begin{array}{l}8.2 \\
8.2 \\
8.1\end{array}$ \\
\hline
\end{tabular}

Notes: - Data are for electric generating plants with a total sleam-electric and combined-cycle nameplate capacity of 50 or more megawatts. - Mct $=$ thousand cubic teet

Source: Federal Energy Regulatory Commission, FEAC Form 423, "M.1onthly Report of Cost and Quality of Fuels for Electric Plants."

Quality of Coal. Data on the quality (sulfur, Btu, and ash content) of coal delivered to electric plants in 1992 show little change at the U.S. level from data reported in 1991. The sulfur content of coal decreased from 1.30 percent by weight in 1991 to 1.29 percent by weight in 1992 (Table ES3). Since 1988, the average sulfur content of coal delivered to electric utilities has remained relatively stable at approximately 1.30 percent (Table ES4). At the State level, coal with the lowest average sulfur content ( 0.38 percent by weight) originated in Wyoming, while coal from Missouri and Iowa had the highest average sulfur content (4.15 and 4.36 percent by' weight, respectively).

On a regional basis, coal from the northern Appalachian Region (Pennsylvania, Ohio, Maryland, and northern West Virginia) and from the Interior Region contained the highest percentage of sulfur. In the castern United States, coal from the central Appalachian Region (Virginia, southern West Virginia, and eastern Kentucky) contained the lowest amount of sulfur based on percent weight. It is expected that receipts of coal from this region will increase in future years as electric utilities turn to low-surfur coal to meet the emission limits set by the CAAA. The sulfur content for the Interior Region coal ranged generally between 1.5 and 4.5 percent. Receipts of coal from the ce.ztral Appalachian Region ranged between 0.5 and 2.0 percent in sulfur content, while receipts of coal from the western United States generally contained less than 1.0 percent sulfur.

The average heat content of coal de'ivered to electric utilities in 1992 was 10,395 Btu per pound, nearly unchanged from the $10,378 \mathrm{Btu}$ per pound reported in 1991 (Table ES3). The average Btu per pound of the 3 primary ranks of coal delivered to electric utilities has remained relatively stable over the last several years (Table ES4). Considering only the major coalproducing States, coal originating in Virginia rated the highest in heat content--averaging 12,872 Btu per pound. Texas lignite rated the lowest in heat content (6,224 Btu per pound). Subbituminous coal originating in the Powder River Basin (located in Montana and Wyoming) ranged approximately from 8,000 to 9,500 Btu per pound. This was 2,,600 to 3,000 Btu per pound less than the heat content of bituminous coal mined in the eastern United States.

The average ash content (any noncombustible material) of coal delivered to electric utilities in 1992 was 9.71 percent--down from the 9.76 percent reported in 1991 (Table ES3). On a State-by-State basis, coal from Wyoming contained the least amount of ash (5.5 percent) of any coal delivered to electric utilities during the year. Coal obtained from Texas, New Mexico, and Washington had an average ash content above 15 percent.

During the past several years, increasing amounts of low-sulfur lignite and western subbituminous coal have contributed substantially to reducing the average sulfur content of coal delivered to electric utilities. Most of this coal is delivered to power plants located in the central and western United States. However, some low-sulfur western coal is now being shipped to electric plants in the eastern United States. Although the cost of transporting coal across this distance is expensive, the relatively low cost of mining western coal results in a delivered cost that is competitive with low-sulfur coal from the eastern United States.

Phase 1 of the CAAA starts on January 1, 1995. One aspect of this law is that it places restrictions on the amount of flue-stack gas (such as sulfur dioxide) that can be emitted into the atmosphere by electric utility generating plants. Electric utilities have a variety of options available to comply with this law. The three primary options are the installation of flue gas desulfluization (FGD) systems, use of lower sulfur fuels, and purchase of emission allowances. ${ }^{17}$ 
Table ES3. Average Quality of Coal by State of Origin, 1991-1992

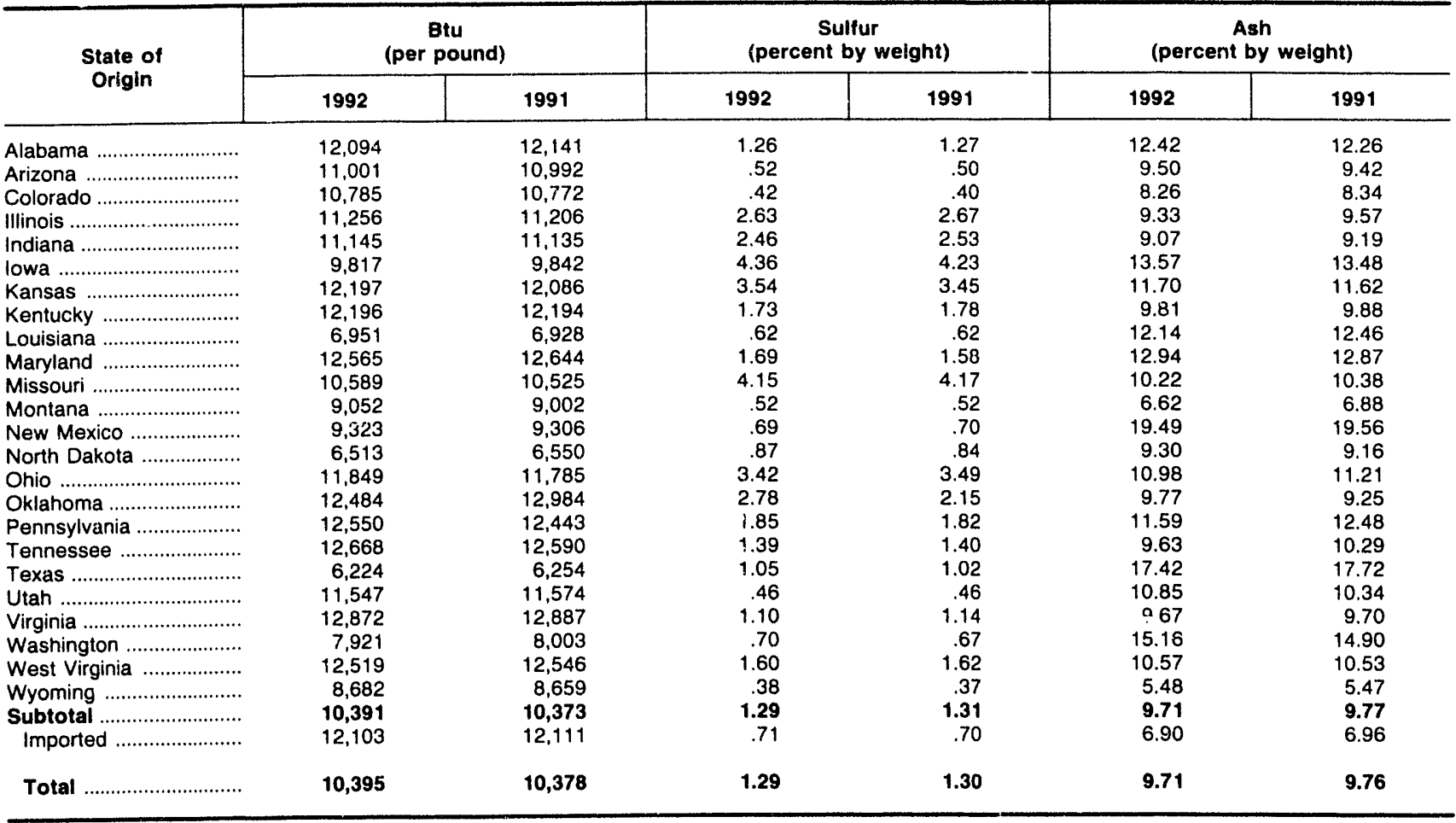

Notes: - Totals may not equal sum of components because of independent rounding. - Data are for electric generating plants with a total steam-electric and combined-cycle nameplate capacity of 50 or more megawatts.

Source: Federal Energy Regulatory Commission, FERC Form 423, "Monthly Report of Cost and Quality of Fuels for Electric Plants."

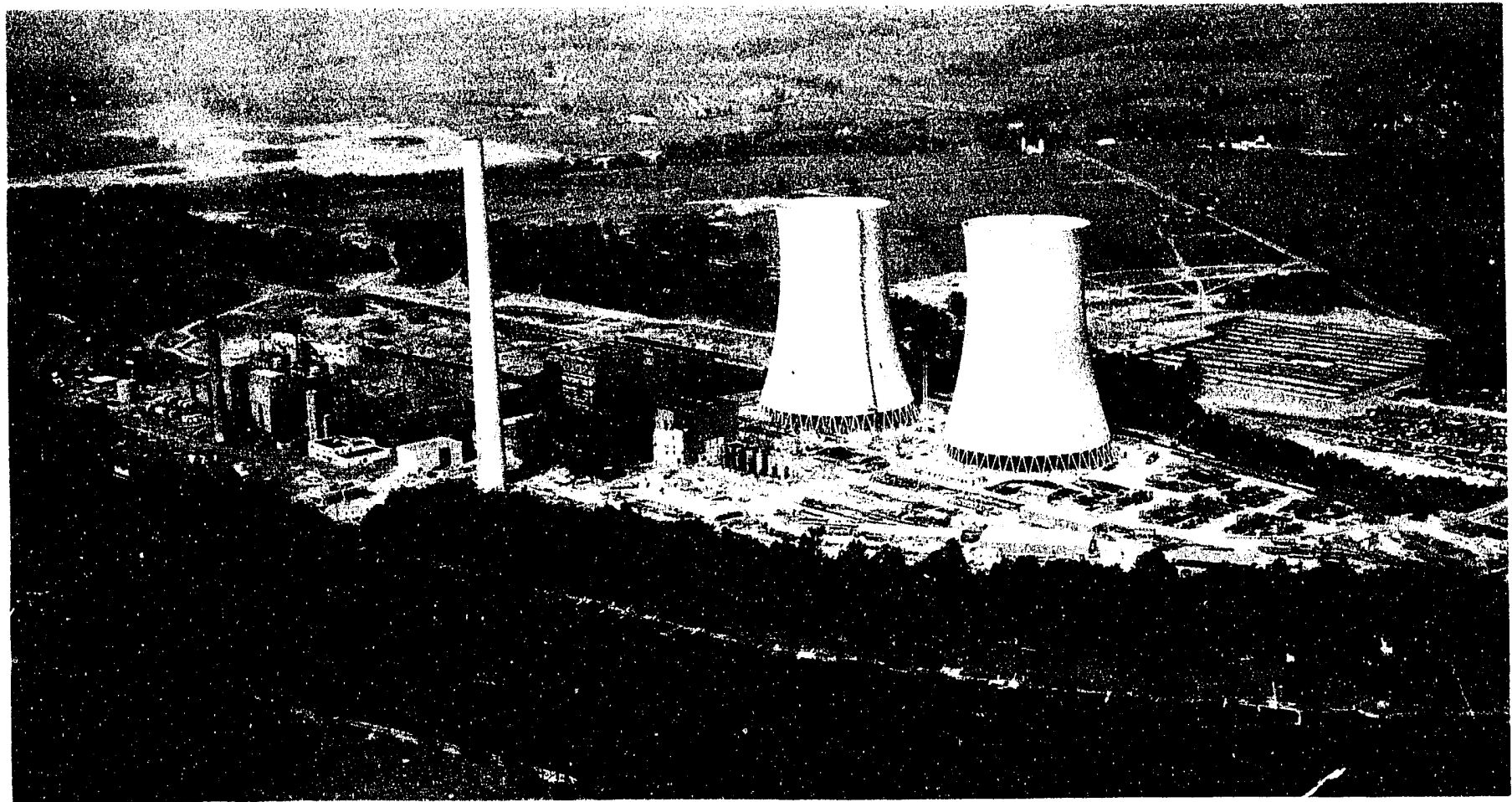

This 1973 photo show construction in progress on two 850 megawatt oil-fired units at the Pennsylvania Power and Light Company's Martins Creek plant. In 1992, Martins Creek received approximat iy 2.3 million barrels of oil and 600 thousand short tons of coal.

${ }^{17}$ For a more detailed discussion regarding the options available to electric utilities for complying with the Clean Air Act Amendments of 1990, see the Energy Information Administration, Annual Outlook for U.S. Electric Power 1991, DOE/EIA-0474(91)(Washington, DC, July 1991). 
Table ES4. Recelpts of Coal by Rank, 1988-1992

\begin{tabular}{|c|c|c|c|c|c|c|}
\hline \multirow[b]{2}{*}{ Rank } & \multirow{2}{*}{$\begin{array}{l}\text { Recelpte } \\
\text { (thousand } \\
\text { short tons) }\end{array}$} & \multicolumn{3}{|c|}{ Average Quallty } & \multicolumn{2}{|c|}{ Average Dellvered Cost } \\
\hline & & $\begin{array}{c}\text { Btu } \\
\text { (per pound) }\end{array}$ & $\begin{array}{c}\text { Sulfur } \\
\text { (percent } \\
\text { by welght) }\end{array}$ & $\begin{array}{c}\text { Aeh } \\
\text { (percent } \\
\text { by weight) }\end{array}$ & $\begin{array}{l}\text { (conte per } \\
\text { Million Btu) }\end{array}$ & $\begin{array}{l}\text { (dollars per } \\
\text { short ton) }\end{array}$ \\
\hline \multicolumn{7}{|l|}{1992} \\
\hline Anthracite ......................... & 503 & 8,470 & 0.67 & 32.0 & 93.7 & 15.88 \\
\hline Bituminous ...................... & 453,732 & 11,987 & 1.81 & 10.2 & 149.6 & 35.86 \\
\hline Subbituminous ............... & 241,291 & 8,754 & .43 & 7.0 & 128.5 & 22.49 \\
\hline Lignite .............................. & 80,438 & 6,346 & .97 & 14.6 & 105.4 & 13.38 \\
\hline Total & 775,863 & 10,395 & 1.29 & 9.71 & 141.2 & 29.36 \\
\hline \multicolumn{7}{|l|}{1991} \\
\hline 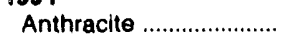 & 723 & 7,961 & .64 & 33.4 & 94.1 & 14.98 \\
\hline 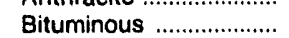 & 450,462 & 11,964 & 1.84 & 10.3 & 153.2 & 36.66 \\
\hline 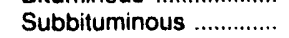 & 239,929 & 8,722 & .42 & 6.9 & 132.3 & 23.08 \\
\hline 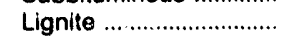 & 78,810 & 6,372 & .95 & 14.9 & 104.9 & 13.37 \\
\hline 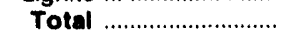 & 769,923 & 10,378 & 1.30 & 9.76 & 144.7 & 30.02 \\
\hline \multicolumn{7}{|l|}{1980} \\
\hline 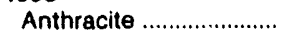 & 753 & 8,070 & .71 & 32.7 & 97.7 & 15.77 \\
\hline 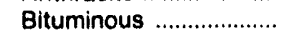 & 477,782 & 11,945 & 1.86 & 10.5 & 153.8 & 36.75 \\
\hline Subbituminous .............. & 232,660 & 8,741 & .43 & 7.2 & 133.5 & 23.34 \\
\hline 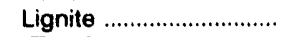 & 75,432 & 6,433 & .92 & 14.0 & 98.3 & 12.65 \\
\hline 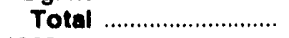 & 786,627 & 10,465 & 1.35 & 9.85 & 145.5 & 30.45 \\
\hline \multicolumn{7}{|l|}{1989} \\
\hline Anthracite ......................... & 633 & 8,153 & .63 & 32.2 & 96.0 & 15.65 \\
\hline Bituminous ....................... & 451,341 & 11,936 & 1.85 & 10.5 & 152.6 & 36.43 \\
\hline Subbituminous .............. & 226,322 & 8,757 & .44 & 7.3 & 134.7 & 23.59 \\
\hline 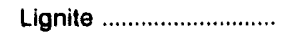 & 74,921 & 6,380 & .88 & 14.1 & 95.8 & 12.22 \\
\hline 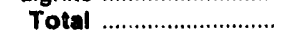 & 753,217 & 10,425 & 1.33 & $\mathbf{0 . 9 3}$ & 144.6 & 30.15 \\
\hline \multicolumn{7}{|l|}{1988} \\
\hline 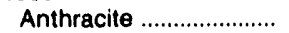 & 725 & 8,656 & .57 & 33.1 & 92.9 & 16.08 \\
\hline Bituminous ...................... & 433,063 & 11,995 & 1.84 & 10.4 & 154.2 & 37.00 \\
\hline Subbituminous .............. & 220,536 & 8,772 & .45 & 7.3 & 138.1 & 24.23 \\
\hline 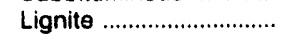 & 73,451 & 6,404 & .83 & 14.0 & 98.0 & 12.55 \\
\hline 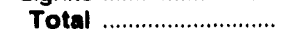 & 727,775 & 10,451 & 1.32 & 9.88 & 146.6 & 30.84 \\
\hline
\end{tabular}

Notes: - Totals may not equal sum of components because of independent rounding. - As of 1991, data are for electric generating plants with a total steam-electric and combined-cycle nameplate capacity of 50 or more megawatts. - Data for 1988-1990 are for steam-electric plants with a generator nameplate capacity of 50 or more megawatts.

Source: Federal Energy Regulatory Commission, FERC Form 423, "Monthly Report of Cost and Quality of Fuels for Electric Plants." 


\section{Fossil-Fuel Data at the Census Division and State Level}

\section{Coal}

In 1992, electric utilities received 776 million short tons of coal, an increase of 6 million short tons from 1991 (Table 1). This annual change in total receipts amounted to less than 1 percent, the smallest yearto-year change reported in the last 10 years. At the Census division level, receipts of coal decreased in the New England, East North Central, and West North Central Census Divisions, while all other Census divisions showed increases in receipts. The largest increase, on a percentage basis, occurred in the Pacific Contiguous Census Division, where receipts of coal increased 17 percent. A substantial decrease in hydroelectric generation in the western United States in 1992 led to increased use of fossil fuels. ${ }^{18}$ Receipts of coal in the Mountain Census Division increased by 3 million short tons ( 3 percent) due, in part, to the above mentioned shortfall in hydroelectric generation. Receipts of coal in the East South Central Census Division increased 3 million short tons; electric utilities increased their coalfired generation to meet higher sales of electricity to industrial customers. Receipts of coal in both the East North Central and West North Central Census Divisions decreased from 1991 due to a reduction in coalfired generation. This decrease was due in part to mild weather conditions, which are reflected in the substantial decrease in electricity sales to residential consumers in both Census divisions. ${ }^{19}$

The average cost of coal delivered to electric utilities in 1992 was $\$ 29.36$ per short ton, a decrease of $\$ 0.66$ per short ton from 1991 (Table 2). Abundant supplies of coal available to electric utilities during 1992 resulted in lower coal costs. The highest average delivered cost of coal at the Census division level was $\$ 45.14$ per short ton for coal delivercd to the New England Census Division. This high average cost of coal is due to the fact that most of the coal delivered to the New England Census Division was high-Btu low-sulfur coal from the Appalachian Region (Kentucky, Virginia, Pennsylvania, and West Virginia). Coal of this quality usually commands premium prices. Transporting this coal also added substantially to its delivered cost. Among all States, the average cost of coal delivered to Connecticut was the highest at $\$ 51.30$ per short ton $(194.8$ cents per million Btu). Coal delivered to Connecticut had an average sulfur content of 0.55 percent by weight, the lowest sulfur value for any State in the eastern United States (Table 22). The lowest average cost of coal at the Census division level was $\$ 18.92$ per short ton ( 110.0 cents per million Btu) for coal delivered to electric utilities in the West North Central Census Division. A major percentage of the coal delivered to States in this Census division originated in Wyoming and Montana and was delivered to electric plants by unit train. A combination of low-mining costs for western coal and efficient transportation methods resulted in the relatively low average delivered cost. In addition, the low cost of lignite purchased by electric utilities in North Dakota reduced the average delivered cost for this division. The lowest average delivered cost of coal at the State level was $\$ 9.45$ per short ton for coal delivered to North Dakota. Nearly all of the coal delivered to North Dakota was low-cost lignite. The average cost per short ton of coal delivered to Wyoming and Montana in 1992 was $\$ 13.42$ and $\$ 12.14$, respectively (Table 2). Generally, plants locited in these States are near the coal mines, thereby reducing transportation costs.

\section{Petroleum}

In 1992, receipts of petroleum products at electric utilities totaled 144 million barrels, down 25 million barrels from 1991 (Table 6). This decrease in receipts can be attributed to a substantial decrease in consumption of fuel oil Number 6. The New England, Middle Atlantic, and South Atlantic Census Divisions accounted for 89 percent (129 million barrels) of total U.S. petroleum receipts. Receipts of petroleum products were highest in the South Atlantic Census Division, with 54 million barrels being received in 1992 . While the national trend over the last 5 years has been a large reduction in receipts of petroleum, receipts in the South Atlantic Census Division have remained relatively steady at approximately 50 to 60 million barrels per year. Since 1988,

\footnotetext{
${ }^{18}$ Energy Information Administration, Electric Power Monthly (EPM), DOE/EIA-0226(93-03), Table 14.

${ }^{19}$ Energy Information Administration, Electric Power Monthly (EPM), DOE/EIA-0226(93-03), Table 54.
} 
receipts of petroleum in the New England and Middle Atlantic Census Divisions have decreased 40 and 56 percent, respectively. At the State level, Florida received the highest quantity of petroleum (43 million barrels), followed by New York ( 33 million barrels), and Massachusetts (22 million barrels). Receipts of petroleum to California totaled only 1,000 barrels, a stark contrast to prior years when the State was heavily dependant on petroleum as a major fuel for electric generation.

The average delivered cost of petroleum is primarily dependent on three factors: the type of fuel oil purchased, the quality (sulfur content) of the fuel oil, and the supply of and demand for petroleum. These factors result in a wise variation in the average delivered cost of petroleum at the State and Census division level. Fuel oil Number 2 is more expensive than fuel oil Number 6; and low-sulfur fuel oil is generally more expensive than high-sulfur fuel oil.

he average cost of petroleum delivered to electric utilities in 1992 was $\$ 16.15$ per barrel, an increase of \$0.06 per barrel from 1991 (Table 7). The lowest average delivered cost at the State level was $\$ 12.23$ per barrel ( 185.8 cents per million Btu) for petroleum delivered to New Hampshire. Nearly all of this petroleum was medium-to high-sv ifur Number 6 fuel oil. In comparison, Montana reforted the highest average delivered cost at $\$ 30.15$ per barrel $(509.1$ cents per million Btu). All receipts of petroleum in the State were Number 2 fuel oil. The national average delivered cost of Number 2 fuel oil was $\$ 26.26$ per barrel (451.4 cents per million Btu), compared with $\$ 15.71$ per barrel ( 247.3 cent per million Btu) for Number 6 fuel oil (Table 8).

\section{Gas}

Receipts of natural gas at electric utilities amounted to 2,638 billion cubic feet in 1992 (Table 11). This represented an increase of 7 billion cubic feet from 1991. Data on gas receipts include natural gas delivered to steam, combined-cycle steam, and combined-cycle gas turbine units.

The West South Central and Pacific Contiguous Census Divisions accounted for 74 percent (1,946 billion cubic feet) of all receipts of natural gas. Receipts of natural gas in Texas were 956 billion cubic feet--the largest total for any State. California ranked second with total natural gas receipts of 566 billion cubic feet. Louisiana received the third highest volume of natural gas receipts ( 238 billion cubic feet).

The average delivered cost of natural gas increased by $\$ 0.18$ cents per thousand cubic feet in 1992, to a level of $\$ 2.38$ per thousand cubic feet (Table 12). The lowest average delivered cost, $\$ 0.81$ per thousand cubic feet was reported in Michigan. This was due to the large quantity of low-Btu blast-furnace gas delivered to the Detroit Edison Company. On a cents-per-million-Btu basis, this cost was 195.4 cents. The highest average cost was $\$ 418$ per thousand cubic feet for a minimal amount of 1 atural gas delivered to electric plants located in North Dakota. It is not unusual for a low volume of natural gas receipts (such as in North Dakota) to be delivered to electric plants at a relatively high cost, because the allocation of the fixed costs associated with pipeline deliveries of gas are based on the volume of deliveries. The cost of natural gas delivered to electric utilities in Texas averaged $\$ 2.25$ per thousand cubic feet, an increase of \$0.22 per thousand cubic feet. Receipts of natural gas in Texas accounted for 36 percent of all natural gas delivered to electric utilities in 1992. 
Table 1. Receipts of Coal by Census Division and State, 1988-1992 (Thousand Short Tons)

\begin{tabular}{|c|c|c|c|c|c|}
\hline $\begin{array}{l}\text { Census Division } \\
\text { and State }\end{array}$ & 1992 & 1991 & 1980 & 1989 & 1988 \\
\hline 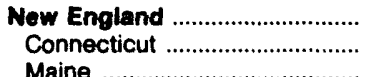 & $\begin{array}{r}6,213 \\
793\end{array}$ & $\begin{array}{r}6,433 \\
871\end{array}$ & $\begin{array}{r}6,345 \\
954\end{array}$ & $\begin{array}{r}6,326 \\
875\end{array}$ & $\begin{array}{r}6,377 \\
830\end{array}$ \\
\hline 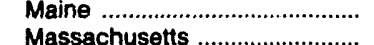 & - & - & - & - & - \\
\hline 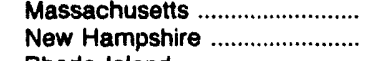 & $\begin{array}{l}4,194 \\
1,226\end{array}$ & $\begin{array}{l}4,278 \\
1,284\end{array}$ & $\begin{array}{l}4,120 \\
1,271\end{array}$ & $\begin{array}{l}4,387 \\
1,064\end{array}$ & $\begin{array}{l}4,285 \\
1,262\end{array}$ \\
\hline 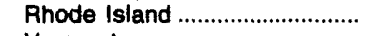 & -- & - & - & - & - \\
\hline 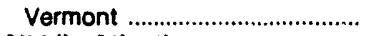 & - & - & -- & - & - \\
\hline Middle Atiantic .............................. & 53,680 & 52,066 & 58,200 & 55,869 & 51,532 \\
\hline 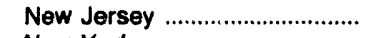 & 2,205 & 2,027 & 2,835 & 3,324 & 2,477 \\
\hline 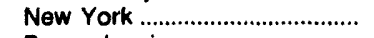 & 10,393 & 9,235 & 10,568 & 9,879 & 8,562 \\
\hline 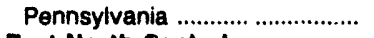 & 41,082 & 40,804 & 44,796 & 42,766 & 40,493 \\
\hline East North Central .................... & 169,346 & 170,575 & 174,585 & 161,663 & 155,300 \\
\hline 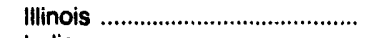 & 25,449 & 26.813 & 26,456 & 25,067 & 26,920 \\
\hline 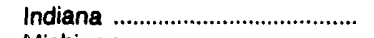 & 47,838 & 46.292 & 49,194 & 40,560 & 36,414 \\
\hline 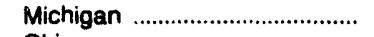 & 27,875 & 28,866 & 29,688 & 28,996 & 28,344 \\
\hline Ohio & 50,596 & 49,517 & 51,436 & 49,505 & 46,008 \\
\hline 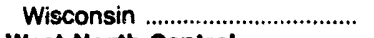 & 17,589 & 19,087 & 17,811 & 17,535 & 17,613 \\
\hline West North Central ................... & 101,643 & $10: i, 054$ & 103,252 & 100,899 & on 540 \\
\hline 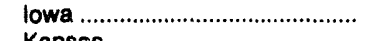 & 15,037 & 16,344 & 15,639 & 14,316 & 13,974 \\
\hline 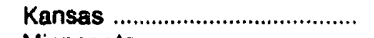 & 13,634 & 14,401 & 15,772 & 14,725 & 14,798 \\
\hline 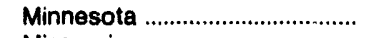 & 15,154 & 16,187 & 16,559 & 16,176 & 15,451 \\
\hline 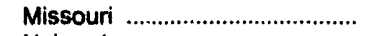 & 24,502 & 25,204 & 24,351 & 24,788 & 23,959 \\
\hline 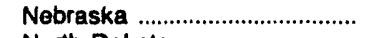 & 7,759 & 8,908 & 7,940 & 7,473 & 7,485 \\
\hline 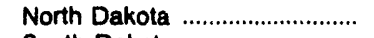 & 23,427 & 21,683 & 20,915 & 21,359 & 21,714 \\
\hline South Dakota ............................. & 2,130 & 2,326 & 2,078 & 2,063 & 2,160 \\
\hline 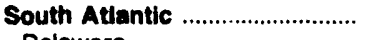 & 125,181 & 124,355 & 134,943 & 128,322 & 120,976 \\
\hline 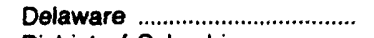 & 1,532 & 2,002 & 2,192 & 1,918 & 2,525 \\
\hline District of Columbia ...................... & - & - & - & - & - \\
\hline Florida & 24,377 & 24,461 & 24,288 & 23,375 & 23,770 \\
\hline 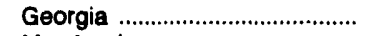 & 22,851 & 24,694 & 27,888 & 25,434 & 25,135 \\
\hline 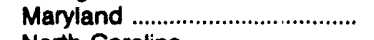 & 9,284 & 8,668 & 10,002 & 8,494 & 8,854 \\
\hline 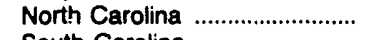 & 20,660 & 18,167 & 19,606 & 18,413 & 16,785 \\
\hline 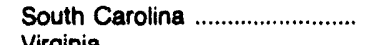 & 9,255 & 9,215 & 9,388 & 9,805 & 9,002 \\
\hline 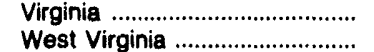 & $\begin{array}{r}8,915 \\
28,307\end{array}$ & $\begin{array}{r}8.599 \\
28.549\end{array}$ & 8,488 & 9,739 & 7.459 \\
\hline 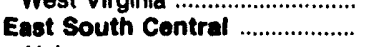 & $\begin{array}{l}28,307 \\
80,758\end{array}$ & $\begin{array}{l}28,549 \\
77,397\end{array}$ & $\begin{array}{l}33,092 \\
82,726\end{array}$ & 31,143 & 27,436 \\
\hline 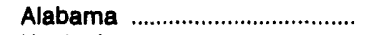 & 24,886 & 24,350 & $22,2.08$ & $\begin{array}{l}73,798 \\
21,311\end{array}$ & $\begin{array}{l}73,868 \\
19,895\end{array}$ \\
\hline 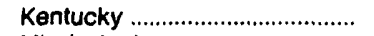 & 32,292 & 30,591 & 35,151 & 30,733 & $\begin{array}{l}19,895 \\
29,344\end{array}$ \\
\hline 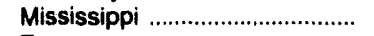 & 3,208 & 3,727 & 3,921 & 3,455 & 4,870 \\
\hline 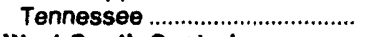 & 20,372 & 18,730 & 21,446 & 18,300 & 19,759 \\
\hline Weot South Central ................. & 128,757 & 127,713 & 120,651 & 121,925 & 117,144 \\
\hline 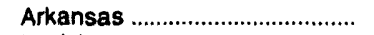 & 11,630 & 12,443 & 10,939 & 11,502 & 11,807 \\
\hline 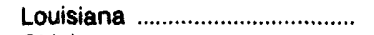 & 12,675 & 12,212 & 11,593 & 11,594 & 12,078 \\
\hline 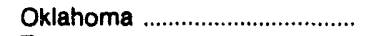 & 16,840 & 15,868 & 14,471 & 14,635 & 13,355 \\
\hline 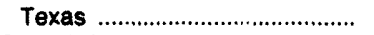 & 87,613 & 87,189 & 83,649 & 84,185 & 79,803 \\
\hline 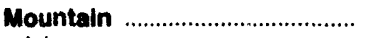 & 102,617 & 99,693 & 99,912 & 98,709 & 97,184 \\
\hline 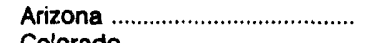 & 16,315 & 17,020 & 15,385 & 15,244 & 14,121 \\
\hline Colorado & 15,597 & 15,500 & 15,343 & 15,752 & 14,949 \\
\hline 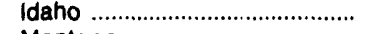 & - & - & - & - & - \\
\hline 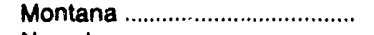 & 10,860 & 10,398 & 9,519 & 10,224 & 10,474 \\
\hline 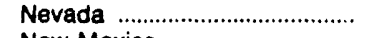 & 7,894 & 8,084 & 7,477 & 7,067 & 7,886 \\
\hline 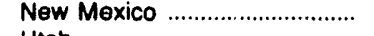 & 14,929 & 12,888 & 15,241 & 15,238 & 14.522 \\
\hline 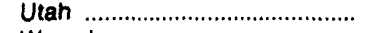 & 12,840 & 13,254 & 14,014 & 13,385 & 12,256 \\
\hline 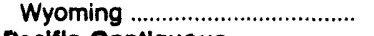 & 24,181 & 22,549 & 22,932 & 21,798 & 22,976 \\
\hline Pacific Contiguous ..................... & 7,768 & 6,636 & 6,012 & 5,606 & 5,856 \\
\hline 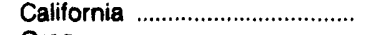 & -- & - & - & - & - \\
\hline 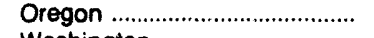 & 1,932 & 1,719 & 968 & $-\infty$ & 235 \\
\hline 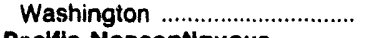 & 5,836 & 4,917 & 5.044 & 5,606 & 5,621 \\
\hline Paclfic Noncontiguous .............. & - & - & - & - & - \\
\hline Alaska & -- & - & - & - & - \\
\hline 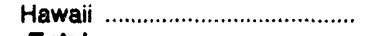 & - & - & - & - & - \\
\hline 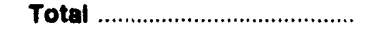 & 775,963 & 769,923 & 786,627 & 753,217 & 727,775 \\
\hline
\end{tabular}

Notes: - Totais may not equal sum of components because of independent rounding. - As of 1991, data are for electric generating plants with a total steam-electric and combined-cycle nameplate capacity of 50 or more megawatts. Data for 1988-1980 are for steam-electric plants with a generator nameplate capacity of 50 or more megawatts.

Source: Federal Energy Regulatory Commission, FERC Form 423, "Monthly Report of Cost and Quality of Fuels for Electric Plants." 
Table 2. Average Delivered Cost of Coal by Census Division and State, 1988-1992

\begin{tabular}{|c|c|c|c|c|c|c|c|c|c|c|}
\hline \multirow{2}{*}{$\begin{array}{l}\text { Census Division } \\
\text { and State }\end{array}$} & 1992 & 1991 & 1990 & 1989 & 1988 & 1992 & 1991 & 1990 & 1989 & 1988 \\
\hline & \multicolumn{5}{|c|}{ (cents per million Btu) } & \multicolumn{5}{|c|}{ (dollare per short ton) } \\
\hline $\begin{array}{l}\text { New England } \\
\text { Connecticut }\end{array}$ & $\begin{array}{l}172.0 \\
194.8\end{array}$ & $\begin{array}{l}178.9 \\
216.6\end{array}$ & $\begin{array}{l}180.3 \\
212.9\end{array}$ & $\begin{array}{l}169.9 \\
213.7\end{array}$ & $\begin{array}{l}173.2 \\
228.6\end{array}$ & $\begin{array}{l}45.14 \\
51.30\end{array}$ & $\begin{array}{l}47.13 \\
57.35\end{array}$ & $\begin{array}{l}47.38 \\
56.35\end{array}$ & $\begin{array}{l}44.54 \\
56.88\end{array}$ & $\begin{array}{l}45.59 \\
60.07\end{array}$ \\
\hline Maine & - & - & - & -- & - & $\overline{11}$ & $\overline{a n}$ & - & - & $\overline{--}$ \\
\hline Massachusetts ............................ & $\begin{array}{l}168.7 \\
168.5\end{array}$ & $\begin{array}{l}172.5 \\
174.4\end{array}$ & $\begin{array}{l}173.4 \\
178.1\end{array}$ & $\begin{array}{l}160.2 \\
172.8\end{array}$ & $\begin{array}{l}161.2 \\
177.7\end{array}$ & $\begin{array}{l}44.11 \\
44.69\end{array}$ & $\begin{array}{l}45.33 \\
46.20\end{array}$ & $\begin{array}{l}45.30 \\
47.39\end{array}$ & $\begin{array}{l}41.68 \\
46.18\end{array}$ & $\begin{array}{l}42.25 \\
47.38\end{array}$ \\
\hline 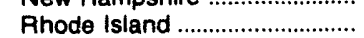 & - & -- & -- & - & - & - & 40.20 & - & 40.10 & - \\
\hline 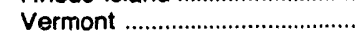 & -- & -- & -- & -- & -- & -- & -- & -. & -- & -- \\
\hline 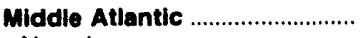 & 149.6 & 156.5 & 155.4 & 148.9 & 148.8 & 37.56 & 38.99 & 38.56 & 37.03 & 36.92 \\
\hline New Jersey ....................................... & 173.1 & 178.2 & 180.1 & 175.8 & 171.7 & 46.62 & 47.76 & 48.37 & 46.84 & 45.75 \\
\hline 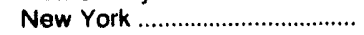 & 148.8 & 159.4 & 161.3 & 157.2 & 158.1 & 38.62 & 41.19 & $\$ 1.45$ & 40.32 & 40.52 \\
\hline 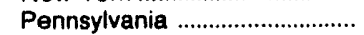 & 148.4 & 154.7 & 152.2 & 144.6 & 145.3 & 36.81 & 38.05 & 37.25 & 35.50 & 35.62 \\
\hline East North Central ........................... & 145.6 & 148.7 & 150.9 & 154.4 & 160.4 & 32.05 & 32.63 & 33.17 & 34.10 & 35.70 \\
\hline 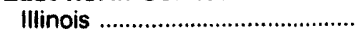 & 173.7 & 171.4 & 175.1 & 181.1 & 190.6 & 37.06 & 36.76 & 37.79 & 38.78 & 40.53 \\
\hline 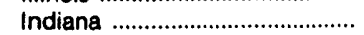 & 131.2 & 134.4 & 136.2 & 135.9 & 143.2 & 27.89 & 28.41 & 28.78 & 29.08 & 31.03 \\
\hline 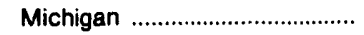 & 155.6 & 159.2 & 159.9 & 172.1 & 175.7 & 34.23 & 35.20 & 35.60 & 38.83 & 40.80 \\
\hline 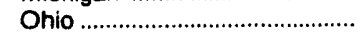 & 143.5 & 147.9 & 151.5 & 148.7 & 152.2 & 34.40 & 35.33 & 36.01 & 35.21 & 36.22 \\
\hline Wisconsin ................................... & 133.3 & 135.8 & 135.8 & 144.8 & 146.4 & 25.92 & 26.19 & 26.18 & 28.10 & 28.39 \\
\hline West North Central .................. & $110 . \mathrm{C}$ & 112.2 & 113.0 & 114.4 & 115.4 & 18.92 & 19.44 & 19.66 & 19.85 & 20.11 \\
\hline 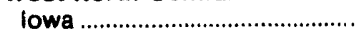 & 110.4 & 110.4 & 111.8 & 121.8 & 123.5 & 19.58 & 19.62 & 19.89 & 21.77 & 22.74 \\
\hline 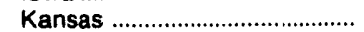 & 117.9 & 122.6 & 124.2 & 123.9 & 133.9 & 20.99 & 22.06 & 22.23 & 22.00 & 22.25 \\
\hline 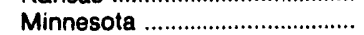 & 118.6 & 126.0 & 125.2 & 119.8 & 119.6 & 20.96 & 22.18 & 22.00 & 21.01 & 20.91 \\
\hline Missouri ............................................. & 133.6 & 134.2 & 134.8 & 135.0 & 138.2 & 27.57 & 27.55 & 28.03 & 28.00 & 28.75 \\
\hline 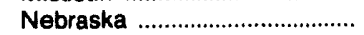 & 74.6 & 74.5 & 75.2 & 82.7 & 84.1 & 12.77 & 12.73 & 12.88 & 14.32 & 14.49 \\
\hline North Dakota ................................ & 72.1 & 70.9 & 68.6 & 69.4 & 70.3 & 9.45 & 9.37 & 9.10 & 9.13 & 9.26 \\
\hline South Dakota & 113.3 & 113.3 & 114.6 & 124.1 & 121.4 & 13.68 & 13.65 & 13.97 & 15.24 & 15.39 \\
\hline South Atlantic ........................... & 165.6 & 169.7 & 168.9 & 165.8 & 166.5 & 41.28 & 42.18 & $\$ 1.86$ & 41.19 & 41.54 \\
\hline 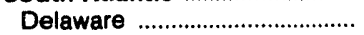 & 173.4 & 178.2 & 181.5 & 179.3 & 180.6 & 45.31 & 46.51 & 47.31 & 46.41 & 46.60 \\
\hline District of Columbia ....................... & -- & - & -- & - & - & -- & - & -- & - & - \\
\hline 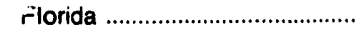 & 182.0 & 185.7 & 184.9 & 178.7 & 177.7 & 45.03 & 45.87 & 45.72 & 44.26 & 44.16 \\
\hline 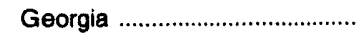 & 180.1 & 179.9 & 178.6 & 177.5 & 174.7 & 43.36 & 42.95 & 42.48 & 42.96 & 42.53 \\
\hline Maryland .................................... & 159.5 & 163.4 & 164.7 & 161.1 & 157.6 & 40.68 & 41.83 & 41.96 & 40.92 & 40.12 \\
\hline North Carolina ............................... & 172.6 & 177.9 & 178.0 & 177.0 & 177.5 & 43.00 & 44.49 & 44.64 & 44.35 & 44.65 \\
\hline South Carolina ............................... & 152.7 & 162.6 & 172.0 & 170.7 & 176.0 & 39.13 & 41.37 & 43.54 & 43.08 & 44.63 \\
\hline 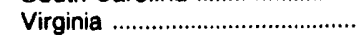 & 147.3 & 152.2 & 154.5 & 154.8 & 155.1 & 37.81 & 38.87 & 39.29 & 39.29 & 39.72 \\
\hline 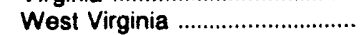 & 147.2 & 151.7 & 147.2 & 142.5 & 144.1 & 36.88 & 37.93 & 36.66 & 35.33 & 35.95 \\
\hline East South Central ........................ & 138.5 & 142.3 & 143.3 & 142.9 & 148.4 & 33.05 & 33.93 & 33.88 & 33.73 & 35.36 \\
\hline 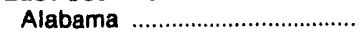 & 172.7 & 181.0 & 184.3 & 186.5 & 194.7 & 41.67 & 43.82 & 44.58 & 44.84 & 47.37 \\
\hline 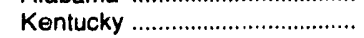 & 116.2 & 117.7 & 119.3 & 113.7 & 119.8 & 27.01 & 27.19 & 27.58 & 26.13 & 27.61 \\
\hline Mississippi ………………….......... & 159.7 & 166.9 & 165.4 & 167.1 & 181.2 & 39.94 & 41.92 & 41.49 & 42.29 & 45.88 \\
\hline Tennessee ................................... & 127.3 & 125.2 & 134.2 & 134.3 & 133.5 & 31.01 & 30.48 & 32.12 & 31.94 & 32.17 \\
\hline West South Central ..................... & 147.4 & 148.9 & 148.8 & 147.5 & 149.5 & 22.55 & 22.98 & 22.91 & 22.69 & 23.08 \\
\hline Arkansas .................................. & 165.3 & 159.7 & 161.1 & 163.1 & 158.5 & 28.84 & 27.90 & 28.17 & 28.45 & 27.47 \\
\hline Louisiana ................................ & 153.5 & 164.7 & 169.5 & 162.7 & 155.5 & 24.93 & 27.09 & 27.78 & 26.64 & 25.48 \\
\hline Oklahoma ................................. & 123.4 & 131.8 & 140.4 & 136.1 & 148.2 & 21.47 & 23.17 & 24.98 & 24.03 & 26.42 \\
\hline Texas ...……………………...... & 149.1 & 149.9 & 145.3 & 144.9 & 147.2 & 21.58 & 21.66 & 21.19 & 21.12 & 21.50 \\
\hline 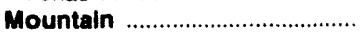 & 111.3 & 113.6 & 113.3 & 111.6 & 109.5 & 21.64 & 22.22 & 22.19 & 21.80 & 21.32 \\
\hline 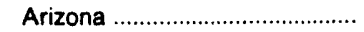 & 137.4 & 140.8 & 143.0 & 136.0 & 140.5 & 28.31 & 29.16 & 29.98 & 28.81 & 29.92 \\
\hline Colorado ...................................... & 109.2 & 108.7 & 106.1 & 106.4 & 106.6 & 21.67 & 21.49 & 20.81 & 20.95 & 20.84 \\
\hline Idaho & - & -- & -- & -- & - & -- & -- & - & - & - \\
\hline Montana ................................. & 70.8 & 67.1 & 67.0 & 57.7 & 54.5 & 12.14 & 11.44 & 11.47 & 9.81 & 9.29 \\
\hline Nevada & 146.2 & 140.6 & 149.1 & 152.0 & 136.3 & 32.32 & 31.28 & 33.16 & 33.80 & 30.21 \\
\hline 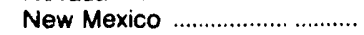 & 132.2 & 137.6 & 131.8 & 123.8 & 117.5 & 23.83 & 25.02 & 24.03 & 22.61 & 21.24 \\
\hline 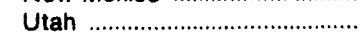 & 120.9 & 119.4 & 116.7 & 123.9 & 126.5 & 27.54 & 27.40 & 26.80 & 28.05 & 29.07 \\
\hline 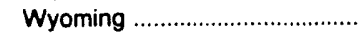 & 75.9 & 83.1 & 83.6 & 84.5 & 84.0 & 13.42 & 14.55 & 14.74 & 14.86 & 14.71 \\
\hline Pacific Contigueus ....................... & 129.6 & 142.6 & 149.4 & 155.6 & 154.5 & 22.17 & 23.16 & 24.42 & 25.40 & 25.41 \\
\hline California & -- & -- & -- & -- & - & - & - & - & - & - \\
\hline 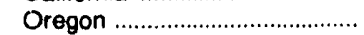 & 110.1 & 108.4 & 107.9 & -- & 139.0 & 21.23 & 18.28 & 18.02 & - & 23.70 \\
\hline Washington .............................. & 137.3 & 155.1 & 157.6 & 155.6 & 155.2 & 22.48 & 24.86 & 25.64 & 25.40 & 25.48 \\
\hline Pacific Noncontiguous ............. & - & -- & -- & - & - & - & - & - & - & - \\
\hline Alaska & - & - & - & -- & - & - & - & - & -- & -- \\
\hline 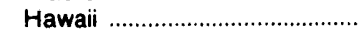 & -- & -- & -- & -- & -- & -- & -- & -- & -- & - \\
\hline Total & 141.2 & 144.7 & 145.5 & 144.6 & 146.6 & 29.36 & 30.02 & 30.45 & 30.15 & 30.64 \\
\hline
\end{tabular}

Notes: - Totals may not equal sum of components because of independent rounding. - As of 1991, data are for electric generating plants with a total steam-electric and combined-cycle nameplate capacity of 50 or more megawatts. Data for 1988.1990 are for steam-electric plants with a generator nameplate capacity of 50 or more megawatts.

Source: Federal Energy Regulatory Commission, FERC Form 423, "Monthly Report of Cost and Quality of Fuels for Electric Plants." 
Table 3. Receipts and Average Delivered Cost of Coal by Census Division and State, 1992

\begin{tabular}{|c|c|c|c|c|c|c|c|c|c|c|c|c|}
\hline \multirow{3}{*}{$\begin{array}{l}\text { Census Division } \\
\text { and State }\end{array}$} & \multicolumn{6}{|c|}{ Type of Purchase } & \multicolumn{6}{|c|}{ Mine Type } \\
\hline & \multicolumn{3}{|c|}{ Contract } & \multicolumn{3}{|c|}{ Spot } & \multicolumn{3}{|c|}{ Surface } & \multicolumn{3}{|c|}{ Underground } \\
\hline & $\begin{array}{c}\text { Pecelpts } \\
\text { (1,000 } \\
\text { short } \\
\text { tons) }\end{array}$ & $\begin{array}{l}\text { (cents } \\
\text { per } \\
10^{8} \\
\text { Btu) }\end{array}$ & $\begin{array}{l}\text { (\$ per } \\
\text { short } \\
\text { ton) }\end{array}$ & $\begin{array}{c}\text { Receipts } \\
(1,000 \\
\text { short } \\
\text { tons) }\end{array}$ & $\begin{array}{l}\text { (cents } \\
\text { per } \\
10^{4} \\
\text { Btu) }\end{array}$ & $\begin{array}{l}\text { (S per } \\
\text { short } \\
\text { ton) }\end{array}$ & $\begin{array}{c}\text { Recelpts } \\
(1,000 \\
\text { short } \\
\text { tons) }\end{array}$ & $\begin{array}{c}\text { (cents } \\
\text { per } \\
10^{8} \\
\text { Btu) }\end{array}$ & $\begin{array}{l}\text { (s per } \\
\text { short } \\
\text { ton) }\end{array}$ & $\begin{array}{c}\text { Recelpts } \\
(1,000 \\
\text { short } \\
\text { tons) }\end{array}$ & $\begin{array}{c}\text { (cents } \\
\text { per } \\
10^{6} \\
\text { Btu) }\end{array}$ & $\begin{array}{l}\text { (\$ per } \\
\text { short } \\
\text { ton) }\end{array}$ \\
\hline 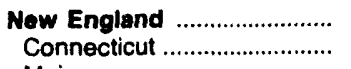 & $\begin{array}{r}5,514 \\
713\end{array}$ & $\begin{array}{l}172.7 \\
196.7\end{array}$ & $\begin{array}{l}45.35 \\
51.85\end{array}$ & $\begin{array}{r}699 \\
80\end{array}$ & $\begin{array}{l}166.4 \\
177.9\end{array}$ & $\begin{array}{l}43.48 \\
46.34\end{array}$ & 117 & 156.8 & 39.83 & $\begin{array}{r}6,095 \\
793\end{array}$ & $\begin{array}{l}172.3 \\
194.8\end{array}$ & $\begin{array}{l}45.24 \\
51.30\end{array}$ \\
\hline 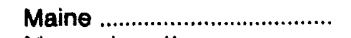 & $-\bar{r}$ & -5 & $\bar{n}$ & - & $-\overline{0}$ & $\bar{x}$ & $\bar{z}$ & $\overline{-}$ & $\overline{-}$ & $\overline{-}$ & -- & $\overline{16}$ \\
\hline 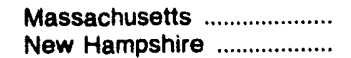 & 3,725 & $\begin{array}{l}169.3 \\
168.9\end{array}$ & $\begin{array}{l}44.24 \\
44.89\end{array}$ & $\begin{array}{l}468 \\
151\end{array}$ & $\begin{array}{l}164.6 \\
165.8\end{array}$ & $\begin{array}{l}43.06 \\
43.27\end{array}$ & $\begin{array}{l}35 \\
83\end{array}$ & $\begin{array}{l}145.3 \\
161.8\end{array}$ & $\begin{array}{l}37.47 \\
40.83\end{array}$ & $\begin{array}{l}4,159 \\
1,144\end{array}$ & 168.9 & $\begin{array}{l}44.16 \\
44.97\end{array}$ \\
\hline 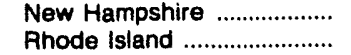 & $\begin{array}{r}.076 \\
-\end{array}$ & 38.9 & 44.89 & $\begin{array}{r}151 \\
-\end{array}$ & $\begin{array}{c}5.8 \\
-\end{array}$ & $\begin{array}{l}3.21 \\
--\end{array}$ & - & $\begin{aligned} 61.8 \\
--\end{aligned}$ & $\begin{array}{r}0.83 \\
-\end{array}$ & $\begin{array}{r}144 \\
--\end{array}$ & $\begin{array}{l}99.0 \\
--\end{array}$ & $\begin{array}{l}4.97 \\
--\end{array}$ \\
\hline Vermont ......................... & - & - & 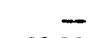 & 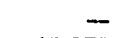 & -- & 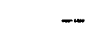 & 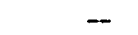 & -- & -- & -- & -- & - \\
\hline Middle Attantic .......................... & 38,005 & 158.7 & 39.90 & 15,675 & 127.5 & 31.89 & 18,549 & 139.4 & 34.38 & 35,131 & 154.8 & 39.24 \\
\hline New Jersey ................................ & 2,055 & 173.9 & 46.94 & 150 & 161.5 & 42.24 & 632 & 169.8 & 44.06 & 1.573 & 174.4 & 47.65 \\
\hline New York ................................ & 5,739 & 156.5 & 41.08 & 4,654 & 139.0 & 35.58 & 1,740 & 140.8 & 33.84 & 8,653 & 150.2 & 39.58 \\
\hline 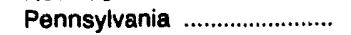 & 30,211 & 158.0 & 39.20 & 10,871 & 121.9 & 30.16 & 16,177 & 138.0 & 34.06 & 24,905 & 155.2 & 38.60 \\
\hline East North Contral .................. & 132,373 & 153.8 & 33.72 & 36,973 & 116.7 & 26.06 & 112,825 & 141.9 & 30.01 & 56,521 & 152.3 & 36.13 \\
\hline 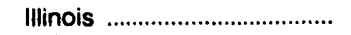 & 22,731 & 179.9 & 38.13 & 2,718 & 124.9 & 28.10 & 13,718 & 201.1 & 41.12 & 11,731 & 144.4 & 32.31 \\
\hline Indiana & 34,846 & 136.9 & 28.68 & 12,992 & 116.8 & 25.78 & 35,423 & 122.5 & 25.57 & 12,415 & 154.6 & 34.54 \\
\hline 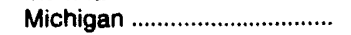 & 22,958 & 160.6 & 35.26 & 4,917 & 132.7 & 29.39 & 21,487 & 151.0 & 31.40 & 6,388 & 168.1 & 43.73 \\
\hline 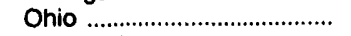 & 39,311 & 153.9 & 36.85 & 11,284 & 107.5 & 25.87 & 27,445 & 138.1 & 32.71 & 23,151 & 149.9 & 36.40 \\
\hline 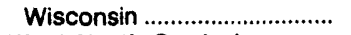 & 12,528 & 138.8 & 27.14 & 5,062 & 119.2 & 22.90 & 14,754 & 127.6 & 23.30 & 2,83 & 154.4 & 39.54 \\
\hline Weat North Central .............. & 86,379 & 113.2 & 19.35 & 15,265 & 92.5 & 16.48 & 92,543 & 102.5 & 17.05 & 9,101 & 164.6 & 37.99 \\
\hline $\begin{array}{l}\text { lowa } \\
\text { Kansas }\end{array}$ & 10,948 & 120.9 & 21.6 & 4,088 & 81.1 & 13.92 & 14,325 & 108.7 & 19.00 & 712 & 136.2 & $\begin{array}{l}31.21 \\
34.93\end{array}$ \\
\hline 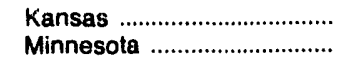 & 9,917 & 126.4 & 22.26 & $\begin{array}{r}3.717 \\
590\end{array}$ & $\begin{array}{r}96.2 \\
114.4\end{array}$ & $\begin{array}{l}17.60 \\
20.89\end{array}$ & $\begin{array}{l}12,970 \\
15080\end{array}$ & $\begin{array}{l}115.6 \\
118.3\end{array}$ & 20.27 & 665 & 152.3 & $\begin{array}{l}34.93 \\
38.29\end{array}$ \\
\hline 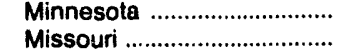 & $\begin{array}{l}14,564 \\
20,251\end{array}$ & $\begin{array}{l}118.7 \\
137.8\end{array}$ & $\begin{array}{l}20.96 \\
28.89\end{array}$ & $\begin{array}{r}590 \\
4,251\end{array}$ & $\begin{array}{l}114.4 \\
111.5\end{array}$ & $\begin{array}{l}20.89 \\
21.25\end{array}$ & $\begin{array}{l}15,080 \\
16,883\end{array}$ & $\begin{array}{l}118.3 \\
115.0\end{array}$ & $\begin{array}{l}20.87 \\
22.45\end{array}$ & $\begin{array}{r}74 \\
7,619\end{array}$ & $\begin{array}{l}158.8 \\
168.4\end{array}$ & $\begin{array}{l}38.29 \\
38.90\end{array}$ \\
\hline 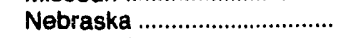 & 5,635 & 77.6 & 13.37 & 2,124 & 66.5 & 11.17 & 7,728 & 74.2 & 12.68 & 31 & 151.1 & 33.99 \\
\hline 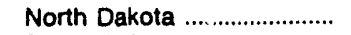 & 22,933 & 72.6 & 9.53 & 494 & 45.1 & 5.72 & 23,427 & 72.1 & 9.45 & -- & -- & -- \\
\hline South Dakota ............................ & 2,130 & 113.3 & 13.68 & - & - & -- & 2,130 & 113.3 & 13.68 & -- & - & -- \\
\hline $\begin{array}{c}\text { South Atlantic } \\
\text { Delaware }\end{array}$ & $\begin{array}{r}97,236 \\
1,509\end{array}$ & $\begin{array}{l}175.0 \\
173.4\end{array}$ & $\begin{array}{l}43.58 \\
45.31\end{array}$ & $\begin{array}{r}27,946 \\
22\end{array}$ & $\begin{array}{l}133.1 \\
174.4\end{array}$ & $\begin{array}{l}33.27 \\
45.39\end{array}$ & $\begin{array}{r}44,753 \\
76\end{array}$ & $\begin{array}{l}166.8 \\
173.1\end{array}$ & $\begin{array}{l}41.31 \\
44.77\end{array}$ & $\begin{array}{r}80,428 \\
1,455\end{array}$ & $\begin{array}{l}165.0 \\
173.4\end{array}$ & $\begin{array}{l}41.26 \\
45.34\end{array}$ \\
\hline of Columbia .................. & & - & - & - & - & - & - & - & - & - & - & $\begin{array}{r}40.34 \\
-\end{array}$ \\
\hline 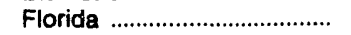 & 18,828 & 194.8 & 48.37 & 5,550 & 137.9 & 33.69 & 7,805 & 182.8 & 44.83 & 16,572 & 181.6 & 45.12 \\
\hline 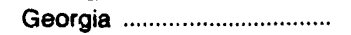 & 19,539 & 35.9 & 44.74 & 3,312 & 145.9 & 35.24 & 9,690 & 162.8 & 41 & 161 & & 46.27 \\
\hline d & 7,062 & 163.2 & 41.56 & 2,222 & 147.6 & 37.87 & 5,541 & 165.6 & 41.67 & 3,743 & 150.8 & 39.21 \\
\hline arolina ............................ & 15,726 & 182.4 & 45.41 & 4,934 & 141.4 & 5.32 & 8,691 & 172.8 & & 11,969 & 172.4 & 42.97 \\
\hline Carolina .......................... & 5,514 & 159.0 & 40.61 & 3,741 & 143.4 & 36.96 & 1,646 & 153.7 & 39.51 & 7,610 & 152.4 & 39.05 \\
\hline Virgin & 6,463 & 150.1 & 38.58 & 2,452 & 140.1 & 5.76 & 3,389 & 43.9 & & & & \\
\hline irginia ......................... & 22,594 & 159.5 & 39.98 & 5,713 & 98.4 & 24.61 & 7,916 & 163.0 & 40.28 & 20,391 & 141.2 & 35.56 \\
\hline East South Central ............... & 67,542 & 143.2 & 34.19 & 13,217 & 114.4 & 27.20 & $\mathbf{3 8 , 5 1 0}$ & 136.9 & 32.54 & 2,248 & 139.9 & 33.51 \\
\hline Alabama & 21,173 & 180.9 & 43.63 & 3,713 & 126.2 & 0.48 & 11,527 & 172.5 & 41.97 & 13,360 & 172.9 & 41.40 \\
\hline 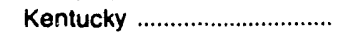 & 24,686 & 119.0 & 27.53 & 7,607 & 107.3 & 25.33 & 20,924 & 117.9 & 27.80 & 11,368 & 113.0 & 25.55 \\
\hline$\ldots \ldots \ldots \ldots \ldots \ldots \ldots \ldots \ldots$ & 2,626 & 165.3 & 42.02 & 582 & 131.9 & 30.53 & 1,094 & 141.6 & 4.58 & 2,114 & & 42.71 \\
\hline 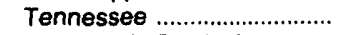 & 19,057 & 128.2 & 31.27 & 1,316 & 114.1 & 27.32 & 4,965 & 130.3 & 30.19 & 15,407 & 126.4 & 31.28 \\
\hline West South Central .............. & 122,561 & 148.6 & 22.55 & 6,196 & 127.7 & 22.64 & 128,183 & 147.3 & 22.48 & 574 & 166.0 & 38.50 \\
\hline 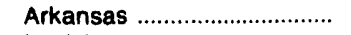 & 11,156 & 166.9 & 29.17 & 474 & 125.9 & 21.19 & 30 & 165.3 & 28.84 & -- & -- & - \\
\hline 19 & 12,675 & 153.5 & 24.93 & -- & - & -- & & 153.5 & 24.93 & - & -- & -- \\
\hline$\ldots$ & 14,960 & 127.2 & 22.16 & 1,880 & 92.2 & 15.95 & 16,840 & 123.4 & 21.47 & -- & -- & -- \\
\hline 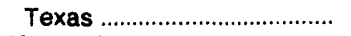 & 83,771 & 149.4 & 21.37 & 3,842 & 144.5 & 26.10 & 87,039 & 149.0 & 21.47 & 574 & 166.0 & 38.50 \\
\hline 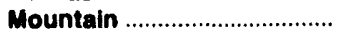 & 94,908 & 113.4 & 22.00 & 7,709 & & 17.20 & 84,065 & 107.1 & 20.05 & 18,552 & 126.7 & 28.86 \\
\hline$\ldots \ldots \ldots \ldots \ldots . .$. & 14,734 & 140.8 & 29.18 & 1,581 & 103.1 & 20.19 & & 137.1 & 28.22 & 119 & 167.5 & 40.74 \\
\hline$\ldots \ldots \ldots \ldots . .$. & 13,663 & 110.8 & 21.75 & 1,934 & $\mathbf{9 9 . 0}$ & 21.07 & 12,121 & 110.0 & 21.08 & 3,476 & 106.7 & 23.71 \\
\hline 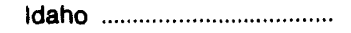 & & -- & - & - & - & -- & -- & -- & - & -- & -- & \\
\hline ........... & 10,860 & 70.8 & & - & - & -- & 10,860 & 70.8 & & -. & - & \\
\hline .......... & 7,894 & 146.2 & 32.32 & -- & -- & -- & 5,777 & 129.0 & 27.79 & 2,117 & 189.2 & 44.70 \\
\hline 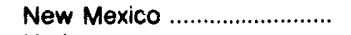 & & 132.2 & 23.83 & -- & - & -- & 14,929 & 132.2 & 23.83 & -- & -- & -- \\
\hline 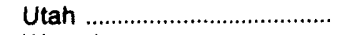 & 11,733 & 123.9 & 28.05 & 1,107 & 91.8 & 22.10 & - & - & -- & 12,840 & 120.9 & 27.54 \\
\hline Wyoming. & 21,095 & 77.8 & 13.70 & 3.086 & 63.3 & 11.49 & 24,181 & 75.9 & 13.42 & - & -- & \\
\hline 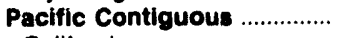 & 4,943 & 139.7 & 22.06 & 2,825 & 115.3 & 22.37 & 7,669 & 130.0 & 22.14 & 99 & 106.9 & 24.37 \\
\hline$\ldots \ldots \ldots \ldots \ldots \ldots \ldots \ldots$ & -- & -- & -- & -- & -- & $\overline{-}$ & $-\overline{-}$ & $\overline{-}$ & -- & -- & -- & \\
\hline$\ldots \ldots \ldots \ldots \ldots \ldots$ & $\overline{-}$ & $\overline{7}$ & $\overline{-}$ & 1,932 & 110.1 & 21.23 & 1,833 & 110.3 & 21.06 & 99 & 106.9 & 24.37 \\
\hline & 4,943 & 139.7 & 22.06 & 893 & 126.4 & 24.84 & 5,836 & 137.3 & 22.48 & -- & -- & \\
\hline Pacific Noncontiguous ........ & - & - & - & - & - & - & - & - & -- & - & - & - \\
\hline Alask & -- & - & - & - & - & - & - & - & - & -- & -- & \\
\hline$\ldots$ & - & - & -- & - & -- & -- & - & - & -- & -- & -- & \\
\hline 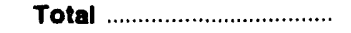 & 649,460 & 146.0 & 29.89 & 126,503 & 118.7 & 26.64 & 527,214 & 133.5 & 25.50 & 248,749 & 154.0 & 37.53 \\
\hline
\end{tabular}

Notes: - Totals may not equal sum of components because of independent rounding. - Data are for electric generating plants with a total steamelectric and combined-cycle nameplate capacity of 50 or more megawatts.

Source: Federal Energy Regulatory Commission, FERC Form 423, "Monthly Report of Cost and Quality of Fuels for Electric Plants." 
Table 4. Recelpts of Coal by Rank, Census Division, and State, 1992

(Thousand Short Tons)

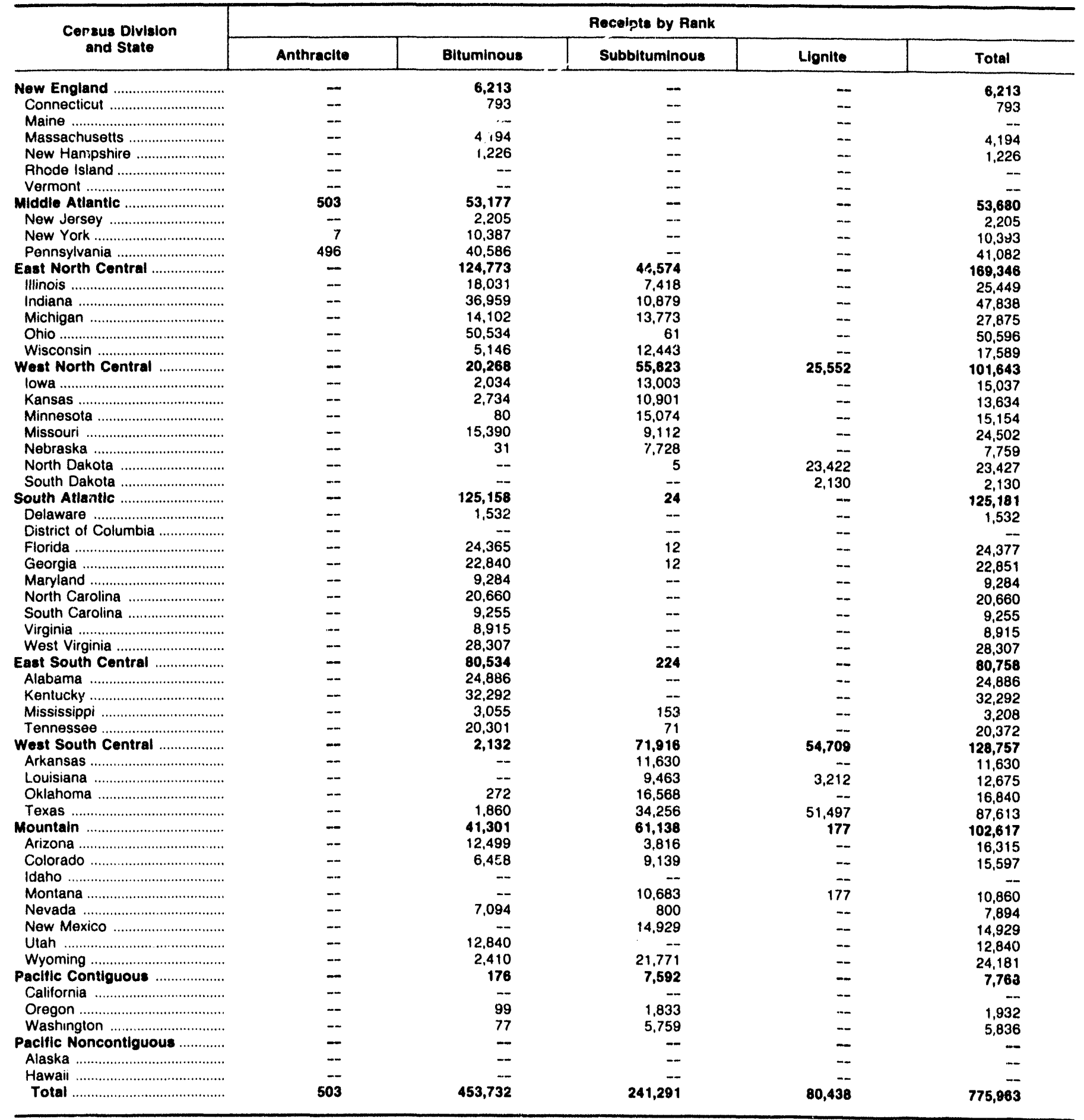

Notes: - Totals may not equal sum of components because of independent rounding. - Data are for electric generating plants with a total steamelectric and combined-cycle nameplate capacity of 50 or more megawatts.

Source: Federal Energy Regulatory Commission, FERC Form 423. "Monthly Report of Cost and Quality of Fuels for Electric Plants." 
Table 5. Receipts and Average Delivered Cost of Coal by Sulfur Content, Census Division and State, 1992

\begin{tabular}{|c|c|c|c|c|c|c|c|c|c|}
\hline \multirow[b]{2}{*}{$\begin{array}{l}\text { Census Division } \\
\text { and State }\end{array}$} & \multicolumn{3}{|c|}{$0.5 \%$ or Less } & \multicolumn{3}{|c|}{ More than $0.5 \%$ up to $1.0 \%$} & \multicolumn{3}{|c|}{ More thain $1.0 \%$ up to $1.5 \%$} \\
\hline & $\begin{array}{c}\text { Recelpts } \\
(1,000 \text { short } \\
\text { tons) }\end{array}$ & $\begin{array}{c}\text { (cents } \\
\text { per } \\
10^{6} \text { Btu) }\end{array}$ & $\begin{array}{l}\text { (5 per } \\
\text { st.urt } \\
\text { ton) }\end{array}$ & $\begin{array}{c}\text { Recelpts } \\
(1,000 \text { short } \\
\text { tons) }\end{array}$ & $\begin{array}{c}\text { (cents } \\
\text { per } \\
10^{\circ} \text { Btu) }\end{array}$ & $\begin{array}{l}\text { (5 per } \\
\text { short } \\
\text { ton) }\end{array}$ & $\begin{array}{c}\text { Receipts } \\
(1,000 \text { short } \\
\text { tons) }\end{array}$ & $\begin{array}{c}\text { (cents } \\
\text { per } \\
10^{\circ} \text { Btu) }\end{array}$ & $\begin{array}{l}\text { (\$ per } \\
\text { short } \\
\text { ton) }\end{array}$ \\
\hline New England ............................ & -- & - & - & 1,950 & 180.9 & 47.2 .4 & 3,280 & 168.0 & 44.04 \\
\hline 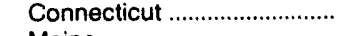 & -- & -- & -- & 793 & 194.8 & 51.30 & -- & -- & - \\
\hline Maine & - & -- & -- & $-\cdots$ & -- & -- & -- & -- & -- \\
\hline Massachusetts ...................... & -- & -- & -- & 942 & 171.5 & 44.51 & 3,090 & 167.8 & 43.96 \\
\hline New Hampshire ...................... & -- & -- & -- & 215 & 170.2 & 44.28 & 190 & 170.7 & 45.35 \\
\hline 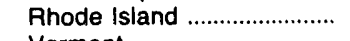 & -- & -- & -- & - & -- & -- & - & -- & -- \\
\hline Vermont & $\overline{-}$ & $\vec{a}$ & $\overline{-\overline{-}}$ & $5 \overline{-12}$ & 10 & $\overline{--}$ & $\overline{-i n}$ & $\overline{-}$ & $\overline{-}=$ \\
\hline Middle Atiantic ........................ & 140 & 164.3 & 36.52 & 5,643 & 169.2 & 43.02 & 4,431 & 132.7 & 41.35 \\
\hline 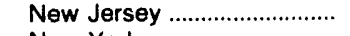 & 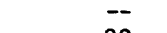 & -- & -- & 1,553 & 176.1 & 48.06 & -- & - & -- \\
\hline New York .................................. & 82 & 187.4 & 47.61 & 1,678 & 186.8 & 47.60 & 1,322 & 144.2 & 36.99 \\
\hline Pennsylvania ........................... & 58 & 117.4 & 20.82 & 2,412 & 151.3 & 36.58 & 3,109 & 170.6 & 43.20 \\
\hline East North Central .................. & 43,865 & 149.3 & 27.10 & 29,209 & 160.6 & 38.58 & 15,267 & 153.2 & 36.81 \\
\hline 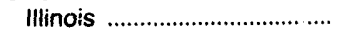 & 8,208 & 245.2 & 47.14 & 2,034 & 161.9 & 41.28 & 184 & 123.5 & 27.34 \\
\hline 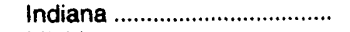 & 11,619 & 123.1 & 21.74 & 5,055 & 151.2 & 36.10 & 3,983 & 153.1 & 33.36 \\
\hline 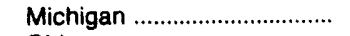 & 13,084 & 140.3 & 26.11 & 10,424 & 168.5 & 41.46 & 3,596 & 163.9 & 42.81 \\
\hline 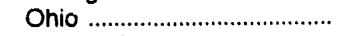 & 104 & 142.2 & 28.07 & 8,964 & 156.4 & 37.71 & 5,870 & 147.3 & 35.45 \\
\hline 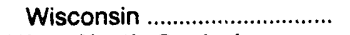 & 10,849 & 109.0 & 18.87 & 2,731 & 159.5 & 33.02 & 1,633 & 151.7 & 37.98 \\
\hline & 50,287 & 102.0 & 17.74 & 31,316 & 89.2 & 12.63 & 4,665 & 163.0 & 32.20 \\
\hline 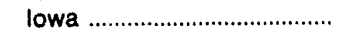 & 12,706 & 100.8 & 17.14 & 106 & 108.4 & 19.57 & 215 & 101.6 & 17.65 \\
\hline 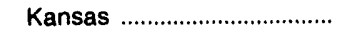 & 12,556 & 114.8 & 19.95 & 174 & 123.1 & 25.83 & - & - & - \\
\hline Minnesota & 8,172 & 116.1 & 20.58 & 6,902 & 121.0 & 21.21 & 32 & 164.4 & 37.21 \\
\hline 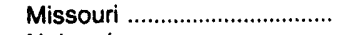 & 9,126 & 96.2 & 17.24 & 590 & 111.8 & 20.08 & 2,833 & 194.7 & 45.47 \\
\hline Nebraska ................................. & 7,728 & 74.2 & 12.68 & 31 & 151.0 & 33.97 & -- & -- & - \\
\hline North Dakota ............................. & -- & -- & -- & 21,601 & 72.1 & 9.42 & 1,368 & 71.6 & 9.90 \\
\hline South Dakota & $\overline{-}$ & - & $\overline{-}$ & 1,912 & 113.6 & 13.72 & 218 & 110.7 & 13.27 \\
\hline 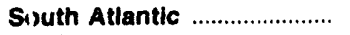 & 302 & 148.1 & 36.83 & 48,825 & 171.5 & 42.97 & 32,832 & 165.4 & 41.67 \\
\hline 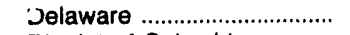 & -- & -- & -- & 863 & 179.8 & 46.89 & 561 & 166.8 & 43.65 \\
\hline District of Columbia ............... & -- & -- & -- & -- & $-\overline{7}$ & $\overline{-}$ & $-\bar{n}$ & -- & -- \\
\hline Florida & 224 & 148.6 & 37.60 & 8,379 & 176.7 & 44.37 & 5,801 & 188.3 & 47.88 \\
\hline 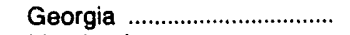 & 37 & 156.1 & 35.65 & 5,079 & 187.4 & 46.01 & 8,536 & 166.3 & 40.88 \\
\hline 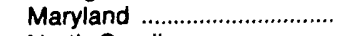 & - & -- & -- & 3,644 & 155.6 & 39.84 & 1,034 & 143.9 & 36.75 \\
\hline North Carolina ......................... & 40 & 138.1 & 33.61 & 14,531 & 173.5 & 42.99 & 6,072 & 170.8 & 43.08 \\
\hline South Carolina .......................... & -- & -- & -- & 3,178 & 154.5 & 39.84 & 5,224 & 152.1 & 38.90 \\
\hline 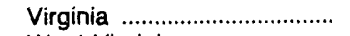 & -- & -- & - & 5,270 & 145.8 & 37.20 & 3,322 & 148.0 & 38.23 \\
\hline West Virginia ........................... & -- & -- & - & 7,882 & 183.7 & 45.65 & 2,282 & 155.0 & 38.15 \\
\hline East South Central .................. & 433 & 194.1 & 39.22 & 24,079 & 166.1 & 40.81 & 7,852 & 129.4 & 32.06 \\
\hline 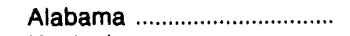 & 209 & 217.9 & 54.47 & 12,165 & 199.4 & 48.33 & 2,081 & 141.7 & 34.52 \\
\hline 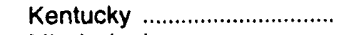 & $=-$ & -- & -- & 7,972 & 126.2 & 30.95 & 1,854 & 120.5 & 29.02 \\
\hline 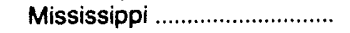 & 153 & 143.6 & 26.11 & 1,381 & 184.9 & 47.06 & 216 & 192.7 & 47.67 \\
\hline 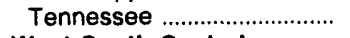 & 71 & 132.1 & 22.73 & 2,561 & 125.8 & 32.44 & 3,702 & 123.4 & 31.30 \\
\hline West South Central .............. & 80,136 & 159.3 & 26.82 & 17,451 & 117.9 & 15.25 & 26,686 & 123.7 & 15.87 \\
\hline 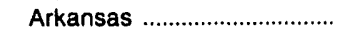 & 11,630 & 165.3 & 28.84 & -- & ..- & - & - & -- & -- \\
\hline 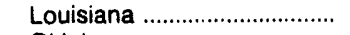 & 9,416 & 157.5 & 26.83 & 3,259 & 139.4 & 19.45 & 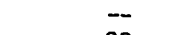 & -- & - \\
\hline 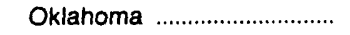 & 16,623 & 123.6 & 21.38 & 11 & 161.2 & 37.69 & 33 & 118.2 & 30.90 \\
\hline 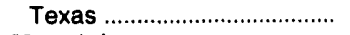 & 42,468 & 172.6 & 20.39 & 14,181 & 112.4 & 14.26 & 26,654 & 123.7 & 15.85 \\
\hline 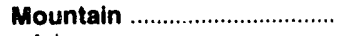 & 47,031 & 114.1 & 22.67 & 55,516 & 108.9 & 20.78 & 69 & 77.2 & 14.81 \\
\hline 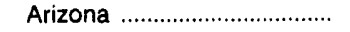 & 7.433 & 158.1 & 31.78 & 8,883 & 120.8 & 25.40 & -- & - & -- \\
\hline Colorado ……........................ & 14,526 & 110.1 & 21.77 & 1,034 & 97.3 & 20.44 & 36 & 93.0 & 15.51 \\
\hline Idaho & $\overline{-}$ & -- & -- & $\overline{-}$ & - & - & -- & - & - \\
\hline 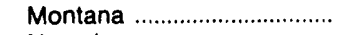 & 123 & 107.4 & 14.11 & 10,737 & 70.5 & 12.12 & -- & -- & -- \\
\hline 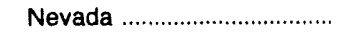 & 4,043 & 149.6 & 33.12 & 3,850 & 142.7 & 31.48 & -- & -- & -- \\
\hline New Mexico ............................. & -- & -- & -- & 14,929 & 132.2 & 23.83 & - & -- & -- \\
\hline 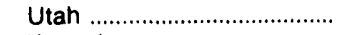 & 10,081 & 122.2 & 27.87 & 2,759 & 116.2 & 26.31 & -- & -- & -- \\
\hline 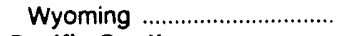 & 10,825 & 54.9 & 8.97 & 13,323 & 90.8 & 17.04 & 33 & 64.1 & 14.05 \\
\hline Pacific Contiguous ................ & 2,781 & 115.0 & 22.26 & 4,986 & 139.6 & 22.12 & - & - & - \\
\hline California .................................... & -- & -- & $-\overline{0}$ & -- & -- & -- & -- & -- & - \\
\hline 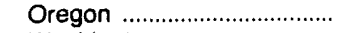 & 1,932 & 110.1 & 21.23 & - & -- & -- & - & - & - \\
\hline 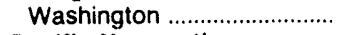 & 849 & 126.0 & 24.62 & 4,986 & 139.6 & 22.12 & - & - & -- \\
\hline Pacific Noncontiguous ........ & - & -- & -- & -- & -- & -- & - & - & - \\
\hline Alaska & - & - & - & - & -- & - & -- & -- & -- \\
\hline Hawaii .................................. & -- & -- & $\overline{--}$ & -- & -- & $\overline{-}$ & -- & - & -- \\
\hline Total & 224,975 & 133.8 & 23.96 & 218,974 & 143.1 & 29.54 & 95,082 & 152.5 & 32.44 \\
\hline
\end{tabular}

Notes: - Totals may not equal sum of components because of independent rounding. - Data are for electric generating plants with a total steamelectric and combined-cycle nameplate capacity of 50 or more megawatts.

Source: Federal Energy Regulatory Commission, FERC Form 423, "Monthly Report of Cost and Quality of Fuels for Electric Plants." 
Table 5. Receipts and Average Delivered Cost of Coal by Sulfur Content, by Census Division and State, 1992 (Continued)

\begin{tabular}{|c|c|c|c|c|c|c|c|c|c|c|c|}
\hline \multirow[b]{2}{*}{$\begin{array}{l}\text { Consus Diviloion } \\
\text { and State }\end{array}$} & \multicolumn{3}{|c|}{ More than $1.5 \%$ up to $2.0 \%$} & \multicolumn{3}{|c|}{ More than $2.0 \%$ up to $3.0 \%$} & \multicolumn{3}{|c|}{ More than $3.0 \%$} & \multicolumn{2}{|c|}{ All Recolpts } \\
\hline & $\begin{array}{c}\text { Recolpte } \\
\text { (1,000 } \\
\text { ahort } \\
\text { tons })\end{array}$ & $\begin{array}{c}\text { (cents } \\
\text { per } \\
10^{\circ} \\
\text { Btu) }\end{array}$ & $\begin{array}{l}\text { (\$ per } \\
\text { short } \\
\text { ton) }\end{array}$ & $\begin{array}{c}\text { Receipts } \\
\text { (1,000 } \\
\text { short } \\
\text { tons) }\end{array}$ & $\begin{array}{c}\text { cents } \\
\text { per } \\
10^{\prime} \\
\text { Btu) }\end{array}$ & $\begin{array}{l}\text { (5 per } \\
\text { short } \\
\text { ton) }\end{array}$ & $\begin{array}{c}\text { Recelpts } \\
\text { (1,000 } \\
\text { short } \\
\text { tons) }\end{array}$ & $\begin{array}{c}\text { (cents } \\
\text { por } \\
10^{\circ} \\
\text { Btu) }\end{array}$ & $\begin{array}{l}\text { (\$ per } \\
\text { short } \\
\text { ton) }\end{array}$ & $\begin{array}{c}\text { (cents } \\
\text { per } \\
10^{\circ} \\
\text { Btu) }\end{array}$ & $\begin{array}{l}\text { (\$ per } \\
\text { short } \\
\text { (on) }\end{array}$ \\
\hline Now England ............................ & 731 & 170.1 & 45.07 & 252 & 161.7 & 43.38 & - & - & - & 172.0 & 45.14 \\
\hline 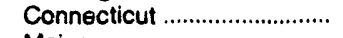 & -- & - & - & -- & - & - & -- & -- & -- & 194.8 & 51.30 \\
\hline 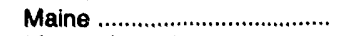 & -- & -- & - & -- & - & - & - & -- & -- & -- & - \\
\hline Massachusetts ........................... & 162 & 169.7 & 44.60 & - & - & - & -- & -- & -- & 168.7 & 44.11 \\
\hline New Hampshire ........................ & 569 & 170.2 & 45.20 & 252 & 161.7 & 43.38 & -- & - & -- & 168.5 & 44.69 \\
\hline 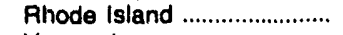 & - & -- & - & -- & - & - & -- & - & - & - & - \\
\hline Vermont ................................... & - & - & -- & - & - & - & -- & - & - & - & -- \\
\hline Middio Atlantic ....................... & 17,798 & 147.5 & 37.30 & 20,782 & 138.7 & 34.71 & 4,886 & 168.8 & 40.96 & 149.6 & 37.56 \\
\hline New Jersey .................................. & & 148.3 & 40.16 & 644 & 165.9 & 43.22 & -- & -- & -- & 173.1 & 46.62 \\
\hline Now York ................................ & 4,397 & 143.9 & 37.47 & 2,915 & 135.9 & 35.67 & - & -- & -- & 148.8 & 38.62 \\
\hline Pennsylvania .............................. & 13,394 & 148.7 & 37.25 & 17,223 & 138.1 & 34.22 & 4,886 & 168.8 & 40.96 & 148.4 & 36.81 \\
\hline East North Central ................. & 9,144 & 134.9 & 31.85 & 30,537 & 131.0 & 30.06 & 41,325 & 141.8 & 32.43 & 145.6 & 32.05 \\
\hline 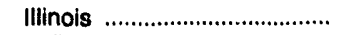 & 717 & 107.3 & 24.74 & 8,075 & 139.0 & 30.95 & 6,230 & 150.2 & 32.03 & 173.7 & 37.06 \\
\hline 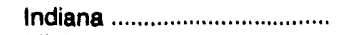 & 3,798 & 129.2 & 28.45 & 11,390 & 113.0 & 25.21 & 11,992 & 139.4 & 30.96 & 131.2 & 27.89 \\
\hline Michigan ........................................ & 223 & 122.4 & 32.44 & 456 & 140.4 & 33.44 & 92 & 170.9 & 42.26 & 155.6 & 34.23 \\
\hline Ohio & 3,192 & 138.1 & 34.67 & 9,460 & 137.5 & 33.34 & 23,005 & 140.8 & 33.26 & 143.5 & 34.40 \\
\hline 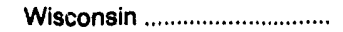 & 1,214 & 159.8 & 39.93 & 1,155 & 190.7 & 43.50 & 6 & 119.6 & 26.77 & 133.3 & 25.92 \\
\hline Weat North Central ............. & 819 & 127.4 & 29.07 & 6,441 & 147.3 & 33.11 & 8,115 & 142.1 & 30.63 & 110.0 & 18.92 \\
\hline 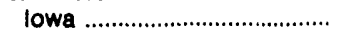 & 346 & 125.6 & 27.79 & 950 & 144.8 & 32.73 & 714 & 188.9 & 42.05 & 110.4 & 19.58 \\
\hline 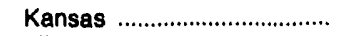 & 169 & 131.5 & 30.56 & 235 & 213.3 & 49.58 & 500 & 125.9 & 28.69 & 117.9 & 20.99 \\
\hline 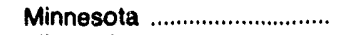 & 8 & 157.0 & 40.04 & 40 & 150.1 & 36.50 & - & -- & -- & 118.6 & 20.96 \\
\hline 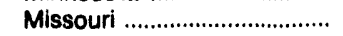 & 296 & 126.1 & 29.41 & 5,215 & 144.7 & 32.41 & 6,442 & 141.0 & 30.99 & 133.6 & 27.57 \\
\hline 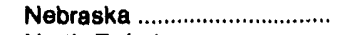 & -- & - & -- & -- & - & - & -- & -- & -- & 74.6 & 12.77 \\
\hline North Dakota .............................. & -- & -- & -- & -- & -- & - & 458 & 74.4 & 9.84 & 72.1 & 9.45 \\
\hline South Dakota .......................... & - & -- & -- & - & -- & - & -- & -- & -- & 113.3 & 13.68 \\
\hline South Atlantlc ........................... & 14,141 & 156.3 & 39.08 & 17,618 & 172.0 & 41.89 & 11,464 & 142.8 & 34.81 & 165.6 & 41.28 \\
\hline 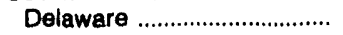 & 108 & 157.7 & 41.36 & -- & -- & -- & - & -- & -- & 173.4 & 45.31 \\
\hline District of Columbia .............. & - & -- & - & -- & - & - & - & - & -- & -- & -- \\
\hline Florida ................................ & 92 & 197.4 & 47.69 & 9,552 & 184.5 & 44.32 & 329 & 153.0 & 36.16 & 182.0 & 45.03 \\
\hline Georgia & 2,418 & 181.4 & 45.61 & 3,452 & 196.4 & 45.66 & 3,329 & 188.3 & 41.75 & 180.1 & 43.36 \\
\hline 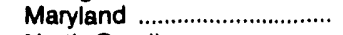 & 3,654 & 169.2 & 42.78 & 952 & 154.7 & 40.12 & -- & -- & -- & 159.5 & 40.68 \\
\hline North Carolina .......................... & 15 & 151.9 & 37.53 & 2 & 149.2 & 38.04 & -- & - & -- & 172.6 & 43.00 \\
\hline South Carolina .......................... & 853 & 148.9 & 37.90 & $\cdot$ & 146.1 & 36.46 & -- & -- & -- & 152.7 & 39.13 \\
\hline 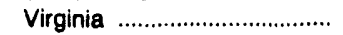 & 183 & 154.1 & 40.35 & 140 & 177.3 & 47.38 & -- & -- & -- & 147.3 & 37.81 \\
\hline West Virginia ........................... & 6,817 & 140.7 & 34.74 & 3,520 & 123.5 & 31.85 & 7,806 & 125.4 & 31.79 & 147.2 & 36.88 \\
\hline East South Central .................... & 11,125 & 140.2 & 34.03 & 24,705 & 125.7 & 29.52 & 12,564 & 109.9 & 24.63 & 138.5 & 33.05 \\
\hline Alabama & 5,535 & 151.9 & 36.50 & 2,996 & 160.0 & 38.37 & 1,901 & 109.0 & 25.66 & 172.7 & 41.67 \\
\hline 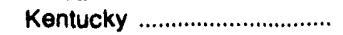 & 1,332 & 127.5 & 31.08 & 10,613 & 111.9 & 25.79 & 10,522 & 109.9 & 24.38 & 116.2 & 27.01 \\
\hline 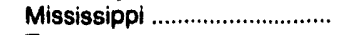 & - & $\overline{-}$ & -- & 1,458 & 132.1 & $\mathbf{3 3 . 4 9}$ & -- & - & -- & 159.7 & 39.94 \\
\hline 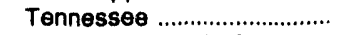 & 4,258 & 129.3 & 31.75 & 9,639 & 128.5 & 30.28 & 141 & 117.2 & 29.21 & 127.3 & 31.01 \\
\hline West South Contral .............. & 3,623 & 131.4 & 14.55 & 698 & 100.4 & 11.02 & 163 & 104.8 & 27.03 & 147.4 & 22.55 \\
\hline 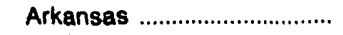 & -- & -- & - & - & -- & -- & -- & - & -- & 165.3 & 28.84 \\
\hline 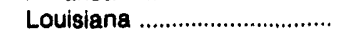 & -- & - & -- & -- & - & -- & - & -- & -. & 153.5 & 24.93 \\
\hline 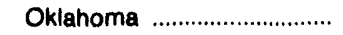 & -- & - & - & 10 & 113.8 & 26.19 & 163 & 104.9 & 27.03 & 123.4 & 21.47 \\
\hline Texas ......................................... & 3,623 & 131.4 & 14.55 & 688 & 100.0 & 10.79 & -- & -- & -- & 149.1 & 21.58 \\
\hline 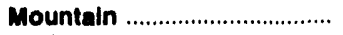 & - & - & - & - & - & -- & - & - & - & 111.3 & 21.64 \\
\hline Arizona & - & -- & -- & - & -- & - & - & -- & -- & 137.4 & 28.31 \\
\hline 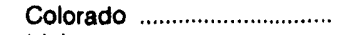 & - & -- & - & - & - & - & -- & - & -- & 108.2 & 21.67 \\
\hline Idaho & -- & -- & -- & -- & -- & - & -- & -- & -- & -- & -- \\
\hline Montana & -- & - & - & - & -- & -- & -- & -- & -- & 70.8 & 12.14 \\
\hline 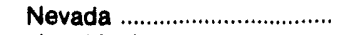 & -- & - & -- & - & -- & - & -- & -- & -- & 146.2 & 32.32 \\
\hline New Mexico ............................. & -- & -- & -- & -- & - & -- & -- & -- & -- & 132.2 & 23.83 \\
\hline 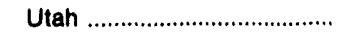 & -- & - & - & -- & - & -- & -- & -- & -- & 120.9 & 27.54 \\
\hline 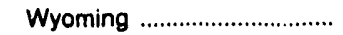 & -- & - & - & -. & -- & -- & - & - & -- & 75.9 & 13.42 \\
\hline Pacific Contiguous ................ & - & - & - & - & - & - & - & - & - & 129.6 & 22.17 \\
\hline 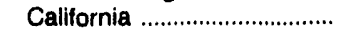 & - & - & - & -- & -- & - & -- & - & -- & -- & - \\
\hline 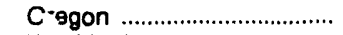 & - & -- & -- & - & - & -- & -- & - & -- & 110.1 & 21.23 \\
\hline 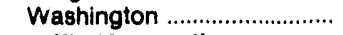 & -- & - & -- & - & -- & - & -- & - & -- & 137.3 & 22.48 \\
\hline Pacific Noncontiguous ........ & - & - & - & - & $-\infty$ & - & - & - & - & - & - \\
\hline Alaska & -- & -- & - & -- & - & -- & - & - & -- & -- & -- \\
\hline 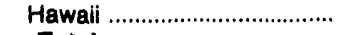 & & $-\overline{0}$ & $\bar{m}-$ & -- & - & - & - & - & -- & -- & -- \\
\hline Total ..................................... & $\mathbf{5 7 , 3 8 2}$ & 145.9 & $\mathbf{3 4 . 8 0}$ & 101,033 & 139.7 & 33.04 & 78,517 & 138.7 & 31.86 & 141.2 & 29.36 \\
\hline
\end{tabular}

- = Number less than 0.5 .

Notes: - Totals may not equal sum of components because of independent rounding. - Data are for electric generating planis with a total steam-electric and combined-cyicle nameplate capacity of 50 or more megawatts.

Source: Federal Energy Fiegulatory Commission, FERC Form 423, "Monthly Feport of Cost and Quality of Fuels for Electric Plants." 
Table 6. Receipts of Petroleum by Census Division and State, 1988-1992 (Thousand Barrels)

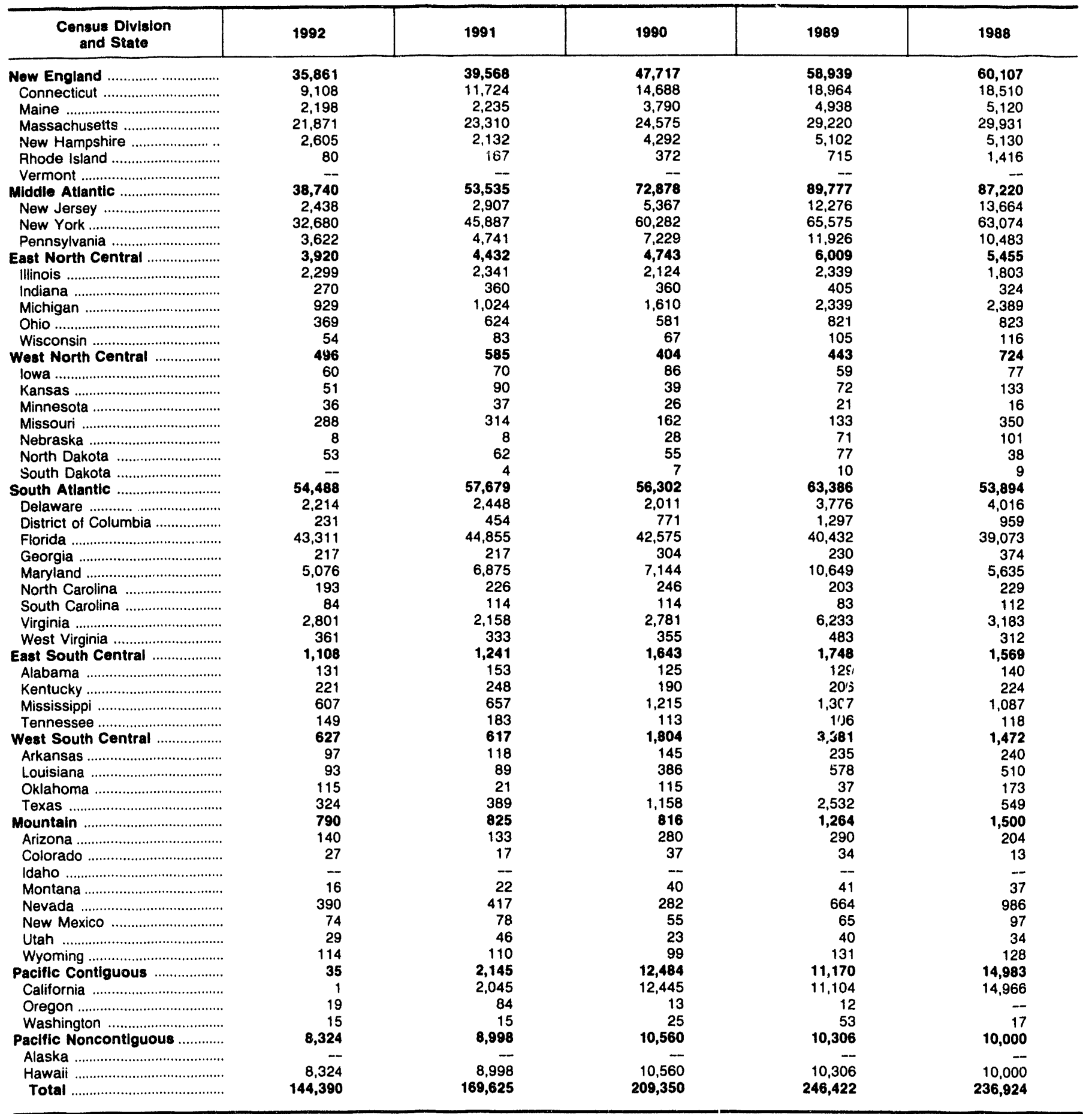

Notes: - Totals may not equal sum of components because of independent rounding. - As of 1991, data are for electric generating plants with a total steam-electric and combined-cycle nameplate capacity of 50 or more megawatts. - Data for $1988-1990$ are for steam-electric plants with a generator nameplate capacity of 50 or more megawatts.

Source: Federal Energy Regulatory Commission, FERC Form 423, "Monthly Report of Cost and Quality of Fuels for Electric Plants." 
Table 7. Average Delivered Cost of Petroleum by Census Division and State, 1988-1992

\begin{tabular}{|c|c|c|c|c|c|c|c|c|c|c|}
\hline \multirow{2}{*}{$\begin{array}{l}\text { Census Division } \\
\text { and State }\end{array}$} & 1992 & 1991 & 1990 & 1989 & 1988 & 1992 & 1991 & 1990 & 1989 & 1988 \\
\hline & \multicolumn{5}{|c|}{ (cents per million Btu) } & \multicolumn{5}{|c|}{ (dollars per barrel) } \\
\hline 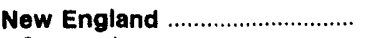 & 233.2 & 225.9 & 285.5 & 269.2 & 227.5 & 14.185 & 14.34 & 18.09 & 17.04 & 14.37 \\
\hline Connecticut ................................. & 241.0 & 247.4 & 301.5 & 285.6 & 239.7 & 15.27 & 15.67 & 19.09 & 18.01 & 15.11 \\
\hline Maine & 228.8 & 208.5 & 278.5 & 278.2 & 235.3 & 14.48 & 13.20 & 17.55 & 17.48 & 14.74 \\
\hline 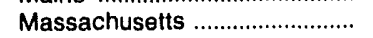 & 236.3 & 221.0 & 286.4 & 264.8 & 225.9 & 15.03 & 14.01 & 18.08 & 16.72 & 14.25 \\
\hline 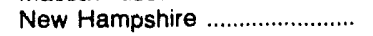 & 185.8 & 179.6 & 226.9 & 226.9 & 186.9 & 12.23 & 11.82 & 14.71 & 14.85 & 12.13 \\
\hline 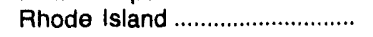 & 195.0 & 241.1 & 358.9 & 270.3 & 224.6 & 12.50 & 15.34 & 22.98 & 17.00 & 14.24 \\
\hline 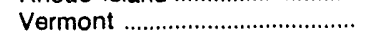 & - & -- & -- & -- & -- & - & - & -- & - & - \\
\hline 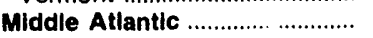 & 267.3 & 273.6 & 359.2 & 296.1 & 248.9 & 16.92 & 17.30 & 22.61 & 18.61 & 15.63 \\
\hline 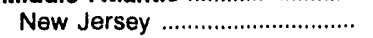 & 303.3 & 302.1 & 359.6 & 303.5 & 251.2 & 18.96 & 18.84 & 22.40 & 18.93 & 15.63 \\
\hline 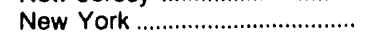 & 263.8 & 271.9 & 360.3 & 295.3 & 248.9 & $16.1^{\prime 2}$ & 17.22 & 22.71 & 18.58 & 15.66 \\
\hline Pennsylvania .............................. & 275.2 & 272.8 & 349.5 & 293.1 & 245.8 & 17.34 & 17.13 & 21.99 & 18.49 & 15.48 \\
\hline East North Central ................... & 326.9 & 336.3 & 387.2 & 342.6 & 301.8 & 20.43 & 20.65 & 23.77 & 20.99 & 18.47 \\
\hline 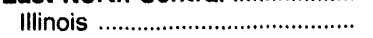 & 305.1 & 308.8 & 394.7 & 353.0 & 312.0 & 19.2 .7 & 19.33 & 24.67 & 22.03 & 19.42 \\
\hline 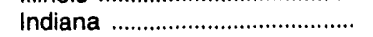 & 443.3 & 493.9 & 512.2 & 421.8 & 363.4 & 25.57 & 28.47 & 29.52 & 24.27 & 20.93 \\
\hline 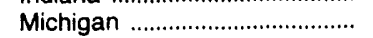 & 296.8 & 285.5 & 320.2 & 315.0 & 279.9 & 18.94 & 17.57 & 19.64 & 19.23 & 17.14 \\
\hline 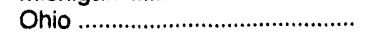 & 451.4 & 428.7 & 458.8 & 345.8 & 311.7 & 26.019 & 25.43 & 27.54 & 21.06 & 18.90 \\
\hline 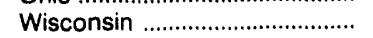 & 463.7 & 445.8 & 526.1 & 410.0 & 364.5 & 27.19 & 26.08 & 30.76 & 23.84 & 21.07 \\
\hline West North Central ................. & 318.5 & 335.8 & 498.4 & 369.0 & 276.9 & 19.5 2 & 20.28 & 29.19 & 22.04 & 16.90 \\
\hline 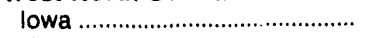 & 424.0 & 437.7 & 518.1 & 445.1 & 372.1 & 24.57 & 25.37 & 30.01 & 25.87 & 21.51 \\
\hline 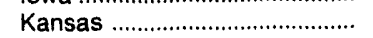 & 437.8 & 431.6 & 540.4 & 432.8 & 318.6 & 25.5 .8 & 25.08 & 31.36 & 25.24 & 19.01 \\
\hline 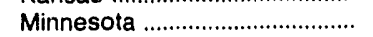 & 450.9 & 382.9 & 533.3 & 441.6 & 369.2 & 26.24 & 22.80 & 30.83 & 25.50 & 21.29 \\
\hline 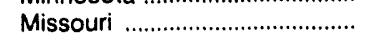 & 234.9 & 261.9 & 434.6 & 323.5 & 237.0 & 14.67 & 16.29 & 25.76 & 19.82 & 14.77 \\
\hline 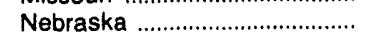 & 464.9 & 457.3 & 703.4 & 248.9 & 241.7 & 26.8 .7 & 26.43 & 40.78 & 15.47 & 15.14 \\
\hline 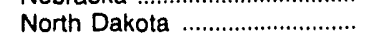 & 457.7 & 426.1 & 499.1 & 421.9 & 362.1 & 26.72 & 24.87 & 29.20 & 24.53 & 21.07 \\
\hline South Dakota ............................ & - & 487.9 & 565.3 & 450.2 & 401.7 & ..- & 28.69 & 33.24 & 26.47 & 23.62 \\
\hline 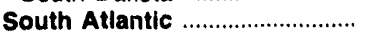 & 244.5 & 230.0 & 311.4 & 277.4 & 227.7 & 15.51 & 14.56 & 19.66 & 17.47 & 14.40 \\
\hline 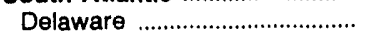 & 241.8 & 237.9 & 278.2 & 277.4 & 232.1 & 15.31 & 15.14 & 17.68 & 17.54 & 14.71 \\
\hline 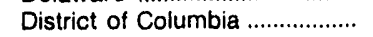 & 350.4 & 318.6 & 363.3 & 345.6 & 278.9 & 21.03 & 19.14 & 21.86 & 20.78 & 16.82 \\
\hline 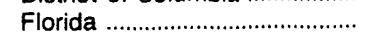 & 241.7 & 224.8 & 301.9 & 271.1 & 221.3 & 15.3 .8 & 14.28 & 19.15 & 17.19 & 14.07 \\
\hline 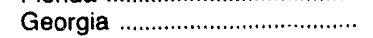 & 434.4 & 473.8 & 485.5 & 426.7 & 283.8 & 25.64 & 27.46 & 28.51 & 24.95 & 17.02 \\
\hline 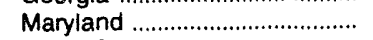 & 230.3 & 226.1 & 315.7 & 276.2 & 236.1 & 14.56 & 14.25 & 19.84 & 17.39 & 14.90 \\
\hline North Carolina ............................. & 441.1 & 473.5 & 512.1 & 398.9 & 348.5 & 25.65 & 27.50 & 29.73 & 23.17 & 20.25 \\
\hline 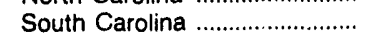 & 461.7 & 475.1 & 622.1 & 426.3 & 373.6 & 26.79 & 27.56 & 36.07 & 24.71 & 21.72 \\
\hline Virginia & 247.1 & 222.7 & 383.5 & 284.4 & 236.3 & 15.45 & 13.72 & 23.57 & 17.48 & 14.61 \\
\hline 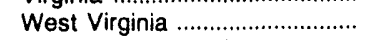 & 483.8 & 537.4 & 572.4 & 450.5 & 395.8 & 28.35 & 31.39 & 33.49 & 26.33 & 23.23 \\
\hline East South Central .................. & 317.5 & $\mathbf{3 4 5 . 4}$ & 322.0 & 308.0 & 340.3 & 19.49 & 21.07 & 20.00 & 19.06 & 20.93 \\
\hline 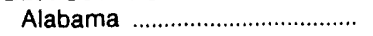 & 459.8 & 511.8 & 556.9 & 414.3 & 366.8 & 26.49 & 29.47 & 32.09 & 23.87 & 21.01 \\
\hline 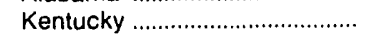 & 479.4 & 505.1 & 575.0 & 475.2 & 384.6 & 27.99 & 29.49 & 33.56 & 27.71 & 22.46 \\
\hline 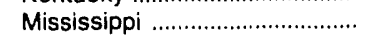 & 200.0 & 215.7 & 243.3 & 267.6 & 327.7 & 12.812 & 13.70 & 15.45 & 16.91 & 20.67 \\
\hline 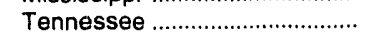 & 480.2 & 498.3 & 560.8 & 394.7 & 350.9 & 27.93 & 29.05 & 32.70 & 22.92 & 20.39 \\
\hline West South Central .................. & 416.4 & 477.3 & 468.4 & 375.0 & 345.5 & 24.42 & 28.02 & 28.16 & 22.54 & 21.14 \\
\hline 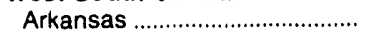 & 480.8 & 560.7 & 470.4 & 370.6 & 435.4 & 27.71 & 32.44 & 27.44 & 22.44 & 26.44 \\
\hline 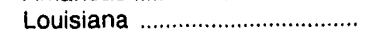 & 387.9 & 413.4 & 371.5 & 379.4 & 347.6 & 23.12 & 24.136 & 22.62 & 23.86 & 21.48 \\
\hline 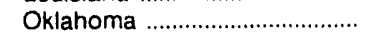 & 435.6 & 408.7 & 320.3 & 415.0 & $<68.2$ & 25.33 & 23.59 & 20.98 & 23.92 & 16.88 \\
\hline Texas & 399.0 & 471.0 & 517.3 & 373.8 & 329.1 & 23.49 & 27.64 & 30.82 & 22.22 & 19.83 \\
\hline 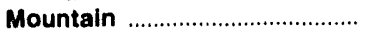 & 405.7 & 445.6 & 424.9 & 342.6 & 289.4 & 24.41 & 26.130 & 25.60 & 20.79 & 17.68 \\
\hline 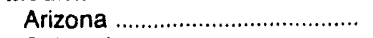 & 466.5 & 499.0 & 446.0 & 403.1 & 407.0 & 27.51 & 29.27 & 26.76 & 23.92 & 24.01 \\
\hline 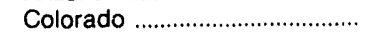 & 479.3 & 512.6 & 534.5 & 409.9 & 384.8 & 27.25 & 29.36 & 30.76 & 23.60 & 22.14 \\
\hline 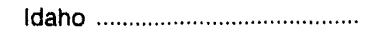 & - & -- & -- & -- & -- & -- & $-\cdot-$ & -- & -- & -- \\
\hline 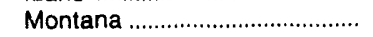 & 509.1 & 471.7 & 543.2 & $43 n .9$ & 403.3 & 30.15 & 27.94 & 32.17 & 25.52 & 23.88 \\
\hline 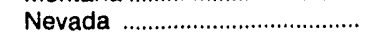 & 331.3 & 393.3 & 314.3 & $2 € 6.5$ & 244.8 & 20.56 & 24.37 & 19.57 & 17.85 & 15.25 \\
\hline New Mexico ................................ & 515.5 & 535.3 & 524.5 & $3: 8.3$ & 308.0 & 29.38 & 30.58 & 30.42 & 22.17 & 18.10 \\
\hline 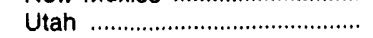 & 484.1 & 490.3 & 541.5 & 445.2 & 398.4 & 28.47 & 28.75 & 31.84 & 26.18 & 23.43 \\
\hline 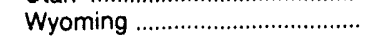 & 479.3 & 494.3 & 526.8 & 415.4 & 379.7 & 28.01 & 28.89 & 30.72 & 24.27 & 22.22 \\
\hline Pacitic Contiguous .................. & 448.7 & 314.4 & 435.8 & 307.9 & 266.0 & 26.42 & 19.22 & 26.73 & 18.93 & 16.35 \\
\hline 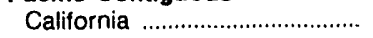 & 217.9 & 306.2 & 435.8 & 307.6 & 265.8 & 13.26 & 18.75 & 26.73 & 18.91 & 16.34 \\
\hline 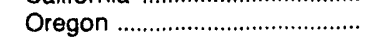 & 449.2 & 475.3 & 347.3 & 452.8 & -- & 26.44 & 28.08 & 20.28 & 26.59 & - \\
\hline 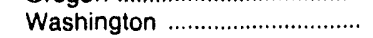 & 466.0 & 572.9 & 511.0 & 336.7 & 403.2 & 27.39 & 33.73 & 30.25 & 20.66 & 23.87 \\
\hline Pacific Noncontiguous ............. & 292.1 & 330.6 & 415.2 & 329.1 & 286.7 & 18.32 & 20.65 & 25.97 & 20.55 & 17.96 \\
\hline 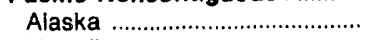 & - & - & -- & - & - & - & - & - & -- & - \\
\hline 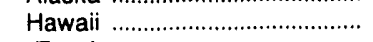 & 292.1 & 330.6 & 415.2 & 329.1 & 286.7 & 18.32 & 20.65 & 25.97 & 20.55 & 17.96 \\
\hline 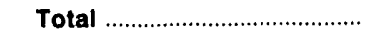 & 255.1 & 254.8 & 338.4 & 289.3 & 243.9 & 16.15 & 16.09 & 21.28 & 18.17 & 15.33 \\
\hline
\end{tabular}

Notes: - Totals may not equal sum of components because of independent rounding. - As of 1991, data are for electric generating plants with a total steam-electric and combined-cycle nameplate capacity of 50 or more megawatts. Data for $1988-1990$ are for steam-electric plants with a generator nameplate capacity of 50 or more megawatts.

Source: Federal Energy Regulatory Commission, FERC Form 423, "Monthly Report of Cost and Quality of Fuels for Electric Plants." 
Table 8. Receipts and Average Delivered Cost of Petroleum by Census Division and State, 1992

\begin{tabular}{|c|c|c|c|c|c|c|c|c|c|c|c|c|}
\hline \multirow{3}{*}{$\begin{array}{l}\text { Census Division } \\
\text { and State }\end{array}$} & \multicolumn{6}{|c|}{ No. 6 Fuel Oll by Type of Durchase } & \multicolumn{6}{|c|}{ Average Dellvered Cost } \\
\hline & \multicolumn{3}{|c|}{ Contract } & \multicolumn{3}{|c|}{ Spot } & \multicolumn{2}{|c|}{$\begin{array}{l}\text { No. } 2 \\
\text { Fuel OII }\end{array}$} & \multicolumn{2}{|c|}{$\begin{array}{l}\text { No. } 4, \text { No. } 5 \\
\text { Fuel Oll }\end{array}$} & \multicolumn{2}{|c|}{$\begin{array}{l}\text { No. } 6 \\
\text { Fuel OII }\end{array}$} \\
\hline & $\begin{array}{c}\text { Recelpts } \\
(1,000 \text { bbls })\end{array}$ & \begin{tabular}{c|} 
(cents \\
per \\
$10^{\circ}$ \\
Btu) \\
\end{tabular} & $\begin{array}{c}\text { (5 per } \\
\text { bbl) }\end{array}$ & $\mid \begin{array}{c}\text { Recelpis } \\
(1,000 \text { bbls })\end{array}$ & $\begin{array}{c}\text { (cents } \\
\text { per } \\
10^{6} \\
\text { Btu) } \\
\end{array}$ & $\begin{array}{c}\text { (5 per } \\
\text { bbl) }\end{array}$ & \begin{tabular}{c|} 
(cents \\
per \\
$10^{8}$ \\
Btu)
\end{tabular} & 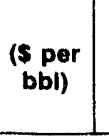 & $\begin{array}{c}\text { (cents } \\
\text { per } \\
10^{8} \\
\text { Btu) } \\
\end{array}$ & (s per & $\begin{array}{c}\text { (cents } \\
\text { per } \\
10^{8} \\
\text { Btu) }\end{array}$ & $\begin{array}{l}\text { (\$ per } \\
\text { bbl) }\end{array}$ \\
\hline New England ........................... & 30,598 & 230.6 & 14.68 & 5,099 & 242.1 & 15.47 & 443.2 & 25.94 & -- & -- & 232.3 & 14.80 \\
\hline 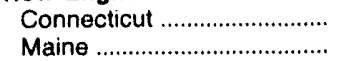 & 8,726 & 240.1 & 15.21 & 347 & 242.4 & 15.36 & 482.1 & 28.06 & -- & -- & 240.1 & 15.22 \\
\hline 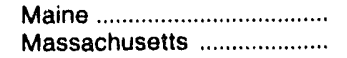 & 2,177 & 227.0 & 14.38 & - & -- & -- & 436.5 & 25.67 & -- & -- & 227.0 & 14.38 \\
\hline Massachusetts ....................... & 17,682 & 232.9 & 14.82 & 4,110 & 247.7 & 15.74 & 428.3 & 25.16 & -- & -- & 235.7 & 14.99 \\
\hline New Hampshire ....................... & 2,012 & 175.6 & 11.54 & 562 & 209.7 & 14.00 & 443.9 & 25.83 & -- & -- & 183.1 & 12.07 \\
\hline 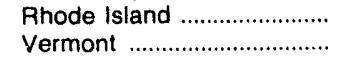 & -- & -- & -- & 80 & 195.0 & 12.50 & -- & -- & - & -- & 195.0 & 12.50 \\
\hline 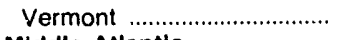 & -- & -- & -- & -- & -- & -- & -- & -- & -- & -- & -- & $\overline{--}$ \\
\hline Middle Atlantic .......................... & 29,053 & 268.1 & 17.00 & 8,969 & 252.2 & 15.98 & 437.1 & 25.48 & - & - & 264.4 & 16.76 \\
\hline 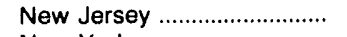 & 2,323 & 301.8 & 18.87 & 92 & 306.4 & 19.51 & 450.7 & 26.13 & - & -- & 302.0 & 18.90 \\
\hline 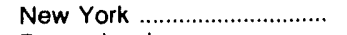 & 24,603 & 266.0 & 16.88 & 8,016 & 255.3 & 16.14 & 495.9 & 28.80 & -- & -- & 263.4 & 16.70 \\
\hline Pennsylvania .......................... & 2,127 & 256.0 & 16.35 & 861 & 218.4 & 14.04 & 431.1 & 25.14 & $-\overline{0}$ & -- & 245.1 & 15.69 \\
\hline East North Central ................... & 1,867 & 281.2 & 18.03 & 720 & 246.9 & 15.62 & 445.7 & 25.82 & 262.0 & 16.38 & 271.7 & 17.36 \\
\hline Illinois & 1,867 & 281.2 & 18.03 & 63 & 277.7 & 17.50 & 444.2 & 25.81 & -- & -- & 281.0 & 18.02 \\
\hline 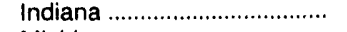 & - & -- & -- & -- & - & -- & 443.3 & 25.57 & -- & -- & -- & - \\
\hline 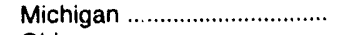 & -- & -- & - & 657 & 244.0 & 15.44 & 438.6 & 25.46 & 262.0 & 16.38 & 244.0 & 15.44 \\
\hline Ohio & - & -- & -- & -- & -- & -- & 451.4 & 26.09 & - & -- & -- & -- \\
\hline 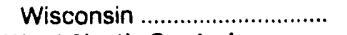 & -- & -- & -- & $-\overline{0}$ & $\overline{-}$ & $\overline{0}$ & 463.7 & 27.19 & -- & $-\infty$ & -- & -- \\
\hline West North Central ............... & -- & - & - & 193 & 147.3 & 9.55 & 439.8 & 25.52 & -- & - & 147.3 & 9.55 \\
\hline 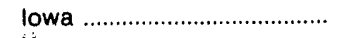 & -- & -- & - & -- & -- & -- & 424.0 & 24.57 & -- & -- & -- & - \\
\hline 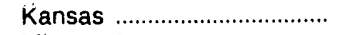 & -- & -- & -- & -- & -- & - & 437.8 & 25.58 & - & -- & -- & -- \\
\hline 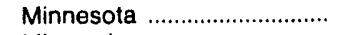 & -- & -- & -- & -- & -- & $\cdots$ & 450.9 & 26.24 & -- & - & -- & -- \\
\hline 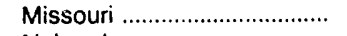 & -- & -- & - & 189 & 145.3 & 9.43 & 426.1 & 24.62 & -- & -- & 145.3 & 9.43 \\
\hline 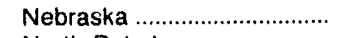 & -- & - & - & -- & $\overline{-}$ & $\overline{--}$ & 464.9 & 26.87 & -- & -- & -- & - \\
\hline North Dakota & -- & -- & -- & 4 & 245.5 & 15.16 & 476.3 & 27.67 & - & - & 245.5 & 15.16 \\
\hline South Dakota .......................... & $\overline{-i}$ & $-\overline{-}$ & $\overline{-i}$ & $\ddot{-}$ & $\overline{-}$ & -- & $\overline{-}$ & $\overline{-}$ & - & $-\overline{-}$ & $\overline{-}$ & -- \\
\hline South Atlantic & 32,149 & 237.5 & 15.11 & 20,329 & 237.5 & 15.11 & 455.5 & 26.55 & 335.1 & 20.23 & 237.5 & 15.11 \\
\hline 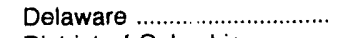 & 1,669 & 238.5 & 15.16 & 431 & 206.0 & 13.14 & 444.2 & 25.79 & -- & $\vec{a}$ & 231.8 & 14.74 \\
\hline District of Colu nbia ............. & -- & -- & $\overline{--}$ & -- & -- & $-\overline{-}$ & 445.3 & 25.80 & 335.1 & 20.23 & -- & - \\
\hline Florida & 25,703 & 240.9 & 15.32 & 17,236 & 238.9 & 15.22 & 446.1 & 26.08 & - & -- & 240.1 & 15.28 \\
\hline 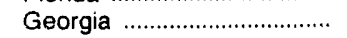 & -- & -- & -- & 40 & 304.9 & 19.14 & 465.9 & 27.10 & - & -- & 304.9 & 19.14 \\
\hline 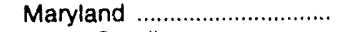 & 4,778 & 218.9 & 13.92 & - & - & -- & 429.9 & 24.96 & -- & - & 218.9 & 13.92 \\
\hline North Carolina .......................... & -- & -- & -- & -- & -- & -- & 441.1 & 25.65 & -- & -- & -- & - \\
\hline 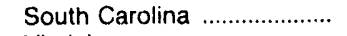 & - & -- & -- & $\overline{-}$ & $\ddot{-}$ & -- & 461.7 & 26.79 & -- & -- & - & - \\
\hline Virginia & -- & -- & - & 2,622 & 232.9 & 14.63 & 470.9 & 27.54 & -- & - & 232.9 & 14.63 \\
\hline West Virginia & -- & -- & - & -- & $\overline{-}$ & $-\bar{m}$ & 483.8 & 28.35 & -- & - & -- & - \\
\hline East South Central .................... & - & - & -- & 572 & 185.0 & 11.93 & 474.1 & 27.55 & - & - & 185.0 & 11.93 \\
\hline Alabama & -- & - & -- & -- & -- & -- & 459.8 & 26.49 & -- & - & -- & -- \\
\hline Kentucky .................................. & - & - & -- & $\overline{57}$ & -- & $\overline{--}$ & 479.4 & 27.99 & -- & -- & -- & $\overline{-}$ \\
\hline 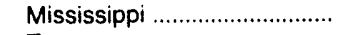 & -- & -- & -- & 572 & 185.0 & 11.93 & 467.5 & 27.23 & -- & -- & 185.0 & 11.93 \\
\hline 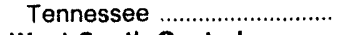 & -- & -- & - & -- & -- & - & 480.2 & 27.93 & -- & - & -- & - \\
\hline West South Central .............. & 14 & 220.0 & 13.91 & 3 & 196.0 & 12.41 & 431.7 & 25.11 & 359.5 & 21.92 & 216.0 & 13.67 \\
\hline Arkansas & $\approx$ & $-\overline{-}$ & $-\overline{-}$ & -- & -- & - & 480.8 & 27.71 & -- & $-\infty$ & -- & -- \\
\hline Louisiana ................................... & 14 & 220.0 & 13.91 & 3 & 196.0 & 12.41 & 430.7 & 25.31 & -- & -- & 216.0 & 13.67 \\
\hline Oklahoma .............................. & -- & -- & -- & - & - & -- & 435.6 & 25.33 & -- & -- & -- & -- \\
\hline 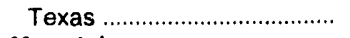 & -- & - & -- & -- & -- & $-\infty$ & 411.3 & 23.95 & 359.5 & 21.92 & -- & -- \\
\hline 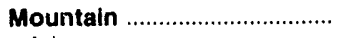 & - & - & - & 369 & 323.0 & 20.11 & 483.3 & 28.18 & - & -- & 323.0 & 20.11 \\
\hline Arizona & -.- & -- & -- & - & -- & -- & 466.5 & 27.51 & - & -- & - & -- \\
\hline 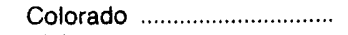 & - & - & - & -- & -- & - & 479.3 & 27.25 & -- & -- & -- & -- \\
\hline Idaho & -- & -- & -- & -- & -- & - & $\overline{--}$ & $\ddot{-}$ & -- & -- & -- & -- \\
\hline Montana & -- & -- & -- & $-\overline{0}$ & -- & -- & 509.1 & 30.15 & -- & -- & -- & -- \\
\hline Nevada & -- & -- & -- & 369 & 323.0 & 20.11 & 490.1 & 28.56 & -- & -- & 323.0 & 20.11 \\
\hline New Mexico .............................. & -- & -- & - & -- & -- & -- & 515.5 & 29.38 & -- & - & -- & -- \\
\hline 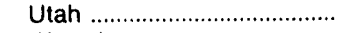 & -- & -- & -- & - & -- & -- & 484.1 & 28.47 & -- & - & - & -- \\
\hline 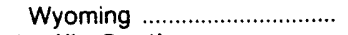 & -- & -- & -- & - & $\overline{-}$ & -- & 479.3 & 28.01 & - & - & -- & -- \\
\hline Pacific Contiguous ................ & - & - & -- & 1 & 217.9 & 13.26 & 456.5 & 26.85 & -- & - & 217.9 & 13.26 \\
\hline 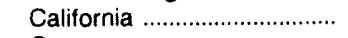 & -- & -- & -- & 1 & 217.9 & 13.26 & $-\overline{0}$ & $-\overline{-}$ & -- & -- & 217.9 & 13.26 \\
\hline Oregon & -- & -- & -- & -- & -- & -- & 449.2 & 26.44 & -- & -- & -- & -- \\
\hline 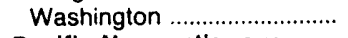 & -- & $\overline{-1}$ & $\overline{--}$ & -- & -- & -- & 466.0 & 27.39 & -- & -- & -- & -- \\
\hline Pacific Noncontiguous ........ & 8,324 & 292.1 & 18.32 & - & -- & - & - & - & - & - & 292.1 & 18.32 \\
\hline Alaska & -- & -- & -- & -- & - & -- & - & -- & -- & -- & -- & -- \\
\hline 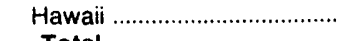 & 8,324 & 292.1 & 18.32 & $36 \overline{--}$ & $\overline{-5}$ & $15 \overline{36}$ & $-\overline{-}$ & $\overline{20}$ & -- & -- & 292.1 & 18.32 \\
\hline Total & 102,006 & 249.3 & 15.83 & 36,255 & 241.5 & 15.36 & 451.4 & 26.26 & 340.4 & 20.62 & 247.3 & 15.71 \\
\hline
\end{tabular}

Notes: - Totals may not equal sum of components because of independent rounding. - Data are for electric generating plants with a total steam-electric and combined-cycle ná ireplate capacity of 50 or more megawalts.

Source: Federal Energy Regulatory Commission, FERC Form 423, "Monthly Report of Cost and Quality of Fuels for Electric Plants." 
Table 9. Receipts of Petroleum by Type, Census Division, and State, 1992

(Thousand Barrels)

\begin{tabular}{|c|c|c|c|c|c|c|}
\hline \multirow{2}{*}{$\begin{array}{l}\text { Census Division } \\
\text { and State }\end{array}$} & \multicolumn{6}{|c|}{ Recolpts by Type } \\
\hline & No. 2 Fuel Oll & No. 4 Fuel OII' & No. 5 Fuel Oll' & No. 6 Fuel Oll & Crude Oil ${ }^{2}$ & Total \\
\hline Now England .................................... & 164 & - & - & 35,697 & - & 35,861 \\
\hline Connecticut ................................... & 34 & -- & -- & 9,074 & -- & 9,108 \\
\hline Maine & 21 & $-\infty$ & - & 2.177 & -- & 2,198 \\
\hline Massachusetts ………................... & 79 & -- & -- & 21,792 & -- & 21,871 \\
\hline New Hampshire ............................. & 31 & -- & -- & 2,574 & -- & 2,605 \\
\hline Rhode Island & -- & -- & - & 80 & -- & 80 \\
\hline 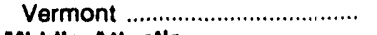 & $\overline{-}$ & -- & - & -- & - & - \\
\hline Middle Atlantlc .............................. & 717 & - & - & 38,023 & -- & 38,740 \\
\hline New Jersey ...................................... & 23 & -- & - & 2,415 & -- & 2,438 \\
\hline 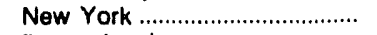 & 60 & - & -- & 32,619 & -- & 32.680 \\
\hline Pennsylvania ................................... & 634 & -- & -- & 2,988 & -. & 3,622 \\
\hline East North Central ..................... & 1,329 & 5 & - & 2,587 & - & 3,920 \\
\hline 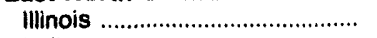 & 369 & -- & -- & 1,930 & $-\infty$ & 2,299 \\
\hline 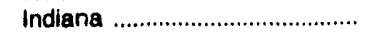 & 270 & $\cdots$ & -- & - & -- & 270 \\
\hline 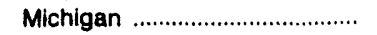 & 268 & 5 & -- & 657 & -- & 929 \\
\hline Ohlo & 369 & -- & - & - & -. & 369 \\
\hline Wisconsin & 54 & -- & - & -- & -- & 54 \\
\hline West North Central ...................... & 304 & - & - & 193 & - & 496 \\
\hline lowa & 60 & -- & -- & -- & - & 60 \\
\hline 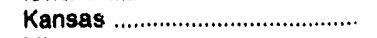 & 51 & -- & $\cdots$ & -- & - & 51 \\
\hline 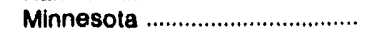 & 36 & -- & -- & - & -- & 36 \\
\hline 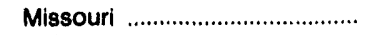 & 99 & -- & - & 189 & - & 288 \\
\hline Nebraska ............................................. & 8 & -- & -- & -- & -- & B \\
\hline 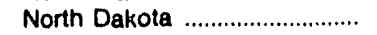 & 49 & - & - & 4 & -- & 53 \\
\hline South Dakota & - & - & - & -- & -- & -- \\
\hline South Atlantic .............................. & 1,811 & 198 & - & 52,479 & - & 54,488 \\
\hline 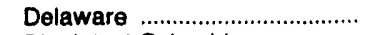 & 114 & - & -- & 2,100 & -- & 2,214 \\
\hline District of Columbia ....................... & 33 & 198 & -- & - & -- & 231 \\
\hline Florida & 372 & -- & -- & 42,939 & -- & 43,311 \\
\hline 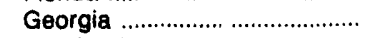 & 177 & -- & - & 40 & $\ldots$ & 217 \\
\hline 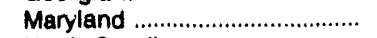 & 298 & -- & - & 4,778 & -- & 5,076 \\
\hline North Carolina ............................. & 193 & -- & - & -- & - & 193 \\
\hline 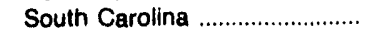 & 84 & -- & - & - & - & 84 \\
\hline Virginia & 179 & -- & - & 2,622 & - & 2,801 \\
\hline 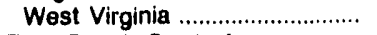 & 361 & -- & -- & -- & -- & 361 \\
\hline East South Central ...................... & 537 & -- & -- & 572 & -- & 1,108 \\
\hline 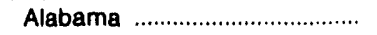 & 131 & -- & -- & - & -- & 131 \\
\hline 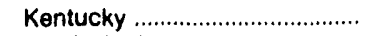 & 221 & -- & -- & - & -- & 221 \\
\hline 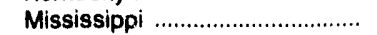 & 35 & -- & -- & 572 & -- & 607 \\
\hline 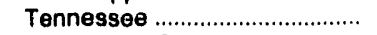 & 149 & -- & -- & -- & -- & 149 \\
\hline Weat South Central ..................... & 536 & 47 & 27 & 17 & -- & 627 \\
\hline 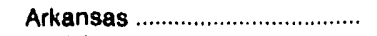 & 97 & -- & - & -- & - & 97 \\
\hline 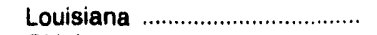 & 75 & -- & -- & 17 & -- & 93 \\
\hline Oklahoma & 115 & -- & -- & -- & -- & 115 \\
\hline 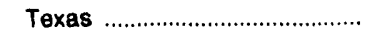 & 250 & 47 & 27 & -- & -- & 324 \\
\hline 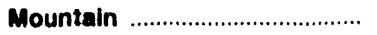 & 421 & - & - & 369 & -- & 790 \\
\hline Arizona & 140 & - & - & - & -- & 140 \\
\hline 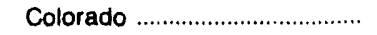 & 27 & -- & -- & -- & -- & 27 \\
\hline Idaho & $=$ & - & -- & -- & -- & -- \\
\hline 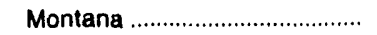 & 16 & -- & -- & - & - & 16 \\
\hline 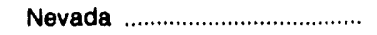 & 21 & -- & - & 369 & - & 390 \\
\hline 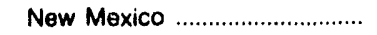 & 74 & - & - & -- & -- & 74 \\
\hline Utah & 29 & -- & -- & -- & -- & 29 \\
\hline 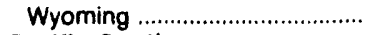 & 114 & -- & - & -- & -- & 114 \\
\hline Paciflc Contiguous ....................... & 34 & - & - & 1 & $\cdots$ & 35 \\
\hline California & -- & -- & -- & 1 & - & 1 \\
\hline 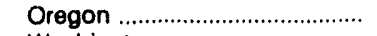 & 19 & -- & -- & -- & -- & 19 \\
\hline 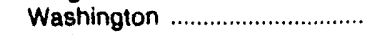 & 15 & -- & -- & - & -- & 15 \\
\hline Pacific Noncontiguous .............. & - & - & - & 8,324 & -- & 8,324 \\
\hline Alaska & - & - & -- & - & -- & - \\
\hline Hawaii & - & -- & $=$ & 8,324 & - & 8,324 \\
\hline Total & 5,853 & 249 & 27 & 138,261 & - & 144,390 \\
\hline
\end{tabular}

Blend of No. 2 Fuel Oil and No. 6 Fuel Oil.

- Includes small quantities of Topped Crude.

Notes: - Totals may not equal sum of components because of independent rounding. - Data are for electric generating plants with a total steamelectric and combined-cycle nameplate capacity of 50 or more megawatts.

Source: Federal Energy Regulatory Commission. FERC Form 423, "Monthly Report of Cost and Quality of Fuels for Electric Plants." 
Table 10. Receipts and Average Delivered Cost of Petroleum by Sulfur Content, Census Division and State, 1992

\begin{tabular}{|c|c|c|c|c|c|c|c|c|c|}
\hline \multirow[b]{2}{*}{$\begin{array}{l}\text { Census Division } \\
\text { and State }\end{array}$} & \multicolumn{3}{|c|}{$0.3 \%$ or Less } & \multicolumn{3}{|c|}{ More than $0.3 \%$ up to $0.5 \%$} & \multicolumn{3}{|c|}{ More than $0.5 \%$ up to $1.0 \%$} \\
\hline & $\begin{array}{c}\text { Receipts } \\
(1,000 \text { bbls })\end{array}$ & $\begin{array}{c}\text { (cents } \\
\text { per } \\
10^{8} \text { Btu) }\end{array}$ & $\begin{array}{l}\text { (\$ per } \\
\text { bbl) }\end{array}$ & $\begin{array}{c}\text { Recelpts } \\
(1,000 \text { bbls })\end{array}$ & $\begin{array}{c}\text { (cents } \\
\text { per } \\
10^{6} \text { Btu) }\end{array}$ & $\begin{array}{l}\text { (s per } \\
\text { bbl) }\end{array}$ & $\begin{array}{c}\text { Receipts } \\
(1,000 \text { bbls })\end{array}$ & $\begin{array}{c}\text { (cents } \\
\text { per } \\
10^{6} \text { Btu) }\end{array}$ & $\begin{array}{l}\text { (5 per } \\
\text { bbl) }\end{array}$ \\
\hline New England ........................... & 150 & 234.0 & 14.60 & 3,709 & 255.6 & 16.10 & 16,563 & 236.4 & 15.04 \\
\hline Connecticut ............................. & -- & -- & -- & 1,696 & 269.0 & 16.87 & 7,377 & 233.6 & 14.84 \\
\hline Maine & -- & -- & $\overline{-}$ & -- & -- & -- & 1,682 & $238 n$ & 15.05 \\
\hline Massachusetts ........................ & 150 & 234.0 & 14.60 & 2,013 & 244.3 & 15.44 & 7.424 & 239.2 & 15.27 \\
\hline New Hampshire ....................... & -- & -- & -- & -- & -- & -- & -- & -- & -- \\
\hline 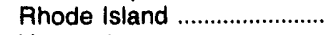 & -- & -- & -- & -- & - & -- & 80 & 195.0 & 12.50 \\
\hline Vermont ................................... & -- & -- & -- & -- & - & -- & - & -- & - \\
\hline Middle Allantic ........................ & 12,125 & 281.1 & 17.57 & 2,548 & 279.7 & 17.70 & 18,025 & 260.4 & 16.63 \\
\hline New Jersey ............................... & 2,092 & 306.1 & 19.10 & 42 & 307.3 & 19.41 & 281 & 271.7 & 17.30 \\
\hline 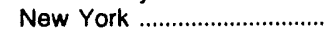 & 9,752 & 274.8 & 17.18 & 1,913 & 279.7 & 17.64 & 15,629 & 264.8 & 16.90 \\
\hline 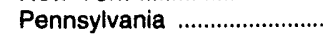 & 280 & 313.1 & 19.92 & 593 & 277.8 & 17.80 & 2,115 & 227.0 & 14.53 \\
\hline East North Central ................ & - & -- & - & - & - & - & 2,591 & 271.7 & 17.36 \\
\hline 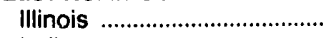 & -- & -- & -- & -- & -- & -- & 1,930 & 281.0 & 18.02 \\
\hline 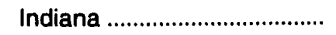 & -- & -- & -- & -- & - & -- & -- & - & - \\
\hline 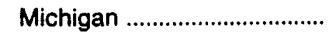 & - & - & -- & -- & - & -- & 661 & 244.1 & 15.45 \\
\hline Ohio & -- & -- & -- & -- & - & -- & -- & -- & - \\
\hline Wisconsin & - & -- & -- & -- & - & -- & -- & - & - \\
\hline West North Central ............... & - & - & - & - & - & -- & - & - & - \\
\hline lowa & -- & - & -- & -- & - & -- & -- & -- & -- \\
\hline 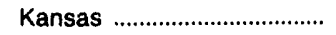 & -- & -- & -- & - & -- & -- & - & -- & -- \\
\hline Minnesota .............................. & - & -- & -- & -- & - & -- & -- & -- & -- \\
\hline 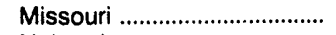 & -- & -- & -- & -- & - & -- & -- & - & -- \\
\hline 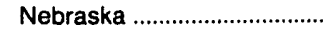 & - & -- & -- & - & - & - & -- & -- & -- \\
\hline North Dakota ............................ & - & -- & -- & -- & $\rightarrow$ & -- & -- & -- & -- \\
\hline South Dakota .......................... & -- & -- & -- & -- & -- & -- & -- & -- & -- \\
\hline South Atlantic ......................... & - & - & -- & 10 & 477.4 & 29.98 & 26,668 & 250.0 & 15.93 \\
\hline 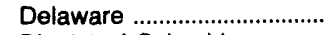 & - & -- & -- & - & -- & -- & 1,730 & 227.9 & 14.52 \\
\hline District of Columbia .................. & -- & -- & -- & -- & -- & - & 198 & 335.1 & 20.23 \\
\hline Florida & -- & -- & -- & -- & -- & -- & 22,162 & 250.3 & 15.98 \\
\hline Georgia & -- & -- & -- & 10 & 477.4 & 29.98 & - & -- & -- \\
\hline 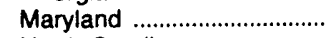 & -- & -- & -- & - & -- & -- & 1,487 & 245.3 & 15.62 \\
\hline North Carolina ......................... & -- & - & -- & -- & -- & - & -- & - & -- \\
\hline South Carolina ......................... & -- & -- & -- & -- & -- & -- & -- & -- & -- \\
\hline 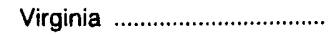 & -- & -- & -- & -- & -- & - & 1,091 & 269.3 & 16.91 \\
\hline West Virginia .......................... & - & - & -- & - & -- & -- & -- & -- & -- \\
\hline East South Central ............... & - & - & -- & -- & - & - & - & -- & - \\
\hline 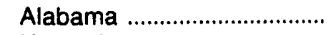 & - & -- & -- & -- & -- & -- & -- & -- & -- \\
\hline 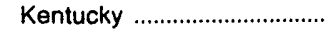 & -- & -- & -- & -- & - & -- & -- & -- & -- \\
\hline 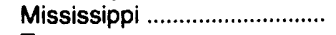 & -- & -- & -- & - & -- & -- & -- & -- & - \\
\hline Tennessee ............................. & -- & - & -- & - & -- & - & - & -- & - \\
\hline West South Central .............. & 6 & 498.7 & 29.94 & 27 & 290.7 & 18.07 & 50 & 356.9 & 21.71 \\
\hline Arkansas ................................ & -- & -- & -- & -- & - & -- & -- & -- & -- \\
\hline 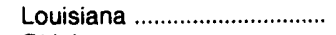 & -- & - & -- & -- & -- & -- & 8 & 216.0 & 13.67 \\
\hline Oklahoma .............................. & - & -- & -- & -- & -- & -- & -- & - & -- \\
\hline Texas ........................................ & 6 & 498.7 & 29.94 & 27 & 290.7 & 18.07 & 41 & 387.1 & 23.35 \\
\hline Mountain & - & - & -- & 17 & 365.6 & 23.76 & 352 & 320.8 & 19.93 \\
\hline 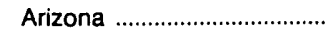 & -- & - & -- & -- & -- & -- & -- & -- & -- \\
\hline Colorado & -- & -- & -- & -- & -- & -- & -- & -- & -- \\
\hline 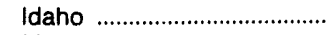 & -- & - & -- & -- & - & -- & -- & - & -- \\
\hline Montana ................................ & - & -- & -- & - & -- & -- & -- & -- & -- \\
\hline Nevada & - & -- & -- & 17 & 365.6 & 23.76 & 352 & 320.8 & 19.93 \\
\hline 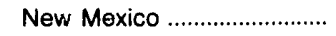 & -- & - & - & -- & - & - & - & - & - \\
\hline Utah & -- & -- & - & - & -- & -- & -- & -- & -- \\
\hline Wyoming .................................. & -- & -- & -- & -- & - & $\cdots$ & - & -- & -- \\
\hline Pacific Contiguous ................ & 1 & 217.9 & 13.26 & -- & - & - & -- & - & -- \\
\hline California & 1 & 217.9 & 13.26 & -- & -- & -- & - & -- & -- \\
\hline 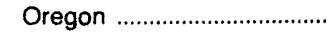 & -- & -- & -- & -- & -- & -- & -- & -- & -- \\
\hline Washington ........................... & -- & -- & - & - & -- & -- & -- & -- & - \\
\hline Pacific Noncontiguous ....... & 389 & 299.6 & 18.60 & 7,934 & 291.8 & 18.30 & - & - & - \\
\hline Alaska & -- & -- & -- & - & -- & -- & -- & - & -- \\
\hline 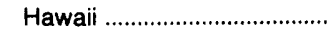 & 389 & 299.6 & 18.60 & 7,934 & 291.8 & 18.30 & -- & -- & -- \\
\hline Total & 12,671 & 281.2 & 17.57 & 14,246 & 280.4 & 17.64 & 64,249 & 250.7 & 15.98 \\
\hline
\end{tabular}

Notes: - Totals may not equal sum of components because of independent rounding. - Data are for electric generating plants with a total steam-electric and combined-cycle nameplate capacity of 50 or more megawatts. - No. 2 Fuel Oil has been omitted from this table.

Source: Federal Energy Regulatory Commission, FERC Form 423, "Monthly Report of Cost and Quality of Fuels for Electric Plants." 
Table 10. Receipts and Average Delivered Cost of Petroleum by Sulfur Content, Census Divison and State, 1992 (Continued)

\begin{tabular}{|c|c|c|c|c|c|c|c|c|c|c|c|}
\hline \multirow[b]{2}{*}{$\begin{array}{l}\text { Consus Division } \\
\text { and State }\end{array}$} & \multicolumn{3}{|c|}{ More than $1.0 \%$ up to $2.0 \%$} & \multicolumn{3}{|c|}{ More than $2.0 \%$ up to $3.0 \%$} & \multicolumn{3}{|c|}{ More than $3.0 \%$} & \multicolumn{2}{|c|}{$\begin{array}{l}\text { Heavy OII } \\
\text { Recelpts }\end{array}$} \\
\hline & $\begin{array}{c}\text { Recelpts } \\
(1,000 \text { bbls })\end{array}$ & $\begin{array}{c}\text { (cents } \\
\text { per } \\
10^{\circ} \\
\text { Btu) }\end{array}$ & $\begin{array}{c}\text { (s por } \\
\text { bbl) }\end{array}$ & $\begin{array}{c}\text { Recolpts } \\
(1,000 \text { bbls })\end{array}$ & $\begin{array}{c}\text { (cents } \\
\text { por } \\
10^{18} \\
\text { Btu) }\end{array}$ & $\begin{array}{c}\text { (s per } \\
\text { bbl) }\end{array}$ & $\mid \begin{array}{c}\text { Recelpts } \\
(1,000 \text { bbls) }\end{array}$ & $\begin{array}{c}\text { (cents } \\
\text { per } \\
10^{\circ} \\
\text { Btu) }\end{array}$ & $\begin{array}{c}\text { (\$ per } \\
\text { bbl) }\end{array}$ & $\begin{array}{c}\text { (cents } \\
\text { per } \\
10^{4} \\
\text { Btu) }\end{array}$ & $\begin{array}{l}\text { (\$ por } \\
\text { bbl) }\end{array}$ \\
\hline Now England ........................... & 3,745 & 206.8 & 13.49 & 11,530 & 227.4 & 14.45 & - & - & - & 232.3 & 14.80 \\
\hline Connecticut ............................ & - & -- & -- & -- & -- & -- & $-\cdots$ & -- & -- & 240.1 & 15.22 \\
\hline 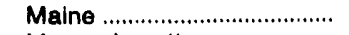 & 495 & 189.9 & 12.09 & $\cdots$ & -- & $\overline{-}$ & - & - & -- & 227.0 & 14.38 \\
\hline Massachusetts ........................ & 676 & 312.7 & 19.91 & 11,530 & 227.4 & 14.45 & -- & -- & - & 235.7 & 14.99 \\
\hline Now Hampshire ...................... & 2,574 & 183.1 & 12.07 & -. & -- & - & - & - & -- & 183.1 & 12.07 \\
\hline 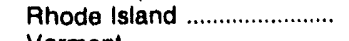 & -- & -- & - & $\cdots$ & - & - & -- & - & - & 195.0 & 12.50 \\
\hline 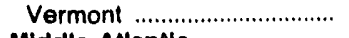 & $-\bar{x}$ & $\overline{--}$ & $\overline{-}$ & -- & -- & - & -- & - & -- & -- & -- \\
\hline Middle Atlantic ....................... & 5,325 & 233.0 & 14.87 & - & - & - & - & -- & -- & 264.4 & 16.76 \\
\hline New Jersey .............................. & $-\overline{-}$ & -- & $\overline{-}$ & -- & -- & -- & -- & - & -- & 302.0 & 18.90 \\
\hline New York .............................. & 5,325 & 233.0 & 14.87 & -- & -- & -- & -- & -- & - & 263.4 & 16.70 \\
\hline Pennsylvani= .......................... & -- & -- & $-\cdots$ & - & -- & -- & -- & -- & -- & 245.1 & 15.69 \\
\hline East North Central ............... & - & - & - & -- & - & - & - & -- & - & 271.7 & 17.36 \\
\hline 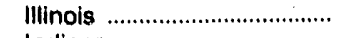 & - & -- & - & - & - & - & -- & -- & - & 281.0 & 18.02 \\
\hline 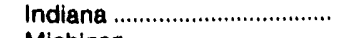 & - & -- & - & - & -- & -- & -- & -- & -- & -- & $-\cdots$ \\
\hline 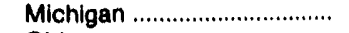 & -- & -- & -- & -- & -- & - & -- & -- & -- & 244.1 & 15.45 \\
\hline Ohio & - & -- & -- & $\cdots$ & -- & -- & -- & -- & -- & -- & -- \\
\hline Wisconsin & - & -- & - & - & $\overline{-}$ & $\overline{-}$ & $\cdots$ & -- & -- & -- & -- \\
\hline Wost North Central ............... & - & -- & -- & 184 & 147.1 & 9.53 & 9 & 153.1 & 10.00 & 147.3 & 9.55 \\
\hline lowa & - & -- & -- & -- & -- & - & $\cdots$ & -- & -- & -- & -- \\
\hline Kansas ............................. & - & -- & -- & - & -- & $\overline{-}$ & - & - & $-\cdots$ & - & - \\
\hline Minnesota & -- & -- & -- & $\overrightarrow{180}$ & $\overline{10}$ & $0 \overline{0}$ & $\overline{0}$ & $15 \overline{1}$ & $10 \bar{n}$ & $-\overline{-}$ & -- \\
\hline 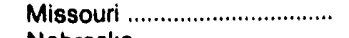 & - & - & $\cdots$ & 180 & 144.9 & 9.40 & 9 & 153.1 & 10.00 & 145.3 & 9.43 \\
\hline 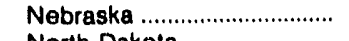 & - & - & - & -- & $\overline{-}$ & -5 & -- & - & - & -- & $-\cdots$ \\
\hline North Dakola .......................... & $\cdots$ & - & - & 4 & 245.5 & 15.16 & -- & -- & - & 245.5 & 15.16 \\
\hline South Dakota & - & -- & $-\infty$ & -- & -- & -- & -- & -- & -- & -- & - \\
\hline 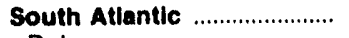 & 19,723 & 227.0 & 14.40 & 6,276 & 219.8 & 13.95 & -- & -- & - & 237.8 & 15.13 \\
\hline 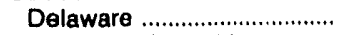 & 305 & 257.6 & 16.23 & 64 & 215.0 & 13.58 & -- & -- & -- & 231.8 & 14.74 \\
\hline District of Columbia .............. & -- & -- & -- & $\overline{-}$ & $\overline{-1}$ & -- & -- & -- & -- & 335.1 & 20.23 \\
\hline Florida & 14,596 & 233.0 & 14.80 & 6,182 & 219.7 & 13.95 & -- & - & -- & 240.1 & 15.28 \\
\hline 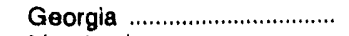 & -- & -- & -- & 30 & 246.6 & 15.48 & -- & - & -- & 304.9 & 19.14 \\
\hline Maryland .................................. & 3,291 & 207.0 & 13.15 & $\cdots$ & -- & -- & -- & - & - & 218.9 & $i 3.92$ \\
\hline North Carolina .......................... & -- & -- & -- & -- & -- & - & - & - & -- & -- & -- \\
\hline South Carolina .......................... & -- & -- & -- & - & - & - & -- & -- & -- & & -- \\
\hline 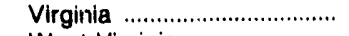 & 1.531 & 207.0 & 13.00 & - & - & $\cdots$ & - & -- & - & 232.9 & 14.63 \\
\hline 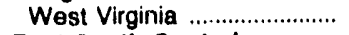 & -- & -- & - & - & -- & -- & - & -- & - & -- & -- \\
\hline East South Central ............... & -- & -- & - & 572 & 185.0 & 11.93 & - & - & - & 185.0 & 11.93 \\
\hline 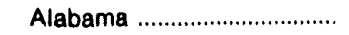 & -- & -- & - & -- & -- & -- & -- & - & -- & -- & -. \\
\hline 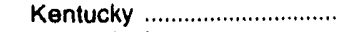 & -- & - & - & $-\bar{x}$ & $-\overline{0}$ & $\overline{0}$ & -- & -- & - & -- & -- \\
\hline 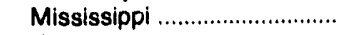 & - & -- & -- & 572 & 185.0 & 11.93 & -- & -- & -- & 185.0 & 11.93 \\
\hline 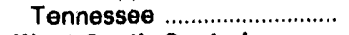 & - & -- & -- & -- & -- & - & -- & -- & -- & - & -- \\
\hline West South Central ............. & 9 & 216.1 & 13.66 & - & -- & - & -- & - & - & 331.3 & 20.35 \\
\hline 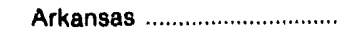 & -- & -- & -- & -- & - & -- & -- & -- & - & -- & - \\
\hline 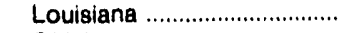 & 9 & 216.1 & 13.66 & -- & -- & $-\infty$ & - & -- & -- & 216.0 & 13.67 \\
\hline 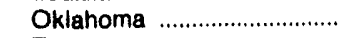 & - & -- & -.. & - & -- & -- & -- & -- & -- & -- & -- \\
\hline 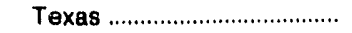 & - & - & $\cdots$ & - & -- & -- & - & -- & -- & 359.5 & 21.92 \\
\hline 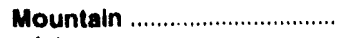 & - & - & - & -- & - & -- & - & -- & - & 323.0 & 20.11 \\
\hline 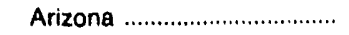 & $\cdots$ & -- & -- & -- & -- & $\cdots$ & - & -- & -- & -- & - \\
\hline Colorado ................................. & - & - & -- & -- & -- & -- & -- & -- & -- & - & - \\
\hline 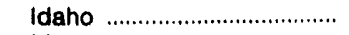 & -- & -- & $\cdots$ & -- & -- & -- & -- & -- & -- & -- & -- \\
\hline Montana ................................... & -- & -- & -- & -- & - & -- & -- & -- & -- & -- & -- \\
\hline 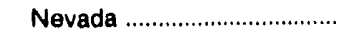 & - & - & -- & -- & -- & -- & -- & -- & -- & 323.0 & 20.11 \\
\hline New Mexico ............................ & -- & -- & -- & -- & - & -- & -.. & $\ldots$ & -- & -- & -- \\
\hline Utah .................................. & -- & -- & -- & -- & -- & -- & -- & -- & -- & $-\infty$ & -- \\
\hline 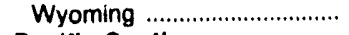 & -- & - & - & -- & -- & - & -- & - & -- & -- & $-\cdots$ \\
\hline Pacific Contiguous ............... & -- & - & - & - & - & - & - & - & - & 217.9 & 13.26 \\
\hline Callfornia & -- & -- & -- & -- & -- & -- & -- & -- & -- & 217.9 & 13.26 \\
\hline Oregon & -- & -- & -- & -- & $\cdots$ & -- & -- & - & -- & -- & -- \\
\hline Washington ........................... & -- & -- & -- & -- & -- & -- & - & - & -- & -- & -- \\
\hline Pacific Noncontiguous ....... & - & - & -- & -- & - & -- & - & - & - & 292.1 & 18.32 \\
\hline Alaska & $\cdots$ & -- & -- & -- & $-\cdots$ & -- & - & -- & - & -- & -- \\
\hline 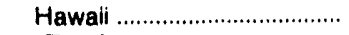 & $-\overline{-}$ & - & 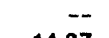 & $-\bar{c}$ & $\overline{-1}$ & $-\bar{c}$ & -- & -- & - & 292.1 & 18.32 \\
\hline Total & 28,802 & 225.4 & 14.37 & 18,561 & 222.7 & 14.15 & 9 & 153.1 & 0.00 & 247.5 & 15.72 \\
\hline
\end{tabular}

Notes: - Totals may not equal sum of components because of independent rounding. - Data are for electric generating plants with a total steam-electric and combined-cycle nameplate capacity of 50 or more megawatts. - No. 2 Fuel Oll has been omilted from this table.

Source: Federal Energy Regulatory Commission, FERC Form 423, "Monthly Report of Cost and Quality of Fuels for Electric Plants." 
Table 11. Receipts of Gas by Census Division and State, 1988-1992 (Thousand Mcf)

\begin{tabular}{|c|c|c|c|c|c|}
\hline $\begin{array}{l}\text { Census Division } \\
\text { and State }\end{array}$ & 1992 & 1991 & 1990 & 1989 & 1988 \\
\hline 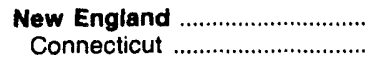 & $\begin{array}{r}42,087 \\
2,000\end{array}$ & $\begin{array}{r}45,852 \\
4,690\end{array}$ & $\begin{array}{r}58,576 \\
4,863\end{array}$ & $\begin{array}{r}48,076 \\
3,297\end{array}$ & $\begin{array}{r}14,978 \\
1,260\end{array}$ \\
\hline Mairie & -- & -- & - & -- & -- \\
\hline 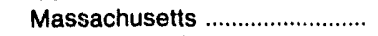 & 37,913 & 38,248 & 47,779 & 42,540 & 13,552 \\
\hline New Hampshire …….................... & 916 & -- & - & - & - \\
\hline 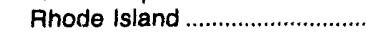 & 458 & 1,821 & 5,933 & 2,239 & 166 \\
\hline 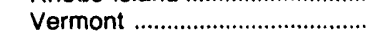 & 800 & 1,093 & - & - & -- \\
\hline 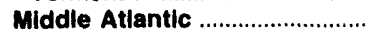 & 229,709 & 246,863 & 253,456 & 211,669 & 176,698 \\
\hline 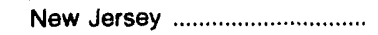 & 32,305 & 51,744 & 34,822 & 39,338 & 34,051 \\
\hline 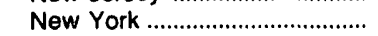 & 195,476 & 194,870 & 218,442 & 172,068 & 142,255 \\
\hline 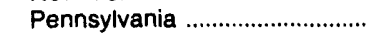 & 1,929 & 249 & 192 & 264 & 392 \\
\hline East North Central ....................... & 43,401 & 45,531 & 36,391 & 27,106 & 22,216 \\
\hline Illinois ........................................ & 8,952 & 11.126 & 7,041 & 5,111 & 4,521 \\
\hline 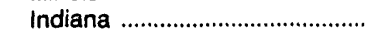 & 7,467 & 9,026 & 6,294 & 3,863 & 3,074 \\
\hline 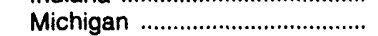 & 22,222 & 20,720 & 20,619 & 16,247 & 13,141 \\
\hline 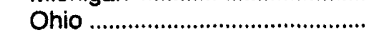 & 2,458 & 2,966 & 941 & 590 & 478 \\
\hline 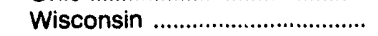 & 2,300 & 1,693 & 1,496 & 1,295 & 1,003 \\
\hline West North Central ................. & 18,203 & 48,575 & 31,325 & 21,058 & 22,480 \\
\hline 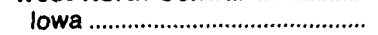 & 1,816 & 2,083 & 2,211 & 2,009 & 3,844 \\
\hline 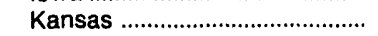 & 10,437 & 28,979 & 21,221 & 14,254 & 12,923 \\
\hline 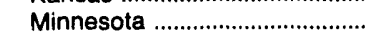 & 3,008 & 3,354 & 2,398 & 1,964 & 3,370 \\
\hline 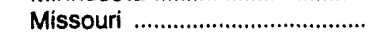 & 1,592 & 10,820 & 2,378 & 606 & 702 \\
\hline 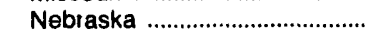 & 1,310 & 3,166 & 3,117 & 2,224 & 1,640 \\
\hline 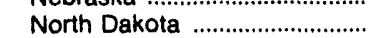 & 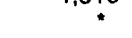 & 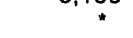 & $\because$ & 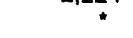 & 1 \\
\hline South Dakota ................................ & 39 & 172 & -- & -_ & -- \\
\hline South Att antic ......................... & 217,976 & 231,677 & 185,818 & 185,448 & 138,859 \\
\hline Delaware ................................... & 2,188 & 5,087 & 4,213 & 6,087 & 1,304 \\
\hline 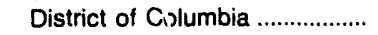 & -- & -- & -- & - & - \\
\hline Florida ......................................... & 191,121 & $191,82.5$ & 157,513 & 155,902 & 129,897 \\
\hline 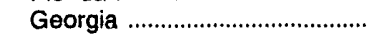 & 1,199 & 790 & 1,757 & 626 & 1,354 \\
\hline Maryland ...................................... & 8,584 & $13,23.4$ & 15,195 & 17,307 & 3,874 \\
\hline 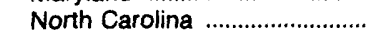 & 2,917 & 2,932 & -- & -- & - \\
\hline South Carolina ............................... & 1,315 & 9,518 & 5,877 & 1,881 & 1,664 \\
\hline 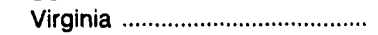 & 10,433 & 8,096 & 1,094 & 3,517 & 700 \\
\hline 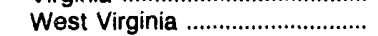 & 219 & 196 & 169 & 129 & 86 \\
\hline East South Central ....................... & 41,671 & 51,819 & 55,419 & 38,538 & 29,958 \\
\hline Alabama .................................. & 2,923 & 3,434 & 2,581 & 1,556 & 1,080 \\
\hline Kentucky ............................................ & 240 & 205 & 236 & 320 & 400 \\
\hline 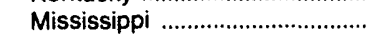 & 38,508 & 48,180 & 52,602 & 36,663 & 28,478 \\
\hline Tennessee .......................................... & -. & -- & - & - & $20,-$ \\
\hline West South Central ........................ & $1,365,720$ & $1,404,965$ & $1,375,523$ & $1,375,525$ & $1,402,134$ \\
\hline Arkansas .................................. & 27,137 & 27,672 & 31,951 & 29,473 & 21,976 \\
\hline 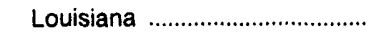 & 237.653 & 223,528 & 236,550 & 212,443 & 237,906 \\
\hline 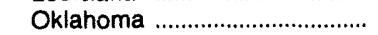 & 145,415 & $163,91.4$ & 141,150 & 150,296 & 151,747 \\
\hline 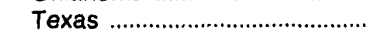 & 955,515 & 989,850 & 965,872 & 983,314 & 990,506 \\
\hline 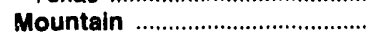 & 80,491 & 76,185 & 61,017 & 80,436 & 46,002 \\
\hline 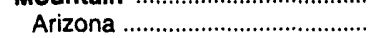 & 29,420 & 22,575 & 11,302 & 28,420 & 11,179 \\
\hline Colorado ......................................... & 1,521 & 2,680 & 2,451 & 4,754 & 5,205 \\
\hline 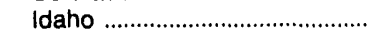 & -- & -- & -- & -- & - \\
\hline 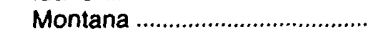 & 118 & 83 & 286 & 330 & 281 \\
\hline 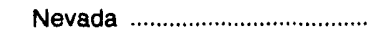 & 22,804 & 19,916 & 22,516 & 20,859 & 9,150 \\
\hline 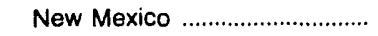 & 21,661 & 26,895 & 24,389 & 25,986 & 20,002 \\
\hline 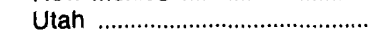 & 4,884 & 3,960 & 1 & - & 0.0 \\
\hline 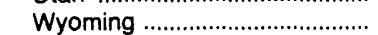 & & 76 & 70 & 87 & 185 \\
\hline Pacific Contiguous ………........... & 580,334 & 460,628 & 433,454 & $\mathbf{4 8 4 , 6 4 9}$ & 509,394 \\
\hline California ................................ & 565,619 & 449,661 & 433,454 & 484,649 & 509,394 \\
\hline 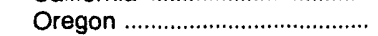 & 14,684 & 10,940 & - & -- & 00,00 \\
\hline 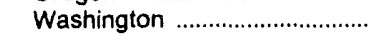 & 30 & 27 & -- & -- & -. \\
\hline Pacific Noncontlguous .............. & 18,086 & 18,722 & - & -- & -- \\
\hline 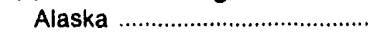 & 18,086 & 18,722 & -- & -- & -. \\
\hline Hawaii & -- & - & -- & -- & - \\
\hline Total & $2,637,678$ & $2,630,818$ & $2,490,979$ & $2,472,506$ & $2,362,721$ \\
\hline
\end{tabular}

* Number less than 0.5

Notes: - Totals may not equal sum of components because of independent rounding. - As of 1991, data are for electric generating plants with a total steam-electric and combined-cycle nameplate capacity of 50 or more megawatts. - Data for 1988-1990 are for steam-electric plants with a generator nameplate capacity of 50 or more megawatts. $\cdot$ Mcf $=$ thousand cubic feet.

Source: Federal Energy Regulatory Commission, FERC Form 423, "Monthly Report of Cost and Quality of Fuels for Electric Plants." 
Table 12. Average Delivered Cost of Gas by Census Division and State, 1988-1992

\begin{tabular}{|c|c|c|c|c|c|c|c|c|c|c|}
\hline \multirow{2}{*}{$\begin{array}{l}\text { Census Division } \\
\text { and State }\end{array}$} & 1992 & 1991 & 1990 & 1989 & 1988 & 1992 & 1991 & 1990 & 1989 & $\cdot 88$ \\
\hline & \multicolumn{5}{|c|}{ (cents per million Btu) } & \multicolumn{5}{|c|}{ (dollars per Mcf) } \\
\hline $\begin{array}{l}\text { New England } \\
\text { Connecticut }\end{array}$ & $\begin{array}{l}256.9 \\
265.9\end{array}$ & $\begin{array}{l}215.6 \\
209.0\end{array}$ & $\begin{array}{l}240.3 \\
270.2\end{array}$ & $\begin{array}{l}238.5 \\
251.1\end{array}$ & $\begin{array}{l}221.6 \\
217.4\end{array}$ & $\begin{array}{l}2.65 \\
2.74\end{array}$ & $\begin{array}{l}2.24 \\
2.16\end{array}$ & $\begin{array}{l}2.52 \\
2.79\end{array}$ & $\begin{array}{l}2.50 \\
2.59\end{array}$ & $\begin{array}{l}2.28 \\
2.24\end{array}$ \\
\hline 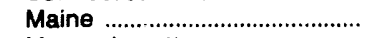 & -- & - & -- & - & - & - & - & - & - & - \\
\hline Massachusetts ................................. & 259.3 & 218.4 & 240.1 & 237.4 & 222.2 & 2.68 & 2.27 & 2.53 & 2.49 & 2.29 \\
\hline New Hampshire ............................. & 205.9 & - & - & - & - & 2.10 & - & - & - & - \\
\hline Rhode Islaild ........................................ & 213.4 & 198.0 & 216.9 & 241.2 & 208. : & 2.20 & 2.04 & 2.24 & 2.49 & 2.15 \\
\hline 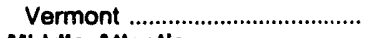 & 202.4 & 174.0 & - & - & - & 2.00 & 1.72 & - & -- & -- \\
\hline & 237.4 & $\begin{array}{l}217.2 \\
195.7\end{array}$ & & $\begin{array}{l}237.4 \\
245.5\end{array}$ & $\begin{array}{l}22 \% .0 \\
2245\end{array}$ & 2.45 & 2.24 & 2.43 & 2.44 & 2.31 \\
\hline $\begin{array}{l}\text { New Jersey } \\
\text { New York }\end{array}$ & 210.9 & $\begin{array}{l}195.7 \\
222.8\end{array}$ & $\begin{array}{l}217.2 \\
238.2\end{array}$ & $\begin{array}{l}245.5 \\
235.3\end{array}$ & $\begin{array}{l}224.5 \\
223.6\end{array}$ & 2.18 & 2.02 & 2.24 & 2.54 & 2.32 \\
\hline & 241.2 & $\begin{array}{l}222.8 \\
295.3\end{array}$ & $\begin{array}{l}238.2 \\
294.9\end{array}$ & $\begin{array}{l}2358.3 \\
348.2\end{array}$ & $\begin{array}{l}223.6 \\
333.0\end{array}$ & 2.48 & 2.30 & 2.46 & 2.42 & 2.30 \\
\hline $\begin{array}{l}\text { Pennsylvania ......................... } \\
\text { East North Ceritral }\end{array}$ & 297.2 & $\begin{array}{l}295.3 \\
218.1\end{array}$ & 252.9 & 285.8 & $\begin{array}{l}333.0 \\
295.7\end{array}$ & 3.06 & 3.05 & 3.04 & 3.58 & 3.45 \\
\hline $\begin{array}{l}\text { East North Ceritral } \\
\text { Illinois }\end{array}$ & $\begin{array}{l}221.2 \\
220.1\end{array}$ & $\begin{array}{l}218.1 \\
210.4\end{array}$ & 267.0 & 326.2 & $\begin{array}{l}295.7 \\
326.9\end{array}$ & 1.56 & 1.59 & 1.43 & 1.34 & $\therefore .50$ \\
\hline Illinois & $\begin{array}{l}220.1 \\
247.7\end{array}$ & 237.7 & 258.0 & 269.5 & 259.1 & 2.24 & 2.14 & 2.73 & 3.32 & 3.34 \\
\hline $\begin{array}{l}\text { Indiana } \\
\text { Michigan ..... }\end{array}$ & 195.4 & 195.9 & 210.6 & 174.8 & 255.5 & 2.48 & 2.38 & 2.58 & 2.70 & 2.60 \\
\hline Ohio & 223.8 & 217.9 & 254.6 & 313.2 & 3465 & .81 & .76 & .47 & .19 & .41 \\
\hline Wisconsin .................................... & 240.0 & 270.3 & 292.7 & 309.5 & 325.2 & 2.31 & 2.19 & 2.57 & 3.15 & 3.51 \\
\hline West North Central ............ & 209.8 & 171.7 & 188.4 & 211.5 & 210.9 & 2.42 & 2.72 & 2.95 & 3.11 & 3.26 \\
\hline lowa & 306.8 & 268.5 & 304.5 & 267.4 & 202.7 & $\begin{array}{l}2.06 \\
3.08\end{array}$ & 1.68 & $\begin{array}{l}1.86 \\
306\end{array}$ & 2.07 & 2.10 \\
\hline 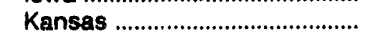 & 199.9 & 170.7 & 175.8 & 197.6 & 206.0 & $\begin{array}{l}3.90 \\
1.94\end{array}$ & 1.65 & $\begin{array}{l}3.06 \\
1.74\end{array}$ & $\begin{array}{l}2.69 \\
1.92\end{array}$ & $\begin{array}{l}2.04 \\
2.05\end{array}$ \\
\hline 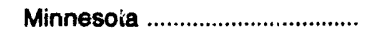 & 183.7 & 170.2 & 192.1 & $2 i 4.6$ & 198.4 & 1.85 & 1.71 & 1.93 & 2.16 & 1.99 \\
\hline 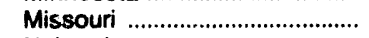 & 187.2 & 149.1 & 171.5 & 245.8 & 277.0 & 1.89 & 1.51 & 1.75 & 2.50 & 2.75 \\
\hline 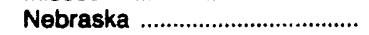 & 238.2 & 196.8 & 200.8 & 236.1 & 268.6 & 2.28 & 1.85 & 1.90 & 2.26 & 2.56 \\
\hline 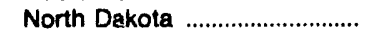 & 403.3 & 433.9 & 386.2 & 439.1 & 428.6 & 4.18 & 4.36 & 4.01 & 461 & 4.56 \\
\hline South Dakota ................................... & 282.7 & 175.8 & - & - & - & 2.88 & 1.77 & - & - & - \\
\hline $\begin{array}{l}\text { Sor all Attantic } \\
\text { Oelaware }\end{array}$ & $\begin{array}{l}230.5 \\
260.0\end{array}$ & $\begin{array}{l}212.0 \\
236.9\end{array}$ & $\begin{array}{l}250.8 \\
257.7\end{array}$ & $\begin{array}{l}248.0 \\
254.4\end{array}$ & $\begin{array}{l}212.2 \\
242.1\end{array}$ & $\begin{array}{l}2.34 \\
2.70\end{array}$ & $\begin{array}{l}2.16 \\
2.49\end{array}$ & $\begin{array}{l}2.55 \\
2.72\end{array}$ & $\begin{array}{l}2.52 \\
273\end{array}$ & 2.14 \\
\hline District of Columbia ...................... & - & - & - & - & - & - & 0.40 & 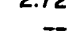 & 2.13 & 2.59 \\
\hline 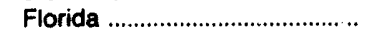 & 227.7 & 213.5 & 253.3 & 246.2 & 210.1 & 2.30 & 2.17 & 2.56 & 2.49 & 2.12 \\
\hline 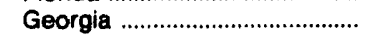 & 282.2 & 276.3 & 296.8 & 315.6 & 273.4 & 2.89 & 2.83 & 3.04 & 3.23 & 2.80 \\
\hline 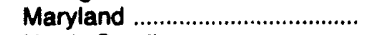 & 255.0 & 225.8 & 244.7 & 260.1 & 259.7 & 2.66 & 2.36 & 2.55 & 2.72 & 2.71 \\
\hline 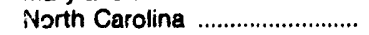 & 286.0 & 267.5 & - & - & - & 2.96 & 2.76 & - & - & - \\
\hline South Carolina ............................... & 169.0 & 148.9 & 171.8 & 222.1 & 180.6 & 1.73 & 1.53 & 1.76 & 2.27 & 1.86 \\
\hline 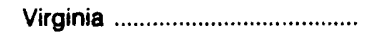 & 237.2 & 182.2 & 258.2 & 247.9 & 204.9 & 2.48 & 1.90 & 2.69 & 2.58 & 2.16 \\
\hline West Virginia ................................ & 352.5 & 363.3 & 513.3 & 458.8 & 389.2 & 3.53 & 3.63 & 5.13 & 4.59 & 3.89 \\
\hline East South Central ......................... & 183.2 & 150.6 & 178.8 & 185.6 & 186.3 & 1.88 & 1.64 & 1.85 & 1.90 & 1.91 \\
\hline 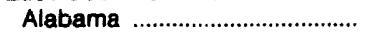 & 222.9 & 187.1 & 215.6 & 220.5 & 207.1 & 2.28 & 1.91 & 2.22 & 2.27 & 2.15 \\
\hline 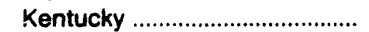 & 271.5 & 259.7 & 297.5 & 267.3 & 246.0 & 2.77 & 2.65 & 3.04 & 2.73 & 2.52 \\
\hline 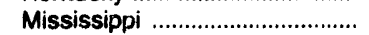 & 179.7 & 157.3 & 176.4 & 183.4 & 184.7 & 1.85 & 1.61 & 1.83 & 1.88 & 1.90 \\
\hline Tennessee .................................. & - & - & - & - & - & - & - & - & - & - \\
\hline Weat South Central ....................... & 221.3 & 199.7 & 210.6 & 215.7 & 207.8 & 2.28 & 2.06 & 2.18 & 2.24 & 2.15 \\
\hline 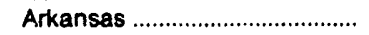 & 153.2 & 140.9 & 154.0 & 165.4 & 135.0 & 1.57 & 1.44 & 1.57 & 1.69 & 1.39 \\
\hline Louisiana ....................................... & 182.8 & 153.1 & 165.9 & 170.2 & 163.1 & 1.91 & 1.59 & 1.73 & 1.78 & 1.70 \\
\hline Oklahoma .......................................... & 308.2 & 286.5 & 300.8 & 292.5 & 281.3 & 3.20 & 2.98 & 3.14 & 3.05 & 2.92 \\
\hline 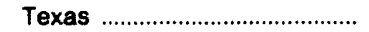 & 219.5 & 197.4 & 210.2 & 215.3 & 209.0 & 2.25 & 2.03 & 2.18 & 2.23 & 2.16 \\
\hline 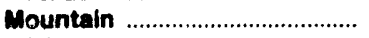 & 201.8 & 181.5 & 202.0 & 217.2 & 229.4 & 2.07 & 1.86 & 2.08 & 2.24 & 2.35 \\
\hline Arizona & 221.3 & 200.5 & 236.9 & 224.4 & 224.1 & 2.28 & 2.06 & 2.45 & 2.32 & 2.32 \\
\hline 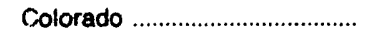 & 214.0 & 214.8 & 217.3 & 228.3 & 228.7 & 2.14 & 2.14 & 2.15 & 2.23 & 2.25 \\
\hline 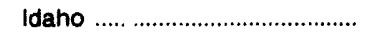 & -- & - & -- & - & - & - & - & - & - & - \\
\hline 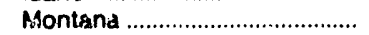 & 341.9 & 393.5 & 145.2 & 113.8 & 126.3 & 4.12 & 4.70 & 1.77 & 1.38 & 1.53 \\
\hline 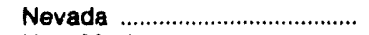 & 186.7 & 173.4 & 195.6 & 211.3 & 271.8 & 1.91 & 1.78 & 2.02 & 2.17 & 2.79 \\
\hline 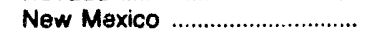 & 195.4 & 170.1 & 190.8 & 213.3 & 213.6 & 1.99 & 1.73 & 1.97 & 2.20 & 2.19 \\
\hline 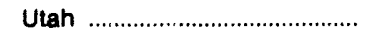 & 174.5 & 161.5 & 503.5 & - & - & 1.87 & 1.72 & 5.04 & - & $-\ldots$ \\
\hline 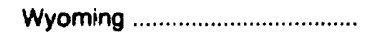 & 320.1 & 333.6 & 314.9 & 348.1 & 367.8 & 3.33 & 3.51 & 3.26 & 3.61 & 3.78 \\
\hline Pactíle Contiguous ....……….... & 269.9 & 283.9 & 303.1 & 292.4 & 283.1 & 2.70 & 2.92 & 3.13 & 3.04 & 2.93 \\
\hline 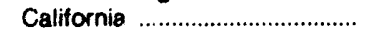 & 271.8 & 286.9 & 303.1 & 292.4 & 283.1 & 2.81 & 2.95 & 3.13 & 3.04 & 2.93 \\
\hline Orggon & 193.7 & 157.0 & - & -- & - & 1.96 & 1.59 & - & -- & - \\
\hline 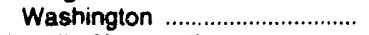 & 315.5 & 383.0 & - & - & - & 3.31 & 4.02 & -- & -- & -- \\
\hline Pacific Noncontiguous .............. & $\$ 17.6$ & 115.6 & - & - & - & 1.18 & 1.16 & - & -- & - \\
\hline Alaska & 117.6 & 115.6 & -- & - & -- & 1.18 & 1.16 & -- & -_ & - \\
\hline 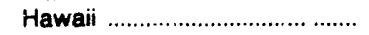 & $\ldots$ & - & -- & - & -- & - & -- & - & -- & - \\
\hline Total & 232.8 & 215.3 & 232.1 & 235.5 & 226.3 & 2.38 & 2.20 & 2.38 & 2.42 & 2.33 \\
\hline
\end{tabular}

Notes: - Totals may not equal sum of components because of independent rounding. - As of 1991, data are for electric generating plants with a total steam-electric and combined-cycle nameplate capacity of 50 or more megawatts. - Data for 1988-1990 are for steam-electric plants with a generator nameplate capacity of 50 or more megawatts. - Mcf $=$ thousand cubic feet.

Source: Foderal Energy Regulatory Commission, FERC Form 423, "Monthly Report of Cost and Quality of Fuels for Electric Plants." 
Table 13. Recelpts and Average Delivered Cost of Gas by Census Division and State, 1992

\begin{tabular}{|c|c|c|c|c|c|c|c|c|c|c|c|c|}
\hline \multirow{3}{*}{$\begin{array}{l}\text { Consus Division } \\
\text { and State }\end{array}$} & \multicolumn{12}{|c|}{ Type of Purchase } \\
\hline & \multicolumn{3}{|c|}{ Firm } & \multicolumn{3}{|c|}{ Interruptible } & \multicolumn{3}{|c|}{ Oft-Peak } & \multicolumn{3}{|c|}{ Total } \\
\hline & $\begin{array}{l}\text { Recelpts } \\
\text { (1,000 Mct) }\end{array}$ & $\begin{array}{l}\text { (cents } \\
\text { per } \\
10^{\circ} \\
\text { Btu) }\end{array}$ & $\begin{array}{l}\text { (\$ } \\
\text { por } \\
\text { Mef) }\end{array}$ & $\begin{array}{c}\text { Recelpts } \\
\text { (1,000 Mcf) }\end{array}$ & $\begin{array}{c}\text { (cents } \\
\text { per } \\
10^{\prime} \\
\text { Btu) }\end{array}$ & $\begin{array}{c}\text { (s } \\
\text { por } \\
\text { Mct) }\end{array}$ & $\begin{array}{l}\text { Recelpts } \\
\text { (1,000 Mcf) }\end{array}$ & $\begin{array}{c}\text { (cents } \\
\text { per } \\
\text { 10‘ } \\
\text { Btu) }\end{array}$ & $\begin{array}{c}\text { (s } \\
\text { per } \\
\text { Mcf) }\end{array}$ & $\begin{array}{l}\text { Recelpts } \\
\text { (1,000 Mcf) }\end{array}$ & $\begin{array}{c}\text { (cents } \\
\text { per } \\
10^{\circ} \\
\text { Btu) }\end{array}$ & $\begin{array}{l}\text { (\$ } \\
\text { por } \\
\text { Mcf) }\end{array}$ \\
\hline $\begin{array}{l}\text { Now England } \\
\text { Connecticut }\end{array}$ & $\begin{array}{l}627 \\
282\end{array}$ & $\begin{array}{l}466.7 \\
567.1\end{array}$ & $\begin{array}{l}4.87 \\
5.84\end{array}$ & $\begin{array}{r}41,460 \\
1,718\end{array}$ & $\begin{array}{l}253.7 \\
216.4\end{array}$ & $\begin{array}{l}2.61 \\
2.23\end{array}$ & $\overline{-}$ & $\overline{-}$ & $\overline{-}$ & $\begin{array}{r}42,087 \\
2,000\end{array}$ & $\begin{array}{l}256.9 \\
265.9\end{array}$ & \\
\hline 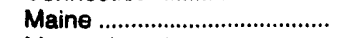 & - & -- & - & -- & - & - & -- & -- & -- & - & - & \\
\hline Massachusetts ......................... & 199 & 523.5 & 5.61 & 37,714 & 257.8 & 2.66 & - & - & - & 37,913 & 259.3 & 2.68 \\
\hline Now Hampshire ......................... & - & - & - & 916 & 205.9 & 2.10 & - & - & - & 916 & 205.9 & \\
\hline 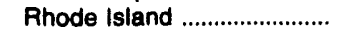 & 145 & 190.5 & 1.96 & 313 & 224.1 & 2.31 & -- & - & -- & 458 & 213.4 & 2.20 \\
\hline Vermont .................................. & - & -- & - & 800 & 202.4 & 2.00 & - & - & - & 800 & 202.4 & 2.00 \\
\hline Middle Atiantic ......................... & 30,453 & 227.6 & 2.35 & 166,576 & 242.9 & 2.50 & 32,681 & 218.3 & 2.25 & 229,709 & 237.4 & 2.45 \\
\hline New Jersey ................................ & & -- & - & 32,305 & 210.9 & 2.18 & - & - & - & 32,305 & 210.9 & 2. \\
\hline New York ............................... & 30,367 & 227.4 & 2.35 & 132,428 & 250.0 & 2.57 & 32,681 & 218.3 & 2.25 & 195,476 & 241.2 & 2.48 \\
\hline Pennsylvania ............................. & 86 & 302.2 & 3.11 & 1,843 & 297.0 & 3.06 & - & - & -- & 1,929 & 297.2 & 3.06 \\
\hline East North Contral ................ & 11,026 & 241.6 & 2.43 & 32,375 & 209.6 & 1.26 & - & - & - & 43,401 & 221.2 & 1.56 \\
\hline 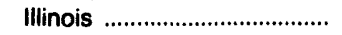 & 1,283 & 255.8 & 2.59 & 7,669 & 214.1 & 2.18 & - & - & -- & 8,952 & 220.1 & 2.24 \\
\hline 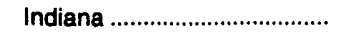 & 7,058 & 247.4 & 2.47 & 409 & 253.4 & 2.59 & - & -- & - & 7,467 & 247.7 & \\
\hline 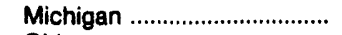 & 364 & 210.0 & 2.10 & 21,859 & 194.8 & .79 & - & -- & - & 22,222 & 195.4 & .81 \\
\hline 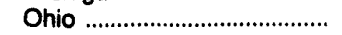 & 2,101 & 207.4 & 2.14 & 357 & 318.9 & 3.34 & - & - & - & 2,458 & 223 & 2.31 \\
\hline 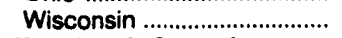 & 220 & 361.8 & 3.66 & 2,080 & 227.1 & 2.29 & - & - & - & 2,3 & 240.0 & 2.42 \\
\hline Wost North Central ............... & 918 & 258.5 & 2.71 & 15,334 & 211.7 & 2.08 & 1,951 & 170.0 & 1.64 & 18,203 & 209 & 2.06 \\
\hline lowa ................................... & 169 & 353.4 & 3.59 & 1,647 & 301.9 & 3.03 & - & - & - & 1,816 & 306.8 & 3.08 \\
\hline 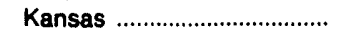 & 675 & 241.4 & 2.56 & 8,378 & 201.9 & 1.95 & 1,384 & 164.9 & 1.56 & 10,437 & 199.9 & 1.94 \\
\hline Minnesota ................................ & - & -- & - & 2,442 & 184.2 & 1.85 & 567 & 181.4 & 1.84 & 3,008 & 183.7 & 1.85 \\
\hline 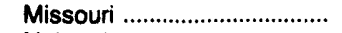 & - & - & - & 1,592 & 187.2 & 1.89 & - & -- & - & 1,592 & 187.2 & 1.89 \\
\hline 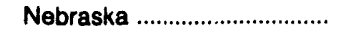 & 74 & 202.3 & 2.02 & 1,235 & 240.4 & 2.30 & - & -- & - & 1,310 & 238 & \\
\hline North Dakota ............................. & - & - & - & $\bullet$ & 403.3 & 4.18 & -- & -- & - & $*$ & 403.3 & 4.18 \\
\hline South Dakota .......................... & -- & - & - & 39 & 282.7 & 2.88 & - & - & -- & 38 & 282 & 2.8 \\
\hline South Atlantic ................... & 161,558 & 230.0 & 2.32 & 56,418 & 231.9 & 2.39 & - & - & - & 217,976 & 230.5 & 2.34 \\
\hline 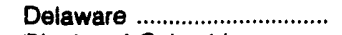 & 1,452 & 266.8 & 2.77 & 736 & 246.6 & 2.56 & -- & - & -- & 2,188 & 260.0 & \\
\hline District of Columbia .............. & - & - & - & - & - & -- & -- & - & - & - & - & \\
\hline 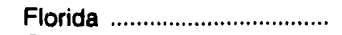 & 160,106 & 229.7 & 2.32 & 31,015 & 218.0 & 2.23 & - & - & - & 191,121 & 227.7 & \\
\hline 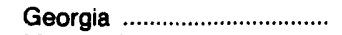 & - & - & -- & 1,199 & 282.2 & 2.89 & - & -- & - & 1,199 & 282 & 2.8 \\
\hline Maryland ................................ & -- & - & - & 8,584 & 255.0 & 2.66 & - & -- & -- & 8,584 & 255 & 2. \\
\hline 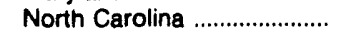 & - & - & - & 2,917 & 286.0 & 2.8 & -- & - & -- & 2,9 & 286.0 & 2.96 \\
\hline South Carolina .......................... & - & -- & - & 1,315 & 169.0 & 1.73 & -- & - & -- & 1,315 & 169.0 & 1.73 \\
\hline 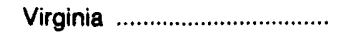 & - & - & -- & 10,433 & & 2. & - & - & - & 10,433 & & \\
\hline West Virginia & - & - & -- & 219 & 352.5 & 3.53 & -- & -- & -- & 219 & 352.5 & 3. \\
\hline East South Contral ................ & 11,474 & 202.6 & 2.10 & 30,009 & 175.3 & 1.8 & 188 & 264.3 & 2.71 & 41,671 & 183 & 1.8 \\
\hline 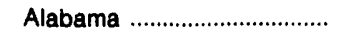 & - & -- & - & 2,923 & 222.9 & 2.28 & - & - & - & 2,923 & 222 & \\
\hline 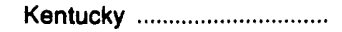 & - & - & - & 52 & 298.6 & 2.9 & 188 & 264.3 & 2.71 & 240 & 271 & 2.7 \\
\hline 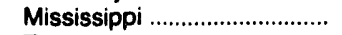 & 11,474 & 202.6 & 2.10 & 27,034 & 169.9 & 1.74 & - & -- & - & 38,508 & 179.7 & 1. \\
\hline Tennessee ............................. & & - & -- & & -- & ... & -- & - & - & & -- & \\
\hline West South Central ............... & $1,013,951$ & 233.4 & 2.41 & 351,768 & 186.3 & 1.92 & - & - & - & $1,365,720$ & 221.3 & \\
\hline 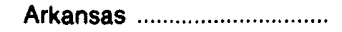 & 3,112 & 110.9 & 1.25 & 24,025 & 159.3 & 1.6 & - & - & - & 27,137 & 153 & 1.57 \\
\hline 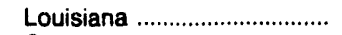 & 109,534 & 170.1 & 1.77 & 128,120 & 193.7 & 2.0 & - & -- & -- & 7,653 & 182 & 1.91 \\
\hline 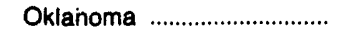 & 134,026 & 320.5 & 3.33 & 11,389 & 158.2 & 1.5 & -- & - & - & 415 & 308.2 & 3.20 \\
\hline Texas ................... & 767,279 & 227.7 & 2.34 & 188,235 & 186.1 & 1.9 & -- & - & - & 955,515 & 219 & \\
\hline Mountain ................ & 38,079 & 203.4 & 2.09 & 42,412 & 200.4 & 2.0 & - & - & - & 80,491 & 201.8 & \\
\hline ....................... & 25,253 & 209.8 & 2.16 & 4,166 & 290.7 & 3.0 & - & $\cdots$ & -- & 29,420 & 221.3 & 2.8 \\
\hline ......................... & 622 & 205.6 & 2.03 & 899 & 219.7 & 2.22 & -- & -- & - & 1,521 & 214.0 & \\
\hline 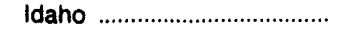 & - & - & - & - & & -- & - & - & -- & - & - & \\
\hline 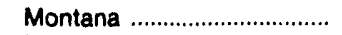 & 111 & 340.0 & 4.12 & & 375.2 & 4.24 & -- & - & -- & 118 & 341.9 & 4.12 \\
\hline 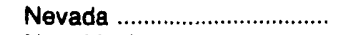 & & - & -- & 22,804 & & & -- & -- & -- & 22,804 & & \\
\hline New Mexico .............................. & 12,093 & 188.2 & 1.91 & 9,568 & 204.5 & 2.08 & -- & -- & - & 21,661 & 195.4 & 1. \\
\hline 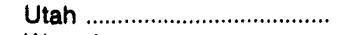 & - & -- & -- & 4,884 & 174.5 & 1.8 & -- & -- & - & 4,884 & 174.5 & \\
\hline 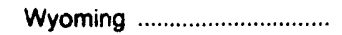 & - & -- & - & 83 & 320.1 & 3.3 & - & -- & -- & 83 & 320.1 & 3.33 \\
\hline Pacific Contiguous ................ & - & - & - & 580,334 & 269.8 & 2.7 & - & - & - & 580,334 & 269.9 & \\
\hline California ……........................ & $\cdots$ & -- & -- & 565,619 & 271.8 & 2.81 & -- & - & - & 565,619 & 271.8 & 2.81 \\
\hline Oregon .................................. & - & - & - & 14,684 & 193.7 & 1.9 & -- & - & - & 14,684 & 193.7 & \\
\hline Washington ............................... & $-\infty$ & - & -- & 30 & 315.5 & 3.31 & - & -- & - & 30 & 315.5 & \\
\hline Pacific Noncontiguous ........ & 18,086 & 117.6 & 1.18 & - & - & - & - & - & - & 18,086 & 117.6 & 1.18 \\
\hline Alaska & 18,086 & 117.6 & 1.18 & -- & -- & -- & - & & - & 18,086 & 117.6 & 1.18 \\
\hline 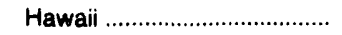 & & & - & -- & - & -- & -- & - & -- & & -- & 7 \\
\hline Total & $1,286,172$ & 230.3 & 2.37 & $4,316,686$ & 235.8 & 2.40 & 34,820 & 216.0 & 2.22 & $2,637,678$ & 232.8 & 2.38 \\
\hline
\end{tabular}

- = Number less than 0.5

Notes: - Totals may not equal sum of components because of independent rounding. - Data are for electric generating plants with a total steam-electric and combined-cycle nameplate capacity of 50 or more megawatts. - Mcf = thousand cubic feet.

Source: Federal Energy Regulatory Commission, FERC Form 423, "Monthly Roport of Cost and Quality of Fuels for Electric Plants." 
Table 14. Receipts of Gas by Type, Census Division, and State, 1992 (Thousand Mcf)

\begin{tabular}{|c|c|c|c|c|}
\hline \multirow{2}{*}{$\begin{array}{l}\text { Consus Division } \\
\text { and State }\end{array}$} & \multicolumn{4}{|c|}{ Recelpts by Type } \\
\hline & Natural Gas & LNG and SNG' & other $^{2}$ & Total \\
\hline Now England & 42,087 & - & - & 42,087 \\
\hline 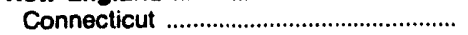 & 2,000 & -- & -- & 2,000 \\
\hline 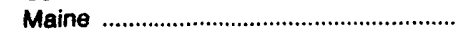 & -- & -- & -- & - \\
\hline Massachusetts …………………………....... & 37,913 & -- & -- & 37,913 \\
\hline New Hampshire ......................................... & 916 & - & -- & 916 \\
\hline 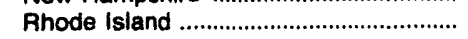 & 458 & -- & -- & 458 \\
\hline 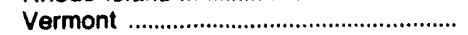 & 800 & -- & -- & 800 \\
\hline Mlddle Attantic ..................................... & 229,709 & - & -- & 229,709 \\
\hline New Jersey .......................................... & 32,305 & - & - & 32,305 \\
\hline Now York ............................................. & 195,476 & - & -- & 195,476 \\
\hline 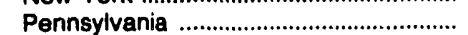 & 1,929 & -- & -- & 1,929 \\
\hline East North Contral .................................... & 29,121 & -- & 14,280 & 43,401 \\
\hline 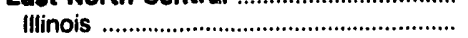 & 8,952 & -- & -- & 8,952 \\
\hline 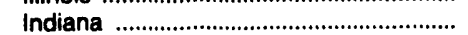 & 7,467 & -- & -- & 7,467 \\
\hline 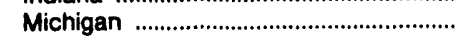 & 7,942 & - & 14,280 & 22,222 \\
\hline 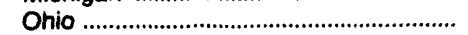 & 2,458 & - & - & 2,458 \\
\hline 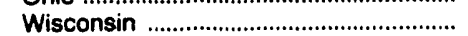 & 2,300 & -- & -- & 2,300 \\
\hline 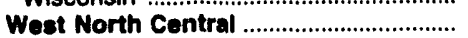 & 18,157 & - & 46 & 18,203 \\
\hline 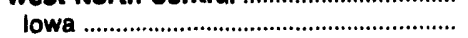 & 1,816 & -- & -- & 1,816 \\
\hline 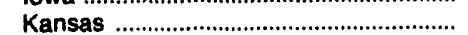 & 10,392 & -- & 46 & 10,437 \\
\hline Minnesota ................................................ & 3,008 & - & - & 3,008 \\
\hline 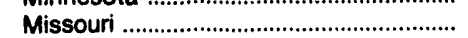 & 1,592 & - & -- & 1,592 \\
\hline 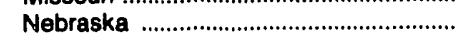 & 1,310 & -- & -- & 1,310 \\
\hline 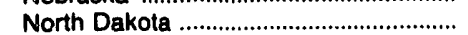 & & -. & -- & $\because$ \\
\hline South Dakota ......................................... & 39 & -- & -- & 39 \\
\hline 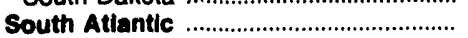 & 217,769 & -- & 207 & 217,976 \\
\hline 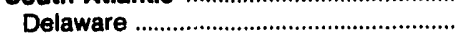 & 2,188 & -- & - & 2,188 \\
\hline District of Columbia ................................... & -1 & -- & -- & -1. \\
\hline 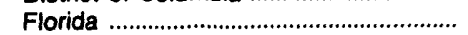 & 191,121 & -- & -- & 191,121 \\
\hline 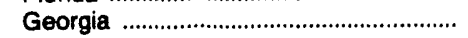 & 1,199 & -- & -- & 1,199 \\
\hline 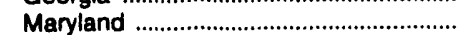 & 8,584 & -- & -- & 8,584 \\
\hline 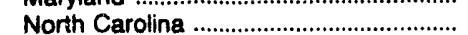 & 2,917 & -- & -- & 2,917 \\
\hline South Carolina …………………………... & 1,315 & -- & -. & 1,315 \\
\hline 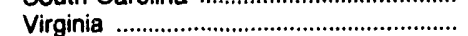 & 10,226 & -- & 207 & 10,433 \\
\hline 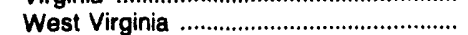 & 219 & -- & - & 219 \\
\hline 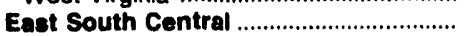 & 41,671 & - & - & $\$ 1,671$ \\
\hline 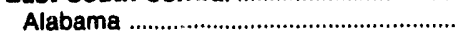 & 2,923 & -- & -- & 2,923 \\
\hline Kentucky ……1- & 240 & -- & -- & 240 \\
\hline 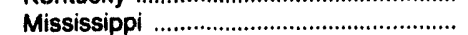 & 38,508 & -- & -- & 38,508 \\
\hline 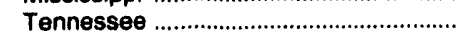 & -- & -- & -- & - \\
\hline West South Contral ............................... & $1,365,720$ & - & -- & $1,365,720$ \\
\hline 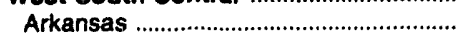 & 27,137 & - & -- & 27,137 \\
\hline 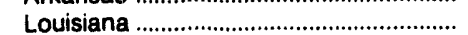 & 237,653 & -- & -- & 237,653 \\
\hline 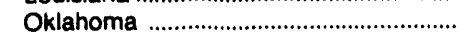 & 145,415 & -- & -- & 145,415 \\
\hline 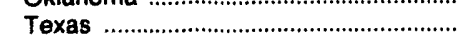 & 955,515 & -. & -- & 955,515 \\
\hline 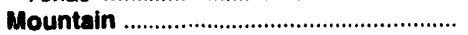 & 80,491 & - & - & 80,491 \\
\hline 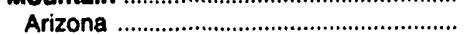 & 29,420 & -- & -_- & 29,420 \\
\hline 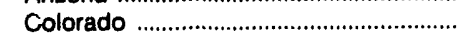 & 1,521 & -- & -- & 1,521 \\
\hline Idaho ………………………………….. & - & -- & -- & - \\
\hline Montana & 118 & $\ldots$ & -. & 118 \\
\hline Nevada & 22,804 & -- & -- & 22,804 \\
\hline New Mexico ……………………………... & 21,661 & -- & -- & 21,661 \\
\hline Utah & 4,884 & -- & -- & 4,884 \\
\hline Wyoming & 83 & -- & -- & 83 \\
\hline 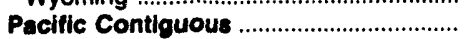 & 580,334 & - & - & 580,334 \\
\hline 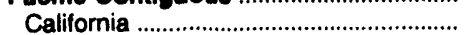 & 565,619 & -- & -- & 565,619 \\
\hline Oregon & 14,684 & -- & -- & 14,684 \\
\hline 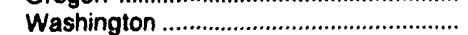 & 30 & -. & -- & 30 \\
\hline Pacific Noncontiguous ............................... & 18,086 & - & - & 18,086 \\
\hline 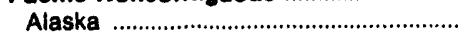 & 18,086 & -- & -- & 18,086 \\
\hline Hawaii .............................................. & & - & -- & - \\
\hline 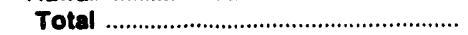 & $2,623,146$ & - & 14,533 & $2,637,678$ \\
\hline
\end{tabular}

1 Liquified Natural Gas and Synthetic Natural Gas.

2 Includes small quantities of Coke-Oven Gas, Refinery Gas, and Blast-Furnace gas - = Number less than 0.5

Notes: - Totals may not equal sum of components because of independent rounding. - Data are for electric generating plants with a total steam-electric and combined-cycle nameplate capacity of 50 or more megawatts. - Mcf = thousand cubic feet. Source: Federal Energy Regulatory Commission, FERC Form 423, "Monthly Report of Cost and Quality of Fuels for Electric Plants." 
Table 15. Total Heating Value and Cost of Fossil-Fuels by Census Division and State, 1992

\begin{tabular}{|c|c|c|c|c|c|c|c|c|c|c|}
\hline \multirow{2}{*}{$\begin{array}{l}\text { Census Division } \\
\text { and State }\end{array}$} & \multicolumn{4}{|c|}{ Total Btu (billions) } & \multicolumn{3}{|c|}{$\%$ of Total Btu } & \multicolumn{3}{|c|}{$\begin{array}{l}\text { Avg. Dellvered Cost } \\
\text { (cents per } 10^{6} \text { Btu) }\end{array}$} \\
\hline & Total & Coal & Petroleum & Gas & Cosl & $\begin{array}{l}\text { Petro- } \\
\text { leum }\end{array}$ & Gas & Coal & $\begin{array}{l}\text { Petro- } \\
\text { leum }\end{array}$ & Gas \\
\hline 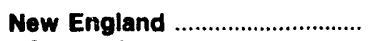 & 434,761 & 163,027 & 228,353 & 43,381 & 37.5 & 52.5 & 10.0 & 172.0 & 233.2 & 256.9 \\
\hline Connecticut ..................................... & 80,648 & 20,883 & 57,703 & 2,062 & 25.9 & 71.5 & 2.6 & 194.8 & 241.0 & 265.9 \\
\hline 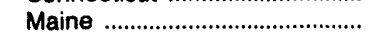 & 13,912 & - & 13,912 & - & - & 100.0 & -- & - & 228.8 & - \\
\hline 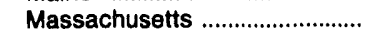 & 287,826 & 109,624 & 139,078 & 39,124 & 38.1 & 48.3 & 13.6 & 168.7 & 236.3 & 259.3 \\
\hline 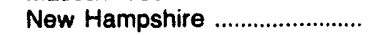 & 50,603 & 32,520 & 17,150 & 933 & 64.3 & 33.9 & 1.8 & 168.5 & 185.8 & 205.9 \\
\hline 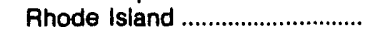 & 983 & -- & 511 & 472 & -- & 52.0 & 48.0 & -- & 195.0 & 213.4 \\
\hline Vermont .......................................... & 790 & -- & -- & 790 & -. & -- & 100.0 & -- & - & 202.4 \\
\hline 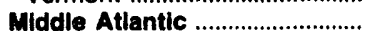 & $1,829,727$ & $1,347,889$ & 245,179 & 236,659 & 73.7 & 13.4 & 12.9 & 149.6 & 267.3 & 237.4 \\
\hline 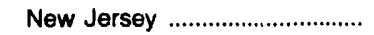 & 108,039 & 59,383 & 15,242 & 33,414 & 55.0 & 14.1 & 30.9 & 173.1 & 303.3 & 210.9 \\
\hline 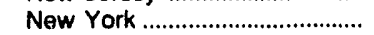 & 678,139 & 269,766 & 207,115 & 201,257 & 39.8 & 30.5 & 29.7 & 148.8 & 263.8 & 241.2 \\
\hline Pennsylvania ......................................... & $1,043,549$ & $1,018,739$ & 22,822 & 1,987 & 97.6 & 2.2 & .2 & 148.4 & 275.2 & 297.2 \\
\hline East North Central ......................... & $3,782,287$ & $3,727,385$ & 24,259 & 30,643 & 98.5 & .6 & .8 & 145.6 & 326.9 & 221.2 \\
\hline Illinois ........................................ & 566,503 & 542,891 & 14,514 & 9,097 & 95.8 & 2.6 & 1.6 & 173.7 & 305.1 & 220.1 \\
\hline 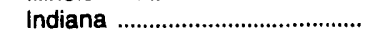 & $1,025,910$ & $1,016,877$ & 1,558 & 7,476 & 99.1 & .2 & .7 & 131.2 & 443.3 & 247.7 \\
\hline 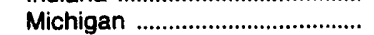 & 627,932 & 612,982 & 5,740 & 9,210 & 97.6 & .9 & 1.5 & 155.6 & 296.8 & 195.4 \\
\hline 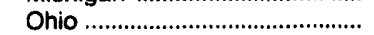 & $1,217,198$ & $1,212,528$ & 2,131 & 2,539 & 99.6 & .2 & .2 & 143.5 & 451.4 & 223.8 \\
\hline 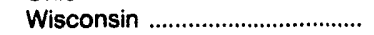 & 344,744 & 342,108 & 315 & 2,321 & 99.2 & .1 & .7 & 133.3 & 463.7 & 240.0 \\
\hline West North Central ........................ & $1,789,513$ & $1,748,618$ & 3,011 & 17,884 & 98.8 & .2 & 1.0 & 110.0 & 318.5 & 209.8 \\
\hline 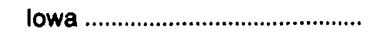 & 268,828 & 266,656 & 348 & 1,824 & 99.2 & .1 & .7 & 110.4 & 424.0 & 306.8 \\
\hline 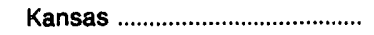 & 253,103 & 242,680 & 295 & 10,128 & 95.9 & .1 & 4.0 & 117.9 & 437.8 & 199.9 \\
\hline 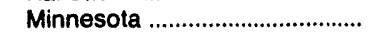 & 271,098 & 267,854 & 211 & 3,033 & 98.8 & .1 & 1.1 & 118.6 & 450.9 & 183.7 \\
\hline Missouri ..................................... & 509,152 & 505.751 & 1,797 & 1,604 & 99.3 & .4 & .3 & 133.6 & 234.9 & 187.2 \\
\hline 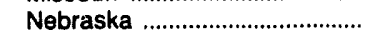 & 134,025 & 132,721 & 48 & 1,256 & 99.0 & - & .9 & 74.6 & 464.9 & 238.2 \\
\hline North Dakota ................................. & 307,561 & 307,249 & 312 & & 99.9 & .1 & $\cdot$ & 72.1 & 457.7 & 403.3 \\
\hline South Dakota & 25,746 & 25,706 & -- & $4 i$ & 99.8 & -- & .2 & 113.3 & - & 282.7 \\
\hline 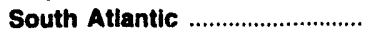 & $3,686,665$ & $3,119,860$ & 345,568 & 221,238 & 84.6 & 9.4 & 6.0 & 165.6 & 244.5 & 230.5 \\
\hline 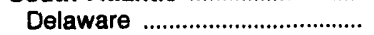 & 56,304 & 40,017 & 14,019 & 2,269 & 71.1 & 24.9 & 4.0 & 173.4 & 241.8 & 260.0 \\
\hline 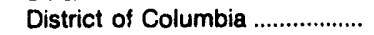 & 1,388 & -- & 1,388 & - & - & 100.0 & -- & - & 350.4 & -- \\
\hline Florida & $1,071,901$ & 603,090 & 275,540 & 193,270 & 56.3 & 25.7 & 18.0 & 182.0 & 241.7 & 227.7 \\
\hline Georgia & 552,726 & 550,214 & 1,284 & 1,228 & 99.5 & .2 & .2 & 180.1 & 434.4 & 282.2 \\
\hline Maryland ……................................. & 277,871 & 236,799 & 32,103 & 8,970 & 85.2 & 11.6 & 3.2 & 159.5 & 230.3 & 255.0 \\
\hline 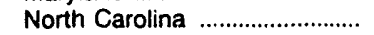 & 518,848 & 514,706 & 1,120 & 3,022 & 99.2 & .2 & .6 & 172.6 & 441.1 & 286.0 \\
\hline 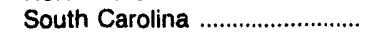 & 239,081 & 237,251 & 485 & 1,345 & 99.2 & .2 & .6 & 152.7 & 461.7 & 169.0 \\
\hline 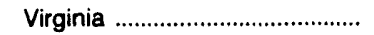 & 257.181 & 228,751 & 17.513 & 10,916 & 88.9 & 6.8 & 4.2 & 147.3 & 247.1 & 237.2 \\
\hline West Virginia ................................. & 711,366 & 709,031 & 2,116 & 219 & 99.7 & .3 & - & 147.2 & 483.8 & 352.5 \\
\hline East South Central ........................ & $1,977,012$ & $1,927,362$ & 6,804 & 42,847 & 97.5 & .3 & 2.2 & 138.5 & 317.5 & 183.2 \\
\hline 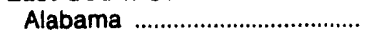 & 604,052 & 600,313 & 755 & 2,984 & 99.4 & .1 & .5 & 172.7 & 459.8 & 222.9 \\
\hline 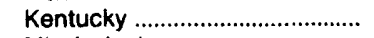 & 752.010 & 750,473 & 1,292 & 245 & 99.8 & .2 & * & 116.2 & 479.4 & 271.5 \\
\hline 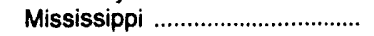 & 123.743 & 80,235 & 3,891 & 39,617 & 64.8 & 3.1 & 32.0 & 159.7 & 200.0 & 179.7 \\
\hline 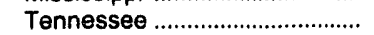 & 497,207 & 496,341 & 865 & - & 99.8 & .2 & - & 127.3 & 480.2 & - \\
\hline West South Central ........................ & $3,380,182$ & $1,969,403$ & 3,680 & $1,407,099$ & 58.3 & .1 & 41.6 & 147.4 & 416.4 & 221.3 \\
\hline 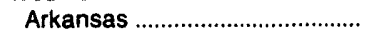 & 231,294 & 202,919 & 558 & 27,818 & 87.7 & .2 & 12.0 & 165.3 & 480.8 & 153.2 \\
\hline 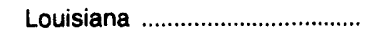 & 454,356 & 205,881 & 552 & 247,923 & 45.3 &.$i$ & 54.6 & 153.5 & 387.9 & 182.8 \\
\hline 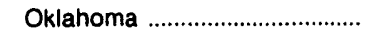 & 444,534 & 293,014 & 666 & 150,855 & 65.9 & .1 & 33.9 & 123.4 & 435.6 & 308.2 \\
\hline 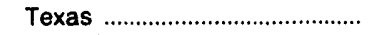 & $2,249,997$ & $1,267,590$ & 1,904 & 980,503 & 56.3 & .1 & 43.6 & 149.1 & 399.0 & 219.5 \\
\hline 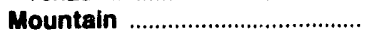 & $2,082,848$ & $1,995,375$ & 4,755 & 82,718 & 95.8 & .2 & 4.0 & 111.3 & 405.7 & 201.8 \\
\hline Arizona & 367,345 & 336,201 & 826 & 30,318 & 91.5 & .2 & 8.3 & 137.4 & 466.5 & 221.3 \\
\hline Colorado & 311,117 & 309,442 & 154 & 1,521 & 99.5 & & .5 & 109.2 & 479.3 & 214.0 \\
\hline Idaho & & -- & - & -- & - & -- & - & - & -- & -- \\
\hline 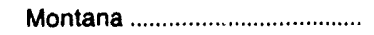 & 186,507 & 186,270 & 95 & 142 & 98.9 & .1 & .1 & 70.8 & 509.1 & 341.9 \\
\hline 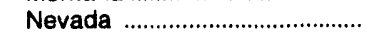 & 200,273 & 174,470 & 2,421 & 23,383 & 87.1 & 1.2 & 11.7 & 146.2 & 331.3 & 186.7 \\
\hline New Mexico …………………....... & 291,558 & 269,108 & 425 & 22,025 & 92.3 & .1 & 7.6 & 132.2 & 515.5 & 195.4 \\
\hline 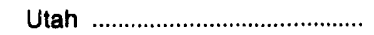 & 297,777 & 292,362 & 171 & 5,244 & 98.2 & .1 & 1.8 & 120.9 & 484.1 & 174.5 \\
\hline 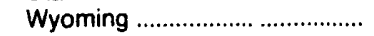 & 428,272 & 427,521 & 664 & 86 & 99.8 & .2 & $\cdot$ & 75.9 & 479.3 & 320.1 \\
\hline Pacific Contiguous ........................ & 732,400 & 132,834 & 204 & 599,363 & 18.1 & & 81.8 & 129.6 & 448.7 & 269.9 \\
\hline 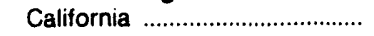 & 584,492 & -- & 7 & 584,485 & - & * & 100.0 & -- & 217.9 & 271.8 \\
\hline 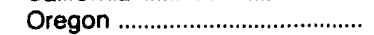 & 52,213 & 37,255 & 112 & 14,846 & 71.4 & .2 & 28.4 & 110.1 & 449.2 & 193.7 \\
\hline 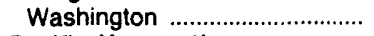 & 95,696 & 95,578 & & 32 & 99.9 & .1 & $\bullet$ & 137.3 & 466.0 & 315.5 \\
\hline Pacific Noncontiguous .............. & 70,277 & - & 52,192 & 18,085 & - & 74.3 & 25.7 & - & 292.1 & 117.6 \\
\hline Alaska & 18,085 & -- & - & 18,085 & -- & - & 100.0 & -- & -- & 117.6 \\
\hline 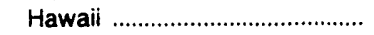 & 52.192 & -- & 52,192 & -- & - & 100.0 & - & -- & 292.1 & - \\
\hline 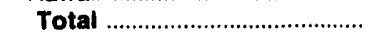 & $19,745,672$ & $16,131,752$ & 914,004 & $2,699,916$ & 81.7 & 4.6 & 13.7 & 141.2 & 255.1 & 232.8 \\
\hline
\end{tabular}

- = Number less than 0.5 billion Btu or 0.05 percent.

Notes: - Totals may not equal sum of components because of independent rounding. - Data are for electric generating plants with a total steamelectric and combined-cycle nameplate capacity of 50 or more megawatts.

Source: Federal Energy Regulatory Commission, FERC Form 423, "Monthly Report of Cost and Quality of Fuels for Electric Plants." 


\section{Origin and Destination of Coal}

This chapter contains information on the origin and destination of coal to steam-electric plants. Table 16 presents data on the volume, quality, and delivered cost of coal from each coal producing State. Table 17 contains company level data on each electric utility that receives lignite while Table 18 provides data on coal imported by electric utilities for the years 1988 through 1992. Tables 19,20 , and 21 provide data on coal receipts to electric utilities from the three main coal-producing regions in the United States. It should be noted that due to its unique characteristics when compared with other coals, lignite receipts have been omitted from Tables 20 and 21 .

Table 22 provides a list of States that received coal for use at electric plants during 1992 . The volume, quality, and delivered cost of coal to each State is shown in bold print. Beneath each bolded line of print are the States of origin of that coal. For example, Table 22 shows that electric plants located in Alabama received 24,886 thousand short tons of coal in 1992. Of this total, 16,265 thousand short tons of coal was received from mines located in Alabama; 956 thousand short tons, from Illinois; 19 thousand short tons, from Indiana; 4,078 thousand short tons, from Kentucky, 817 thousand short tons, from Tennessee, and 2,752 thousand short tons, from West Virginia.

Table 23 provides a list of States of origin from which coal was delivered to electric utilities. Origin State data are shown in bold print. Beneath each bolded line of print are the States of destination for that coal. For example, Table 23 shows that coal originating in Alabama totaled 16,435 thousand short tons and was delivered to electric plants located in Alabama, Florida, and Georgia.

In Table 24, the origin of coal delivered to each electric plant is shown at the State and County of origin level. This table format is similar to that of Table 22. For example, data for the Alabama Power Company shows that the Barry plant received 832 thousand short tons of coal in 1992. Of this total, 816 thousand short tons was received from Alabama. The coal was mined in three counties in Alabama: Tuscaloosa county totaled 500 thousand short tons, while Walker county mines shipped 292 thousand short tons, and Winston county mines shipped 24 thousand short tons. The data also show that 16 thousand short tons of coal was mined in Nicholas County, West Virginia.

It should be noted that it is not uncommon for an electric utility to report a tipple (an apparatus at a central facility used in loading coal for transportation by rail or truck) as the source of the coal and to list the county in which the tipple is located as the county of origin. In some cases the coal delivered to the tipple comes from various surrounding counties and the data have not been adjusted to compensate for this. If an electric utility can not determine the county of origin for the delivered coal, the State and county of origin are designated as "Unknown."

\section{Domestic Coal}

In 1992, 774 million short tons of coal, which originated in 24 coal-producing States, were delivered to coalfired plants located in 43 States (Tables 22 and 23). Wyoming, Kentucky, and West Virginia were ranked highest, respectively, in terms of origin of coal delivered to electric utilities in 1992. These three States accounted for 49 percent (384 million short tons) of all coal delivered to electric utilities (Table 16). Coal receipts from Wyoming totaled 182 million short tons and were delivered to power plants located in 23 States (Table 23). This compares with 184 million short tons delivered to 21 States in 1991. This 2-million-short-ton decrease in receipts of Wyoming coal is the first annual decrease reported on the FERC Form 423. A cool summer and mild winter in the Midwest, an area that receives large amounts of Wyoming coal, contributed to lower demand by electric utilities. ${ }^{20}$ Receipts of Wyoming coal were highest in Texas, where 34 million short tons were delivered in 1992 (Table 23). Wyoming coal is low-sulfur coal with an average sulfur content of approximately 0.4 percent by weight. Coal received from Kentucky totaled 117 million short tons and was delivered primarily to coal-fired plants located east of the Mississippi River. Coal from Kentucky was delivered to electric plants located in 22 States (26 million short tons were delivered to coal-fired plants located within Kentucky). It should be noted that eastern Kentucky is the source for primarily low-sulfur Appala-

${ }^{20}$ B.D. Hong and E.R. Slatick, “Coal 1992 Introduction," Mining Engineering (May 1993), pp.493-495. 
chian Region coal (average percent weight of approximately 1.0 percent), while western Kentucky coal is primarily high-sulfur Interior Region coal with an average sulfur content of approximately 3.0 percent weight.

West Virginia was the origin for 85 million short tons of coal delivered to electric utilities in 1992. This coal was delivered to electric plants in 22 States (including 23 million short tons to in-State coal-fired plants). The average sulfur content of coal from West Virginia ranges from approximately 2.00 percent in the northern part of the State to 0.8 percent sulfur in the southern part of the State. Receipts of coal from Illinois totaled 55 million short tons, fourth-highest among coalproducing States. Illinois coal is primarily high-sulfur coal averaging 2.6 percent by weight. The majority of this coal is delivered to electric plants located in Illinois, Missouri, Indiana, Florida, and Georgia. Coal produced in Texas totaled 51 million short tons, fifth highest among coal-producing States. However, all of this coal was low-Btu, high-ash lignite delivered to mine-mouth electric plants located within the State of Texas.

Some of the longest hauls during 1992 included shipments of coal from Wyoming to Florida and Georgia, and from Utah to Florida. These shipments were delivered to electric plants for the purpose of conducting test-burns of western coal. While it is not uncommon to transport coal up to 1,000 miles from the mine, a large amount of coal never leaves the State in which it is mined. In 1992, 43 percent of all coal mined for electric utilities was delivered to electric plants located in the same State (Table 23). States in which more than 75 percent of the coal produced for domestic electric plants is delivered in-State include Alabama, Indiana, Iowa, Louisiana, Missouri, North Dakota, Ohio, Oklahoma, Texas, Utah, and Washington.

Domestic coal is obtained from three major coalproducing regions in the United States -- the Appalachian, Interior, and Western Regions (Tables 19, 20, and 21).

Appalachian Region Coal is mined in Pennsylvania, Maryland, Virginia, West Virginia, eastern Kentucky, Tennessee, Alabama, and Ohio. With the exception of coal from Ohio, this coal is bituminous in rank and of low-to-medium sulfur content with a heat content that averages more than 12,000 Btu per pound. Appalachian coal is transported primarily to electric plants throughout the eastern United States.

Interior Region Coal is mined primarily in Illinois, Indiana, western Kentucky, and Missouri. This region produces bituminous coal containing a high percentage of sulfur, with approximately 11,000 Btu per pound. Most Interior Region coal is delivered to electric plants in the central and southeastern United States.
Western Region Coal is mined in Montana, Wyoming, Colorado, Utah, North Dakota, Arizona, and New Mexico. It is generally delivered to electric plants throughout the western and central United States. Most of the coal in this region is subbituminous coal that is low in sulfur content (less than 0.5 percent) and contains approximately 9,000 Btu per pound. The Powder River Basin (located in northeast Wyoming, southeast Montana, and part of the Western Region) was the origin for approximatley 200 million short tons of the coal delivered to electric utilities in 1992. Coal from this basin is delivered by unit train to electric plants as far east as New York and Georgia.

Appalachian Region Coal Deliveries. The amount of coal from the Appalachian Region delivered to electric utilities in 1992 was 280 million short tons (Table 19), an increase of 5 million short tons from 1991. The average sulfur content of coal from this region decreased slightly from the previous year while its average delivered cost decreased by $\$ 1.22$ to $\$ 38.86$ per short ton. In 1992, the Alabama Power Company, the Georgia Power Company, and the Pennsylvania Electric Company purchased the largest amounts of Appalachian Region coal.

Interior Region Coal Deliveries. In 1992, coal deliveries to electric utilities from the Interior Region totaled 123 million short tons (Table 20), a decrease of 1 million short tons from 1991. The sulfur content of coal from this region averaged 2.77 percent. The average delivered cost per short ton decreased by $\$ 0.31$ to $\$ 31.67$. As has been the case for the past several years, the Tennessee Valley Authority purchased the largest amount of Interior Region coal (23 million short tons) in 1992.

Western Region Coal Deliveries. Receipts of coal to electric utilities from the Western Region in 1992 were 291 million short tons (Table 21), an increase of 1 million short tons from 1991. The average delivered cost of Western Region coal was $\$ 23.61$ per short ton, a decrease of $\$ 0.50$ per short ton from 1991. On a national basis, the delivered cost of Western Region coal is usually lower than the delivered cost of Appalachian or Interior Region coal. This is due to the relatively low cost of mining western coal (usually large surface mines with thick seams of easily accessible coal) and, to some extent, the low-transportation costs resulting from the proximity of many of the western electric plants to the coal mines. However, transportation costs for Western Region coal delivered to electric plants in the central and southern United States often comprise well over half of the delivered cost of this coal.

Pacificorp purchased the largest amount of Western Region coal in 1992 (30 million short tons). Other electric utilities purchasing more than 10 million short tons of Western Region coal in 1992 include the Arizona Public Service Company, Detroit Edison Company, Montana Power Company, and the Northern States Power Company. 
In 1992, 80 million short tons of lignite were delivered to electric utilities, an increase of nearly 2 million short tons from 1991 lignite receipts (Table 17). The average cost for total U.S. lignite delivered to electric utilities in 1992 was $\$ 13.38$ per short ton, an increase of $\$ 0.01$ per short ton from 1991.

Most (96 percent) of this lignite originated in Texas and North Dakota. Louisiana accounted for just over 3 million short tons of lignite, while receipts from Montana were under 1 million short tons. Because lignite tends to disintegrate when exposed to weather, most lignite-burning plants are located close to the mine. Lignite, compared with other ranks of coal, has a lowBtu, high-moisture content and transporting it long distances is generally uneconomical.

The Texas Utilities (TU) Electric Company received the largest amount of lignite in 1992, 33 million short tons (Table 17). The lignite was burned at the company's four coal-fired plants (Big Brown, Sandow Unit 4, Martin Lake, and Monticello). The Basin Electric Power Cooperative (North Dakota) received a total of 8 million short tons of lignite at its Antelope Valley and Leland Olds Plants, while the Houston Lighting \& Power Company received 7 million short tons of lignite at its Limestone Plant.
During 1992, the level of coal imported to U.S. electric utilities remained minimal (Table 18). A total of 2 million short tons of coal was imported from Colombia, Venezuela, Canada, and Indonesia. The Jacksonville Electric Authority in Florida received the largest amount of imported coal (1.4 million short tons) from Colombia. The New England Power Company received 197 thousand short tons of coal from Venezuela and Canada. The Public Service Company of New Hampshire received 83 thousand short tons of coal from Colombia and Venezuela. The Central Power \& Light Company (Texas) received 80 thousand short tons of coal, from Colombia and Venezuela, for use at the Coleto Creek plant. Tacoma Public Utilities received 15 thousand short tons of coal from Canada; while the Ohio Edison Company received a test shipment of 13 thousand short tons of coal from Indonesia. Ohio Edison's receipt of coal from Indonesia was the company's first receipt of imported coal and only the second delivery of Indonesian coal to a domestic electric utility. This particular shipment of coal was delivered to Ohio Edison's Burger plant from Indonesia for $\$ 32.00$ per short ton (166.9 cents per million Btu). Indonesian coal is unusual in that the average sulfur content is approximately 0.10 percent and the ash content is about 1.2 percent. Coal from Colombia was 83 percent ( 1.5 million short tons) of all imports. The amount of coal imported from Venezuela was 240 thousand short tons. Imports of Canadian coal totaled 48 thousand short tons, while coal from Indonesia totaled 13 thousand short tons.

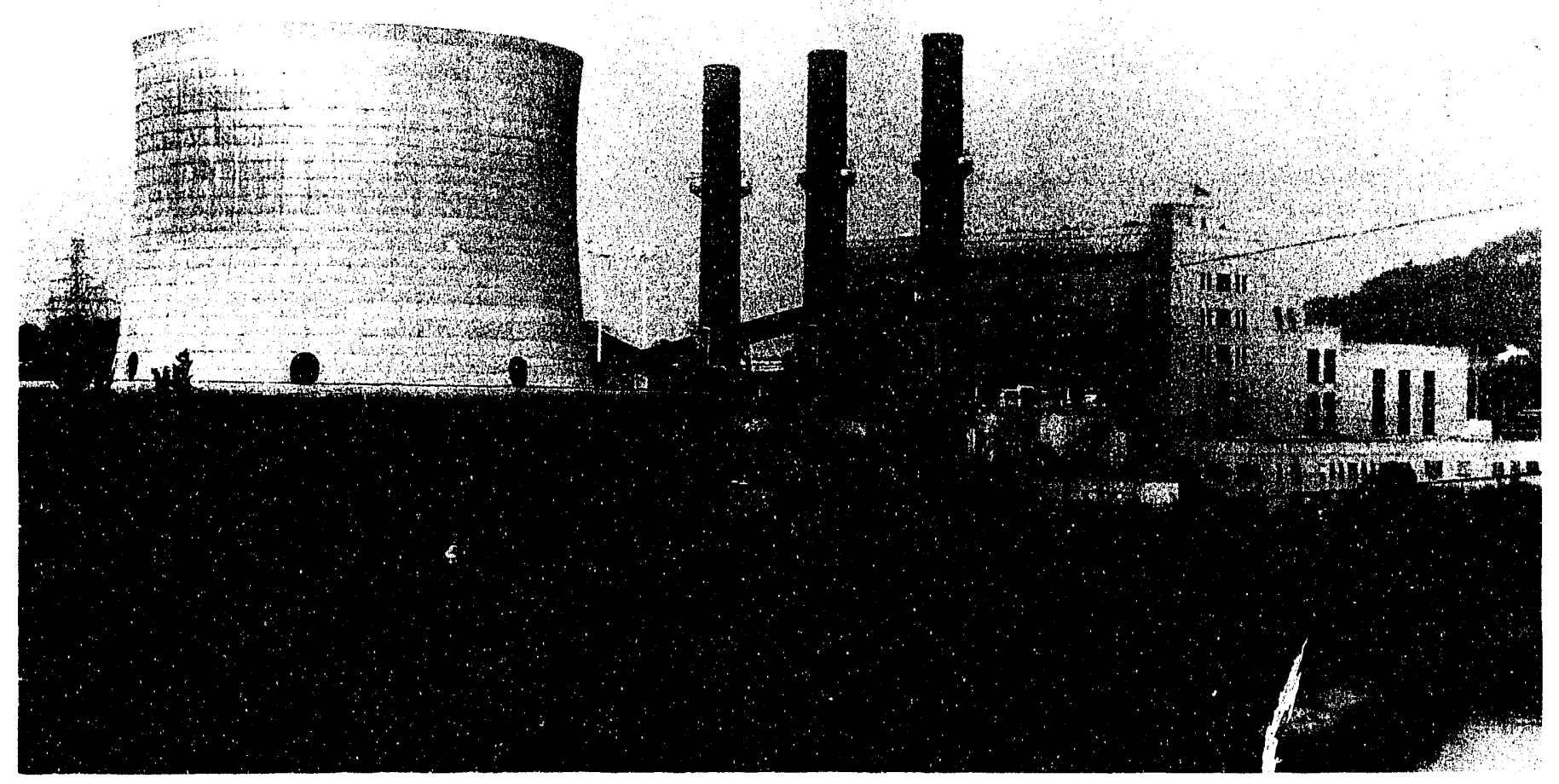

The Metropolitan Edison Company's Titus Station entered commercial operation in 1951. This thre unit coal-fired plant, located in Berks County Pennsylvania, has a coal-fired generator nameplate capacity of 225 megawatts. In 1992, Titus received approximately 400 thousand short tons of Pennsylvania coal. 
Table 16. Origin of Coal by State, 1992

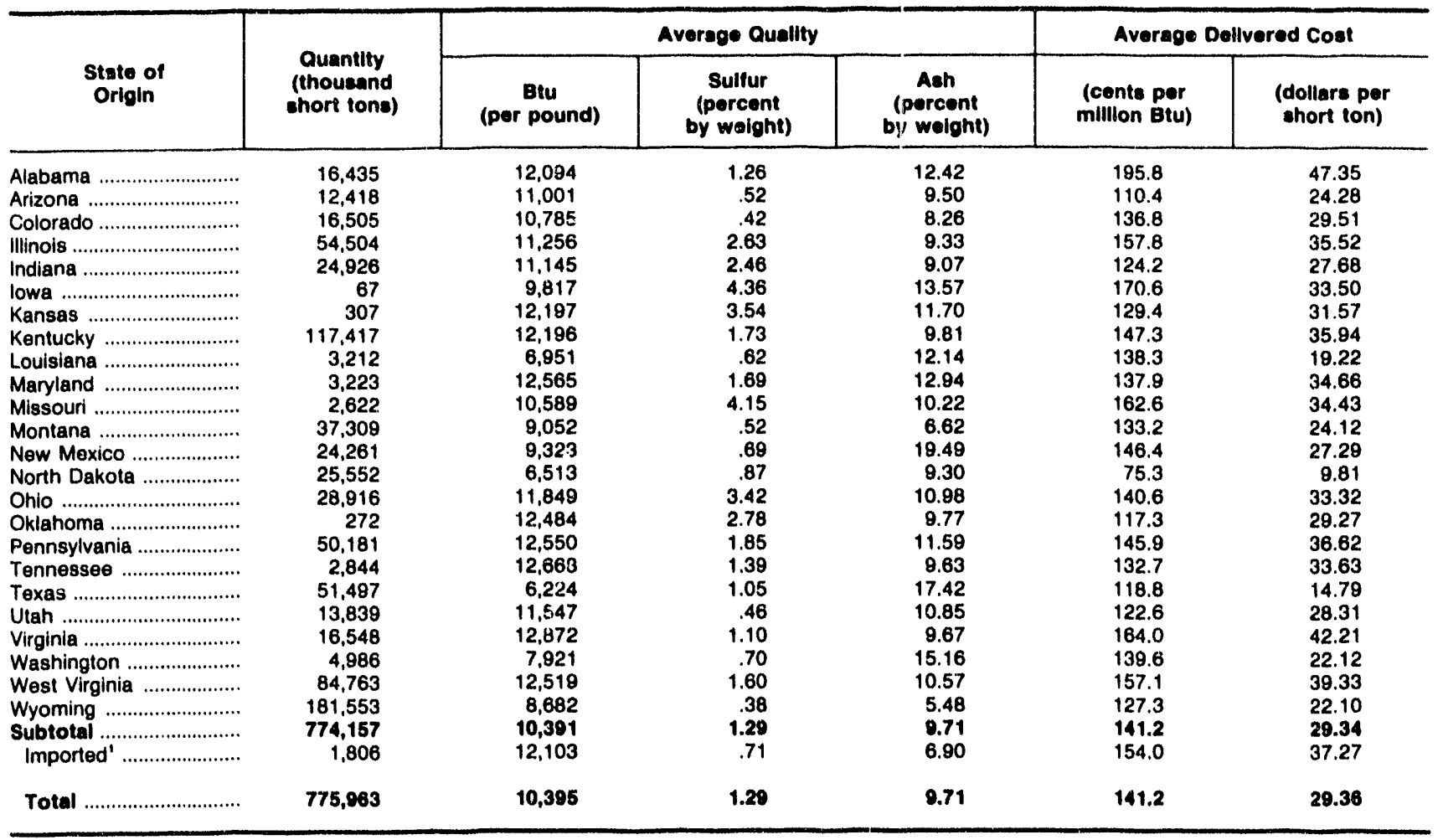

- Imported includes coal from Indonesia, Canada, Colombia South America, and Venezuela.

Notes: - Totals may not equal sum of components because of independent rounding. - Data are for electric generating plants with a total steam-electric and combined-cvcle nameplate capacity of $\mathbf{5 0}$ or more megawatts.

Source: Federal Energy Regulatory Commission, FERC Form 423, "Monthly Pepiort of Cost and Quality of Fuels for Electric Plants."

Table 17. Recelpts of Lignite by Electric Utility, 1992

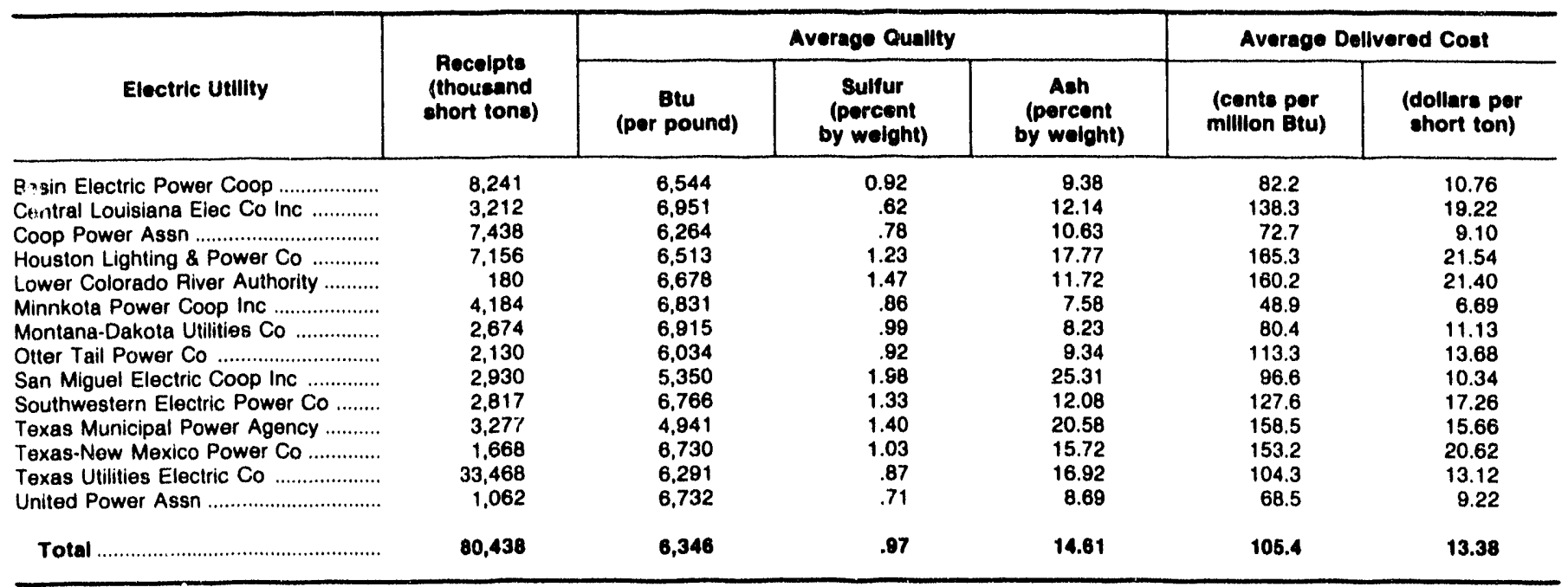

Notes: - Totals may not equal sum of components because of independent rounding. - Data are for electric generating plants with a total steamelectric and combined-cycle nameplate capacity of 50 or more megawatts. - This table includes all lignite mined in the continental United States and reported on FERC Form 423.

Source: Federal Energy Regulatory Commission, FERC Form 423, "Monthly Report of Cost and Quality of Fuels for Electric Plants." 
Table 18. Receipts, Quality, and Average Dellvered Cost of Imported Coal, 1988-1992

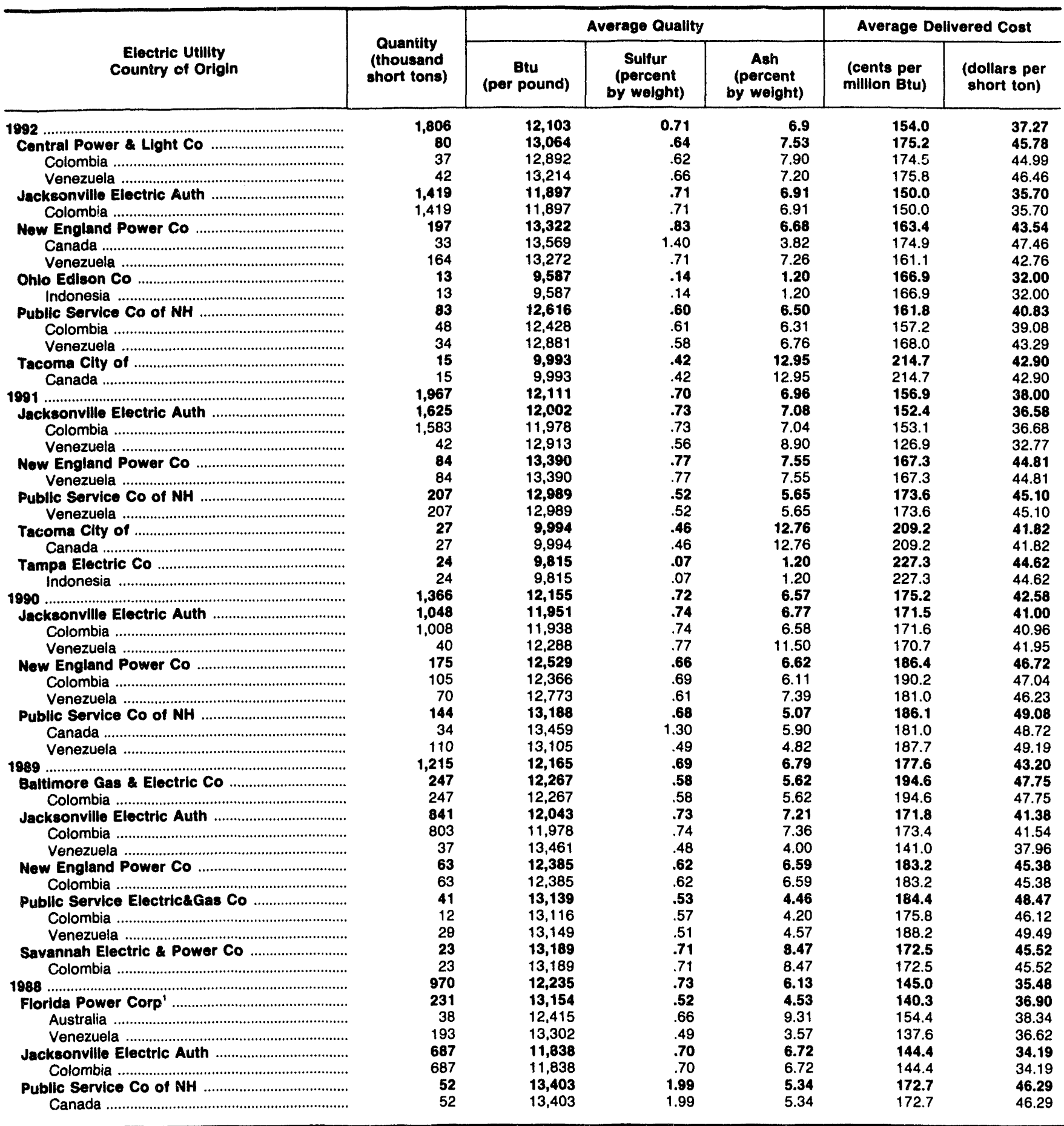

1 The average delivered cost for imported coal to the Florida Power Corporation Crystal River Plant includes only transportation costs to the transfer facility in Myrtle Grove, Louisiana, and excludes the transportation costs of approximately $\$ 7.00$ to $\$ 10.00$ per short ton between the transfer facility and the Crystal River Plant.

Notes: - Totals may not equal sum of components because of independent rounding. - As of 1991, data are for electric generating plants with a total steam-electric and combined-cycle nameplate capacity of 50 or more megawatts. Data for $1988-1990$ are for steam-electric plants with a generator nameplate capacity of 50 or more megawatts.

Source: Federal Energy Regulatory Commission, FERC Form 423, "Monthly Report of Cost and Quality of Fuels for Electric Plants." 
Table 19. Receipts of Appalachian Region Coal by Electric Utility, 1992

\begin{tabular}{|c|c|c|c|c|c|c|}
\hline \multirow[b]{2}{*}{ Electric Utility } & \multirow{2}{*}{$\begin{array}{l}\text { Recelpts } \\
\text { (thousand } \\
\text { short tons) }\end{array}$} & \multicolumn{3}{|c|}{ Average Quality } & \multicolumn{2}{|c|}{ Average Delivered Cost } \\
\hline & & $\begin{array}{c}\text { Btu } \\
\text { (per pound) }\end{array}$ & $\begin{array}{c}\text { Sulfur } \\
\text { (percent } \\
\text { by woight) }\end{array}$ & $\begin{array}{c}\text { Ash } \\
\text { (percent } \\
\text { by weight) }\end{array}$ & $\begin{array}{l}\text { (cents per } \\
\text { million Btu) }\end{array}$ & $\begin{array}{l}\text { (dollars per } \\
\text { short ton) }\end{array}$ \\
\hline Alabama Electric Coop inc ...................... & 1,395 & 12,165 & 1.29 & 12.11 & 148.3 & 36.07 \\
\hline 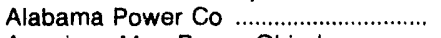 & 17,106 & 12,083 & 1.22 & 12.11 & 193.6 & 46.78 \\
\hline American Mun Power Ohio Inc ............ & 891 & 11,337 & 4.55 & 14.59 & 96.9 & 21.96 \\
\hline Appalachian Power Co .............................. & 9,057 & 12,487 & .76 & 11.28 & 171.9 & 42.93 \\
\hline Atlantic City Electric Co ........................... & 795 & 12,971 & 2.13 & 9.16 & 167.7 & 43.50 \\
\hline Baltimore Gas \& Electric Co ................. & 4,139 & 12,902 & .96 & 8.87 & 154.0 & 39.74 \\
\hline Cardinal Operating Co ............................... & 4,277 & 11,842 & 2.16 & 12.88 & 148.0 & 35.06 \\
\hline Carolina Power \& Light Co ...................... & 10,403 & 12,417 & .88 & 10.33 & 172.6 & 42.86 \\
\hline Central Hudson Gas \& Elec Corp ....... & 881 & 13,018 & .59 & 7.50 & 182.1 & 47.40 \\
\hline Central Illinois Light Co ............................. & 1,069 & 13,359 & .57 & 5.96 & 172.5 & 46.08 \\
\hline Central Operating Co ................................. & 1,367 & 12,354 & 1.20 & 11.61 & 165.0 & 40.77 \\
\hline Cincinnati Gas \& Electric Co .................. & 8,910 & 12,046 & 2.25 & 11.06 & 139.2 & 33.53 \\
\hline Cleveland Electric Illum Co ..................... & 4.649 & 12,792 & 2.60 & 8.69 & 151.8 & 38.83 \\
\hline 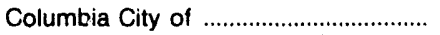 & 37 & 13,975 & .64 & 5.62 & 211.2 & 59.04 \\
\hline Columbus Southern Power Co ............ & 3,729 & 11,983 & 3.21 & 8.40 & 146.1 & 35.00 \\
\hline 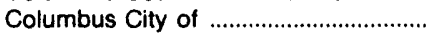 & 29 & 12,645 & .95 & 8.49 & 164.4 & 41.58 \\
\hline Consumers Power Co ............................. & 6,223 & 12,375 & .80 & 10.58 & 163.7 & 40.51 \\
\hline 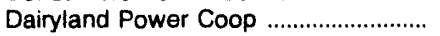 & 153 & 12,206 & .68 & 10.60 & 144.9 & 35.36 \\
\hline Dayton Power \& Light Co ........................ & 6,796 & 11,776 & 1.21 & 13.74 & 142.2 & 33.48 \\
\hline Delmanva Power \& Light Co ................ & 1,532 & 13,064 & 1.03 & 8.83 & 173.4 & 45.31 \\
\hline 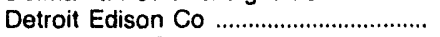 & 5,913 & 12,958 & 1.25 & 7.85 & 165.3 & 42.83 \\
\hline 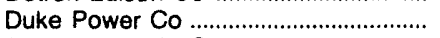 & 10,746 & 12,491 & .96 & 9.96 & 172.2 & 43.03 \\
\hline 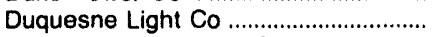 & 2,424 & 12,681 & 1.72 & 10.73 & 148.0 & 37.52 \\
\hline East Kentucky Power Coop Inc ........... & 2,561 & 12,311 & 1.37 & 10.27 & 114.5 & 28.20 \\
\hline Florida Power Corp ................................. & 5,598 & 12,592 & .83 & 8.76 & 178.8 & 45.03 \\
\hline Gainesville Regional Utilities ................ & 523 & 13,193 & .68 & 7.37 & 173.1 & 45.67 \\
\hline 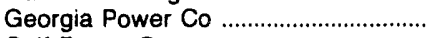 & 15,634 & 12,341 & 1.18 & 10.69 & 174.3 & 43.02 \\
\hline 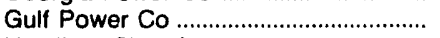 & 72 & 12,060 & 2.75 & 12.94 & 120.6 & 29.09 \\
\hline 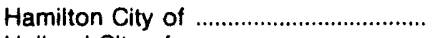 & 26 & 12,515 & .71 & 8.25 & 146.6 & 36.71 \\
\hline Holland City of ........................................ & 153 & 13,011 & .82 & 6.31 & 175.0 & 45.54 \\
\hline Holyoke Water Power Co ........................ & 363 & 13,224 & 1.33 & 6.31 & 168.8 & 44.65 \\
\hline Illinois Power Co ......................................... & 571 & 12,716 & .74 & 10.01 & 153.7 & 39.10 \\
\hline Indiana Michigan Power Co .................. & 450 & 12,154 & .69 & 10.95 & 182.2 & 44.29 \\
\hline Indiana-Kentucky Electric Corp ............ & 156 & 13,648 & .94 & 5.52 & 150.3 & 41.03 \\
\hline 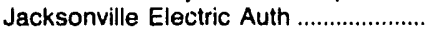 & 2,206 & 12,607 & 1.08 & 9.63 & 171.2 & 43.18 \\
\hline 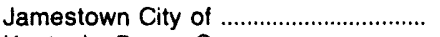 & 114 & 12,656 & 1.79 & 10.36 & 132.6 & 33.56 \\
\hline Kentucky Power Co .................................... & 2,517 & 12,042 & 1.04 & 11.05 & 117.3 & 28.25 \\
\hline 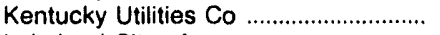 & 4,113 & 12,315 & .98 & 10.46 & 122.9 & 30.27 \\
\hline 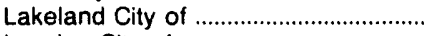 & 818 & 12,999 & 1.04 & 7.71 & 165.0 & 42.90 \\
\hline 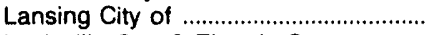 & 889 & 12,925 & .86 & 7.19 & 184.2 & 47.60 \\
\hline Louisville Gas \& Electric Co ................... & 47 & 11,196 & 2.61 & 9.47 & 117.0 & 26.21 \\
\hline Manitowoc Public Utilities .......................... & 122 & 13,309 & .81 & 6.41 & 178.3 & 47.47 \\
\hline 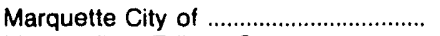 & 10 & 12,345 & .65 & 9.18 & 170.5 & 42.09 \\
\hline Metropolitan Edison Co ........................... & 1,110 & 13,229 & 1.62 & 6.82 & 143.8 & 38.04 \\
\hline Michigan South Central Pwr Agy ......... & 40 & 12,003 & 3.35 & 8.29 & 223.3 & 53.60 \\
\hline Mississippi Power Co ................................. & 856 & 12,939 & .78 & 7.27 & 168.5 & 43.61 \\
\hline Monongahela Power Co ......................... & 11,586 & 12,797 & 2.80 & 9.64 & 127.9 & 32.72 \\
\hline Montaup Electric Co .................................. & 413 & 12,917 & 1.03 & 7.93 & 176.4 & 45.58 \\
\hline New England Power Co ........................ & 3,221 & 13,057 & 1.19 & 8.61 & 168.1 & 43.89 \\
\hline New York State Elec \& Gas Corp ....... & 4,359 & 12,746 & 1.77 & 9.28 & 139.5 & 35.56 \\
\hline Niagara Mohawk Power Corp .............. & 3,540 & 13,180 & 1.87 & 6.98 & 142.6 & 37.58 \\
\hline Northern Indiana Pub Serv Co ............ & 435 & 13,089 & .69 & 7.74 & 160.5 & 42.03 \\
\hline 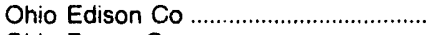 & 7,688 & 12,262 & 2.08 & 10.73 & 126.1 & 30.94 \\
\hline Ohio Power Co & 13,195 & 11,664 & 3.34 & 12.70 & 158.9 & 37.06 \\
\hline Ohio Valley Electric Corp .......................... & 3,464 & 12,041 & 3.73 & 10.82 & 122.0 & 29.39 \\
\hline Orange \& Rockland Utils Inc ................. & 657 & 13,014 & .55 & 7.28 & 205.4 & $\begin{array}{l}29.39 \\
53.45\end{array}$ \\
\hline Orlando Utilities Comm .............................. & 1,024 & 12,755 & .73 & 8.34 & 190.1 & 48.51 \\
\hline 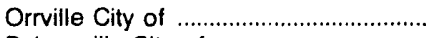 & 180 & 11,872 & 3.50 & 8.63 & 100.2 & 23.79 \\
\hline Painesville City of & 70 & 12,391 & 2.57 & 7.73 & 135.1 & 33.48 \\
\hline Pennsylvania Electric Co ......................... & 16,890 & 12,223 & 1.87 & 14.27 & 131.0 & 32.02 \\
\hline Pennsylvania Power \& Light Co ......... & 8,478 & 12,385 & 1.81 & 13.46 & 175.5 & 43.48 \\
\hline Pennsylvania Power Co ............................. & 5,642 & 12,153 & 3.55 & 11.48 & 163.2 & 39.67 \\
\hline Philadelphia Electric Co .......................... & 1,090 & 13,187 & 1.88 & 7.34 & 155.9 & 41.11 \\
\hline 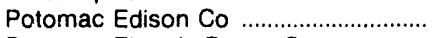 & 154 & 12,539 & .92 & 12.31 & 134.0 & 33.61 \\
\hline Potomac Electric Power Co .................. & 5,775 & 12,673 & 1.59 & 11.22 & 166.4 & 42.16 \\
\hline 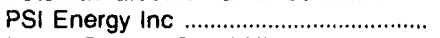 & 1,587 & 12,465 & .77 & 10.35 & 131.6 & 32.82 \\
\hline 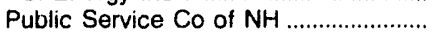 & 1,144 & 13,307 & 1.68 & 6.52 & 169.0 & 44.97 \\
\hline Public Service Electric\&Gas Co ........... & 1.410 & 13,744 & .82 & 5.53 & 176.0 & 48.38 \\
\hline 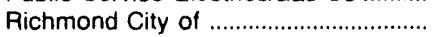 & 78 & 11,753 & 1.65 & 9.47 & 126.3 & 29.69 \\
\hline
\end{tabular}

See footnotes at end of table. 
Table 19. Receipts of Appalachian Region Coal by Electric Utility, 1992 (Continued)

\begin{tabular}{|c|c|c|c|c|c|c|}
\hline \multirow[b]{2}{*}{ Electric Utility } & \multirow{2}{*}{$\begin{array}{l}\text { Receipts } \\
\text { (thousand } \\
\text { short tons) }\end{array}$} & \multicolumn{3}{|c|}{ Average Quality } & \multicolumn{2}{|c|}{ Average Delivered Cost } \\
\hline & & $\begin{array}{c}\text { Btu } \\
\text { (per pound) }\end{array}$ & $\begin{array}{c}\text { Sulfur } \\
\text { (percent } \\
\text { by welght) }\end{array}$ & $\begin{array}{c}\text { Ash } \\
\text { (percent } \\
\text { by weight) }\end{array}$ & $\begin{array}{l}\text { (cents per } \\
\text { million Btu) }\end{array}$ & $\begin{array}{l}\text { (dollars per } \\
\text { short ton) }\end{array}$ \\
\hline Rochester Gas \& Electric Corp ........... & 841 & 13,298 & 2.10 & 6.71 & 145.6 & 38.73 \\
\hline Rochester Public Utilities ......................... & 11 & 13,351 & 2.04 & 6.92 & 142.3 & 38.00 \\
\hline Savannah Electric \& Power Co ........... & 156 & 12,353 & 1.17 & 10.82 & 150.4 & 37.16 \\
\hline Seminole Electric Coop Inc .................... & 503 & 12,756 & 1.17 & 9.03 & 154.2 & 39.35 \\
\hline South Carolina Electric\&Gas Co ......... & 4,222 & 12,883 & 1.10 & 8.57 & 157.7 & 40.63 \\
\hline South Carolina Pub Serv Auth .............. & 4,545 & 12,804 & 1.20 & 8.92 & 146.7 & 37.58 \\
\hline South Mississippi EI Pwr Assn ............ & 757 & 12,370 & .99 & 9.58 & 205.3 & 50.80 \\
\hline 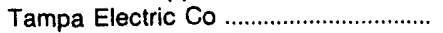 & 2,559 & 12,861 & 1.43 & 6.67 & 224.6 & 57.78 \\
\hline Tennessee Valley Authority ................... & 12,162 & 12,599 & 1.08 & 9.37 & 127.8 & 32.20 \\
\hline 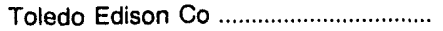 & 1,252 & 12,923 & 1.12 & 8.02 & 201.5 & 52.08 \\
\hline United Illuminating Co ............................... & 793 & 13,167 & .55 & 6.25 & 194.8 & 51.30 \\
\hline Virginia Electric \& Power Co ................ & 10,516 & 12,621 & 1.42 & 11.13 & 145.2 & 36.64 \\
\hline West Penn Power Co .................................. & 5,448 & 12,769 & 2.22 & 10.00 & 144.5 & 36.89 \\
\hline Wisconsin Electric Power Co ................ & 2,073 & 13,184 & 1.36 & 6.58 & 154.4 & 40.71 \\
\hline Wisconsin Power \& Light Co ................ & 62 & 14,122 & .68 & 4.20 & 154.5 & 43.65 \\
\hline Wisconsin Public Service Corp ............ & 204 & 13,245 & .67 & 7.07 & 172.7 & 45.74 \\
\hline Wyandotte Municipal Serv Comm ...... & 104 & 13,289 & .88 & 5.65 & 187.2 & 49.75 \\
\hline 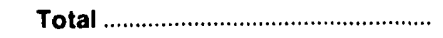 & 279,758 & 12,451 & 1.63 & 10.56 & 156.0 & 38.86 \\
\hline
\end{tabular}

Notes: - Totals may not equal sum of components because of independent rounding. - Data are for electric generating plants with a total steamelectric and combined-cycle nameplate capacity of 50 or more megawatts. - The Appalachian Region includes Alabama, Georgia, eastern Kentucky, Maryland, Ohio, Pennsylvania, Tennessee, Virginia, and West Virginia.

Source: Federal Energy Regulatory Commission, FERC Form 423, "Monthly Report of Cost and Quality of Fuels for Electric Plants."

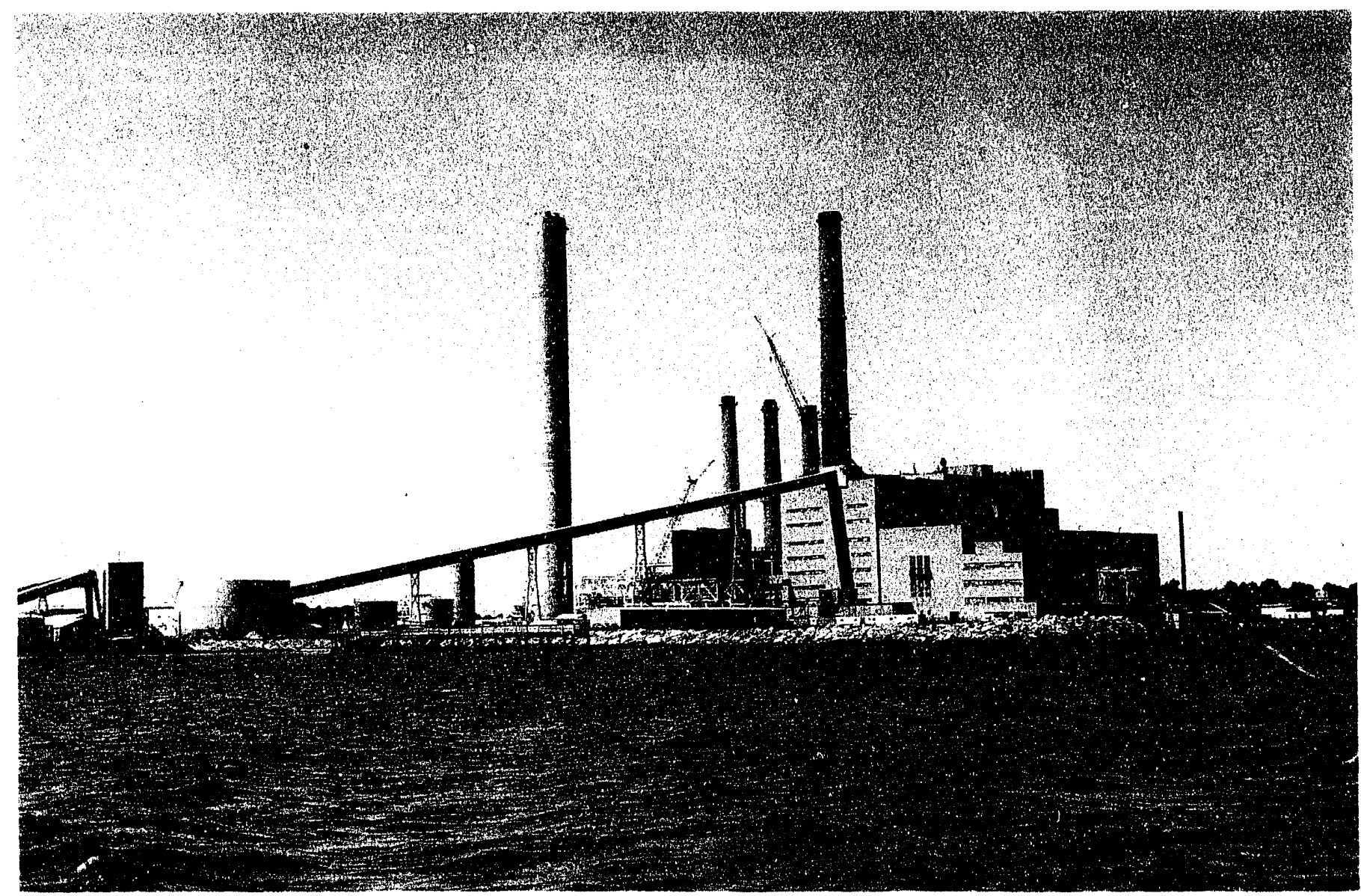

The New England Power Company's Salem Harbor Station has 3 coal-fired units and 1 oil-fired unit. In 1992,

Salem Harbor received nearly 900 thousand short tons of coal and 2.4 million barrels of oil. 
Table 20. Recelpts of Interlor Region Coal by Electric Utility, 1992

\begin{tabular}{|c|c|c|c|c|c|c|}
\hline \multirow[b]{2}{*}{ Electrlc Utlitity } & \multirow{2}{*}{$\begin{array}{l}\text { Recelpts } \\
\text { (thousand } \\
\text { short tons) }\end{array}$} & \multicolumn{3}{|c|}{ Average Quallty } & \multicolumn{2}{|c|}{ Average Dellvered Cost } \\
\hline & & $\begin{array}{c}\text { Btu } \\
\text { (per pound) }\end{array}$ & $\begin{array}{l}\text { Sulfur } \\
\text { (percent } \\
\text { by woight) }\end{array}$ & $\begin{array}{c}\text { Aoh } \\
\text { (porcent } \\
\text { by welght) }\end{array}$ & $\begin{array}{l}\text { (cents per } \\
\text { million Btu) }\end{array}$ & $\begin{array}{l}\text { (dollars per } \\
\text { short ton) }\end{array}$ \\
\hline Associated Electric Coop Inc ................ & 5,238 & 10,730 & 3.60 & 9.96 & 138.9 & 29.82 \\
\hline Big Rivers Electric Corp ............................ & 4,534 & 11,270 & 3.09 & 11.72 & 121.3 & 27.34 \\
\hline Cedar Falls City of ....................................... & 10 & 11,188 & 2.72 & 9.11 & 140.8 & 31.54 \\
\hline Central Electric Pwr Coop-MO ............. & 83 & 10,971 & 3.14 & 9.90 & 118.5 & 26.00 \\
\hline Central Illinois Light Co ........................... & 1.198 & 10,704 & 3.26 & 8.16 & 163.2 & 34.94 \\
\hline Central Illinois Pub Serv Co .................. & 3,973 & 11,052 & 2.76 & 0.22 & 161.9 & 35.79 \\
\hline Central lowa Power Coop ........................ & 148 & 11,206 & 3.09 & 8.75 & 113.4 & 25.42 \\
\hline Cincinnati Gas \& Electric Co ................. & 412 & 11.575 & 2.87 & 8.46 & 101.4 & 23.48 \\
\hline Commonwealth Edison Co ...................... & 1,716 & 10,516 & 3.40 & 8.68 & 166.9 & 35.09 \\
\hline Dairyland Power Coop ............................... & 731 & 11,979 & 1.35 & 7.12 & 135.1 & 32.37 \\
\hline Dayton Power \& Light Co ...................... & 41 & 11,606 & 3.45 & 8.48 & 92.1 & 21.38 \\
\hline 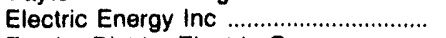 & 2,169 & 11,885 & 2.21 & 8.15 & 108.4 & 25.78 \\
\hline Empire District Electric Co .................... & 147 & 12,390 & 3.36 & 11.26 & 121.2 & 30.04 \\
\hline Georgia Power Co .................................... & 7,050 & 11,367 & 2.80 & 9.42 & 184.9 & 44.30 \\
\hline Grand Haven City of ............................... & 205 & 11,019 & 2.46 & 10.07 & 150.3 & 33.12 \\
\hline Grand Piver Dam Authority .................. & 122 & 13,104 & 4.15 & 8.50 & 101.4 & 26.57 \\
\hline 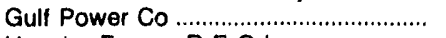 & 2,922 & 11,961 & 2.74 & 8.40 & 188.3 & 45.04 \\
\hline 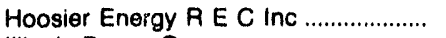 & 3,062 & 11.083 & 3.32 & 10.91 & 125.5 & 27.82 \\
\hline 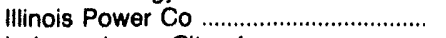 & 5,203 & 10,885 & 2.82 & 10.14 & 138.6 & 30.17 \\
\hline 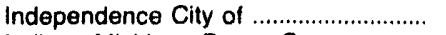 & 44 & 12,114 & 3.23 & 10.39 & 127.9 & 30.99 \\
\hline Indiana Michigan Power Co .................. & 873 & 11,328 & 2.49 & 8.33 & 138.5 & 31.39 \\
\hline Indiana-Kentucky Electric Corp ............. & 3,249 & 11,348 & 3.28 & 10.79 & 105.1 & 23.86 \\
\hline Indianapolis Power \& Light Co ............ & 6,082 & 11,191 & 2.31 & 8.26 & 105.8 & 23.69 \\
\hline Interstate Power Co .............................. & 625 & 11,345 & 2.14 & 8.15 & 149.8 & 33.98 \\
\hline lowa Electric Light \& Power Co ........... & 245 & 11,117 & 2.70 & 9.44 & 144.9 & 32.21 \\
\hline lowa Southern Utilities Co .................... & 179 & 11,439 & 3.09 & 8.94 & 123.3 & 28.20 \\
\hline lowa-Illinois Gas\&Electric Co ................ & 237 & 11,686 & 2.12 & 8.28 & 109.6 & 25.62 \\
\hline 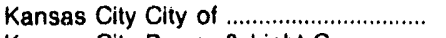 & 192 & 11.720 & 2.43 & 10.05 & 231.3 & 54.21 \\
\hline Kansas City Power \& Light Co ............ & 623 & 11,278 & 2.68 & 9.06 & 128.7 & 29.03 \\
\hline 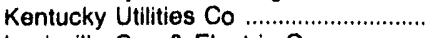 & 1,819 & 11,341 & 2.65 & 8.71 & 100.0 & 22.67 \\
\hline Louisville Gas \& Electric Co ................ & 5,433 & 11,500 & 2.92 & 9.45 & 108.6 & 24.99 \\
\hline Madison Gas \& Electric Co ................ . & 18 & 11,848 & 2.08 & 8.18 & 165.7 & 39.26 \\
\hline Manitowoc Public Utilities .................... & 16 & 11,566 & 1.16 & 8.83 & 140.7 & 32.55 \\
\hline Mississippi Power Co ............................. & 1,442 & 12.684 & 2.73 & 8.65 & 132.1 & 33.52 \\
\hline Missouri Public Service Comm ............ & 929 & 11,131 & 2.75 & 9.45 & 134.1 & 29.85 \\
\hline Muscatine City of ........................................ & 536 & 11,078 & 3.16 & 8.25 & 223.9 & 49.60 \\
\hline Northern Indiana Pub Serv Co ............ & 3,700 & 11,147 & 3.02 & 10.04 & 130.8 & 29.16 \\
\hline Oklahoma Gas \& Electric Co ................. & 84 & 12,463 & 2.57 & 10.81 & 116.8 & 29.11 \\
\hline Owensboro City of .................................... & 1.132 & 11,282 & 2.88 & 9.22 & 107.9 & 24.34 \\
\hline 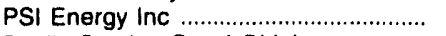 & 12,247 & 10.896 & 2.18 & 8.84 & 146.1 & 31.84 \\
\hline Public Service Co of Oklahoma ........... & 60 & 11,227 & .46 & 10.84 & 149.0 & 33.46 \\
\hline 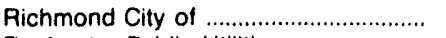 & 214 & 11.307 & 2.16 & 8.88 & 157.3 & 35.57 \\
\hline Rochester Public Utilities ........................ & 63 & 11,830 & 1.83 & 8.80 & 161.8 & 38.27 \\
\hline Seminole Electric Coop Inc .................. & 3,036 & 12,030 & 2.84 & 8.16 & 201.4 & 48.45 \\
\hline 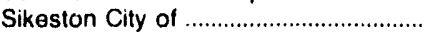 & 587 & 11,735 & 2.49 & 10.03 & 150.7 & 35.36 \\
\hline Southern Illinois Power Coop ............... & 490 & 10,549 & 2.79 & 16.54 & 91.1 & 19.21 \\
\hline Southern Indiana Gas \& Elec Co ........ & 2,694 & 11,300 & 2.81 & 8.53 & 140.6 & 31.78 \\
\hline 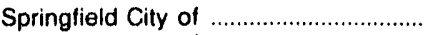 & 696 & 11,606 & 2.08 & 7.98 & 132.3 & 30.71 \\
\hline 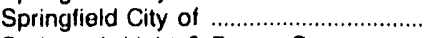 & 933 & 10.382 & 3.04 & 9.36 & 113.1 & 23.49 \\
\hline St Joseph Light \& Power Co .................. & 135 & 11,976 & 3.72 & 12.10 & 139.2 & 33.35 \\
\hline 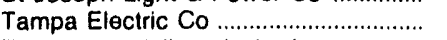 & 3,472 & 11,880 & 2.84 & 8.70 & 162.5 & 38.61 \\
\hline Tennessee Valley Authority ................. & 23,485 & 11.591 & 2.97 & 10.88 & 120.3 & 27.88 \\
\hline Union Electric Co & 7,009 & 11,472 & 2.23 & 9.00 & 168.0 & 38.55 \\
\hline Western Farmers Elec Coop Inc ........ & 6 & 12,676 & .62 & 9.47 & 177.0 & 44.87 \\
\hline Wisconsin Electric Power Co ............... & 304 & 11.935 & 1.77 & 7.60 & 155.2 & 37.05 \\
\hline Wisconsin Power \& Light Co ................ & 1,080 & 11.247 & 2.12 & 8.74 & 185.8 & 41.79 \\
\hline Wisconsin Public Service Corp ........... & 333 & 11,055 & 2.00 & 9.79 & 217.7 & 48.14 \\
\hline Total & 123,267 & 11,336 & 2.77 & 9.70 & 139.7 & 31.67 \\
\hline
\end{tabular}

Notes: - Totals may not equal sum of components because of independent rounding. - Data are for electric generating plants with a total steamelectric and combined-cycle nameplate capacity of 50 or more megawatts. - The Interior Region includes Arkansas, Illinois, Indiana, lowa, Kansas, western Kentucky, Missouri, Oklahorna, and Texas. - This table excludes all lignite receipts.

Source: Federal Energy Regulatory Commission, FERC Form 423, "Monthly Report of Cost and Quality of Fuels for Electric Plants." 
Table 21. Receipts of Western Region Coal by Electric Utility, 1992

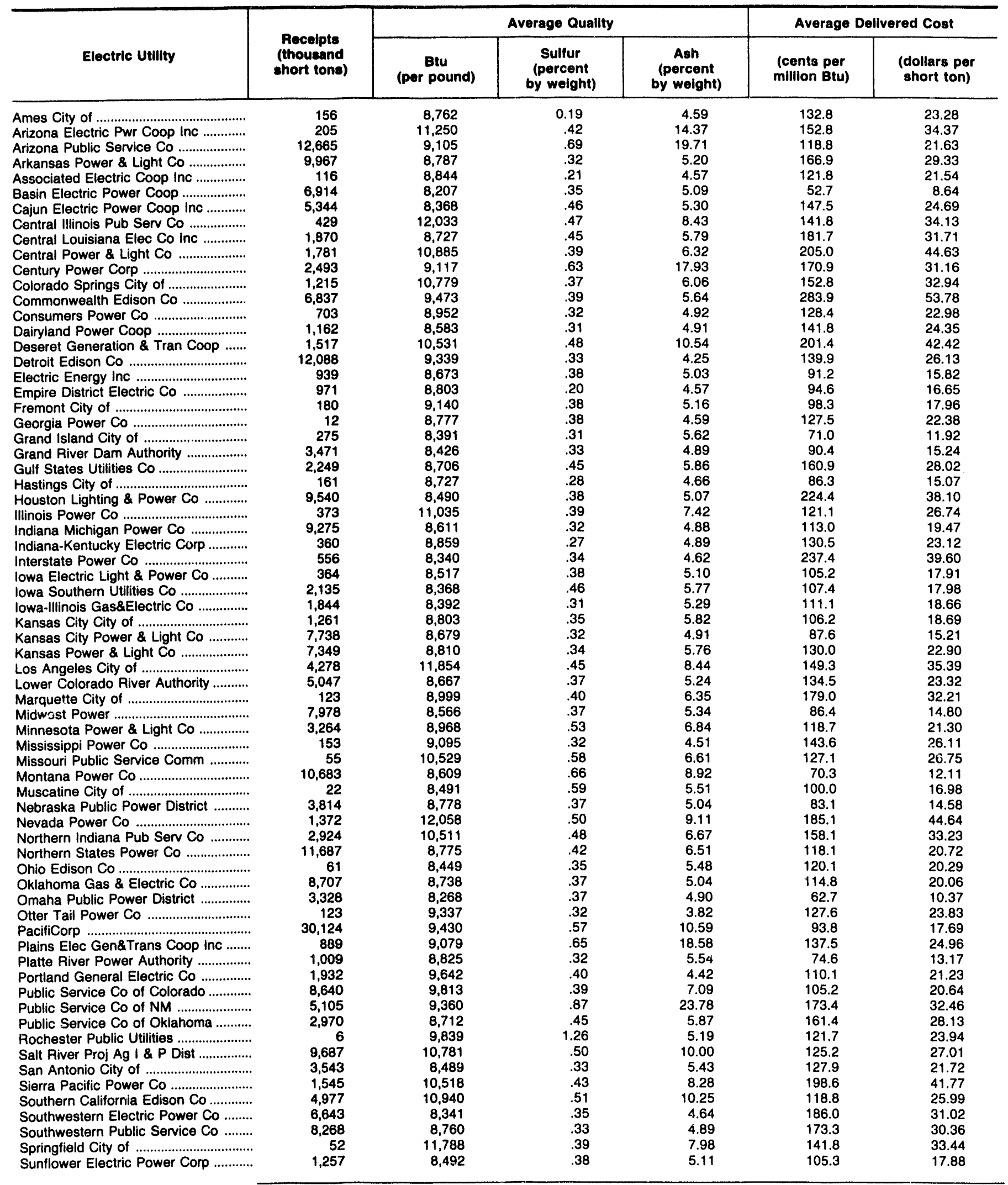

See footnotes at end of table. 
Table 21. Receipts of Western Region Coal by Electric Utility, 1992-Continued

\begin{tabular}{|c|c|c|c|c|c|c|}
\hline \multirow[b]{2}{*}{ Electric Utility } & \multirow{2}{*}{$\begin{array}{l}\text { Recelpts } \\
\text { (thousand } \\
\text { short tons) }\end{array}$} & \multicolumn{3}{|c|}{ Average Quallty } & \multicolumn{2}{|c|}{ Average Dellvered Cost } \\
\hline & & $\begin{array}{c}\text { Btu } \\
\text { (per pound) }\end{array}$ & $\begin{array}{c}\text { Sulfur } \\
\text { (percent } \\
\text { by welght) }\end{array}$ & $\begin{array}{c}\text { Ash } \\
\text { (percont } \\
\text { by welght) }\end{array}$ & $\begin{array}{l}\text { (cents per } \\
\text { million Btu) }\end{array}$ & $\begin{array}{l}\text { (dollars pel } \\
\text { short ton) }\end{array}$ \\
\hline Tacoma Public Utilities ............................. & 8 & 10,136 & 0.45 & 7.08 & 166.6 & 33.78 \\
\hline 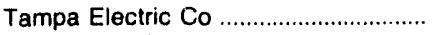 & 224 & 12.651 & .43 & 9.46 & 148.6 & 37.60 \\
\hline Tennessee Valley Authority ................... & 71 & 8,601 & .50 & 7.99 & 132.1 & 22.73 \\
\hline 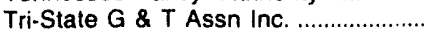 & 4,733 & 10,128 & .39 & 7.42 & 110.8 & 22.45 \\
\hline Tucson Electric Power Co ..................... & 199 & 10,060 & .45 & 12.61 & 234.1 & 47.11 \\
\hline Union Electric Co ....................................... & 3,618 & 9,174 & .30 & 5.37 & 103.1 & 18.92 \\
\hline United Power Assn ................................... & 5 & 9,276 & .52 & 4.30 & 67.8 & 12.58 \\
\hline West Texas Utilities Co .......................... & 2,878 & 8,376 & .35 & 4.84 & 152.7 & 25.59 \\
\hline Western Farmers Elec Coop Inc ........ & 1,420 & 8,389 & .44 & 5.18 & 178.2 & 29.89 \\
\hline Wisconsin Electric Power Co ............... & 5,900 & 8,936 & .42 & 6.04 & 112.0 & 20.02 \\
\hline Wisconsin Power \& Light Co ............... & 5,191 & 8.774 & .42 & 5.97 & 126.2 & 22.15 \\
\hline Wisconsin Public Service Corp ............ & 1,663 & 8,800 & .38 & 4.99 & 131.2 & 23.08 \\
\hline Total & 290,694 & 9,126 & .44 & 7.55 & 129.3 & 23.61 \\
\hline
\end{tabular}

Notes: - Totals may not equal sum of components because of independent rounding. - Data are for electric generating plants with a total steamelectric and combined-cycle nameplate capacity of 50 or more megawatts. - The Western Region includes Arizona, Colorado, Montana, New Mexico, North Dakota, Utah, Washington, and Wyoming. - This table excludes all lignite receipts.

Source: Federal Energy Regulatory Commission, FERC Form 423, "Monthly Report of Cost and Quality' of Fuels for Electric Plants." 
Table 22. Destination and Origin of Coal by State, 1992

\begin{tabular}{|c|c|c|c|c|c|c|}
\hline \multirow[b]{2}{*}{$\begin{array}{l}\text { Destination } \\
\text { Origin }\end{array}$} & \multirow{2}{*}{$\begin{array}{l}\text { Quantity } \\
\text { (thousand } \\
\text { short tons) }\end{array}$} & \multicolumn{3}{|c|}{ Average Quallty } & \multicolumn{2}{|c|}{ Average Dellvered Cost } \\
\hline & & $\begin{array}{c}\text { Btu } \\
\text { (per pound) }\end{array}$ & $\begin{array}{c}\text { Sulfur } \\
\text { (percent } \\
\text { by weight) }\end{array}$ & $\begin{array}{c}\text { Ash } \\
\text { (porcent } \\
\text { by welght) }\end{array}$ & $\begin{array}{l}\text { (cents per } \\
\text { million Btu) }\end{array}$ & $\begin{array}{c}\text { (dollars per } \\
\text { short Ton) }\end{array}$ \\
\hline 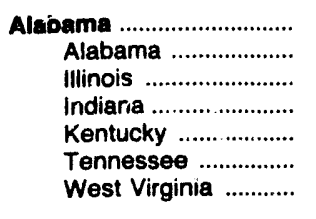 & $\begin{array}{r}24,886 \\
16,265 \\
956 \\
19 \\
4,078 \\
817 \\
2,752\end{array}$ & $\begin{array}{l}12,061 \\
12,093 \\
11,578 \\
11,296 \\
11,992 \\
12,441 \\
12,033\end{array}$ & $\begin{array}{r}1.43 \\
1.25 \\
1.96 \\
3.45 \\
2.48 \\
.80 \\
.96\end{array}$ & $\begin{array}{r}11.80 \\
12.42 \\
9.30 \\
10.98 \\
10.52 \\
12.21 \\
10.77\end{array}$ & $\begin{array}{l}172.7 \\
196.5 \\
121.8 \\
101.5 \\
118.0 \\
: 30.1 \\
143.1\end{array}$ & $\begin{array}{l}41.67 \\
47.52 \\
28.21 \\
22.92 \\
28.30 \\
32.37 \\
34.45\end{array}$ \\
\hline 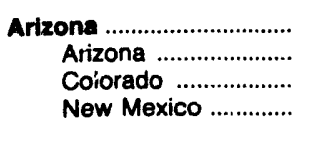 & $\begin{array}{r}16,315 \\
7,441 \\
119 \\
8,754\end{array}$ & $\begin{array}{r}10,303 \\
11,043 \\
12,158 \\
9,650\end{array}$ & $\begin{array}{l}.51 \\
.52 \\
.41 \\
.50\end{array}$ & $\begin{array}{r}12.19 \\
9.00 \\
15.76 \\
14.85\end{array}$ & $\begin{array}{l}137.4 \\
104.8 \\
167.5 \\
168.6\end{array}$ & $\begin{array}{l}28.31 \\
23.14 \\
40.74 \\
32.53\end{array}$ \\
\hline Arkaneas & $\begin{array}{l}11,630 \\
11,630\end{array}$ & $\begin{array}{l}8,724 \\
8,724\end{array}$ & $\begin{array}{l}.32 \\
.32\end{array}$ & $\begin{array}{l}5.12 \\
5.12\end{array}$ & $\begin{array}{l}165.3 \\
165.3\end{array}$ & $\begin{array}{l}28.84 \\
28.84\end{array}$ \\
\hline 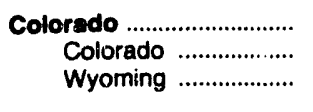 & $\begin{array}{r}15,597 \\
10,661 \\
4,936\end{array}$ & $\begin{array}{r}9,920 \\
10,584 \\
8,486\end{array}$ & $\begin{array}{l}.38 \\
.41 \\
.33\end{array}$ & $\begin{array}{l}7.01 \\
8.02 \\
4.81\end{array}$ & $\begin{array}{l}109.2 \\
112.0 \\
101.7\end{array}$ & $\begin{array}{l}21.67 \\
23.71 \\
17.26\end{array}$ \\
\hline $\begin{array}{l}\text { Connecticut .................... } \\
\text { Kentucky ................. } \\
\text { West Virginia ........... }\end{array}$ & $\begin{array}{r}793 \\
772 \\
21\end{array}$ & $\begin{array}{l}13,167 \\
13,162 \\
13,351\end{array}$ & $\begin{array}{l}.55 \\
.55 \\
.67\end{array}$ & $\begin{array}{l}6.2 .5 \\
6.25 \\
6.20\end{array}$ & $\begin{array}{l}194.8 \\
195.5 \\
168.9\end{array}$ & $\begin{array}{l}51.30 \\
51.47 \\
45.10\end{array}$ \\
\hline 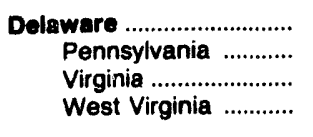 & $\begin{array}{r}1,532 \\
137 \\
90 \\
1,304\end{array}$ & $\begin{array}{l}13,064 \\
13,104 \\
13,101 \\
13,058\end{array}$ & $\begin{array}{r}1.03 \\
1.40 \\
.82 \\
1.00\end{array}$ & $\begin{array}{l}8.83 \\
3.21 \\
8.68 \\
8.79\end{array}$ & $\begin{array}{l}173.4 \\
177.9 \\
201.3 \\
171.0\end{array}$ & $\begin{array}{l}45.31 \\
46.62 \\
52.74 \\
44.66\end{array}$ \\
\hline 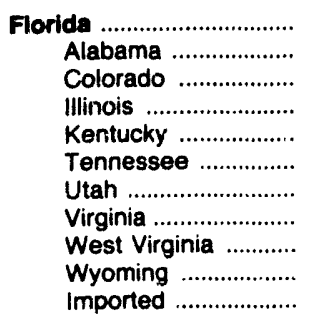 & $\begin{array}{r}24,377 \\
72 \\
181 \\
5,504 \\
14,717 \\
269 \\
32 \\
882 \\
1,290 \\
12 \\
1,419\end{array}$ & $\begin{array}{r}12,370 \\
12,060 \\
13,092 \\
11,711 \\
12,636 \\
12,8 \subset: \\
11,596 \\
12,389 \\
12,526 \\
8,887 \\
11,897\end{array}$ & $\begin{array}{r}1.68 \\
2.75 \\
.45 \\
2.77 \\
1.48 \\
1.19 \\
.39 \\
.72 \\
1.36 \\
.20 \\
.71\end{array}$ & $\begin{array}{r}8.33 \\
12.94 \\
10.01 \\
8.33 \\
8.19 \\
6.20 \\
8.20 \\
9.77 \\
10.44 \\
4.70 \\
6.91\end{array}$ & $\begin{array}{l}182.0 \\
120.6 \\
146.5 \\
194.3 \\
177.0 \\
217.6 \\
163.8 \\
223.4 \\
197.5 \\
142.3 \\
150.0\end{array}$ & $\begin{array}{l}45.03 \\
29.09 \\
38.37 \\
45.50 \\
44.73 \\
55.98 \\
37.99 \\
55.36 \\
49.48 \\
25.29 \\
35.70\end{array}$ \\
\hline 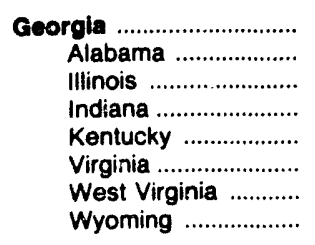 & $\begin{array}{r}22,851 \\
98 \\
5,137 \\
555 \\
11,981 \\
2,615 \\
2,453 \\
12\end{array}$ & $\begin{array}{r}12,039 \\
12,142 \\
11,278 \\
11,294 \\
12,234 \\
12,871 \\
11,977 \\
8,777\end{array}$ & $\begin{array}{r}1.68 \\
2.06 \\
2.78 \\
2.51 \\
1.45 \\
1.34 \\
.68 \\
.38\end{array}$ & $\begin{array}{r}10.29 \\
12.17 \\
9.36 \\
8.13 \\
10.38 \\
9.90 \\
12.64 \\
4.59\end{array}$ & $\begin{array}{l}180.1 \\
135.6 \\
207.9 \\
138.4 \\
163.5 \\
180.5 \\
218.1 \\
127.5\end{array}$ & $\begin{array}{l}43.36 \\
32.92 \\
46.90 \\
31.26 \\
40.01 \\
46.47 \\
52.25 \\
22.38\end{array}$ \\
\hline 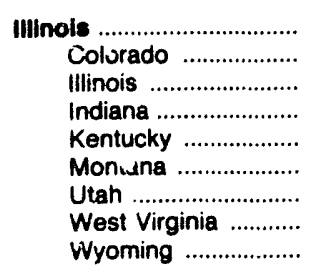 & $\begin{array}{r}25,449 \\
470 \\
14,818 \\
826 \\
1,187 \\
3,036 \\
239 \\
492 \\
4,382\end{array}$ & $\begin{array}{r}10,666 \\
12,020 \\
10,970 \\
11,000 \\
13,157 \\
9,580 \\
11,742 \\
12,893 \\
9,202\end{array}$ & $\begin{array}{r}1.91 \\
.47 \\
2.89 \\
1.80 \\
.64 \\
.35 \\
.43 \\
.73 \\
.41\end{array}$ & $\begin{array}{l}8.19 \\
8.47 \\
9.48 \\
9.32 \\
6.53 \\
4.02 \\
8.17 \\
9.68 \\
6.78\end{array}$ & $\begin{array}{l}173.7 \\
140.7 \\
142.4 \\
137.6 \\
169.4 \\
282.8 \\
121.3 \\
151.8 \\
242.8\end{array}$ & $\begin{array}{l}37.06 \\
33.84 \\
31.24 \\
30.28 \\
44.59 \\
54.18 \\
28.49 \\
39.14 \\
44.69\end{array}$ \\
\hline 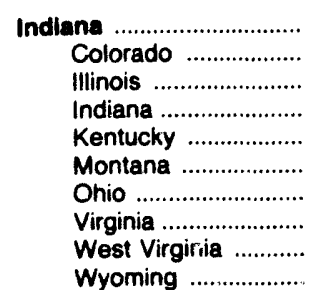 & $\begin{array}{r}47,838 \\
773 \\
9,565 \\
19,005 \\
4,455 \\
452 \\
19 \\
132 \\
1,652 \\
11,786\end{array}$ & $\begin{array}{r}10,628 \\
11,305 \\
10,889 \\
11,130 \\
11,606 \\
9,595 \\
11,458 \\
13,880 \\
12,646 \\
8,914\end{array}$ & $\begin{array}{r}1.88 \\
.42 \\
2.65 \\
2.45 \\
2.65 \\
.36 \\
2.82 \\
.73 \\
.73 \\
.35\end{array}$ & $\begin{array}{r}8.43 \\
828 \\
10.36 \\
9.10 \\
10.27 \\
4.05 \\
9.81 \\
5.38 \\
9.73 \\
5.10\end{array}$ & $\begin{array}{l}131.2 \\
154.1 \\
155.8 \\
120.8 \\
119.5 \\
278.5 \\
128.6 \\
162.2 \\
139.9 \\
123.3\end{array}$ & $\begin{array}{l}27.89 \\
34.84 \\
33.93 \\
26.90 \\
27.73 \\
53.44 \\
29.46 \\
45.04 \\
35.37 \\
21.98\end{array}$ \\
\hline
\end{tabular}

See footnotes at end of table.

Source: Federal Energy Regulatory Cornmission, FERC Form 423, "Monthly Report of Cost and Quality of Fuels for Electric Plants." 
Table 22. Destinaiion and Origin of Coal by State, 1992-Continued

\begin{tabular}{|c|c|c|c|c|c|c|}
\hline \multirow[b]{2}{*}{$\begin{array}{c}\text { Dostination } \\
\text { Origin }\end{array}$} & \multirow{2}{*}{$\begin{array}{l}\text { Quantity } \\
\text { (thousand } \\
\text { short tons) }\end{array}$} & \multicolumn{3}{|c|}{ Average Quellty } & \multicolumn{2}{|c|}{ Average Dollvered Cost } \\
\hline & & $\begin{array}{c}\text { Btu } \\
\text { (por pound) }\end{array}$ & $\begin{array}{c}\text { sulfur } \\
\text { (percent } \\
\text { by wolght) }\end{array}$ & $\begin{array}{l}\text { Aoh } \\
\text { (percent } \\
\text { by woleht) }\end{array}$ & $\begin{array}{l}\text { (cente por } \\
\text { million stu) }\end{array}$ & $\begin{array}{l}\text { (dollare per } \\
\text { short Ton) }\end{array}$ \\
\hline 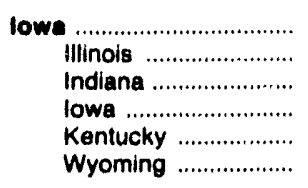 & $\begin{array}{r}15,037 \\
1,017 \\
470 \\
67 \\
27 \\
13,057\end{array}$ & $\begin{array}{r}8,867 \\
11,320 \\
11,290 \\
9,817 \\
12,367 \\
8,500\end{array}$ & $\begin{array}{r}0.67 \\
2.58 \\
2.53 \\
4.36 \\
3.36 \\
.37\end{array}$ & $\begin{array}{r}6.78 \\
8.28 \\
8.57 \\
13.57 \\
9.61 \\
5.36\end{array}$ & $\begin{array}{l}110.4 \\
169.3 \\
128.6 \\
170.6 \\
105.5 \\
100.7\end{array}$ & $\begin{array}{l}18.58 \\
38.36 \\
28.03 \\
33.50 \\
26.09 \\
17.12\end{array}$ \\
\hline 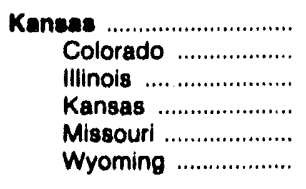 & $\begin{array}{r}13,834 \\
328 \\
767 \\
90 \\
48 \\
12,402\end{array}$ & $\begin{array}{r}8,900 \\
11,183 \\
11,355 \\
12,528 \\
11,812 \\
8,650\end{array}$ & $\begin{array}{r}.49 \\
.45 \\
2.56 \\
3.14 \\
3.60 \\
.33\end{array}$ & $\begin{array}{r}5.71 \\
9.63 \\
9.13 \\
10.53 \\
11.90 \\
5.36\end{array}$ & $\begin{array}{l}117.0 \\
112.2 \\
155.8 \\
120.4 \\
118.3 \\
116.0\end{array}$ & $\begin{array}{l}20.80 \\
25.12 \\
35.38 \\
30.17 \\
27.95 \\
19.90\end{array}$ \\
\hline 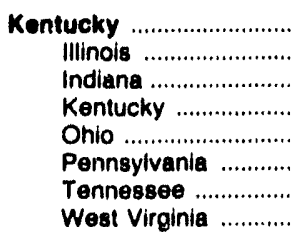 & $\begin{array}{r}32,202 \\
7 \\
2,237 \\
26,187 \\
249 \\
42 \\
500 \\
3,069\end{array}$ & $\begin{array}{l}11,620 \\
11,650 \\
11,217 \\
11,558 \\
11,471 \\
13,005 \\
12,467 \\
12,280\end{array}$ & $\begin{array}{r}2.44 \\
2.50 \\
2.84 \\
2.59 \\
2.16 \\
2.42 \\
2.51 \\
.87\end{array}$ & $\begin{array}{r}11.60 \\
10.20 \\
9.00 \\
11.87 \\
14.22 \\
7.79 \\
11.14 \\
11.14\end{array}$ & $\begin{array}{r}116.2 \\
110.3 \\
98.4 \\
115.8 \\
184.5 \\
99.8 \\
112.8 \\
126.3\end{array}$ & $\begin{array}{l}27.01 \\
25.70 \\
22.31 \\
26.77 \\
42.32 \\
25.96 \\
28.14 \\
31.08\end{array}$ \\
\hline 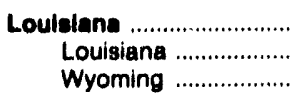 & $\begin{array}{r}12,675 \\
3,212 \\
9,463\end{array}$ & $\begin{array}{l}8,122 \\
8,851 \\
8,619\end{array}$ & $\begin{array}{l}.60 \\
.62 \\
.46\end{array}$ & $\begin{array}{r}7.20 \\
12.14 \\
5.53\end{array}$ & $\begin{array}{l}163.6 \\
138.3 \\
157.7\end{array}$ & $\begin{array}{l}24.93 \\
19.22 \\
26.87\end{array}$ \\
\hline 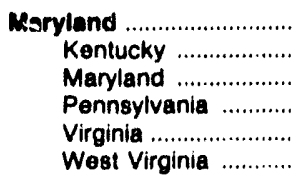 & $\begin{array}{r}9,284 \\
215 \\
1,203 \\
2,893 \\
78 \\
4,896\end{array}$ & $\begin{array}{l}12,763 \\
12,922 \\
12,728 \\
12,586 \\
14,076 \\
12,829\end{array}$ & $\begin{array}{r}1.38 \\
.73 \\
1.59 \\
1.87 \\
.80 \\
1.04\end{array}$ & $\begin{array}{r}10.47 \\
7.38 \\
11.63 \\
12.23 \\
5.05 \\
8.37\end{array}$ & $\begin{array}{l}169.6 \\
154.8 \\
166.4 \\
169.8 \\
169.8 \\
161.8\end{array}$ & $\begin{array}{l}40.68 \\
40.04 \\
42.37 \\
42.75 \\
47.84 \\
38.95\end{array}$ \\
\hline 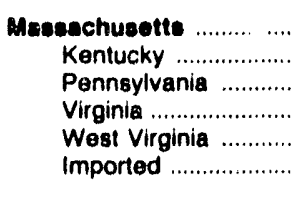 & $\begin{array}{r}4,194 \\
10 \\
395 \\
611 \\
2,981 \\
197\end{array}$ & $\begin{array}{l}13,070 \\
12,934 \\
13,230 \\
12,954 \\
13,057 \\
13,322\end{array}$ & $\begin{array}{r}1.17 \\
.63 \\
1.34 \\
1.06 \\
1.10 \\
.83\end{array}$ & $\begin{array}{l}8.20 \\
6.47 \\
6.31 \\
7.84 \\
6.71 \\
6.68\end{array}$ & $\begin{array}{l}168.7 \\
170.9 \\
167.6 \\
176.3 \\
167.9 \\
163.4\end{array}$ & $\begin{array}{l}44.11 \\
44.21 \\
44.34 \\
45.42 \\
43.85 \\
43.64\end{array}$ \\
\hline 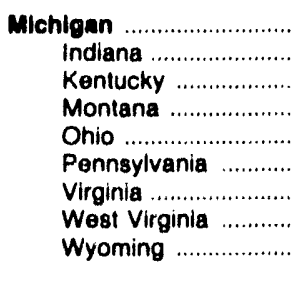 & $\begin{array}{r}27,875 \\
205 \\
6,392 \\
10,544 \\
40 \\
1,753 \\
21 \\
5,665 \\
3,254\end{array}$ & $\begin{array}{r}10,005 \\
11,010 \\
12,770 \\
9,446 \\
12,003 \\
13,159 \\
13,114 \\
12,470 \\
8,766\end{array}$ & $\begin{array}{r}.80 \\
2.46 \\
.93 \\
.37 \\
3.35 \\
1.70 \\
1.33 \\
.84 \\
.29\end{array}$ & $\begin{array}{r}6.76 \\
10.07 \\
8.28 \\
4.31 \\
8.29 \\
6.74 \\
8.40 \\
10.51 \\
4.96\end{array}$ & $\begin{array}{l}165.6 \\
150.3 \\
171.4 \\
151.0 \\
223.3 \\
154.3 \\
149.0 \\
162.0 \\
111.3\end{array}$ & $\begin{array}{l}34.23 \\
33.12 \\
43.78 \\
28.53 \\
53.60 \\
40.61 \\
38.08 \\
40.40 \\
18.52\end{array}$ \\
\hline 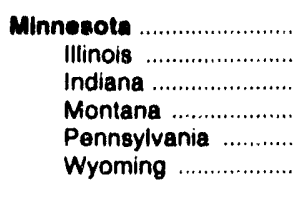 & $\begin{array}{r}16,164 \\
63 \\
7 \\
7,929 \\
11 \\
7,151\end{array}$ & $\begin{array}{r}8,838 \\
11,836 \\
9,940 \\
8,84 ? \\
13,351 \\
8,794\end{array}$ & $\begin{array}{r}.45 \\
1.84 \\
1.10 \\
.61 \\
2.04 \\
.26\end{array}$ & $\begin{array}{r}6.67 \\
8.79 \\
11.70 \\
8.14 \\
6.82 \\
4.81\end{array}$ & $\begin{array}{r}118.6 \\
162.0 \\
90.5 \\
121.5 \\
142.3 \\
114.7\end{array}$ & $\begin{array}{l}20.08 \\
38.34 \\
17.89 \\
21.50 \\
38.00 \\
20.18\end{array}$ \\
\hline 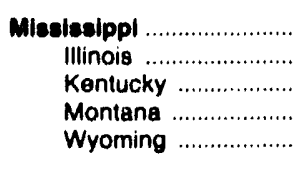 & $\begin{array}{r}3,208 \\
1,238 \\
1,816 \\
82 \\
71\end{array}$ & $\begin{array}{r}12,607 \\
12,757 \\
12,624 \\
9,383 \\
8,760\end{array}$ & $\begin{array}{r}1.60 \\
2.74 \\
1.08 \\
.30 \\
.34\end{array}$ & $\begin{array}{l}8.31 \\
8.75 \\
6.32 \\
4.15 \\
4.82\end{array}$ & $\begin{array}{l}169.7 \\
132.7 \\
179.2 \\
136.0 \\
153.0\end{array}$ & $\begin{array}{l}39.94 \\
33.86 \\
45.24 \\
25.51 \\
26.81\end{array}$ \\
\hline 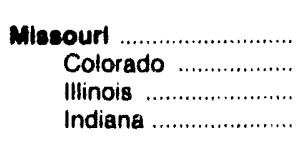 & $\begin{array}{r}24,502 \\
496 \\
11,376 \\
63\end{array}$ & $\begin{array}{l}10,321 \\
11,736 \\
11,319 \\
11,279\end{array}$ & $\begin{array}{r}1.80 \\
.48 \\
2.41 \\
3.03\end{array}$ & $\begin{array}{l}7.71 \\
9.50 \\
9.25 \\
8.50\end{array}$ & $\begin{array}{l}133.6 \\
160.7 \\
152.7 \\
109.9\end{array}$ & $\begin{array}{l}27.57 \\
37.71 \\
34.58 \\
24.78\end{array}$ \\
\hline
\end{tabular}

See footnotes at end of table.

Source: Federal Energy Regulatory Commission, FEFC Form 423, "Monthly Report of Cost and Quality of Fuels for Electric Plants." 
Table 22. Destination and Origin of Coal by State, 1992-Continued

\begin{tabular}{|c|c|c|c|c|c|c|}
\hline \multirow[b]{2}{*}{$\begin{array}{l}\text { Destination } \\
\text { Origin }\end{array}$} & \multirow{2}{*}{$\begin{array}{l}\text { Quantlty } \\
\text { (thousand } \\
\text { chort tone) }\end{array}$} & \multicolumn{3}{|c|}{ Average Quallity } & \multicolumn{2}{|c|}{ Average Dellvered Cost } \\
\hline & & $\begin{array}{l}\text { Btu } \\
\text { (per pound) }\end{array}$ & $\begin{array}{l}\text { Sulfur } \\
\text { (percent } \\
\text { by wolght) }\end{array}$ & $\begin{array}{l}\text { Ach } \\
\text { (percent } \\
\text { by welght) }\end{array}$ & $\begin{array}{l}\text { (conte per } \\
\text { million Btu) }\end{array}$ & $\begin{array}{l}\text { (dollars per } \\
\text { short Ton) }\end{array}$ \\
\hline 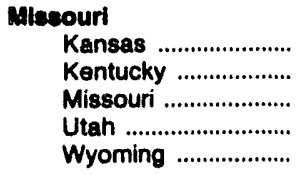 & $\begin{array}{r}217 \\
585 \\
2,574 \\
79 \\
9,112\end{array}$ & $\begin{array}{r}12,060 \\
11,796 \\
10,567 \\
11,725 \\
8,773\end{array}$ & $\begin{array}{r}3.71 \\
3.38 \\
4.16 \\
.41 \\
.29\end{array}$ & $\begin{array}{r}12.18 \\
7.99 \\
10.19 \\
8.09 \\
4.85\end{array}$ & $\begin{array}{r}133.3 \\
125.6 \\
163.5 \\
140.8 \\
91.3\end{array}$ & $\begin{array}{l}32.15 \\
29.63 \\
34.55 \\
33.03 \\
16.02\end{array}$ \\
\hline 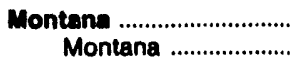 & $\begin{array}{l}10,860 \\
10,860\end{array}$ & $\begin{array}{l}8,676 \\
8,576\end{array}$ & $\begin{array}{l}.68 \\
.66\end{array}$ & $\begin{array}{l}\mathbf{8 . 9 2} \\
\mathbf{8 . 9 2}\end{array}$ & $\begin{array}{l}70.8 \\
70.8\end{array}$ & $\begin{array}{l}12.14 \\
12.14\end{array}$ \\
\hline 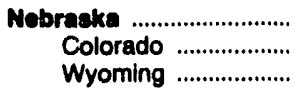 & $\begin{array}{l}7,759 \\
7,759\end{array}$ & $\begin{array}{r}8,553 \\
11,308 \\
8,553\end{array}$ & $\begin{array}{l}.37 \\
.40 \\
.37\end{array}$ & $\begin{array}{l}5.00 \\
8.60 \\
5.00\end{array}$ & $\begin{array}{r}74.6 \\
158.8 \\
74.6\end{array}$ & $\begin{array}{l}12.77 \\
35.91 \\
12.77\end{array}$ \\
\hline 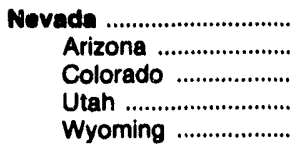 & $\begin{array}{r}7,894 \\
4,977 \\
168 \\
1,948 \\
800\end{array}$ & $\begin{array}{r}11,051 \\
10,940 \\
11,753 \\
11,821 \\
9,724\end{array}$ & $\begin{array}{l}.49 \\
.51 \\
.50 \\
.45 \\
.49\end{array}$ & $\begin{array}{r}9.67 \\
10.25 \\
9.28 \\
8.83 \\
8.17\end{array}$ & $\begin{array}{l}146.2 \\
118.8 \\
215.3 \\
186.9 \\
200.2\end{array}$ & $\begin{array}{l}32.32 \\
25.99 \\
50.60 \\
44.19 \\
38.93\end{array}$ \\
\hline $\begin{array}{l}\text { New Hampehtre .............. } \\
\text { Pennsylvania ............ } \\
\text { West Virginia ........... } \\
\text { Imported ........................ }\end{array}$ & $\begin{array}{r}1,228 \\
680 \\
464 \\
83\end{array}$ & $\begin{array}{l}13,260 \\
13,264 \\
13,369 \\
12,616\end{array}$ & $\begin{array}{r}1.61 \\
1.57 \\
1.85 \\
.60\end{array}$ & $\begin{array}{l}6.52 \\
6.29 \\
6.85 \\
6.50\end{array}$ & $\begin{array}{l}168.5 \\
171.5 \\
165.3 \\
161.8\end{array}$ & $\begin{array}{l}44.69 \\
45.50 \\
44.19 \\
40.83\end{array}$ \\
\hline $\begin{array}{l}\text { Now Jersey ...................... } \\
\text { Kentucky ................. } \\
\text { Pennsylvania ............ } \\
\text { Virginia ........................ } \\
\text { West Virginia ............ }\end{array}$ & $\begin{array}{r}2,205 \\
109 \\
15 \\
806 \\
1,185\end{array}$ & $\begin{array}{l}13,465 \\
13,197 \\
13,394 \\
14,185 \\
13,023\end{array}$ & $\begin{array}{r}1.20 \\
.83 \\
2.62 \\
.83 \\
1.66\end{array}$ & $\begin{array}{l}6.84 \\
6.64 \\
7.10 \\
4.40 \\
8.51\end{array}$ & $\begin{array}{l}173.1 \\
183.3 \\
150.0 \\
175.9 \\
169.7\end{array}$ & $\begin{array}{l}46.62 \\
48.38 \\
40.19 \\
49.90 \\
44.21\end{array}$ \\
\hline $\begin{array}{l}\text { Now Moxico ....................... } \\
\text { New Mexico ............. }\end{array}$ & $\begin{array}{l}14,929 \\
14,929\end{array}$ & $\begin{array}{l}9,013 \\
9,013\end{array}$ & $\begin{array}{l}.81 \\
.81\end{array}$ & $\begin{array}{l}22.49 \\
22.49\end{array}$ & $\begin{array}{l}132.2 \\
132.2\end{array}$ & $\begin{array}{l}23.83 \\
23.83\end{array}$ \\
\hline 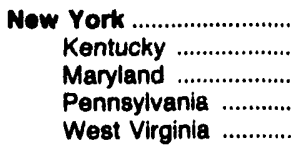 & $\begin{array}{r}10,393 \\
377 \\
18 \\
6,895 \\
3,105\end{array}$ & $\begin{array}{l}12,078 \\
13,035 \\
11,137 \\
12,887 \\
13,182\end{array}$ & $\begin{array}{r}1.65 \\
.56 \\
1.59 \\
1.72 \\
1.63\end{array}$ & $\begin{array}{r}8.02 \\
6.96 \\
16.66 \\
8.47 \\
7.10\end{array}$ & $\begin{array}{l}148.8 \\
206.7 \\
143.2 \\
142.2 \\
156.2\end{array}$ & $\begin{array}{l}38.62 \\
53.90 \\
31.89 \\
36.64 \\
41.19\end{array}$ \\
\hline $\begin{array}{l}\text { North Carollna ................. } \\
\text { Kentucky ................ } \\
\text { Tennessee ................ } \\
\text { Virginia ...................... } \\
\text { West Virginia ........... }\end{array}$ & $\begin{array}{r}20,680 \\
8,659 \\
35 \\
4,637 \\
6,329\end{array}$ & $\begin{array}{l}12,456 \\
12,529 \\
12,400 \\
12,630 \\
12,218\end{array}$ & $\begin{array}{r}.02 \\
.94 \\
1.30 \\
1.07 \\
.77\end{array}$ & $\begin{array}{r}10.17 \\
8.93 \\
9.60 \\
10.83 \\
11.59\end{array}$ & $\begin{array}{l}172.6 \\
175.7 \\
150.6 \\
172.4 \\
167.9\end{array}$ & $\begin{array}{l}43.00 \\
44.04 \\
37.36 \\
43.55 \\
41.04\end{array}$ \\
\hline 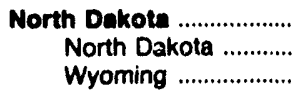 & $\begin{array}{r}23,427 \\
23,422 \\
5\end{array}$ & $\begin{array}{l}6,558 \\
6,557 \\
9,276\end{array}$ & $\begin{array}{l}.87 \\
.87 \\
.52\end{array}$ & $\begin{array}{l}9.20 \\
9.29 \\
4.30\end{array}$ & $\begin{array}{l}72.1 \\
72.1 \\
67.8\end{array}$ & $\begin{array}{r}9.45 \\
9.45 \\
12.58\end{array}$ \\
\hline 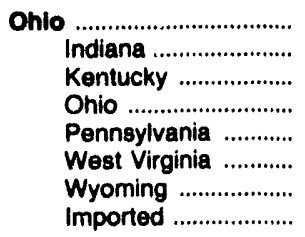 & $\begin{array}{r}50,506 \\
135 \\
7,961 \\
26,877 \\
3,236 \\
12,312 \\
61 \\
13\end{array}$ & $\begin{array}{r}11,983 \\
11,550 \\
11,835 \\
11,813 \\
12,732 \\
12,276 \\
8,449 \\
9,587\end{array}$ & $\begin{array}{l}2.57 \\
3.50 \\
1.14 \\
3.40 \\
2.03 \\
1.81 \\
.35 \\
.14\end{array}$ & $\begin{array}{r}11.24 \\
8.15 \\
13.14 \\
11.01 \\
9.39 \\
11.07 \\
5.48 \\
1.20\end{array}$ & $\begin{array}{r}143.5 \\
90.4 \\
146.4 \\
142.1 \\
128.9 \\
149.3 \\
120.1 \\
166.9\end{array}$ & $\begin{array}{l}34.40 \\
20.88 \\
34.65 \\
33.58 \\
32.83 \\
36.66 \\
20.29 \\
32.00\end{array}$ \\
\hline 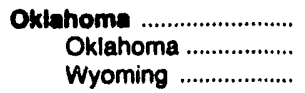 & $\begin{array}{r}16,840 \\
272 \\
16,568\end{array}$ & $\begin{array}{r}8,700 \\
12,484 \\
8,638\end{array}$ & $\begin{array}{r}.42 \\
2.78 \\
.38\end{array}$ & $\begin{array}{l}5.24 \\
8.77 \\
5.17\end{array}$ & $\begin{array}{l}123.4 \\
117.3 \\
123.5\end{array}$ & $\begin{array}{l}21.47 \\
29.27 \\
21.34\end{array}$ \\
\hline 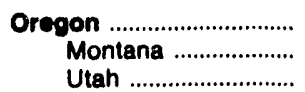 & $\begin{array}{r}1,932 \\
1,833 \\
99\end{array}$ & $\begin{array}{r}9,842 \\
9,547 \\
11,396\end{array}$ & $\begin{array}{l}.40 \\
.40 \\
.37\end{array}$ & $\begin{array}{l}4.42 \\
4.22 \\
7.86\end{array}$ & $\begin{array}{l}110.1 \\
110.3 \\
106.9\end{array}$ & $\begin{array}{l}21.23 \\
21.06 \\
24.37\end{array}$ \\
\hline
\end{tabular}

See footnotes at end of table.

Source: Federal Energy Regulatory Commission, FERC Form 423, "Monthly Report of Cost and Quality of Fuels for Electric Plants." 
Table 22. Destination and Origin of Coal by State, 1992-Continued

\begin{tabular}{|c|c|c|c|c|c|c|}
\hline \multirow[b]{2}{*}{$\begin{array}{l}\text { Destination } \\
\text { Origin }\end{array}$} & \multirow{2}{*}{$\begin{array}{l}\text { Quantity } \\
\text { (thousand } \\
\text { short tons) }\end{array}$} & \multicolumn{3}{|c|}{ Average Quallty } & \multicolumn{2}{|c|}{ Average Delivered Cos! } \\
\hline & & $\begin{array}{c}\text { Btu } \\
\text { (per pound) }\end{array}$ & $\begin{array}{c}\text { Sulfur } \\
\text { (percent } \\
\text { by welght) }\end{array}$ & $\begin{array}{c}\text { Ash } \\
\text { (percent } \\
\text { by weight) }\end{array}$ & $\begin{array}{l}\text { (conts per } \\
\text { million Btu) }\end{array}$ & $\begin{array}{l}\text { (dollars per } \\
\text { short Ton) }\end{array}$ \\
\hline 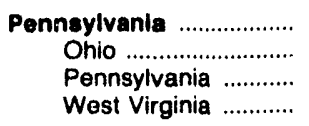 & $\begin{array}{r}41,082 \\
485 \\
31,312 \\
9,284\end{array}$ & $\begin{array}{l}12,399 \\
12,189 \\
12,358 \\
12,549\end{array}$ & $\begin{array}{l}2.12 \\
3.43 \\
1.86 \\
2.92\end{array}$ & $\begin{array}{l}12.56 \\
11.36 \\
13.18 \\
10.52\end{array}$ & $\begin{array}{l}148.4 \\
160.0 \\
145.6 \\
157.2\end{array}$ & $\begin{array}{l}36.81 \\
39.00 \\
35.99 \\
39.45\end{array}$ \\
\hline 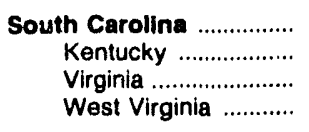 & $\begin{array}{r}9,255 \\
8,353 \\
827 \\
76\end{array}$ & $\begin{array}{l}12,817 \\
12,801 \\
13,028 \\
12,248\end{array}$ & $\begin{array}{r}1.14 \\
1.12 \\
1.35 \\
.99\end{array}$ & $\begin{array}{l}8.77 \\
8.72 \\
9.21 \\
9.28\end{array}$ & $\begin{array}{l}152.7 \\
152.3 \\
154.1 \\
181.7\end{array}$ & $\begin{array}{l}39.13 \\
38.98 \\
40.17 \\
44.52\end{array}$ \\
\hline $\begin{array}{l}\text { South Dakota } \\
\text { North Dakota }\end{array}$ & $\begin{array}{l}2,130 \\
2,130\end{array}$ & $\begin{array}{l}6,034 \\
6,034\end{array}$ & $\begin{array}{l}.92 \\
.92\end{array}$ & $\begin{array}{l}9.34 \\
9.34\end{array}$ & $\begin{array}{l}113.3 \\
113.3\end{array}$ & $\begin{array}{l}13.68 \\
13.68\end{array}$ \\
\hline 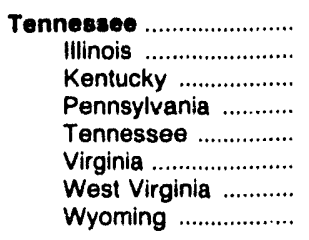 & $\begin{array}{r}20,372 \\
2,831 \\
14,824 \\
3 \\
3,223 \\
1,392 \\
28 \\
71\end{array}$ & $\begin{array}{r}12,182 \\
11,813 \\
12,145 \\
13,200 \\
12,867 \\
12,909 \\
12,000 \\
8,601\end{array}$ & $\begin{array}{r}2.02 \\
2.05 \\
2.13 \\
2.40 \\
1.37 \\
1.50 \\
1.40 \\
.50\end{array}$ & $\begin{array}{r}8.31 \\
8.92 \\
8.20 \\
7.40 \\
8.04 \\
8.32 \\
12.00 \\
7.99\end{array}$ & $\begin{array}{l}127.3 \\
123.4 \\
128.2 \\
120.0 \\
123.1 \\
129.1 \\
126.5 \\
132.1\end{array}$ & $\begin{array}{l}31.01 \\
29.15 \\
31.13 \\
31.68 \\
31.69 \\
33.34 \\
30.36 \\
22.73\end{array}$ \\
\hline 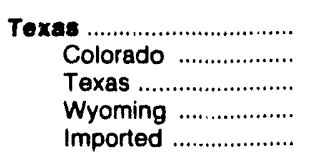 & $\begin{array}{r}87,613 \\
1,781 \\
51,497 \\
34,256 \\
80\end{array}$ & $\begin{array}{r}7,234 \\
10,885 \\
6,224 \\
8,540 \\
13,064\end{array}$ & $\begin{array}{r}.76 \\
.39 \\
1.05 \\
.35 \\
.64\end{array}$ & $\begin{array}{r}12.33 \\
6.32 \\
17.42 \\
5.01 \\
7.53\end{array}$ & $\begin{array}{l}149.1 \\
205.0 \\
118.8 \\
178.5 \\
175.2\end{array}$ & $\begin{array}{l}21.58 \\
44.63 \\
14.79 \\
30.53 \\
45.78\end{array}$ \\
\hline 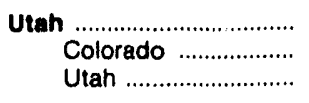 & $\begin{array}{r}12,840 \\
1,517 \\
11,323\end{array}$ & $\begin{array}{l}11,384 \\
10,531 \\
11,499\end{array}$ & $\begin{array}{l}.47 \\
.48 \\
.47\end{array}$ & $\begin{array}{l}11.24 \\
10.54 \\
11.33\end{array}$ & $\begin{array}{l}120.9 \\
201.4 \\
111.1\end{array}$ & $\begin{array}{l}27.54 \\
42.42 \\
25.54\end{array}$ \\
\hline 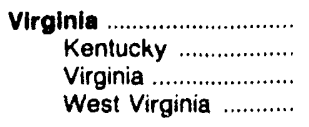 & $\begin{array}{l}8,915 \\
2,663 \\
4,395 \\
1,857\end{array}$ & $\begin{array}{l}12,830 \\
12,730 \\
12,857 \\
12,911\end{array}$ & $\begin{array}{r}1.03 \\
1.07 \\
.96 \\
1.13\end{array}$ & $\begin{array}{r}9.48 \\
8.62 \\
10.33 \\
8.68\end{array}$ & $\begin{array}{l}147.3 \\
150.4 \\
142.1 \\
155.3\end{array}$ & $\begin{array}{l}37.81 \\
38.29 \\
36.55 \\
40.09\end{array}$ \\
\hline 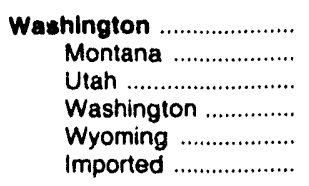 & $\begin{array}{r}5,836 \\
714 \\
118 \\
4,986 \\
2 \\
15\end{array}$ & $\begin{array}{r}8,189 \\
9,513 \\
11,274 \\
7,921 \\
8,846 \\
9,993\end{array}$ & $\begin{array}{l}.66 \\
.41 \\
.34 \\
.70 \\
.22 \\
.42\end{array}$ & $\begin{array}{r}13.69 \\
4.38 \\
8.17 \\
15.16 \\
4.67 \\
12.95\end{array}$ & $\begin{array}{l}137.3 \\
123.5 \\
128.2 \\
139.6 \\
181.0 \\
214.7\end{array}$ & $\begin{array}{l}22.48 \\
23.49 \\
28.91 \\
22.12 \\
32.02 \\
42.90\end{array}$ \\
\hline 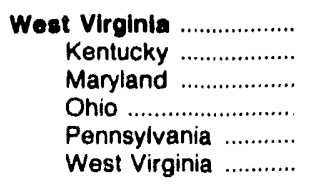 & $\begin{array}{r}28,307 \\
524 \\
2,003 \\
1,246 \\
1,275 \\
23,259\end{array}$ & $\begin{array}{l}12,524 \\
12,508 \\
12,480 \\
12,587 \\
12,544 \\
12,524\end{array}$ & $\begin{array}{r}2.05 \\
.86 \\
1.74 \\
4.03 \\
2.61 \\
1.97\end{array}$ & $\begin{array}{r}11.32 \\
8.96 \\
13.70 \\
9.56 \\
11.44 \\
11.25\end{array}$ & $\begin{array}{r}147.2 \\
182.5 \\
120.4 \\
92.4 \\
111.6 \\
153.6\end{array}$ & $\begin{array}{l}36.88 \\
45.64 \\
30.06 \\
23.27 \\
27.99 \\
38.49\end{array}$ \\
\hline 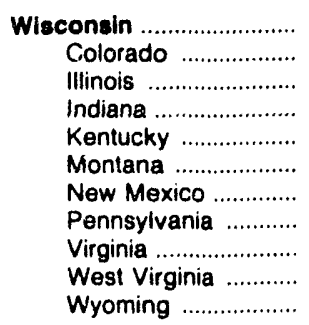 & $\begin{array}{r}17,589 \\
10 \\
823 \\
1,411 \\
446 \\
1,858 \\
578 \\
1,534 \\
62 \\
282 \\
10,585 \\
\end{array}$ & $\begin{array}{r}9,725 \\
12,731 \\
11,834 \\
11,197 \\
12,591 \\
8,794 \\
12,394 \\
13,254 \\
14,122 \\
12,981 \\
8,635\end{array}$ & $\begin{array}{r}.71 \\
.46 \\
1.48 \\
2.09 \\
1.15 \\
.67 \\
.55 \\
1.59 \\
.68 \\
.67 \\
.34\end{array}$ & $\begin{array}{r}6.18 \\
11.40 \\
6.89 \\
9.00 \\
8.37 \\
8.08 \\
12.49 \\
6.19 \\
4.20 \\
8.01 \\
4.94\end{array}$ & $\begin{array}{l}133.3 \\
141.2 \\
144.6 \\
193.5 \\
146.5 \\
154.9 \\
150.7 \\
157.1 \\
154.5 \\
165.8 \\
108.8\end{array}$ & $\begin{array}{l}25.82 \\
35.95 \\
34.23 \\
43.32 \\
36.88 \\
27.24 \\
37.36 \\
41.65 \\
43.65 \\
43.05 \\
18.78\end{array}$ \\
\hline $\begin{array}{c}\text { Wyoming } \\
\text { Wyoming }\end{array}$ & $\begin{array}{l}24,181 \\
24,181\end{array}$ & $\begin{array}{l}8,840 \\
8,840\end{array}$ & $\begin{array}{l}.52 \\
.52\end{array}$ & $\begin{array}{l}7.54 \\
7.54\end{array}$ & $\begin{array}{l}75.9 \\
75.9\end{array}$ & $\begin{array}{l}13.42 \\
13.42\end{array}$ \\
\hline Total & 775,963 & 10,395 & 1.29 & 9.71 & 141.2 & 29.36 \\
\hline
\end{tabular}

- = Number less than 0.5 rounded to zero.

Notes: - Totals may not equal sum of components because of independent rounding. - Data are for electric generating plants with a total steamelectric and combined-cycle nameplate capacity of 50 or more megawatts.

Source: Federal Energy Regulatory Commission, FERC Form 423, "Monthly Report of Cost and Quality of Fuels for Electric Plants." 
Table 23. Origin and Destination of Coal by State, 1992

\begin{tabular}{|c|c|c|c|c|c|c|}
\hline \multirow[b]{2}{*}{$\begin{array}{l}\text { Origin } \\
\text { Destination }\end{array}$} & \multirow{2}{*}{$\begin{array}{l}\text { Quantity } \\
\text { (thousand } \\
\text { short tons) }\end{array}$} & \multicolumn{3}{|c|}{ Average Quality } & \multicolumn{2}{|c|}{ Average Delivered Cost } \\
\hline & & $\begin{array}{c}\text { Btu } \\
\text { (per pound) }\end{array}$ & $\begin{array}{l}\text { Sulfur } \\
\text { (percent } \\
\text { by welght) }\end{array}$ & $\begin{array}{c}\text { Ash } \\
\text { (percent } \\
\text { by weight) }\end{array}$ & $\begin{array}{l}\text { (cents per } \\
\text { million Btu) }\end{array}$ & $\begin{array}{l}\text { (dollars per } \\
\text { short Ton) }\end{array}$ \\
\hline 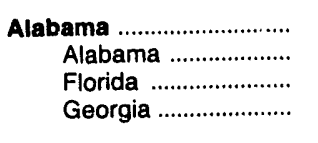 & $\begin{array}{r}16,435 \\
16,265 \\
72 \\
98\end{array}$ & $\begin{array}{l}12,094 \\
12,093 \\
12,060 \\
12,142\end{array}$ & $\begin{array}{l}1.26 \\
1.25 \\
2.75 \\
2.06\end{array}$ & $\begin{array}{l}12.42 \\
12.42 \\
12.94 \\
12.17\end{array}$ & $\begin{array}{l}195.8 \\
196.5 \\
120.6 \\
135.6\end{array}$ & $\begin{array}{l}47.35 \\
47.52 \\
29.09 \\
32.92\end{array}$ \\
\hline 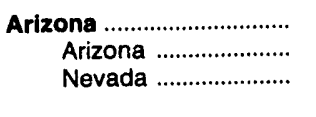 & $\begin{array}{r}12,418 \\
7,441 \\
4,977\end{array}$ & $\begin{array}{l}11,001 \\
11,043 \\
10,940\end{array}$ & $\begin{array}{l}.52 \\
.52 \\
.51\end{array}$ & $\begin{array}{r}9.50 \\
9.00 \\
10.25\end{array}$ & $\begin{array}{l}110.4 \\
104.8 \\
118.8\end{array}$ & $\begin{array}{l}24.28 \\
23.14 \\
25.99\end{array}$ \\
\hline 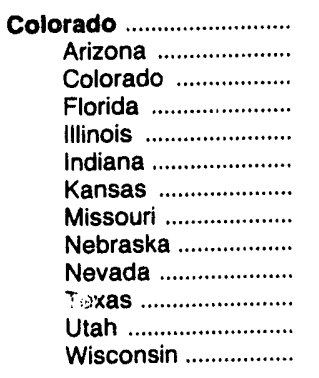 & $\begin{array}{r}16,505 \\
119 \\
10,661 \\
181 \\
470 \\
773 \\
328 \\
496 \\
* \\
168 \\
1,781 \\
1,517 \\
10\end{array}$ & $\begin{array}{l}10,785 \\
12,158 \\
10,584 \\
13,092 \\
12,020 \\
11,305 \\
11,193 \\
11,736 \\
11,308 \\
11,753 \\
10,885 \\
10,531 \\
12,731\end{array}$ & $\begin{array}{l}.42 \\
.41 \\
.41 \\
.45 \\
.47 \\
.42 \\
.45 \\
.48 \\
.40 \\
.50 \\
.39 \\
.48 \\
.46\end{array}$ & $\begin{array}{r}8.26 \\
15.76 \\
8.02 \\
10.01 \\
8.47 \\
8.28 \\
9.63 \\
9.50 \\
8.60 \\
9.28 \\
6.32 \\
10.54 \\
11.40\end{array}$ & $\begin{array}{l}136.8 \\
167.5 \\
112.0 \\
146.5 \\
140.7 \\
154.1 \\
112.2 \\
160.7 \\
158.8 \\
215.3 \\
205.0 \\
201.4 \\
141.2\end{array}$ & $\begin{array}{l}29.51 \\
40.74 \\
23.71 \\
38.37 \\
33.84 \\
34.84 \\
25.12 \\
37.71 \\
35.91 \\
50.60 \\
44.63 \\
42.42 \\
35.95\end{array}$ \\
\hline 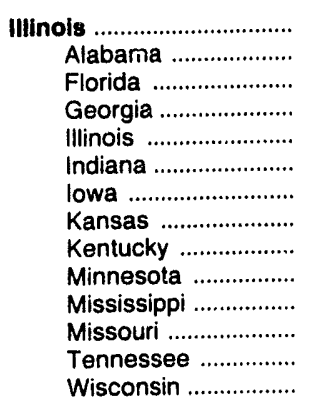 & $\begin{array}{r}\mathbf{5 4 , 5 0 4} \\
956 \\
5,504 \\
5,137 \\
14,818 \\
9,565 \\
1,417 \\
767 \\
7 \\
63 \\
1,239 \\
11,376 \\
2,831 \\
823\end{array}$ & $\begin{array}{l}11,256 \\
11,578 \\
11,711 \\
11,278 \\
10,970 \\
10,889 \\
11,329 \\
11,355 \\
11,650 \\
11,836 \\
12,757 \\
11,319 \\
11,813 \\
11,834\end{array}$ & $\begin{array}{l}2.63 \\
1.96 \\
2.77 \\
2.78 \\
2.89 \\
2.65 \\
2.58 \\
2.56 \\
2.50 \\
1.84 \\
2.74 \\
2.41 \\
2.05 \\
1.48\end{array}$ & $\begin{array}{r}9.03 \\
9.30 \\
8.33 \\
9.36 \\
9.48 \\
10.36 \\
8.28 \\
9.13 \\
10.20 \\
8.79 \\
8.75 \\
9.25 \\
8.92 \\
6.89\end{array}$ & $\begin{array}{l}157.8 \\
121.8 \\
194.3 \\
207.9 \\
142.4 \\
155.8 \\
169.3 \\
155.8 \\
110.3 \\
162.0 \\
132.7 \\
152.7 \\
123.4 \\
144.6\end{array}$ & $\begin{array}{l}35.52 \\
28.21 \\
45.50 \\
46.90 \\
31.24 \\
33.93 \\
38.36 \\
35.38 \\
25.70 \\
38.34 \\
33.86 \\
34.58 \\
29.15 \\
34.23\end{array}$ \\
\hline 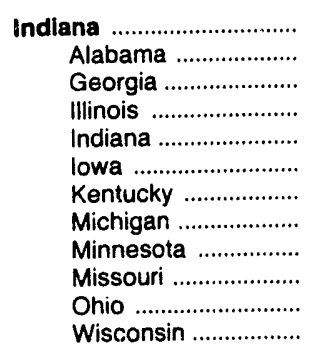 & $\begin{array}{r}24,926 \\
19 \\
555 \\
826 \\
19,005 \\
470 \\
2,237 \\
205 \\
* \\
63 \\
135 \\
1,411\end{array}$ & $\begin{array}{r}11,145 \\
11,296 \\
11,294 \\
11,000 \\
11,130 \\
11,290 \\
11,217 \\
11,019 \\
9,940 \\
11,279 \\
11,550 \\
11,197\end{array}$ & $\begin{array}{l}2.46 \\
3.45 \\
2.51 \\
1.80 \\
2.45 \\
2.53 \\
2.84 \\
2.46 \\
1.10 \\
3.03 \\
3.50 \\
2.09\end{array}$ & $\begin{array}{r}9.07 \\
10.98 \\
8.13 \\
9.32 \\
9.10 \\
8.57 \\
9.00 \\
10.07 \\
11.70 \\
8.50 \\
8.15 \\
9.00\end{array}$ & $\begin{array}{r}124.2 \\
101.5 \\
138.4 \\
137.6 \\
120.8 \\
128.6 \\
99.4 \\
150.3 \\
90.5 \\
109.9 \\
90.4 \\
193.5\end{array}$ & $\begin{array}{l}27.68 \\
22.92 \\
31.26 \\
30.28 \\
26.90 \\
29.03 \\
22.31 \\
33.12 \\
17.99 \\
24.79 \\
20.88 \\
43.32\end{array}$ \\
\hline 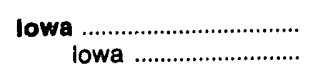 & $\begin{array}{l}67 \\
67\end{array}$ & $\begin{array}{l}9,817 \\
9,817\end{array}$ & $\begin{array}{l}4.36 \\
4.36\end{array}$ & $\begin{array}{l}13.57 \\
13.57\end{array}$ & $\begin{array}{l}170.6 \\
170.6\end{array}$ & $\begin{array}{l}33.50 \\
33.50\end{array}$ \\
\hline 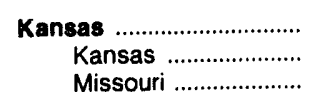 & $\begin{array}{r}307 \\
90 \\
217\end{array}$ & $\begin{array}{l}12,197 \\
12,529 \\
12,060\end{array}$ & $\begin{array}{l}3.54 \\
3.14 \\
3.71\end{array}$ & $\begin{array}{l}11.70 \\
10.53 \\
12.18\end{array}$ & $\begin{array}{l}129.4 \\
120.4 \\
133.3\end{array}$ & $\begin{array}{l}31.57 \\
30.17 \\
32.15\end{array}$ \\
\hline 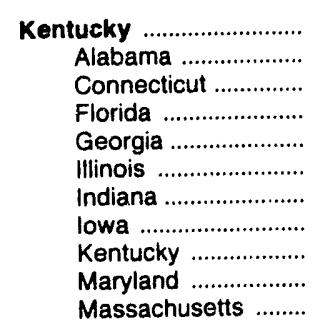 & $\begin{array}{r}117,417 \\
4,078 \\
772 \\
14,717 \\
11,981 \\
1,187 \\
4,455 \\
27 \\
26,187 \\
215 \\
10\end{array}$ & $\begin{array}{l}12,196 \\
11,992 \\
13,162 \\
12,636 \\
12,234 \\
13,157 \\
11,606 \\
12,367 \\
11,559 \\
12,922 \\
12,934\end{array}$ & $\begin{array}{r}1.73 \\
2.48 \\
.55 \\
1.48 \\
1.45 \\
.64 \\
2.65 \\
3.36 \\
2.59 \\
.73 \\
.63\end{array}$ & $\begin{array}{r}9.81 \\
10.52 \\
6.25 \\
8.19 \\
10.38 \\
6.53 \\
10.27 \\
9.61 \\
11.87 \\
7.38 \\
6.47\end{array}$ & $\begin{array}{l}147.3 \\
118.0 \\
195.5 \\
177.0 \\
163.5 \\
169.4 \\
119.5 \\
105.5 \\
115.8 \\
154.9 \\
170.9\end{array}$ & $\begin{array}{l}35.94 \\
28.30 \\
51.47 \\
44.73 \\
40.01 \\
44.59 \\
27.73 \\
26.09 \\
26.77 \\
40.04 \\
44.21\end{array}$ \\
\hline
\end{tabular}

See footnotes at end of table.

Source: Federal Energy Regulatory Commission, FERC Form 423, "Monthly Report of Cost and Quality of Fuels for Electric Plants." 
Table 23. Origin and Destination of Coal by State, 1992-Continued

\begin{tabular}{|c|c|c|c|c|c|c|}
\hline \multirow[b]{2}{*}{$\begin{array}{c}\text { Origin } \\
\text { Destination }\end{array}$} & \multirow{2}{*}{$\begin{array}{l}\text { Quantity } \\
\text { (thousand } \\
\text { short tons) }\end{array}$} & \multicolumn{3}{|c|}{ Average Quality } & \multicolumn{2}{|c|}{ Average Delivered Cost } \\
\hline & & $\begin{array}{c}\text { Btu } \\
\text { (per pound) }\end{array}$ & $\begin{array}{c}\text { Sulfur } \\
\text { (percent } \\
\text { by wolght) }\end{array}$ & $\begin{array}{c}\text { Ash } \\
\text { (percent } \\
\text { by welght) }\end{array}$ & $\begin{array}{l}\text { (cents per } \\
\text { million Btu) }\end{array}$ & $\begin{array}{l}\text { (dollars per } \\
\text { short Ton) }\end{array}$ \\
\hline \multicolumn{7}{|l|}{ Kentucky } \\
\hline Michigan ..................... & 6,392 & 12,770 & 0.93 & 8.28 & 171.4 & 43.78 \\
\hline Mississippi ................... & 1,816 & 12,624 & 1.08 & 8.32 & 179.2 & 45.24 \\
\hline Missouri .................... & 585 & 11.796 & 3.38 & 7.99 & 125.6 & 29.63 \\
\hline New Jersey ................ & 189 & 13,197 & .83 & 6.64 & 183.3 & 48.38 \\
\hline New York .................. & 377 & 13,035 & .56 & 6.96 & 206.7 & 53.90 \\
\hline North Carolina .......... & 9,659 & 12,529 & .94 & 8.93 & 175.7 & 44.04 \\
\hline Ohio & 7,961 & 11,835 & 1.14 & 13.14 & 146.4 & 34.65 \\
\hline South Carolina ......... & 8,353 & 12,801 & 1.12 & 8.72 & 152.3 & 38.98 \\
\hline Tennessee ................. & 14,824 & 12,145 & 2.13 & 8.20 & 128.2 & 31.13 \\
\hline 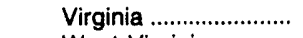 & 2,663 & 12,730 & 1.07 & 8.62 & 150.4 & 38.29 \\
\hline West Virginia ............ & 524 & 12,508 & .86 & 8.96 & 182.5 & 45.64 \\
\hline Wisconsin ...................... & 446 & 12,591 & 1.15 & 8.37 & 146.5 & 36.88 \\
\hline Loulsiana ............................ & 3,212 & 6,951 & .62 & 12.14 & 138.3 & 19.22 \\
\hline 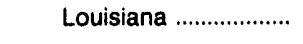 & 3,212 & 6,951 & .62 & 12.14 & 138.3 & 19.22 \\
\hline Maryland ............................... & 3,223 & 12,565 & 1.69 & 12.94 & 137.9 & 34.66 \\
\hline 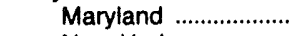 & 1,203 & 12,728 & 1.59 & 11.63 & 166.4 & 42.37 \\
\hline New York ..................... & 18 & 11,137 & 1.59 & 16.66 & 143.2 & 31.89 \\
\hline West Virginia .............. & 2,003 & 12,480 & 1.74 & 13.70 & 120.4 & 30.06 \\
\hline Missouri ................................. & 2,622 & 10,589 & 4.15 & 10.22 & 162.6 & 34.43 \\
\hline Kansas .......................... & 48 & 11,812 & 3.60 & 11.90 & 118.3 & 27.95 \\
\hline 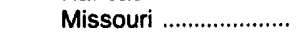 & 2,574 & 10,567 & 4.16 & 10.19 & 163.5 & 34.55 \\
\hline Montana ............................... & 37,309 & 9,052 & .52 & 6.62 & 133.2 & 24.12 \\
\hline 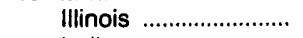 & 3,036 & 9,580 & .35 & 4.02 & 282.8 & 54.18 \\
\hline Indiana ............................ & 452 & 9,595 & .36 & 4.05 & 278.5 & 53.44 \\
\hline Michigan ........................ & 10,544 & 9,446 & .37 & 4.31 & 151.0 & 28.53 \\
\hline Minnesota ................. & 7,929 & 8,847 & .61 & 8.14 & 121.5 & 21.50 \\
\hline Mississippi .................. & 82 & 9,383 & .30 & 4.15 & 136.0 & 25.51 \\
\hline Montana ..................... & 10,860 & 8,576 & .66 & 8.92 & 70.8 & 12.14 \\
\hline Oregon ......................... & 1,833 & 9,547 & .40 & 4.22 & 110.3 & 21.06 \\
\hline Washington ................ & 714 & 9,513 & .41 & 4.38 & 123.5 & 23.49 \\
\hline Wisconsin ...................... & 1,858 & 8,794 & .67 & 8.08 & 154.9 & 27.24 \\
\hline New Mexico ........................ & 24,261 & 9,323 & .69 & 19.49 & 146.4 & 27.29 \\
\hline Arizona & 8,754 & 9,650 & .50 & 14.85 & 168.6 & 32.53 \\
\hline New Mexico .............. & 14,929 & 9,013 & .81 & 22.49 & 132.2 & 23.83 \\
\hline Wisconsin ...................... & 578 & 12,394 & .55 & 12.49 & 150.7 & 37.36 \\
\hline North Dakota ...................... & 25,552 & 6,513 & .87 & 9.30 & 75.3 & 9.81 \\
\hline North Dakota ............ & 23,422 & 6,557 & .87 & 9.29 & 72.1 & 9.45 \\
\hline South Dakota .............. & 2,130 & 6,034 & .92 & 9.34 & 113.3 & 13.68 \\
\hline Ohio & 28,916 & 11,849 & 3.42 & 10.98 & 140.6 & 33.32 \\
\hline 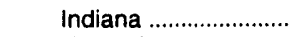 & 19 & 11,458 & 2.82 & 9.81 & 128.6 & 29.46 \\
\hline Kentucky ..................... & 249 & 11,471 & 2.16 & 14.22 & 184.5 & 42.32 \\
\hline Michigan .................... & 40 & 12,003 & 3.35 & 8.29 & 223.3 & 53.60 \\
\hline 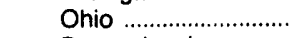 & 26,877 & 11,813 & 3.40 & 11.01 & 142.1 & 33.58 \\
\hline Pennsylvania ............. & 485 & 12.189 & 3.43 & 11.36 & 160.0 & 39.00 \\
\hline West Virginia ............. & 1,246 & 12,587 & 4.03 & 9.56 & 92.4 & 23.27 \\
\hline 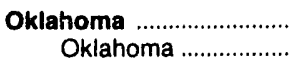 & $\begin{array}{l}272 \\
272\end{array}$ & $\begin{array}{l}12,484 \\
12,484\end{array}$ & $\begin{array}{l}2.78 \\
2.78\end{array}$ & $\begin{array}{l}9.77 \\
9.77\end{array}$ & $\begin{array}{l}117.3 \\
117.3\end{array}$ & $\begin{array}{l}29.27 \\
29.27\end{array}$ \\
\hline Pennsylvania ...................... & 50,181 & 12,550 & 1.85 & 11.59 & 145.9 & 36.62 \\
\hline Delaware ..................... & 137 & 13,104 & 1.40 & 9.31 & 177.9 & 46.62 \\
\hline Kentucky ................... & 42 & 13,005 & 2.42 & 7.79 & 99.8 & 25.96 \\
\hline Maryland .................... & 2,893 & 12,586 & 1.87 & 12.23 & 169.8 & 42.75 \\
\hline Massachusetts ........ & 395 & 13,230 & 1.34 & 6.31 & 167.6 & 44.34 \\
\hline Michigan ...................... & 1,753 & 13,159 & 1.70 & 6.74 & 154.3 & 40.61 \\
\hline Minnesota ................... & 11 & 13,351 & 2.04 & 6.92 & 142.3 & 38.00 \\
\hline New Hampshire ....... & 680 & 13,264 & 1.57 & 6.29 & 171.5 & 45.50 \\
\hline New Jersey .............. & 15 & 13,394 & 2.62 & 7.10 & 150.0 & 40.19 \\
\hline New York .................... & 6,895 & 12,887 & 1.72 & 8.47 & 142.2 & 36.64 \\
\hline Ohio & 3,236 & 12,732 & 2.03 & 9.39 & 128.9 & 32.83 \\
\hline
\end{tabular}

See footnotes at end of table.

Source: Federal Energy Regulatory Commission, FERC Form 423, "Monthly Report of Cost and Quality of Fuels for Electric Plants." 
Table 23. Origin and Destination of Coal by State, 1992-Continued

\begin{tabular}{|c|c|c|c|c|c|c|}
\hline \multirow[b]{2}{*}{$\begin{array}{c}\text { Origin } \\
\text { Destination }\end{array}$} & \multirow{2}{*}{$\begin{array}{l}\text { Quantity } \\
\text { (thousand } \\
\text { short tons) }\end{array}$} & \multicolumn{3}{|c|}{ Average Quality } & \multicolumn{2}{|c|}{ Average Delivered Cost } \\
\hline & & $\begin{array}{c}\text { Btu } \\
\text { (per pound) }\end{array}$ & $\begin{array}{c}\text { Sulfur } \\
\text { (percent } \\
\text { by weight) }\end{array}$ & $\begin{array}{c}\text { Ash } \\
\text { (percent } \\
\text { by weight) }\end{array}$ & $\begin{array}{l}\text { (cents per } \\
\text { mililon Btu) }\end{array}$ & $\begin{array}{l}\text { (dollars per } \\
\text { short Ton) }\end{array}$ \\
\hline \multicolumn{7}{|l|}{ Pennsylvania } \\
\hline Pennsylvania ............... & 31,312 & 12,358 & 1.86 & 13.18 & 145.6 & 35.99 \\
\hline Tennessee ................. & 3 & 13,200 & 2.40 & 7.40 & 120.0 & 31.68 \\
\hline West Virginia ............. & 1,275 & 12,544 & 2.61 & 11.44 & 111.6 & 27.99 \\
\hline Wisconsin ...................... & 1,534 & 13,254 & 1.59 & 6.19 & 157.1 & 41.65 \\
\hline 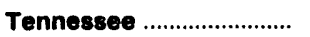 & 2,844 & 12,668 & 1.39 & 9.63 & 132.7 & 33.63 \\
\hline 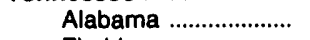 & 817 & 12,441 & .80 & 12.21 & 130.1 & 32.37 \\
\hline Florida .......................... & 269 & 12,861 & 1.19 & 6.20 & 217.6 & 55.98 \\
\hline Kentucky .................. & 500 & 12,467 & 2.51 & 11.14 & 112.8 & 28.14 \\
\hline North Carolina .......... & 35 & 12,400 & 1.30 & 9.60 & 150.6 & 37.36 \\
\hline Tennessee ..................... & 1,223 & 12,867 & 1.37 & 8.04 & 123.1 & 31.69 \\
\hline Texas & 51,497 & 6,224 & 1.05 & 17.42 & 118.8 & 14.79 \\
\hline Texas & 51,497 & 6,224 & 1.05 & 17.42 & 118.8 & 14.79 \\
\hline 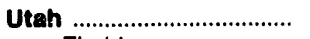 & 13,839 & 11,547 & .46 & 10.85 & 122.6 & 28.31 \\
\hline Florida & 32 & 11,596 & .39 & 8.20 & 163.8 & 37.99 \\
\hline Illinois ............................ & 239 & 11,742 & .43 & 8.17 & 121.3 & 28.49 \\
\hline Missouri ......................... & 79 & 11,725 & .41 & 8.09 & 140.8 & 33.03 \\
\hline Nevada ...................... & 1,948 & 11,821 & .45 & 8.83 & 186.9 & 44.19 \\
\hline Oregon .......................... & 99 & 11,396 & .37 & 7.96 & 106.9 & 24.37 \\
\hline Utah & 11,323 & 11,499 & .47 & 11.33 & 111.1 & 25.54 \\
\hline Washington .................... & 118 & 11,274 & .34 & 8.17 & 128.2 & 28.91 \\
\hline 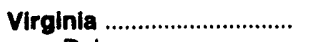 & 16,548 & 12,872 & 1.10 & 9.67 & 164.0 & 42.21 \\
\hline 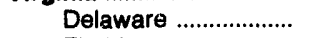 & 90 & 13,101 & .82 & 8.68 & 201.3 & 52.74 \\
\hline Florida ............................ & 882 & 12,389 & .72 & 9.77 & 223.4 & 55.36 \\
\hline 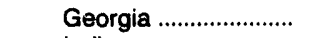 & 2,615 & 12,871 & 1.34 & 9.90 & 180.5 & 46.47 \\
\hline Indiana .......................... & 132 & 13,880 & .73 & 5.38 & 162.2 & 45.04 \\
\hline Maryland ....................... & 78 & 14,076 & .80 & 5.05 & 169.9 & 47.84 \\
\hline Massachusetts ........ & 611 & 12,954 & 1.06 & 7.84 & 175.3 & 45.42 \\
\hline Michigan ....................... & 21 & 13,114 & 1.33 & 8.40 & 149.0 & 39.08 \\
\hline New Jersey ................ & 806 & 14,185 & .83 & 4.40 & 175.9 & 49.90 \\
\hline North Carolina .......... & 4,637 & 12,630 & 1.07 & 10.83 & 172.4 & 43.55 \\
\hline South Carolina ......... & 827 & 13,028 & 1.35 & 9.21 & 154.1 & 40.17 \\
\hline Tennessee ................. & 1,392 & 12,909 & 1.50 & 8.32 & 129.1 & 33.34 \\
\hline 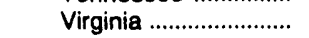 & 4,395 & 12,857 & .96 & 10.33 & 142.1 & 36.55 \\
\hline 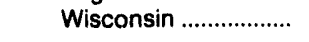 & 62 & 14,122 & .68 & 4.20 & 154.5 & 43.65 \\
\hline 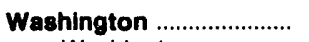 & 4,986 & 7,921 & .70 & 15.16 & 139.6 & 22.12 \\
\hline Washington & 4,986 & 7,921 & .70 & 15.16 & 139.6 & 22.12 \\
\hline 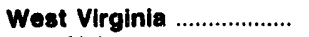 & 84,763 & 12,519 & 1.60 & 10.57 & 157.1 & 39.33 \\
\hline Alabama ........................ & 2,752 & 12,033 & .96 & 10.77 & 143.1 & 34.45 \\
\hline Connecticut .................... & 21 & 13,351 & .67 & 6.20 & 168.9 & 45.10 \\
\hline Delaware ....................... & 1,304 & 13,058 & 1.00 & 8.79 & 171.0 & 44.66 \\
\hline Florida & 1,290 & 12,526 & 1.36 & 10.44 & 197.5 & 49.48 \\
\hline Georgia ......................... & 2,453 & 11,977 & .68 & 12.64 & 218.1 & 52.25 \\
\hline Illinois ........................... & 492 & 12,893 & .73 & 9.68 & 151.8 & 39.14 \\
\hline Indiana .......................... & 1,652 & 12,646 & .73 & 9.73 & 139.9 & 35.37 \\
\hline Kentucky ...................... & 3,069 & 12,290 & .87 & 11.14 & 126.3 & 31.06 \\
\hline Maryland ..................... & 4,896 & 12,829 & 1.04 & 9.37 & 151.8 & 38.95 \\
\hline Massachusetts ........ & 2,981 & 13,057 & 1.19 & 8.71 & 167.9 & 43.85 \\
\hline Michigan ....................... & 5,665 & 12,470 & .84 & 10.51 & 162.0 & 40.40 \\
\hline New Hampshire ...... & 464 & 13,369 & 1.85 & 6.85 & 165.3 & 44.19 \\
\hline New Jersey ................ & 1,195 & 13,023 & 1.66 & 8.51 & 169.7 & 44.21 \\
\hline New York ..................... & 3,105 & 13,182 & 1.63 & 7.10 & 156.2 & 41.19 \\
\hline North Carolina .......... & 6,329 & 12,218 & .77 & 11.59 & 167.9 & 41.04 \\
\hline 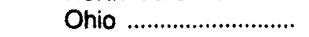 & 12,312 & 12,276 & 1.81 & 11.07 & 149.3 & 36.66 \\
\hline Pennsylvania ............ & 9,284 & 12,549 & 2.92 & 10.52 & 157.2 & 39.45 \\
\hline South Carolina ......... & 76 & 12,248 & .99 & 9.28 & 181.7 & 44.52 \\
\hline 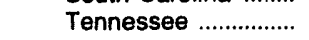 & 28 & 12,000 & 1.40 & 12.00 & 126.5 & 30.36 \\
\hline 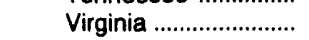 & 1,857 & 12,911 & 1.13 & 8.68 & 155.3 & 40.09 \\
\hline West Virginia ............. & 23,259 & 12,524 & 1.97 & 11.25 & $153 . t$ & 38.49 \\
\hline 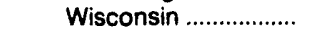 & 282 & 12,981 & .67 & 8.01 & 165.8 & 43.05 \\
\hline
\end{tabular}

See footnotes at end of table.

Source: Federal Energy Regulatory Commission, FERC Form 423, "Monthly Report of Cost and Quality of Fuels for Electric Plants." 
Table 23. Origin and Destination of Coal by State, 1992-Continued

\begin{tabular}{|c|c|c|c|c|c|c|}
\hline \multirow[b]{2}{*}{$\begin{array}{c}\text { Origin } \\
\text { Destination }\end{array}$} & \multirow{2}{*}{$\begin{array}{l}\text { Quantlty } \\
\text { (thousand } \\
\text { short tons) }\end{array}$} & \multicolumn{3}{|c|}{ Average Quallty } & \multicolumn{2}{|c|}{ Average Dellvered Cost } \\
\hline & & $\begin{array}{c}\text { Btu } \\
\text { (per pound) }\end{array}$ & $\begin{array}{c}\text { Sulfur } \\
\text { (percent } \\
\text { by weight) }\end{array}$ & $\begin{array}{c}\text { Ash } \\
\text { (percent } \\
\text { by wolght) }\end{array}$ & $\begin{array}{l}\text { (centa per } \\
\text { million Btu) }\end{array}$ & $\begin{array}{l}\text { (dollars per } \\
\text { short Ton) }\end{array}$ \\
\hline 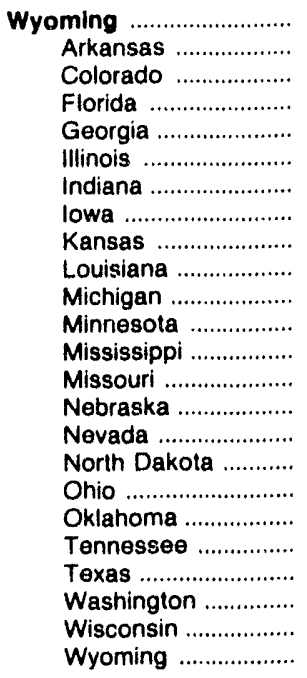 & $\begin{array}{r}181,553 \\
11,630 \\
4,936 \\
12 \\
12 \\
4,382 \\
11,786 \\
13,057 \\
12,402 \\
9,463 \\
3,254 \\
7,151 \\
71 \\
9,112 \\
7,759 \\
800 \\
5 \\
61 \\
16,568 \\
71 \\
34,256 \\
2 \\
10,585 \\
24,181\end{array}$ & $\begin{array}{l}8,682 \\
8,724 \\
8,486 \\
8,887 \\
8,777 \\
9,202 \\
8,914 \\
8,500 \\
8,650 \\
8,519 \\
8,766 \\
8,794 \\
8,760 \\
8,773 \\
8,553 \\
9,724 \\
9,276 \\
8,449 \\
8,638 \\
8,601 \\
8,549 \\
8,846 \\
8,635 \\
8,840\end{array}$ & $\begin{array}{l}0.38 \\
.32 \\
.33 \\
.20 \\
.38 \\
.41 \\
.35 \\
.37 \\
.33 \\
.46 \\
.29 \\
.26 \\
.34 \\
.29 \\
.37 \\
.49 \\
.52 \\
.35 \\
.38 \\
.50 \\
.35 \\
.22 \\
.34 \\
52\end{array}$ & $\begin{array}{l}5.48 \\
5.12 \\
4.81 \\
4.70 \\
4.59 \\
6.78 \\
5.10 \\
5.36 \\
5.36 \\
5.53 \\
4.96 \\
4.81 \\
4.92 \\
4.85 \\
5.00 \\
8.17 \\
4.30 \\
5.48 \\
5.17 \\
7.99 \\
5.01 \\
4.67 \\
4.94 \\
7.54\end{array}$ & $\begin{array}{r}127.3 \\
165.3 \\
101.7 \\
142.3 \\
127.5 \\
242.8 \\
123.3 \\
100.7 \\
115.0 \\
157.7 \\
111.3 \\
114.7 \\
153.0 \\
91.3 \\
74.6 \\
200.2 \\
67.8 \\
120.1 \\
123.5 \\
132.1 \\
178.5 \\
181.0 \\
108.8 \\
75.9\end{array}$ & $\begin{array}{l}22.10 \\
28.84 \\
17.26 \\
25.29 \\
22.38 \\
44.69 \\
21.98 \\
17.12 \\
19.90 \\
26.87 \\
19.52 \\
20.18 \\
26.81 \\
16.02 \\
12.77 \\
38.93 \\
12.58 \\
20.29 \\
21.34 \\
22.73 \\
30.53 \\
32.02 \\
18.78 \\
13.42\end{array}$ \\
\hline 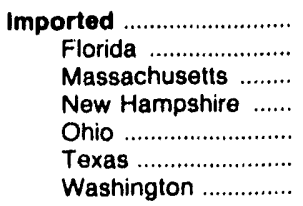 & $\begin{array}{r}1,806 \\
1,419 \\
197 \\
83 \\
13 \\
80 \\
15\end{array}$ & $\begin{array}{r}12,103 \\
11,897 \\
13,322 \\
12,616 \\
9,587 \\
13,064 \\
9,993\end{array}$ & $\begin{array}{l}.71 \\
.71 \\
.83 \\
.60 \\
.14 \\
.64 \\
42\end{array}$ & $\begin{array}{r}6.90 \\
6.91 \\
6.68 \\
6.50 \\
1.20 \\
7.53 \\
12.95\end{array}$ & $\begin{array}{l}154.0 \\
150.0 \\
163.4 \\
161.8 \\
166.9 \\
175.2 \\
214.7\end{array}$ & $\begin{array}{l}37.27 \\
35.70 \\
43.54 \\
40.83 \\
32.00 \\
45.78 \\
42.90\end{array}$ \\
\hline 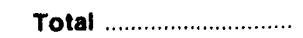 & 775,963 & 10,395 & 1.29 & 9.71 & 141.2 & 29.36 \\
\hline
\end{tabular}

- Number less than 0.5 rounded to zero.

Notes: - Totals may not equal sum of components because of independent rounding. - Data are for electric generating plants with a total steamelectric and combined-cycle nameplate capacity of 50 or more megawatts.

Source: Federal Energy Regulatory Commission, FERC Form 423, "Monthly Report of Cost and Quality of Fuels for Electric Plants." 
Table 24. Origin of Coal Received by Electric Utility and Plant, 1992

\begin{tabular}{|c|c|c|c|c|c|c|}
\hline \multirow{2}{*}{$\begin{array}{l}\text { Electric Utility Plant } \\
\text { Origin State } \\
\text { County }\end{array}$} & \multirow{2}{*}{$\begin{array}{l}\text { Quantity } \\
\text { (thousand } \\
\text { short tons) }\end{array}$} & \multicolumn{3}{|c|}{ Average Quality } & \multicolumn{2}{|c|}{ Average Dellvered Cost } \\
\hline & & $\begin{array}{c}\text { Btu } \\
\text { (per pound) }\end{array}$ & $\begin{array}{l}\text { Sulfur } \\
\text { (percent } \\
\text { by weight) }\end{array}$ & $\begin{array}{l}\text { Ash } \\
\text { (percent } \\
\text { by weight) }\end{array}$ & $\begin{array}{l}\text { (cents per } \\
\text { million Btu) }\end{array}$ & $\begin{array}{l}\text { (dollars per } \\
\text { short ton) }\end{array}$ \\
\hline $\begin{array}{l}\text { Alabama Electric Coop Inc } \quad \text { Lowman } \\
\text { Alabama } \\
\text { Fayette } \\
\text { Jefferson } \\
\text { Tuscaloosa }\end{array}$ & $\begin{array}{r}1,395 \\
1,395 \\
218 \\
668 \\
510\end{array}$ & $\begin{array}{l}12,165 \\
12,165 \\
12,116 \\
12,228 \\
12,104\end{array}$ & $\begin{array}{l}1.29 \\
1.29 \\
1.85 \\
1.32 \\
1.01\end{array}$ & $\begin{array}{l}12.11 \\
12.11 \\
11.51 \\
11.93 \\
12.61\end{array}$ & $\begin{array}{l}148.3 \\
148.3 \\
155.1 \\
149.7 \\
143.4\end{array}$ & $\begin{array}{l}36.07 \\
36.07 \\
37.57 \\
36.62 \\
34.72\end{array}$ \\
\hline $\begin{array}{l}\text { Alabama Power Co } \\
\text { Alabama . Barry } \\
\text { Tuscaloosa } \\
\text { Walker . } \\
\text { Winston } \\
\text { West Virginia } \\
\text { Nicholas }\end{array}$ & $\begin{array}{r}832 \\
816 \\
500 \\
292 \\
24 \\
16 \\
16\end{array}$ & $\begin{array}{l}12,311 \\
12,322 \\
12,547 \\
11,987 \\
11,701 \\
11,744 \\
11,744\end{array}$ & $\begin{array}{r}.93 \\
.92 \\
.93 \\
.91 \\
.96 \\
1.08 \\
1.08\end{array}$ & $\begin{array}{l}11.30 \\
11.25 \\
10.60 \\
12.37 \\
11.24 \\
13.77 \\
13.77\end{array}$ & $\begin{array}{l}213.1 \\
214.6 \\
243.7 \\
167.6 \\
148.9 \\
132.4 \\
132.4\end{array}$ & $\begin{array}{l}52.46 \\
52.88 \\
61.16 \\
40.17 \\
34.84 \\
31.10 \\
31.10\end{array}$ \\
\hline 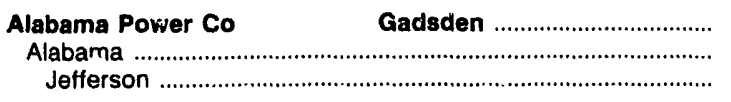 & $\begin{array}{l}135 \\
135 \\
135\end{array}$ & $\begin{array}{l}12,530 \\
12,530 \\
12,530\end{array}$ & $\begin{array}{l}1.79 \\
1.79 \\
1.79\end{array}$ & $\begin{array}{l}12.45 \\
12.45 \\
12.45\end{array}$ & $\begin{array}{l}182.7 \\
182.7 \\
182.7\end{array}$ & $\begin{array}{l}45.80 \\
45.80 \\
45.80\end{array}$ \\
\hline 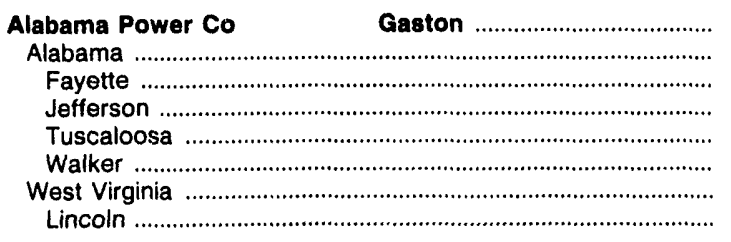 & $\begin{array}{r}3,840 \\
2,642 \\
1,558 \\
595 \\
58 \\
431 \\
1,198 \\
1,198\end{array}$ & $\begin{array}{l}12,059 \\
12,126 \\
12,033 \\
12,326 \\
12,055 \\
12,194 \\
11,911 \\
11,911\end{array}$ & $\begin{array}{r}1.67 \\
2.08 \\
2.14 \\
1.83 \\
1.92 \\
2.22 \\
.77 \\
.77\end{array}$ & $\begin{array}{l}11.93 \\
12.46 \\
12.28 \\
12.63 \\
12.24 \\
12.88 \\
10.77 \\
10.77\end{array}$ & $\begin{array}{l}174.7 \\
185.2 \\
203.7 \\
181.1 \\
113.3 \\
134.7 \\
151.2 \\
151.2\end{array}$ & $\begin{array}{l}42.14 \\
44.92 \\
49.02 \\
44.65 \\
27.31 \\
32.86 \\
36.02 \\
36.02\end{array}$ \\
\hline 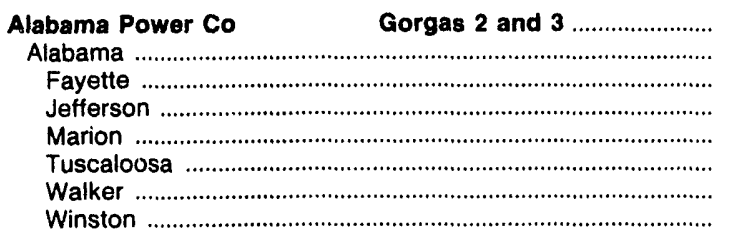 & $\begin{array}{r}6,595 \\
6,595 \\
4 \\
1,510 \\
30 \\
635 \\
4,265 \\
150\end{array}$ & $\begin{array}{l}11,828 \\
11,828 \\
12,161 \\
12,032 \\
11,638 \\
11,837 \\
11,746 \\
12,085\end{array}$ & $\begin{array}{l}1.33 \\
1.33 \\
1.85 \\
1.72 \\
1.57 \\
1.81 \\
1.12 \\
1.41\end{array}$ & $\begin{array}{l}13.51 \\
13.51 \\
11.70 \\
13.25 \\
13.11 \\
13.17 \\
13.73 \\
11.50\end{array}$ & $\begin{array}{l}172.0 \\
172.0 \\
114.7 \\
159.8 \\
110.7 \\
119.3 \\
185.4 \\
156.6\end{array}$ & $\begin{array}{l}40.69 \\
40.69 \\
27.90 \\
38.45 \\
25.77 \\
28.24 \\
43.56 \\
37.85\end{array}$ \\
\hline 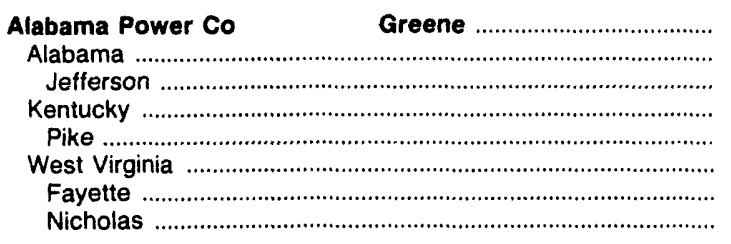 & $\begin{array}{r}1,345 \\
346 \\
346 \\
414 \\
414 \\
585 \\
566 \\
19\end{array}$ & $\begin{array}{l}12,221 \\
12,158 \\
12,158 \\
12,277 \\
12,277 \\
12,218 \\
12,238 \\
11,600\end{array}$ & $\begin{array}{l}1.47 \\
1.72 \\
1.72 \\
1.34 \\
1.34 \\
1.42 \\
1.40 \\
2.04\end{array}$ & $\begin{array}{r}9.51 \\
12.19 \\
12.19 \\
8.28 \\
8.28 \\
8.80 \\
8.61 \\
14.35\end{array}$ & $\begin{array}{l}139.9 \\
153.2 \\
153.2 \\
136.2 \\
136.2 \\
134.8 \\
135.1 \\
122.3\end{array}$ & $\begin{array}{l}34.20 \\
37.26 \\
37.26 \\
33.44 \\
33.44 \\
32.93 \\
33.08 \\
28.37\end{array}$ \\
\hline $\begin{array}{l}\text { Alabama Power Co } \\
\text { Alabama . James Miller } \\
\text { Jefferson } \\
\text { Tuscaloosa } \\
\text { Kalker } \\
\text { Kntucky } \\
\text { West Virginia } \\
\text { Boone }\end{array}$ & $\begin{array}{r}4,359 \\
4,336 \\
2,001 \\
932 \\
1,402 \\
16 \\
16 \\
8 \\
8\end{array}$ & $\begin{array}{l}12,392 \\
12,393 \\
12,292 \\
12,536 \\
12,442 \\
12,441 \\
12,441 \\
11,813 \\
11,813\end{array}$ & $\begin{array}{l}.60 \\
.60 \\
.53 \\
.67 \\
.66 \\
.72 \\
.72 \\
.66 \\
.66\end{array}$ & $\begin{array}{r}11.09 \\
11.09 \\
11.66 \\
11.18 \\
10.21 \\
9.30 \\
9.30 \\
13.30 \\
13.30\end{array}$ & $\begin{array}{l}253.7 \\
254.3 \\
228.0 \\
245.5 \\
297.2 \\
153.4 \\
153.4 \\
146.8 \\
146.8\end{array}$ & $\begin{array}{l}62.88 \\
63.02 \\
56.04 \\
61.55 \\
73.97 \\
38.17 \\
38.17 \\
34.68 \\
34.68\end{array}$ \\
\hline $\begin{array}{l}\text { American Mun Power Ohio Inc } \quad \text { Richard Gorsuch } \\
\text { Ohio } \\
\text { Noble }\end{array}$ & $\begin{array}{l}891 \\
891 \\
891\end{array}$ & $\begin{array}{l}11,337 \\
11,337 \\
11,337\end{array}$ & $\begin{array}{l}4.55 \\
4.55 \\
4.55\end{array}$ & $\begin{array}{l}14.59 \\
14.59 \\
14.59\end{array}$ & $\begin{array}{l}96.9 \\
96.9 \\
96.9\end{array}$ & $\begin{array}{l}21.96 \\
21.96 \\
21.96\end{array}$ \\
\hline $\begin{array}{c}\text { Ames City of } \\
\text { Wyoming } \\
\text { Campbell }\end{array}$ & $\begin{array}{l}156 \\
156 \\
156\end{array}$ & $\begin{array}{l}8,762 \\
8,762 \\
8,762\end{array}$ & $\begin{array}{l}.19 \\
.19 \\
.19\end{array}$ & $\begin{array}{l}4.59 \\
4.59 \\
4.59\end{array}$ & $\begin{array}{l}132.8 \\
132.8 \\
132.8\end{array}$ & $\begin{array}{l}23.28 \\
23.28 \\
23.28\end{array}$ \\
\hline $\begin{array}{l}\text { Appalachian Power Co } \\
\text { West Virginia } \\
\text { Boone } \\
\text { Logan } \\
\text { Raleigh }\end{array}$ & $\begin{array}{r}4,244 \\
4,244 \\
3,737 \\
276 \\
228\end{array}$ & $\begin{array}{l}12,378 \\
12,378 \\
12,310 \\
12,302 \\
13,592\end{array}$ & $\begin{array}{l}.79 \\
.79 \\
.79 \\
.72 \\
.80\end{array}$ & $\begin{array}{r}11.27 \\
11.27 \\
11.46 \\
11.56 \\
7.69\end{array}$ & $\begin{array}{l}193.5 \\
193.5 \\
194.4 \\
173.8 \\
201.3\end{array}$ & $\begin{array}{l}47.90 \\
47.90 \\
47.87 \\
42.76 \\
54.72\end{array}$ \\
\hline 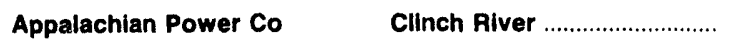 & 1,703 & 12,582 & .75 & 12.79 & 128.6 & 32.35 \\
\hline
\end{tabular}

See footnotes at end of table.

Source: Federal Energy Regulatory Commission, FERC Form 423, "Monthly Report of Cost and Quality of Fuels for Electric Plants." 
Table 24. Origin of Coal Recelved by Electric Utillty and Plant, 1992 (Continued)

\begin{tabular}{|c|c|c|c|c|c|c|}
\hline \multirow[b]{2}{*}{$\begin{array}{l}\text { Electric Utility Plant } \\
\text { Origin state } \\
\text { County }\end{array}$} & \multirow[b]{2}{*}{$\begin{array}{l}\text { Quantity } \\
\text { (thoueand } \\
\text { short tons) }\end{array}$} & \multicolumn{3}{|c|}{ Average Quallty } & \multicolumn{2}{|c|}{ Average Dellvered Cost } \\
\hline & & $\begin{array}{c}\text { Btu } \\
\text { (per pound) }\end{array}$ & $\begin{array}{l}\text { sulfur } \\
\text { (porcent } \\
\text { by wetght) }\end{array}$ & $\begin{array}{l}\text { Ach } \\
\text { (percent } \\
\text { by wolght) }\end{array}$ & $\begin{array}{l}\text { (cente por } \\
\text { million Btu) }\end{array}$ & $\begin{array}{l}\text { (dollare per } \\
\text { chort ton) }\end{array}$ \\
\hline Appalachian Power Co $\quad$ Clinch River & & & & & & \\
\hline 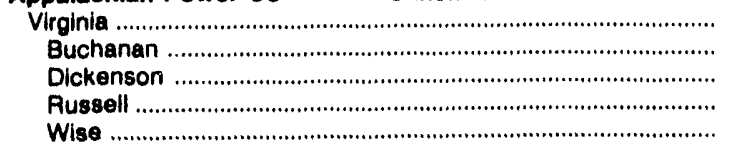 & $\begin{array}{r}1,703 \\
7 \\
828 \\
613 \\
255\end{array}$ & $\begin{array}{l}12,582 \\
12,629 \\
12,584 \\
12,456 \\
12,876\end{array}$ & $\begin{array}{r}0.75 \\
.85 \\
.73 \\
.74 \\
.86\end{array}$ & $\begin{array}{r}12.79 \\
12.36 \\
12.88 \\
13.80 \\
8.84\end{array}$ & $\begin{array}{l}128.6 \\
119.5 \\
131.6 \\
128.2 \\
120.0\end{array}$ & $\begin{array}{l}32.35 \\
30.19 \\
33.13 \\
31.93 \\
30.90\end{array}$ \\
\hline 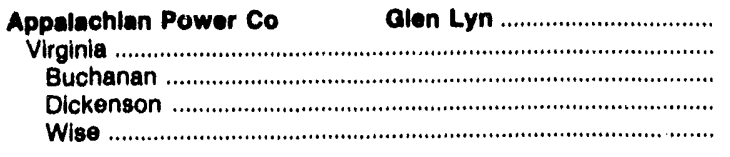 & $\begin{array}{r}452 \\
452 \\
164 \\
3 \\
285\end{array}$ & $\begin{array}{l}12,880 \\
12,889 \\
12,675 \\
12,457 \\
13,017\end{array}$ & $\begin{array}{l}.01 \\
.91 \\
.86 \\
.89 \\
.83\end{array}$ & $\begin{array}{r}10.13 \\
10.13 \\
11.76 \\
10.90 \\
9.18\end{array}$ & $\begin{array}{l}138.6 \\
138.6 \\
130.9 \\
131.1 \\
143.0\end{array}$ & $\begin{array}{l}35.72 \\
35.72 \\
33.19 \\
32.66 \\
37.22\end{array}$ \\
\hline $\begin{array}{l}\text { Appalechian Power Co Kanawha Alver } \\
\text { West Virginia } \\
\text { Fayette } \\
\text { Kanawha }\end{array}$ & $\begin{array}{r}388 \\
368 \\
298 \\
70\end{array}$ & $\begin{array}{l}12,578 \\
12,578 \\
12,612 \\
12,434\end{array}$ & $\begin{array}{l}.80 \\
.80 \\
.80 \\
.70\end{array}$ & $\begin{array}{l}11.49 \\
11.49 \\
11.25 \\
12.52\end{array}$ & $\begin{array}{l}172.6 \\
172.6 \\
172.5 \\
172.8\end{array}$ & $\begin{array}{l}43.41 \\
43.41 \\
43.51 \\
43.01\end{array}$ \\
\hline 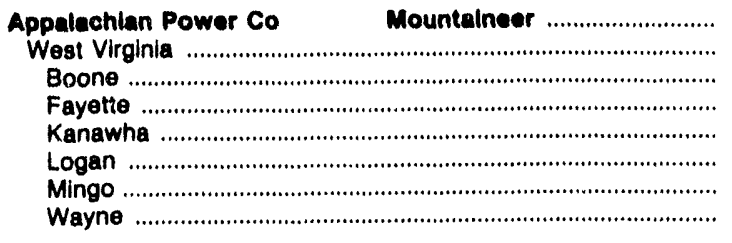 & $\begin{array}{r}2,289 \\
2,289 \\
1,646 \\
10 \\
36 \\
312 \\
47 \\
238\end{array}$ & $\begin{array}{l}12,523 \\
12,523 \\
12,561 \\
12,590 \\
12,584 \\
12,637 \\
12,412 \\
12,117\end{array}$ & $\begin{array}{l}.68 \\
.68 \\
.70 \\
.66 \\
.68 \\
.68 \\
.53 \\
.60\end{array}$ & $\begin{array}{r}10.37 \\
10.37 \\
10.52 \\
11.89 \\
11.16 \\
9.64 \\
10.91 \\
10.01\end{array}$ & $\begin{array}{l}171.4 \\
171.4 \\
186.3 \\
131.6 \\
130.0 \\
131.2 \\
150.0 \\
132.5\end{array}$ & $\begin{array}{l}42.93 \\
42.93 \\
46.80 \\
33.13 \\
32.71 \\
33.17 \\
37.23 \\
32.12\end{array}$ \\
\hline 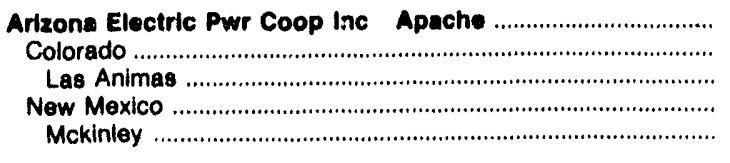 & $\begin{array}{r}205 \\
119 \\
119 \\
86 \\
86\end{array}$ & $\begin{array}{r}11,260 \\
12,158 \\
12,158 \\
9,984 \\
9,984\end{array}$ & $\begin{array}{l}.42 \\
.41 \\
.41 \\
.43 \\
.43\end{array}$ & $\begin{array}{l}14.37 \\
15.76 \\
15.76 \\
12.42 \\
12.42\end{array}$ & $\begin{array}{l}162.8 \\
167.5 \\
167.5 \\
127.7 \\
127.7\end{array}$ & $\begin{array}{l}34.37 \\
40.74 \\
40.74 \\
25.50 \\
25.50\end{array}$ \\
\hline $\begin{array}{l}\text { Arizona Publlc Service Co Cholla } \\
\text { New Mexico } \\
\text { Colfax } \\
\text { Mckinley }\end{array}$ & $\begin{array}{l}3,730 \\
3,730 \\
3,730\end{array}$ & $\begin{array}{r}9,816 \\
9,816 \\
12,865 \\
9,816\end{array}$ & $\begin{array}{l}.44 \\
.44 \\
.56 \\
.44\end{array}$ & $\begin{array}{r}13.89 \\
13.89 \\
9.20 \\
13.89\end{array}$ & $\begin{array}{r}144.9 \\
144.9 \\
69.6 \\
144.9\end{array}$ & $\begin{array}{l}28.44 \\
28.44 \\
17.91 \\
28.44\end{array}$ \\
\hline 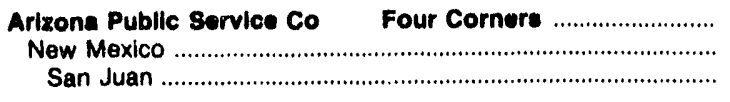 & $\begin{array}{l}8,935 \\
8,835 \\
8,935\end{array}$ & $\begin{array}{l}8,808 \\
8,808 \\
8,808\end{array}$ & $\begin{array}{l}.79 \\
.79 \\
.79\end{array}$ & $\begin{array}{l}22.14 \\
22.14 \\
22.14\end{array}$ & $\begin{array}{l}106.7 \\
106.7 \\
106.7\end{array}$ & $\begin{array}{l}18.79 \\
18.79 \\
18.79\end{array}$ \\
\hline $\begin{array}{c}\text { Arkaneas Power \& Light Co Independence } \\
\text { Wyoming } \\
\text { Campbell }\end{array}$ & $\begin{array}{l}5,014 \\
5,014 \\
5,014\end{array}$ & $\begin{array}{l}8,843 \\
8,843 \\
8,843\end{array}$ & $\begin{array}{l}.21 \\
.21 \\
.21\end{array}$ & $\begin{array}{l}4.71 \\
4.71 \\
4.71\end{array}$ & $\begin{array}{l}161.0 \\
181.0 \\
161.0\end{array}$ & $\begin{array}{l}28.47 \\
28.47 \\
28.47\end{array}$ \\
\hline $\begin{array}{c}\text { Arkanana Power Light Co } \\
\text { Wyoming } \\
\text { Campbell }\end{array}$ & $\begin{array}{l}4,953 \\
4,953 \\
4,953\end{array}$ & $\begin{array}{l}8,730 \\
8,730 \\
8,730\end{array}$ & $\begin{array}{l}.43 \\
.43 \\
.43\end{array}$ & $\begin{array}{l}5.70 \\
5.70 \\
5.70\end{array}$ & $\begin{array}{l}173.0 \\
173.0 \\
173.0\end{array}$ & $\begin{array}{l}30.21 \\
30.21 \\
30.21\end{array}$ \\
\hline 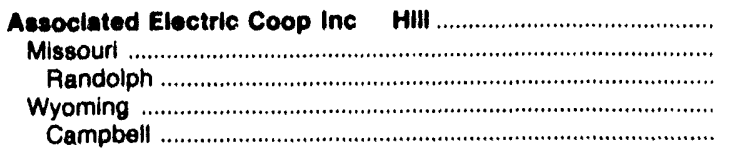 & $\begin{array}{r}2,622 \\
2,506 \\
2,506 \\
116 \\
116\end{array}$ & $\begin{array}{r}10,480 \\
10,555 \\
10,555 \\
8,844 \\
8,844\end{array}$ & $\begin{array}{r}4.01 \\
4.19 \\
4.19 \\
.21 \\
.21\end{array}$ & $\begin{array}{r}0.04 \\
10.19 \\
10.19 \\
4.57 \\
4.57\end{array}$ & $\begin{array}{l}163.2 \\
164.8 \\
164.8 \\
121.8 \\
121.8\end{array}$ & $\begin{array}{l}34.20 \\
34.79 \\
34.79 \\
21.54 \\
21.54\end{array}$ \\
\hline $\begin{array}{l}\text { Assoclated Electric Coop Inc } \\
\text { Illinois } \\
\text { Pandolph } \\
\text { Indiana } \\
\text { Warrick } \\
\text { Kentucky } \\
\text { Muhlenberg }\end{array}$ & $\begin{array}{r}2,732 \\
2,121 \\
2,121 \\
63 \\
63 \\
548 \\
548\end{array}$ & $\begin{array}{l}10,890 \\
10,682 \\
10,682 \\
11,279 \\
11,279 \\
11,651 \\
11,651\end{array}$ & $\begin{array}{l}3.08 \\
2.93 \\
2.83 \\
3.03 \\
3.03 \\
3.56 \\
3.56\end{array}$ & $\begin{array}{r}9.74 \\
10.19 \\
10.19 \\
8.50 \\
8.50 \\
8.15 \\
8.15\end{array}$ & $\begin{array}{l}116.0 \\
115.4 \\
115.4 \\
108.8 \\
109.9 \\
118.7 \\
118.7\end{array}$ & $\begin{array}{l}25.25 \\
24.65 \\
24.65 \\
24.79 \\
24.79 \\
27.66 \\
27.66\end{array}$ \\
\hline $\begin{array}{l}\text { Atlantic Clty Electric Co } \quad \text { Deepwater } \\
\text { West Virginla } \\
\text { Nicholas } \\
\text { Webster }\end{array}$ & $\begin{array}{r}143 \\
143 \\
38 \\
106\end{array}$ & $\begin{array}{l}12,704 \\
12,704 \\
12,630 \\
12,730\end{array}$ & $\begin{array}{l}.77 \\
.77 \\
.82 \\
.75\end{array}$ & $\begin{array}{l}10.34 \\
10.34 \\
10.26 \\
10.37\end{array}$ & $\begin{array}{l}176.9 \\
176.9 \\
171.6 \\
178.7\end{array}$ & $\begin{array}{l}44.94 \\
44.94 \\
43.34 \\
45.51\end{array}$ \\
\hline 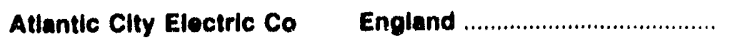 & 652 & 13,020 & 2.42 & 8.01 & 165.7 & 43.18 \\
\hline
\end{tabular}

See footnotes at end of table.

Source: Federal Energy Regulatory Commission, FERC Form 423, "Monthly Report of Cost and Quality of Fuels for Electric Plants." 
Table 24. Origin of Coal Received by Electric Utility and Plant, 1992 (Continued)

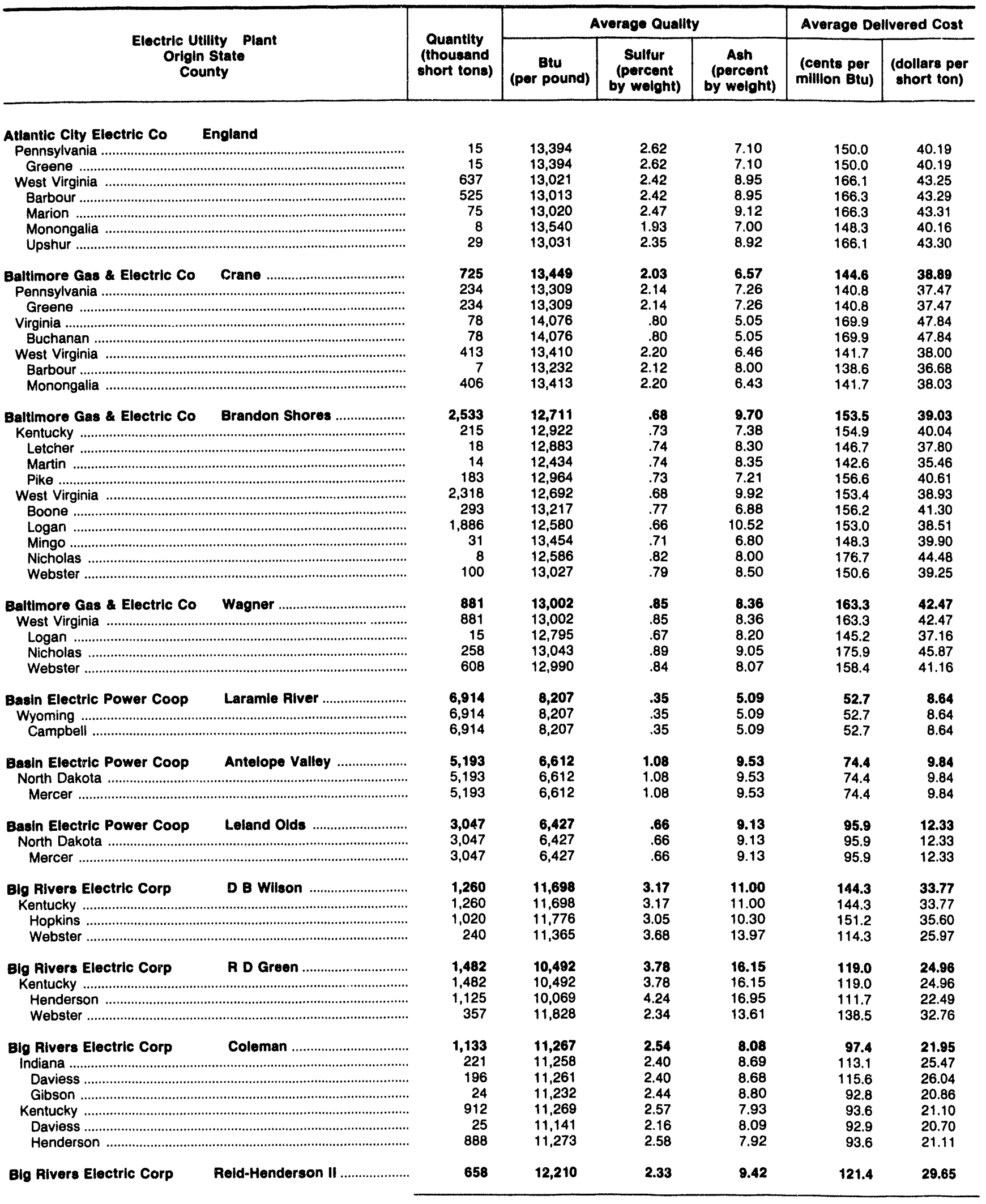

See footnotes at end of table.

Source: Federal Energy Regulatory Commission, FERC Form 423, "Monthly Report of Cost and Quality of Fuels for Electric Plants." 
Table 24. Origin of Coal Recelved by Electrlc Utility and Plant, 1992 (Continued)

\begin{tabular}{|c|c|c|c|c|c|c|}
\hline \multirow{2}{*}{$\begin{array}{c}\text { Electric Utility Plant } \\
\text { Origin State } \\
\text { County }\end{array}$} & \multirow{2}{*}{$\begin{array}{l}\text { Quantlly } \\
\text { (thousand } \\
\text { short tons) }\end{array}$} & \multicolumn{3}{|c|}{ Average Quallty } & \multicolumn{2}{|c|}{ Average Dellvered Cost } \\
\hline & & Btu & $\begin{array}{l}\text { Sulfur } \\
\text { (percent }\end{array}$ & $\begin{array}{c}\text { Ash } \\
\text { (percent }\end{array}$ & (cents per & (dollare per \\
\hline \multicolumn{7}{|l|}{ Elg Rlvers Eloctric Corp Aeld-Henderson II } \\
\hline Indlana & 140 & 11,240 & 2.54 & 7.77 & 104.4 & 23.47 \\
\hline 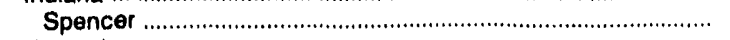 & 140 & 11,240 & 2.54 & 7.77 & 104.4 & 23.47 \\
\hline 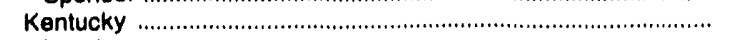 & 518 & 12,472 & 2.28 & 9.86 & 125.6 & 31.32 \\
\hline 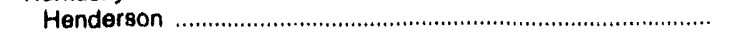 & 20 & 11,329 & 2.63 & 7.84 & 90.0 & 20.39 \\
\hline 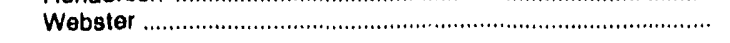 & 498 & 12,518 & 2.26 & 9.94 & 126.8 & 31.76 \\
\hline Cajun Electric Power Coop Inc Blg Cajun No.2 ...................... & 5,344 & 8,368 & .46 & 5.30 & 147.5 & 24.69 \\
\hline \multirow{2}{*}{$\begin{array}{l}\text { Wyoming } \\
\text { Campboll }\end{array}$} & 5,344 & 8,368 & .46 & 5.30 & 147.5 & 24.69 \\
\hline & 5,344 & 8,368 & .46 & 5.30 & 147.5 & 24.69 \\
\hline \multirow{2}{*}{$\begin{array}{l}\text { Cardinal Operating Co } \quad \text { Cardinal } \\
\text { Ohio }\end{array}$} & 1,277 & 11,842 & 2.16 & 12.88 & 148.0 & 35.08 \\
\hline & 1,086 & 12,211 & 3.17 & 11.29 & 133.5 & 32.59 \\
\hline 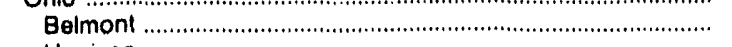 & 123 & 11,614 & 3.16 & 13.31 & 106.6 & 24.75 \\
\hline 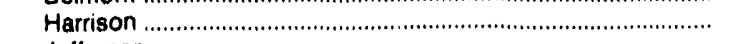 & 500 & 12,225 & 3.01 & 11.47 & 152.9 & 37.40 \\
\hline & 463 & 12,355 & 3.34 & 10.57 & 119.3 & 29.49 \\
\hline 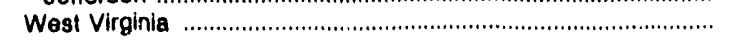 & 3,191 & 11,717 & 1.81 & 13.42 & 153.2 & 35.89 \\
\hline 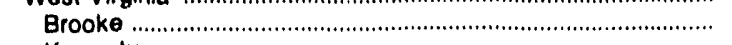 & 1,548 & 12,116 & 2.87 & 10.40 & 143.4 & 34.75 \\
\hline 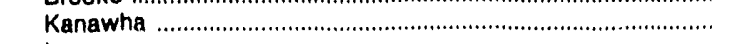 & 1,400 & 11,219 & .80 & 16.91 & 169.8 & 38.09 \\
\hline 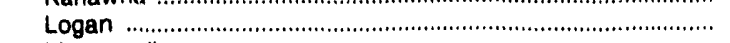 & 183 & 12,055 & .70 & 12.52 & 131.0 & 31.59 \\
\hline 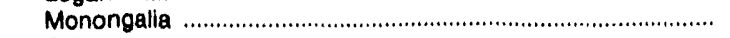 & 25 & 12,082 & 1.10 & 12.47 & 108.7 & 26.28 \\
\hline Ohio . . & 11 & 11.680 & 2.83 & 12.33 & 135.5 & 31.65 \\
\hline 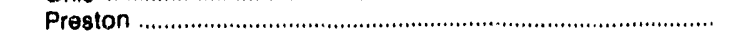 & 25 & 12,082 & 1.10 & 12.47 & 108.7 & 26.28 \\
\hline 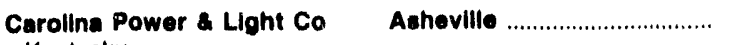 & 789 & 13,080 & 1.18 & 8.80 & 133.1 & 34.82 \\
\hline 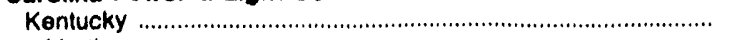 & 40 & 12,822 & .96 & 8.10 & 203.9 & 52.29 \\
\hline Martin & 40 & 12,822 & .96 & 8.10 & 203.8 & 52.20 \\
\hline Virginia & 749 & 13,094 & 1.19 & 8.84 & 129.4 & 33.88 \\
\hline 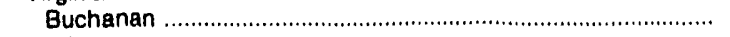 & 16 & 13.095 & 1.21 & 7.19 & 145.5 & 38.11 \\
\hline Wise & 733 & 13,094 & 1.19 & 8.87 & 129.0 & 33.79 \\
\hline Cape Foar ................................ & 427 & 12,788 & .97 & 8.64 & 197.1 & 50.40 \\
\hline 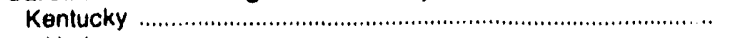 & 399 & 12,815 & .96 & 8.41 & 200.5 & 51.40 \\
\hline 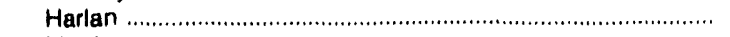 & 41 & 12,851 & .87 & 7.63 & 145.2 & 37.31 \\
\hline Martin & 303 & 12,790 & .96 & 8.39 & 211.5 & 54.11 \\
\hline Pike & 55 & 12,932 & 1.02 & 9.10 & 181.5 & 46.94 \\
\hline Virginia & 22 & 12,417 & 1.18 & 12.06 & 145.4 & 36.12 \\
\hline Wise & 22 & 12,417 & 1.18 & 12.06 & 145.4 & 36.12 \\
\hline 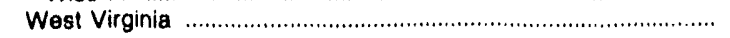 & 6 & 12,297 & .85 & 11.45 & 148.1 & 36.43 \\
\hline Fayette & 6 & 12,297 & .85 & 11.45 & 148.1 & 36.43 \\
\hline Carolina Power Llght Co & 580 & 12,680 & .98 & 9.12 & 190.9 & 48.40 \\
\hline 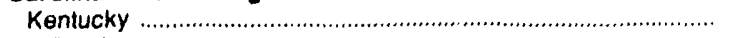 & 402 & 12,823 & 1.02 & 8.29 & 207.2 & 53.13 \\
\hline Floyd & 14 & 12,550 & .85 & 8.60 & 150.3 & 37.73 \\
\hline 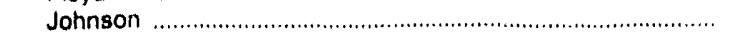 & 11 & 12,142 & 1.24 & 10.60 & 151.7 & 36.84 \\
\hline Martin & 364 & 12,855 & 1.02 & 8.17 & 211.5 & 54.37 \\
\hline 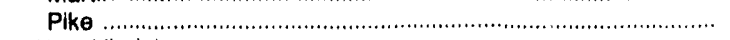 & 13 & 12,800 & .97 & 9.48 & 193.1 & 49.43 \\
\hline 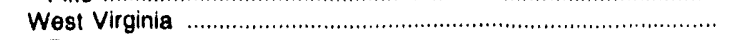 & 1,7 & 12,356 & .90 & 11.00 & 152.4 & 37.66 \\
\hline Boone & 44 & 12,630 & .93 & 11.36 & 166.2 & 41.98 \\
\hline 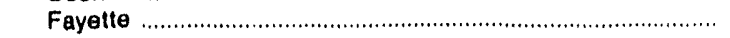 & 4 & 12,788 & .87 & 9.80 & 147.9 & 37.83 \\
\hline Logan & 106 & 12,187 & .88 & 11.21 & 140.8 & 34.32 \\
\hline Mingo (1) & 22 & 12,526 & .94 & 9.54 & 179.4 & 44.83 \\
\hline 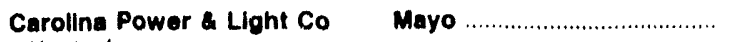 & 1,585 & 12,071 & .64 & 11.76 & 186.7 & 45.08 \\
\hline 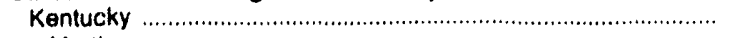 & 10 & 12,209 & .67 & 7.90 & 164.9 & 40.27 \\
\hline Martin & 10 & 12,209 & .67 & 7.90 & 164.9 & 40.27 \\
\hline 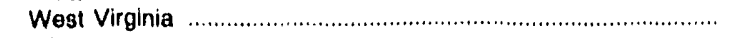 & 1,585 & 12,070 & .64 & 11.79 & 186.8 & 45.11 \\
\hline Logan & 39 & 12,869 & .72 & 10.14 & 137.0 & 35.27 \\
\hline 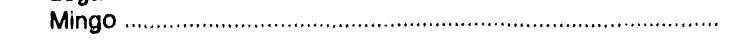 & 1,546 & 12,050 & 64 & 11.83 & 188.2 & 45.36 \\
\hline Roblnson ................................. & 271 & 12,448 & 1.05 & 9.16 & 171.4 & 42.67 \\
\hline 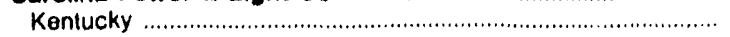 & 195 & 12.526 & 1.07 & 9.12 & 167.5 & 41.96 \\
\hline Harlan & 55 & 12,535 & 1.04 & 0.01 & 162.3 & 40.69 \\
\hline 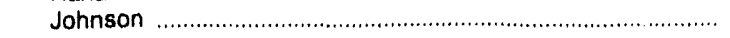 & 1 & 12,000 & 1.00 & 12.00 & 156.4 & 37.54 \\
\hline 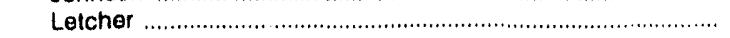 & 16 & 12,371 & .98 & 9.70 & 158.2 & 39.14 \\
\hline 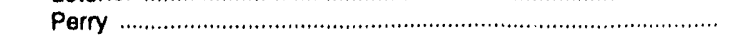 & 15 & 13,112 & .84 & 7.00 & 151.3 & 39.68 \\
\hline Pike & 108 & 12,468 & 1.13 & 9.35 & 173.9 & 43.37 \\
\hline
\end{tabular}

Soe footnotes at end of table.

Source: Federat Enorgy Regulatory Commission, FEAC Form 423, "Monthly Report of Cost and Quality of Fuels tor Electric Plants." 
Table 24. Origin of Coal Received by Electric Utility and Plant, 1992 (Continued)

\begin{tabular}{|c|c|c|c|c|c|c|}
\hline \multirow[b]{2}{*}{$\begin{array}{l}\text { Electric Utility Plant } \\
\text { Origln State } \\
\text { County }\end{array}$} & \multirow[b]{2}{*}{$\begin{array}{l}\text { Quantity } \\
\text { (thousand } \\
\text { short tons) }\end{array}$} & \multicolumn{3}{|c|}{ Average Quallty } & \multicolumn{2}{|c|}{ Average Dellvered Cost } \\
\hline & & $\begin{array}{c}\text { Btu } \\
\text { (per pound) }\end{array}$ & $\begin{array}{l}\text { Sulfur } \\
\text { (percent }\end{array}$ & $\begin{array}{c}\text { Ash } \\
\text { (percent }\end{array}$ & $\begin{array}{l}\text { (cents per } \\
\text { million Btu) }\end{array}$ & $\begin{array}{l}\text { (dollars per } \\
\text { short ton) }\end{array}$ \\
\hline $\begin{array}{c}\text { Carolina Power Light Co Robinson } \\
\text { West Virginia } \\
\text { Boone } \\
\text { Mingo }\end{array}$ & $\begin{array}{l}76 \\
15 \\
61\end{array}$ & $\begin{array}{l}12,248 \\
12,308 \\
12,233\end{array}$ & $\begin{array}{r}0.99 \\
.95 \\
1.00\end{array}$ & $\begin{array}{r}9.28 \\
12.02 \\
8.60\end{array}$ & $\begin{array}{l}181.7 \\
164.8 \\
186.0\end{array}$ & $\begin{array}{l}44.52 \\
40.56 \\
45.50\end{array}$ \\
\hline $\begin{array}{l}\text { Carolina Power \& Light Co Roxboro } \\
\text { Kentucky . } \\
\text { Harlan } \\
\text { Martin } \\
\text { Pike } \\
\text { Virginia } \\
\text { Wise } \\
\text { West Virginia } \\
\text { Boone } \\
\text { Logan } \\
\text { Mingo }\end{array}$ & $\begin{array}{r}5,737 \\
2,375 \\
10 \\
2,335 \\
30 \\
98 \\
98 \\
3,264 \\
1,540 \\
70 \\
1,654\end{array}$ & $\begin{array}{l}12,364 \\
12,618 \\
12,691 \\
12,624 \\
12,131 \\
12,393 \\
12,393 \\
12,178 \\
12,258 \\
12,965 \\
12,071\end{array}$ & $\begin{array}{r}.86 \\
.94 \\
1.28 \\
.94 \\
.49 \\
1.03 \\
1.03 \\
.79 \\
.89 \\
.72 \\
.71\end{array}$ & $\begin{array}{r}10.47 \\
8.36 \\
8.80 \\
8.31 \\
12.00 \\
12.56 \\
12.56 \\
11.94 \\
12.88 \\
9.54 \\
11.16\end{array}$ & $\begin{array}{l}173.5 \\
180.5 \\
146.4 \\
181.2 \\
137.5 \\
135.1 \\
135.1 \\
169.5 \\
158.9 \\
137.7 \\
180.9\end{array}$ & $\begin{array}{l}42.92 \\
45.56 \\
37.16 \\
45.75 \\
33.36 \\
33.49 \\
33.49 \\
41.28 \\
38.95 \\
35.71 \\
43.68\end{array}$ \\
\hline $\begin{array}{l}\text { Carolina Power \& Light Co } \\
\text { Kentucky } \\
\text { Breathitt . Sutton } \\
\text { Floyd . } \\
\text { Harlan . } \\
\text { Letcher } \\
\text { Perry } \\
\text { Pike } \\
\text { Best Virginia } \\
\text { Loone } \\
\text { Mingo }\end{array}$ & $\begin{array}{r}767 \\
434 \\
43 \\
61 \\
68 \\
163 \\
36 \\
63 \\
332 \\
159 \\
146 \\
27\end{array}$ & $\begin{array}{l}12,436 \\
12,498 \\
11,939 \\
12,577 \\
12,807 \\
12,353 \\
13,124 \\
12,486 \\
12,354 \\
12,423 \\
12,299 \\
12,249\end{array}$ & $\begin{array}{r}.93 \\
.94 \\
.85 \\
.89 \\
1.03 \\
.94 \\
.87 \\
1.01 \\
.90 \\
.89 \\
.92 \\
.91\end{array}$ & $\begin{array}{r}10.36 \\
9.57 \\
9.98 \\
8.88 \\
8.63 \\
10.57 \\
6.80 \\
9.93 \\
11.40 \\
11.60 \\
11.73 \\
8.53\end{array}$ & $\begin{array}{l}155.1 \\
152.9 \\
152.6 \\
149.7 \\
156.1 \\
152.6 \\
155.7 \\
151.8 \\
157.9 \\
163.2 \\
146.7 \\
186.5\end{array}$ & $\begin{array}{l}38.57 \\
38.22 \\
36.44 \\
37.67 \\
39.99 \\
37.71 \\
46.87 \\
37.90 \\
39.02 \\
40.56 \\
36.08 \\
45.69\end{array}$ \\
\hline $\begin{array}{l}\text { Carolina Power \& LIght Co } \\
\text { Kentucky } \\
\text { Breathitt .... } \\
\text { Clay . } \\
\text { Harlan } \\
\text { Johnson } \\
\text { Letcher } \\
\text { Pike } \\
\text { Tennessee } \\
\text { Campbell } \\
\text { West Virginia } \\
\text { Boone }\end{array}$ & $\begin{array}{r}238 \\
201 \\
33 \\
2 \\
61 \\
3 \\
8 \\
95 \\
8 \\
8 \\
29 \\
29\end{array}$ & $\begin{array}{l}12,412 \\
12,402 \\
11,802 \\
11,551 \\
12,697 \\
11,632 \\
12,093 \\
12,485 \\
12,617 \\
12,617 \\
12,424 \\
12,424\end{array}$ & $\begin{array}{r}1.07 \\
1.08 \\
1.05 \\
1.19 \\
1.05 \\
1.09 \\
.92 \\
1.13 \\
1.29 \\
1.29 \\
.91 \\
.91\end{array}$ & $\begin{array}{r}9.95 \\
9.70 \\
9.81 \\
15.20 \\
9.16 \\
14.10 \\
11.30 \\
9.64 \\
7.30 \\
7.30 \\
12.43 \\
12.43\end{array}$ & $\begin{array}{l}162.1 \\
160.6 \\
152.4 \\
160.0 \\
162.3 \\
155.6 \\
150.2 \\
163.2 \\
153.2 \\
153.2 \\
174.9 \\
174.9\end{array}$ & $\begin{array}{l}40.23 \\
39.83 \\
35.96 \\
36.96 \\
41.21 \\
36.20 \\
36.34 \\
40.74 \\
38.66 \\
38.66 \\
43.46 \\
43.46\end{array}$ \\
\hline 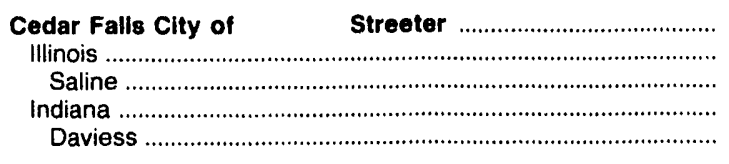 & $\begin{array}{r}10 \\
1 \\
1 \\
9 \\
9\end{array}$ & $\begin{array}{l}11,188 \\
12,200 \\
12,200 \\
11,022 \\
11,022\end{array}$ & $\begin{array}{l}2.72 \\
2.20 \\
2.20 \\
2.80 \\
2.80\end{array}$ & $\begin{array}{l}9.11 \\
8.00 \\
8.00 \\
9.30 \\
9.30\end{array}$ & $\begin{array}{l}140.9 \\
162.9 \\
162.9 \\
136.9 \\
136.9\end{array}$ & $\begin{array}{l}31.54 \\
39.75 \\
39.75 \\
30.19 \\
30.19\end{array}$ \\
\hline 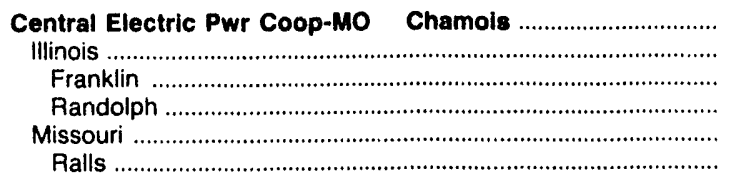 & $\begin{array}{r}83 \\
15 \\
2 \\
13 \\
68 \\
68\end{array}$ & $\begin{array}{r}10,971 \\
10,905 \\
9,969 \\
11,049 \\
10,986 \\
10,986\end{array}$ & $\begin{array}{l}3.14 \\
2.85 \\
1.90 \\
3.00 \\
3.20 \\
3.20\end{array}$ & $\begin{array}{r}9.90 \\
9.83 \\
13.90 \\
9.20 \\
9.92 \\
9.92\end{array}$ & $\begin{array}{r}118.5 \\
126.0 \\
83.7 \\
131.9 \\
116.9 \\
116.9\end{array}$ & $\begin{array}{l}26.00 \\
27.48 \\
16.68 \\
29.14 \\
25.67 \\
25.67\end{array}$ \\
\hline $\begin{array}{l}\text { Central Hudson Gas \& Elec Corp Danskammer } \\
\text { Kentucky . } \\
\text { Martin . } \\
\text { Pike } \\
\text { West Virginia } \\
\text { Mingo }\end{array}$ & $\begin{array}{r}881 \\
62 \\
59 \\
2 \\
820 \\
82.0\end{array}$ & $\begin{array}{l}13,018 \\
12,983 \\
12,986 \\
12,896 \\
13,021 \\
13,021\end{array}$ & $\begin{array}{l}.59 \\
.64 \\
.64 \\
.51 \\
.59 \\
.59\end{array}$ & $\begin{array}{l}7.50 \\
6.62 \\
6.55 \\
8.29 \\
7.56 \\
7.56\end{array}$ & $\begin{array}{l}182.1 \\
185.4 \\
184.4 \\
209.2 \\
181.8 \\
181.8\end{array}$ & $\begin{array}{l}47.40 \\
48.13 \\
47.90 \\
53.95 \\
47.35 \\
47.35\end{array}$ \\
\hline 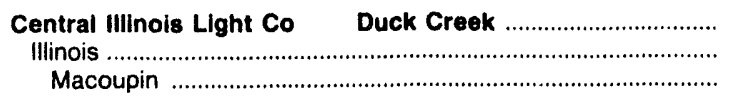 & $\begin{array}{l}1,014 \\
1,014 \\
1,014\end{array}$ & $\begin{array}{l}10,730 \\
10,730 \\
10,730\end{array}$ & $\begin{array}{l}3.32 \\
3.32 \\
3.32\end{array}$ & $\begin{array}{l}7.93 \\
7.93 \\
7.93\end{array}$ & $\begin{array}{l}165.7 \\
165.7 \\
165.7\end{array}$ & $\begin{array}{l}35.57 \\
35.57 \\
35.57\end{array}$ \\
\hline Edwards & 1,253 & 12,947 & .91 & 6.47 & 169.7 & 43.94 \\
\hline
\end{tabular}

See footnotes at end of table.

Source: Federal Energy Regulatory Commission, FERC Form 423, "Monthly Report of Cost and Quality of Fuels for Electric Plants." 
Table 24. Origin of Coal Recelved by Electric Utility and Plant, 1992 (Continued)

\begin{tabular}{|c|c|c|c|c|c|c|}
\hline \multirow[b]{2}{*}{$\begin{array}{c}\text { Electric Utility Plant } \\
\text { Origin State } \\
\text { County }\end{array}$} & \multirow[b]{2}{*}{$\begin{array}{l}\text { Quantity } \\
\text { (thousand } \\
\text { ohort tons) }\end{array}$} & \multicolumn{3}{|c|}{ Average Quality } & \multicolumn{2}{|c|}{ Average Dellvered Coat } \\
\hline & & $\begin{array}{c}\text { Btu } \\
\text { (por pound) }\end{array}$ & $\begin{array}{l}\text { Sultur } \\
\text { (percent } \\
\text { by welght) }\end{array}$ & $\begin{array}{c}\text { Ash } \\
\text { (porcent } \\
\text { by welght) }\end{array}$ & $\begin{array}{l}\text { (cents per } \\
\text { million Etu) }\end{array}$ & $\begin{array}{l}\text { (dollare per } \\
\text { short ton) }\end{array}$ \\
\hline \multicolumn{7}{|l|}{ Central Illinols Light Co Edwards } \\
\hline Illinols & 184 & 10,556 & 2.89 & 9.41 & 149.2 & 31.50 \\
\hline Fulton & 97 & 10,413 & 2.55 & 10.78 & 137.5 & 28.63 \\
\hline 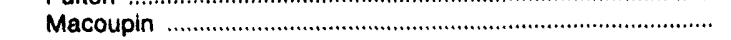 & 87 & 10,715 & 3.28 & 7.88 & 161.9 & 34.70 \\
\hline 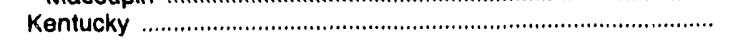 & 930 & 13,358 & .56 & 5.95 & 173.7 & 46.42 \\
\hline 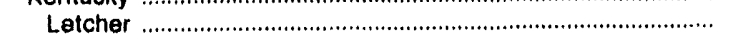 & 47 & 13,202 & .65 & 7.03 & 150.4 & 39.71 \\
\hline Porry fon & 62 & 13,353 & .58 & 5.64 & 164.5 & 43.94 \\
\hline 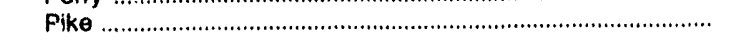 & 821 & 13,367 & .55 & 5.92 & 175.8 & 46.99 \\
\hline 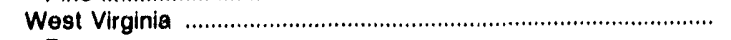 & 139 & 13,367 & .68 & 6.02 & 164.1 & 43.87 \\
\hline 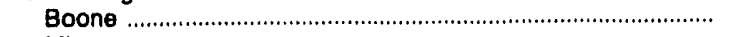 & 85 & 13,379 & .69 & 5.65 & 164.2 & 43.93 \\
\hline 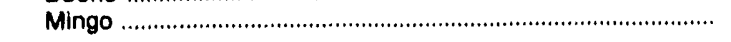 & 54 & 13,347 & .67 & 6.60 & 164.0 & 43.77 \\
\hline 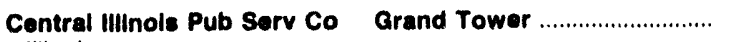 & 180 & 11,643 & 2.82 & 11.63 & 176.5 & 40.75 \\
\hline Illinois & 180 & 11,543 & 2.82 & 11.63 & 176.5 & 40.75 \\
\hline 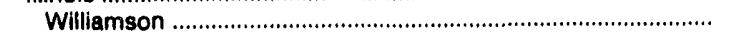 & 180 & 11,543 & 2.82 & 11.63 & 176.5 & 40.75 \\
\hline & 229 & 11,315 & $\begin{array}{l}2.27 \\
2.27\end{array}$ & 8.44 & 148.3 & 33.56 \\
\hline Indiana & $\begin{array}{l}229 \\
149\end{array}$ & $\begin{array}{l}11,315 \\
11,388\end{array}$ & $\begin{array}{l}2.27 \\
2.47\end{array}$ & $\begin{array}{l}8.44 \\
8.27\end{array}$ & $\begin{array}{l}148.3 \\
152.3\end{array}$ & $\begin{array}{l}33.56 \\
34.70\end{array}$ \\
\hline Greene & 56 & 11,358 & 2.38 & 8.36 & 145.7 & 33.09 \\
\hline 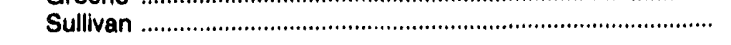 & 25 & 10.776 & .82 & 8.60 & 128.6 & 27.72 \\
\hline 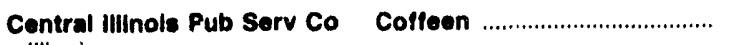 & 1,755 & 10,562 & 3.00 & 8.53 & 155.6 & 32.87 \\
\hline Illinois & 1,755 & 10,562 & 3.00 & 8.53 & 155.6 & 32.87 \\
\hline 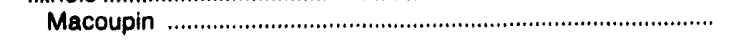 & 1,755 & 10,562 & 3.00 & 8.53 & 155.6 & 32.87 \\
\hline 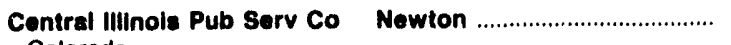 & 1,709 & 11,554 & 2.01 & 10.55 & 165.7 & 38.28 \\
\hline Colorado . & 376 & 12,058 & .47 & 8.38 & 139.9 & 33.73 \\
\hline 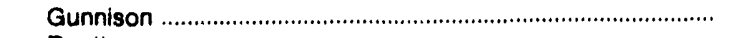 & 346 & 12,123 & .47 & 8.28 & 139.3 & 33.78 \\
\hline 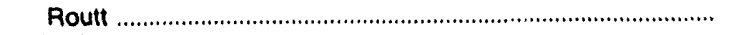 & 31 & 11,316 & .41 & 9.50 & 146.8 & 33.22 \\
\hline 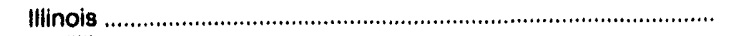 & 1,100 & 11,539 & 2.84 & 11.50 & 178.9 & 41.29 \\
\hline 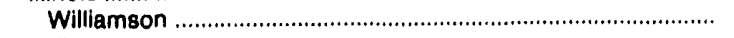 & 1,100 & 11,539 & 2.84 & 11.50 & 178.8 & 41.29 \\
\hline 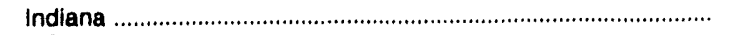 & 233 & 10,809 & .62 & 9.09 & 145.2 & 31.39 \\
\hline 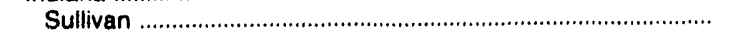 & 233 & 10,809 & .62 & 9.09 & 145.2 & 31.39 \\
\hline 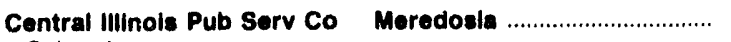 & 529 & 11,570 & 2.71 & 6.08 & 152.9 & 35.38 \\
\hline 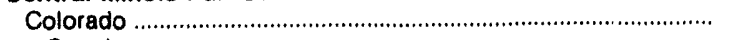 & 53 & 11,861 & .46 & 8.80 & 155.7 & 36.94 \\
\hline 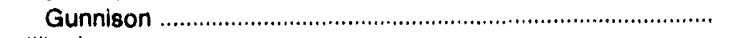 & 53 & 11,861 & .46 & 8.80 & 155.7 & 36.94 \\
\hline 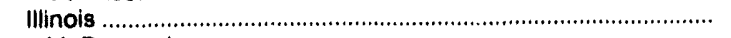 & 476 & 11,537 & 2.96 & 5.78 & 152.6 & 35.21 \\
\hline 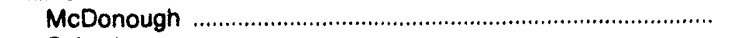 & 13 & 11,438 & 3.16 & 6.30 & 133.5 & 30.54 \\
\hline 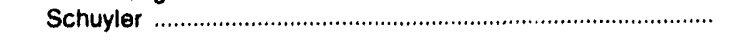 & 463 & 11,540 & 2.95 & 5.77 & 153.1 & 35.34 \\
\hline 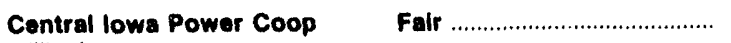 & 148 & 11,206 & 3.09 & 9.75 & 113.4 & 25.42 \\
\hline 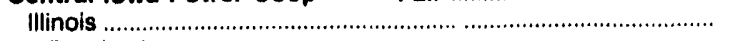 & 90 & 10.760 & 2.93 & 10.39 & 118.7 & 25.54 \\
\hline Randolph . . . . & 90 & 10,760 & 2.93 & 10.39 & 118.7 & 25.54 \\
\hline Indiana & 31 & 11,493 & 3.32 & 8.00 & 106.5 & 24.48 \\
\hline 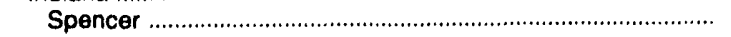 & 31 & 11.493 & 3.32 & 8.00 & 106.5 & 24.48 \\
\hline 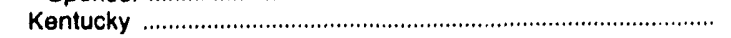 & 27 & 12,367 & 3.36 & 9.61 & 105.5 & 26.09 \\
\hline Hopkins & 27 & 12,367 & 3.36 & 9.61 & 105.5 & 26.09 \\
\hline 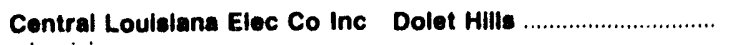 & 3,212 & 6,851 & .62 & 12.14 & 138.3 & 18.22 \\
\hline 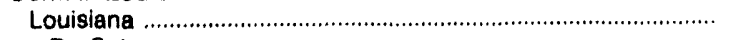 & 3.212 & 6,951 & .62 & 12.14 & 138.3 & 19.22 \\
\hline De Soto & 2,655 & 6,999 & .60 & 11.33 & 136.1 & 19.05 \\
\hline 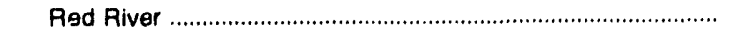 & 557 & 6,722 & .72 & 15.97 & 148.9 & 20.01 \\
\hline 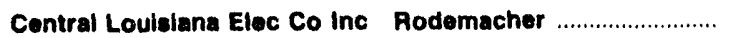 & 1,870 & 8,727 & .46 & 5.79 & 181.7 & 31.71 \\
\hline 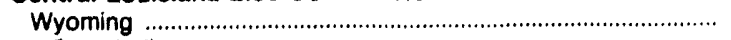 & 1,870 & 8,727 & .45 & 5.70 & 181.7 & 31.71 \\
\hline 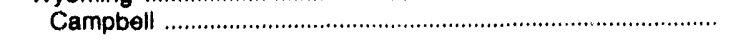 & 1,870 & 8,727 & .45 & 5.79 & 181.7 & 31.71 \\
\hline 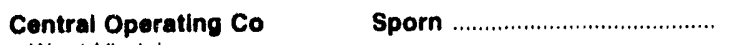 & 1,367 & 12,354 & 1.20 & 11.61 & 165.0 & 40.77 \\
\hline 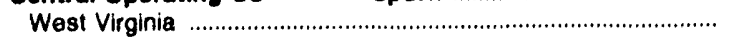 & 1,367 & 12,354 & 1.20 & 11.61 & 165.0 & 40.77 \\
\hline 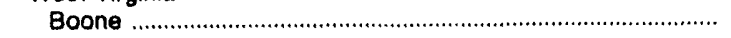 & 192 & $12,45 i$ & .82 & 11.13 & 214.2 & 53.35 \\
\hline 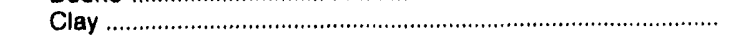 & 182 & 12,181 & 1.33 & 12.71 & 150.9 & 36.76 \\
\hline 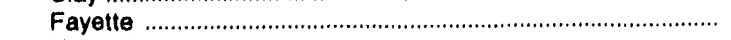 & 319 & 12,615 & 1.35 & 10.87 & 177.5 & 44.79 \\
\hline 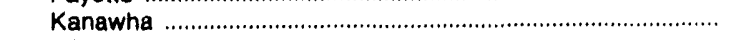 & 486 & 12,278 & 1.16 & 11.47 & 147.3 & 36.18 \\
\hline Mingo & 6 & 12,008 & .79 & 11.70 & 174.7 & 41.96 \\
\hline 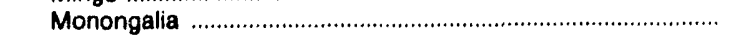 & 1 & 12,216 & 1.37 & 12.50 & 117.3 & 28.66 \\
\hline 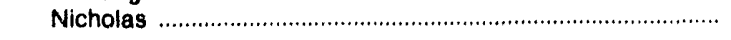 & 182 & 12,181 & 1.33 & 12.71 & 150.8 & 36.76 \\
\hline Coleto Creek ............................ & 1,860 & 10,978 & .40 & 6.37 & 203.5 & 44.68 \\
\hline
\end{tabular}

See footnotes at end of table.

Source: Federal Energy Regulatory Commission, FERC Form 423, "Monthly Report of Cost and Quality of Fuels for Electric Plants." 
Table 24. Origin of Coal Recelved by Electric Utility and Plant, 1992 (Continued)

\begin{tabular}{|c|c|c|c|c|c|c|}
\hline \multirow{2}{*}{$\begin{array}{l}\text { Electric Utility Plant } \\
\text { Origin State } \\
\text { County }\end{array}$} & \multirow{2}{*}{$\begin{array}{l}\text { Quantity } \\
\text { (thousand } \\
\text { short tons) }\end{array}$} & \multicolumn{3}{|c|}{ Average Quallty } & \multicolumn{2}{|c|}{ Average Delivered Cost } \\
\hline & & $\begin{array}{c}\text { Btu } \\
\text { (per pound) }\end{array}$ & $\begin{array}{l}\text { Sulfur } \\
\text { (porcent }\end{array}$ & $\begin{array}{c}\text { Ash } \\
\text { (percent }\end{array}$ & (cents per & (dollare per \\
\hline 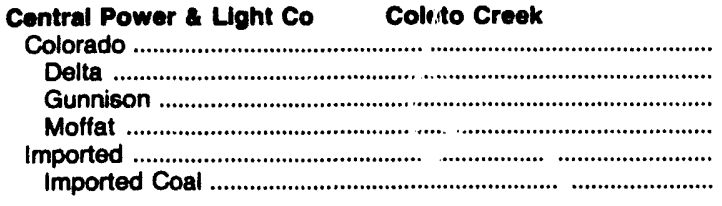 & $\begin{array}{r}1,781 \\
105 \\
385 \\
1,291 \\
80 \\
80\end{array}$ & $\begin{array}{l}10,885 \\
11,342 \\
11,869 \\
10,555 \\
13,064 \\
10,064\end{array}$ & $\begin{array}{r}0.39 \\
.41 \\
.48 \\
.36 \\
.64 \\
.64\end{array}$ & $\begin{array}{l}6.32 \\
8.06 \\
8.76 \\
5.45 \\
7.53 \\
7.53\end{array}$ & $\begin{array}{l}205.0 \\
170.9 \\
163.7 \\
221.9 \\
175.2 \\
175.2\end{array}$ & $\begin{array}{l}44.63 \\
38.77 \\
38.85 \\
46.83 \\
45.78 \\
45.78\end{array}$ \\
\hline $\begin{array}{c}\text { Century Power Corp } \\
\text { New Mexico }\end{array}$ Springerville & $\begin{array}{l}2,483 \\
2,493 \\
2,493\end{array}$ & $\begin{array}{l}9,117 \\
9,117 \\
9,117\end{array}$ & $\begin{array}{l}.63 \\
.63 \\
.63\end{array}$ & $\begin{array}{l}17.93 \\
17.93 \\
17.93\end{array}$ & $\begin{array}{l}170.9 \\
170.9 \\
170.9\end{array}$ & $\begin{array}{l}31.16 \\
31.16 \\
31.16\end{array}$ \\
\hline 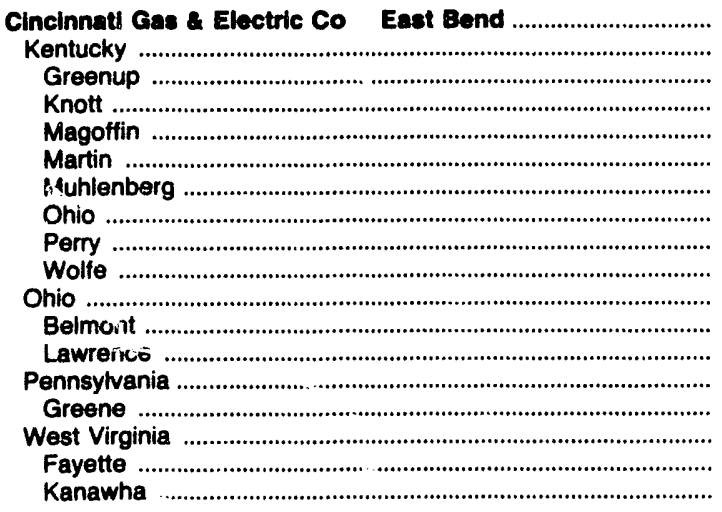 & $\begin{array}{r}1,176 \\
804 \\
12 \\
179 \\
237 \\
264 \\
44 \\
26 \\
36 \\
6 \\
249 \\
2 \\
248 \\
9 \\
9 \\
113 \\
9 \\
104\end{array}$ & $\begin{array}{l}11,770 \\
11,886 \\
11,559 \\
11,616 \\
12 ., 924 \\
11.079 \\
11,666 \\
11,610 \\
11,625 \\
11,075 \\
11,471 \\
12,754 \\
11,462 \\
13,245 \\
13,245 \\
11,487 \\
11,293 \\
11,504\end{array}$ & $\begin{array}{l}1.51 \\
1.21 \\
2.01 \\
1.06 \\
1.27 \\
.80 \\
2.80 \\
2.83 \\
1.10 \\
1.02 \\
2.16 \\
3.23 \\
2.15 \\
2.03 \\
2.03 \\
2.20 \\
2.60 \\
2.17\end{array}$ & $\begin{array}{r}13.13 \\
12.74 \\
14.68 \\
14.04 \\
12.62 \\
12.66 \\
8.61 \\
8.68 \\
14.40 \\
16.70 \\
14.22 \\
8.70 \\
14.26 \\
6.95 \\
6.95 \\
13.99 \\
13.03 \\
4.08\end{array}$ & $\begin{array}{r}161.7 \\
152.8 \\
185.8 \\
101.4 \\
178.6 \\
182.2 \\
103.6 \\
104.2 \\
100.4 \\
100.2 \\
184.5 \\
104.7 \\
185.1 \\
95.7 \\
95.7 \\
183.8 \\
183.3 \\
183.8\end{array}$ & $\begin{array}{l}36.07 \\
36.32 \\
42.94 \\
23.55 \\
42.95 \\
44.02 \\
24.17 \\
24.19 \\
23.35 \\
22.19 \\
42.32 \\
26.71 \\
42.43 \\
25.35 \\
25.35 \\
42.22 \\
41.40 \\
42.29\end{array}$ \\
\hline 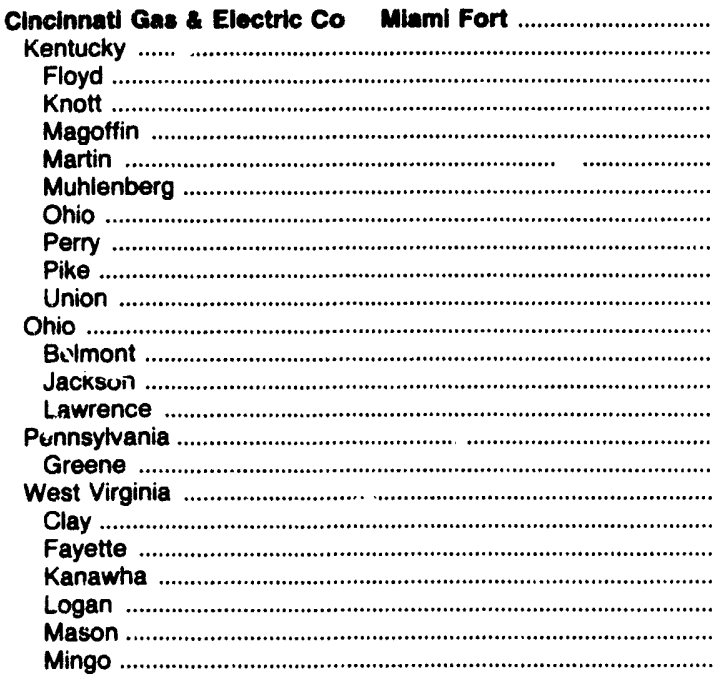 & $\begin{array}{r}2,501 \\
1,039 \\
276 \\
5 \\
207 \\
371 \\
73 \\
40 \\
8 \\
35 \\
23 \\
466 \\
43 \\
2 \\
422 \\
40 \\
40 \\
956 \\
13 \\
8 \\
606 \\
50 \\
11 \\
268\end{array}$ & $\begin{array}{l}12,166 \\
11,971 \\
12,283 \\
11,728 \\
12,022 \\
11,857 \\
11,634 \\
1,588 \\
11,668 \\
12,003 \\
11,425 \\
11,423 \\
12,635 \\
10,853 \\
11,300 \\
13,263 \\
13,263 \\
12,696 \\
12,104 \\
11,216 \\
12,546 \\
11,975 \\
11,784 \\
13,284\end{array}$ & $\begin{array}{r}1.32 \\
1.15 \\
.67 \\
1.30 \\
1.40 \\
.81 \\
2.80 \\
2.82 \\
.92 \\
.57 \\
2.84 \\
2.56 \\
3.17 \\
3.54 \\
2.50 \\
2.39 \\
2.39 \\
.85 \\
.64 \\
2.61 \\
.88 \\
.64 \\
2.60 \\
.68\end{array}$ & $\begin{array}{r}11.04 \\
12.32 \\
11.59 \\
14.40 \\
12.56 \\
14.04 \\
8.53 \\
8.53 \\
12.92 \\
12.97 \\
8.16 \\
12.62 \\
8.98 \\
13.70 \\
12.99 \\
7.13 \\
7.13 \\
9.04 \\
12.58 \\
12.99 \\
9.56 \\
12.45 \\
9.31 \\
6.92\end{array}$ & $\begin{array}{r}163.5 \\
153.8 \\
133.3 \\
99.8 \\
173.7 \\
182.0 \\
104.3 \\
105.4 \\
106.8 \\
110.8 \\
100.6 \\
175.1 \\
104.6 \\
80.6 \\
183.5 \\
99.0 \\
99.0 \\
171.2 \\
116.0 \\
181.5 \\
183.1 \\
119.0 \\
96.7 \\
159.6\end{array}$ & $\begin{array}{l}39.79 \\
36.82 \\
32.74 \\
23.40 \\
41.76 \\
43.16 \\
24.28 \\
24.44 \\
24.92 \\
26.60 \\
22.99 \\
40.01 \\
26.44 \\
17.50 \\
41.48 \\
26.26 \\
26.26 \\
43.48 \\
28.09 \\
40.72 \\
45.94 \\
28.49 \\
22.78 \\
42.41\end{array}$ \\
\hline $\begin{array}{l}\text { Cincinnati Ges E Electric Co Beckjord } \\
\text { Kentucky } \\
\text { Breathitt } \\
\text { Floyd } \\
\text { Greenup } \\
\text { Knott ... } \\
\text { Magofin } \\
\text { Martin } \\
\text { Muhlenberg } \\
\text { Ohio } \\
\text { Perry } \\
\text { Union }\end{array}$ & $\begin{array}{r}1,351 \\
829 \\
2 \\
48 \\
10 \\
28 \\
255 \\
357 \\
73 \\
33 \\
18 \\
5\end{array}$ & $\begin{array}{l}11,754 \\
11,955 \\
11,139 \\
12,320 \\
11,471 \\
11,540 \\
12,063 \\
12,033 \\
11,566 \\
11,563 \\
11,338 \\
11,443\end{array}$ & $\begin{array}{r}1.76 \\
1.25 \\
.89 \\
.72 \\
2.22 \\
1.12 \\
1.27 \\
.81 \\
2.79 \\
2.81 \\
1.14 \\
2.81\end{array}$ & $\begin{array}{r}12.46 \\
12.30 \\
12.00 \\
12.14 \\
14.17 \\
14.26 \\
12.49 \\
12.99 \\
8.80 \\
8.67 \\
14.42 \\
8.20\end{array}$ & $\begin{array}{r}164.7 \\
161.7 \\
98.3 \\
131.5 \\
181.7 \\
98.3 \\
176.7 \\
179.2 \\
106.9 \\
107.3 \\
95.7 \\
102.1\end{array}$ & $\begin{array}{l}38.71 \\
38.67 \\
21.90 \\
32.41 \\
41.69 \\
22.69 \\
42.62 \\
43.12 \\
24.72 \\
24.80 \\
21.70 \\
24.37\end{array}$ \\
\hline
\end{tabular}

See footnotes at end of table.

Source: Federal Energy Regulatory Commission, FERC Form 423, "Monthly Report of Cost and Quality of Fuels for Electric Plants." 
Table 24. Origin of Coal Recelved by Electric Utility and Plant, 1992 (Continued)

\begin{tabular}{|c|c|c|c|c|c|c|}
\hline \multirow[b]{2}{*}{$\begin{array}{l}\text { Electric Utility Piant } \\
\text { Origin State } \\
\text { County }\end{array}$} & \multirow{2}{*}{$\begin{array}{l}\text { Quantity } \\
\text { (thousand } \\
\text { chort tons) }\end{array}$} & \multicolumn{3}{|c|}{ Average Quallty } & \multicolumn{2}{|c|}{ Average Dellvered Cost } \\
\hline & & $\begin{array}{c}\text { Btu } \\
\text { (por pound) }\end{array}$ & $\begin{array}{c}\text { Sulfur } \\
\text { (percent } \\
\text { by wolght) }\end{array}$ & $\begin{array}{c}\text { Ast, } \\
\text { (percent } \\
\text { by weight) }\end{array}$ & $\begin{array}{l}\text { (cents per } \\
\text { million Btu) }\end{array}$ & $\begin{array}{l}\text { (dollars per } \\
\text { siort ton) }\end{array}$ \\
\hline 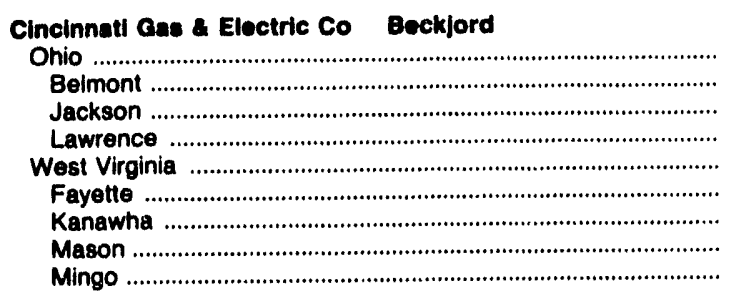 & $\begin{array}{r}442 \\
58 \\
6 \\
377 \\
80 \\
6 \\
71 \\
1 \\
2\end{array}$ & $\begin{array}{l}11,430 \\
12,669 \\
10,993 \\
11,247 \\
11,454 \\
11,247 \\
11,427 \\
11,821 \\
13,112\end{array}$ & $\begin{array}{l}2.64 \\
3.18 \\
4.37 \\
2.53 \\
2.27 \\
2.66 \\
2.27 \\
2.55 \\
.70\end{array}$ & $\begin{array}{r}12.58 \\
8.99 \\
13.10 \\
13.12 \\
13.52 \\
13.60 \\
13.72 \\
9.30 \\
7.40\end{array}$ & $\begin{array}{r}168.2 \\
102.7 \\
78.3 \\
181.1 \\
177.1 \\
178.9 \\
178.7 \\
95.0 \\
158.1\end{array}$ & $\begin{array}{l}38.45 \\
26.01 \\
17.22 \\
40.73 \\
40.56 \\
40.24 \\
40.84 \\
22.46 \\
41.46\end{array}$ \\
\hline 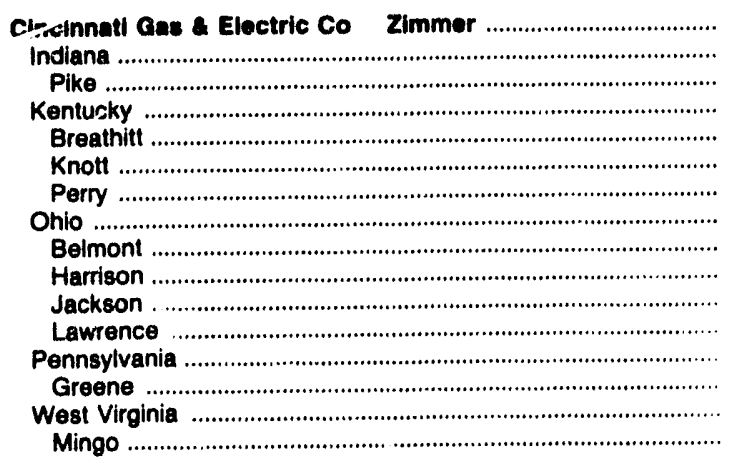 & $\begin{array}{r}4,294 \\
95 \\
95 \\
372 \\
267 \\
10 \\
95 \\
3,551 \\
862 \\
1,557 \\
26 \\
1,106 \\
268 \\
268 \\
8 \\
8\end{array}$ & $\begin{array}{l}12,097 \\
11,526 \\
11,526 \\
11,619 \\
11,606 \\
11,732 \\
11,643 \\
12,074 \\
12,596 \\
12,062 \\
10,684 \\
11,717 \\
13,278 \\
13,278 \\
11,669 \\
11,669\end{array}$ & $\begin{array}{l}3.22 \\
3.52 \\
3.52 \\
1.41 \\
1.41 \\
1.07 \\
1.43 \\
3.49 \\
3.96 \\
3.76 \\
3.51 \\
2.73 \\
2.22 \\
2.22 \\
1.35 \\
1.35\end{array}$ & $\begin{array}{r}9.81 \\
8.01 \\
8.01 \\
13.68 \\
13.58 \\
14.20 \\
13.91 \\
9.65 \\
9.11 \\
10.65 \\
14.09 \\
8.55 \\
7.05 \\
7.05 \\
12.70 \\
12.70\end{array}$ & $\begin{array}{r}107.7 \\
89.6 \\
89.6 \\
98.2 \\
97.9 \\
96.4 \\
99.4 \\
110.2 \\
105.6 \\
109.2 \\
81.3 \\
116.0 \\
94.9 \\
94.9 \\
95.0 \\
95.0\end{array}$ & $\begin{array}{l}26.05 \\
20.66 \\
20.66 \\
22.83 \\
22.73 \\
22.62 \\
23.14 \\
26.60 \\
26.59 \\
26.34 \\
17.37 \\
27.20 \\
25.20 \\
25.20 \\
22.17 \\
22.17\end{array}$ \\
\hline $\begin{array}{l}\text { Cleveland Electric Illum Co Ashtabula } \\
\text { Ohio } \\
\text { Belmont } \\
\text { West Virginia } \\
\text { Kanawha } \\
\text { Monongalia } \\
\text { Nicholas }\end{array}$ & $\begin{array}{r}901 \\
509 \\
509 \\
392 \\
32 \\
337 \\
23\end{array}$ & $\begin{array}{l}12,840 \\
12,446 \\
12,446 \\
13,353 \\
12,397 \\
13,482 \\
12,794\end{array}$ & $\begin{array}{r}3.22 \\
3.95 \\
3.95 \\
2.28 \\
.80 \\
2.51 \\
.84\end{array}$ & $\begin{array}{r}8.50 \\
9.52 \\
9.52 \\
7.18 \\
10.59 \\
6.72 \\
9.20\end{array}$ & $\begin{array}{l}150.8 \\
175.7 \\
175.7 \\
120.8 \\
161.6 \\
115.3 \\
150.3\end{array}$ & $\begin{array}{l}38.73 \\
43.72 \\
43.72 \\
32.25 \\
40.06 \\
31.09 \\
38.46\end{array}$ \\
\hline 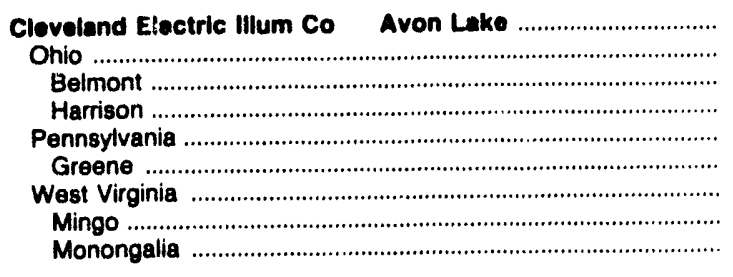 & $\begin{array}{r}1,527 \\
1,345 \\
262 \\
1,083 \\
125 \\
125 \\
57 \\
30 \\
27\end{array}$ & $\begin{array}{r}12,543 \\
12,444 \\
12,420 \\
12,449 \\
13,306 \\
13,306 \\
3,225 \\
13,079 \\
13,388\end{array}$ & $\begin{array}{r}2.45 \\
2.49 \\
3.15 \\
2.33 \\
2.35 \\
2.35 \\
1.60 \\
.70 \\
2.61\end{array}$ & $\begin{array}{l}9.45 \\
9.76 \\
9.54 \\
9.81 \\
6.93 \\
6.93 \\
7.58 \\
9.10 \\
5.90\end{array}$ & $\begin{array}{l}153.5 \\
158.3 \\
214.4 \\
144.8 \\
117.7 \\
117.7 \\
125.5 \\
135.1 \\
115.1\end{array}$ & $\begin{array}{l}38.51 \\
39.41 \\
53.26 \\
36.06 \\
31.31 \\
31.31 \\
33.20 \\
35.34 \\
30.82\end{array}$ \\
\hline 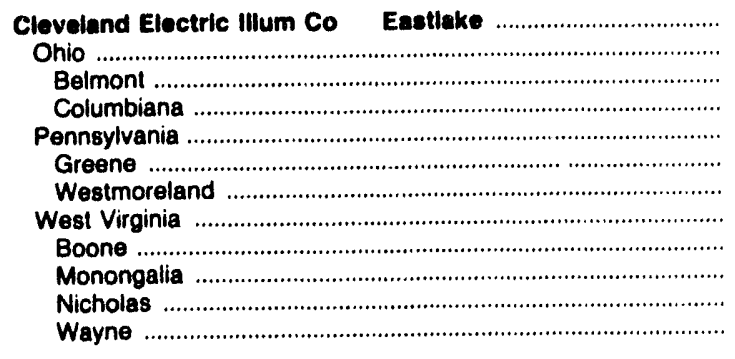 & $\begin{array}{r}2,029 \\
987 \\
830 \\
157 \\
675 \\
605 \\
70 \\
367 \\
72 \\
156 \\
125 \\
14\end{array}$ & $\begin{array}{l}12,920 \\
12,591 \\
12,618 \\
12,444 \\
13,234 \\
13,345 \\
12,275 \\
13,227 \\
13,450 \\
13,266 \\
13,122 \\
12,595\end{array}$ & $\begin{array}{r}2.63 \\
3.46 \\
3.73 \\
2.05 \\
1.99 \\
1.95 \\
2.54 \\
1.58 \\
.85 \\
2.60 \\
.83 \\
.78\end{array}$ & $\begin{array}{r}8.37 \\
9.34 \\
8.35 \\
9.23 \\
7.33 \\
6.83 \\
11.66 \\
7.70 \\
6.33 \\
7.45 \\
8.78 \\
8.00\end{array}$ & $\begin{array}{l}149.6 \\
170.0 \\
176.3 \\
135.9 \\
127.9 \\
128.7 \\
120.5 \\
137.4 \\
155.9 \\
117.9 \\
149.7 \\
152.0\end{array}$ & $\begin{array}{l}38.66 \\
42.80 \\
44.48 \\
33.83 \\
33.85 \\
34.34 \\
29.57 \\
36.36 \\
41.95 \\
31.28 \\
39.28 \\
38.29\end{array}$ \\
\hline $\begin{array}{l}\text { Cleveland Electric Illum Co Lake Shore } \\
\text { West Virginia } \\
\text { Mingo }\end{array}$ & $\begin{array}{l}192 \\
192 \\
192\end{array}$ & $\begin{array}{l}13,180 \\
13,180 \\
13,180\end{array}$ & $\begin{array}{l}.64 \\
.64 \\
.64\end{array}$ & $\begin{array}{l}6.78 \\
6.78 \\
6.78\end{array}$ & $\begin{array}{l}165.4 \\
165.4 \\
165.4\end{array}$ & $\begin{array}{l}43.61 \\
43.61 \\
43.61\end{array}$ \\
\hline $\begin{array}{r}\text { Colorado Springs City of } \quad \text { Drake } \\
\text { Colorado } \\
\text { Moffat } \\
\text { Routt }\end{array}$ & $\begin{array}{r}604 \\
604 \\
570 \\
34\end{array}$ & $\begin{array}{l}10,646 \\
10,646 \\
10,622 \\
11,053\end{array}$ & $\begin{array}{l}.36 \\
.36 \\
.35 \\
.40\end{array}$ & $\begin{array}{l}5.25 \\
5.25 \\
5.07 \\
8.25\end{array}$ & $\begin{array}{l}164.3 \\
164.3 \\
166.6 \\
128.0\end{array}$ & $\begin{array}{l}34.99 \\
34.99 \\
35.40 \\
28.29\end{array}$ \\
\hline 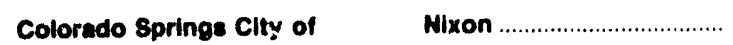 & 610 & 10,910 & .38 & 6.85 & 141.6 & 30.90 \\
\hline
\end{tabular}

See footnotes at end of table.

Source: Federal Energy Regulatory Commission, FEP.C Form 423, "Monthly Report of Cost and Quality of Fuels for Electric Plants." 
Table 24. Origin of Coal Recelved by Electric Utlity and Plant, 1992 (Continued)

\begin{tabular}{|c|c|c|c|c|c|c|}
\hline \multirow{2}{*}{$\begin{array}{c}\text { Electric Utility Plant } \\
\text { Origin State } \\
\text { County }\end{array}$} & \multirow{2}{*}{$\begin{array}{l}\text { Quantity } \\
\text { (thousand } \\
\text { short tons) }\end{array}$} & \multicolumn{3}{|c|}{ Average Quallity } & \multicolumn{2}{|c|}{ Average Delivered Cost } \\
\hline & & $\begin{array}{c}\text { Btu } \\
\text { (per pound) }\end{array}$ & $\begin{array}{l}\text { Sulfur } \\
\text { (percent } \\
\text { by welght) }\end{array}$ & $\begin{array}{l}\text { Ash } \\
\text { (percent } \\
\text { by welght) }\end{array}$ & $\begin{array}{l}\text { (cents per } \\
\text { million Btu) }\end{array}$ & $\begin{array}{l}\text { (dollars per } \\
\text { short ton) }\end{array}$ \\
\hline $\begin{array}{l}\text { Colorado Springs Clty of } \quad \text { Nixon } \\
\text { Colorado } \\
\text { Gunnison } \\
\text { Moffat } \\
\text { Routt }\end{array}$ & $\begin{array}{r}610 \\
18 \\
316 \\
276\end{array}$ & $\begin{array}{l}10,910 \\
11,850 \\
10,552 \\
11,258\end{array}$ & $\begin{array}{r}0.38 \\
.43 \\
.36 \\
.40\end{array}$ & $\begin{array}{l}6.85 \\
8.08 \\
5.09 \\
8.78\end{array}$ & $\begin{array}{r}141.6 \\
94.5 \\
149.5 \\
136.5\end{array}$ & $\begin{array}{l}30.90 \\
22.39 \\
31.56 \\
30.73\end{array}$ \\
\hline $\begin{array}{c}\text { Columbia City of } \\
\text { Kentucky } \\
\text { Pike }\end{array}$ & $\begin{array}{l}37 \\
37 \\
37\end{array}$ & $\begin{array}{l}13,975 \\
13,975 \\
13,975\end{array}$ & $\begin{array}{l}.64 \\
.64 \\
.64\end{array}$ & $\begin{array}{l}5.62 \\
5.62 \\
5.62\end{array}$ & $\begin{array}{l}211.2 \\
211.2 \\
211.2\end{array}$ & $\begin{array}{l}59.04 \\
59.04 \\
59.04\end{array}$ \\
\hline 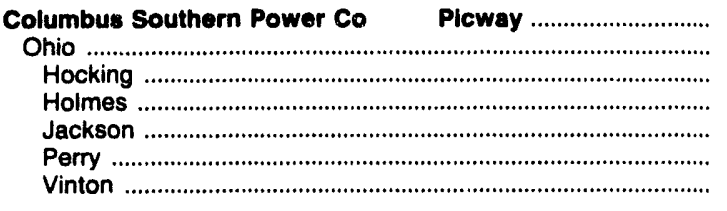 & $\begin{array}{r}307 \\
307 \\
16 \\
5 \\
20 \\
98 \\
169\end{array}$ & $\begin{array}{l}11,457 \\
11,457 \\
11,487 \\
11,747 \\
11,554 \\
11,375 \\
11,481\end{array}$ & $\begin{array}{l}3.05 \\
3.05 \\
3.15 \\
3.70 \\
3.24 \\
3.25 \\
2.88\end{array}$ & $\begin{array}{r}9.86 \\
9.86 \\
9.55 \\
8.11 \\
10.14 \\
9.64 \\
10.03\end{array}$ & $\begin{array}{r}105.4 \\
105.4 \\
100.8 \\
99.1 \\
104.0 \\
99.6 \\
109.6\end{array}$ & $\begin{array}{l}24.16 \\
24.16 \\
23.15 \\
23.29 \\
24.04 \\
22.67 \\
25.16\end{array}$ \\
\hline 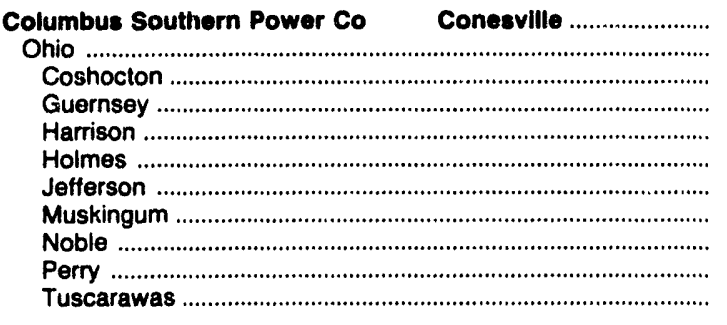 & $\begin{array}{r}3,422 \\
3,422 \\
1,895 \\
20 \\
195 \\
205 \\
72 \\
105 \\
8 \\
127 \\
795\end{array}$ & $\begin{array}{l}12,031 \\
12,031 \\
12,166 \\
11,719 \\
12,462 \\
11,801 \\
11,946 \\
11,901 \\
11,697 \\
11,171 \\
11,835\end{array}$ & $\begin{array}{l}3.23 \\
3.23 \\
3.26 \\
2.45 \\
2.92 \\
3.30 \\
2.86 \\
3.99 \\
3.47 \\
2.57 \\
3.25\end{array}$ & $\begin{array}{r}8.27 \\
8.27 \\
7.37 \\
10.63 \\
8.97 \\
8.23 \\
11.45 \\
8.99 \\
12.91 \\
13.27 \\
8.96\end{array}$ & $\begin{array}{r}149.5 \\
149.5 \\
169.5 \\
99.8 \\
122.4 \\
98.5 \\
103.7 \\
101.4 \\
95.2 \\
121.8 \\
137.2\end{array}$ & $\begin{array}{l}35.98 \\
35.98 \\
41.24 \\
23.39 \\
30.52 \\
23.25 \\
24.77 \\
24.14 \\
22.26 \\
27.22 \\
32.48\end{array}$ \\
\hline $\begin{array}{l}\text { Columbus City of } \\
\text { Kentucky } \\
\text { Floyd } \\
\text { Pike } \\
\text { Unknown } \\
\text { Ohio }\end{array}$ & $\begin{array}{r}29 \\
24 \\
4 \\
16 \\
3 \\
5 \\
5\end{array}$ & $\begin{array}{l}12,645 \\
12,856 \\
13,046 \\
12,824 \\
12,749 \\
11,563 \\
11,563\end{array}$ & $\begin{array}{r}.95 \\
.99 \\
.76 \\
1.10 \\
.79 \\
.74 \\
.74\end{array}$ & $\begin{array}{l}8.49 \\
8.55 \\
6.80 \\
9.13 \\
8.10 \\
8.15 \\
8.15\end{array}$ & $\begin{array}{l}164.4 \\
162.8 \\
159.6 \\
163.7 \\
163.0 \\
173.4 \\
173.4\end{array}$ & $\begin{array}{l}41.58 \\
41.87 \\
41.65 \\
41.99 \\
41.56 \\
40.10 \\
40.10\end{array}$ \\
\hline 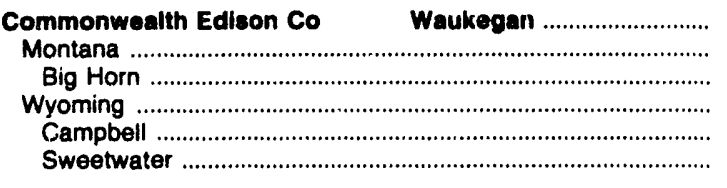 & $\begin{array}{r}880 \\
270 \\
270 \\
610 \\
55 \\
555\end{array}$ & $\begin{array}{l}9,408 \\
9,549 \\
9,549 \\
9,345 \\
8,836 \\
9,386\end{array}$ & $\begin{array}{l}.40 \\
.35 \\
.35 \\
.43 \\
.41 \\
.43\end{array}$ & $\begin{array}{l}6.21 \\
3.95 \\
3.95 \\
7.21 \\
5.10 \\
7.42\end{array}$ & $\begin{array}{l}266.9 \\
282.0 \\
282.0 \\
260.1 \\
105.4 \\
274.5\end{array}$ & $\begin{array}{l}50.22 \\
53.86 \\
53.86 \\
48.61 \\
18.63 \\
51.59\end{array}$ \\
\hline 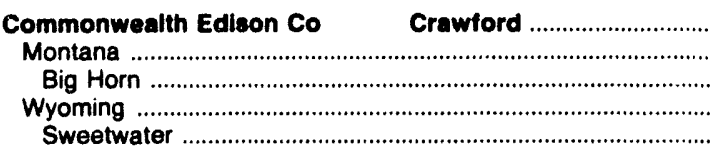 & $\begin{array}{r}303 \\
8 \\
8 \\
295 \\
295\end{array}$ & $\begin{array}{l}9,392 \\
9,541 \\
9,541 \\
9,388 \\
9,388\end{array}$ & $\begin{array}{l}.42 \\
.38 \\
.38 \\
.42 \\
.42\end{array}$ & $\begin{array}{l}7.24 \\
4.57 \\
4.57 \\
7.31 \\
7.31\end{array}$ & $\begin{array}{l}314.8 \\
306.8 \\
306.8 \\
315.2 \\
315.2\end{array}$ & $\begin{array}{l}58.16 \\
58.55 \\
58.55 \\
59.18 \\
59.18\end{array}$ \\
\hline 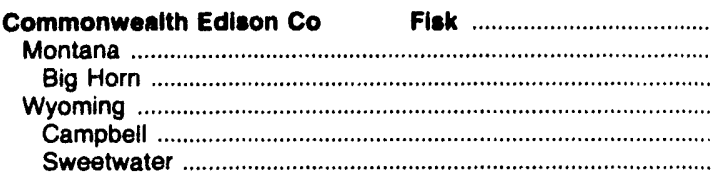 & $\begin{array}{r}321 \\
57 \\
57 \\
264 \\
68 \\
196\end{array}$ & $\begin{array}{l}9,314 \\
9,627 \\
9,627 \\
9,246 \\
8,758 \\
9,415\end{array}$ & $\begin{array}{l}.38 \\
.39 \\
.39 \\
.38 \\
.17 \\
.45\end{array}$ & $\begin{array}{l}6.34 \\
4.23 \\
4.23 \\
6.81 \\
4.39 \\
7.65\end{array}$ & $\begin{array}{l}275.8 \\
307.0 \\
307.0 \\
268.7 \\
118.0 \\
317.4\end{array}$ & $\begin{array}{l}51.37 \\
59.12 \\
59.12 \\
49.69 \\
20.66 \\
59.76\end{array}$ \\
\hline 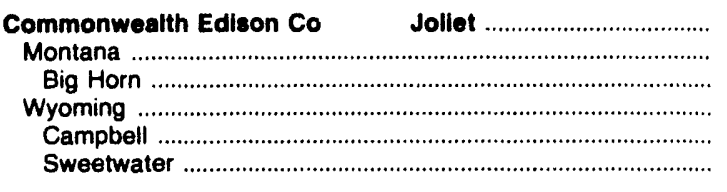 & $\begin{array}{r}1,919 \\
387 \\
387 \\
1,532 \\
57 \\
1,475\end{array}$ & $\begin{array}{l}9,419 \\
9,596 \\
9,596 \\
9,375 \\
8,771 \\
9,398\end{array}$ & $\begin{array}{l}.42 \\
.35 \\
.35 \\
.44 \\
.18 \\
.45\end{array}$ & $\begin{array}{l}6.77 \\
4.07 \\
4.07 \\
7.46 \\
4.46 \\
7.57\end{array}$ & $\begin{array}{l}280.4 \\
282.3 \\
282.3 \\
279.9 \\
103.2 \\
286.2\end{array}$ & $\begin{array}{l}52.82 \\
54.18 \\
54.18 \\
52.47 \\
18.11 \\
53.80\end{array}$ \\
\hline 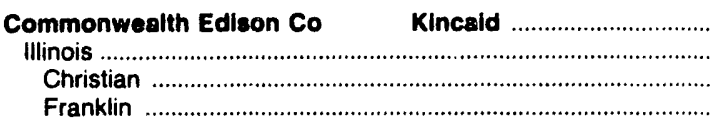 & $\begin{array}{r}1,716 \\
1,716 \\
1,611 \\
105\end{array}$ & $\begin{array}{l}10,516 \\
10,516 \\
10,445 \\
11,611\end{array}$ & $\begin{array}{l}3.40 \\
3.40 \\
3.52 \\
1.46\end{array}$ & $\begin{array}{l}8.68 \\
8.68 \\
8.74 \\
7.77\end{array}$ & $\begin{array}{l}186.9 \\
166.9 \\
170.6 \\
115.7\end{array}$ & $\begin{array}{l}35.09 \\
35.09 \\
35.63 \\
26.87\end{array}$ \\
\hline
\end{tabular}

See footnotes at end of table.

Source: Federal Energy Regulatory Commission, FERC Form 423, "Monthly Report of Cost and Quality of Fuels for Electric Plants." 
Table 24. Origin of Coal Received by Electric Utility and Plant, 1992 (Continued)

\begin{tabular}{|c|c|c|c|c|c|c|}
\hline \multirow[b]{2}{*}{$\begin{array}{l}\text { Electric Utility Plant } \\
\text { Origin State } \\
\text { County }\end{array}$} & \multirow{2}{*}{$\begin{array}{l}\text { Quantity } \\
\text { (thousand } \\
\text { short tons) }\end{array}$} & \multicolumn{3}{|c|}{ Average Quallty } & \multicolumn{2}{|c|}{ Average Dellvered Cost } \\
\hline & & $\begin{array}{c}\text { Btu } \\
\text { (per pound) }\end{array}$ & $\begin{array}{l}\text { Sulfur } \\
\text { (percent } \\
\text { by woight) }\end{array}$ & $\begin{array}{l}\text { Ash } \\
\text { (percent } \\
\text { by wolght) }\end{array}$ & $\begin{array}{l}\text { (cents per } \\
\text { million Btu) }\end{array}$ & $\begin{array}{l}\text { (dollare per } \\
\text { short ton) }\end{array}$ \\
\hline 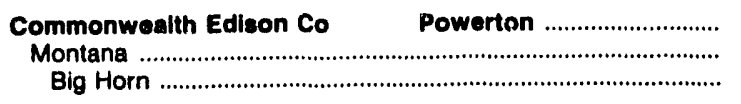 & $\begin{array}{l}1,279 \\
1,279 \\
1,279\end{array}$ & $\begin{array}{l}9,583 \\
9,583 \\
9,583\end{array}$ & $\begin{array}{r}0.35 \\
.35 \\
.35\end{array}$ & $\begin{array}{l}4.03 \\
4.03 \\
4.03\end{array}$ & $\begin{array}{l}267.6 \\
267.6 \\
267.6\end{array}$ & $\begin{array}{l}51.29 \\
51.29 \\
51.29\end{array}$ \\
\hline 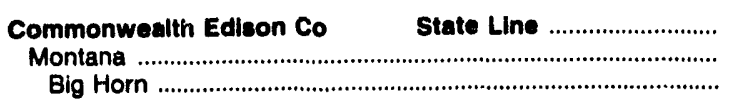 & $\begin{array}{l}452 \\
452 \\
452\end{array}$ & $\begin{array}{l}9,595 \\
9,595 \\
9,595\end{array}$ & $\begin{array}{l}.36 \\
.36 \\
.36\end{array}$ & $\begin{array}{l}4.05 \\
4.05 \\
4.05\end{array}$ & $\begin{array}{l}278.5 \\
278.5 \\
278.5\end{array}$ & $\begin{array}{l}53.44 \\
53.44 \\
53.44\end{array}$ \\
\hline 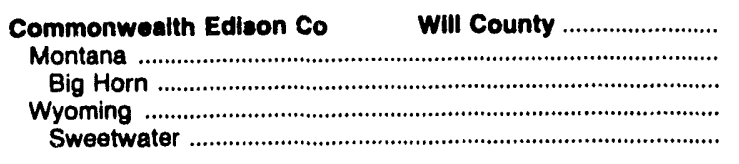 & $\begin{array}{r}1,682 \\
1,034 \\
1,034 \\
648 \\
648\end{array}$ & $\begin{array}{l}9,497 \\
9,576 \\
9,576 \\
9,371 \\
9,371\end{array}$ & $\begin{array}{l}.37 \\
.34 \\
.34 \\
.42 \\
.42\end{array}$ & $\begin{array}{l}5.29 \\
4.00 \\
4.00 \\
7.34 \\
7.34\end{array}$ & $\begin{array}{l}306.5 \\
300.4 \\
300.4 \\
316.4 \\
316.4\end{array}$ & $\begin{array}{l}58.21 \\
57.53 \\
57.53 \\
59.30 \\
59.30\end{array}$ \\
\hline 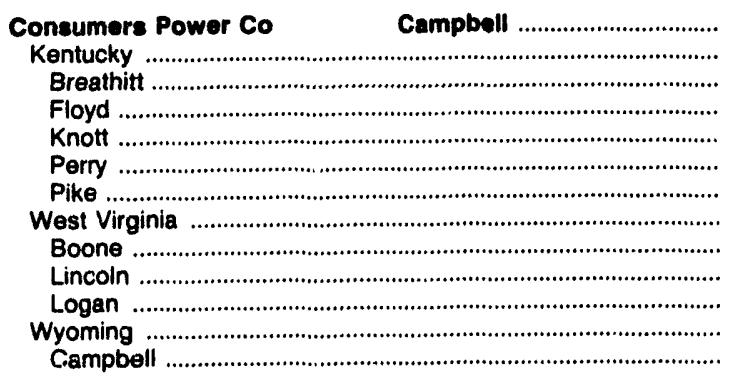 & $\begin{array}{r}3,036 \\
1,727 \\
28 \\
212 \\
41 \\
662 \\
783 \\
1,281 \\
1,047 \\
18 \\
215 \\
58 \\
58\end{array}$ & $\begin{array}{r}12,432 \\
12,695 \\
12,073 \\
12,715 \\
12,642 \\
12,463 \\
12,811 \\
12,249 \\
12,228 \\
11,854 \\
12,381 \\
8,687 \\
8,687\end{array}$ & $\begin{array}{l}.74 \\
.77 \\
.91 \\
.89 \\
.94 \\
.83 \\
.68 \\
.72 \\
.73 \\
.85 \\
.65 \\
.27 \\
.27\end{array}$ & $\begin{array}{r}9.81 \\
8.89 \\
11.75 \\
11.05 \\
8.30 \\
9.31 \\
7.87 \\
11.52 \\
11.43 \\
10.80 \\
12.03 \\
4.76 \\
4.76\end{array}$ & $\begin{array}{l}171.9 \\
174.6 \\
154.1 \\
165.0 \\
152.2 \\
171.9 \\
181.2 \\
169.6 \\
171.4 \\
147.4 \\
162.9 \\
126.4 \\
126.4\end{array}$ & $\begin{array}{l}42.74 \\
44.33 \\
37.20 \\
41.95 \\
38.50 \\
42.84 \\
46.79 \\
41.56 \\
41.92 \\
34.95 \\
40.34 \\
21.96 \\
21.96\end{array}$ \\
\hline 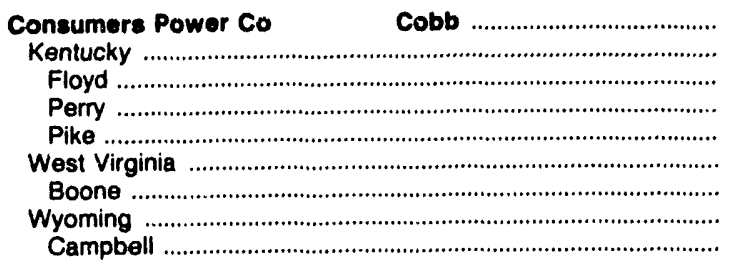 & $\begin{array}{r}859 \\
456 \\
141 \\
162 \\
153 \\
44 \\
44 \\
359 \\
359\end{array}$ & $\begin{array}{r}11,078 \\
12,557 \\
12,545 \\
12,546 \\
12,580 \\
12,195 \\
12,195 \\
9,065 \\
9,065\end{array}$ & $\begin{array}{l}.62 \\
.83 \\
.91 \\
.81 \\
.77 \\
.89 \\
.89 \\
.33 \\
.33\end{array}$ & $\begin{array}{r}7.57 \\
9.49 \\
11.24 \\
8.57 \\
8.86 \\
11.13 \\
11.13 \\
4.70 \\
4.70\end{array}$ & $\begin{array}{l}161.1 \\
179.1 \\
163.6 \\
179.3 \\
193.2 \\
155.4 \\
155.4 \\
130.3 \\
130.3\end{array}$ & $\begin{array}{l}35.69 \\
44.98 \\
41.04 \\
44.99 \\
48.62 \\
37.91 \\
37.81 \\
23.63 \\
23.63\end{array}$ \\
\hline $\begin{array}{l}\text { Coneumers Power Co } \\
\text { Kentucky } \\
\text { Martin . } \\
\text { Perry } \\
\text { Pike } \\
\text { West Virginia } \\
\text { Boone } \\
\text { Lincoln } \\
\text { Logan } \\
\text { Mingo }\end{array}$ & $\begin{array}{r}1,274 \\
120 \\
19 \\
61 \\
40 \\
1,154 \\
1,065 \\
28 \\
51 \\
9\end{array}$ & $\begin{array}{l}12,186 \\
12,498 \\
12,471 \\
12,252 \\
12,887 \\
12,153 \\
12,154 \\
11,846 \\
12,335 \\
12,000\end{array}$ & $\begin{array}{l}.85 \\
.83 \\
.79 \\
.89 \\
.76 \\
.85 \\
.86 \\
.88 \\
.76 \\
.98\end{array}$ & $\begin{array}{r}11.62 \\
9.06 \\
7.93 \\
10.18 \\
7.90 \\
11.89 \\
11.87 \\
11.07 \\
12.73 \\
12.00\end{array}$ & $\begin{array}{l}153.8 \\
149.8 \\
138.6 \\
145.5 \\
161.4 \\
154.3 \\
154.6 \\
137.0 \\
159.1 \\
142.2\end{array}$ & $\begin{array}{l}37.49 \\
37.44 \\
34.57 \\
35.66 \\
41.59 \\
37.49 \\
37.57 \\
32.46 \\
39.25 \\
34.13\end{array}$ \\
\hline $\begin{array}{c}\text { Consumers Power Co } \\
\text { Kentucky } \\
\text { Martin ..... } \\
\text { Perry } \\
\text { Pike } \\
\text { West Virginia } \\
\text { Boone } \\
\text { Logan } \\
\text { Mingo } \\
\text { Campbell } \\
\text { Converse }\end{array}$ & $\begin{array}{r}944 \\
151 \\
20 \\
41 \\
90 \\
517 \\
476 \\
31 \\
10 \\
277 \\
183 \\
94\end{array}$ & $\begin{array}{r}11,220 \\
12,419 \\
12,300 \\
12,140 \\
12,570 \\
12,133 \\
12,144 \\
12,011 \\
12,000 \\
8,864 \\
8,889 \\
8,818\end{array}$ & $\begin{array}{l}.69 \\
.86 \\
.98 \\
.88 \\
.82 \\
.84 \\
.84 \\
.70 \\
.92 \\
.31 \\
.31 \\
.32\end{array}$ & $\begin{array}{r}9.53 \\
10.28 \\
10.00 \\
10.89 \\
10.06 \\
11.63 \\
11.56 \\
12.74 \\
11.50 \\
5.22 \\
4.93 \\
5.78\end{array}$ & $\begin{array}{l}148.9 \\
157.5 \\
138.6 \\
149.2 \\
165.2 \\
155.2 \\
155.4 \\
157.1 \\
142.2 \\
126.0 \\
125.8 \\
126.4\end{array}$ & $\begin{array}{l}33.41 \\
39.12 \\
34.10 \\
36.21 \\
41.53 \\
37.67 \\
37.74 \\
37.73 \\
34.13 \\
22.34 \\
22.36 \\
22.30\end{array}$ \\
\hline $\begin{array}{l}\text { Consumers Power Co } \\
\text { Kentucky } \\
\text { Floyd } \\
\text { Martin } \\
\text { Perry } \\
\text { Pike }\end{array}$ & $\begin{array}{r}783 \\
193 \\
46 \\
10 \\
98 \\
39\end{array}$ & $\begin{array}{l}12,208 \\
12,262 \\
12,617 \\
12,000 \\
11,676 \\
12,878\end{array}$ & $\begin{array}{l}.87 \\
.87 \\
.95 \\
.99 \\
.87 \\
.74\end{array}$ & $\begin{array}{r}11.02 \\
10.80 \\
11.78 \\
12.00 \\
11.30 \\
8.10\end{array}$ & $\begin{array}{l}142.5 \\
146.2 \\
149.6 \\
146.4 \\
134.5 \\
169.4\end{array}$ & $\begin{array}{l}34.79 \\
35.86 \\
37.75 \\
35.14 \\
31.94 \\
43.62\end{array}$ \\
\hline
\end{tabular}

See tootnotes at end of table.

Source: Federal Energy Regulatory Commission, FERC Form 423, "Monthly Report of Cost and Quality of Fuels for Electric Plants." 
Table 24. Origin of Coal Recelved by Electric Utility and Plant, 1992 (Continued)

\begin{tabular}{|c|c|c|c|c|c|c|}
\hline \multirow{2}{*}{$\begin{array}{l}\text { Electric Utility Plant } \\
\text { Origin State } \\
\text { County }\end{array}$} & \multirow{2}{*}{$\begin{array}{l}\text { Quantity } \\
\text { (thousand } \\
\text { chort tons) }\end{array}$} & \multicolumn{3}{|c|}{ Avorage Quallty } & \multicolumn{2}{|c|}{ Average Dellvered Cost } \\
\hline & & $\begin{array}{c}\text { Btu } \\
\text { (per pound) }\end{array}$ & $\begin{array}{l}\text { Sulfur } \\
\text { (percent } \\
\text { by weight) }\end{array}$ & $\begin{array}{l}\text { Aeh } \\
\text { (percent } \\
\text { by weight) }\end{array}$ & $\begin{array}{l}\text { (cents per } \\
\text { million Btu) }\end{array}$ & $\begin{array}{l}\text { (dollars per } \\
\text { short ton) }\end{array}$ \\
\hline 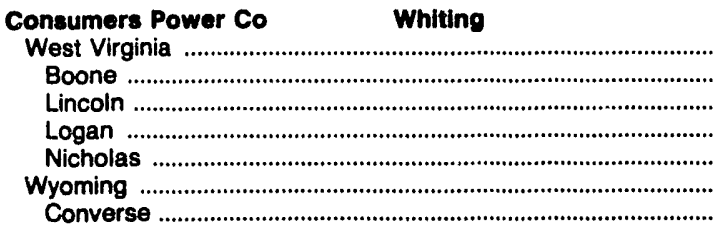 & $\begin{array}{r}582 \\
500 \\
56 \\
18 \\
9 \\
8 \\
8\end{array}$ & $\begin{array}{r}12,234 \\
12,266 \\
11,837 \\
12,476 \\
12,448 \\
8,859 \\
8,859\end{array}$ & $\begin{array}{r}0.88 \\
.88 \\
.87 \\
.63 \\
.99 \\
.34 \\
.34\end{array}$ & $\begin{array}{r}11.16 \\
11.28 \\
10.13 \\
11.22 \\
11.00 \\
5.64 \\
5.64\end{array}$ & $\begin{array}{l}141.4 \\
142.4 \\
131.7 \\
146.8 \\
133.2 \\
133.0 \\
133.0\end{array}$ & $\begin{array}{l}34.59 \\
34.93 \\
31.18 \\
36.62 \\
33.16 \\
23.56 \\
23.56\end{array}$ \\
\hline $\begin{array}{l}\text { Coop Power Aasn } \quad \text { Coal Creak } \\
\text { North Dakota } \\
\text { Mclean }\end{array}$ & $\begin{array}{l}7,438 \\
7,438 \\
7,438\end{array}$ & $\begin{array}{l}6,264 \\
6,264 \\
6,264\end{array}$ & $\begin{array}{l}.78 \\
.78 \\
.78\end{array}$ & $\begin{array}{l}10.63 \\
10.63 \\
10.63\end{array}$ & $\begin{array}{l}72.7 \\
72.7 \\
72.7\end{array}$ & $\begin{array}{l}9.10 \\
9.10 \\
9.10\end{array}$ \\
\hline 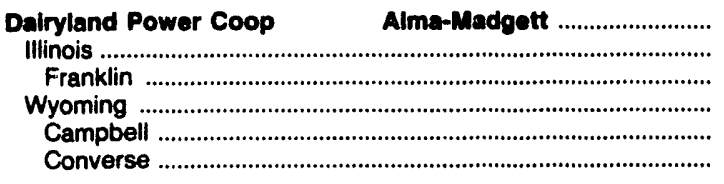 & $\begin{array}{r}1,248 \\
200 \\
200 \\
1,048 \\
950 \\
98\end{array}$ & $\begin{array}{r}9,012 \\
11,502 \\
11,502 \\
8,536 \\
8,519 \\
8,700\end{array}$ & $\begin{array}{r}.46 \\
1.24 \\
1.24 \\
.31 \\
.30 \\
.35\end{array}$ & $\begin{array}{l}5.15 \\
6.81 \\
6.81 \\
4.83 \\
4.77 \\
5.38\end{array}$ & $\begin{array}{l}142.7 \\
139.3 \\
139.3 \\
143.6 \\
146.2 \\
119.2\end{array}$ & $\begin{array}{l}25.72 \\
32.04 \\
32.04 \\
24.51 \\
24.90 \\
20.75\end{array}$ \\
\hline $\begin{array}{l}\text { Dairyland Power Coop } \\
\text { Colorado . Conos No.3 } \\
\text { Las Animas .llinois . } \\
\text { Jefferson } \\
\text { Perry } \\
\text { Kentucky } \\
\text { Pike } \\
\text { Webster } \\
\text { West Virginia } \\
\text { Boone } \\
\text { Wyoming } \\
\text { Converse }\end{array}$ & $\begin{array}{r}773 \\
10 \\
10 \\
257 \\
251 \\
6 \\
324 \\
75 \\
249 \\
78 \\
78 \\
103 \\
103\end{array}$ & $\begin{array}{r}11,702 \\
12,731 \\
12,731 \\
11,929 \\
11,947 \\
11,192 \\
12,322 \\
12,115 \\
12,384 \\
12,292 \\
12,292 \\
8,643 \\
8,643\end{array}$ & $\begin{array}{r}1.10 \\
.46 \\
.46 \\
1.34 \\
1.30 \\
3.03 \\
1.28 \\
.68 \\
1.46 \\
.68 \\
.68 \\
.32 \\
.32\end{array}$ & $\begin{array}{r}7.72 \\
11.40 \\
11.40 \\
6.06 \\
5.95 \\
10.30 \\
8.10 \\
10.74 \\
8.61 \\
10.46 \\
10.46 \\
5.09 \\
5.09\end{array}$ & $\begin{array}{l}135.1 \\
141.2 \\
141.2 \\
136.4 \\
136.8 \\
119.6 \\
133.6 \\
143.0 \\
130.8 \\
146.6 \\
146.6 \\
124.3 \\
124.3\end{array}$ & $\begin{array}{l}31.62 \\
35.95 \\
35.95 \\
32.54 \\
32.68 \\
26.77 \\
32.91 \\
34.66 \\
32.39 \\
36.04 \\
36.04 \\
21.48 \\
21.48\end{array}$ \\
\hline 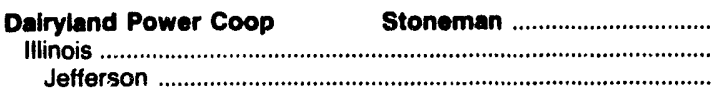 & $\begin{array}{l}24 \\
24 \\
24\end{array}$ & $\begin{array}{l}12,283 \\
12,283 \\
12,283\end{array}$ & $\begin{array}{l}1.11 \\
1.11 \\
1.11\end{array}$ & $\begin{array}{l}\mathbf{5 . 5 0} \\
\mathbf{5 . 5 0} \\
\mathbf{5 . 5 0}\end{array}$ & $\begin{array}{l}134.0 \\
134.0 \\
134.0\end{array}$ & $\begin{array}{l}32.92 \\
32.92 \\
32.92\end{array}$ \\
\hline $\begin{array}{l}\text { Dayton Power } \\
\text { Indiana Light Co } \\
\text { Kentucky } \\
\text { Bell } \\
\text { Carter } \\
\text { Floyd } \\
\text { Johnson } \\
\text { Knott } \\
\text { Lawrence } \\
\text { Magoffin } \\
\text { Perry } \\
\text { Pike } \\
\text { Wolfe } \\
\text { Ohio } \\
\text { Belmont } \\
\text { Jackson } \\
\text { Jefferson } \\
\text { Lawrence } \\
\text { Vinton } \\
\text { Pennsylvania } \\
\text { Fayette } \\
\text { Greene } \\
\text { Washington } \\
\text { West Virginia } \\
\text { Boone } \\
\text { Fayette } \\
\text { Kanawha } \\
\text { Logan } \\
\text { Mingo } \\
\text { Monongalia }\end{array}$ & $\begin{array}{r}5,981 \\
41 \\
41 \\
4,625 \\
247 \\
70 \\
142 \\
148 \\
31 \\
54 \\
149 \\
51 \\
2,614 \\
1,104 \\
15 \\
266 \\
40 \\
109 \\
14 \\
21 \\
82 \\
109 \\
2 \\
43 \\
64 \\
941 \\
109 \\
33 \\
35 \\
136 \\
36 \\
22\end{array}$ & $\begin{array}{l}11,718 \\
11,606 \\
11,606 \\
11,709 \\
12,629 \\
11,260 \\
11,462 \\
11,249 \\
11,683 \\
11,412 \\
11,736 \\
11,213 \\
11,519 \\
12,116 \\
11,125 \\
11,227 \\
11,947 \\
10,899 \\
11,995 \\
11,321 \\
11,016 \\
12,540 \\
11,269 \\
13,069 \\
12,219 \\
11,812 \\
11,599 \\
11,743 \\
11,797 \\
11,960 \\
11,435 \\
12,015\end{array}$ & $\begin{array}{r}1.30 \\
3.45 \\
3.45 \\
1.16 \\
1.20 \\
1.39 \\
1.17 \\
1.39 \\
1.29 \\
1.25 \\
1.19 \\
1.00 \\
1.03 \\
1.40 \\
1.20 \\
3.45 \\
3.50 \\
3.67 \\
3.36 \\
1.37 \\
3.66 \\
2.92 \\
1.03 \\
2.42 \\
3.30 \\
1.14 \\
1.16 \\
1.16 \\
.94 \\
1.38 \\
1.27 \\
1.96\end{array}$ & $\begin{array}{r}13.90 \\
8.48 \\
8.48 \\
14.15 \\
8.54 \\
15.44 \\
14.06 \\
14.46 \\
14.97 \\
13.17 \\
14.19 \\
14.71 \\
15.30 \\
12.52 \\
15.42 \\
13.18 \\
11.94 \\
13.43 \\
13.06 \\
13.87 \\
13.31 \\
10.37 \\
13.10 \\
7.58 \\
12.17 \\
13.52 \\
14.87 \\
16.60 \\
15.03 \\
13.55 \\
14.27 \\
13.99\end{array}$ & $\begin{array}{r}140.7 \\
92.1 \\
92.1 \\
151.1 \\
173.3 \\
95.7 \\
97.2 \\
95.3 \\
91.8 \\
95.2 \\
97.7 \\
97.5 \\
152.8 \\
173.0 \\
98.3 \\
91.9 \\
97.1 \\
91.2 \\
93.3 \\
86.9 \\
90.9 \\
89.4 \\
92.5 \\
84.3 \\
92.9 \\
111.2 \\
94.0 \\
88.3 \\
100.0 \\
155.9 \\
97.5 \\
95.5\end{array}$ & $\begin{array}{l}32.86 \\
21.38 \\
21.38 \\
35.38 \\
43.77 \\
21.54 \\
22.28 \\
21.44 \\
21.46 \\
21.74 \\
22.92 \\
21.87 \\
35.21 \\
41.92 \\
21.87 \\
20.62 \\
23.20 \\
20.06 \\
22.39 \\
19.67 \\
20.03 \\
22.41 \\
20.85 \\
22.05 \\
22.70 \\
26.28 \\
21.80 \\
20.74 \\
23.60 \\
37.29 \\
22.31 \\
22.95\end{array}$ \\
\hline
\end{tabular}

See footnotes at end of table.

Source: Federal Energy Regulatory Commission, FERC Form 423, "Monthly Report of Cost and Quality of Fuels for Electric Plants." 
Table 24. Origin of Coal Recelved by Electric Ut!lity and Plant, 1992 (Continued)

\begin{tabular}{|c|c|c|c|c|c|c|}
\hline \multirow[b]{2}{*}{$\begin{array}{l}\text { Electric Utility Plant } \\
\text { Origin State } \\
\text { County }\end{array}$} & \multirow[b]{2}{*}{$\begin{array}{l}\text { Quantity } \\
\text { (thousand } \\
\text { short tons) }\end{array}$} & \multicolumn{3}{|c|}{ Average Quallty } & \multicolumn{2}{|c|}{ Average Dellvered Cost } \\
\hline & & $\begin{array}{l}\text { Btu } \\
\text { (per pound) }\end{array}$ & $\begin{array}{l}\text { Sulfur } \\
\text { (percent } \\
\text { by welght) }\end{array}$ & $\begin{array}{l}\text { Aah } \\
\text { (percent } \\
\text { by welght) }\end{array}$ & $\begin{array}{l}\text { (cents per } \\
\text { million Btu) }\end{array}$ & $\begin{array}{l}\text { (dollars per } \\
\text { short ton) }\end{array}$ \\
\hline $\begin{array}{l}\text { Dayton Power Light Co Stuart } \\
\text { West Virginia }\end{array}$ & & & & & & \\
\hline 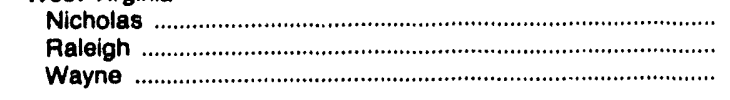 & $\begin{array}{r}50 \\
22 \\
497\end{array}$ & $\begin{array}{l}11,636 \\
11,987 \\
11,853\end{array}$ & $\begin{array}{r}1.18 \\
.80 \\
1.06\end{array}$ & $\begin{array}{l}14.74 \\
13.81 \\
12.69\end{array}$ & $\begin{array}{r}91.6 \\
97.8 \\
109.1\end{array}$ & $\begin{array}{l}21.33 \\
23.45 \\
25.87\end{array}$ \\
\hline $\begin{array}{l}\text { Dayton Power a Loht Co Hutchings } \\
\text { Kentucky . } \\
\text { Breathitt . } \\
\text { Perry . } \\
\text { West Virginia } \\
\text { Logan } \\
\text { Nicholas }\end{array}$ & $\begin{array}{r}51 \\
15 \\
3 \\
12 \\
36 \\
1 \\
35\end{array}$ & $\begin{array}{l}12,595 \\
13,067 \\
12,059 \\
13,315 \\
12,401 \\
11,285 \\
12,443\end{array}$ & $\begin{array}{l}.89 \\
.85 \\
.86 \\
.85 \\
.91 \\
.91 \\
.91\end{array}$ & $\begin{array}{r}10.34 \\
6.79 \\
8.80 \\
6.30 \\
11.79 \\
13.90 \\
11.71\end{array}$ & $\begin{array}{l}131.3 \\
134.5 \\
123.1 \\
137.0 \\
129.9 \\
126.1 \\
130.0\end{array}$ & $\begin{array}{l}33.06 \\
35.14 \\
29.70 \\
36.48 \\
32.21 \\
28.46 \\
32.35\end{array}$ \\
\hline 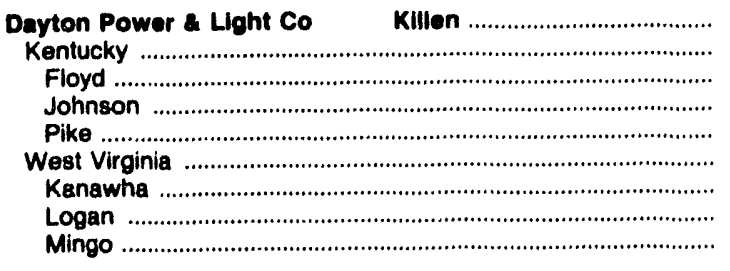 & $\begin{array}{r}805 \\
180 \\
67 \\
51 \\
61 \\
625 \\
18 \\
566 \\
42\end{array}$ & $\begin{array}{l}12,147 \\
11,884 \\
12,165 \\
11,687 \\
11,739 \\
12,222 \\
12,249 \\
12,258 \\
11,733\end{array}$ & $\begin{array}{l}.64 \\
.63 \\
.65 \\
.61 \\
.63 \\
.64 \\
.67 \\
.65 \\
.62\end{array}$ & $\begin{array}{l}12.51 \\
11.75 \\
10.86 \\
12.54 \\
12.07 \\
12.72 \\
10.09 \\
12.83 \\
12.49\end{array}$ & $\begin{array}{c}151.3 \\
110.2 \\
112.6 \\
107.5 \\
109.6 \\
162.7 \\
112.4 \\
168.4 \\
105.0\end{array}$ & $\begin{array}{l}36.75 \\
26.19 \\
27.41 \\
25.12 \\
25.74 \\
39.78 \\
27.55 \\
41.29 \\
24.64\end{array}$ \\
\hline 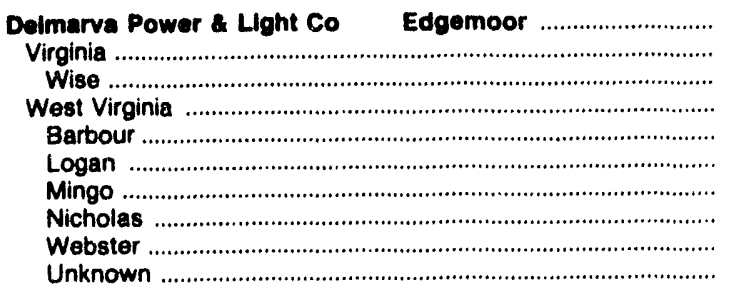 & $\begin{array}{r}554 \\
90 \\
90 \\
464 \\
21 \\
8 \\
152 \\
78 \\
204 \\
\end{array}$ & $\begin{array}{l}13,101 \\
13,101 \\
13,101 \\
13,101 \\
12,801 \\
12,989 \\
13,022 \\
13,084 \\
13,201 \\
13,000\end{array}$ & $\begin{array}{l}.80 \\
.82 \\
.82 \\
.79 \\
.78 \\
.78 \\
.70 \\
.81 \\
.85 \\
.90\end{array}$ & $\begin{array}{l}8.65 \\
8.68 \\
8.68 \\
8.64 \\
9.40 \\
7.88 \\
8.68 \\
8.89 \\
8.47 \\
8.00\end{array}$ & $\begin{array}{l}183.4 \\
201.3 \\
201.3 \\
180.0 \\
171.1 \\
177.6 \\
161.4 \\
174.4 \\
196.7 \\
207.0\end{array}$ & $\begin{array}{l}48.08 \\
52.74 \\
52.74 \\
47.16 \\
43.81 \\
46.14 \\
42.02 \\
45.64 \\
51.94 \\
53.82\end{array}$ \\
\hline $\begin{array}{l}\text { Delmarva Power Llght Co Indlan River } \\
\text { Pennsylvania } \\
\text { Jefferson } \\
\text { West Virginia } \\
\text { Barbour } \\
\text { Boone } \\
\text { Mingo } \\
\text { Nicholas } \\
\text { Preston } \\
\text { Webster }\end{array}$ & $\begin{array}{r}978 \\
137 \\
137 \\
840 \\
410 \\
7 \\
251 \\
51 \\
66 \\
54\end{array}$ & $\begin{array}{l}13,044 \\
13,104 \\
13,104 \\
13,034 \\
13,096 \\
13,241 \\
12,922 \\
12,979 \\
13,090 \\
13,031\end{array}$ & $\begin{array}{r}1.16 \\
1.40 \\
1.40 \\
1.12 \\
1.40 \\
.75 \\
.69 \\
.72 \\
1.33 \\
1.18\end{array}$ & $\begin{array}{r}8.94 \\
9.31 \\
9.31 \\
8.88 \\
8.64 \\
7.00 \\
8.81 \\
9.40 \\
10.07 \\
9.29\end{array}$ & $\begin{array}{l}167.7 \\
177.9 \\
177.9 \\
166.1 \\
160.2 \\
184.1 \\
173.2 \\
171.0 \\
166.5 \\
170.3\end{array}$ & $\begin{array}{l}43.76 \\
46.62 \\
46.62 \\
43.29 \\
41.90 \\
48.75 \\
44.75 \\
44.38 \\
43.60 \\
44.39\end{array}$ \\
\hline $\begin{array}{l}\text { Deseret Generation a Tran Coop Bonanza } \\
\text { Colorado } \\
\text { Rio Blanco }\end{array}$ & $\begin{array}{l}1,517 \\
1,517 \\
1,517\end{array}$ & $\begin{array}{l}10,531 \\
10,531 \\
10,531\end{array}$ & $\begin{array}{l}.48 \\
.48 \\
.48\end{array}$ & $\begin{array}{l}10.54 \\
10.54 \\
10.54\end{array}$ & $\begin{array}{l}201.4 \\
201.4 \\
201.4\end{array}$ & $\begin{array}{l}42.42 \\
42.42 \\
42.42\end{array}$ \\
\hline 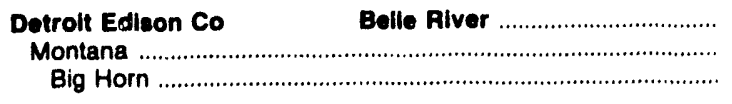 & $\begin{array}{l}3,474 \\
3,474 \\
3,474\end{array}$ & $\begin{array}{l}9,505 \\
9,505 \\
9,505\end{array}$ & $\begin{array}{l}.35 \\
.35 \\
.35\end{array}$ & $\begin{array}{l}4.07 \\
4.07 \\
4.07\end{array}$ & $\begin{array}{l}150.1 \\
150.1 \\
150.1\end{array}$ & $\begin{array}{l}28.53 \\
28.53 \\
28.53\end{array}$ \\
\hline 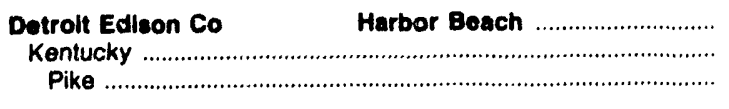 & $\begin{array}{l}39 \\
38 \\
39\end{array}$ & $\begin{array}{l}13,142 \\
13,142 \\
13,142\end{array}$ & $\begin{array}{l}.85 \\
.85 \\
.85\end{array}$ & $\begin{array}{l}7.27 \\
7.27 \\
7.27\end{array}$ & $\begin{array}{l}162.3 \\
162.3 \\
162.3\end{array}$ & $\begin{array}{l}42.66 \\
42.66 \\
42.66\end{array}$ \\
\hline 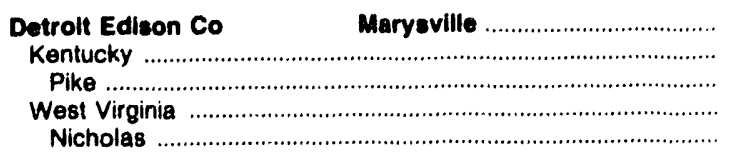 & $\begin{array}{l}61 \\
32 \\
32 \\
29 \\
29\end{array}$ & $\begin{array}{l}13,065 \\
12,955 \\
12,955 \\
13,187 \\
13,187\end{array}$ & $\begin{array}{l}.85 \\
.83 \\
.83 \\
.86 \\
.66\end{array}$ & $\begin{array}{l}7.78 \\
8.17 \\
8.17 \\
7.35 \\
7.35\end{array}$ & $\begin{array}{l}183.2 \\
182.1 \\
182.1 \\
184.3 \\
184.3\end{array}$ & $\begin{array}{l}47.86 \\
47.10 \\
47.19 \\
48.61 \\
48.61\end{array}$ \\
\hline $\begin{array}{l}\text { Detrolt Edison Co } \\
\text { Kentucky } \\
\text { Floyd } \\
\text { Knott } \\
\text { Leslie } \\
\text { Letcher }\end{array}$ & $\begin{array}{r}7,820 \\
2,028 \\
292 \\
278 \\
70 \\
39\end{array}$ & $\begin{array}{l}11,157 \\
12,858 \\
12,615 \\
13,070 \\
12,884 \\
12,570\end{array}$ & $\begin{array}{l}.83 \\
1.21 \\
1.20 \\
1.10 \\
1.22 \\
1.12\end{array}$ & $\begin{array}{l}5.95 \\
7.80 \\
8.44 \\
7.35 \\
8.29 \\
9.92\end{array}$ & $\begin{array}{l}150.5 \\
164.3 \\
176.9 \\
149.7 \\
133.3 \\
124.4\end{array}$ & $\begin{array}{l}33.59 \\
42.25 \\
44.62 \\
39.12 \\
34.34 \\
31.26\end{array}$ \\
\hline
\end{tabular}

See footnotes at end of table.

Source: Federal Energy Regulatory Commission, FERC Form 423. "Monthly Report of Cost and Quality of Fuels for Electric Plants." 
Table 24. Origin of Coal Received by Electric Utility and Plant, 1992 (Continued)

\begin{tabular}{|c|c|c|c|c|c|c|}
\hline \multirow{2}{*}{$\begin{array}{c}\text { Electric Utilly Plant } \\
\text { Origin State } \\
\text { County }\end{array}$} & \multirow{2}{*}{$\begin{array}{l}\text { Quantity } \\
\text { (thousand } \\
\text { short tons) }\end{array}$} & \multicolumn{3}{|c|}{ Average Quality } & \multicolumn{2}{|c|}{ Average Dellvered Cost } \\
\hline & & $\begin{array}{c}\text { Btu } \\
\text { (per pound) }\end{array}$ & $\begin{array}{c}\text { Sulfur } \\
\text { (percent } \\
\text { by weight) }\end{array}$ & $\begin{array}{c}\text { Ash } \\
\text { (percent } \\
\text { by weight) }\end{array}$ & $\begin{array}{l}\text { (cents per } \\
\text { million Btu) }\end{array}$ & $\begin{array}{l}\text { (dollars per } \\
\text { short ton) }\end{array}$ \\
\hline \multicolumn{7}{|l|}{$\begin{array}{l}\text { Detroit Edlson Co } \\
\text { Kentucky }\end{array}$} \\
\hline 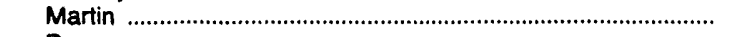 & 245 & 12,554 & 0.84 & 8.76 & 206.1 & 51.74 \\
\hline 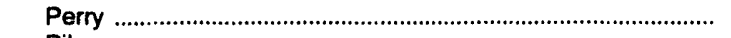 & 50 & 12,985 & .99 & 7.94 & 163.6 & 42.49 \\
\hline Pike & 1,054 & 12,943 & 1.32 & 7.40 & 158.9 & 41.12 \\
\hline 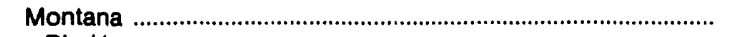 & 1,739 & 9,518 & .35 & 4.05 & 154.0 & 29.31 \\
\hline Big Horn & 1,739 & 9,518 & .35 & 4.05 & 154.0 & 29.31 \\
\hline 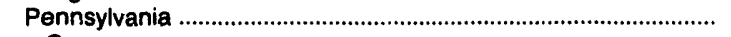 & 1,432 & 13,272 & 1.46 & 6.19 & 158.2 & 41.98 \\
\hline Greene & 1,432 & 13,272 & 1.46 & 6.19 & 158.2 & 41.98 \\
\hline Virginia & 21 & 13,114 & 1.33 & 8.40 & 149.0 & 39.08 \\
\hline 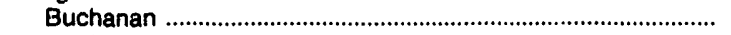 & 21 & 13,114 & 1.33 & 8.40 & 149.0 & 39.08 \\
\hline West Virginia & 618 & 13,107 & 1.28 & 7.76 & 179.5 & 47.05 \\
\hline 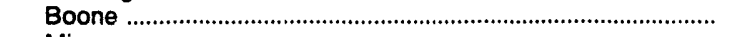 & 469 & 13,134 & 1.32 & 7.69 & 179.4 & 47.13 \\
\hline Mingo & 103 & 12,947 & 1.35 & 8.31 & 181.6 & 47.02 \\
\hline 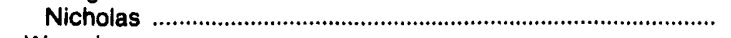 & 46 & 13,195 & .72 & 7.26 & 175.6 & 46.33 \\
\hline 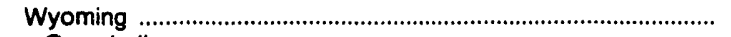 & 1,982 & 8,699 & .28 & 4.94 & 104.5 & 18.18 \\
\hline 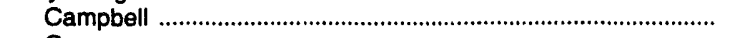 & 1,691 & 8,677 & .27 & 4.83 & 104.6 & 18.16 \\
\hline 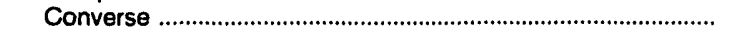 & 291 & 8,828 & .32 & 5.60 & 103.6 & 18.30 \\
\hline River Rouge ............................... & 968 & 11,753 & .59 & 9.50 & 150.6 & 35.41 \\
\hline 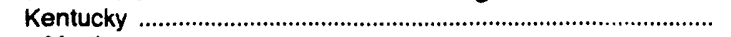 & 62 & 12,795 & .80 & 8.07 & 194.5 & 49.77 \\
\hline Martin & 41 & 12,739 & .78 & 7.83 & 207.1 & 52.77 \\
\hline Pike & 21 & 12.905 & .85 & 8.54 & 170.1 & 43.91 \\
\hline 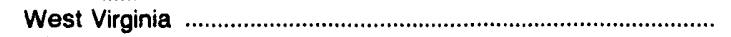 & 697 & 12,570 & .68 & 11.04 & 156.1 & 39.24 \\
\hline Logan & 464 & 12,440 & .64 & 11.70 & 157.9 & 39.28 \\
\hline 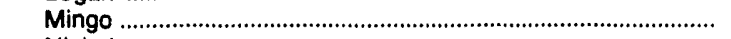 & 185 & 12,742 & .75 & 10.29 & 146.1 & 37.24 \\
\hline 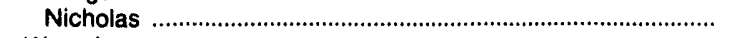 & 48 & 13,172 & .79 & 7.55 & 177.1 & 46.66 \\
\hline 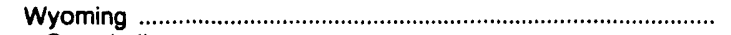 & 209 & 8,720 & .24 & 4.80 & 105.3 & 18.37 \\
\hline 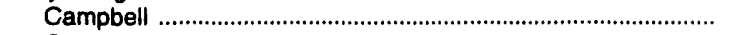 & 175 & 8,699 & .23 & 4.70 & 105.5 & 18.36 \\
\hline 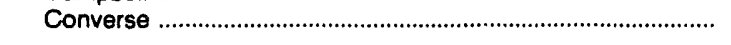 & 34 & 8,829 & .31 & 5.32 & 104.4 & 18.43 \\
\hline 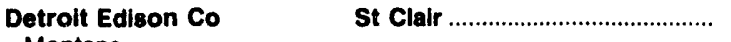 & 4,439 & 9,664 & .52 & 4.51 & 144.9 & 28.00 \\
\hline 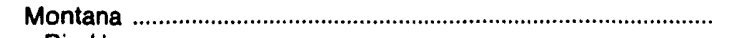 & 3,809 & 9,509 & .35 & 4.07 & 148.3 & 28.21 \\
\hline 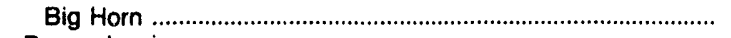 & 3,809 & 9,509 & .35 & 4.07 & 148.3 & 28.21 \\
\hline 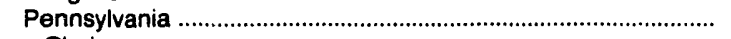 & 295 & 12,626 & 2.96 & 9.34 & 132.8 & 33.55 \\
\hline 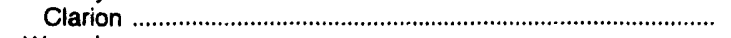 & 295 & 12,626 & 2.96 & 9.34 & 132.8 & 33.55 \\
\hline Wyoming & 335 & 8,820 & .35 & 5.27 & 117.6 & 20.74 \\
\hline 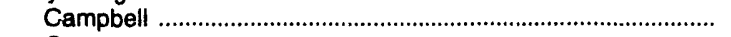 & 111 & 8,813 & .39 & 5.11 & 118.4 & 20.88 \\
\hline Converse & 224 & 8,823 & .33 & 5.34 & 117.2 & 20.68 \\
\hline Detroit Edison Co $\quad$ Trenton Channel ......................... & 1,200 & 11,371 & .59 & 5.96 & 161.8 & 36.80 \\
\hline Kentucky & 381 & 12,783 & .78 & 8.14 & 191.3 & 48.90 \\
\hline Letcher & 21 & 12,783 & .78 & 8.61 & 145.5 & 37.21 \\
\hline Martin & 231 & 12,590 & .81 & 8.52 & 210.2 & 52.93 \\
\hline Pike & 129 & 13,129 & .71 & 7.38 & 166.0 & 43.58 \\
\hline 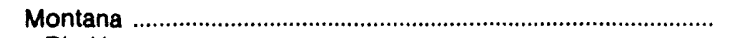 & 540 & 9,397 & .34 & 3.89 & 113.3 & 21.29 \\
\hline Big Horn & 540 & 9,397 & .34 & 3.89 & 113.3 & 21.29 \\
\hline Pennsylvania & 16 & 13,332 & 1.36 & 5.90 & 175.2 & 46.72 \\
\hline 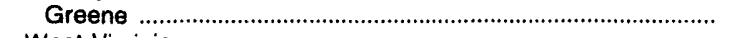 & 16 & 13,332 & 1.36 & 5.90 & 175.2 & 46.72 \\
\hline West Virginia & 263 & 13,261 & .81 & 7.08 & 190.5 & 50.53 \\
\hline 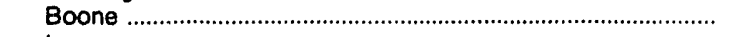 & 145 & 13,557 & .88 & 5.43 & 207.0 & 56.14 \\
\hline Logan & 41 & 12,583 & .73 & 11.63 & 155.5 & 39.14 \\
\hline 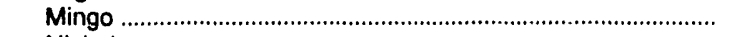 & 19 & 12,769 & .79 & 9.34 & 150.2 & 38.36 \\
\hline Nicholas & 58 & 13,162 & .71 & 7.24 & 184.4 & 48.54 \\
\hline Allen & 877 & 12,503 & 1.07 & 11.47 & 187.4 & 46.85 \\
\hline Virginia & 877 & 12,503 & 1.07 & 11.47 & 187.4 & 46.85 \\
\hline 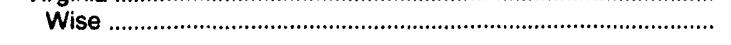 & 877 & 12,503 & 1.07 & 11.47 & 187.4 & 46.85 \\
\hline Belews Creek ............................ & 4,388 & 12,429 & .90 & 9.58 & 172.1 & 42.78 \\
\hline 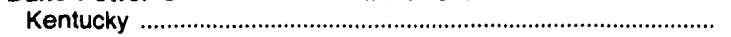 & 3,401 & 12,388 & .90 & 9.26 & 177.2 & 43.90 \\
\hline Bell & 158 & 12,522 & .95 & 8.77 & 165.2 & 41.36 \\
\hline Martin & 2,825 & 12,356 & .88 & 9.21 & 178.5 & 44.12 \\
\hline Pike & 418 & 12,558 & .98 & 9.75 & 172.5 & 43.32 \\
\hline 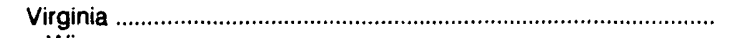 & 470 & 12,668 & 1.00 & 10.84 & 176.1 & 44.62 \\
\hline Wise & 470 & 12,668 & 1.00 & 10.84 & 176.1 & 44.62 \\
\hline West Virginia & 517 & 12,477 & .82 & 10.56 & 135.4 & 33.79 \\
\hline Mingo & 499 & 12,481 & .82 & 10.65 & 135.4 & 33.79 \\
\hline Wayne & 18 & 12,369 & .85 & 8.15 & 137.2 & 33.93 \\
\hline
\end{tabular}

See footnotes at end of table.

Source: Federal Energy Regulatory Commission, FERC Form 423, "Monthly Report of Cost and Quality of Fuels for Electric Plants." 
Table 24. Origin of Coal Received by Electric Utility and Plant, 1992 (Continued)

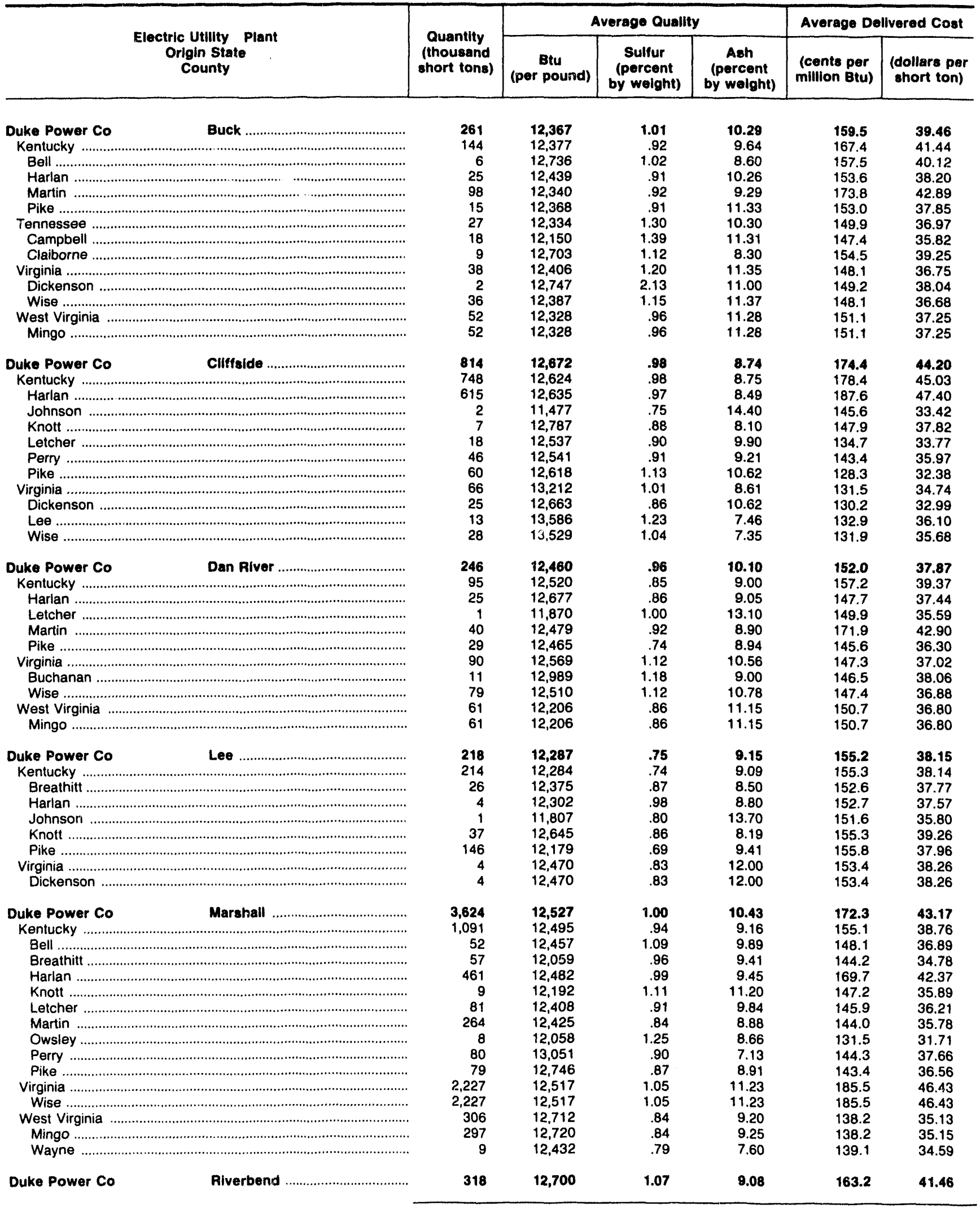

See footnotes at end of table.

Source: Federal Energy Regulatory Commission, FERC Form 423, "Monthly Report of Cost and Quality of Fuels for Electric Plants." 
Table 24. Origin of Coal Received by Electric Utility and Plant, 1992 (Continued)

\begin{tabular}{|c|c|c|c|c|c|c|}
\hline \multirow{2}{*}{$\begin{array}{c}\text { Electric Utillty Plant } \\
\text { Origin State } \\
\text { County }\end{array}$} & \multirow{2}{*}{$\begin{array}{l}\text { Quantity } \\
\text { (thousand } \\
\text { short tons) }\end{array}$} & \multicolumn{3}{|c|}{ Average Quallty } & \multicolumn{2}{|c|}{ Average Delivered Cost } \\
\hline & & $\begin{array}{c}\text { Btu } \\
\text { (per pound) }\end{array}$ & $\begin{array}{c}\text { Sulfur } \\
\text { (percent } \\
\text { by weight) }\end{array}$ & $\begin{array}{c}\text { Ash } \\
\text { (percent } \\
\text { by weight) }\end{array}$ & $\begin{array}{l}\text { (cents per } \\
\text { million Btu) }\end{array}$ & $\begin{array}{l}\text { (dollars per } \\
\text { short ton) }\end{array}$ \\
\hline \multicolumn{7}{|l|}{ Duke Power Co Riverbend } \\
\hline 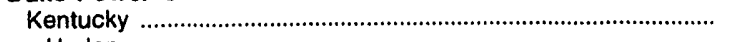 & 318 & 12,700 & 1.07 & 9.08 & 163.2 & 41.46 \\
\hline Harlan & 235 & 12,740 & 1.09 & 8.88 & 169.8 & 43.26 \\
\hline Knott & 14 & 12,622 & .84 & 8.45 & 148.0 & 37.36 \\
\hline Letcher & 9 & 12,495 & .98 & 10.10 & 149.7 & 37.41 \\
\hline Perry & 45 & 12,514 & .92 & 9.50 & 142.8 & 35.75 \\
\hline 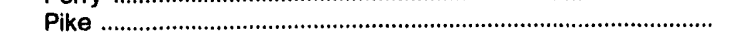 & 15 & 12,830 & 1.36 & 10.80 & 142.4 & 36.54 \\
\hline Cheswick ..................................... & 1,320 & 12,975 & 1.75 & 9.39 & 128.1 & 33.23 \\
\hline 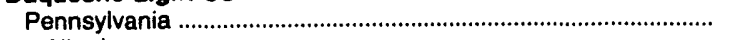 & 975 & 13,047 & 1.82 & 8.89 & 127.9 & 33.36 \\
\hline Allegheny & 261 & 12,832 & 1.19 & 8.83 & 135.7 & 34.83 \\
\hline Armstrong & 10 & 12,998 & 2.01 & 11.35 & 107.4 & 27.92 \\
\hline Fayette & 121 & 12,854 & 1.16 & 9.46 & 133.5 & 34.32 \\
\hline Greene & 551 & 13,181 & 2.27 & 8.82 & 123.6 & 32.59 \\
\hline Washington & 32 & $13,2.35$ & 1.51 & 7.64 & 123.6 & 32.70 \\
\hline West Virginia & 345 & 12.771 & 1.56 & 10.79 & 128.7 & 32.87 \\
\hline 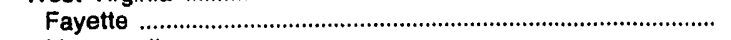 & 148 & 12,937 & 1.10 & 9.77 & 130.8 & 33.85 \\
\hline 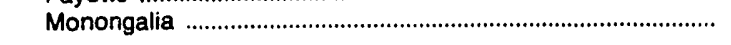 & 197 & 12,647 & 1.91 & $\$ 1.55$ & 127.0 & 32.13 \\
\hline 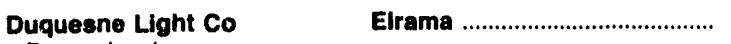 & 1,104 & 12,330 & 1.68 & 12.33 & 173.0 & 42.66 \\
\hline 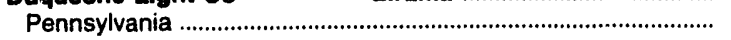 & 1,029 & 12,320 & 1.68 & 12.42 & 176.2 & 43.41 \\
\hline Allegheny & 239 & 12,108 & 1.91 & 12.31 & 115.7 & 28.03 \\
\hline 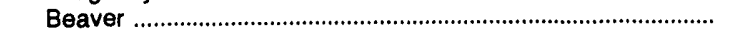 & 53 & 12,323 & 2.25 & 12.42 & 98.0 & 24.15 \\
\hline 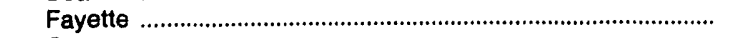 & 145 & 12,126 & 2.28 & 12.79 & 97.9 & 23.75 \\
\hline 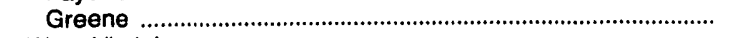 & 592 & 12,453 & 1.39 & 12.38 & 225.5 & 56.16 \\
\hline West Virginia & 75 & 12,470 & 1.61 & 11.07 & 129.5 & 32.29 \\
\hline 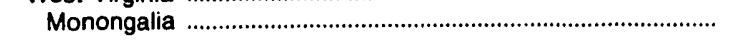 & 75 & 12,470 & 1.61 & 11.07 & 129.5 & 32.29 \\
\hline 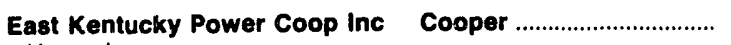 & 732 & 12,361 & 1.62 & 10.09 & $\$ 13.1$ & 27.95 \\
\hline 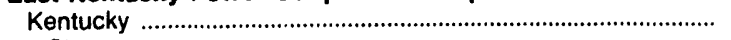 & 700 & 12,339 & 1.60 & 10.08 & $1\} 3.5$ & 28.01 \\
\hline 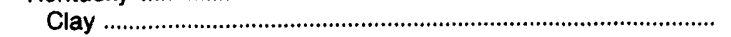 & 114 & 12,677 & 1.45 & 8.35 & 109.9 & 27.86 \\
\hline Jackson & 8 & 11,566 & 2.19 & 11.96 & 103.4 & 23.92 \\
\hline 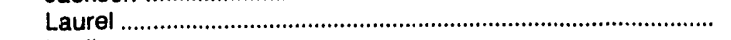 & 13 & 11,985 & 1.41 & 11.32 & 90.1 & 21.60 \\
\hline 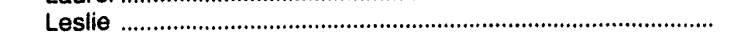 & 46 & 12,661 & 1.95 & 9.16 & 110.9 & 28.08 \\
\hline 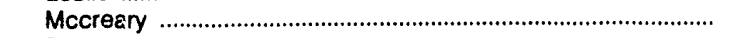 & 25 & 13,250 & .99 & 5.17 & 106.9 & 28.34 \\
\hline 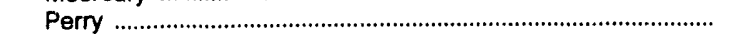 & 48 & 12,456 & 1.30 & 9.06 & 107.0 & 26.66 \\
\hline 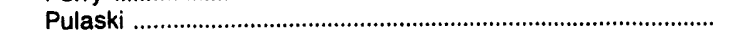 & 394 & 12,198 & 1.65 & 11.03 & 118.0 & 28.80 \\
\hline Whitley & 34 & 12,131 & 1.62 & 9.95 & 107.1 & 25.98 \\
\hline Wolfe & 18 & 11,876 & 1.98 & 10.58 & 105.5 & 25.06 \\
\hline 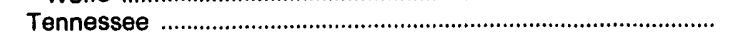 & 32 & 12,837 & 2.02 & 10.31 & 103.8 & 26.64 \\
\hline 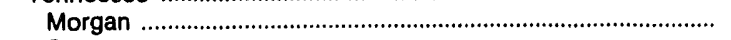 & 32 & 12,835 & 2.03 & 10.36 & 103.7 & 26.62 \\
\hline Scott & * & 13,099 & .82 & 4.80 & 109.6 & 28.71 \\
\hline 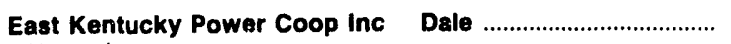 & 287 & 12,385 & .84 & 8.22 & 106.8 & 26.47 \\
\hline Kentucky & 287 & 12,385 & .84 & 8.22 & 106.8 & 26.47 \\
\hline 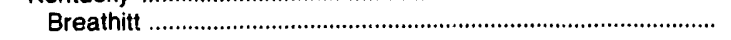 & 101 & 11,957 & .80 & 9.77 & 106.0 & 25.35 \\
\hline Perry & 81 & 12,613 & .82 & 8.43 & 107.1 & 27.02 \\
\hline 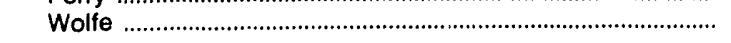 & 105 & 12,620 & .89 & 6.56 & 107.4 & 27.11 \\
\hline 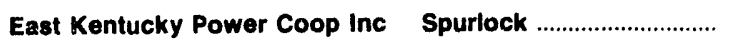 & 1,542 & 12,273 & 1.35 & 10.74 & 116.7 & 28.64 \\
\hline Kentucky & 726 & 12,126 & 1.46 & 10.50 & 116.1 & 28.16 \\
\hline Boyd & 205 & 12,666 & .80 & 9.21 & 116.1 & 29.40 \\
\hline Floyd & 159 & 11,980 & 1.45 & 11.26 & 122.1 & 29.26 \\
\hline Greenup & 215 & 11,493 & 2.50 & 11.69 & 110.2 & 25.34 \\
\hline Johnson & 3 & 11,205 & 2.47 & 12.70 & 100.4 & 22.50 \\
\hline Knott & 121 & 12,617 & .70 & 9.31 & 121.3 & 30.60 \\
\hline 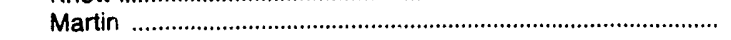 & 11 & 11,583 & .80 & 11.73 & 106.5 & 24.68 \\
\hline 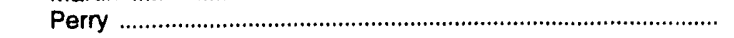 & 3 & 11,758 & 1.84 & 15.00 & 76.7 & 18.04 \\
\hline Wolfe & 9 & 11,995 & 2.16 & 10.27 & 100.4 & 24.08 \\
\hline 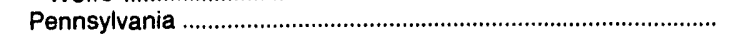 & 33 & 12,939 & 2.52 & 8.02 & 101.0 & 26.13 \\
\hline Greene & 19 & 13,273 & 2.26 & 6.94 & 98.9 & 26.26 \\
\hline Washington & 14 & 12,487 & 2.87 & 9.49 & 103.9 & 25.96 \\
\hline West Virginia & 783 & 12,382 & 1.20 & 11.08 & 117.9 & 29.19 \\
\hline Fayette & 356 & 12,556 & 1.76 & 12.50 & 122.8 & 30.83 \\
\hline Harrison & 13 & 12,330 & 2.67 & 12.48 & 101.6 & 25.06 \\
\hline Kanawha & 27 & 12,293 & .69 & 11.91 & 109.5 & 26.92 \\
\hline Logan & 100 & 12,159 & .67 & 11.07 & 115.2 & 28.01 \\
\hline Mingo & 140 & 12,175 & .66 & 9.56 & 114.3 & 27.84 \\
\hline 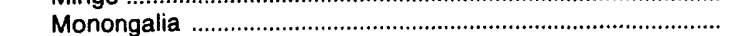 & 3 & 11,295 & 1.86 & 15.70 & 96.2 & 21.73 \\
\hline Wayne & 144 & 12,350 & .63 & 8.66 & 114.2 & 28.21 \\
\hline
\end{tabular}

See footnotes at end of table.

Source: Federal Energy Regulatory Commission, FERC Form 423, "Monthly Report of Cost and Quality of Fuels for Electric Plants." 
Table 24. Origin of Coal Received by Electric Utillty and Plant, 1992 (Continued)

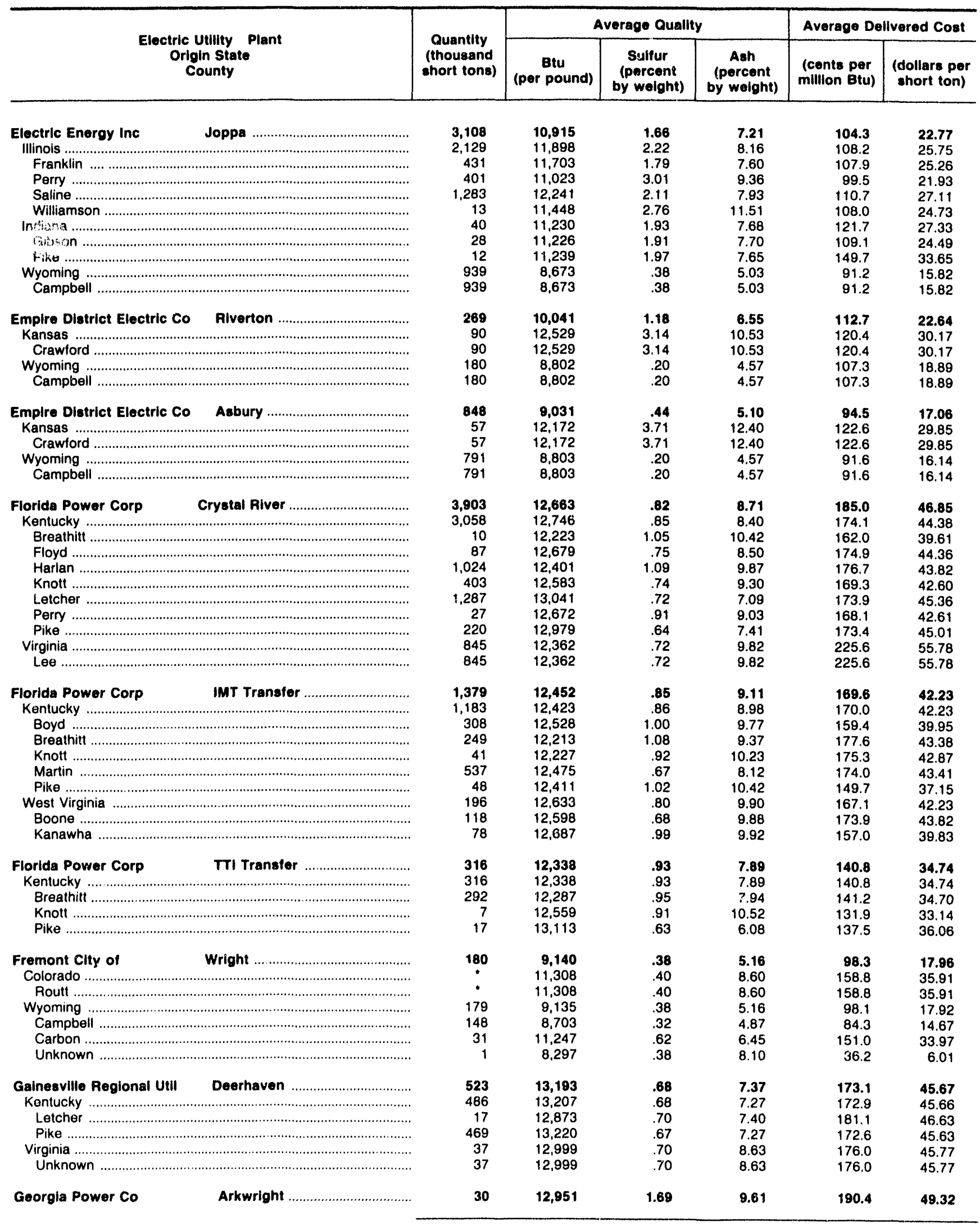

See footnotes at end of table.

Source: Federal Energy Regulatory Commission, FERC Form 423, "Monthly Report of Cost and Quality of Fuels for Electric Plants." 
Table 24. Origin of Coal Recelved by Electric Utility and Plant, 1992 (Continued)

\begin{tabular}{|c|c|c|c|c|c|c|}
\hline \multirow{2}{*}{$\begin{array}{c}\text { Electric Utility Plant } \\
\text { Origin State } \\
\text { County }\end{array}$} & \multirow{2}{*}{$\begin{array}{l}\text { Quantity } \\
\text { (thousand } \\
\text { short tons) }\end{array}$} & \multicolumn{3}{|c|}{ Average Quallity } & \multicolumn{2}{|c|}{ Average Dellvered Cost } \\
\hline & & $\begin{array}{c}\text { Btu } \\
\text { (per pound) }\end{array}$ & $\begin{array}{c}\text { Sulfur } \\
\text { (percent } \\
\text { by weight) }\end{array}$ & $\begin{array}{c}\text { Ash } \\
\text { (percent } \\
\text { by welght) }\end{array}$ & $\begin{array}{l}\text { (cents per } \\
\text { million Btu) }\end{array}$ & $\begin{array}{l}\text { (dollars per } \\
\text { short ton) }\end{array}$ \\
\hline \multicolumn{7}{|l|}{ Georgia Power Co } \\
\hline Virginia & 30 & 12,951 & 1.69 & 9.61 & 190.4 & 49.32 \\
\hline 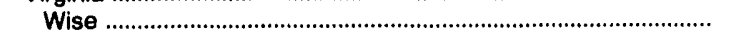 & 30 & 12,951 & 1.69 & 9.61 & 190.4 & 49.32 \\
\hline Atkinson-Mcdonoug .................. & 1,383 & 11,877 & 1.88 & 9.59 & 162.9 & 38.70 \\
\hline Illinois ......................... & 34 & 11,259 & 2.86 & 9.48 & 208.9 & 47.05 \\
\hline 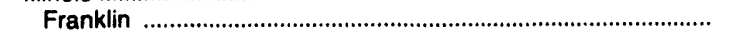 & 34 & 11,259 & 2.86 & 9.48 & 208.9 & 47.05 \\
\hline 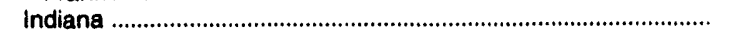 & 555 & 11,294 & 2.51 & 8.13 & 138.4 & 31.26 \\
\hline 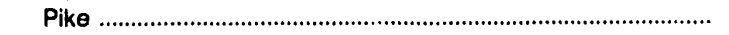 & 555 & 11,294 & 2.51 & 8.13 & 138.4 & 31.26 \\
\hline 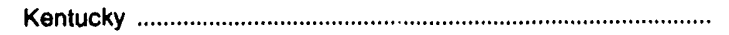 & 607 & 12,243 & 1.38 & 10.48 & 174.8 & 42.79 \\
\hline 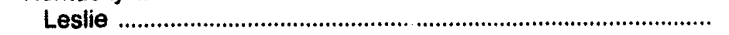 & 170 & 12,642 & 1.30 & 9.59 & 174.7 & 44.18 \\
\hline 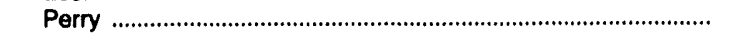 & 434 & 12,103 & 1.42 & 10.74 & 174.9 & 42.33 \\
\hline 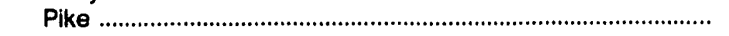 & 3 & 9,595 & .81 & 24.70 & 154.6 & 29.67 \\
\hline 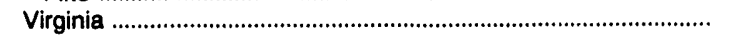 & 187 & 12,537 & 1.42 & 11.07 & 183.3 & 45.96 \\
\hline Le日 & 159 & 12,439 & 1.38 & 11.33 & 185.3 & 46.09 \\
\hline 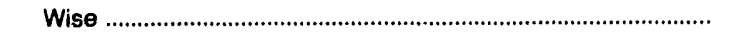 & 28 & 13,097 & 1.69 & 9.55 & 172.7 & 45.24 \\
\hline 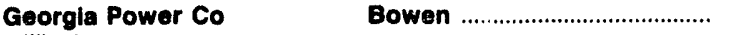 & 8,082 & 12,186 & 1.54 & 10.47 & 162.0 & 39.47 \\
\hline 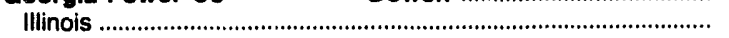 & 82 & 11,793 & 2.49 & 7.67 & 215.8 & 50.90 \\
\hline 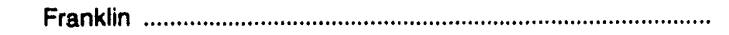 & 82 & 11,793 & 2.49 & 7.67 & 215.8 & 50.90 \\
\hline 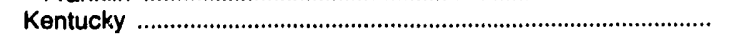 & 8,000 & 12,190 & 1.53 & 10.50 & 161.4 & 39.36 \\
\hline 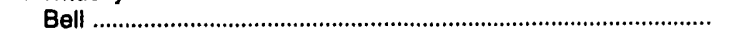 & 947 & 12,095 & 1.36 & 11.13 & 181.4 & 43.88 \\
\hline 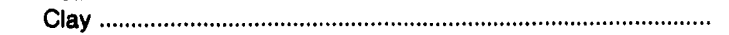 & 229 & 12,560 & 1.21 & 9.75 & 158.6 & 39.85 \\
\hline Hopkins & 1,357 & 11,737 & 3.01 & 10.15 & 169.6 & 39.80 \\
\hline Knott ...1-1-1) & 760 & 12,082 & 1.36 & 11.55 & 156.9 & 37.90 \\
\hline 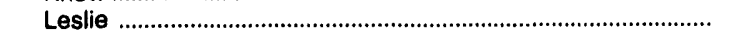 & 2,713 & 12,325 & 1.28 & 10.48 & 158.9 & 39.17 \\
\hline 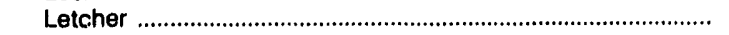 & 104 & 12,402 & 1.39 & 11.19 & 174.8 & 43.36 \\
\hline 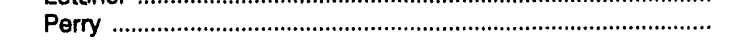 & 1,890 & 12,354 & 1.03 & 10.08 & 151.1 & 37.34 \\
\hline 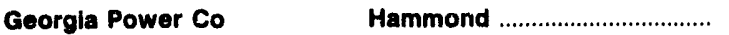 & 803 & 12,971 & 1.66 & 9.86 & 174.9 & 45.36 \\
\hline 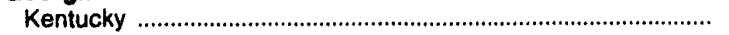 & 5 & 12,594 & 1.04 & 9.01 & 152.0 & 38.29 \\
\hline 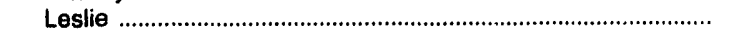 & 5 & 12,594 & 1.04 & 9.01 & 152.0 & 38.29 \\
\hline Virginia & 798 & 12,973 & 1.67 & 9.86 & 175.0 & 45.40 \\
\hline Le日 & 137 & 12,722 & 1.39 & 10.60 & 179.5 & 45.68 \\
\hline 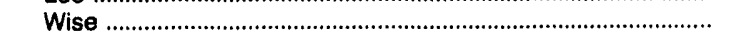 & 661 & 13,025 & 1.72 & 9.71 & 174.1 & 45.35 \\
\hline Harllee Branch .......................... & 3,137 & 12,368 & 1.30 & 9.97 & 166.0 & 41.06 \\
\hline . & 2,851 & 12,373 & 1.33 & 9.86 & 166.2 & 41.13 \\
\hline 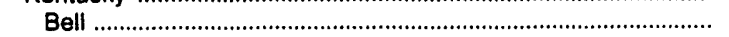 & 348 & 12,056 & 1.39 & 11.12 & 199.0 & 47.99 \\
\hline 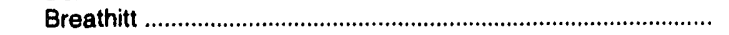 & 277 & 12,087 & 1.08 & 9.17 & 147.8 & 35.72 \\
\hline Floyd & 54 & 12,557 & .89 & 8.07 & 146.0 & 36.67 \\
\hline Harlan & 292 & 12,197 & 1.19 & 9.49 & 140.6 & 34.31 \\
\hline 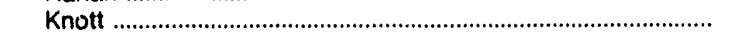 & 568 & 12,656 & 1.55 & 10.32 & 173.9 & 44.02 \\
\hline 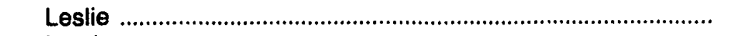 & 127 & 12,371 & 1.29 & 10.13 & 171.5 & 42.43 \\
\hline 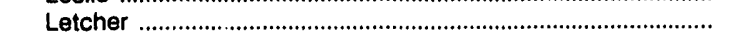 & 257 & 12,370 & 1.38 & 11.43 & 171.0 & 42.31 \\
\hline 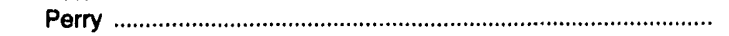 & 493 & 12,148 & 1.08 & 10.26 & 148.8 & 36.15 \\
\hline 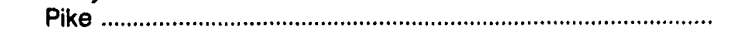 & 434 & 12,794 & 1.59 & 7.68 & 175.9 & 45.02 \\
\hline 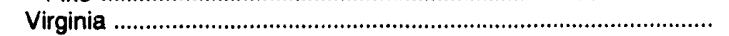 & 94 & 12,557 & 1.33 & 11.18 & 195.8 & 49.18 \\
\hline Lee & 83 & 12,498 & 1.30 & 11.44 & 197.1 & 49.27 \\
\hline Wise & 11 & 13,027 & 1.59 & 9.05 & 186.3 & 48.54 \\
\hline 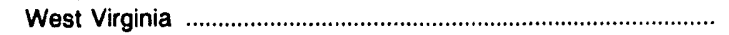 & 193 & 12,191 & .87 & 10.96 & 148.3 & 36.16 \\
\hline 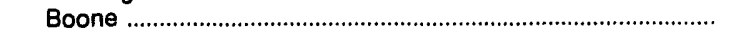 & 183 & 12,154 & .87 & 11.06 & 148.0 & 35.97 \\
\hline 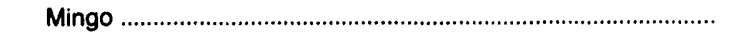 & 10 & 12,852 & .75 & 9.14 & 154.1 & 39.61 \\
\hline 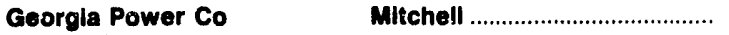 & 154 & 12,697 & 1.32 & 8.82 & 185.6 & 47.13 \\
\hline 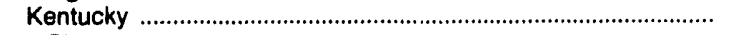 & 154 & 12,697 & 1.32 & 8.82 & 185.6 & 47.13 \\
\hline Clay & 10 & 12,083 & 1.41 & 10.98 & 198.2 & 47.90 \\
\hline 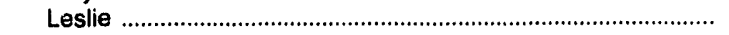 & 35 & 12,483 & 1.30 & 10.16 & 209.5 & 52.31 \\
\hline 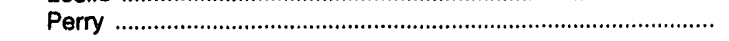 & 110 & 12,819 & 1.32 & 8.21 & 177.1 & 45.42 \\
\hline 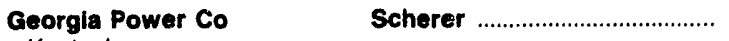 & 2,810 & 12,466 & .67 & 10.34 & 217.7 & 54.28 \\
\hline Kentucky & 204 & 12,349 & .61 & 10.30 & 167.1 & 41.28 \\
\hline 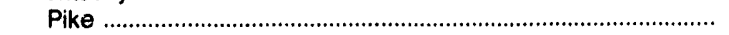 & 204 & 12,349 & .61 & 10.30 & 167.1 & 41.28 \\
\hline 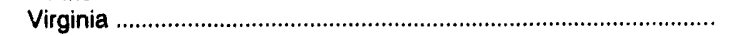 & 603 & 13,316 & .75 & 7.81 & 183.4 & 48.83 \\
\hline Wise & 603 & 13,316 & .75 & 7.81 & 183.4 & 48.83 \\
\hline West Virginia . & 2,002 & 12,222 & .65 & 11.11 & 234.2 & 57.25 \\
\hline 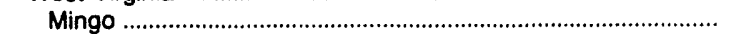 & 2,002 & 12,222 & .65 & 11.11 & 234.2 & 57.25 \\
\hline 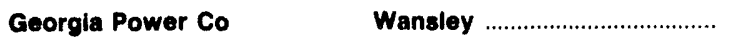 & 4,719 & 11,192 & 2.65 & 10.36 & 202.8 & 45.39 \\
\hline
\end{tabular}

See footnotes at end of table.

Source: Federal Energy Regulatory Commission, FERC Form 423, "Monthly Report of Cost and Quality of Fuels for Electric Plants." 
Table 24. Origin of Coal Received by Electric Utility and Plant, 1992 (Continued)

\begin{tabular}{|c|c|c|c|c|c|c|}
\hline \multirow[b]{2}{*}{$\begin{array}{l}\text { Electric Utillty Piant } \\
\text { Origin Btate } \\
\text { County }\end{array}$} & \multirow{2}{*}{$\begin{array}{l}\text { Quantity } \\
\text { (thousand } \\
\text { short tons) }\end{array}$} & \multicolumn{3}{|c|}{ Avorage Quallty } & \multicolumn{2}{|c|}{ Avorage Delivered Cost } \\
\hline & & $\begin{array}{c}\text { Btu } \\
\text { (per pound) }\end{array}$ & $\begin{array}{l}\text { Sullur } \\
\text { (porcent } \\
\text { by wolght) }\end{array}$ & $\begin{array}{l}\text { Aeh } \\
\text { (percent } \\
\text { by woight) }\end{array}$ & $\begin{array}{l}\text { (cente pur } \\
\text { million Btu) }\end{array}$ & $\begin{array}{l}\text { (dollars per } \\
\text { short ton) }\end{array}$ \\
\hline 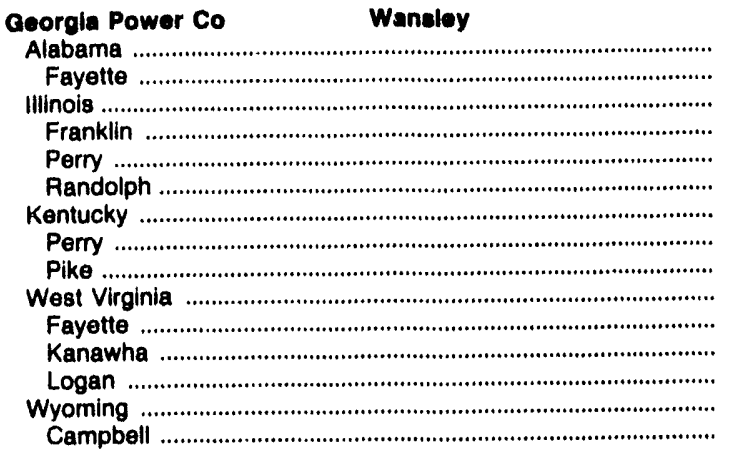 & $\begin{array}{r}54 \\
54 \\
4,378 \\
3,224 \\
1,077 \\
77 \\
48 \\
3 \\
46 \\
227 \\
53 \\
133 \\
41 \\
11 \\
11\end{array}$ & $\begin{array}{r}12,172 \\
12,172 \\
11,269 \\
11,409 \\
10,879 \\
10,862 \\
9,657 \\
8,980 \\
9,698 \\
9,818 \\
10,504 \\
9,822 \\
8,476 \\
8,777 \\
8,777\end{array}$ & $\begin{array}{r}1.89 \\
1.89 \\
2.79 \\
2.67 \\
3.11 \\
2.85 \\
.68 \\
.60 \\
.68 \\
.73 \\
.73 \\
.78 \\
.56 \\
.38 \\
.38\end{array}$ & $\begin{array}{r}12.11 \\
12.11 \\
9.40 \\
8.94 \\
10.77 \\
9.50 \\
23.87 \\
28.04 \\
23.61 \\
25.85 \\
22.68 \\
26.71 \\
27.12 \\
4.59 \\
4.59\end{array}$ & $\begin{array}{l}135.7 \\
135.7 \\
207.8 \\
213.8 \\
194.0 \\
131.0 \\
147.9 \\
146.6 \\
148.0 \\
127.8 \\
138.7 \\
125.3 \\
120.8 \\
127.5 \\
127.5\end{array}$ & $\begin{array}{l}33.03 \\
33.03 \\
46.83 \\
48.81 \\
42.21 \\
28.45 \\
28.57 \\
26.33 \\
28.71 \\
25.36 \\
29.14 \\
24.62 \\
22.89 \\
22.38 \\
22.38\end{array}$ \\
\hline $\begin{array}{l}\text { Coorgla Power Co } \\
\text { Alabama } \\
\text { Fayette } \\
\text { Illinois } \\
\text { Franklin } \\
\text { Perry } \\
\text { Randolph } \\
\text { Kentucky } \\
\text { Harlan } \\
\text { Pike } \\
\text { Virginia } \\
\text { Lee } \\
\text { Wise } \\
\text { West Virginia } \\
\text { Fayette } \\
\text { Kanawha } \\
\text { Logan } \\
\text { Wyoming } \\
\text { Campbell . }\end{array}$ & $\begin{array}{r}1,576 \\
44 \\
44 \\
644 \\
470 \\
164 \\
10 \\
15 \\
3 \\
13 \\
843 \\
632 \\
210 \\
30 \\
9 \\
13 \\
8 \\
\end{array}$ & $\begin{array}{r}11,966 \\
12,106 \\
12,106 \\
11,273 \\
11,423 \\
10,867 \\
10,886 \\
10,138 \\
12,493 \\
9,637 \\
12,596 \\
12,458 \\
13,009 \\
9,875 \\
10,323 \\
8,821 \\
9,485 \\
8,777 \\
8,777\end{array}$ & $\begin{array}{l}1.09 \\
2.14 \\
2.14 \\
2.79 \\
2.67 \\
3.09 \\
2.94 \\
1.05 \\
2.37 \\
.77 \\
1.44 \\
1.39 \\
1.60 \\
.72 \\
.79 \\
.77 \\
.56 \\
.38 \\
.38\end{array}$ & $\begin{array}{r}10.70 \\
12.24 \\
12.24 \\
9.36 \\
8.90 \\
10.67 \\
9.31 \\
21.87 \\
8.43 \\
24.52 \\
10.81 \\
11.30 \\
9.71 \\
25.67 \\
22.32 \\
26.91 \\
27.19 \\
4.59 \\
4.69\end{array}$ & $\begin{array}{l}190.3 \\
135.4 \\
135.4 \\
207.7 \\
213.7 \\
194.3 \\
130.9 \\
152.1 \\
148.5 \\
153.1 \\
183.5 \\
187.2 \\
172.6 \\
130.5 \\
147.7 \\
124.5 \\
120.7 \\
127.5 \\
127.5\end{array}$ & $\begin{array}{l}45.54 \\
32.77 \\
32.77 \\
46.82 \\
48.81 \\
42.23 \\
28.50 \\
30.84 \\
37.10 \\
29.51 \\
46.21 \\
46.65 \\
44.91 \\
25.77 \\
30.50 \\
24.45 \\
22.90 \\
22.38 \\
22.38\end{array}$ \\
\hline 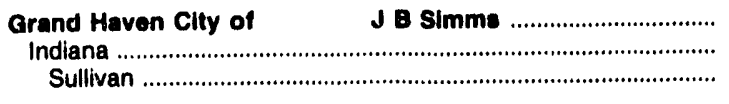 & $\begin{array}{l}205 \\
205 \\
205\end{array}$ & $\begin{array}{l}11,019 \\
11,018 \\
11,019\end{array}$ & $\begin{array}{l}2.46 \\
2.46 \\
2.46\end{array}$ & $\begin{array}{l}10.07 \\
10.07 \\
10.07\end{array}$ & $\begin{array}{l}150.3 \\
150.3 \\
150.3\end{array}$ & $\begin{array}{l}33.12 \\
33.12 \\
33.12\end{array}$ \\
\hline $\begin{array}{c}\text { Crand laland Clty of } \\
\text { Wyoming } \\
\text { Campbell }\end{array}$ & $\begin{array}{l}275 \\
275 \\
275\end{array}$ & $\begin{array}{l}8,391 \\
8,391 \\
8,391\end{array}$ & $\begin{array}{l}.31 \\
.31 \\
.31\end{array}$ & $\begin{array}{l}5.62 \\
5.62 \\
5.62\end{array}$ & $\begin{array}{l}71.0 \\
71.0 \\
71.0\end{array}$ & $\begin{array}{l}11.02 \\
11.02 \\
11.92\end{array}$ \\
\hline $\begin{array}{l}\text { Grand Alver Dam Authority } \\
\text { Oklahoma } \\
\text { Nowata } \\
\text { Wyoming } \\
\text { Campbell }\end{array}$ & $\begin{array}{r}3,593 \\
122 \\
122 \\
3,471 \\
3,471\end{array}$ & $\begin{array}{r}8,586 \\
13,104 \\
13,104 \\
8,426 \\
8,426\end{array}$ & $\begin{array}{r}.48 \\
4.15 \\
4.15 \\
.33 \\
.33\end{array}$ & $\begin{array}{l}5.01 \\
8.50 \\
8.50 \\
4.89 \\
4.89\end{array}$ & $\begin{array}{r}91.0 \\
101.4 \\
101.4 \\
80.4 \\
90.4\end{array}$ & $\begin{array}{l}15.62 \\
26.57 \\
26.57 \\
15.24 \\
15.24\end{array}$ \\
\hline $\begin{array}{l}\text { Gult Power Co } \\
\text { Alabama . } \\
\text { Walker } \\
\text { Illinois } \\
\text { Franklin } \\
\text { Gallatin } \\
\text { Saline } \\
\text { Kentucky } \\
\text { Ohio } \\
\text { Union }\end{array}$ & $\begin{array}{r}2,077 \\
72 \\
72 \\
1,780 \\
497 \\
1,068 \\
214 \\
226 \\
10 \\
216\end{array}$ & $\begin{array}{l}11,945 \\
12,060 \\
12,060 \\
11,926 \\
11,734 \\
12,016 \\
11,922 \\
12,062 \\
11,687 \\
12,079\end{array}$ & $\begin{array}{l}2.71 \\
2.75 \\
2.75 \\
2.70 \\
2.64 \\
2.74 \\
2.65 \\
2.73 \\
2.83 \\
2.72\end{array}$ & $\begin{array}{r}6.63 \\
12.94 \\
12.94 \\
8.37 \\
8.28 \\
8.55 \\
7.70 \\
8.38 \\
7.80 \\
8.40\end{array}$ & $\begin{array}{l}172.2 \\
120.6 \\
120.6 \\
180.8 \\
116.5 \\
222.2 \\
119.7 \\
121.4 \\
117.7 \\
121.5\end{array}$ & $\begin{array}{l}41.13 \\
29.09 \\
29.09 \\
43.12 \\
27.34 \\
53.39 \\
28.53 \\
29.28 \\
27.51 \\
29.36\end{array}$ \\
\hline $\begin{array}{l}\text { Gulf Power Co } \\
\text { Kentucky } \\
\text { Hopkins } \\
\text { Webster }\end{array}$ & $\begin{array}{r}32 \\
32 \\
24 \\
8\end{array}$ & $\begin{array}{l}12,192 \\
12,192 \\
11,967 \\
12,895\end{array}$ & $\begin{array}{l}3.06 \\
3.06 \\
3.09 \\
2.97\end{array}$ & $\begin{array}{l}8.84 \\
8.84 \\
9.21 \\
7.70\end{array}$ & $\begin{array}{l}148.7 \\
148.7 \\
150.6 \\
143.3\end{array}$ & $\begin{array}{l}38.27 \\
36.27 \\
36.05 \\
36.96\end{array}$ \\
\hline Smith & 885 & 11,008 & 2.00 & 8.45 & 221,9 & 53.23 \\
\hline
\end{tabular}

See footnotes at end of table.

Source: Federal Energy Regulatory Commission, FERC Form 423, "Monthly Report of Cost and Quality of Fuels for Electric Plants." 
Table 24. Origin of Coal Received by Electric Utility and Plant, 1992 (Continued)

\begin{tabular}{|c|c|c|c|c|c|c|}
\hline \multirow{2}{*}{$\begin{array}{l}\text { Electric Utilty Plant } \\
\text { Origin State } \\
\text { County }\end{array}$} & \multirow{2}{*}{$\begin{array}{l}\text { Quantity } \\
\text { (thousand } \\
\text { short tons) }\end{array}$} & \multicolumn{3}{|c|}{ Average Quality } & \multicolumn{2}{|c|}{ Average Delivered Cost } \\
\hline & & $\begin{array}{c}\text { Btu } \\
\text { (por pound) }\end{array}$ & $\begin{array}{l}\text { Sulfur } \\
\text { (percent } \\
\text { by wolght) }\end{array}$ & $\begin{array}{l}\text { Ash } \\
\text { (percent } \\
\text { by welght) }\end{array}$ & $\begin{array}{l}\text { (cents per } \\
\text { million Btu) }\end{array}$ & $\begin{array}{l}\text { (dollars per } \\
\text { short ton) }\end{array}$ \\
\hline $\begin{array}{l}\text { Gulf Power Co } \\
\text { Illinois ... Smith } \\
\text { Franklin } \\
\text { Gallatin } \\
\text { Kentucky } \\
\text { Union }\end{array}$ & $\begin{array}{r}878 \\
19 \\
860 \\
6 \\
6\end{array}$ & $\begin{array}{l}11,996 \\
11,723 \\
12,002 \\
11,982 \\
11,982\end{array}$ & $\begin{array}{l}2.80 \\
2.66 \\
2.81 \\
2.54 \\
2.54\end{array}$ & $\begin{array}{l}8.46 \\
8.08 \\
8.47 \\
7.10 \\
7.10\end{array}$ & $\begin{array}{l}222.5 \\
128.8 \\
224.5 \\
129.5 \\
129.5\end{array}$ & $\begin{array}{l}53.39 \\
30.20 \\
53.89 \\
31.03 \\
31.03\end{array}$ \\
\hline $\begin{array}{c}\text { Gulf Ststes Utilltes Co } \\
\text { Wyoming } \\
\text { Campbell }\end{array}$ & $\begin{array}{l}2,249 \\
2,249 \\
2,249\end{array}$ & $\begin{array}{l}8,706 \\
8,706 \\
8,706\end{array}$ & $\begin{array}{l}.45 \\
.45 \\
.45\end{array}$ & $\begin{array}{l}5.86 \\
5.86 \\
5.86\end{array}$ & $\begin{array}{l}160.9 \\
160.9 \\
160.9\end{array}$ & $\begin{array}{l}28.02 \\
28.02 \\
28.02\end{array}$ \\
\hline $\begin{array}{c}\text { Hamilton Clty of } \\
\text { West Virginia } \\
\text { Fayette }\end{array}$ & $\begin{array}{l}26 \\
26 \\
26\end{array}$ & $\begin{array}{l}12,515 \\
12,515 \\
12,515\end{array}$ & $\begin{array}{l}.71 \\
.71 \\
.71\end{array}$ & $\begin{array}{l}8.25 \\
8.25 \\
8.25\end{array}$ & $\begin{array}{l}146.6 \\
146.6 \\
146.6\end{array}$ & $\begin{array}{l}36.71 \\
36.71 \\
36.71\end{array}$ \\
\hline $\begin{array}{c}\text { Hastings Clty of } \\
\text { Wyoming } \\
\text { Campbell }\end{array}$ & $\begin{array}{l}161 \\
161 \\
161\end{array}$ & $\begin{array}{l}8,727 \\
8,727 \\
8,727\end{array}$ & $\begin{array}{l}.28 \\
.28 \\
.28\end{array}$ & $\begin{array}{l}4.66 \\
4.66 \\
4.66\end{array}$ & $\begin{array}{l}86.3 \\
86.3 \\
86.3\end{array}$ & $\begin{array}{l}15.07 \\
15.07 \\
15.07\end{array}$ \\
\hline 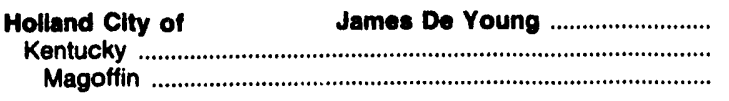 & $\begin{array}{l}153 \\
153 \\
153\end{array}$ & $\begin{array}{l}13,011 \\
13,011 \\
13,011\end{array}$ & $\begin{array}{l}.82 \\
.82 \\
.82\end{array}$ & $\begin{array}{l}6.31 \\
6.31 \\
6.31\end{array}$ & $\begin{array}{l}175.0 \\
175.0 \\
175.0\end{array}$ & $\begin{array}{l}45.54 \\
45.54 \\
45.54\end{array}$ \\
\hline 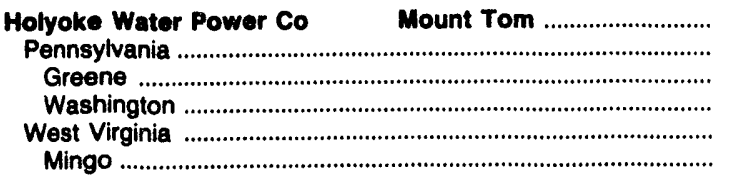 & $\begin{array}{r}363 \\
355 \\
232 \\
123 \\
8 \\
8\end{array}$ & $\begin{array}{l}13,224 \\
13,234 \\
13,161 \\
13,371 \\
12,800 \\
12,800\end{array}$ & $\begin{array}{r}1.33 \\
1.34 \\
1.46 \\
1.13 \\
.80 \\
.80\end{array}$ & $\begin{array}{l}6.31 \\
6.26 \\
6.18 \\
6.41 \\
8.50 \\
8.50\end{array}$ & $\begin{array}{l}168.8 \\
168.2 \\
169.5 \\
165.7 \\
198.2 \\
198.2\end{array}$ & $\begin{array}{l}44.65 \\
44.51 \\
44.62 \\
44.31 \\
50.74 \\
50.74\end{array}$ \\
\hline 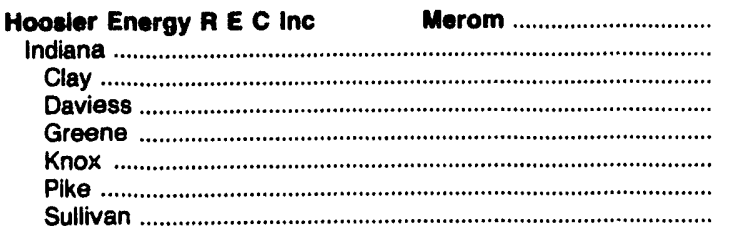 & $\begin{array}{r}2,426 \\
2,426 \\
983 \\
243 \\
85 \\
11 \\
371 \\
733\end{array}$ & $\begin{array}{l}11,042 \\
11,042 \\
10,917 \\
10,965 \\
11,531 \\
11,129 \\
11,259 \\
11,068\end{array}$ & $\begin{array}{l}3.47 \\
3.47 \\
3.86 \\
3.50 \\
2.71 \\
3.52 \\
4.22 \\
2.65\end{array}$ & $\begin{array}{r}11.39 \\
11.39 \\
11.37 \\
11.78 \\
8.73 \\
11.60 \\
11.96 \\
11.31\end{array}$ & $\begin{array}{r}122.5 \\
122.5 \\
168.1 \\
85.5 \\
112.4 \\
79.8 \\
100.5 \\
87.4\end{array}$ & $\begin{array}{l}27.05 \\
27.05 \\
36.71 \\
18.76 \\
25.91 \\
17.76 \\
22.64 \\
19.35\end{array}$ \\
\hline $\begin{array}{c}\text { Hoosier Energy R E C Inc } \quad \text { Frank E Ratte } \\
\text { Indiana } \\
\text { Pike }\end{array}$ & $\begin{array}{l}635 \\
635 \\
635\end{array}$ & $\begin{array}{l}11,240 \\
11,240 \\
11,240\end{array}$ & $\begin{array}{l}2.72 \\
2.72 \\
2.72\end{array}$ & $\begin{array}{l}9.08 \\
9.08 \\
9.08\end{array}$ & $\begin{array}{l}136.8 \\
136.8 \\
136.8\end{array}$ & $\begin{array}{l}30.74 \\
30.74 \\
30.74\end{array}$ \\
\hline 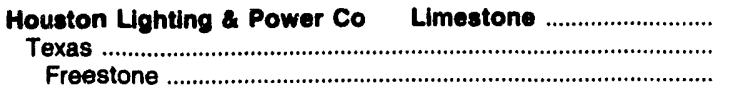 & $\begin{array}{l}7,156 \\
7,156 \\
7,156\end{array}$ & $\begin{array}{l}6,513 \\
6,513 \\
6,513\end{array}$ & $\begin{array}{l}1.23 \\
1.23 \\
1.23\end{array}$ & $\begin{array}{l}17.77 \\
17.77 \\
17.77\end{array}$ & $\begin{array}{l}165.3 \\
165.3 \\
165.3\end{array}$ & $\begin{array}{l}21.54 \\
21.54 \\
21.54\end{array}$ \\
\hline 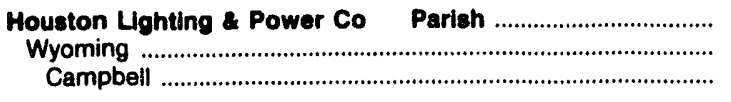 & $\begin{array}{l}9,540 \\
9,540 \\
9,540\end{array}$ & $\begin{array}{l}8,490 \\
8,490 \\
8,490\end{array}$ & $\begin{array}{l}.38 \\
.38 \\
.38\end{array}$ & $\begin{array}{l}\mathbf{5 . 0 7} \\
\mathbf{5 . 0 7} \\
5.07\end{array}$ & $\begin{array}{l}224.4 \\
224.4 \\
224.4\end{array}$ & $\begin{array}{l}38.10 \\
38.10 \\
38.10\end{array}$ \\
\hline $\begin{array}{l}\text { Illinols Power Co } \\
\text { Illinois } \\
\text { Perry } \\
\text { Pandolph } \\
\text { Washington } \\
\text { Wyoming } \\
\text { Campbell }\end{array}$ & $\begin{array}{r}4,310 \\
4,216 \\
2,066 \\
1,227 \\
923 \\
93 \\
93\end{array}$ & $\begin{array}{r}10,792 \\
10,834 \\
10,874 \\
10,799 \\
10,792 \\
8,858 \\
8,858\end{array}$ & $\begin{array}{l}2.91 \\
2.97 \\
2.98 \\
2.95 \\
2.95 \\
.24 \\
.24\end{array}$ & $\begin{array}{r}10.25 \\
10.37 \\
10.24 \\
10.49 \\
10.48 \\
4.86 \\
4.86\end{array}$ & $\begin{array}{l}137.1 \\
137.5 \\
136.4 \\
138.5 \\
138.8 \\
115.8 \\
115.8\end{array}$ & $\begin{array}{l}29.60 \\
29.80 \\
29.66 \\
29.92 \\
29.95 \\
20.52 \\
20.52\end{array}$ \\
\hline $\begin{array}{l}\text { Illinols Power Co } \\
\text { Colorado ... Havana } \\
\text { Gunnison } \\
\text { Kentucky } \\
\text { Letcher } \\
\text { Martin } \\
\text { Perry } \\
\text { Utah }\end{array}$ & $\begin{array}{r}386 \\
32 \\
32 \\
218 \\
197 \\
12 \\
9 \\
125 \\
125\end{array}$ & $\begin{array}{l}12,335 \\
12,099 \\
12,099 \\
12,733 \\
12,795 \\
12,208 \\
12,047 \\
11,736 \\
11,736\end{array}$ & $\begin{array}{l}.60 \\
.52 \\
.52 \\
.70 \\
.71 \\
.69 \\
.65 \\
.43 \\
.43\end{array}$ & $\begin{array}{r}8.39 \\
8.60 \\
8.60 \\
8.22 \\
8.09 \\
9.10 \\
10.00 \\
8.43 \\
8.43\end{array}$ & $\begin{array}{l}150.0 \\
130.8 \\
130.8 \\
165.1 \\
168.5 \\
130.0 \\
130.3 \\
127.6 \\
127.6\end{array}$ & $\begin{array}{l}37.00 \\
31.66 \\
31.66 \\
42.04 \\
43.13 \\
31.74 \\
31.40 \\
29.94 \\
29.94\end{array}$ \\
\hline
\end{tabular}

See footnotes at end of table.

Source: Federal Energy Regulatory Commission, FERC Form 423, "Monthly Report of Cost and Quality of Fuels for Electric Plants." 
Table 24. Origin of Coal Recelved by Electric Utility and Plant, 1992 (Continued)

\begin{tabular}{|c|c|c|c|c|c|c|}
\hline \multirow{2}{*}{$\begin{array}{l}\text { Electric Utllity Plant } \\
\text { Origin State } \\
\text { County }\end{array}$} & \multirow{2}{*}{$\begin{array}{l}\text { Quantity } \\
\text { (thousand } \\
\text { short tons) }\end{array}$} & \multicolumn{3}{|c|}{ Average Quality } & \multicolumn{2}{|c|}{ Average Dellyered Cost } \\
\hline & & $\begin{array}{c}\text { Btu } \\
\text { (per pound) }\end{array}$ & $\begin{array}{l}\text { Sulfur } \\
\text { (percent } \\
\text { by wolght) }\end{array}$ & $\begin{array}{l}\text { Ash } \\
\text { (percent } \\
\text { by welght) }\end{array}$ & $\begin{array}{l}\text { (cents per } \\
\text { million Btu) }\end{array}$ & $\begin{array}{l}\text { (dollars por } \\
\text { short ton) }\end{array}$ \\
\hline $\begin{array}{l}\text { Ullinols Power Co Mavana } \\
\text { West Virginia } \\
\text { Logan } \\
\text { Mingo }\end{array}$ & $\begin{array}{r}11 \\
3 \\
8\end{array}$ & $\begin{array}{l}11,978 \\
11,410 \\
12,184\end{array}$ & $\begin{array}{r}0.64 \\
.65 \\
.63\end{array}$ & $\begin{array}{l}10.67 \\
10.30 \\
10.80\end{array}$ & $\begin{array}{l}138.9 \\
152.0 \\
134.4\end{array}$ & $\begin{array}{l}33.28 \\
34.70 \\
32.76\end{array}$ \\
\hline 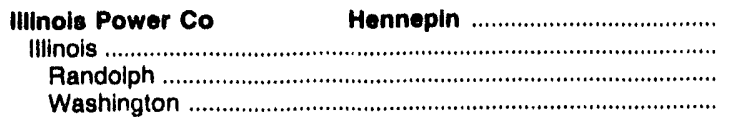 & $\begin{array}{l}422 \\
422 \\
234 \\
188\end{array}$ & $\begin{array}{l}10,699 \\
10,699 \\
10,703 \\
10,693\end{array}$ & $\begin{array}{l}2.92 \\
2.92 \\
2.92 \\
2.93\end{array}$ & $\begin{array}{l}10.61 \\
10.61 \\
10.62 \\
10.59\end{array}$ & $\begin{array}{l}148.9 \\
148.9 \\
148.5 \\
149.5\end{array}$ & $\begin{array}{l}31.86 \\
31.86 \\
31.78 \\
31.97\end{array}$ \\
\hline $\begin{array}{l}\text { Illinols Power Co } \quad \text { Vermillion } \\
\text { Indiana } \\
\text { Clay } \\
\text { Owen } \\
\text { Vermillion }\end{array}$ & $\begin{array}{r}123 \\
323 \\
137 \\
162 \\
25\end{array}$ & $\begin{array}{l}10,887 \\
10,887 \\
11,065 \\
10,750 \\
10,797\end{array}$ & $\begin{array}{l}2.31 \\
2.31 \\
2.20 \\
2.43 \\
2.12\end{array}$ & $\begin{array}{r}10.31 \\
10.31 \\
9.54 \\
10.91 \\
10.58\end{array}$ & $\begin{array}{l}126.3 \\
126.3 \\
128.2 \\
123.8 \\
132.6\end{array}$ & $\begin{array}{l}27.51 \\
27.51 \\
28.36 \\
26.61 \\
28.63\end{array}$ \\
\hline $\begin{array}{l}\text { Illinols Power Co } \\
\text { Colorado } \\
\text { Routt } \\
\text { Illinols } \\
\text { Jefferson } \\
\text { Saline } \\
\text { Utah } \\
\text { Carbon } \\
\text { West Virginia } \\
\text { Boone } \\
\text { Kanawha }\end{array}$ & $\begin{array}{r}705 \\
9 \\
9 \\
241 \\
235 \\
6 \\
6 \\
114 \\
114 \\
341 \\
46 \\
295\end{array}$ & $\begin{array}{l}12,333 \\
11,062 \\
11,062 \\
12,093 \\
12,110 \\
11,433 \\
11,749 \\
11,749 \\
12,730 \\
11,960 \\
12,850\end{array}$ & $\begin{array}{r}.72 \\
.46 \\
.46 \\
.82 \\
.81 \\
1.06 \\
.44 \\
.44 \\
.76 \\
.96 \\
.73\end{array}$ & \begin{tabular}{r|}
8.58 \\
8.90 \\
9.90 \\
5.23 \\
5.12 \\
9.40 \\
7.89 \\
7.89 \\
11.14 \\
12.06 \\
10.99
\end{tabular} & $\begin{array}{l}144.0 \\
123.0 \\
123.0 \\
153.8 \\
154.4 \\
132.7 \\
114.4 \\
114.4 \\
146.9 \\
133.1 \\
149.0\end{array}$ & $\begin{array}{l}35.52 \\
27.21 \\
27.21 \\
37.21 \\
37.39 \\
30.35 \\
26.89 \\
26.89 \\
37.41 \\
31.85 \\
38.28\end{array}$ \\
\hline 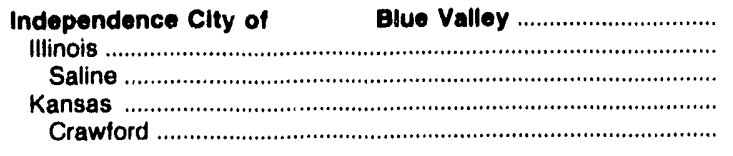 & $\begin{array}{l}44 \\
19 \\
19 \\
25 \\
25\end{array}$ & $\begin{array}{l}12,114 \\
11,925 \\
11,925 \\
12,255 \\
12,255\end{array}$ & $\begin{array}{l}3.23 \\
2.63 \\
2.63 \\
3.68 \\
3.68\end{array}$ & $\begin{array}{r}10.39 \\
8.17 \\
8.17 \\
12.05 \\
12.05\end{array}$ & $\begin{array}{l}127.9 \\
129.9 \\
129.9 \\
126.5 \\
126.5\end{array}$ & $\begin{array}{l}30.99 \\
30.98 \\
30.98 \\
30.99 \\
30.99\end{array}$ \\
\hline $\begin{array}{c}\text { Indiana Michigan Power Co Tanners Creek } \\
\text { Indiana } \\
\text { Warrick } \\
\text { Kentucky } \\
\text { Hopkins }\end{array}$ & $\begin{array}{r}1,323 \\
499 \\
499 \\
823 \\
373 \\
450\end{array}$ & $\begin{array}{l}11,609 \\
11,163 \\
11,163 \\
1:, 879 \\
11,549 \\
12,154\end{array}$ & $\begin{array}{r}1.88 \\
2.44 \\
2.44 \\
1.53 \\
2.55 \\
.69\end{array}$ & $\begin{array}{r}9.22 \\
8.38 \\
8.38 \\
9.73 \\
8.25 \\
10.95\end{array}$ & $\begin{array}{l}154.1 \\
143.7 \\
143.7 \\
160.0 \\
131.9 \\
182.2\end{array}$ & $\begin{array}{l}35.78 \\
32.08 \\
32.08 \\
38.01 \\
30.46 \\
44.29\end{array}$ \\
\hline $\begin{array}{c}\text { Indiana Michigan Power Co Rockport } \\
\text { Wyoming } \\
\text { Campbell } \\
\text { Converse }\end{array}$ & $\begin{array}{r}9,275 \\
9,275 \\
9,274 \\
1\end{array}$ & $\begin{array}{l}8,611 \\
8,611 \\
8,611 \\
8,711\end{array}$ & $\begin{array}{l}.32 \\
.32 \\
.32 \\
.34\end{array}$ & $\begin{array}{l}4.88 \\
4.88 \\
4.88 \\
6.20\end{array}$ & $\begin{array}{l}113.0 \\
113.0 \\
113.0 \\
111.4\end{array}$ & $\begin{array}{l}19.47 \\
19.47 \\
19.47 \\
19.41\end{array}$ \\
\hline 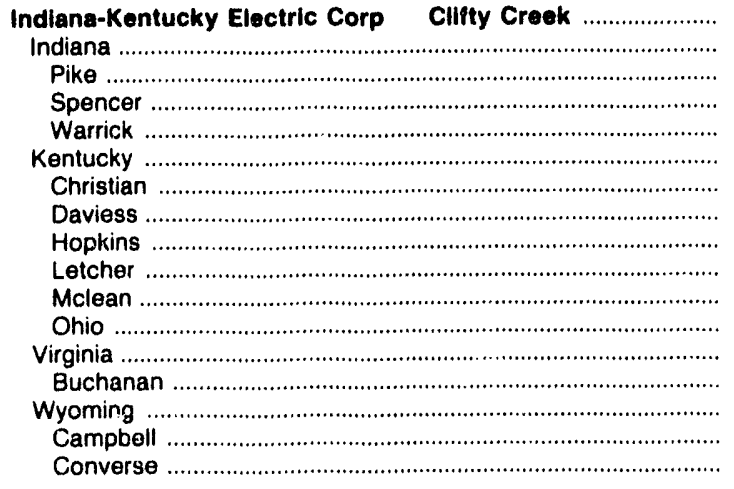 & $\begin{array}{r}3,765 \\
306 \\
61 \\
91 \\
154 \\
2,987 \\
121 \\
856 \\
1,454 \\
44 \\
61 \\
451 \\
112 \\
112 \\
360 \\
64 \\
296\end{array}$ & $\begin{array}{r}11,205 \\
10,892 \\
11,463 \\
10,818 \\
10,710 \\
11,419 \\
11,319 \\
11,223 \\
11,498 \\
13,037 \\
11,688 \\
11,372 \\
13,888 \\
13,888 \\
8,859 \\
8,837 \\
8,864\end{array}$ & $\begin{array}{l}2.90 \\
3.23 \\
3.45 \\
2.98 \\
3.29 \\
3.26 \\
3.08 \\
3.25 \\
3.47 \\
1.47 \\
3.01 \\
2.85 \\
.73 \\
.73 \\
.27 \\
.33 \\
.26\end{array}$ & $\begin{array}{r}10.01 \\
10.34 \\
8.29 \\
11.05 \\
10.74 \\
10.77 \\
10.27 \\
10.26 \\
11.95 \\
6.14 \\
11.44 \\
8.41 \\
5.28 \\
5.28 \\
4.89 \\
4.82 \\
4.90\end{array}$ & $\begin{array}{r}109.3 \\
94.6 \\
98.3 \\
89.3 \\
96.2 \\
106.5 \\
101.4 \\
113.2 \\
105.2 \\
124.0 \\
101.2 \\
98.2 \\
160.0 \\
160.0 \\
130.5 \\
126.1 \\
131.4\end{array}$ & $\begin{array}{l}24.50 \\
20.61 \\
22.54 \\
19.33 \\
20.61 \\
24.32 \\
22.97 \\
25.42 \\
24.18 \\
32.33 \\
23.66 \\
22.34 \\
44.44 \\
44.44 \\
23.12 \\
22.29 \\
23.29\end{array}$ \\
\hline 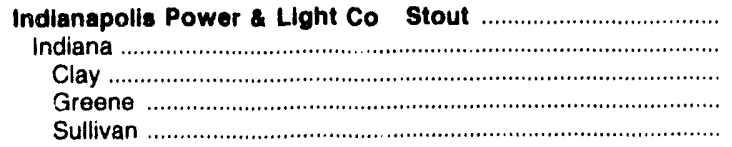 & $\begin{array}{r}1,069 \\
1,069 \\
297 \\
534 \\
238\end{array}$ & $\begin{array}{l}11,213 \\
11,213 \\
11,273 \\
11,287 \\
10,973\end{array}$ & $\begin{array}{l}1.60 \\
1.60 \\
1.56 \\
1.43 \\
2.02\end{array}$ & $\begin{array}{l}8.06 \\
8.06 \\
7.04 \\
7.94 \\
9.59\end{array}$ & $\begin{array}{l}128.0 \\
128.0 \\
115.9 \\
120.2 \\
161.4\end{array}$ & $\begin{array}{l}28.70 \\
28.70 \\
26.14 \\
27.14 \\
35.42\end{array}$ \\
\hline
\end{tabular}

See footnotes at end of table.

Source: Federal Energy Regulatory Commission, FERC Form 423, "Monthly Report of Cost and Quality of Fuels for Electric Plants." 
Table 24. Origin of Coal Received by Electric Utility and Plant, 1992 (Continued)

\begin{tabular}{|c|c|c|c|c|c|c|}
\hline \multirow{2}{*}{$\begin{array}{l}\text { Electric Utllity Plane } \\
\text { Origin State } \\
\text { County }\end{array}$} & \multirow{2}{*}{$\begin{array}{l}\text { Quantity } \\
\text { (thousand } \\
\text { short tons) }\end{array}$} & \multicolumn{3}{|c|}{ Average Quality } & \multicolumn{2}{|c|}{ Average Delivered Cost } \\
\hline & & $\begin{array}{c}\text { Btu } \\
\text { (par pound) }\end{array}$ & $\begin{array}{c}\text { Sulfur } \\
\text { (percent } \\
\text { hy weight) }\end{array}$ & $\begin{array}{l}\text { Aah } \\
\text { (percent } \\
\text { by weight) }\end{array}$ & $\begin{array}{l}\text { (cents per } \\
\text { million Btu) }\end{array}$ & $\begin{array}{l}\text { (dollars per } \\
\text { short ton) }\end{array}$ \\
\hline $\begin{array}{l}\text { Indianapolis Power Llght Co Petersburg } \\
\text { Indiana } \\
\text { Daviess } \\
\text { Greene } \\
\text { Knox } \\
\text { Pike } \\
\text { Sullivan } \\
\text { Warrick }\end{array}$ & $\begin{array}{r}4,655 \\
4,655 \\
926 \\
72 \\
148 \\
741 \\
199 \\
2,569\end{array}$ & $\begin{array}{l}11,172 \\
11,172 \\
11,460 \\
11,276 \\
11,041 \\
11,256 \\
10,991 \\
11,063\end{array}$ & $\begin{array}{l}2.57 \\
2.57 \\
2.17 \\
2.40 \\
1.12 \\
2.43 \\
2.01 \\
2.89\end{array}$ & $\begin{array}{l}8.42 \\
8.42 \\
7.79 \\
9.69 \\
8.65 \\
8.05 \\
9.26 \\
8.63\end{array}$ & $\begin{array}{r}99.5 \\
99.5 \\
99.9 \\
126.1 \\
113.3 \\
97.1 \\
157.3 \\
94.0\end{array}$ & $\begin{array}{l}22.23 \\
22.23 \\
22.90 \\
28.44 \\
25.01 \\
21.86 \\
34.57 \\
20.80\end{array}$ \\
\hline $\begin{array}{l}\text { Indianapolls Power \& Light C: Pritchard } \\
\text { Indiana } \\
\text { Greene } \\
\text { Knox }\end{array}$ & $\begin{array}{r}358 \\
358 \\
297 \\
61\end{array}$ & $\begin{array}{l}11,376 \\
11,376 \\
11,445 \\
11,040\end{array}$ & $\begin{array}{r}1.07 \\
1.07 \\
1.10 \\
.95\end{array}$ & $\begin{array}{l}6.79 \\
6.79 \\
6.40 \\
8.69\end{array}$ & $\begin{array}{l}121.9 \\
121.9 \\
119.1 \\
136.1\end{array}$ & $\begin{array}{l}27.73 \\
27.73 \\
27.26 \\
30.04\end{array}$ \\
\hline 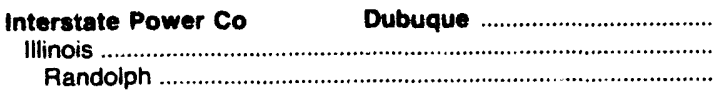 & $\begin{array}{l}90 \\
90 \\
90\end{array}$ & $\begin{array}{l}11,038 \\
11,038 \\
11,038\end{array}$ & $\begin{array}{l}3.00 \\
\mathbf{3 . 0 0} \\
\mathbf{3 . 0 0}\end{array}$ & $\begin{array}{l}9.31 \\
9.31 \\
9.31\end{array}$ & $\begin{array}{l}200.0 \\
200.0 \\
200.0\end{array}$ & $\begin{array}{l}44.15 \\
44.15 \\
44.15\end{array}$ \\
\hline 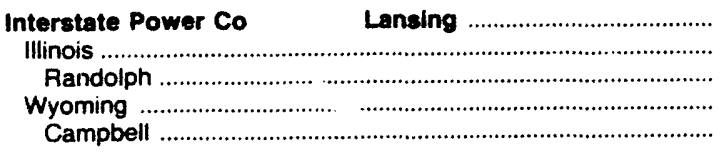 & $\begin{array}{r}590 \\
34 \\
34 \\
556 \\
556\end{array}$ & $\begin{array}{r}1, \quad 38 \\
11,6-2 \\
11,642 \\
8,340 \\
8,340\end{array}$ & $\begin{array}{r}.40 \\
1.51 \\
1.51 \\
.34 \\
.34\end{array}$ & $\begin{array}{l}4.78 \\
7.50 \\
7.50 \\
4.62 \\
4.62\end{array}$ & $\begin{array}{l}233.8 \\
191.1 \\
191.1 \\
237.4 \\
237.4\end{array}$ & $\begin{array}{l}39.87 \\
44.48 \\
44.48 \\
39.60 \\
39.60\end{array}$ \\
\hline $\begin{array}{l}\text { Interstate Power Co } \\
\text { Illinois . Kapp } \\
\text { Perry } \\
\text { Indiana } \\
\text { Pike }\end{array}$ & $\begin{array}{l}501 \\
250 \\
250 \\
251 \\
251\end{array}$ & $\begin{array}{l}11,381 \\
11,593 \\
11,593 \\
11,170 \\
11,170\end{array}$ & $\begin{array}{l}2.02 \\
2.03 \\
2.03 \\
2.02 \\
2.02\end{array}$ & $\begin{array}{l}7.98 \\
7.62 \\
7.62 \\
8.35 \\
8.35\end{array}$ & $\begin{array}{l}138.1 \\
141.3 \\
141.3 \\
134.9 \\
134.9\end{array}$ & $\begin{array}{l}31.44 \\
32.76 \\
32.76 \\
30.13 \\
30.13\end{array}$ \\
\hline 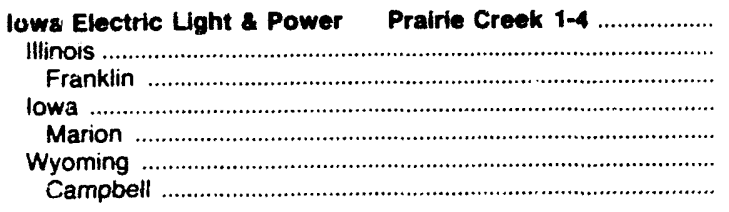 & $\begin{array}{r}439 \\
153 \\
153 \\
55 \\
55 \\
231 \\
231\end{array}$ & $\begin{array}{r}9,763 \\
11,605 \\
11,605 \\
9,811 \\
9,811 \\
8,531 \\
8,531\end{array}$ & $\begin{array}{r}1.47 \\
2.08 \\
2.08 \\
4.37 \\
4.37 \\
.38 \\
.38\end{array}$ & $\begin{array}{r}7.15 \\
7.90 \\
7.90 \\
13.56 \\
13.56 \\
5.12 \\
5.12\end{array}$ & $\begin{array}{l}129.1 \\
136.6 \\
136.6 \\
172.4 \\
172.4 \\
110.4 \\
110.4\end{array}$ & $\begin{array}{l}25.21 \\
31.72 \\
31.72 \\
33.84 \\
33.84 \\
18.84 \\
18.84\end{array}$ \\
\hline $\begin{array}{l}\text { lowa Electric Light \& Power } \quad \text { 6th St } \\
\text { Illinois } \\
\text { Franklin }\end{array}$ & $\begin{array}{l}25 \\
25 \\
25\end{array}$ & $\begin{array}{l}11,6: \\
11,614 \\
11,614\end{array}$ & $\begin{array}{l}2.05 \\
2.05 \\
2.05\end{array}$ & $\begin{array}{l}7.82 \\
7.82 \\
7.82\end{array}$ & $\begin{array}{l}136.7 \\
136.7 \\
136.7\end{array}$ & $\begin{array}{l}31.75 \\
31.75 \\
31.75\end{array}$ \\
\hline $\begin{array}{l}\text { lowa Electric Light \& Power Sutherland } \\
\text { lowa } \\
\text { Marion } \\
\text { Wyoming } \\
\text { Campbell }\end{array}$ & $\begin{array}{r}145 \\
12 \\
12 \\
133 \\
133\end{array}$ & $\begin{array}{l}8,605 \\
9,847 \\
9,847 \\
8,493 \\
8,493\end{array}$ & $\begin{array}{r}.71 \\
4.33 \\
4.33 \\
.38 \\
.38\end{array}$ & $\begin{array}{r}5.77 \\
13.61 \\
13.61 \\
5.07 \\
5.07\end{array}$ & $\begin{array}{r}102.3 \\
162.3 \\
162.3 \\
96.0 \\
96.0\end{array}$ & $\begin{array}{l}17.60 \\
31.96 \\
31.96 \\
16.30 \\
16.30\end{array}$ \\
\hline $\begin{array}{l}\text { lowa Southern Utilities Co Ottumwa } \\
\text { Wyoming } \\
\text { Campbell }\end{array}$ & $\begin{array}{l}1,838 \\
1,838 \\
1,838\end{array}$ & $\begin{array}{l}8,376 \\
8,376 \\
8,376\end{array}$ & $\begin{array}{l}.32 \\
.32 \\
.32\end{array}$ & $\begin{array}{l}5.54 \\
5.54 \\
5.54\end{array}$ & $\begin{array}{l}110.6 \\
110.6 \\
110.6\end{array}$ & $\begin{array}{l}18.52 \\
18.52 \\
18.52\end{array}$ \\
\hline $\begin{array}{l}\text { Iowa Southern Utilities Co Burlington } \\
\text { Indiana } \\
\text { Perry } \\
\text { Warrick } \\
\text { Wyoming } \\
\text { Campbell }\end{array}$ & $\begin{array}{r}476 \\
179 \\
3 \\
175 \\
297 \\
297\end{array}$ & $\begin{array}{r}9,489 \\
11,439 \\
10,149 \\
11,464 \\
8,316 \\
8,316\end{array}$ & $\begin{array}{l}1.95 \\
3.09 \\
1.19 \\
3.13 \\
1.27 \\
1.27\end{array}$ & $\begin{array}{r}7.86 \\
8.94 \\
11.85 \\
8.88 \\
7.21 \\
7.21\end{array}$ & $\begin{array}{r}104.0 \\
123.3 \\
84.9 \\
123.9 \\
88.1 \\
88.1\end{array}$ & $\begin{array}{l}19.74 \\
28.20 \\
17.23 \\
28.42 \\
14.65 \\
14.65\end{array}$ \\
\hline 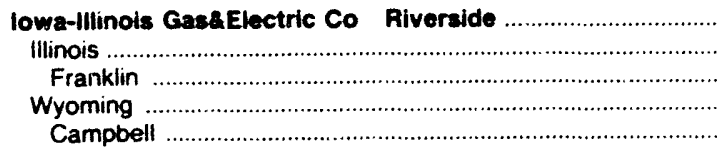 & $\begin{array}{r}281 \\
237 \\
237 \\
44 \\
44\end{array}$ & $\begin{array}{r}11,162 \\
11,686 \\
11,686 \\
8,338 \\
8,338\end{array}$ & $\begin{array}{r}1.85 \\
2.12 \\
2.12 \\
.40 \\
.40\end{array}$ & $\begin{array}{l}7.93 \\
8.28 \\
8.28 \\
6.05 \\
6.05\end{array}$ & $\begin{array}{l}110.9 \\
109.6 \\
109.6 \\
120.7 \\
120.7\end{array}$ & $\begin{array}{l}24.76 \\
25.62 \\
25.62 \\
20.12 \\
20.12\end{array}$ \\
\hline $\begin{array}{l}\text { lowa-lllinois GaskElectric Co Loulsa } \\
\text { Wyoming } \\
\text { Campbell }\end{array}$ & $\begin{array}{l}1,800 \\
1,800 \\
1,800\end{array}$ & $\begin{array}{l}8,394 \\
8,394 \\
8,394\end{array}$ & $\begin{array}{l}.31 \\
.31 \\
.31\end{array}$ & $\begin{array}{l}5.27 \\
5.27 \\
5.27\end{array}$ & $\begin{array}{l}110.9 \\
110.9 \\
110.9\end{array}$ & $\begin{array}{l}18.62 \\
18.62 \\
18.62\end{array}$ \\
\hline 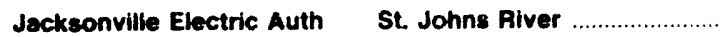 & 3,624 & 12,329 & .93 & 8.57 & 163.2 & 40.25 \\
\hline
\end{tabular}

See footnotes at end of table.

Source: Federal Energy Pegulatory Commission, FERC Form 423. "Monthly Repont of Cost and Quality of Fuels for Electric Plants." 
Table 24. Origin of Coal Recelved by Electric Utility and Plant, 1992 (Continued)

\begin{tabular}{|c|c|c|c|c|c|c|}
\hline \multirow{2}{*}{$\begin{array}{l}\text { Electrle Utility Plant } \\
\text { Origin State } \\
\text { County }\end{array}$} & \multirow{2}{*}{$\begin{array}{l}\text { Cuantity } \\
\text { (thoueand } \\
\text { short tons) }\end{array}$} & \multicolumn{3}{|c|}{ Averege Cusilty } & \multicolumn{2}{|c|}{ Averaç Dellivered Cost } \\
\hline & & Btu & $\begin{array}{c}\text { Eultur } \\
\text { (percent }\end{array}$ & $\underset{\text { (percent }}{\text { Ach }}$ & (cents pay & (dollare per \\
\hline \multicolumn{7}{|l|}{ Jecksonville Electric Auth $\quad$ st. Johns River } \\
\hline 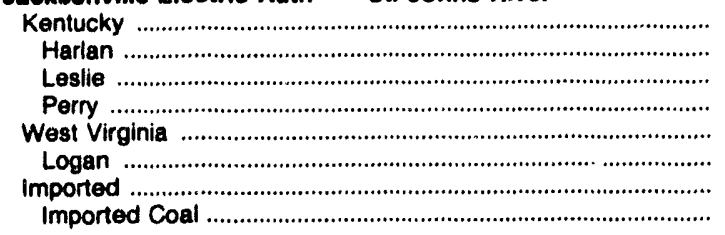 & $\begin{array}{r}1,563 \\
1,421 \\
114 \\
28 \\
642 \\
642 \\
1,419 \\
1,419\end{array}$ & $\begin{array}{l}12,831 \\
12,840 \\
12,840 \\
12,353 \\
12,063 \\
12,063 \\
11,897 \\
11,897\end{array}$ & $\begin{array}{r}1.18 \\
1.20 \\
1.04 \\
.81 \\
.82 \\
.82 \\
.71 \\
.71\end{array}$ & $\begin{array}{r}8.43 \\
8.35 \\
9.12 \\
9.60 \\
12.58 \\
12.58 \\
6.91 \\
6.81\end{array}$ & $\begin{array}{l}160.2 \\
163.0 \\
124.2 \\
164.1 \\
199.9 \\
199.8 \\
150.0 \\
160.0\end{array}$ & $\begin{array}{l}41.11 \\
41.86 \\
31.00 \\
40.54 \\
48.22 \\
48.22 \\
35.70 \\
35.70\end{array}$ \\
\hline $\begin{array}{l}\text { Jamestown Clty of Samud A Carison } \\
\text { Pennsylvania } \\
\text { Armstrong } \\
\text { Eutler . } \\
\text { Clarion . } \\
\text { Elk } \\
\text { Jefferson }\end{array}$ & $\begin{array}{r}114 \\
114 \\
21 \\
9 \\
57 \\
20 \\
7\end{array}$ & $\begin{array}{l}12,668 \\
12,656 \\
12,637 \\
12,748 \\
12,617 \\
12,797 \\
12,506\end{array}$ & $\begin{array}{l}1.70 \\
1.79 \\
2.10 \\
1.82 \\
1.81 \\
1.37 \\
1.68\end{array}$ & $\begin{array}{r}10.36 \\
10.38 \\
11.17 \\
8.50 \\
10.41 \\
9.58 \\
12.30\end{array}$ & $\begin{array}{l}132.8 \\
132.6 \\
132.2 \\
133.6 \\
133.3 \\
130.8 \\
131.3\end{array}$ & $\begin{array}{l}33.66 \\
33.56 \\
33.40 \\
34.06 \\
33.65 \\
33.51 \\
32.84\end{array}$ \\
\hline 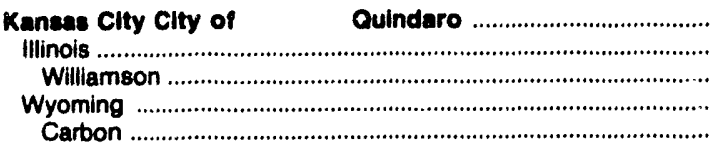 & $\begin{array}{l}355 \\
192 \\
192 \\
164 \\
164\end{array}$ & $\begin{array}{l}11,100 \\
11,720 \\
11,720 \\
10,373 \\
10,373\end{array}$ & $\begin{array}{r}1.40 \\
2.43 \\
2.43 \\
.40 \\
.40\end{array}$ & $\begin{array}{r}9.41 \\
10.05 \\
10.05 \\
8.88 \\
8.68\end{array}$ & $\begin{array}{l}186.6 \\
231.3 \\
231.3 \\
127.5 \\
127.5\end{array}$ & $\begin{array}{l}41.43 \\
54.21 \\
54.21 \\
26.46 \\
26.46\end{array}$ \\
\hline $\begin{array}{c}\text { Kanase City Clty of Kaw } \\
\text { Wyoming } \\
\text { Carbon }\end{array}$ & $\begin{array}{l}138 \\
138 \\
138\end{array}$ & $\begin{array}{l}10,388 \\
10,368 \\
10,368\end{array}$ & $\begin{array}{l}.38 \\
.38 \\
.38\end{array}$ & $\begin{array}{l}9.10 \\
9.10 \\
9.10\end{array}$ & $\begin{array}{l}127.4 \\
127.4 \\
127.4\end{array}$ & $\begin{array}{l}26.41 \\
26.41 \\
26.41\end{array}$ \\
\hline 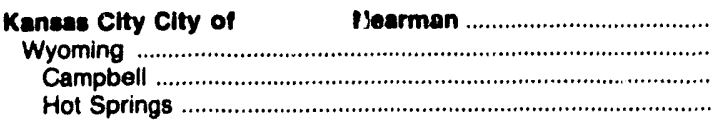 & $\begin{array}{r}890 \\
960 \\
894 \\
66\end{array}$ & $\begin{array}{l}8,312 \\
8,312 \\
8,297 \\
8,516\end{array}$ & $\begin{array}{l}.34 \\
.34 \\
.34 \\
.31\end{array}$ & $\begin{array}{l}4.87 \\
4.87 \\
4.82 \\
5.48\end{array}$ & $\begin{array}{l}97.8 \\
97.8 \\
98.1 \\
94.3\end{array}$ & $\begin{array}{l}16.28 \\
16.26 \\
16.28 \\
16.06\end{array}$ \\
\hline $\begin{array}{l}\text { Kanaas City Power L Light Co Hawthorne } \\
\text { Wyoming } \\
\text { Campbell }\end{array}$ & $\begin{array}{l}1,259 \\
1,259 \\
1,259\end{array}$ & $\begin{array}{l}8,857 \\
8,857 \\
8,857\end{array}$ & $\begin{array}{l}.20 \\
.20 \\
.20\end{array}$ & $\begin{array}{l}4.60 \\
4.60 \\
4.80\end{array}$ & $\begin{array}{l}\mathbf{9 4 . 4} \\
94.4 \\
94.4\end{array}$ & $\begin{array}{l}16.72 \\
16.72 \\
16.72\end{array}$ \\
\hline $\begin{array}{c}\text { Kansas Clty Power \& Light Co Iatan } \\
\text { Wyoming } \\
\text { Campbell }\end{array}$ & $\begin{array}{l}2,365 \\
2,365 \\
2,365\end{array}$ & $\begin{array}{l}8,786 \\
8,786 \\
8,786\end{array}$ & $\begin{array}{l}.38 \\
.38 \\
.38\end{array}$ & $\begin{array}{l}\mathbf{5 . 0 0} \\
\mathbf{5 . 0 9} \\
\mathbf{5 . 0 9}\end{array}$ & $\begin{array}{l}85.0 \\
85.0 \\
85.0\end{array}$ & $\begin{array}{l}14.03 \\
14.83 \\
14.83\end{array}$ \\
\hline 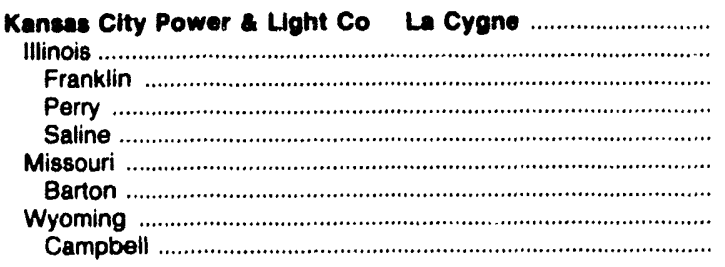 & $\begin{array}{r}3,306 \\
576 \\
169 \\
397 \\
10 \\
48 \\
48 \\
2,682 \\
2,682\end{array}$ & $\begin{array}{r}9,035 \\
11,233 \\
11,622 \\
11,060 \\
11,535 \\
11,812 \\
11,812 \\
8,514 \\
8,514\end{array}$ & $\begin{array}{r}.75 \\
2.60 \\
1.63 \\
3.02 \\
2.60 \\
3.60 \\
3.60 \\
.30 \\
.30\end{array}$ & $\begin{array}{r}6.88 \\
8.82 \\
7.34 \\
8.42 \\
10.50 \\
11.80 \\
11.80 \\
4.77 \\
4.77\end{array}$ & $\begin{array}{r}92.7 \\
122.6 \\
131.5 \\
128.7 \\
133.0 \\
118.3 \\
118.3 \\
81.6 \\
81.6\end{array}$ & $\begin{array}{l}16.75 \\
29.12 \\
30.56 \\
28.46 \\
30.68 \\
27.95 \\
27.95 \\
13.89 \\
13.88\end{array}$ \\
\hline 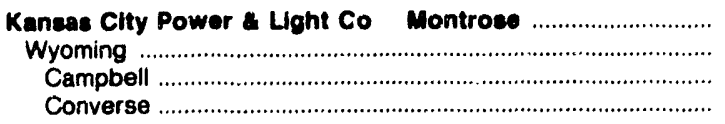 & $\begin{array}{r}1,431 \\
1,431 \\
839 \\
592\end{array}$ & $\begin{array}{l}8,865 \\
8,655 \\
8,548 \\
8,807\end{array}$ & $\begin{array}{l}.34 \\
.34 \\
.38 \\
.30\end{array}$ & $\begin{array}{l}5.13 \\
5.13 \\
5.05 \\
5.25\end{array}$ & $\begin{array}{r}97.0 \\
87.0 \\
100.6 \\
82.1\end{array}$ & $\begin{array}{l}16.80 \\
16.80 \\
17.20 \\
16.23\end{array}$ \\
\hline 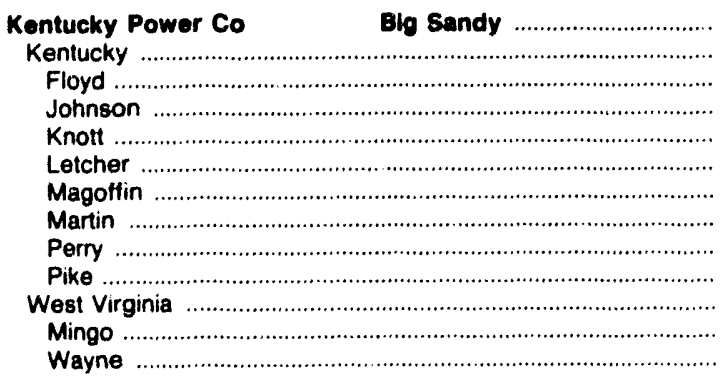 & $\begin{array}{r}2,517 \\
2,479 \\
1,212 \\
313 \\
28 \\
170 \\
285 \\
269 \\
24 \\
176 \\
38 \\
26 \\
13\end{array}$ & $\begin{array}{l}12,042 \\
12,042 \\
12,050 \\
11,989 \\
11,769 \\
12,391 \\
11,937 \\
12,042 \\
11,721 \\
11,897 \\
12,069 \\
12,069 \\
12,069\end{array}$ & $\begin{array}{r}1.04 \\
1.05 \\
.07 \\
1.21 \\
1.04 \\
1.10 \\
1.03 \\
1.28 \\
1.04 \\
.89 \\
.78 \\
.78 \\
.78\end{array}$ & $\begin{array}{l}11.06 \\
11.05 \\
11.24 \\
10.62 \\
11.37 \\
10.60 \\
10.80 \\
10.88 \\
11.66 \\
11.27 \\
11.59 \\
11.59 \\
11.59\end{array}$ & $\begin{array}{r}117.3 \\
117.6 \\
120.6 \\
131.2 \\
99.6 \\
105.3 \\
113.6 \\
108.3 \\
100.0 \\
110.9 \\
99.8 \\
99.9 \\
99.8\end{array}$ & $\begin{array}{l}26.25 \\
28.32 \\
29.06 \\
31.45 \\
23.45 \\
26.10 \\
27.12 \\
26.08 \\
23.44 \\
26.60 \\
24.11 \\
24.11 \\
24.11\end{array}$ \\
\hline
\end{tabular}

See footnotes at end of table.

Source: Federal Energy Regulatory Commission, FERC Form 423, "Monthly Report of Cost and Quality of Fuels for Electric Plants." 
Table 24. Origin of Coal Recelved by Electric Utility and Plant, 1992 (Continued)

\begin{tabular}{|c|c|c|c|c|c|c|}
\hline \multirow[b]{2}{*}{$\begin{array}{l}\text { Eloctric Utility Plant } \\
\text { Origin State } \\
\text { County }\end{array}$} & \multirow[b]{2}{*}{$\begin{array}{l}\text { Quantity } \\
\text { (thousand } \\
\text { chort tons) }\end{array}$} & \multicolumn{3}{|c|}{ Average Quality } & \multicolumn{2}{|c|}{ Average Delivered Cost } \\
\hline & & $\begin{array}{c}\text { Btu } \\
\text { (per pound) }\end{array}$ & $\begin{array}{l}\text { Sulfur } \\
\text { (percent } \\
\text { by woight) }\end{array}$ & $\begin{array}{l}\text { Ash } \\
\text { (percent } \\
\text { by weight) }\end{array}$ & $\begin{array}{l}\text { (cents per } \\
\text { million Btu) }\end{array}$ & $\begin{array}{l}\text { (dollars per } \\
\text { short ton) }\end{array}$ \\
\hline 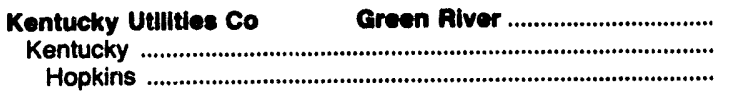 & $\begin{array}{l}304 \\
304 \\
304\end{array}$ & $\begin{array}{l}11,886 \\
11,886 \\
11,886\end{array}$ & $\begin{array}{l}2.33 \\
2.33 \\
2.33\end{array}$ & $\begin{array}{l}8.08 \\
8.08 \\
8.08\end{array}$ & $\begin{array}{l}109.0 \\
109.0 \\
109.0\end{array}$ & $\begin{array}{l}25.91 \\
25.91 \\
25.91\end{array}$ \\
\hline 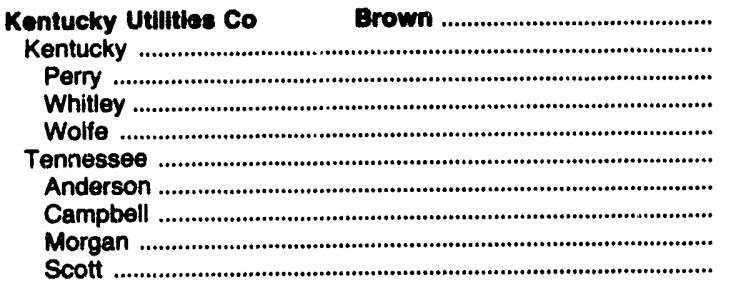 & $\begin{array}{r}1,002 \\
547 \\
482 \\
50 \\
16 \\
455 \\
413 \\
33 \\
8\end{array}$ & $\begin{array}{l}12,149 \\
11,908 \\
11,900 \\
11,945 \\
12,025 \\
12,440 \\
12,441 \\
12,244 \\
13,198 \\
12,000\end{array}$ & $\begin{array}{l}1.98 \\
1.46 \\
1.28 \\
3.00 \\
2.26 \\
2.60 \\
2.58 \\
2.78 \\
2.80 \\
1.50\end{array}$ & $\begin{array}{r}11.94 \\
12.58 \\
12.72 \\
12.15 \\
9.56 \\
11.17 \\
11.14 \\
11.84 \\
10.10 \\
12.00\end{array}$ & $\begin{array}{l}112.6 \\
112.2 \\
112.4 \\
110.2 \\
110.3 \\
113.1 \\
113.3 \\
111.3 \\
110.7 \\
114.5\end{array}$ & $\begin{array}{l}27.36 \\
26.71 \\
26.76 \\
26.33 \\
26.54 \\
28.14 \\
28.19 \\
27.26 \\
29.22 \\
27.48\end{array}$ \\
\hline 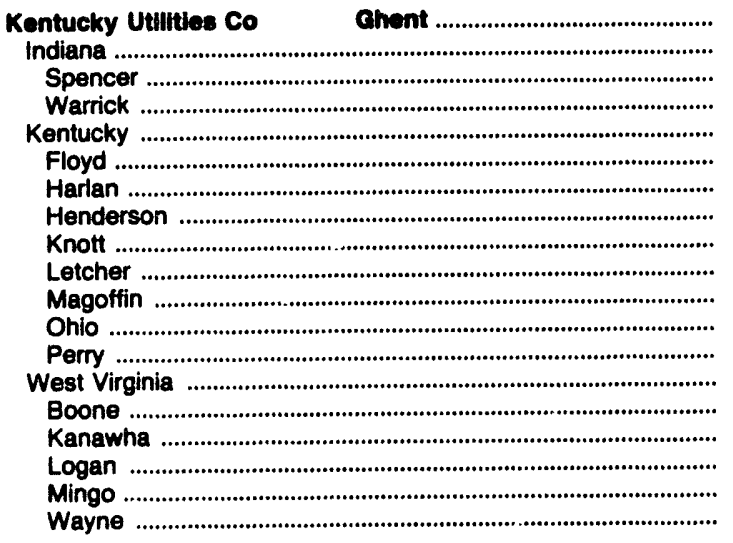 & $\begin{array}{r}4,595 \\
513 \\
347 \\
166 \\
2,664 \\
334 \\
726 \\
720 \\
308 \\
135 \\
36 \\
282 \\
122 \\
1,418 \\
75 \\
147 \\
833 \\
328 \\
35\end{array}$ & $\begin{array}{l}11,905 \\
11,071 \\
11,023 \\
11,170 \\
11,997 \\
12,114 \\
12,522 \\
11,190 \\
12,443 \\
12,784 \\
12,041 \\
11,629 \\
12,152 \\
12,325 \\
12,087 \\
12,551 \\
12,320 \\
12,305 \\
12,190\end{array}$ & $\begin{array}{r}1.34 \\
2.74 \\
2.66 \\
2.92 \\
1.43 \\
.64 \\
.67 \\
2.61 \\
.68 \\
.70 \\
.64 \\
2.90 \\
.61 \\
.66 \\
.63 \\
.66 \\
.66 \\
.65 \\
.60\end{array}$ & $\begin{array}{r}9.60 \\
9.92 \\
9.89 \\
9.96 \\
8.94 \\
10.90 \\
8.40 \\
8.23 \\
9.50 \\
8.38 \\
10.47 \\
8.40 \\
10.86 \\
10.72 \\
12.20 \\
10.66 \\
11.01 \\
9.69 \\
10.47\end{array}$ & $\begin{array}{r}117.6 \\
97.5 \\
95.7 \\
101.3 \\
116.4 \\
115.3 \\
132.3 \\
96.9 \\
130.9 \\
127.5 \\
113.9 \\
101.7 \\
109.8 \\
126.3 \\
136.5 \\
113.6 \\
133.4 \\
112.8 \\
115.4\end{array}$ & $\begin{array}{l}28.20 \\
21.59 \\
21.09 \\
22.64 \\
27.92 \\
27.92 \\
33.13 \\
21.69 \\
32.57 \\
32.61 \\
27.43 \\
23.66 \\
26.68 \\
31.13 \\
33.00 \\
28.52 \\
32.87 \\
27.77 \\
28.12\end{array}$ \\
\hline $\begin{array}{l}\text { Kentucky Utillties Co } \\
\text { Kentucky } \\
\text { Knott } \\
\text { Perry }\end{array}$ & $\begin{array}{l}31 \\
31 \\
10 \\
21\end{array}$ & $\begin{array}{l}12,178 \\
12,178 \\
12,141 \\
12,197\end{array}$ & $\begin{array}{l}.92 \\
.92 \\
.94 \\
.90\end{array}$ & $\begin{array}{l}10.73 \\
10.73 \\
10.82 \\
10.68\end{array}$ & $\begin{array}{l}115.1 \\
115.1 \\
110.8 \\
117.2\end{array}$ & $\begin{array}{l}28.03 \\
28.03 \\
26.90 \\
28.59\end{array}$ \\
\hline 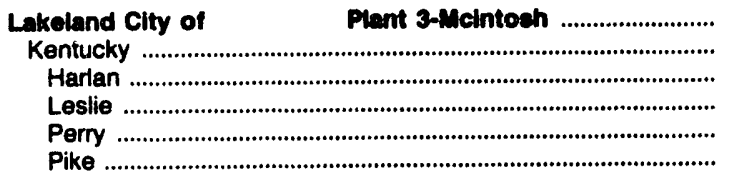 & $\begin{array}{r}818 \\
818 \\
397 \\
390 \\
19 \\
12\end{array}$ & $\begin{array}{l}12,899 \\
12,999 \\
13,244 \\
12,837 \\
11,992 \\
11,796\end{array}$ & $\begin{array}{r}1.04 \\
1.04 \\
.95 \\
1.14 \\
.92 \\
.86\end{array}$ & $\begin{array}{r}7.71 \\
7.71 \\
6.69 \\
8.35 \\
12.90 \\
12.10\end{array}$ & $\begin{array}{l}165.0 \\
165.0 \\
165.0 \\
165.5 \\
157.4 \\
162.7\end{array}$ & $\begin{array}{l}42.90 \\
42.90 \\
43.70 \\
42.48 \\
37.75 \\
38.38\end{array}$ \\
\hline $\begin{array}{l}\text { Lansing Clty of } \\
\text { Kentucky } \\
\text { Letcher } \\
\text { Pike } \\
\text { West Virginia } \\
\text { Boone } \\
\text { Logan } \\
\text { Nicholas }\end{array}$ & $\begin{array}{r}463 \\
427 \\
19 \\
408 \\
36 \\
10 \\
21 \\
5\end{array}$ & $\begin{array}{l}12,908 \\
12,892 \\
13,041 \\
12,885 \\
13,096 \\
13,136 \\
13,168 \\
12,736\end{array}$ & $\begin{array}{l}.87 \\
.88 \\
.91 \\
.87 \\
.80 \\
.76 \\
.77 \\
1.00\end{array}$ & $\begin{array}{l}7.31 \\
7.32 \\
7.55 \\
7.31 \\
7.17 \\
7.65 \\
6.36 \\
9.46\end{array}$ & $\begin{array}{l}190.2 \\
192.4 \\
166.3 \\
193.6 \\
164.8 \\
165.2 \\
165.0 \\
163.6\end{array}$ & $\begin{array}{l}49.10 \\
49.60 \\
43.38 \\
49.88 \\
43.17 \\
43.39 \\
43.44 \\
41.67\end{array}$ \\
\hline 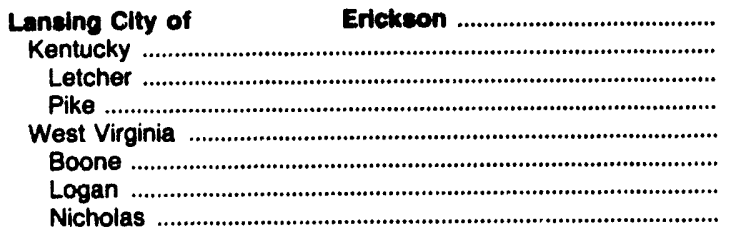 & $\begin{array}{r}426 \\
362 \\
65 \\
297 \\
64 \\
20 \\
26 \\
19\end{array}$ & $\begin{array}{l}12,945 \\
12,938 \\
12,876 \\
12,952 \\
12,981 \\
13,038 \\
12,992 \\
12,905\end{array}$ & $\begin{array}{l}.85 \\
.85 \\
.89 \\
.84 \\
.83 \\
.79 \\
.80 \\
.94\end{array}$ & $\begin{array}{l}7.05 \\
6.83 \\
7.37 \\
6.71 \\
8.35 \\
8.42 \\
7.68 \\
9.20\end{array}$ & $\begin{array}{l}177.6 \\
180.3 \\
166.9 \\
183.2 \\
162.6 \\
166.4 \\
160.4 \\
161.5\end{array}$ & $\begin{array}{l}45.98 \\
46.65 \\
42.97 \\
47.46 \\
42.20 \\
43.39 \\
41.67 \\
41.68\end{array}$ \\
\hline 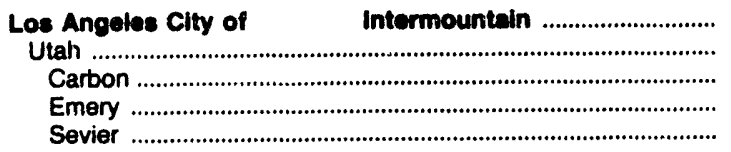 & $\begin{array}{r}4,278 \\
4,278 \\
3,525 \\
487 \\
267\end{array}$ & $\begin{array}{l}11,854 \\
11,854 \\
11,798 \\
12,356 \\
11,688\end{array}$ & $\begin{array}{l}.45 \\
.45 \\
.44 \\
.53 \\
.38\end{array}$ & $\begin{array}{l}8.44 \\
8.44 \\
8.46 \\
8.50 \\
8.10\end{array}$ & $\begin{array}{l}149.3 \\
149.3 \\
151.0 \\
130.5 \\
162.9\end{array}$ & $\begin{array}{l}35.39 \\
35.39 \\
35.62 \\
32.24 \\
38.08\end{array}$ \\
\hline
\end{tabular}

See footnotes at ind of table.

Source: Federal Energy Regulatory Commission, FERC Form 423, "Monthly Report of Cost and Quality of Fuels for Electric Plants." 
Table 24. Origin of Coal Received by Electric Utility and Plant, 1992 (Continued)

\begin{tabular}{|c|c|c|c|c|c|c|}
\hline \multirow[b]{2}{*}{$\begin{array}{l}\text { Slectric Utllty Plant } \\
\text { Orlgin State } \\
\text { County }\end{array}$} & \multirow[b]{2}{*}{$\begin{array}{l}\text { Quantity } \\
\text { (thousand } \\
\text { short tons) }\end{array}$} & \multicolumn{3}{|c|}{ Average Quallty } & \multicolumn{2}{|c|}{ Average Dellvered Cost } \\
\hline & & $\begin{array}{c}\text { Btu } \\
\text { (per pound) }\end{array}$ & $\begin{array}{l}\text { Sulfur } \\
\text { (percerit } \\
\text { by welght) }\end{array}$ & $\begin{array}{l}\text { Ash } \\
\text { (porcent } \\
\text { by weight) }\end{array}$ & $\begin{array}{l}\text { (cents per } \\
\text { million Btu) }\end{array}$ & $\begin{array}{l}\text { (dollare per } \\
\text { short ton) }\end{array}$ \\
\hline 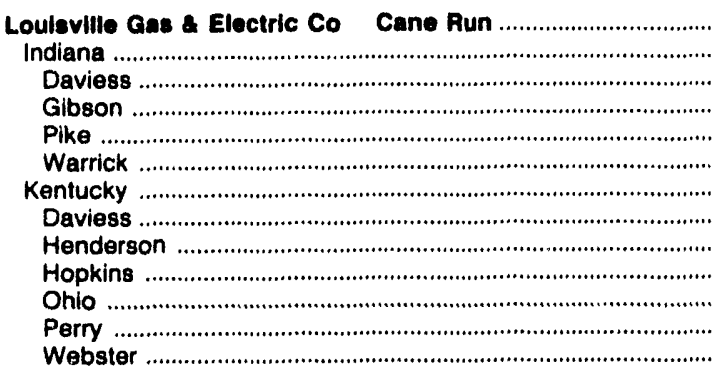 & $\begin{array}{r}809 \\
198 \\
14 \\
29 \\
132 \\
22 \\
611 \\
28 \\
18 \\
508 \\
32 \\
17 \\
8\end{array}$ & $\begin{array}{l}11,542 \\
11,356 \\
11,049 \\
11,12 \% \\
11,494 \\
11,041 \\
11,602 \\
11,051 \\
11,629 \\
11,646 \\
11,444 \\
11,321 \\
11,967\end{array}$ & $\begin{array}{l}2.94 \\
3.15 \\
2.63 \\
2.79 \\
3.36 \\
2.75 \\
2.88 \\
2.63 \\
2.71 \\
2.90 \\
3.01 \\
2.54 \\
2.86\end{array}$ & $\begin{array}{r}9.39 \\
8.36 \\
8.29 \\
9.28 \\
8.03 \\
9.14 \\
9.73 \\
8.29 \\
8.11 \\
9.97 \\
8.17 \\
9.45 \\
10.08\end{array}$ & $\begin{array}{r}109.1 \\
91.0 \\
111.8 \\
108.4 \\
81.7 \\
112.2 \\
114.8 \\
111.8 \\
127.3 \\
114.8 \\
108.5 \\
120.6 \\
112.7\end{array}$ & $\begin{array}{l}25.18 \\
20.68 \\
24.71 \\
24.12 \\
18.77 \\
24.77 \\
26.64 \\
24.71 \\
29.60 \\
26.73 \\
24.84 \\
27.30 \\
26.97\end{array}$ \\
\hline 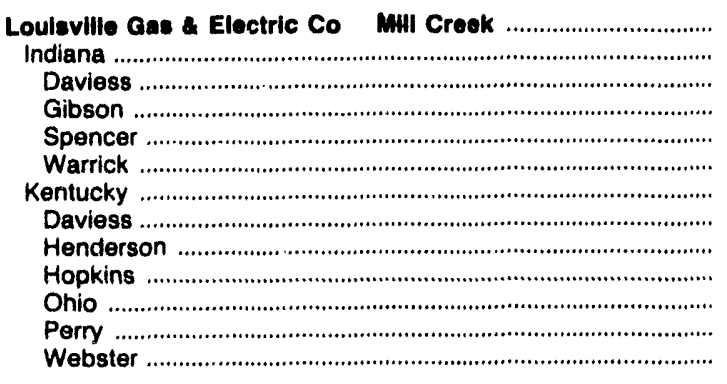 & $\begin{array}{r}3,353 \\
478 \\
46 \\
311 \\
2 \\
120 \\
2,875 \\
101 \\
189 \\
2,341 \\
134 \\
23 \\
88\end{array}$ & $\begin{array}{l}11,537 \\
11,083 \\
11,045 \\
11,140 \\
10,687 \\
10,955 \\
11,612 \\
11,031 \\
11,347 \\
11,660 \\
11,444 \\
11,077 \\
11,974\end{array}$ & $\begin{array}{l}2.86 \\
2.78 \\
2.61 \\
2.78 \\
2.97 \\
2.87 \\
2.87 \\
2.61 \\
2.61 \\
2.90 \\
3.01 \\
2.63 \\
2.89\end{array}$ & $\begin{array}{r}9.62 \\
9.16 \\
8.33 \\
9.21 \\
10.90 \\
9.35 \\
9.69 \\
8.48 \\
8.25 \\
9.95 \\
8.24 \\
9.51 \\
9.50\end{array}$ & $\begin{array}{r}111.4 \\
100.1 \\
105.9 \\
100.1 \\
77.7 \\
98.1 \\
113.2 \\
106.0 \\
114.7 \\
114.2 \\
100.6 \\
114.9 \\
108.4\end{array}$ & $\begin{array}{l}25.70 \\
22.19 \\
23.39 \\
22.30 \\
16.61 \\
21.50 \\
26.29 \\
23.39 \\
26.02 \\
26.64 \\
23.03 \\
25.46 \\
25.95\end{array}$ \\
\hline 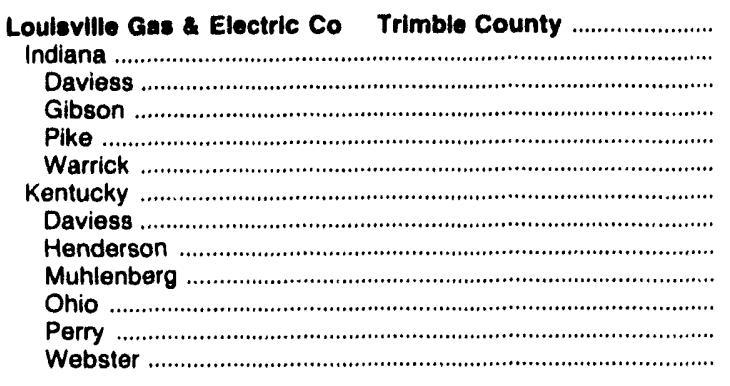 & $\begin{array}{r}1,317 \\
639 \\
44 \\
274 \\
285 \\
36 \\
679 \\
89 \\
237 \\
6 \\
252 \\
8 \\
87\end{array}$ & $\begin{array}{l}11,368 \\
11,362 \\
11,150 \\
11,248 \\
11,549 \\
11,011 \\
11,374 \\
11,141 \\
11,039 \\
11,656 \\
11,531 \\
11,283 \\
12,055\end{array}$ & $\begin{array}{l}3.06 \\
3.08 \\
2.68 \\
2.87 \\
3.38 \\
2.75 \\
3.03 \\
2.68 \\
3.18 \\
2.76 \\
3.08 \\
2.69 \\
2.90\end{array}$ & $\begin{array}{r}9.04 \\
8.73 \\
8.56 \\
9.39 \\
8.07 \\
9.12 \\
9.34 \\
8.59 \\
10.38 \\
9.30 \\
8.52 \\
9.40 \\
9.67\end{array}$ & $\begin{array}{r}101.6 \\
97.7 \\
105.7 \\
99.9 \\
94.1 \\
100.7 \\
105.2 \\
105.8 \\
107.7 \\
102.9 \\
100.8 \\
115.4 \\
110.3\end{array}$ & $\begin{array}{l}23.10 \\
22.20 \\
23.58 \\
22.48 \\
21.73 \\
22.17 \\
23.94 \\
23.57 \\
23.78 \\
23.99 \\
23.24 \\
26.04 \\
26.58\end{array}$ \\
\hline 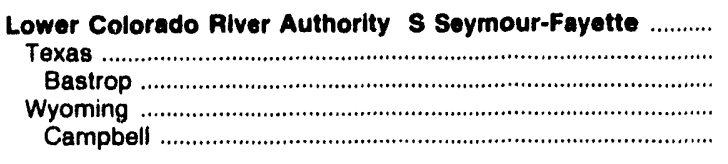 & $\begin{array}{r}5,227 \\
180 \\
180 \\
5,047 \\
5,047\end{array}$ & $\begin{array}{l}8,598 \\
6,678 \\
6,678 \\
8,667 \\
8,667\end{array}$ & $\begin{array}{r}.41 \\
1.47 \\
1.47 \\
.37 \\
.37\end{array}$ & $\begin{array}{r}5.47 \\
11.72 \\
11.72 \\
5.24 \\
5.24\end{array}$ & $\begin{array}{l}135.2 \\
160.2 \\
160.2 \\
134.5 \\
134.5\end{array}$ & $\begin{array}{l}23.25 \\
21.40 \\
21.40 \\
23.32 \\
23.32\end{array}$ \\
\hline 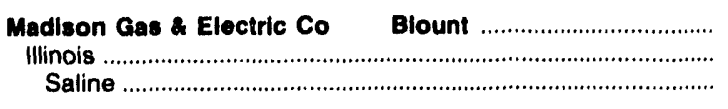 & $\begin{array}{l}18 \\
18 \\
18\end{array}$ & $\begin{array}{l}11,848 \\
11,848 \\
11,848\end{array}$ & $\begin{array}{l}2.08 \\
2.08 \\
2.08\end{array}$ & $\begin{array}{l}8.18 \\
8.18 \\
8.18\end{array}$ & $\begin{array}{l}165.7 \\
165.7 \\
165.7\end{array}$ & $\begin{array}{l}39.26 \\
39.26 \\
39.26\end{array}$ \\
\hline 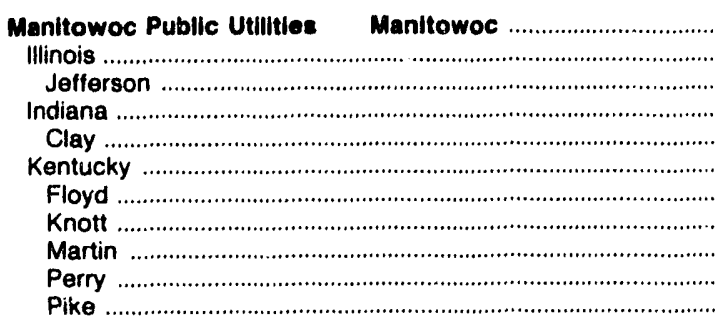 & $\begin{array}{r}138 \\
8 \\
8 \\
8 \\
8 \\
122 \\
14 \\
23 \\
23 \\
52 \\
9\end{array}$ & $\begin{array}{l}13,101 \\
11,336 \\
11,336 \\
11,786 \\
11,786 \\
13,309 \\
13,573 \\
13,048 \\
12,758 \\
13,536 \\
13,671\end{array}$ & $\begin{array}{l}.85 \\
1.70 \\
1.70 \\
.65 \\
.65 \\
.81 \\
.80 \\
.88 \\
.67 \\
.82 \\
.93\end{array}$ & $\begin{array}{r}6.71 \\
12.20 \\
12.20 \\
5.81 \\
5.81 \\
6.41 \\
6.27 \\
7.14 \\
6.65 \\
6.15 \\
5.55\end{array}$ & $\begin{array}{l}174.4 \\
128.4 \\
128.4 \\
152.0 \\
152.0 \\
178.3 \\
171.1 \\
175.4 \\
174.3 \\
182.3 \\
184.2\end{array}$ & $\begin{array}{l}45.69 \\
29.11 \\
29.11 \\
35.83 \\
35.83 \\
47.47 \\
46.45 \\
45.77 \\
44.47 \\
48.34 \\
50.36\end{array}$ \\
\hline 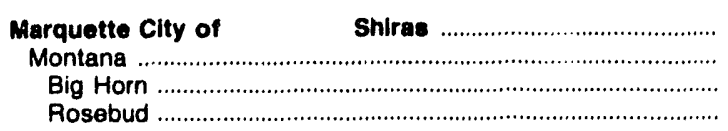 & $\begin{array}{r}134 \\
123 \\
93 \\
31\end{array}$ & $\begin{array}{l}9,259 \\
8,999 \\
8,998 \\
9,000\end{array}$ & $\begin{array}{l}.42 \\
.40 \\
.40 \\
.40\end{array}$ & $\begin{array}{l}6.57 \\
6.35 \\
6.35 \\
6.35\end{array}$ & $\begin{array}{l}178.1 \\
179.0 \\
179.0 \\
178.9\end{array}$ & $\begin{array}{l}32.98 \\
32.21 \\
32.21 \\
32.21\end{array}$ \\
\hline
\end{tabular}

See footnotes at end of table.

Source: Federal Energy Regulatory Commission, FERC Form 423, "Monthly Heport of Cost and Quality of Fuels for Electric Plants." 
Table 24. Origin of Coal Received by Electric Utility and Plant, 1992 (Continued)

\begin{tabular}{|c|c|c|c|c|c|c|}
\hline \multirow{2}{*}{$\begin{array}{c}\text { Electric Utility Plant } \\
\text { Origin State } \\
\text { County }\end{array}$} & \multirow{2}{*}{$\begin{array}{l}\text { Quantity } \\
\text { (thousand } \\
\text { short tons) }\end{array}$} & \multicolumn{3}{|c|}{ Average Quality } & \multicolumn{2}{|c|}{ Average Dellvered Cost } \\
\hline & & $\begin{array}{c}\text { Btu } \\
\text { (per pound) }\end{array}$ & $\begin{array}{c}\text { Sulfur } \\
\text { (percent } \\
\text { by welght) }\end{array}$ & $\begin{array}{l}\text { Ash } \\
\text { (parcent } \\
\text { by weight) }\end{array}$ & $\begin{array}{l}\text { (cents per } \\
\text { million Btu) }\end{array}$ & $\begin{array}{l}\text { (dollars per } \\
\text { short ton) }\end{array}$ \\
\hline \multicolumn{7}{|l|}{ Marquette Clty of $\quad$ Shiras } \\
\hline Pennsylvania & 10 & 12,345 & 0.65 & 9.18 & 170.5 & 42.09 \\
\hline 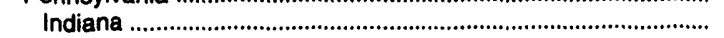 & 5 & 12,287 & .64 & 9.01 & 171.3 & 42.10 \\
\hline 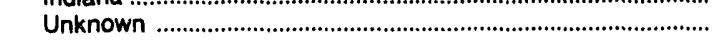 & 5 & 12,401 & .65 & 9.34 & 169.7 & 42.09 \\
\hline $\begin{array}{l}\text { Metropolltan Edison Co } \quad \text { Portiand } \\
\text { Pennsylvania }\end{array}$ & $\begin{array}{l}723 \\
536\end{array}$ & $\begin{array}{l}13,188 \\
13,167\end{array}$ & $\begin{array}{l}1.70 \\
1.65\end{array}$ & $\begin{array}{l}6.97 \\
6.80\end{array}$ & $\begin{array}{l}140.6 \\
138.7\end{array}$ & $\begin{array}{l}37.08 \\
36.53\end{array}$ \\
\hline Armstrong & $\begin{array}{r}530 \\
15\end{array}$ & 12,889 & 1.65 & 9.29 & 136.0 & $\begin{array}{l}36.53 \\
37.64\end{array}$ \\
\hline Clarion & 24 & 12,838 & 2.17 & 8.68 & 138.: & 35.49 \\
\hline 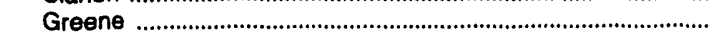 & 497 & 13,191 & 1.63 & 6.63 & 123.5 & 36.55 \\
\hline West Virginia & 187 & 13,250 & 1.84 & 7.45 & 145.9 & 38.66 \\
\hline 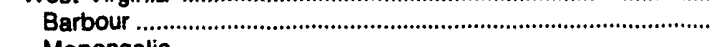 & 57 & 13,100 & 1.70 & 7.42 & 166.3 & 43.57 \\
\hline 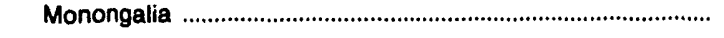 & 129 & 13,317 & 1.90 & 7.46 & 137.0 & 36.50 \\
\hline 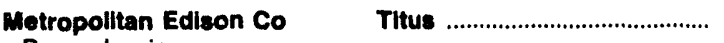 & 387 & 13,305 & 1.47 & 6.55 & 149.6 & 39.82 \\
\hline 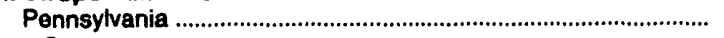 & 387 & 13,305 & 1.47 & 6.55 & 149.6 & 39.82 \\
\hline 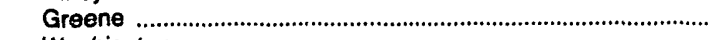 & 380 & 13,305 & 1.46 & 6.56 & 150.2 & 39.96 \\
\hline 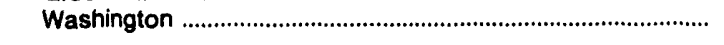 & 7 & 13,317 & 1.63 & 5.85 & 121.0 & 32.23 \\
\hline Michigan South Central Pwr Agy Endicott ............................. & 40 & 12,003 & 3.35 & 8.29 & 223.3 & 53.60 \\
\hline Ohio & 40 & 12,003 & 3.35 & 8.29 & 223.3 & 53.60 \\
\hline 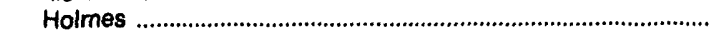 & 40 & 12,003 & 3.35 & 8.29 & 223.3 & 53.60 \\
\hline 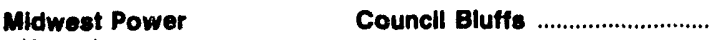 & 2,859 & 8,267 & .37 & 4.63 & 89.0 & 14.72 \\
\hline 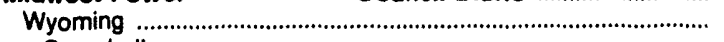 & 2,859 & 8,267 & .37 & 4.63 & 89.0 & 14.72 \\
\hline 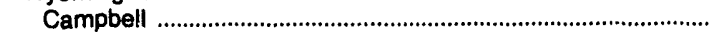 & 2,859 & 8,267 & .37 & 4.63 & 89.0 & 14.72 \\
\hline 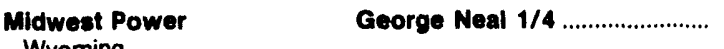 & 5,119 & 8,733 & .37 & 5.74 & 85.0 & 14.85 \\
\hline 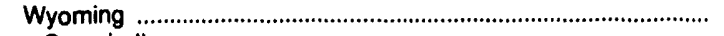 & 5,119 & 8,733 & .37 & 5.74 & 85.0 & 14.85 \\
\hline 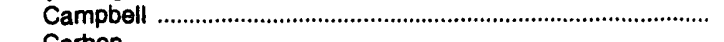 & 4,454 & 8,483 & .37 & 5.26 & 77.9 & 13.21 \\
\hline 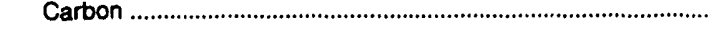 & 665 & 10,409 & .41 & 8.98 & 124.0 & 25.81 \\
\hline Minnesota Power \& Light Co Boswell Energy Cen .......... & 3,199 & 8,971 & .53 & 6.81 & 119.3 & 21.40 \\
\hline Montana & 2,901 & 9,005 & .55 & 6.98 & 121.4 & 21.86 \\
\hline 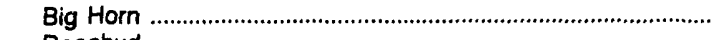 & 903 & 9,378 & .34 & 3.82 & 124.4 & 23.34 \\
\hline 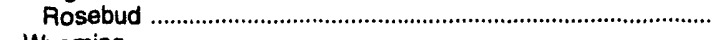 & 1,997 & 8,836 & .65 & 8.41 & 119.9 & 21.19 \\
\hline 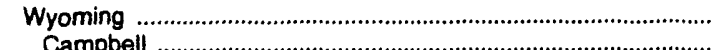 & 298 & 8,638 & .35 & 5.19 & 98.1 & 16.94 \\
\hline 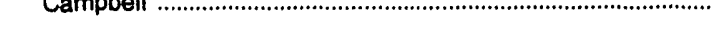 & & 8,638 & .30 & 5.19 & 98.1 & 16.94 \\
\hline Minnesota Power \& Light Co Laskin Energy Cen ........... & 65 & 8,854 & .65 & 8.21 & 92.1 & 16.31 \\
\hline Montana & 65 & 8,854 & .65 & 8.21 & 92.1 & 16.31 \\
\hline 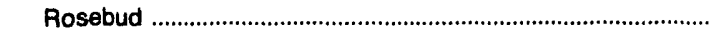 & 65 & 8,854 & .65 & 8.21 & 92.1 & 16.31 \\
\hline 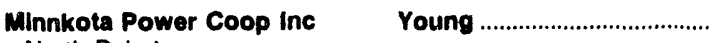 & 4,184 & 6,831 & .86 & 7.58 & 48.9 & 6.69 \\
\hline North Dakota & 4,184 & 6,831 & .86 & 7.58 & 48.9 & 6.69 \\
\hline 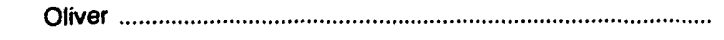 & 4,184 & 6,831 & .86 & 7.58 & 48.9 & 6.69 \\
\hline $\begin{array}{l}\text { Mlssissippl Power Co } \quad \text { Daniel } \\
\text { Kentucky }\end{array}$ & $\begin{array}{l}964 \\
811\end{array}$ & $\begin{array}{l}12,369 \\
12,988\end{array}$ & .66 & $\begin{array}{l}6.79 \\
7.22\end{array}$ & $\begin{array}{l}166.9 \\
170.0\end{array}$ & $\begin{array}{l}41.29 \\
44.15\end{array}$ \\
\hline 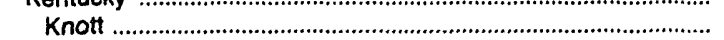 & 567 & 12,988 & .73 & 7.22 & 170.0 & 44.15 \\
\hline Letcher . . & 243 & 12,988 & .73 & 7.22 & 170.0 & 44.15 \\
\hline 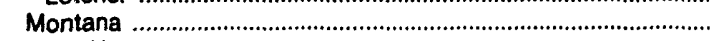 & 82 & 9,383 & .30 & 4.15 & 136.0 & 25.51 \\
\hline Big Horn & 82 & 9,383 & .30 & 4.15 & 136.0 & 25.51 \\
\hline Wyoming & 71 & 8,760 & .34 & 4.92 & 153.0 & 26.81 \\
\hline 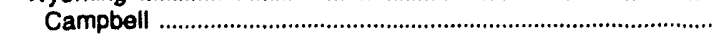 & 71 & 6,760 & .34 & 4.92 & 153.0 & 26.81 \\
\hline 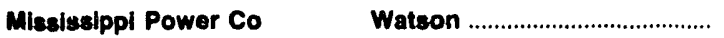 & 1,487 & 12,665 & 2.70 & 8.64 & 132.4 & 33.53 \\
\hline Illinois & 1,239 & 12,757 & 2.74 & 8.75 & 132.7 & 33.86 \\
\hline Gallatin & 1,239 & 12,757 & 2.74 & 8.75 & 132.7 & 33.86 \\
\hline Kentucky & 248 & 12,208 & 2.50 & 8.08 & 130.5 & 31.87 \\
\hline Greenup & 26 & 12,047 & 1.85 & 8.28 & 140.0 & 33.73 \\
\hline 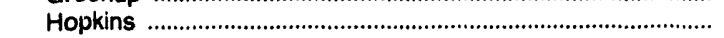 & 143 & 12,102 & 2.66 & 8.51 & 129.3 & 31.30 \\
\hline Pike & 19 & 12,090 & 1.62 & 8.06 & 141.9 & 34.31 \\
\hline 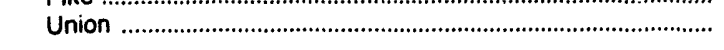 & 60 & 12,568 & 2.69 & 6.98 & 125.8 & 31.63 \\
\hline Miseouri Public Service Comm Sibley ..................................... & 985 & 11,097 & 2.63 & 9.29 & 133.7 & 29.68 \\
\hline Colorado & 9 & 10,964 & 1.21 & 4.07 & 141.0 & 30.92 \\
\hline 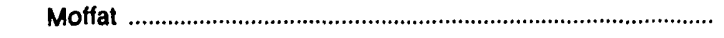 & 9 & 10,964 & 1.21 & 4.07 & 141.0 & 30.92 \\
\hline
\end{tabular}

See footnotes at end of table.

Source: Federal Energy Regulatory Commission, FERC Form 423, "Monthly Report of Cost and Quality of Fuels for Electric Plants." 
Table 24. Origin of Coal Received by Electric Utility and Plant, 1992 (Continued)

\begin{tabular}{|c|c|c|c|c|c|c|}
\hline \multirow{2}{*}{$\begin{array}{c}\text { Electric Utility Plant } \\
\text { Origln State } \\
\text { County }\end{array}$} & \multirow{2}{*}{$\begin{array}{l}\text { Quantity } \\
\text { (thousand } \\
\text { short tons) }\end{array}$} & \multicolumn{3}{|c|}{ Average Quality } & \multicolumn{2}{|c|}{ Average Delivered Cost } \\
\hline & & $\begin{array}{c}\text { Btu } \\
\text { (per pound) }\end{array}$ & $\begin{array}{l}\text { Sulfur } \\
\text { (percent } \\
\text { by weight) }\end{array}$ & $\begin{array}{l}\text { Aeh } \\
\text { (porcent } \\
\text { by weight) }\end{array}$ & $\begin{array}{l}\text { (cente per } \\
\text { million Btu) }\end{array}$ & $\begin{array}{l}\text { (dollare per } \\
\text { short ton) }\end{array}$ \\
\hline $\begin{array}{l}\text { Missouri Public Servlce Comm Sibley } \\
\text { Illinois } \\
\text { Franklin . } \\
\text { Perry } \\
\text { Randolph } \\
\text { Saline } \\
\text { Utah } \\
\text { Carbon } \\
\text { Campbell }\end{array}$ & $\begin{array}{c}929 \\
148 \\
306 \\
476 \\
27 \\
27 \\
19 \\
19\end{array}$ & $\begin{array}{r}11,131 \\
11,759 \\
10,935 \\
11,062 \\
11,875 \\
11,606 \\
11,606 \\
8,763 \\
8,763\end{array}$ & $\begin{array}{r}2.75 \\
2.15 \\
2.92 \\
2.83 \\
2.60 \\
.45 \\
.45 \\
.46 \\
.46\end{array}$ & $\begin{array}{r}9.45 \\
8.23 \\
10.28 \\
9.30 \\
7.50 \\
8.29 \\
8.29 \\
5.39 \\
5.39\end{array}$ & $\begin{array}{r}134.1 \\
107.7 \\
125.0 \\
148.6 \\
106.0 \\
138.9 \\
138.9 \\
96.0 \\
96.0\end{array}$ & $\begin{array}{l}29.85 \\
25.33 \\
27.33 \\
32.87 \\
25.17 \\
32.25 \\
32.25 \\
16.82 \\
16.82\end{array}$ \\
\hline 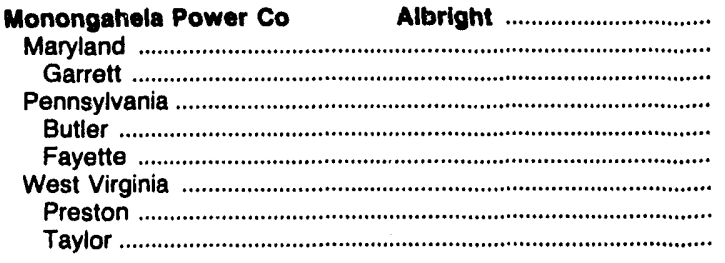 & $\begin{array}{r}502 \\
19 \\
19 \\
93 \\
24 \\
68 \\
390 \\
373 \\
17\end{array}$ & $\begin{array}{l}12,341 \\
12,897 \\
12,897 \\
12,247 \\
12,274 \\
12,238 \\
12,336 \\
12,341 \\
12,234\end{array}$ & $\begin{array}{l}1.54 \\
1.57 \\
1.57 \\
1.61 \\
1.78 \\
1.55 \\
1.53 \\
1.52 \\
1.59\end{array}$ & $\begin{array}{l}12.88 \\
11.49 \\
11.49 \\
13.14 \\
12.95 \\
13.20 \\
12.88 \\
12.87 \\
13.20\end{array}$ & $\begin{array}{r}100.8 \\
108.1 \\
108.1 \\
97.5 \\
96.0 \\
98.0 \\
101.3 \\
101.2 \\
101.6\end{array}$ & $\begin{array}{l}24.89 \\
27.89 \\
27.89 \\
23.88 \\
23.57 \\
23.99 \\
24.98 \\
24.99 \\
24.85\end{array}$ \\
\hline 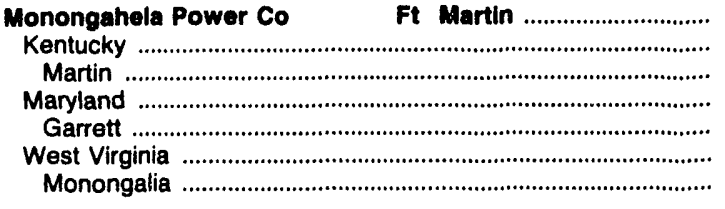 & $\begin{array}{r}2,478 \\
501 \\
501 \\
453 \\
453 \\
1,524 \\
1,524\end{array}$ & $\begin{array}{l}12,719 \\
12,526 \\
12,526 \\
12,814 \\
12,814 \\
12,754 \\
12,754\end{array}$ & $\begin{array}{r}1.79 \\
.83 \\
.83 \\
1.59 \\
1.59 \\
2.15 \\
2.15\end{array}$ & $\begin{array}{r}10.50 \\
8.86 \\
8.86 \\
12.22 \\
12.22 \\
10.53 \\
10.53\end{array}$ & $\begin{array}{l}145.4 \\
185.5 \\
185.5 \\
127.3 \\
127.3 \\
137.8 \\
137.8\end{array}$ & $\begin{array}{l}36.98 \\
46.48 \\
46.48 \\
32.64 \\
32.64 \\
35.15 \\
35.15\end{array}$ \\
\hline 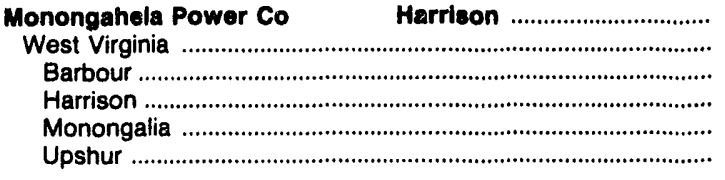 & $\begin{array}{r}4,619 \\
4,619 \\
52 \\
3,646 \\
695 \\
226\end{array}$ & $\begin{array}{l}13,158 \\
13,158 \\
13,127 \\
13,131 \\
13,296 \\
13,189\end{array}$ & $\begin{array}{l}3.05 \\
3.05 \\
2.89 \\
3.13 \\
2.63 \\
3.02\end{array}$ & $\begin{array}{l}7.77 \\
7.77 \\
8.39 \\
7.89 \\
6.94 \\
8.32\end{array}$ & $\begin{array}{r}141.4 \\
141.4 \\
104.4 \\
147.3 \\
127.5 \\
99.2\end{array}$ & $\begin{array}{l}37.22 \\
37.22 \\
27.40 \\
38.68 \\
33.91 \\
26.16\end{array}$ \\
\hline $\begin{array}{l}\text { Monongahela Power Co } \\
\text { Ohio .mont } \\
\text { Belmofleaseants } \\
\text { Jefferson } \\
\text { Pennsylvania } \\
\text { Greene } \\
\text { Washington } \\
\text { West Virginia } \\
\text { Barbour } \\
\text { Fayette } \\
\text { Harrison } \\
\text { Marion } \\
\text { Marshall } \\
\text { Monongalia } \\
\text { Ohio }\end{array}$ & $\begin{array}{r}3,657 \\
1,240 \\
1,203 \\
38 \\
1,013 \\
837 \\
175 \\
1,405 \\
338 \\
17 \\
242 \\
87 \\
528 \\
41 \\
151\end{array}$ & $\begin{array}{l}12,491 \\
12,591 \\
12,609 \\
12,030 \\
12,590 \\
12,681 \\
12,155 \\
12,332 \\
12,282 \\
12,265 \\
12,540 \\
12,090 \\
12,284 \\
13,044 \\
12,235\end{array}$ & $\begin{array}{l}3.45 \\
4.05 \\
4.05 \\
3.98 \\
2.90 \\
2.77 \\
3.57 \\
3.33 \\
2.65 \\
1.67 \\
3.27 \\
3.45 \\
4.00 \\
2.81 \\
2.87\end{array}$ & $\begin{array}{r}10.82 \\
9.57 \\
9.49 \\
12.28 \\
11.34 \\
11.13 \\
12.33 \\
11.54 \\
13.33 \\
13.30 \\
11.08 \\
12.93 \\
11.16 \\
7.64 \\
9.71\end{array}$ & $\begin{array}{r}102.4 \\
92.4 \\
92.6 \\
88.3 \\
112.4 \\
117.4 \\
87.2 \\
103.9 \\
117.6 \\
89.6 \\
131.7 \\
86.4 \\
89.2 \\
114.0 \\
87.8\end{array}$ & $\begin{array}{l}25.57 \\
23.28 \\
23.34 \\
21.25 \\
28.30 \\
29.79 \\
21.19 \\
25.63 \\
28.88 \\
21.98 \\
33.02 \\
20.89 \\
21.93 \\
29.73 \\
21.48\end{array}$ \\
\hline 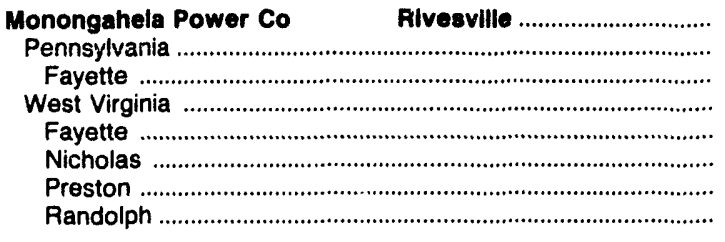 & $\begin{array}{l}68 \\
56 \\
56 \\
12 \\
2 \\
5 \\
5\end{array}$ & $\begin{array}{l}12,181 \\
12,178 \\
12,178 \\
12,194 \\
12,146 \\
12,129 \\
12,403 \\
12,011\end{array}$ & $\begin{array}{r}.97 \\
.96 \\
.96 \\
1.01 \\
.59 \\
1.15 \\
.97 \\
1.04\end{array}$ & $\begin{array}{r}11.08 \\
10.66 \\
10.66 \\
13.02 \\
9.90 \\
11.44 \\
12.50 \\
14.30\end{array}$ & $\begin{array}{l}120.8 \\
119.8 \\
119.8 \\
125.5 \\
123.0 \\
119.1 \\
125.0 \\
128.3\end{array}$ & $\begin{array}{l}29.42 \\
29.17 \\
29.17 \\
30.60 \\
29.88 \\
28.90 \\
31.01 \\
30.82\end{array}$ \\
\hline $\begin{array}{l}\text { Monongahela Power Co } \\
\text { Kentucky . . } \\
\text { Floyd } \\
\text { Ohio } \\
\text { Guernsey } \\
\text { Pennsylvania } \\
\text { Greene } \\
\text { Washington }\end{array}$ & $\begin{array}{r}261 \\
24 \\
24 \\
6 \\
6 \\
66 \\
45 \\
21\end{array}$ & $\begin{array}{l}12,488 \\
12,132 \\
12,132 \\
11,623 \\
11,623 \\
13,176 \\
13,134 \\
13,267\end{array}$ & $\begin{array}{l}1.62 \\
1.43 \\
1.43 \\
1.72 \\
1.72 \\
1.47 \\
1.61 \\
1.18\end{array}$ & $\begin{array}{r}11.39 \\
11.11 \\
11.11 \\
7.10 \\
7.10 \\
7.06 \\
7.35 \\
6.45\end{array}$ & $\begin{array}{r}115.6 \\
115.1 \\
115.1 \\
95.7 \\
95.7 \\
113.9 \\
112.8 \\
116.4\end{array}$ & $\begin{array}{l}28.86 \\
27.93 \\
27.93 \\
22.25 \\
22.25 \\
30.03 \\
29.63 \\
30.88\end{array}$ \\
\hline
\end{tabular}

See footnotes at end of table.

Source: Federal Energy Regulatory Commission, FERC Form 423, "Monthly Report of Cost and Quality of Fuels for Electric Plants." 
Table 24. Origin of Coal Received by Electric Utility and Plant, 1992 (Continued)

\begin{tabular}{|c|c|c|c|c|c|c|}
\hline \multirow{2}{*}{$\begin{array}{l}\text { Electric Utilly Plant } \\
\text { Origin Stato } \\
\text { County }\end{array}$} & \multirow{2}{*}{$\begin{array}{l}\text { Quantity } \\
\text { (thousend } \\
\text { chort tons) }\end{array}$} & \multicolumn{3}{|c|}{ Average Quality } & \multicolumn{2}{|c|}{ Average Delivered Cost } \\
\hline & & $\begin{array}{c}\text { Btu } \\
\text { (per pound) }\end{array}$ & $\begin{array}{l}\text { sulfur } \\
\text { (porcont } \\
\text { by welght) }\end{array}$ & $\begin{array}{l}\text { Ach } \\
\text { (porcent } \\
\text { by wolght) }\end{array}$ & $\begin{array}{l}\text { (cente per } \\
\text { million Btu) }\end{array}$ & $\begin{array}{l}\text { (dollars per } \\
\text { short ton) }\end{array}$ \\
\hline 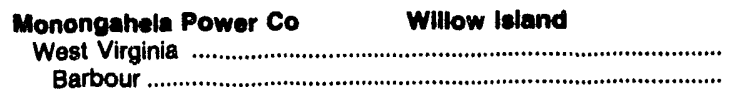 & $\begin{array}{l}167 \\
167\end{array}$ & $\begin{array}{l}12,297 \\
12,297\end{array}$ & $\begin{array}{l}1.70 \\
1.70\end{array}$ & $\begin{array}{l}13.27 \\
13.27\end{array}$ & $\begin{array}{l}117.0 \\
117.0\end{array}$ & $\begin{array}{l}28.79 \\
28.79\end{array}$ \\
\hline 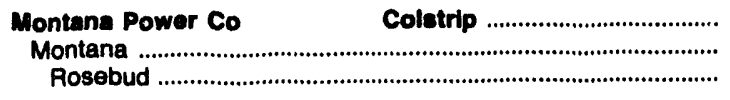 & $\begin{array}{l}9,934 \\
9,934 \\
9,934\end{array}$ & $\begin{array}{l}8,596 \\
8,596 \\
8,596\end{array}$ & $\begin{array}{l}.66 \\
.66 \\
.66\end{array}$ & $\begin{array}{l}8.98 \\
8.98 \\
8.98\end{array}$ & $\begin{array}{l}70.4 \\
70.4 \\
70.4\end{array}$ & $\begin{array}{l}12.10 \\
12.10 \\
12.10\end{array}$ \\
\hline 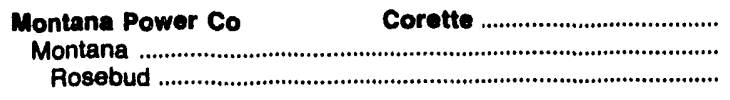 & $\begin{array}{l}749 \\
749 \\
749\end{array}$ & $\begin{array}{l}8,782 \\
8,782 \\
8,782\end{array}$ & $\begin{array}{l}.63 \\
.63 \\
.63\end{array}$ & $\begin{array}{l}8.11 \\
8.11 \\
8.11\end{array}$ & $\begin{array}{l}69.1 \\
69.1 \\
69.1\end{array}$ & $\begin{array}{l}12.13 \\
12.13 \\
12.13\end{array}$ \\
\hline $\begin{array}{l}\text { Montana-Dakota Utilties Co Coyote } \\
\text { North Dakota } \\
\text { Mercer }\end{array}$ Oliver & $\begin{array}{r}2,151 \\
2,151 \\
958 \\
1,194\end{array}$ & $\begin{array}{l}6,931 \\
6,931 \\
6,948 \\
6,917\end{array}$ & $\begin{array}{l}1.06 \\
1.06 \\
1.04 \\
1.08\end{array}$ & $\begin{array}{l}8.12 \\
8.12 \\
7.98 \\
8.23\end{array}$ & $\begin{array}{l}74.3 \\
74.3 \\
74.0 \\
74.5\end{array}$ & $\begin{array}{l}10.30 \\
10.30 \\
10.29 \\
10.30\end{array}$ \\
\hline 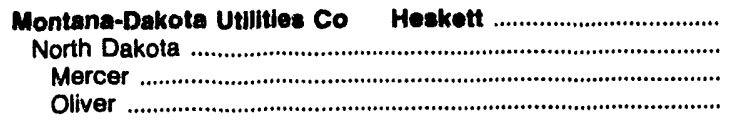 & $\begin{array}{l}345 \\
345 \\
138 \\
206\end{array}$ & $\begin{array}{l}7,009 \\
7,009 \\
7,046 \\
6,985\end{array}$ & $\begin{array}{l}.82 \\
.82 \\
.79 \\
.83\end{array}$ & $\begin{array}{l}8.53 \\
8.53 \\
8.23 \\
8.73\end{array}$ & $\begin{array}{l}105.3 \\
105.3 \\
104.8 \\
105.6\end{array}$ & $\begin{array}{l}14.76 \\
14.76 \\
14.76 \\
14.75\end{array}$ \\
\hline 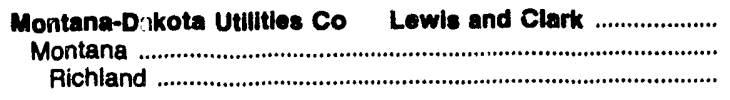 & $\begin{array}{l}177 \\
177 \\
177\end{array}$ & $\begin{array}{l}6,542 \\
6,542 \\
6,542\end{array}$ & $\begin{array}{l}.51 \\
.51 \\
.51\end{array}$ & $\begin{array}{l}9.04 \\
9.04 \\
9.04\end{array}$ & $\begin{array}{l}107.8 \\
107.8 \\
107.8\end{array}$ & $\begin{array}{l}14.10 \\
14.10 \\
14.10\end{array}$ \\
\hline 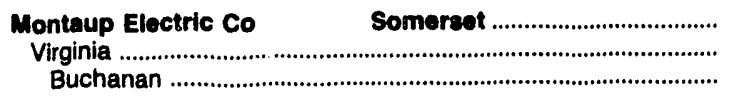 & $\begin{array}{l}413 \\
413 \\
413\end{array}$ & $\begin{array}{l}12,917 \\
12,917 \\
12,917\end{array}$ & $\begin{array}{l}1.03 \\
1.03 \\
1.03\end{array}$ & $\begin{array}{l}7.83 \\
7.93 \\
7.93\end{array}$ & $\begin{array}{l}176.4 \\
176.4 \\
176.4\end{array}$ & $\begin{array}{l}45.58 \\
45.58 \\
45.58\end{array}$ \\
\hline 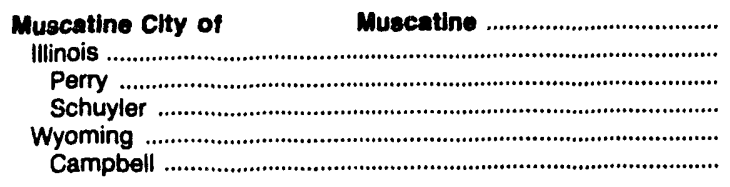 & $\begin{array}{r}559 \\
536 \\
248 \\
288 \\
22 \\
22\end{array}$ & $\begin{array}{r}10,974 \\
11,078 \\
10,952 \\
11,186 \\
8,491 \\
\mathbf{8 , 4 9 1}\end{array}$ & $\begin{array}{r}3.06 \\
3.16 \\
3.16 \\
3.16 \\
.59 \\
.59\end{array}$ & $\begin{array}{r}8.14 \\
8.25 \\
10.00 \\
6.74 \\
5.51 \\
5.51\end{array}$ & $\begin{array}{l}220.0 \\
223.9 \\
208.9 \\
236.4 \\
100.0 \\
100.0\end{array}$ & $\begin{array}{l}48.29 \\
49.60 \\
45.76 \\
52.90 \\
16.98 \\
16.98\end{array}$ \\
\hline 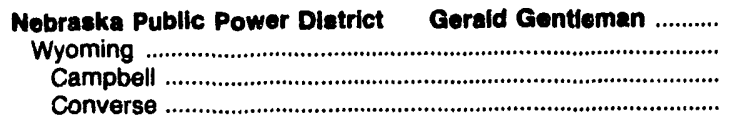 & $\begin{array}{r}3,256 \\
3,256 \\
3,183 \\
73\end{array}$ & $\begin{array}{l}8,778 \\
8,778 \\
8,777 \\
8,816\end{array}$ & $\begin{array}{l}.37 \\
.37 \\
.37 \\
.32\end{array}$ & $\begin{array}{l}5.04 \\
5.04 \\
5.03 \\
5.40\end{array}$ & $\begin{array}{l}83.9 \\
83.9 \\
84.2 \\
71.7\end{array}$ & $\begin{array}{l}14.73 \\
14.73 \\
14.78 \\
12.64\end{array}$ \\
\hline 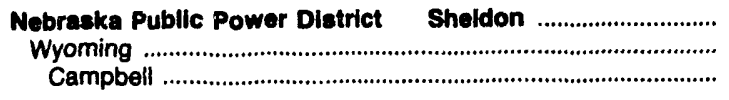 & $\begin{array}{l}558 \\
558 \\
558\end{array}$ & $\begin{array}{l}8,779 \\
8,779 \\
8,779\end{array}$ & $\begin{array}{l}.38 \\
.38 \\
.38\end{array}$ & $\begin{array}{l}5.04 \\
5.04 \\
5.04\end{array}$ & $\begin{array}{l}78.1 \\
78.1 \\
78.1\end{array}$ & $\begin{array}{l}13.71 \\
13.71 \\
13.71\end{array}$ \\
\hline 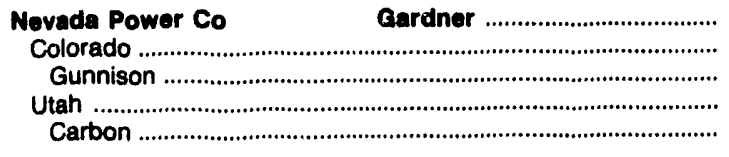 & $\begin{array}{r}1,372 \\
168 \\
168 \\
1,203 \\
1,203\end{array}$ & $\begin{array}{l}12,058 \\
11,753 \\
11,753 \\
12,100 \\
12,100\end{array}$ & $\begin{array}{l}.50 \\
.50 \\
.50 \\
.50 \\
.50\end{array}$ & $\begin{array}{l}9.11 \\
9.28 \\
9.28 \\
9.09 \\
9.09\end{array}$ & $\begin{array}{l}185.1 \\
215.3 \\
215.3 \\
181.0 \\
181.0\end{array}$ & $\begin{array}{l}44.64 \\
50.60 \\
50.60 \\
43.61 \\
43.81\end{array}$ \\
\hline $\begin{array}{l}\text { New England Power Co } \\
\text { Kentucky ... Brayton } \\
\text { Martin . } \\
\text { Pike } \\
\text { Virginia } \\
\text { Wise } \\
\text { West Virginia } \\
\text { Barbour } \\
\text { Grant } \\
\text { Greenbrier } \\
\text { Kanawha } \\
\text { Logan } \\
\text { Mcdowell } \\
\text { Mingo } \\
\text { Randolph }\end{array}$ & $\begin{array}{r}2,547 \\
10 \\
10 \\
198 \\
198 \\
2,210 \\
721 \\
547 \\
12 \\
40 \\
81 \\
5 \\
779 \\
25\end{array}$ & $\begin{array}{l}13,040 \\
12,934 \\
12,938 \\
12,732 \\
13,030 \\
13,030 \\
13,032 \\
13,041 \\
13,110 \\
12,607 \\
12,640 \\
12,194 \\
12,819 \\
13,091 \\
12,834\end{array}$ & $\begin{array}{r}1.09 \\
.63 \\
.63 \\
.75 \\
1.12 \\
1.12 \\
1.11 \\
1.18 \\
1.40 \\
.93 \\
.62 \\
.68 \\
.80 \\
.91 \\
1.12\end{array}$ & $\begin{array}{r}8.32 \\
6.47 \\
6.45 \\
7.44 \\
7.64 \\
7.64 \\
8.45 \\
8.15 \\
9.33 \\
11.53 \\
7.60 \\
11.75 \\
9.87 \\
7.78 \\
7.54\end{array}$ & $\begin{array}{l}168.3 \\
170.9 \\
170.7 \\
181.4 \\
173.1 \\
173.1 \\
168.1 \\
166.8 \\
163.7 \\
171.7 \\
162.1 \\
171.4 \\
167.1 \\
172.4 \\
165.5\end{array}$ & $\begin{array}{l}43.94 \\
44.21 \\
44.17 \\
46.19 \\
45.11 \\
45.11 \\
43.81 \\
43.50 \\
42.92 \\
43.29 \\
40.98 \\
41.79 \\
42.84 \\
45.14 \\
42.48\end{array}$ \\
\hline
\end{tabular}

See footnotes at end of table.

Source: Federal Energy Regulatory Commission, FERC Form 423, "Monthly Report of Cost and Quality of Fuels tor Electric Plants." 
Table 24. Origin of Coal Recelved by Electric Utillty and Plant, 1992 (Continued)

\begin{tabular}{|c|c|c|c|c|c|c|}
\hline \multirow{2}{*}{$\begin{array}{c}\text { Electric Utility Plant } \\
\text { Origin State } \\
\text { County }\end{array}$} & \multirow{2}{*}{$\begin{array}{l}\text { Quantity } \\
\text { (thousand } \\
\text { short tons) }\end{array}$} & \multicolumn{3}{|c|}{ Average Quality } & \multicolumn{2}{|c|}{ Average Dellvered Cost } \\
\hline & & $\begin{array}{c}\text { Blu } \\
\text { (per pound) }\end{array}$ & $\begin{array}{c}\text { Sulfur } \\
\text { (percent } \\
\text { by weight) }\end{array}$ & $\begin{array}{c}\text { Ash } \\
\text { (percent } \\
\text { by welght) }\end{array}$ & $\begin{array}{l}\text { (cents per } \\
\text { million Btu) }\end{array}$ & $\begin{array}{l}\text { (dollars per } \\
\text { ahort ton) }\end{array}$ \\
\hline New England Power Co $\quad$ Brayton & & & & & & \\
\hline Imported & $\begin{array}{l}129 \\
129\end{array}$ & $\begin{array}{l}13,375 \\
13,375\end{array}$ & $\begin{array}{r}0.75 \\
.75\end{array}$ & $\begin{array}{l}7.32 \\
7.32\end{array}$ & $\begin{array}{r}165.2 \\
165.2\end{array}$ & $\begin{array}{l}44.18 \\
44.18\end{array}$ \\
\hline $\begin{array}{l}\text { New England Power Co Salem Harbor } \\
\text { Pennsylvania . } \\
\text { Washington } \\
\text { West Virginia } \\
\text { Grant } \\
\begin{array}{l}\text { Imported } \\
\text { Imported Coal }\end{array}\end{array}$ & $\begin{array}{r}871 \\
40 \\
40 \\
763 \\
763 \\
68 \\
68\end{array}$ & $\begin{array}{l}13,140 \\
13,193 \\
13,193 \\
13,130 \\
13,130 \\
13,221 \\
13,221\end{array}$ & $\begin{array}{r}1.41 \\
1.26 \\
1.26 \\
1.46 \\
1.46 \\
.98 \\
.98\end{array}$ & $\begin{array}{l}9.04 \\
6.80 \\
6.80 \\
9.47 \\
9.47 \\
5.47 \\
5.47\end{array}$ & $\begin{array}{l}166.3 \\
162.3 \\
162.3 \\
167.0 \\
167.0 \\
160.0 \\
160.0\end{array}$ & $\begin{array}{l}43.70 \\
42.82 \\
42.82 \\
43.86 \\
43.86 \\
42.32 \\
42.32\end{array}$ \\
\hline $\begin{array}{l}\text { Now York State Elec a Gas Corp } \\
\text { Pennsylvania } \\
\text { Armstrong } \\
\text { Clarion } \\
\text { Clearfield } \\
\text { Greene } \\
\text { Jefferson } \\
\text { Washington } \\
\text { West Virginia } \\
\text { Monongalia }\end{array}$ & $\begin{array}{r}337 \\
266 \\
26 \\
64 \\
8 \\
100 \\
7 \\
60 \\
71 \\
71\end{array}$ & $\begin{array}{l}13,116 \\
13,085 \\
12,872 \\
12,830 \\
12,277 \\
13,249 \\
12,821 \\
13,319 \\
13,231 \\
13,231\end{array}$ & $\begin{array}{l}1.83 \\
1.73 \\
1.85 \\
1.97 \\
2.19 \\
1.65 \\
2.27 \\
1.44 \\
2.17 \\
2.17\end{array}$ & $\begin{array}{r}7.48 \\
7.85 \\
9.69 \\
8.67 \\
14.30 \\
6.96 \\
12.20 \\
6.24 \\
6.11 \\
6.11\end{array}$ & $\begin{array}{l}138.4 \\
140.3 \\
141.9 \\
134.2 \\
144.4 \\
142.1 \\
146.8 \\
141.5 \\
131.3 \\
131.3\end{array}$ & $\begin{array}{l}36.30 \\
36.71 \\
36.54 \\
34.45 \\
35.44 \\
37.65 \\
37.64 \\
37.69 \\
34.75 \\
34.75\end{array}$ \\
\hline $\begin{array}{l}\text { New York State Elec } \text { Gas Corp } \\
\text { Pennsylvania . Greenidge } \\
\text { Armstrong } \\
\text { Clarion . } \\
\text { Clearfield } \\
\text { Elk } \\
\text { Greene } \\
\text { Jefferson } \\
\text { Washington } \\
\text { West Virginia } \\
\text { Monongalia }\end{array}$ & $\begin{array}{r}510 \\
391 \\
12 \\
84 \\
130 \\
4 \\
94 \\
16 \\
50 \\
119 \\
119\end{array}$ & $\begin{array}{l}12,808 \\
12,661 \\
12,735 \\
12,717 \\
12,128 \\
11,993 \\
13,209 \\
12,997 \\
12,845 \\
13,290 \\
13,290\end{array}$ & $\begin{array}{l}2.04 \\
1.94 \\
1.68 \\
2.07 \\
1.94 \\
2.27 \\
2.04 \\
1.90 \\
1.63 \\
2.36 \\
2.36\end{array}$ & $\begin{array}{r}8.98 \\
9.81 \\
9.41 \\
8.75 \\
13.09 \\
13.63 \\
7.06 \\
8.95 \\
8.30 \\
6.27 \\
6.27\end{array}$ & $\begin{array}{l}137.6 \\
139.8 \\
143.6 \\
134.9 \\
144.3 \\
143.2 \\
135.7 \\
145.8 \\
141.4 \\
130.6 \\
130.6\end{array}$ & $\begin{array}{l}35.24 \\
35.39 \\
36.57 \\
34.31 \\
35.01 \\
34.34 \\
35.85 \\
37.90 \\
36.32 \\
34.72 \\
34.72\end{array}$ \\
\hline $\begin{array}{l}\text { New York State Elec Gas Corp } \\
\text { Maryland . Hickllng } \\
\text { Allegany } \\
\text { Pennsylvania } \\
\text { Armstrong } \\
\text { Cambria } \\
\text { Centre } \\
\text { Clearfield } \\
\text { Flinton } \\
\text { Jefferson } \\
\text { Lycoming } \\
\text { Somerset } \\
\text { Sullivan . }\end{array}$ & $\begin{array}{r}327 \\
6 \\
6 \\
321 \\
61 \\
10 \\
11 \\
41 \\
36 \\
9 \\
11 \\
114 \\
28\end{array}$ & $\begin{array}{l}10,720 \\
11,208 \\
11,208 \\
10,711 \\
10,605 \\
10,390 \\
10,703 \\
10,633 \\
10,695 \\
10,887 \\
10,555 \\
10,984 \\
10,097 \\
10,189\end{array}$ & $\begin{array}{r}1.31 \\
1.59 \\
1.59 \\
1.31 \\
1.80 \\
1.34 \\
1.47 \\
1.58 \\
.64 \\
1.41 \\
1.63 \\
.99 \\
1.74 \\
.52\end{array}$ & $\begin{array}{l}21.28 \\
14.70 \\
14.70 \\
21.41 \\
22.83 \\
24.77 \\
18.12 \\
17.59 \\
22.32 \\
14.93 \\
17.74 \\
22.56 \\
21.74 \\
24.03\end{array}$ & $\begin{array}{l}130.1 \\
134.1 \\
134.1 \\
130.1 \\
126.5 \\
122.5 \\
130.6 \\
127.8 \\
139.2 \\
134.5 \\
129.8 \\
131.2 \\
125.4 \\
121.4\end{array}$ & $\begin{array}{l}27.90 \\
30.06 \\
30.06 \\
27.86 \\
26.83 \\
25.45 \\
27.96 \\
27.18 \\
29.77 \\
29.28 \\
27.40 \\
28.82 \\
25.33 \\
24.74\end{array}$ \\
\hline $\begin{array}{l}\text { New York State Elec a Gas Corp } \\
\text { Maryland ...... Jennison } \\
\text { Allegany } \\
\text { Pennsylyania } \\
\text { Armstrong } \\
\text { Centre } \\
\text { Clarion } \\
\text { Clearfield } \\
\text { Flinton } \\
\text { Hunttengdon } \\
\text { Jefferson } \\
\text { Lycoming } \\
\text { Somerset } \\
\text { Sullivan . } \\
\text { Unknown }\end{array}$ & $\begin{array}{r}250 \\
12 \\
12 \\
238 \\
14 \\
42 \\
3 \\
53 \\
4 \\
1 \\
5 \\
1 \\
94 \\
4 \\
7 \\
9\end{array}$ & $\begin{array}{r}10,753 \\
11,101 \\
11,101 \\
10,736 \\
10,933 \\
10,639 \\
10,935 \\
10,319 \\
11,071 \\
10,803 \\
10,972 \\
11,590 \\
11,153 \\
11,114 \\
9,592 \\
9,130\end{array}$ & $\begin{array}{r}1.14 \\
1.59 \\
1.59 \\
1.12 \\
1.62 \\
1.06 \\
1.54 \\
1.38 \\
1.38 \\
.71 \\
1.59 \\
1.22 \\
.95 \\
1.53 \\
.55 \\
.48\end{array}$ & $\begin{array}{l}21.72 \\
17.62 \\
17.62 \\
21.93 \\
22.27 \\
20.76 \\
16.68 \\
22.97 \\
21.68 \\
10.38 \\
17.71 \\
15.00 \\
21.66 \\
18.76 \\
24.80 \\
28.92\end{array}$ & $\begin{array}{l}148.6 \\
147.7 \\
147.7 \\
148.6 \\
144.6 \\
143.4 \\
144.4 \\
139.2 \\
160.6 \\
157.9 \\
147.0 \\
136.4 \\
159.0 \\
148.9 \\
125.5 \\
131.1\end{array}$ & $\begin{array}{l}31.96 \\
32.79 \\
32.79 \\
31.81 \\
31.61 \\
30.51 \\
31.58 \\
28.72 \\
35.56 \\
34.44 \\
32.26 \\
31.62 \\
35.46 \\
33.10 \\
24.08 \\
23.94\end{array}$ \\
\hline New York State Elec Gas Corp & 2,080 & 13,147 & 1.77 & 6.68 & 140.4 & 38.80 \\
\hline
\end{tabular}

See footnotes at end of table.

Source: Federal Energy Regulatory Commission, FERC Form 423, "Monthly Report of Cost and Quality of Fuels for Electric Plants." 
Table 24. Origin of Coal Received by Electric Utility and Plant, 1992 (Continued)

\begin{tabular}{|c|c|c|c|c|c|c|}
\hline \multirow[b]{2}{*}{$\begin{array}{c}\text { Electric Utility Plant } \\
\text { Origin State } \\
\text { County }\end{array}$} & \multirow[b]{2}{*}{$\begin{array}{l}\text { Quantity } \\
\text { (thousand } \\
\text { short tons) }\end{array}$} & \multicolumn{3}{|c|}{ Average Quality } & \multicolumn{2}{|c|}{ Average Delivered Cost } \\
\hline & & $\begin{array}{c}\text { Btu } \\
\text { (per pound) }\end{array}$ & $\begin{array}{c}\text { Sulfur } \\
\text { (percent } \\
\text { by welght) }\end{array}$ & $\begin{array}{l}\text { Ash } \\
\text { (percent } \\
\text { by weight) }\end{array}$ & $\begin{array}{l}\text { (cents per } \\
\text { million Btu) }\end{array}$ & $\begin{array}{l}\text { (dollars per } \\
\text { short ton) }\end{array}$ \\
\hline \multicolumn{7}{|l|}{ New York State Elec \& Gas Corp KIntigh } \\
\hline 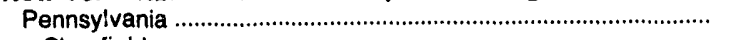 & 1,462 & 13,151 & 1.54 & 6.23 & 141.3 & 37.16 \\
\hline 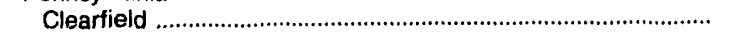 & 4 & 12,442 & 2.34 & 13.10 & 164.7 & 40.98 \\
\hline Greene & 1,458 & 13,153 & 1.54 & 6.22 & 141.2 & 37.15 \\
\hline West Virginia & 617 & 13,138 & 2.30 & 7.68 & 138.1 & 36.29 \\
\hline 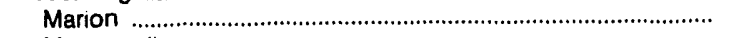 & 87 & 13,173 & 2.57 & 7.77 & 141.3 & 37.22 \\
\hline Monongatia & 530 & 13,132 & 2.25 & 7.67 & 137.6 & 36.14 \\
\hline \multirow{2}{*}{$\begin{array}{l}\text { New York State Elec \& Gas Corp } \quad \text { Mulliken } \\
\text { Pennsylvania }\end{array}$} & 855 & 12,946 & 1.94 & 8.32 & 139.7 & 36.18 \\
\hline & 713 & 12,869 & 1.88 & 8.74 & 141.4 & 36.40 \\
\hline $\begin{array}{l}\text { Pennsylvania } \\
\text { Armstrong }\end{array}$ & 15 & 12,457 & 1.81 & 11.22 & 133.4 & 33.23 \\
\hline 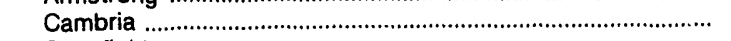 & 31 & 12,329 & 2.05 & 12.74 & 142.5 & 35.13 \\
\hline 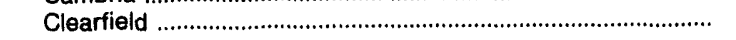 & 86 & 12,372 & 2.04 & 12.61 & 143.1 & 35.42 \\
\hline Greene & 425 & 13,115 & 1.83 & 6.95 & 140.7 & 36.89 \\
\hline 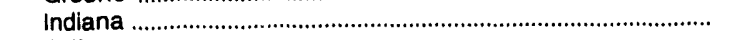 & 58 & 12,289 & 2.00 & 11.58 & 140.9 & 34.63 \\
\hline 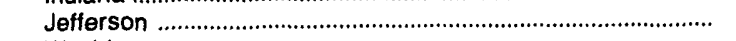 & 81 & 12,770 & 1.91 & 10.39 & 144.9 & 37.01 \\
\hline 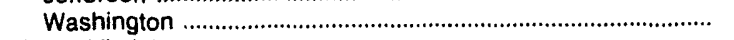 & 15 & 13,087 & 1.33 & 6.48 & 142.5 & 37.30 \\
\hline \multirow{2}{*}{ West Virginia } & 142 & 13,334 & 2.26 & 6.22 & 131.5 & 35.08 \\
\hline & 142 & 13,334 & 2.26 & 6.22 & 131.5 & 35.08 \\
\hline Nlagara-Mohawk Power Corp & 1,531 & 13,178 & 2.06 & 6.96 & 136.0 & 35.84 \\
\hline 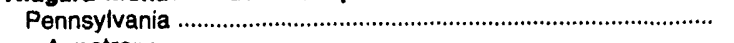 & 1,117 & 13,401 & 1.96 & 7.19 & 137.6 & 36.05 \\
\hline 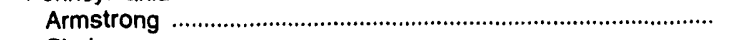 & 62 & 12,996 & 1.80 & 7.27 & 146.9 & 38.18 \\
\hline Clarion & 302 & 12,686 & 2.06 & 8.59 & 143.6 & 36.44 \\
\hline Greene & 483 & 13,281 & 1.75 & 6.42 & 140.8 & 37.41 \\
\hline Indiana & 39 & 13,260 & 2.37 & 7.11 & 134.1 & 35.56 \\
\hline 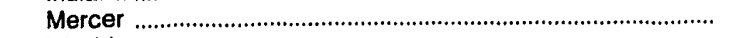 & 71 & 13,143 & 2.46 & 7.08 & 129.3 & 33.98 \\
\hline 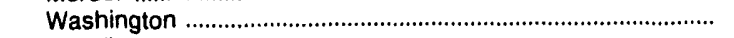 & 160 & 13,323 & 2.10 & 6.87 & 117.9 & 31.42 \\
\hline West Virginia & 414 & 13,385 & 2.36 & 6.34 & 131.8 & 35.27 \\
\hline 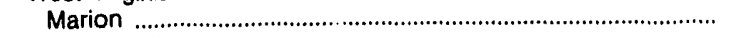 & 16 & 13,550 & 2.65 & 7.19 & 139.0 & 37.67 \\
\hline 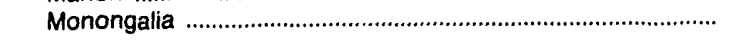 & 398 & 13,379 & 2.35 & 6.31 & 131.5 & 35.18 \\
\hline Niagara-Mohawk Power Corp $\quad$ Huntley .............................. & 2,009 & 13,183 & 1.72 & 6.99 & 147.6 & 38.91 \\
\hline 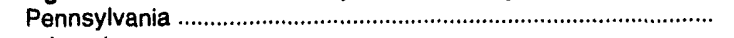 & 1,772 & 13,163 & 1.72 & 7.03 & 147.3 & 38.77 \\
\hline 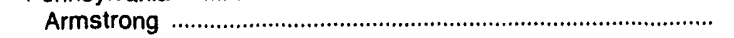 & 211 & 12,955 & 1.69 & 7.82 & 149.4 & 38.70 \\
\hline 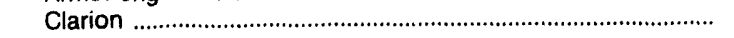 & 37 & 12,695 & 1.88 & 8.69 & 145.2 & 36.86 \\
\hline 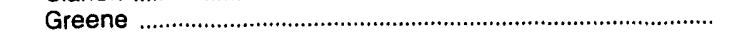 & 675 & 13,252 & 1.61 & 6.51 & 148.6 & 39.38 \\
\hline Indiana & 331 & 13,173 & 1.88 & 6.89 & 140.6 & 37.03 \\
\hline 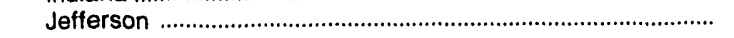 & 42 & 13,084 & 1.37 & 8.80 & 139.3 & 36.46 \\
\hline 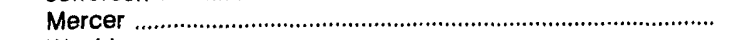 & 165 & 12,913 & 1.77 & 8.37 & 159.4 & 41.16 \\
\hline 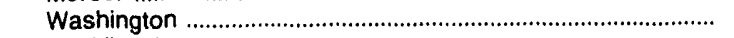 & 309 & 13,302 & 1.77 & 6.63 & 145.1 & 38.61 \\
\hline 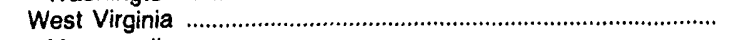 & 238 & 13,326 & 1.79 & 6.70 & 149.7 & 39.91 \\
\hline 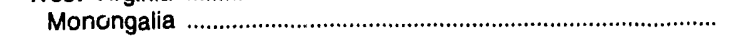 & 238 & 13,326 & 1.79 & 6.70 & 149.7 & 39.91 \\
\hline Northern Indlana Pub Serv Co & 1,415 & 11,105 & 2.86 & 9.81 & 134.4 & 29.84 \\
\hline 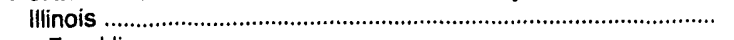 & 1,347 & 11,103 & 2.97 & 9.98 & 131.7 & 29.25 \\
\hline 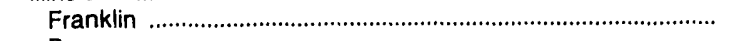 & 193 & 11,679 & 2.31 & 8.03 & 111.6 & 26.06 \\
\hline 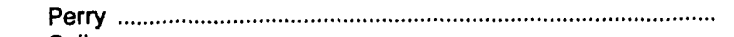 & 1,094 & 10,961 & 3.11 & 10.43 & 137.1 & 30.05 \\
\hline 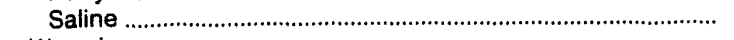 & 60 & 11,828 & 2.62 & 8.02 & 105.8 & 25.02 \\
\hline 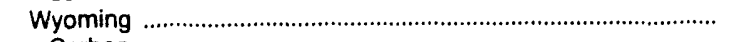 & 68 & 11,154 & .61 & 6.57 & 186.2 & 41.53 \\
\hline Carbon & 68 & 11,154 & .61 & 6.57 & 186.2 & 41.53 \\
\hline Northern Indiana Pub Serv Co Michigan City .................... & 1,022 & 11,232 & 2.41 & 8.34 & 135.9 & 30.54 \\
\hline Illinois & 472 & 11,198 & 2.97 & 9.67 & 128.0 & 28.67 \\
\hline 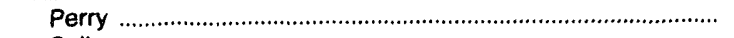 & 366 & 10,987 & 3.07 & 10.31 & 135.3 & 29.72 \\
\hline 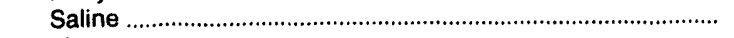 & 106 & 11,929 & 2.61 & 7.46 & 104.9 & 25.02 \\
\hline 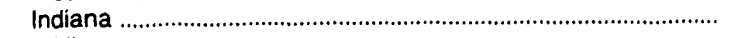 & 255 & 11,543 & 3.52 & 8.20 & 108.7 & 25.09 \\
\hline Pike & 255 & 11,543 & 3.52 & 8.20 & 408.7 & 25.09 \\
\hline 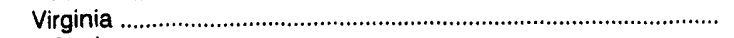 & 20 & 13,835 & .72 & 6.00 & 175.0 & 48.42 \\
\hline 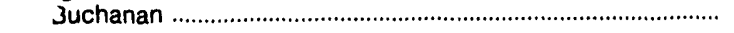 & 20 & 13,835 & .72 & 6.00 & 175.0 & 48.42 \\
\hline Wyoming & 276 & 10,815 & .56 & 6.34 & 173.3 & 37.49 \\
\hline 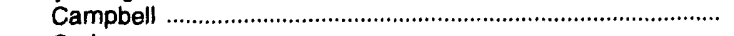 & 40 & 8,584 & .30 & 4.70 & 100.2 & 17.21 \\
\hline Carbon & 235 & 11,199 & .60 & 6.63 & 183.0 & 40.99 \\
\hline Northern Indiana Pub Serv Co $\quad$ Mitchell ............................. & 1,079 & 9,969 & .44 & 5.94 & 123.5 & 24.63 \\
\hline 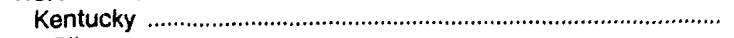 & 10 & 12,693 & .61 & 8.90 & 162.9 & 41.35 \\
\hline 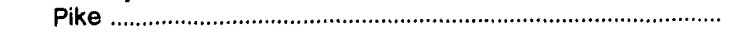 & 10 & 12,693 & .61 & 8.90 & 162.9 & 41.35 \\
\hline
\end{tabular}

See footnotes at end of table.

Source: Federal Energy Regulatory Commission, FERC Form 423, "Monthly Report of Cost and Quality of Fuels for Electric Plants." 
Table 24. Origin of Coal Received by Electric Utility and Plant, 1992 (Continued)

\begin{tabular}{|c|c|c|c|c|c|c|}
\hline \multirow{2}{*}{$\begin{array}{l}\text { Electric Utility Plant } \\
\text { Origin State } \\
\text { County }\end{array}$} & \multirow{2}{*}{$\begin{array}{l}\text { Quantity } \\
\text { (thousand } \\
\text { short tons) }\end{array}$} & \multicolumn{3}{|c|}{ Average Quality } & \multicolumn{2}{|c|}{ Average Delivered Cost } \\
\hline & & $\begin{array}{c}\text { Btu } \\
\text { (per pound) }\end{array}$ & $\begin{array}{l}\text { Sulfur } \\
\text { (percent } \\
\text { by weight) }\end{array}$ & $\begin{array}{l}\text { Ash } \\
\text { (percent } \\
\text { by weight) }\end{array}$ & $\begin{array}{l}\text { (cents per } \\
\text { million Btu) }\end{array}$ & $\begin{array}{l}\text { (dollars per } \\
\text { short ton) }\end{array}$ \\
\hline $\begin{array}{l}\text { Northern Indiana Pub Serv Co } \\
\text { West Virginia } \\
\text { Mingo } \\
\text { Wyoming } \\
\text { Campbell }\end{array}$ & $\begin{array}{l}318 \\
318 \\
751 \\
365 \\
386\end{array}$ & $\begin{array}{r}13,106 \\
13,106 \\
8,609 \\
8,514 \\
8,698\end{array}$ & $\begin{array}{r}0.68 \\
.68 \\
.34 \\
.34 \\
.33\end{array}$ & $\begin{array}{l}7.76 \\
7.76 \\
5.13 \\
4.92 \\
5.34\end{array}$ & $\begin{array}{l}158.2 \\
158.2 \\
100.5 \\
100.7 \\
100.3\end{array}$ & $\begin{array}{l}41.46 \\
41.46 \\
17.30 \\
17.14 \\
17.44\end{array}$ \\
\hline $\begin{array}{l}\text { Northern Indiana Pub Serv Co } \\
\text { Colorado } \\
\text { Delta } \\
\text { Gunnison } \\
\text { Moffat } \\
\text { Routt } \\
\text { Illinois } \\
\text { Perry } \\
\text { Saline } \\
\text { Indiana } \\
\text { Daviess } \\
\text { Kentucky } \\
\text { Letcher } \\
\text { West Virginia } \\
\text { Boone } \\
\text { Logan } \\
\text { Mingo } \\
\text { Wyoming } \\
\text { Carbon . }\end{array}$ & $\begin{array}{r}3,543 \\
773 \\
622 \\
75 \\
54 \\
21 \\
1,613 \\
1,312 \\
301 \\
13 \\
13 \\
36 \\
36 \\
52 \\
18 \\
27 \\
7 \\
1,055 \\
1,055\end{array}$ & $\begin{array}{l}11,211 \\
11,305 \\
11,298 \\
11,883 \\
10,576 \\
11,302 \\
11,103 \\
10,949 \\
11,771 \\
11,546 \\
11,546 \\
12,777 \\
12,777 \\
12,992 \\
13,240 \\
12,909 \\
12,681 \\
11,163 \\
11,163\end{array}$ & $\begin{array}{r}1.67 \\
.42 \\
.40 \\
.47 \\
.48 \\
.41 \\
3.01 \\
3.12 \\
2.50 \\
2.39 \\
2.39 \\
.74 \\
.74 \\
.72 \\
.78 \\
.70 \\
.63 \\
.60 \\
.60\end{array}$ & $\begin{array}{r}8.81 \\
8.28 \\
8.11 \\
9.19 \\
8.28 \\
9.80 \\
10.52 \\
10.65 \\
9.96 \\
7.05 \\
7.05 \\
8.38 \\
8.38 \\
7.64 \\
6.20 \\
8.50 \\
8.10 \\
6.67 \\
6.67\end{array}$ & $\begin{array}{l}155.2 \\
154.1 \\
154.8 \\
150.5 \\
153.0 \\
150.8 \\
134.4 \\
139.2 \\
114.8 \\
135.3 \\
135.3 \\
164.9 \\
164.9 \\
165.7 \\
164.7 \\
167.2 \\
162.8 \\
187.0 \\
187.0\end{array}$ & $\begin{array}{l}34.81 \\
34.84 \\
34.97 \\
35.78 \\
32.36 \\
34.09 \\
29.84 \\
30.49 \\
27.03 \\
31.23 \\
31.23 \\
42.15 \\
42.15 \\
43.06 \\
43.61 \\
43.17 \\
41.29 \\
41.75 \\
41.75\end{array}$ \\
\hline $\begin{array}{l}\text { Northern States Power Co } \quad \text { Black Dog } \\
\text { Wyoming } \\
\text { Campbell } \\
\text { Converse }\end{array}$ & $\begin{array}{l}725 \\
725 \\
269 \\
456\end{array}$ & $\begin{array}{l}8,836 \\
8,836 \\
8,836 \\
8,836\end{array}$ & $\begin{array}{l}.28 \\
.28 \\
.21 \\
.32\end{array}$ & $\begin{array}{l}5.12 \\
5.12 \\
4.75 \\
5.34\end{array}$ & $\begin{array}{l}114.3 \\
114.3 \\
106.4 \\
119.0\end{array}$ & $\begin{array}{l}20.20 \\
20.20 \\
18.80 \\
21.03\end{array}$ \\
\hline 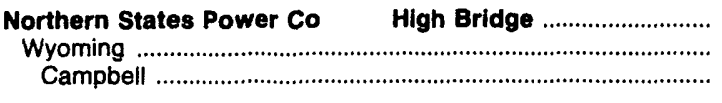 & $\begin{array}{l}468 \\
468 \\
468\end{array}$ & $\begin{array}{l}8,780 \\
8,780 \\
8,780\end{array}$ & $\begin{array}{l}.22 \\
.22 \\
.22\end{array}$ & $\begin{array}{l}4.58 \\
4.58 \\
4.58\end{array}$ & $\begin{array}{l}112.7 \\
112.7 \\
112.7\end{array}$ & $\begin{array}{l}19.79 \\
19.79 \\
19.79\end{array}$ \\
\hline $\begin{array}{l}\text { Northern States Power Co King } \\
\text { Montana . } \\
\text { Big Horn } \\
\text { Wyoming } \\
\text { Campbell } \\
\text { Converse }\end{array}$ & $\begin{array}{r}1,567 \\
314 \\
314 \\
1,252 \\
734 \\
518\end{array}$ & $\begin{array}{l}8,828 \\
8,764 \\
8,764 \\
8,844 \\
8,840 \\
8,850\end{array}$ & $\begin{array}{l}.33 \\
.62 \\
.62 \\
.25 \\
.21 \\
.31\end{array}$ & $\begin{array}{l}5.77 \\
9.05 \\
9.05 \\
4.95 \\
4.67 \\
5.35\end{array}$ & $\begin{array}{l}113.3 \\
101.5 \\
101.5 \\
116.2 \\
109.2 \\
126.2\end{array}$ & $\begin{array}{l}20.00 \\
17.79 \\
17.79 \\
20.56 \\
19.30 \\
22.34\end{array}$ \\
\hline 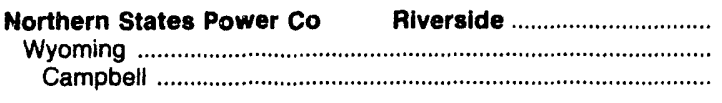 & $\begin{array}{l}829 \\
829 \\
829\end{array}$ & $\begin{array}{l}8,772 \\
8,772 \\
8,772\end{array}$ & $\begin{array}{l}.22 \\
.22 \\
.22\end{array}$ & $\begin{array}{l}4.56 \\
4.56 \\
4.56\end{array}$ & $\begin{array}{l}114.3 \\
114.3 \\
114.3\end{array}$ & $\begin{array}{l}20.06 \\
20.06 \\
20.06\end{array}$ \\
\hline 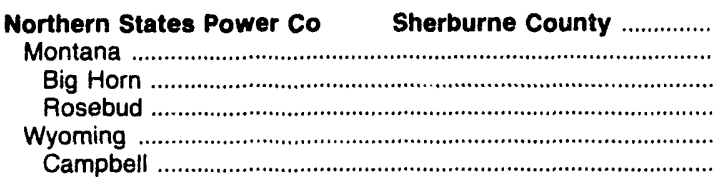 & $\begin{array}{l}8,098 \\
4,525 \\
2,896 \\
1,629 \\
3,572 \\
3,572\end{array}$ & $\begin{array}{l}8,759 \\
8,738 \\
8,757 \\
8,705 \\
8,786 \\
8,786\end{array}$ & $\begin{array}{l}.48 \\
.65 \\
.62 \\
.71 \\
.26 \\
.26\end{array}$ & $\begin{array}{l}7.09 \\
8.94 \\
9.06 \\
8.73 \\
4.75 \\
4.75\end{array}$ & $\begin{array}{l}120.0 \\
123.2 \\
110.2 \\
146.5 \\
116.0 \\
116.0\end{array}$ & $\begin{array}{l}21.03 \\
21.53 \\
19.30 \\
25.51 \\
20.38 \\
20.38\end{array}$ \\
\hline $\begin{array}{l}\text { Ohio Edison Co } \\
\text { Kentucky } \\
\text { Martin . } \\
\text { Ohio } \\
\text { Belmont . } \\
\text { Harrison } \\
\text { Jefferson } \\
\text { Pennsylvania } \\
\text { Washington } \\
\text { Campbell } \\
\text { Converse } \\
\text { Imported } \\
\text { Imported Coal }\end{array}$ & $\begin{array}{r}1,208 \\
41 \\
41 \\
964 \\
225 \\
120 \\
619 \\
128 \\
128 \\
61 \\
49 \\
13 \\
13 \\
13\end{array}$ & $\begin{array}{r}11,913 \\
12,143 \\
12,143 \\
12,135 \\
12,265 \\
12,345 \\
12,046 \\
12,070 \\
12,070 \\
8,449 \\
8,456 \\
8,418 \\
9,587 \\
9,587\end{array}$ & $\begin{array}{r}3.24 \\
.84 \\
.84 \\
3.62 \\
3.74 \\
3.33 \\
3.63 \\
2.83 \\
2.83 \\
.35 \\
.35 \\
.37 \\
.14 \\
.14\end{array}$ & $\begin{array}{r}10.88 \\
10.37 \\
10.37 \\
11.27 \\
10.11 \\
9.80 \\
11.97 \\
11.73 \\
11.73 \\
5.48 \\
5.24 \\
6.40 \\
1.20 \\
1.20\end{array}$ & $\begin{array}{r}109.2 \\
130.5 \\
130.5 \\
104.4 \\
90.1 \\
111.4 \\
108.4 \\
129.8 \\
129.8 \\
120.1 \\
118.4 \\
126.7 \\
166.9 \\
166.9\end{array}$ & $\begin{array}{l}26.01 \\
31.69 \\
31.69 \\
25.35 \\
22.11 \\
27.49 \\
26.11 \\
31.32 \\
31.32 \\
20.29 \\
20.02 \\
21.33 \\
32.00 \\
32.00\end{array}$ \\
\hline 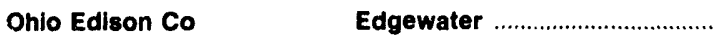 & 166 & 11,965 & 1.55 & 10.52 & 136.0 & 32.55 \\
\hline
\end{tabular}

See footnotes at end of table.

Source: Federal Energy Regulatory Commission, FERC Form 423, "Monthly Report of Cost and Quality of Fuels for Electric Plants." 
Table 24. Origin of Coal Recelved by Electric Utility and Plant, 1992 (Continued)

\begin{tabular}{|c|c|c|c|c|c|c|}
\hline \multirow{2}{*}{$\begin{array}{c}\text { Electric Utility Plant } \\
\text { Origin State } \\
\text { County }\end{array}$} & \multirow[b]{2}{*}{$\begin{array}{l}\text { Quantity } \\
\text { (thousand } \\
\text { short tons) }\end{array}$} & \multicolumn{3}{|c|}{ Average Quallty } & \multicolumn{2}{|c|}{ Average Delivered Cost } \\
\hline & & $\begin{array}{c}\text { Btu } \\
\text { (per pound) }\end{array}$ & $\begin{array}{c}\text { Sulfur } \\
\text { (percent } \\
\text { by welght) }\end{array}$ & $\begin{array}{c}\text { Ash } \\
\text { (percent } \\
\text { by weight) }\end{array}$ & $\begin{array}{l}\text { (cents per } \\
\text { million Btu) }\end{array}$ & $\begin{array}{l}\text { (dollars per } \\
\text { short ton) }\end{array}$ \\
\hline \multirow{2}{*}{\multicolumn{7}{|c|}{$\begin{array}{l}\text { Ohio Edison Co } \quad \text { Edgewater } \\
\text { Ohio }\end{array}$}} \\
\hline & 166 & 11,965 & 1.55 & 10.52 & 136.0 & 32.55 \\
\hline 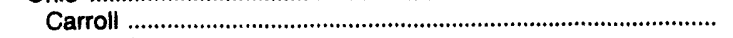 & 12 & 11,805 & .64 & 10.89 & 144.8 & 34.18 \\
\hline Columbiana & 57 & 12,235 & 1.76 & 10.61 & 133.8 & 32.74 \\
\hline 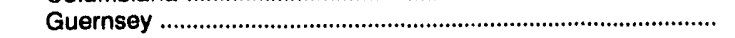 & 41 & 12,013 & 1.62 & 9.71 & 136.3 & 32.75 \\
\hline 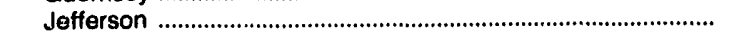 & 17 & 12,056 & 1.43 & 10.33 & 140.0 & 33.75 \\
\hline Tuscarawas & 39 & 11,531 & 1.48 & 11.22 & 134.5 & 31.01 \\
\hline 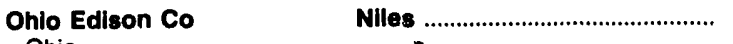 & 517 & 12,006 & 2.74 & 10.83 & 109.2 & 26.21 \\
\hline 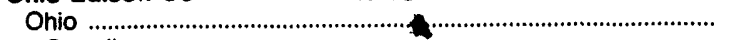 & 337 & 12,001 & 2.72 & 10.55 & 111.3 & 26.72 \\
\hline 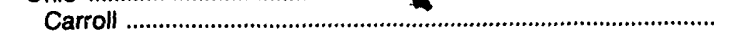 & 45 & 12,041 & 2.56 & 10.59 & 117.0 & 28.17 \\
\hline 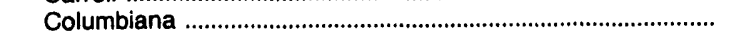 & 108 & 12,054 & 2.51 & 10.51 & 110.3 & 26.60 \\
\hline 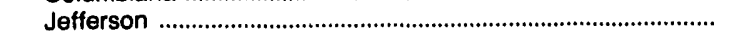 & 146 & 12,028 & 2.89 & 10.82 & 110.6 & 26.59 \\
\hline Stark & 2 & 11,643 & 2.66 & 11.67 & 100.9 & 23.49 \\
\hline 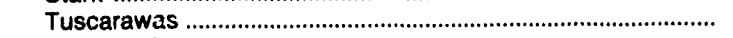 & 36 & 11,701 & 2.89 & 9.46 & 110.7 & 25.91 \\
\hline 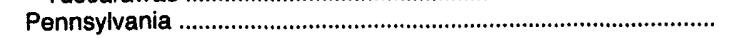 & 181 & 12,015 & 2.77 & 11.33 & 105.2 & 25.27 \\
\hline 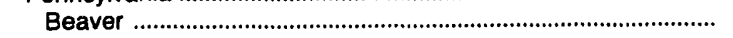 & 42 & 1,930 & 2.76 & 12.80 & 106.5 & 25.40 \\
\hline Butler & 85 & 11,976 & 2.78 & 11.19 & 104.7 & 25.07 \\
\hline 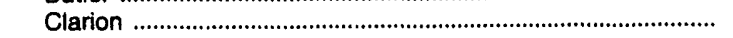 & 1 & 11,139 & 1.96 & 11.70 & 103.2 & 22.99 \\
\hline Lawrence & 46 & 12,135 & 2.78 & 10.64 & 105.9 & 25.70 \\
\hline 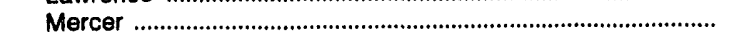 & 8 & 12,306 & 2.80 & 9.07 & 99.5 & 24.50 \\
\hline 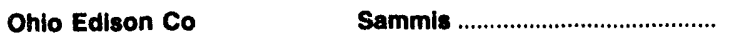 & $\mathbf{5 , 5 3 1}$ & 12,343 & 1.67 & 10.52 & 132.3 & 32.65 \\
\hline 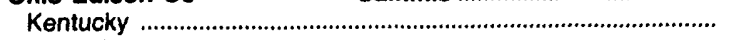 & 668 & 12,091 & .86 & 10.57 & 125.6 & 30.37 \\
\hline Floyd & 157 & 11,955 & .84 & 10.99 & 114.2 & 27.32 \\
\hline Lawrence & 72 & 11,889 & .93 & 10.32 & 113.9 & 27.08 \\
\hline Martin & 440 & 12,172 & .86 & 10.47 & 131.5 & 32.00 \\
\hline Ohio & 1,452 & 12,147 & 2.65 & 10.78 & 124.0 & 30.14 \\
\hline 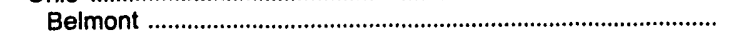 & 3 & 12,154 & 3.37 & 10.60 & 98.7 & 23.99 \\
\hline Carroll & 443 & 12,114 & 2.55 & 10.32 & 112.4 & 27.24 \\
\hline Harrison & 399 & 12,343 & 3.37 & 10.82 & 106.2 & 26.22 \\
\hline Jefferson & 607 & 12,042 & 2.25 & 11.09 & 144.7 & 34.86 \\
\hline Pennsylvania & 1,707 & 12,532 & 1.80 & 10.36 & 141.6 & 35.49 \\
\hline Greene & 1,505 & 12,602 & 1.71 & 10.16 & 141.2 & 35.59 \\
\hline Washington & 176 & 11,998 & 2.37 & 11.93 & 151.3 & 36.31 \\
\hline Westmoreland & 26 & 12,104 & 2.56 & 11.65 & 99.6 & 24.10 \\
\hline West Virginia & 1,703 & 12,418 & 1.04 & 10.42 & 132.3 & 32.85 \\
\hline Fayette & 47 & 12,679 & .82 & 9.20 & 111.8 & 28.35 \\
\hline Kanawha & 976 & 12,394 & .75 & 10.44 & 132.8 & 32.93 \\
\hline Lincoln & 103 & 12,006 & .81 & 10.72 & 113.7 & 27.31 \\
\hline Logan & 14 & 12,124 & .65 & 11.20 & 111.4 & 27.01 \\
\hline 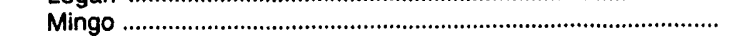 & 3 & 11,579 & 1.01 & 11.17 & 115.3 & 26.70 \\
\hline 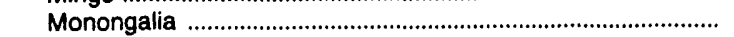 & 4 & 11,876 & 2.92 & 12.10 & 102.7 & 24.39 \\
\hline Nicholas & 79 & 12,102 & .90 & 11.93 & 112.1 & 27.13 \\
\hline Preston & 475 & 12,602 & 1.72 & 10.16 & 141.2 & 35.59 \\
\hline 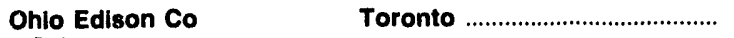 & 340 & 11,932 & 3.44 & 12.35 & 104.8 & 25.01 \\
\hline Ohio & 337 & 11,927 & 3.44 & 12.38 & 104.9 & 25.02 \\
\hline 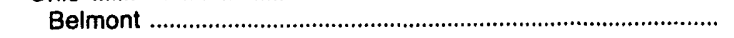 & 10 & 12,152 & 3.50 & 11.29 & 98.7 & 24.00 \\
\hline Carroll & 82 & 12,071 & 2.77 & 11.24 & 112.5 & 27.17 \\
\hline 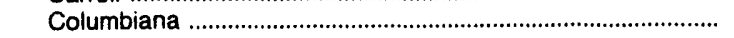 & 5 & 12,081 & 3.60 & 11.24 & 93.5 & 22.60 \\
\hline 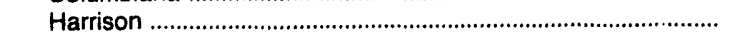 & 46 & 12,049 & 3.50 & 11.90 & 99.1 & 23.89 \\
\hline 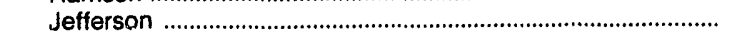 & 191 & 11,825 & 3.72 & 13.07 & 103.6 & 24.51 \\
\hline 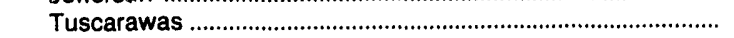 & 2 & 11,435 & 3.15 & 11.40 & 104.9 & 23.99 \\
\hline 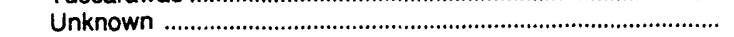 & 1 & 12,163 & 3.69 & 13.30 & 92.5 & 22.50 \\
\hline Pennsylvania & 4 & 12,351 & 3.30 & 9.79 & 96.2 & 23.75 \\
\hline 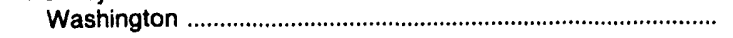 & 4 & 12,351 & 3.30 & 9.79 & 96.2 & 23.75 \\
\hline 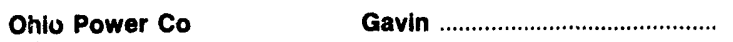 & 5,979 & 11,381 & 3.30 & 12.37 & 166.4 & 37.87 \\
\hline Ohio & 5,857 & 11,364 & 3.31 & 12.41 & 167.0 & 37.95 \\
\hline 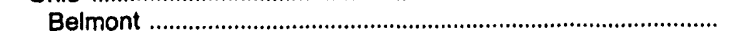 & 486 & 11,698 & 2.73 & 12.56 & 155.1 & 36.30 \\
\hline 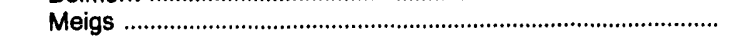 & 5,208 & 11,337 & 3.36 & 12.44 & 170.2 & 38.58 \\
\hline 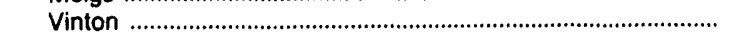 & 163 & 11,214 & 3.37 & 11.29 & 100.9 & 22.63 \\
\hline West Virginia & 122 & 12,224 & 2.93 & 10.08 & 140.7 & 34.39 \\
\hline Brooke & 122 & 12,224 & 2.93 & 10.08 & 140.7 & 34.39 \\
\hline Kammer ........................................ & 1,912 & 12,250 & 4.07 & 12.39 & 118.3 & 28.98 \\
\hline
\end{tabular}

See footnotes at end of table.

Source: Federal Energy Regulatory Commission, FERC Form 423, "Monthly Report of Cost and Quality of Fuels for Electric Plants." 
Table 24. Origin of Coal Recelved by Electric Utility and Plant, 1992 (Continued)

\begin{tabular}{|c|c|c|c|c|c|c|}
\hline \multirow{2}{*}{$\begin{array}{l}\text { Electric Utility Plant } \\
\text { Origin State } \\
\text { County }\end{array}$} & \multirow{2}{*}{$\begin{array}{l}\text { Quantity } \\
\text { (thousand } \\
\text { short tons) }\end{array}$} & \multicolumn{3}{|c|}{ Average Quallty } & \multicolumn{2}{|c|}{ Average Dellvered Cost } \\
\hline & & $\begin{array}{l}\text { Btu } \\
\text { (per pound) }\end{array}$ & $\begin{array}{l}\text { Sulfur } \\
\text { (percent } \\
\text { by weight) }\end{array}$ & $\begin{array}{l}\text { Ash } \\
\text { (percent } \\
\text { by welght) }\end{array}$ & $\begin{array}{l}\text { (cents per } \\
\text { million Btu) }\end{array}$ & $\begin{array}{l}\text { (dollars per } \\
\text { short ton) }\end{array}$ \\
\hline Ohlo Power Co Kammer & & & & & & \\
\hline West Virginia & $\begin{array}{l}1,912 \\
1,912\end{array}$ & $\begin{array}{l}12,250 \\
12,250\end{array}$ & $\begin{array}{l}4.07 \\
4.07\end{array}$ & $\begin{array}{l}12.39 \\
12.39\end{array}$ & $\begin{array}{l}118.3 \\
118.3\end{array}$ & $\begin{array}{l}28.98 \\
28.98\end{array}$ \\
\hline 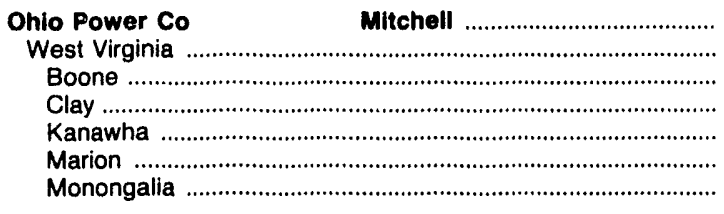 & $\begin{array}{r}1,999 \\
1,999 \\
14 \\
106 \\
40 \\
1,674 \\
165\end{array}$ & $\begin{array}{l}12,190 \\
12,190 \\
12,361 \\
12,135 \\
12,185 \\
12,183 \\
12,283\end{array}$ & $\begin{array}{r}1.45 \\
1.45 \\
.88 \\
.81 \\
.78 \\
1.54 \\
1.18\end{array}$ & $\begin{array}{l}14.14 \\
14.14 \\
11.11 \\
12.68 \\
12.10 \\
14.35 \\
13.69\end{array}$ & $\begin{array}{l}166.3 \\
166.3 \\
148.6 \\
144.9 \\
143.1 \\
170.7 \\
143.2\end{array}$ & $\begin{array}{l}40.55 \\
40.55 \\
36.73 \\
35.16 \\
34.87 \\
41.59 \\
35.18\end{array}$ \\
\hline $\begin{array}{l}\text { Ohlo Power Co } \\
\text { Kentucky } \\
\text { Floyd } \\
\text { Magoffin } \\
\text { Martin } \\
\text { Ohio } \\
\text { Muskingum } \\
\text { Noble } \\
\text { Fest Virginia } \\
\text { Kayette } \\
\text { Loganha }\end{array}$ & $\begin{array}{r}3,238 \\
14 \\
11 \\
1 \\
1 \\
3,074 \\
338 \\
2,736 \\
150 \\
13 \\
6 \\
131\end{array}$ & $\begin{array}{l}11,504 \\
12,191 \\
12,183 \\
12,222 \\
12,222 \\
11,453 \\
11,453 \\
11,453 \\
12,480 \\
12,376 \\
12,380 \\
12,495\end{array}$ & $\begin{array}{r}4.17 \\
.60 \\
.60 \\
.61 \\
.61 \\
4.36 \\
4.36 \\
4.36 \\
.64 \\
.66 \\
.66 \\
.64\end{array}$ & $\begin{array}{r}12.65 \\
11.30 \\
11.30 \\
11.30 \\
11.30 \\
12.76 \\
12.76 \\
12.76 \\
10.39 \\
9.57 \\
9.54 \\
10.51\end{array}$ & $\begin{array}{l}166.3 \\
150.4 \\
149.3 \\
155.0 \\
155.0 \\
166.5 \\
166.5 \\
166.5 \\
163.5 \\
146.1 \\
146.3 \\
166.0\end{array}$ & $\begin{array}{l}38.25 \\
36.67 \\
36.38 \\
37.89 \\
37.89 \\
38.14 \\
38.14 \\
38.14 \\
40.81 \\
36.15 \\
36.22 \\
41.49\end{array}$ \\
\hline $\begin{array}{l}\text { Ohio Power Co } \\
\text { Ohio } \\
\text { Jefferson } \\
\text { West Virginia } \\
\text { Preston }\end{array}$ & $\begin{array}{r}66 \\
66 \\
66 \\
1 \\
1\end{array}$ & $\begin{array}{l}12,192 \\
12,194 \\
12,194 \\
12,000 \\
12,000\end{array}$ & $\begin{array}{l}2.94 \\
2.94 \\
2.94 \\
2.50 \\
2.50\end{array}$ & $\begin{array}{l}11.66 \\
11.65 \\
11.65 \\
13.00 \\
13.00\end{array}$ & $\begin{array}{l}133.5 \\
133.4 \\
133.4 \\
135.4 \\
135.4\end{array}$ & $\begin{array}{l}32.54 \\
32.54 \\
32.54 \\
32.50 \\
32.50\end{array}$ \\
\hline $\begin{array}{l}\text { Ohio Valley Electric Corp } \\
\text { Kentucky } \\
\text { Floyd . Kyger Creek } \\
\text { Letcher } \\
\text { Pike } \\
\text { Ohio } \\
\text { Belmont } \\
\text { Hocking } \\
\text { Jackson } \\
\text { West Virginia } \\
\text { Marshall } \\
\text { Mingo }\end{array}$ & $\begin{array}{r}3,464 \\
125 \\
37 \\
53 \\
35 \\
1,097 \\
230 \\
448 \\
419 \\
2,242 \\
2,192 \\
50\end{array}$ & $\begin{array}{l}12,041 \\
13,128 \\
12,998 \\
13,423 \\
12,820 \\
11,569 \\
12,551 \\
11,396 \\
11,216 \\
12,211 \\
12,192 \\
13,056\end{array}$ & $\begin{array}{l}3.73 \\
1.50 \\
1.63 \\
1.54 \\
1.31 \\
3.65 \\
4.23 \\
3.52 \\
3.47 \\
3.90 \\
3.95 \\
1.58\end{array}$ & $\begin{array}{r}10.82 \\
6.19 \\
6.77 \\
5.27 \\
6.95 \\
11.01 \\
9.38 \\
11.34 \\
11.55 \\
10.99 \\
11.08 \\
7.07\end{array}$ & $\begin{array}{r}122.0 \\
122.2 \\
118.7 \\
123.7 \\
123.7 \\
95.9 \\
89.9 \\
97.7 \\
97.7 \\
134.1 \\
134.4 \\
123.1\end{array}$ & $\begin{array}{l}29.39 \\
32.09 \\
30.84 \\
33.20 \\
31.71 \\
22.20 \\
22.57 \\
22.27 \\
21.92 \\
32.76 \\
32.77 \\
32.15\end{array}$ \\
\hline $\begin{array}{l}\text { Oklahoma Gas \& Electric Co Muskogee } \\
\text { Oklahoma } \\
\text { Muskogee } \\
\text { Wyoming } \\
\text { Campbell }\end{array}$ & $\begin{array}{r}5,127 \\
44 \\
44 \\
5,083 \\
5,083\end{array}$ & $\begin{array}{r}8,789 \\
12,717 \\
12,717 \\
8,755 \\
8,755\end{array}$ & $\begin{array}{r}.38 \\
1.53 \\
1.53 \\
.37 \\
.37\end{array}$ & $\begin{array}{r}5.07 \\
11.03 \\
11.03 \\
5.02 \\
5.02\end{array}$ & $\begin{array}{l}116.7 \\
116.8 \\
116.8 \\
116.7 \\
116.7\end{array}$ & $\begin{array}{l}20.51 \\
29.70 \\
29.70 \\
20.43 \\
20.43\end{array}$ \\
\hline $\begin{array}{l}\text { Oklahoma Gas \& Electric Co Sooner } \\
\text { Oklahoma } \\
\text { Rogers } \\
\text { Wyoming } \\
\text { Campbell }\end{array}$ & $\begin{array}{r}3,664 \\
39 \\
39 \\
3,625 \\
3,625\end{array}$ & $\begin{array}{r}8,750 \\
12,175 \\
12,175 \\
8,713 \\
8,713\end{array}$ & $\begin{array}{r}.42 \\
3.75 \\
3.75 \\
.38 \\
.38\end{array}$ & $\begin{array}{r}5.13 \\
10.55 \\
10.55 \\
5.07 \\
5.07\end{array}$ & $\begin{array}{l}112.2 \\
116.8 \\
116.8 \\
112.1 \\
112.1\end{array}$ & $\begin{array}{l}19.63 \\
28.44 \\
28.44 \\
19.54 \\
19.54\end{array}$ \\
\hline $\begin{array}{c}\text { Omaha Public Power District } \\
\text { Wyoming }\end{array}$ & $\begin{array}{l}1,736 \\
1,736 \\
1,736\end{array}$ & $\begin{array}{l}8,238 \\
8,238 \\
8,238\end{array}$ & $\begin{array}{l}.37 \\
.37 \\
.37\end{array}$ & $\begin{array}{l}4.76 \\
4.76 \\
4.76\end{array}$ & $\begin{array}{l}62.1 \\
62.1 \\
62.1\end{array}$ & $\begin{array}{l}10.24 \\
10.24 \\
10.24\end{array}$ \\
\hline $\begin{array}{l}\text { Omaha Public Power District North Omaha } \\
\text { Wyoming } \\
\text { Campbell }\end{array}$ & $\begin{array}{l}1,592 \\
1,592 \\
1,592\end{array}$ & $\begin{array}{l}8,300 \\
8,300 \\
8,300\end{array}$ & $\begin{array}{l}.37 \\
.37 \\
.37\end{array}$ & $\begin{array}{l}5.06 \\
5.06 \\
5.06\end{array}$ & $\begin{array}{l}63.3 \\
63.3 \\
63.3\end{array}$ & $\begin{array}{l}10.51 \\
10.51 \\
10.51\end{array}$ \\
\hline $\begin{array}{c}\text { Orange and Rockland Utlls Inc Lovett } \\
\text { Kentucky } \\
\text { Pike }\end{array}$ & $\begin{array}{l}657 \\
315 \\
315\end{array}$ & $\begin{array}{l}13,014 \\
13,046 \\
13,046\end{array}$ & $\begin{array}{l}.55 \\
.54 \\
.54\end{array}$ & $\begin{array}{l}7.28 \\
7.02 \\
7.02\end{array}$ & $\begin{array}{l}205.4 \\
210.9 \\
210.9\end{array}$ & $\begin{array}{l}\mathbf{5 3 . 4 5} \\
55.03 \\
55.03\end{array}$ \\
\hline
\end{tabular}

See foolnotes at end of table.

Source: Federal Energy Regulatory Commission, FERC Form 423, "Monthly Report of Cost and Quality of Fuels for Electric Plants." 
Table 24. Origin of Coal Received by Electric Utility and Plant, 1992 (Continued)

\begin{tabular}{|c|c|c|c|c|c|c|}
\hline \multirow{2}{*}{$\begin{array}{l}\text { Electric Utility Plant } \\
\text { Origin State } \\
\text { County }\end{array}$} & \multirow{2}{*}{$\begin{array}{l}\text { Quantlty } \\
\text { (thousand } \\
\text { short tons) }\end{array}$} & \multicolumn{3}{|c|}{ Average Quality } & \multicolumn{2}{|c|}{ Average Dellvered Cost } \\
\hline & & $\begin{array}{c}\text { Btu } \\
\text { (per pound) }\end{array}$ & $\begin{array}{c}\text { Sulfur } \\
\text { (percent } \\
\text { by weight) }\end{array}$ & $\begin{array}{c}\text { Ash } \\
\text { (percent } \\
\text { by weight) }\end{array}$ & $\begin{array}{l}\text { (cents per } \\
\text { million Btu) }\end{array}$ & $\begin{array}{l}\text { (dollars per } \\
\text { short ton) }\end{array}$ \\
\hline $\begin{array}{l}\text { Orange and Rockland Utlls Inc Lovett } \\
\text { West Virginia } \\
\text { Mingo }\end{array}$ & $\begin{array}{l}342 \\
342\end{array}$ & $\begin{array}{l}12,984 \\
12,984\end{array}$ & $\begin{array}{r}0.55 \\
.55\end{array}$ & $\begin{array}{l}7.51 \\
7.51\end{array}$ & $\begin{array}{l}200.3 \\
200.3\end{array}$ & $\begin{array}{l}52.00 \\
52.00\end{array}$ \\
\hline $\begin{array}{l}\text { Orlando Utilities Comm } \\
\text { Kentucky } \\
\text { Letcher } \\
\text { Perry }\end{array}$ & $\begin{array}{r}1,024 \\
1,024 \\
922 \\
102\end{array}$ & $\begin{array}{l}12,755 \\
12,755 \\
12,757 \\
12,736\end{array}$ & $\begin{array}{l}.73 \\
.73 \\
.73 \\
.74\end{array}$ & $\begin{array}{l}8.34 \\
8.34 \\
8.36 \\
8.14\end{array}$ & $\begin{array}{l}190.1 \\
190.1 \\
190.5 \\
187.0\end{array}$ & $\begin{array}{l}48.51 \\
48.51 \\
48.60 \\
47.64\end{array}$ \\
\hline 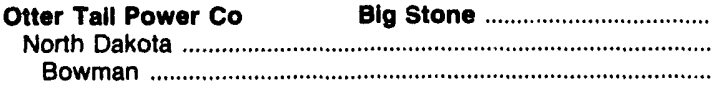 & $\begin{array}{l}2,130 \\
2,130 \\
2,130\end{array}$ & $\begin{array}{l}6,034 \\
6,034 \\
6,034\end{array}$ & $\begin{array}{l}.92 \\
.92 \\
.92\end{array}$ & $\begin{array}{l}9.34 \\
9.34 \\
9.34\end{array}$ & $\begin{array}{l}113.3 \\
113.3 \\
113.3\end{array}$ & $\begin{array}{l}13.68 \\
13.68 \\
13.68\end{array}$ \\
\hline 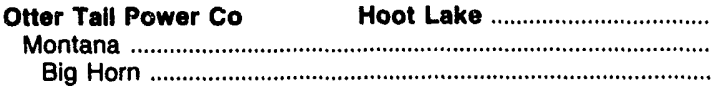 & $\begin{array}{l}123 \\
123 \\
123\end{array}$ & $\begin{array}{l}9.337 \\
9,337 \\
9,337\end{array}$ & $\begin{array}{l}.32 \\
.32 \\
.32\end{array}$ & $\begin{array}{l}3.82 \\
3.82 \\
3.82\end{array}$ & $\begin{array}{l}127.6 \\
127.6 \\
127.6\end{array}$ & $\begin{array}{l}23.83 \\
23.83 \\
23.83\end{array}$ \\
\hline 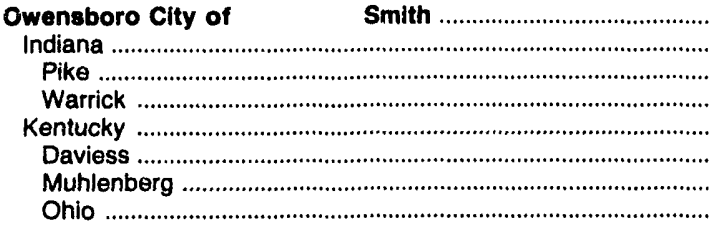 & $\begin{array}{r}1,132 \\
48 \\
15 \\
33 \\
1,084 \\
819 \\
38 \\
227\end{array}$ & $\begin{array}{l}11,282 \\
11,353 \\
11,432 \\
11,318 \\
11,279 \\
11,166 \\
11,614 \\
11,630\end{array}$ & $\begin{array}{l}2.88 \\
2.84 \\
3.08 \\
2.73 \\
2.88 \\
2.82 \\
2.89 \\
3.07\end{array}$ & $\begin{array}{l}9.22 \\
8.85 \\
7.90 \\
9.27 \\
9.24 \\
9.20 \\
8.86 \\
9.45\end{array}$ & $\begin{array}{r}107.9 \\
94.0 \\
98.8 \\
91.9 \\
108.5 \\
114.7 \\
100.9 \\
88.2\end{array}$ & $\begin{array}{l}24.34 \\
21.35 \\
22.59 \\
20.79 \\
24.47 \\
25.62 \\
23.44 \\
20.50\end{array}$ \\
\hline $\begin{array}{l}\text { PacifiCorp } \\
\text { Utah }\end{array}$ & $\begin{array}{l}593 \\
593 \\
593\end{array}$ & $\begin{array}{l}11,985 \\
11,985 \\
11,985\end{array}$ & $\begin{array}{l}.44 \\
.44 \\
.44\end{array}$ & $\begin{array}{l}8.56 \\
8.56 \\
8.56\end{array}$ & $\begin{array}{l}79.1 \\
79.1 \\
79.1\end{array}$ & $\begin{array}{l}18.95 \\
18.95 \\
18.95\end{array}$ \\
\hline $\begin{array}{l}\text { PaciflCorp } \\
\text { Montana } \\
\text { Big Horn } \\
\text { Utah } \\
\text { Sevier } \\
\text { Washington } \\
\text { King } \\
\text { Lewis } \\
\text { Thurston }\end{array}$ & $\begin{array}{r}5,812 \\
710 \\
710 \\
118 \\
118 \\
4,984 \\
41 \\
2,126 \\
2,817\end{array}$ & $\begin{array}{r}8,182 \\
9,513 \\
9,513 \\
11,274 \\
11,274 \\
7,919 \\
10,971 \\
7,883 \\
7,901\end{array}$ & $\begin{array}{l}.66 \\
.41 \\
.41 \\
.34 \\
.34 \\
.70 \\
.72 \\
.69 \\
.71\end{array}$ & $\begin{array}{r}13.70 \\
4.38 \\
4.38 \\
8.17 \\
8.17 \\
15.16 \\
19.66 \\
15.13 \\
15.12\end{array}$ & $\begin{array}{l}137.0 \\
123.2 \\
123.2 \\
128.2 \\
128.2 \\
139.6 \\
130.8 \\
139.5 \\
139.9\end{array}$ & $\begin{array}{l}22.41 \\
23.45 \\
23.45 \\
28.91 \\
28.91 \\
22.11 \\
28.71 \\
21.99 \\
22.10\end{array}$ \\
\hline $\begin{array}{c}\text { PacifiCorp } \\
\text { Utah }\end{array}$ & $\begin{array}{l}3,676 \\
3,676 \\
3,676\end{array}$ & $\begin{array}{l}11,075 \\
11,075 \\
11,075\end{array}$ & $\begin{array}{l}.50 \\
.50 \\
.50\end{array}$ & $\begin{array}{l}13.78 \\
13.78 \\
13.78\end{array}$ & $\begin{array}{l}94.2 \\
94.2 \\
94.2\end{array}$ & $\begin{array}{l}20.86 \\
20.86 \\
20.86\end{array}$ \\
\hline 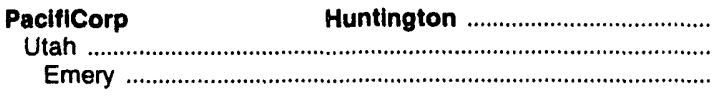 & $\begin{array}{l}2,776 \\
2,776 \\
2,776\end{array}$ & $\begin{array}{l}11,408 \\
11,408 \\
11,408\end{array}$ & $\begin{array}{l}.45 \\
.45 \\
.45\end{array}$ & $\begin{array}{l}13.13 \\
13.13 \\
13.13\end{array}$ & $\begin{array}{l}78.7 \\
78.7 \\
78.7\end{array}$ & $\begin{array}{l}17.96 \\
17.96 \\
17.96\end{array}$ \\
\hline $\begin{array}{l}\text { PacifiCorp } \\
\text { Wyoming } \\
\text { Carbon } \\
\text { Sweetwater }\end{array}$ & $\begin{array}{r}8,708 \\
8,708 \\
69 \\
8,639\end{array}$ & $\begin{array}{r}9,692 \\
9,692 \\
10,625 \\
9,684\end{array}$ & $\begin{array}{l}.61 \\
.61 \\
.46 \\
.61\end{array}$ & $\begin{array}{l}9.65 \\
9.65 \\
5.30 \\
9.69\end{array}$ & $\begin{array}{l}88.1 \\
88.1 \\
79.6 \\
88.2\end{array}$ & $\begin{array}{l}17.08 \\
17.08 \\
16.92 \\
17.09\end{array}$ \\
\hline $\begin{array}{l}\text { PacifiCorp } \\
\text { Wyoming }\end{array}$ Johnston & $\begin{array}{l}4,204 \\
4,204 \\
1,421 \\
2,783\end{array}$ & $\begin{array}{l}7,990 \\
7,990 \\
8,417 \\
7,771\end{array}$ & $\begin{array}{l}.43 \\
.43 \\
.33 \\
.49\end{array}$ & $\begin{array}{r}8.51 \\
8.51 \\
5.48 \\
10.06\end{array}$ & $\begin{array}{l}58.2 \\
58.2 \\
46.2 \\
64.8\end{array}$ & $\begin{array}{r}9.29 \\
9.29 \\
7.78 \\
10.07\end{array}$ \\
\hline 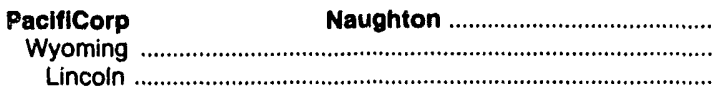 & $\begin{array}{l}2,385 \\
2,385 \\
2,385\end{array}$ & $\begin{array}{l}9,822 \\
9,822 \\
9,822\end{array}$ & $\begin{array}{l}.70 \\
.70 \\
.70\end{array}$ & $\begin{array}{l}4.95 \\
4.95 \\
4.95\end{array}$ & $\begin{array}{l}121.6 \\
121.6 \\
121.6\end{array}$ & $\begin{array}{l}23.88 \\
23.88 \\
23.88\end{array}$ \\
\hline 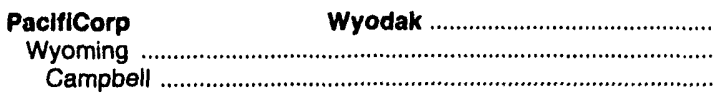 & $\begin{array}{l}1,970 \\
1,970 \\
1,970\end{array}$ & $\begin{array}{l}7,925 \\
7,925 \\
7,925\end{array}$ & $\begin{array}{l}.66 \\
.66 \\
.66\end{array}$ & $\begin{array}{l}7.90 \\
7.90 \\
7.90\end{array}$ & $\begin{array}{l}63.8 \\
63.8 \\
63.8\end{array}$ & $\begin{array}{c}10.12 \\
10.12 \\
10.12\end{array}$ \\
\hline Painesville ..................................... & 70 & 12,391 & 2.57 & 7.73 & 135.1 & 33.48 \\
\hline
\end{tabular}

See footnotes at end of table.

Source: Federal Energy Regulatory Commission, FERC Form in3, "Monthly Report of Cost and Quality of Fuels for Electric Plants." 
Table 24. Origin of Coal Recelved by Electric Utllity and Plant, 1992 (Continued)

\begin{tabular}{|c|c|c|c|c|c|c|}
\hline \multirow[b]{2}{*}{$\begin{array}{l}\text { Electric Utilly Plant } \\
\text { Origin State } \\
\text { County }\end{array}$} & \multirow{2}{*}{$\begin{array}{l}\text { Quantity } \\
\text { (thousand } \\
\text { chort tons) }\end{array}$} & \multicolumn{3}{|c|}{ Average Quality } & \multicolumn{2}{|c|}{ Average Dellvered Cost } \\
\hline & & $\begin{array}{c}\text { Btu } \\
\text { (per pound) }\end{array}$ & $\begin{array}{l}\text { Sulfur } \\
\text { (percent } \\
\text { by wolght) }\end{array}$ & $\begin{array}{l}\text { Ash } \\
\text { (porcent } \\
\text { by welght) }\end{array}$ & $\begin{array}{l}\text { (cents per } \\
\text { million Btu) }\end{array}$ & $\begin{array}{l}\text { (dollars per } \\
\text { short ton) }\end{array}$ \\
\hline $\begin{array}{l}\text { Painesville Clty of } \\
\text { Ohio } \\
\text { Columbiana }\end{array}$ & $\begin{array}{l}70 \\
70\end{array}$ & $\begin{array}{l}12,391 \\
12,391\end{array}$ & $\begin{array}{l}2.57 \\
2.57\end{array}$ & $\begin{array}{l}7.73 \\
7.73\end{array}$ & $\begin{array}{l}135.1 \\
135.1\end{array}$ & $\begin{array}{l}33.48 \\
33.48\end{array}$ \\
\hline $\begin{array}{l}\text { Pennayivania Electric Co Conemaugh } \\
\text { Pennsylvania .... } \\
\text { Allegheny . } \\
\text { Armstrong . } \\
\text { Cambria . } \\
\text { Centre } \\
\text { Fayette } \\
\text { Indiana } \\
\text { Somerset } \\
\text { Westmoreland }\end{array}$ & $\begin{array}{r}4,815 \\
4,815 \\
89 \\
461 \\
358 \\
58 \\
88 \\
999 \\
2,251 \\
511\end{array}$ & $\begin{array}{l}12,502 \\
12,502 \\
13,100 \\
12,538 \\
12,324 \\
12,664 \\
12,406 \\
12,479 \\
12,529 \\
12,418\end{array}$ & $\begin{array}{l}2.20 \\
2.20 \\
2.42 \\
2.11 \\
2.10 \\
2.06 \\
2.17 \\
2.14 \\
2.25 \\
2.24\end{array}$ & $\begin{array}{r}13.17 \\
13.17 \\
6.70 \\
12.07 \\
13.84 \\
12.18 \\
13.09 \\
13.78 \\
13.39 \\
12.74\end{array}$ & $\begin{array}{l}118.8 \\
118.9 \\
134.5 \\
126.1 \\
117.3 \\
117.2 \\
111.0 \\
117.5 \\
118.6 \\
116.6\end{array}$ & $\begin{array}{l}29.74 \\
29.74 \\
35.24 \\
31.62 \\
28.92 \\
29.68 \\
27.54 \\
29.33 \\
29.72 \\
28.96\end{array}$ \\
\hline $\begin{array}{l}\text { Pennaylvania Electric Co } \\
\text { Pennsylvania } \\
\text { Armstrong } \\
\text { Blair ... Homer Clty } \\
\text { Cambria } \\
\text { Clarion } \\
\text { Clearfield } \\
\text { Fayette } \\
\text { Indiana } \\
\text { Jefferson } \\
\text { Somerset } \\
\text { Westmoreland } \\
\text { Unknown } \\
\text { West Virginia } \\
\text { Monongalia }\end{array}$ & $\begin{array}{r}5,070 \\
5,068 \\
290 \\
10 \\
44 \\
5 \\
39 \\
10 \\
3,985 \\
174 \\
469 \\
37 \\
5 \\
2 \\
2\end{array}$ & $\begin{array}{l}11,602 \\
11,802 \\
12,365 \\
13,124 \\
11,707 \\
12,668 \\
12,042 \\
12,678 \\
11,623 \\
12,259 \\
12,655 \\
12,600 \\
13,415 \\
12,341 \\
12,341\end{array}$ & $\begin{array}{r}1.73 \\
1.73 \\
1.04 \\
1.83 \\
1.75 \\
.72 \\
1.38 \\
.68 \\
1.90 \\
1.24 \\
1.12 \\
.70 \\
.69 \\
1.24 \\
1.24\end{array}$ & $\begin{array}{r}17.15 \\
17.15 \\
12.05 \\
11.32 \\
17.96 \\
11.20 \\
14.29 \\
9.30 \\
18.43 \\
12.08 \\
12.44 \\
10.65 \\
9.00 \\
13.80 \\
13.80\end{array}$ & $\begin{array}{l}149.4 \\
149.4 \\
139.6 \\
137.1 \\
117.3 \\
159.6 \\
135.7 \\
151.2 \\
151.6 \\
133.0 \\
147.2 \\
155.8 \\
150.8 \\
126.1 \\
126.1\end{array}$ & $\begin{array}{l}35.26 \\
35.26 \\
34.53 \\
36.00 \\
27.47 \\
40.44 \\
32.69 \\
38.34 \\
35.24 \\
32.61 \\
37.24 \\
39.27 \\
40.46 \\
31.13 \\
31.13\end{array}$ \\
\hline $\begin{array}{l}\text { Pennsylvania Eloctric Co Keystone } \\
\text { Pennsylvania ... } \\
\text { Armstrong } \\
\text { Clearfield } \\
\text { Faystte } \\
\text { Indiana } \\
\text { Jefferson } \\
\text { Venango } \\
\text { Unknown }\end{array}$ & $\begin{array}{r}4,799 \\
4,799 \\
2,863 \\
13 \\
12 \\
1,863 \\
18 \\
15 \\
15\end{array}$ & $\begin{array}{l}12,369 \\
12,369 \\
12,361 \\
12,338 \\
13,340 \\
12,372 \\
12,299 \\
12,680 \\
12,352\end{array}$ & $\begin{array}{l}1.68 \\
1.68 \\
1.69 \\
1.99 \\
2.27 \\
1.66 \\
1.88 \\
1.62 \\
2.02\end{array}$ & $\begin{array}{r}12.89 \\
12.89 \\
12.90 \\
14.18 \\
7.05 \\
12.91 \\
13.15 \\
11.20 \\
13.37\end{array}$ & $\begin{array}{l}134.0 \\
134.0 \\
13 \\
105.4 \\
106.4 \\
134.6 \\
109.2 \\
111.9 \\
105.9\end{array}$ & $\begin{array}{l}33.15 \\
33.15 \\
33.19 \\
26.01 \\
28.38 \\
33.31 \\
26.86 \\
28.38 \\
26.17\end{array}$ \\
\hline 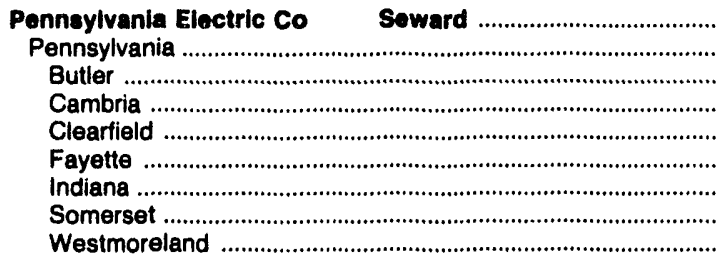 & $\begin{array}{r}572 \\
572 \\
3 \\
3 \\
13 \\
43 \\
236 \\
171 \\
103\end{array}$ & $\begin{array}{l}12,252 \\
12,252 \\
12,261 \\
11,956 \\
12,291 \\
12,183 \\
12,287 \\
12,273 \\
12,168\end{array}$ & $\begin{array}{l}1.54 \\
1.54 \\
1.48 \\
1.52 \\
1.31 \\
1.56 \\
1.55 \\
1.53 \\
1.54\end{array}$ & $\begin{array}{l}13.76 \\
13.76 \\
13.30 \\
13.90 \\
14.21 \\
13.17 \\
13.87 \\
13.51 \\
14.13\end{array}$ & $\begin{array}{l}113.2 \\
113.2 \\
113.7 \\
108.3 \\
113.3 \\
111.5 \\
114.4 \\
113.5 \\
111.0\end{array}$ & $\begin{array}{l}27.75 \\
27.75 \\
27.88 \\
25.90 \\
27.85 \\
27.18 \\
28.10 \\
27.87 \\
27.00\end{array}$ \\
\hline $\begin{array}{l}\text { Penneylvania Electric Co } \quad \text { Shawville } \\
\text { Pennsylvania } \\
\text { Cambria } \\
\text { Clearfield } \\
\text { Jefferson }\end{array}$ & $\begin{array}{r}1,417 \\
1,417 \\
4 \\
1,401 \\
12\end{array}$ & $\begin{array}{l}12,277 \\
12,277 \\
12,299 \\
12,278 \\
12,168\end{array}$ & $\begin{array}{l}1.97 \\
1.97 \\
2.18 \\
1.97 \\
1.86\end{array}$ & $\begin{array}{l}13.09 \\
13.08 \\
14.70 \\
13.09 \\
12.53\end{array}$ & $\begin{array}{l}108.5 \\
108.5 \\
104.7 \\
108.5 \\
106.3\end{array}$ & $\begin{array}{l}26.63 \\
26.63 \\
25.75 \\
26.64 \\
25.87\end{array}$ \\
\hline $\begin{array}{l}\text { Pennsylvania Electric Co } \\
\text { Pennsylvania . } \\
\text { Armstrong } \\
\text { Butler . } \\
\text { Clarion } \\
\text { Clearfield } \\
\text { Elk } \\
\text { Jefferson }\end{array}$ & $\begin{array}{r}217 \\
217 \\
6 \\
58 \\
46 \\
5 \\
22 \\
80\end{array}$ & $\begin{array}{l}12,218 \\
12,218 \\
12,111 \\
12,208 \\
12,302 \\
12,038 \\
12,215 \\
12,196\end{array}$ & $\begin{array}{l}1.77 \\
1.77 \\
2.11 \\
1.97 \\
1.40 \\
1.56 \\
1.85 \\
1.81\end{array}$ & $\begin{array}{r}11.09 \\
11.09 \\
12.13 \\
10.73 \\
9.53 \\
12.10 \\
12.26 \\
11.79\end{array}$ & $\begin{array}{l}116.7 \\
116.7 \\
112.5 \\
118.7 \\
113.3 \\
123.7 \\
117.8 \\
116.9\end{array}$ & $\begin{array}{l}28.53 \\
28.53 \\
27.25 \\
28.97 \\
27.88 \\
29.78 \\
28.77 \\
28.53\end{array}$ \\
\hline Pennaylvania Power Llght Co Brunner Island .................. & 3,471 & 12,718 & 1.83 & 11.46 & 186.9 & 47.53 \\
\hline
\end{tabular}

See footnotes at end of table.

Source: Federal Energy Regulatory Commission, FERC Form 423, "Monthly Report of Cost and Quality of Fuels for Electric Plants." 
Table 24. Origin of Coal Received by Electric Utility and Plant, 1992 (Continued)

\begin{tabular}{|c|c|c|c|c|c|c|}
\hline \multirow[b]{2}{*}{$\begin{array}{c}\text { Flectric Utility Plant } \\
\text { Origin State } \\
\text { County }\end{array}$} & \multirow{2}{*}{$\begin{array}{l}\text { Quantity } \\
\text { (thousand } \\
\text { short tons) }\end{array}$} & \multicolumn{3}{|c|}{ Average Quality } & \multicolumn{2}{|c|}{ Average Dellvered Cost } \\
\hline & & $\begin{array}{c}\text { Btu } \\
\text { (per pound) }\end{array}$ & $\begin{array}{c}\text { Sulfur } \\
\text { (percent } \\
\text { by weight) }\end{array}$ & $\begin{array}{l}\text { Ash } \\
\text { (percent } \\
\text { by weight) }\end{array}$ & $\begin{array}{l}\text { (cents per } \\
\text { million Btu) }\end{array}$ & $\begin{array}{l}\text { (dollars per } \\
\text { short ton) }\end{array}$ \\
\hline 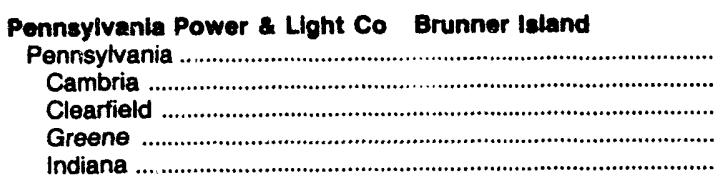 & $\begin{array}{r}3,471 \\
233 \\
680 \\
920 \\
1,638\end{array}$ & $\begin{array}{l}12,718 \\
12,547 \\
12,514 \\
13,303 \\
12,498\end{array}$ & $\begin{array}{l}1.83 \\
1.92 \\
1.84 \\
1.72 \\
1.88\end{array}$ & $\begin{array}{r}11.46 \\
12.60 \\
13.41 \\
7.15 \\
12.91\end{array}$ & $\begin{array}{l}186.9 \\
163.6 \\
179.7 \\
144.7 \\
218.4\end{array}$ & $\begin{array}{l}47.53 \\
41.06 \\
44.98 \\
38.51 \\
54.59\end{array}$ \\
\hline $\begin{array}{l}\text { Pennsylvania Power Light Co Holtwood } \\
\text { Pennsylvania . } \\
\text { Carbon } \\
\text { Chester } \\
\text { Dauphin } \\
\text { Northumberland } \\
\text { Schuylkill }\end{array}$ & $\begin{array}{r}193 \\
193 \\
2 \\
27 \\
1 \\
0 \\
157\end{array}$ & $\begin{array}{r}8,772 \\
8,772 \\
7,721 \\
10,502 \\
10,921 \\
10,714 \\
8,400\end{array}$ & $\begin{array}{l}.60 \\
.60 \\
.44 \\
.50 \\
.78 \\
.84 \\
.61\end{array}$ & $\begin{array}{l}29.85 \\
29.85 \\
33.20 \\
15.40 \\
18.60 \\
18.42 \\
32.81\end{array}$ & $\begin{array}{l}116.2 \\
116.2 \\
100.0 \\
158.4 \\
162.2 \\
161.0 \\
104.8\end{array}$ & $\begin{array}{l}20.39 \\
20.39 \\
15.45 \\
33.27 \\
35.43 \\
34.50 \\
17.60\end{array}$ \\
\hline $\begin{array}{l}\text { Pennsylvania Power Light Co Martins Creek } \\
\text { Pennsylvania . } \\
\text { Armstrong } \\
\text { Clarion . } \\
\text { Clearfield } \\
\text { Greene } \\
\text { Indiana } \\
\text { Jefferson } \\
\text { Washington }\end{array}$ & $\begin{array}{r}603 \\
603 \\
10 \\
10 \\
11 \\
244 \\
288 \\
20 \\
20\end{array}$ & $\begin{array}{l}12,954 \\
12,954 \\
12,569 \\
12,892 \\
12,487 \\
13,312 \\
12,641 \\
13,201 \\
13,320\end{array}$ & $\begin{array}{l}1.91 \\
1.91 \\
3.28 \\
2.06 \\
2.23 \\
1.75 \\
2.06 \\
1.58 \\
1.61\end{array}$ & $\begin{array}{r}9.80 \\
9.80 \\
11.60 \\
9.30 \\
13 \\
9 \\
1: \\
9.80 \\
6.75\end{array}$ & $\begin{array}{l}186.5 \\
186.5 \\
138.4 \\
138.7 \\
187.9 \\
149.6 \\
229.4 \\
136.6 \\
145.5\end{array}$ & $\begin{array}{l}48.32 \\
48.32 \\
34.79 \\
35.76 \\
46.93 \\
39.82 \\
57.99 \\
36.07 \\
38.77\end{array}$ \\
\hline 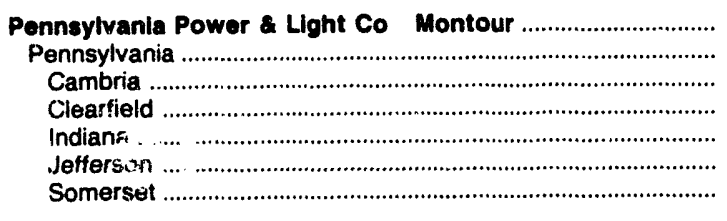 & $\begin{array}{r}3,255 \\
3,255 \\
1,083 \\
1,326 \\
653 \\
183 \\
10\end{array}$ & $\begin{array}{l}12,559 \\
12,559 \\
12,545 \\
12,680 \\
12,353 \\
12,516 \\
12,437\end{array}$ & $\begin{array}{l}1.92 \\
1.92 \\
1.84 \\
2.00 \\
1.90 \\
1.94 \\
2.06\end{array}$ & $\begin{array}{l}13.16 \\
13.16 \\
13.18 \\
12.77 \\
13.84 \\
13.27 \\
14.80\end{array}$ & $\begin{array}{l}176.4 \\
176.4 \\
220.9 \\
146.8 \\
175.0 \\
137.4 \\
139.2\end{array}$ & $\begin{array}{l}44.32 \\
44.32 \\
55.42 \\
37.23 \\
43.23 \\
34.39 \\
34.62\end{array}$ \\
\hline $\begin{array}{l}\text { Penn ytvania Power } 2 \text { Lighi Co Sunbury } \\
\text { Pennsylvania } \\
\text { Armstrong } \\
\text { Bedford } \\
\text { Centre } \\
\text { Clarion } \\
\text { Cleartield } \\
\text { Fulton } \\
\text { Jefterson } \\
\text { Lycoming } \\
\text { Northumberland } \\
\text { Schuylkill } \\
\text { Somerset } \\
\text { Sullivan }\end{array}$ & $\begin{array}{r}956 \\
956 \\
12 \\
9 \\
75 \\
14 \\
454 \\
13 \\
14 \\
9 \\
81 \\
221 \\
53 \\
1\end{array}$ & $\begin{array}{r}10,950 \\
10,950 \\
12,835 \\
9,490 \\
12,203 \\
12,758 \\
12,154 \\
12,556 \\
12,587 \\
12,612 \\
8,091 \\
8,313 \\
12,522 \\
8,215\end{array}$ & $\begin{array}{r}1.57 \\
1.57 \\
-1.71 \\
1.17 \\
1.96 \\
2.15 \\
1.98 \\
2.38 \\
1.62 \\
1.35 \\
.96 \\
.63 \\
2.02 \\
.61\end{array}$ & $\begin{array}{r}20.78 \\
20.78 \\
9.89 \\
32.07 \\
14.74 \\
9.16 \\
15.05 \\
12.76 \\
12.79 \\
14.18 \\
30.03 \\
34.74 \\
14.56 \\
37.00\end{array}$ & $\begin{array}{r}125.7 \\
125.7 \\
129.4 \\
81.6 \\
131.3 \\
134.0 \\
145.0 \\
135.9 \\
135.3 \\
134.7 \\
75.8 \\
78.4 \\
134.0 \\
71.0\end{array}$ & $\begin{array}{l}27.53 \\
27.53 \\
33.23 \\
15.49 \\
32.05 \\
34.19 \\
35.26 \\
34.12 \\
34.05 \\
33.98 \\
12.27 \\
13.03 \\
33.55 \\
11.67\end{array}$ \\
\hline 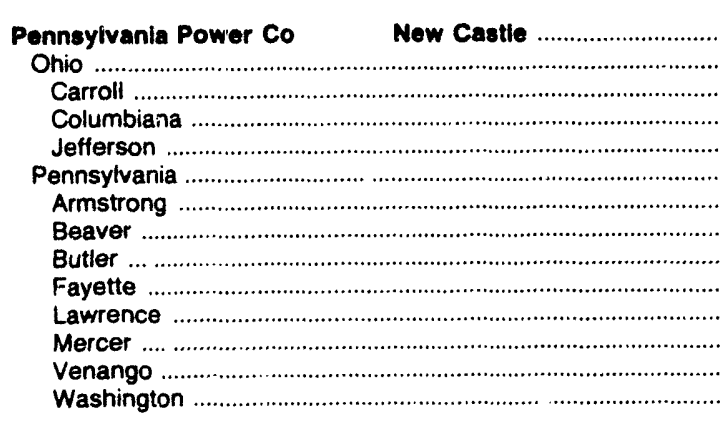 & $\begin{array}{r}762 \\
88 \\
5 \\
39 \\
44 \\
674 \\
375 \\
52 \\
161 \\
20 \\
2 \\
12 \\
2 \\
50\end{array}$ & $\begin{array}{l}12,243 \\
12,391 \\
11,451 \\
12,399 \\
12,489 \\
12,224 \\
12,297 \\
12,219 \\
12,043 \\
12,417 \\
12,352 \\
12,199 \\
12,159 \\
12,192\end{array}$ & $\begin{array}{r}1.46 \\
1.53 \\
.47 \\
1.59 \\
1.60 \\
1.45 \\
1.41 \\
1.55 \\
1.49 \\
1.20 \\
1.46 \\
1.49 \\
1.86 \\
1.65\end{array}$ & $\begin{array}{r}10.39 \\
9.90 \\
12.25 \\
10.10 \\
9.46 \\
10.45 \\
10.93 \\
10.09 \\
9.32 \\
8.98 \\
7.00 \\
11.20 \\
11.19 \\
11.37\end{array}$ & $\begin{array}{l}127.3 \\
114.3 \\
134.0 \\
113.5 \\
113.0 \\
129.0 \\
136.8 \\
116.5 \\
119.7 \\
130.5 \\
121.8 \\
107.4 \\
110.0 \\
117.9\end{array}$ & $\begin{array}{l}31.17 \\
28.33 \\
30.69 \\
28.15 \\
28.22 \\
31.64 \\
33.66 \\
28.48 \\
28.83 \\
32.40 \\
30.08 \\
26.21 \\
26.75 \\
28.75\end{array}$ \\
\hline 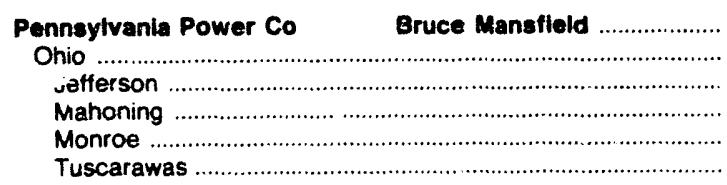 & $\begin{array}{r}4,880 \\
397 \\
209 \\
22 \\
106 \\
60\end{array}$ & $\begin{array}{l}12,139 \\
12,144 \\
12,136 \\
12,222 \\
12,147 \\
12,137\end{array}$ & $\begin{array}{l}3.88 \\
3.85 \\
3.79 \\
4.01 \\
3.87 \\
3.97\end{array}$ & $\begin{array}{l}11.65 \\
11.68 \\
11.71 \\
11.30 \\
11.76 \\
11.60\end{array}$ & $\begin{array}{l}168.8 \\
170.3 \\
167.8 \\
176.6 \\
171.8 \\
173.8\end{array}$ & $\begin{array}{r}1.99 \\
41.36 \\
40.74 \\
43.17 \\
41.74 \\
42.18\end{array}$ \\
\hline
\end{tabular}

See footnotes at end of table.

Suurce: Federal Energy Regulatory Commission, FERC Form 423, "Monthly Report of Cost and Quality of Fuels for Electric Plants." 
Table 24. Origin of Coal Received by Electric Utility and Plant, 1992 (Continued)

\begin{tabular}{|c|c|c|c|c|c|c|}
\hline \multirow[b]{2}{*}{$\begin{array}{l}\text { Electric Utility Piant } \\
\text { Origin State } \\
\text { County }\end{array}$} & \multirow{2}{*}{$\begin{array}{l}\text { Quantity } \\
\text { (thousand } \\
\text { short tons) }\end{array}$} & \multicolumn{3}{|c|}{ Average Quality } & \multicolumn{2}{|c|}{ Average Delivered Cost } \\
\hline & & $\begin{array}{c}\text { Btu } \\
\text { (per pound) }\end{array}$ & $\begin{array}{l}\text { Sulfur } \\
\text { (percent } \\
\text { by welght) }\end{array}$ & $\begin{array}{l}\text { Aah } \\
\text { (percent } \\
\text { by weight) }\end{array}$ & $\begin{array}{l}\text { (cents per } \\
\text { million Btu) }\end{array}$ & $\begin{array}{l}\text { (dollars per } \\
\text { short ton) }\end{array}$ \\
\hline Pennsylvanla Power Co $\quad$ Bruce Mansfleld & & & & & & \\
\hline $\begin{array}{l}\text { Pennsylvania } \\
\text { Greene ...... } \\
\text { Washington } \\
\text { West Virginia } \\
\text { Marshall } \\
\text { Monongalia }\end{array}$ & $\begin{array}{r}499 \\
53 \\
211 \\
235 \\
3,984 \\
3,959 \\
25\end{array}$ & $\begin{array}{l}12,146 \\
12,188 \\
12,158 \\
12,126 \\
12,138 \\
12,138 \\
12,202\end{array}$ & $\begin{array}{l}3.79 \\
3.96 \\
3.70 \\
3.84 \\
3.89 \\
3.89 \\
3.47\end{array}$ & $\begin{array}{l}11.63 \\
11.50 \\
11.59 \\
11.70 \\
11.65 \\
11.65 \\
11.60\end{array}$ & $\begin{array}{l}568.7 \\
181.7 \\
167.2 \\
167.2 \\
168.7 \\
168.7 \\
163.6\end{array}$ & $\begin{array}{l}40.99 \\
44.29 \\
40.66 \\
40.54 \\
40.96 \\
40.96 \\
39.92\end{array}$ \\
\hline $\begin{array}{l}\text { Philadelphia Electric Co } \quad \text { Cromby } \\
\text { Pennsylvania } \\
\text { Clarion } \\
\text { Greene } \\
\text { Washington } \\
\text { West Virginia } \\
\text { Fiarbour } \\
\text { Monongalia }\end{array}$ & $\begin{array}{r}288 \\
232 \\
16 \\
73 \\
143 \\
56 \\
20 \\
36\end{array}$ & $\begin{array}{l}13,304 \\
13,314 \\
12,549 \\
13,258 \\
13,429 \\
13,259 \\
13,247 \\
13,266\end{array}$ & $\begin{array}{l}1.72 \\
1.69 \\
2.23 \\
1.91 \\
1.51 \\
1.84 \\
1.91 \\
1.80\end{array}$ & $\begin{array}{l}7.20 \\
7.23 \\
9.30 \\
7.41 \\
6.91 \\
7.08 \\
7.85 \\
6.65\end{array}$ & $\begin{array}{l}154.2 \\
152.4 \\
150.3 \\
145.9 \\
155.9 \\
161.6 \\
162.7 \\
161.0\end{array}$ & $\begin{array}{l}41.03 \\
40.59 \\
37.73 \\
38.69 \\
41.88 \\
42.85 \\
43.11 \\
42.71\end{array}$ \\
\hline 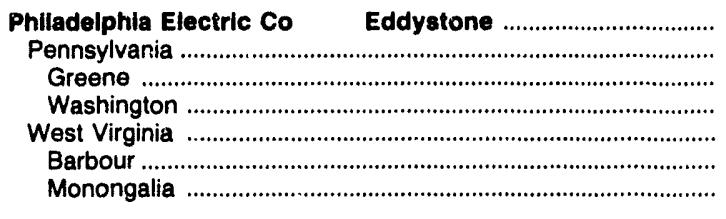 & $\begin{array}{r}802 \\
609 \\
441 \\
168 \\
193 \\
111 \\
82\end{array}$ & $\begin{array}{l}13,146 \\
13,159 \\
13,121 \\
13,259 \\
13,102 \\
13,035 \\
13,192\end{array}$ & $\begin{array}{l}1.94 \\
1.95 \\
2.07 \\
1.63 \\
1.91 \\
1.94 \\
1.85\end{array}$ & $\begin{array}{l}7.39 \\
7.27 \\
7.44 \\
6.81 \\
7.79 \\
8.49 \\
6.84\end{array}$ & $\begin{array}{l}156.5 \\
153.2 \\
150.3 \\
160.7 \\
166.9 \\
173.2 \\
158.4\end{array}$ & $\begin{array}{l}41.14 \\
40.32 \\
39.45 \\
42.61 \\
43.72 \\
45.15 \\
41.79\end{array}$ \\
\hline $\begin{array}{l}\text { Plains Elec Gen\&Trans Coop Inc Escalante } \\
\text { New Mexico } \\
\text { Mckinley }\end{array}$ & $\begin{array}{l}889 \\
889 \\
889\end{array}$ & $\begin{array}{l}9,079 \\
9,079 \\
9,079\end{array}$ & $\begin{array}{l}.65 \\
.65 \\
.65\end{array}$ & $\begin{array}{l}18.58 \\
18.58 \\
18.58\end{array}$ & $\begin{array}{l}137.5 \\
137.5 \\
137.5\end{array}$ & $\begin{array}{l}24.96 \\
24.96 \\
24.96\end{array}$ \\
\hline $\begin{array}{l}\text { Platte River Power Authority Rawhide } \\
\text { Wyoming } \\
\text { Converse }\end{array}$ & $\begin{array}{l}.009 \\
., 009 \\
1,009\end{array}$ & $\begin{array}{l}8,825 \\
8,825 \\
8,825\end{array}$ & $\begin{array}{l}.32 \\
.32 \\
.32\end{array}$ & $\begin{array}{l}5.54 \\
5.54 \\
5.54\end{array}$ & $\begin{array}{l}74.6 \\
74.6 \\
74.6\end{array}$ & $\begin{array}{l}13.17 \\
13.17 \\
13.17\end{array}$ \\
\hline 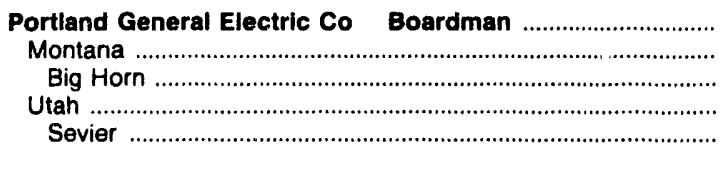 & $\begin{array}{r}1,932 \\
1,833 \\
1,833 \\
99 \\
99\end{array}$ & $\begin{array}{r}9,642 \\
9,547 \\
9,547 \\
11,396 \\
11,396\end{array}$ & $\begin{array}{l}.40 \\
.40 \\
.40 \\
.37 \\
.37\end{array}$ & $\begin{array}{l}4.42 \\
4.22 \\
4.22 \\
7.96 \\
7.96\end{array}$ & $\begin{array}{l}110.1 \\
110.3 \\
110.3 \\
106.9 \\
106.9\end{array}$ & $\begin{array}{l}21.23 \\
21.06 \\
21.06 \\
24.37 \\
24.37\end{array}$ \\
\hline 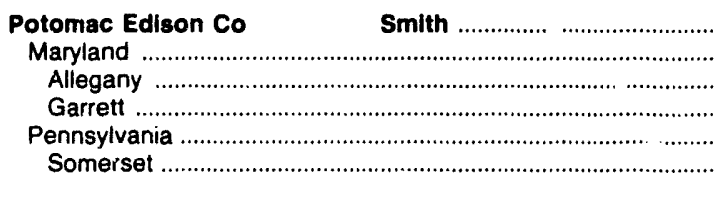 & $\begin{array}{r}154 \\
135 \\
64 \\
71 \\
18 \\
18\end{array}$ & $\begin{array}{l}12,539 \\
12,451 \\
12,578 \\
12,337 \\
13,192 \\
13,192\end{array}$ & $\begin{array}{l}.92 \\
.93 \\
.92 \\
.94 \\
.85 \\
.85\end{array}$ & $\begin{array}{l}12.31 \\
12.52 \\
11.94 \\
13.05 \\
10.77 \\
10.77\end{array}$ & $\begin{array}{l}134.0 \\
134.8 \\
134.8 \\
134.9 \\
128.5 \\
128.5\end{array}$ & $\begin{array}{l}33.61 \\
33.57 \\
33.90 \\
33.28 \\
33.90 \\
33.90\end{array}$ \\
\hline 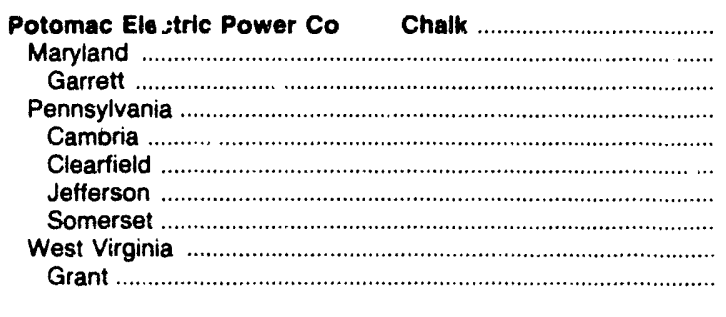 & $\begin{array}{r}1,615 \\
392 \\
392 \\
1,200 \\
417 \\
400 \\
7 \\
375 \\
23 \\
23\end{array}$ & $\begin{array}{l}12,535 \\
12,682 \\
12,682 \\
12,477 \\
12,345 \\
12,445 \\
12,378 \\
12,659 \\
13,044 \\
13,044\end{array}$ & $\begin{array}{l}1.83 \\
1.73 \\
1.73 \\
1.88 \\
1.97 \\
1.90 \\
1.61 \\
1.75 \\
1.53 \\
1.53\end{array}$ & $\begin{array}{r}12.26 \\
11.58 \\
11.58 \\
12.53 \\
12.67 \\
12.24 \\
11.50 \\
12.71 \\
9.98 \\
9.98\end{array}$ & $\begin{array}{l}172.8 \\
171.8 \\
171.8 \\
173.5 \\
174.3 \\
176.8 \\
167.4 \\
169.2 \\
156.2 \\
156.2\end{array}$ & $\begin{array}{l}43.33 \\
43.58 \\
43.58 \\
43.29 \\
43.05 \\
44.01 \\
41.44 \\
42.84 \\
40.75 \\
40.75\end{array}$ \\
\hline 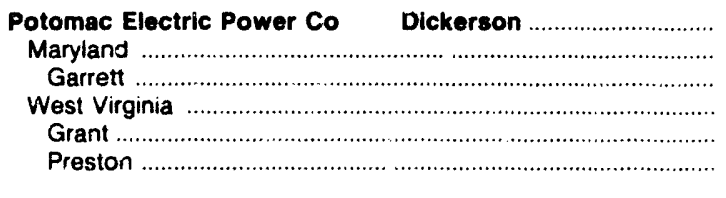 & $\begin{array}{r}1,212 \\
15 \\
15 \\
1,197 \\
116 \\
1.081\end{array}$ & $\begin{array}{l}12,752 \\
13,125 \\
13,125 \\
12,748 \\
13,121 \\
12,707\end{array}$ & $\begin{array}{l}1.43 \\
1.58 \\
1.58 \\
1.43 \\
1.45 \\
1.42\end{array}$ & $\begin{array}{r}10.04 \\
10.80 \\
10.80 \\
10.03 \\
9.44 \\
10.10\end{array}$ & $\begin{array}{l}143.2 \\
128.6 \\
128.6 \\
143.4 \\
121.5 \\
145.8\end{array}$ & $\begin{array}{l}36.52 \\
33.76 \\
33.76 \\
36.55 \\
31.85 \\
37.06\end{array}$ \\
\hline 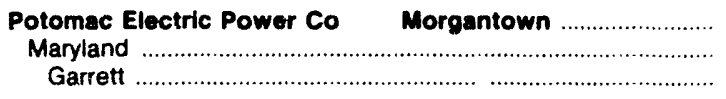 & $\begin{array}{r}2,165 \\
660 \\
660\end{array}$ & $\begin{array}{l}12,645 \\
12,803 \\
12,803\end{array}$ & $\begin{array}{l}1.77 \\
1.65 \\
1.65\end{array}$ & $\begin{array}{l}12.33 \\
11.51 \\
11.51\end{array}$ & $\begin{array}{l}171.4 \\
170.4 \\
170.4\end{array}$ & $\begin{array}{l}43.34 \\
43.64 \\
43.64\end{array}$ \\
\hline
\end{tabular}

See tootnotes at end of table.

Source: Federal Energy Regulatory Commission, FERC Form 423, "Monthly Report of Cost and Quality of Fuels for Electric Plants." 
Table 24. Origin of Coal Received by Electric Utility and Plant, 1992 (Continued)

\begin{tabular}{|c|c|c|c|c|c|c|}
\hline \multirow[b]{2}{*}{$\begin{array}{l}\text { Electric Utility Plant } \\
\text { Origin State } \\
\text { County }\end{array}$} & \multirow[b]{2}{*}{$\begin{array}{l}\text { Quantity } \\
\text { (thousand } \\
\text { short tons) }\end{array}$} & \multicolumn{3}{|c|}{ Average Quallty } & \multicolumn{2}{|c|}{ Average Delivered Cost } \\
\hline & & $\begin{array}{c}\text { Btu } \\
\text { (per pound) }\end{array}$ & $\begin{array}{l}\text { Sulfur } \\
\text { (percent } \\
\text { by wolght) }\end{array}$ & $\begin{array}{l}\text { Ash } \\
\text { (percent } \\
\text { by weight) }\end{array}$ & $\begin{array}{l}\text { (cents per } \\
\text { million Btu) }\end{array}$ & $\begin{array}{l}\text { (dollars per } \\
\text { short ton) }\end{array}$ \\
\hline 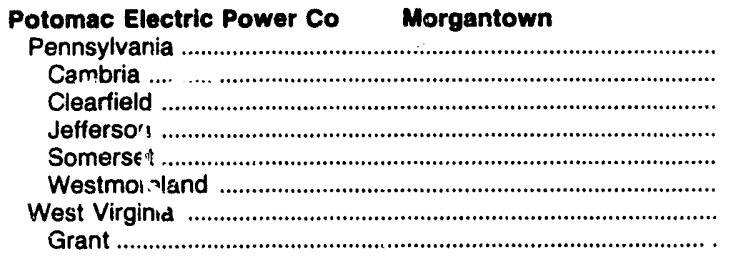 & $\begin{array}{r}1,441 \\
466 \\
433 \\
16 \\
511 \\
14 \\
64 \\
64\end{array}$ & $\begin{array}{l}12,553 \\
12,482 \\
12,504 \\
12,051 \\
12,670 \\
12,697 \\
13,101 \\
13,101\end{array}$ & $\begin{array}{l}1.83 \\
1.88 \\
1.86 \\
1.84 \\
1.76 \\
1.99 \\
1.52 \\
1.52\end{array}$ & $\begin{array}{r}12.81 \\
12.62 \\
12.87 \\
14.10 \\
13.00 \\
8.80 \\
9.88 \\
9.88\end{array}$ & $\begin{array}{l}172.4 \\
175.7 \\
177.3 \\
173.8 \\
165.5 \\
166.1 \\
159.5 \\
159.5\end{array}$ & $\begin{array}{l}43.28 \\
43.85 \\
44.33 \\
41.89 \\
41.93 \\
42.18 \\
41.80 \\
41.80\end{array}$ \\
\hline 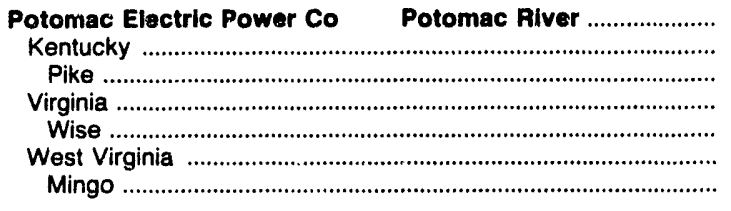 & $\begin{array}{l}784 \\
177 \\
177 \\
261 \\
261 \\
345 \\
345\end{array}$ & $\begin{array}{l}12,910 \\
12,777 \\
12,777 \\
12,965 \\
12,965 \\
12,937 \\
12,937\end{array}$ & $\begin{array}{l}.81 \\
.79 \\
.79 \\
.83 \\
.83 \\
.80 \\
.80\end{array}$ & $\begin{array}{l}7.80 \\
8.00 \\
8.00 \\
7.48 \\
7.48 \\
7.94 \\
7.94\end{array}$ & $\begin{array}{l}175.2 \\
175.3 \\
175.3 \\
181.1 \\
181.1 \\
170.8 \\
170.8\end{array}$ & $\begin{array}{l}45.25 \\
44.80 \\
44.80 \\
46.95 \\
46.95 \\
44.19 \\
44.19\end{array}$ \\
\hline 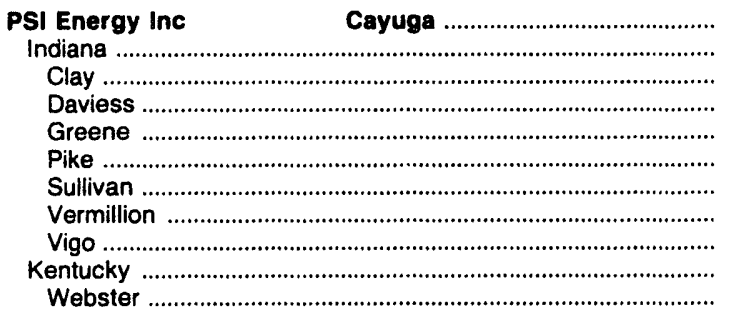 & $\begin{array}{r}2,863 \\
2,853 \\
53 \\
147 \\
122 \\
312 \\
1,982 \\
227 \\
9 \\
9 \\
9\end{array}$ & $\begin{array}{l}10,942 \\
10,938 \\
11,371 \\
11,110 \\
11,124 \\
11,143 \\
10,891 \\
10,749 \\
11,119 \\
12,022 \\
12,022\end{array}$ & $\begin{array}{l}2.01 \\
2.01 \\
2.10 \\
1.72 \\
2.15 \\
2.18 \\
1.99 \\
2.09 \\
1.95 \\
2.41 \\
2.41\end{array}$ & $\begin{array}{r}9.93 \\
9.92 \\
7.15 \\
8.38 \\
9.41 \\
9.22 \\
10.18 \\
10.62 \\
10.00 \\
10.00 \\
10.00\end{array}$ & $\begin{array}{l}123.9 \\
124.0 \\
110.8 \\
122.4 \\
121.0 \\
117.7 \\
127.5 \\
108.2 \\
119.2 \\
101.9 \\
101.9\end{array}$ & $\begin{array}{l}27.12 \\
27.13 \\
25.20 \\
27.19 \\
26.91 \\
26.24 \\
27.77 \\
23.27 \\
26.51 \\
24.50 \\
24.50\end{array}$ \\
\hline $\begin{array}{l}\text { PSI Energy Inc } \\
\text { Indiana } \\
\text { Daviess } \\
\text { Greene }\end{array}$ & $\begin{array}{r}71 \\
71 \\
70 \\
1\end{array}$ & $\begin{array}{l}11,197 \\
11,197 \\
11,193 \\
11,616\end{array}$ & $\begin{array}{l}2.45 \\
2.45 \\
2.44 \\
3.04\end{array}$ & $\begin{array}{l}9.45 \\
9.45 \\
9.48 \\
7.40\end{array}$ & $\begin{array}{l}96.4 \\
96.4 \\
96.6 \\
83.1\end{array}$ & $\begin{array}{l}21.59 \\
21.59 \\
21.61 \\
19.31\end{array}$ \\
\hline $\begin{array}{l}\text { PSI Energy Inc } \\
\text { Illinois ... Gallagher } \\
\text { Clinton } \\
\text { Indiana } \\
\text { Warrick } \\
\text { Kentucky } \\
\text { Bell } \\
\text { Daviess } \\
\text { Hopkins } \\
\text { Perry } \\
\text { Kanawha Virginia } \\
\text { Mingo }\end{array}$ & $\begin{array}{r}1,144 \\
51 \\
51 \\
827 \\
827 \\
120 \\
28 \\
27 \\
5 \\
59 \\
146 \\
8 \\
139\end{array}$ & $\begin{array}{l}11,240 \\
10,841 \\
10,841 \\
10,901 \\
10,901 \\
11,907 \\
12,502 \\
10,766 \\
11,469 \\
12,191 \\
12,744 \\
12,411 \\
12,763\end{array}$ & $\begin{array}{l}2.04 \\
3.41 \\
3.41 \\
2.26 \\
2.26 \\
1.49 \\
1.53 \\
2.27 \\
2.25 \\
1.03 \\
.77 \\
.70 \\
.78\end{array}$ & $\begin{array}{r}\mathbf{8 . 8 2} \\
7.97 \\
7.97 \\
8.78 \\
\mathbf{8 . 7 8} \\
9.48 \\
9.44 \\
10.29 \\
9.50 \\
9.12 \\
8.82 \\
13.06 \\
8.58\end{array}$ & $\begin{array}{l}137.2 \\
185.5 \\
185.5 \\
142.3 \\
142.3 \\
114.9 \\
106.5 \\
109.9 \\
112.0 \\
121.4 \\
115.4 \\
119.4 \\
115.2\end{array}$ & $\begin{array}{l}30.84 \\
40.21 \\
40.21 \\
31.01 \\
31.01 \\
27.37 \\
26.62 \\
23.66 \\
25.69 \\
29.59 \\
29.41 \\
29.64 \\
29.40\end{array}$ \\
\hline 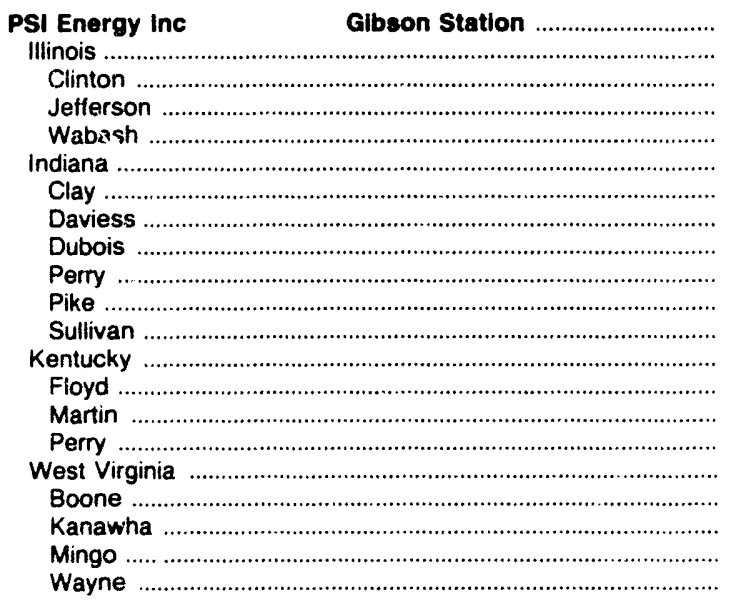 & $\begin{array}{r}8,297 \\
6,082 \\
3,031 \\
91 \\
2,960 \\
862 \\
145 \\
476 \\
6 \\
51 \\
53 \\
130 \\
217 \\
134 \\
25 \\
58 \\
1,136 \\
202 \\
377 \\
434 \\
123\end{array}$ & $\begin{array}{l}11,106 \\
10,761 \\
10,822 \\
12,206 \\
10,655 \\
11,435 \\
11,618 \\
11,535 \\
11,381 \\
11,243 \\
11,503 \\
10,912 \\
12,219 \\
12,211 \\
12,568 \\
12,090 \\
12,489 \\
12,434 \\
12,357 \\
12,766 \\
12,013\end{array}$ & $\begin{array}{r}2.01 \\
2.45 \\
3.46 \\
.81 \\
1.46 \\
.96 \\
.63 \\
.84 \\
1.00 \\
.89 \\
3.51 \\
.72 \\
.80 \\
.82 \\
.77 \\
.77 \\
.73 \\
.73 \\
.72 \\
.74 \\
.75\end{array}$ & $\begin{array}{r}10.14 \\
10.47 \\
8.10 \\
4.89 \\
13.07 \\
7.12 \\
6.44 \\
6.54 \\
8.30 \\
7.94 \\
7.90 \\
9.29 \\
11.06 \\
11.41 \\
7.74 \\
11.66 \\
10.49 \\
11.15 \\
12.27 \\
8.27 \\
11.79\end{array}$ & $\begin{array}{r}157.2 \\
169.2 \\
171.5 \\
119.9 \\
168.4 \\
116.3 \\
128.5 \\
114.5 \\
102.3 \\
118.2 \\
89.4 \\
119.8 \\
123.5 \\
123.9 \\
125.0 \\
121.9 \\
136.5 \\
130.1 \\
135.9 \\
141.3 \\
130.9\end{array}$ & $\begin{array}{l}34.91 \\
36.41 \\
37.13 \\
29.26 \\
35.89 \\
26.59 \\
29.85 \\
26.42 \\
23.29 \\
26.59 \\
20.57 \\
26.14 \\
30.18 \\
30.26 \\
31.42 \\
29.48 \\
34.09 \\
32.35 \\
33.60 \\
36.06 \\
31.46\end{array}$ \\
\hline
\end{tabular}

See footnotes at end of table.

Source: Federal Energy Regulatory Commission, FERC Form 423, "Monthly Report of Cost and Quality of Fuels for Electric Plants." 
Table 24. Origin of Coal Received by Electric Utility and Plant, 1992 (Continued)

\begin{tabular}{|c|c|c|c|c|c|c|}
\hline \multirow[b]{2}{*}{$\begin{array}{l}\text { Electric Utility Plant } \\
\text { Origin State } \\
\text { County }\end{array}$} & \multirow[b]{2}{*}{$\begin{array}{l}\text { Quantity } \\
\text { (thousand } \\
\text { short tons) }\end{array}$} & \multicolumn{3}{|c|}{ Average Quality } & \multicolumn{2}{|c|}{ Average Dellvered Cost } \\
\hline & & $\begin{array}{c}\text { Btu } \\
\text { (per pound) }\end{array}$ & $\begin{array}{l}\text { Sulfur } \\
\text { (percent } \\
\text { by weight) }\end{array}$ & $\begin{array}{l}\text { Ash } \\
\text { (percent } \\
\text { by weight) }\end{array}$ & $\begin{array}{l}\text { (cents per } \\
\text { million Btu) }\end{array}$ & $\begin{array}{l}\text { (dollars per } \\
\text { short ton) }\end{array}$ \\
\hline 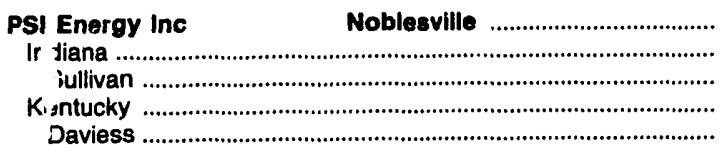 & $\begin{array}{l}29 \\
29 \\
29 \\
\vdots\end{array}$ & $\begin{array}{l}11,045 \\
11,041 \\
11,041 \\
11,402 \\
11,402\end{array}$ & $\begin{array}{l}2.37 \\
2.37 \\
2.37 \\
2.70 \\
2.70\end{array}$ & $\begin{array}{l}9.79 \\
9.81 \\
9.81 \\
7.80 \\
7.80\end{array}$ & $\begin{array}{r}145.1 \\
145.6 \\
145.6 \\
96.6 \\
96.6\end{array}$ & $\begin{array}{l}32.06 \\
32.16 \\
32.16 \\
22.03 \\
22.03\end{array}$ \\
\hline 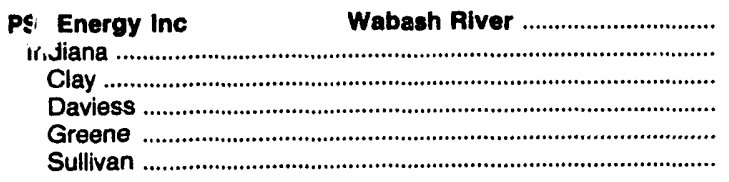 & $\begin{array}{r}1,430 \\
1,430 \\
35 \\
389 \\
169 \\
838\end{array}$ & $\begin{array}{l}11,036 \\
11,036 \\
11,354 \\
11,136 \\
11,312 \\
10,921\end{array}$ & $\begin{array}{l}2.00 \\
2.00 \\
2.08 \\
2.03 \\
2.04 \\
1.98\end{array}$ & $\begin{array}{l}9.33 \\
9.33 \\
6.92 \\
8.98 \\
8.00 \\
9.87\end{array}$ & $\begin{array}{l}117.2 \\
117.2 \\
107.7 \\
107.0 \\
112.4 \\
123.5\end{array}$ & $\begin{array}{l}25.87 \\
25.87 \\
24.46 \\
23.82 \\
25.42 \\
26.97\end{array}$ \\
\hline $\begin{array}{l}\text { Public Service Co of Colorado Araphoe } \\
\text { Colorado } \\
\text { Las Animas . } \\
\text { Routt . }\end{array}$ & $\begin{array}{r}462 \\
462 \\
11 \\
452\end{array}$ & $\begin{array}{l}11,225 \\
11,225 \\
12,817 \\
11,188\end{array}$ & $\begin{array}{l}.47 \\
.47 \\
.43 \\
.47\end{array}$ & $\begin{array}{r}9.10 \\
9.10 \\
11.18 \\
9.05\end{array}$ & $\begin{array}{l}113.8 \\
113.8 \\
101.0 \\
114.2\end{array}$ & $\begin{array}{l}25.55 \\
25.55 \\
25.89 \\
25.54\end{array}$ \\
\hline $\begin{array}{l}\text { Public Service Co of Colorado Cameo } \\
\text { Colorado } \\
\text { Mesa }\end{array}$ & $\begin{array}{l}246 \\
246 \\
246\end{array}$ & $\begin{array}{l}11,315 \\
11,315 \\
11,315\end{array}$ & $\begin{array}{l}.59 \\
.59 \\
.59\end{array}$ & $\begin{array}{l}8.76 \\
8.76 \\
8.76\end{array}$ & $\begin{array}{l}90.2 \\
90.2 \\
90.2\end{array}$ & $\begin{array}{l}20.41 \\
20.41 \\
20.41\end{array}$ \\
\hline $\begin{array}{l}\text { Public Service Co of Colorado Cherokee } \\
\text { Colorado } \\
\text { Motfat } \\
\text { Routt }\end{array}$ & $\begin{array}{r}1,935 \\
1,935 \\
313 \\
1,622\end{array}$ & $\begin{array}{l}11,097 \\
11,097 \\
10,498 \\
11,213\end{array}$ & $\begin{array}{l}.42 \\
.42 \\
.46 \\
.41\end{array}$ & $\begin{array}{l}9.44 \\
9.44 \\
8.34 \\
9.65\end{array}$ & $\begin{array}{l}108.2 \\
108.2 \\
110.3 \\
107.9\end{array}$ & $\begin{array}{l}24.02 \\
24.02 \\
23.15 \\
24.19\end{array}$ \\
\hline $\begin{array}{c}\text { Public Service Co of Colorado Comanche } \\
\text { Wyoming } \\
\text { Campbell }\end{array}$ & $\begin{array}{l}2,064 \\
2,064 \\
2,064\end{array}$ & $\begin{array}{l}8,519 \\
8,519 \\
8,519\end{array}$ & $\begin{array}{l}.30 \\
.30 \\
.30\end{array}$ & $\begin{array}{l}4.68 \\
4.68 \\
4.68\end{array}$ & $\begin{array}{l}112.7 \\
112.7 \\
112.7\end{array}$ & $\begin{array}{l}19.21 \\
19.21 \\
19.21\end{array}$ \\
\hline $\begin{array}{l}\text { Public Service Co of Colorado Hayden } \\
\text { Colorado } \\
\text { Routt }\end{array}$ & $\begin{array}{l}1,501 \\
1,501 \\
1,501\end{array}$ & $\begin{array}{l}10,639 \\
10,639 \\
10,639\end{array}$ & $\begin{array}{l}.40 \\
.40 \\
.40\end{array}$ & $\begin{array}{l}8.98 \\
8.98 \\
8.98\end{array}$ & $\begin{array}{l}91.9 \\
91.9 \\
91.9\end{array}$ & $\begin{array}{l}19.55 \\
19.55 \\
19.55\end{array}$ \\
\hline $\begin{array}{c}\text { Public Service Co of Colorado } \\
\text { Wyoming } \\
\text { Campbell }\end{array}$ & $\begin{array}{l}1,863 \\
1,863 \\
1,863\end{array}$ & $\begin{array}{l}8,266 \\
8,266 \\
8,266\end{array}$ & $\begin{array}{l}.36 \\
.36 \\
.36\end{array}$ & $\begin{array}{l}4.56 \\
4.56 \\
4.56\end{array}$ & $\begin{array}{l}104.8 \\
104.8 \\
104.8\end{array}$ & $\begin{array}{l}17.32 \\
17.32 \\
17.32\end{array}$ \\
\hline $\begin{array}{l}\text { Public Service Co of Colorado } \\
\text { Colorado } \\
\text { Las Animas } \\
\text { Routt }\end{array}$ & $\begin{array}{r}570 \\
570 \\
11 \\
559\end{array}$ & $\begin{array}{l}11,224 \\
11,224 \\
12,808 \\
11,193\end{array}$ & $\begin{array}{l}.50 \\
.50 \\
.43 \\
.50\end{array}$ & $\begin{array}{r}8.68 \\
8.68 \\
11.09 \\
8.64\end{array}$ & $\begin{array}{l}107.9 \\
107.9 \\
101.1 \\
108.1\end{array}$ & $\begin{array}{l}24.22 \\
24.22 \\
25.90 \\
24.19\end{array}$ \\
\hline 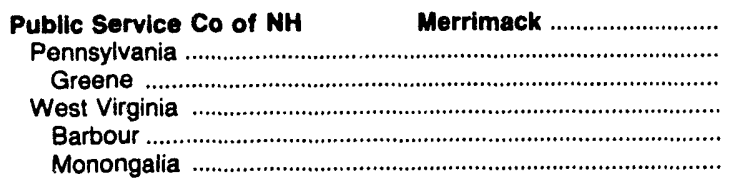 & $\begin{array}{r}1,003 \\
671 \\
671 \\
332 \\
20 \\
311\end{array}$ & $\begin{array}{l}13,316 \\
13,266 \\
13,266 \\
13,416 \\
13,470 \\
13,412\end{array}$ & $\begin{array}{l}1.80 \\
1.57 \\
1.57 \\
2.27 \\
2.18 \\
2.28\end{array}$ & $\begin{array}{l}6.51 \\
6.30 \\
6.30 \\
6.94 \\
7.55 \\
6.90\end{array}$ & $\begin{array}{l}168.1 \\
171.5 \\
171.5 \\
161.4 \\
161.5 \\
161.3\end{array}$ & $\begin{array}{l}44.77 \\
45.50 \\
45.50 \\
43.30 \\
43.51 \\
43.28\end{array}$ \\
\hline $\begin{array}{l}\text { Publle Service Co of } \mathrm{NH} \\
\text { Pennsylvania } \\
\text { Greene } \\
\text { West Virginia } \\
\text { Boone } \\
\text { Mingo } \\
\text { Imported } \\
\text { Imported Coal }\end{array}$ & $\begin{array}{r}223 \\
8 \\
8 \\
132 \\
117 \\
15 \\
83 \\
83\end{array}$ & $\begin{array}{l}13,010 \\
13,080 \\
13,080 \\
13,252 \\
13,253 \\
13,244 \\
12,616 \\
12,616\end{array}$ & $\begin{array}{r}.73 \\
1.46 \\
1.46 \\
.77 \\
.78 \\
.72 \\
.60 \\
.60\end{array}$ & $\begin{array}{l}6.56 \\
6.25 \\
6.25 \\
6.62 \\
6.68 \\
6.17 \\
6.50 \\
6.50\end{array}$ & $\begin{array}{l}170.3 \\
173.0 \\
173.0 \\
175.2 \\
175.8 \\
170.8 \\
161.8 \\
161.8\end{array}$ & $\begin{array}{l}44.31 \\
45.26 \\
45.26 \\
46.44 \\
46.59 \\
45.24 \\
40.83 \\
40.83\end{array}$ \\
\hline 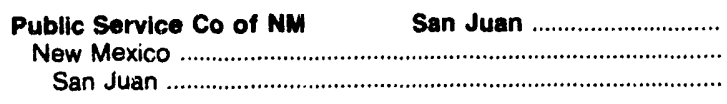 & $\begin{array}{l}5,105 \\
5,105 \\
5,105\end{array}$ & $\begin{array}{l}9,360 \\
9,360 \\
9,360\end{array}$ & $\begin{array}{l}.87 \\
.87 \\
.87\end{array}$ & $\begin{array}{l}23.78 \\
23.78 \\
23.78\end{array}$ & $\begin{array}{l}173.4 \\
173.4 \\
173.4\end{array}$ & $\begin{array}{l}32.46 \\
32.46 \\
32.46\end{array}$ \\
\hline $\begin{array}{l}\text { Public Service Co of Oklahoma Northeastern } \\
\text { Oklahoma } \\
\text { Craig }\end{array}$ & $\begin{array}{r}3,030 \\
60 \\
60\end{array}$ & $\begin{array}{r}8,762 \\
11,227 \\
11,227\end{array}$ & $\begin{array}{l}.45 \\
.46 \\
.46\end{array}$ & $\begin{array}{r}5.97 \\
10.94 \\
10.94\end{array}$ & $\begin{array}{l}161.1 \\
149.0 \\
149.0\end{array}$ & $\begin{array}{l}28.24 \\
33.46 \\
33.46\end{array}$ \\
\hline
\end{tabular}

See footnotes at end of table.

Source: Federal Energy Regulatory Commission, FERC Form 423, "Monthly Report of Cost and Quality of Fuels for Eleutric Plants." 
Table 24. Origin of Coal Received by Electric Utility and Plant, 1992 (Continued)

\begin{tabular}{|c|c|c|c|c|c|c|}
\hline \multirow{2}{*}{$\begin{array}{l}\text { Electric Utillty Plant } \\
\text { Origin State } \\
\text { County }\end{array}$} & \multirow{2}{*}{$\begin{array}{l}\text { Quantity } \\
\text { (thousand } \\
\text { short tons) }\end{array}$} & \multicolumn{3}{|c|}{ Average Quality } & \multicolumn{2}{|c|}{ Average Delivered Cost } \\
\hline & & $\begin{array}{c}\text { Btu } \\
\text { (per pound) }\end{array}$ & $\begin{array}{l}\text { Sulfur } \\
\text { (percent } \\
\text { by weight) }\end{array}$ & $\begin{array}{l}\text { Ash } \\
\text { (percent } \\
\text { by weight) }\end{array}$ & $\begin{array}{l}\text { (cents per } \\
\text { million Btu) }\end{array}$ & $\begin{array}{l}\text { (dollars per } \\
\text { short ton) }\end{array}$ \\
\hline 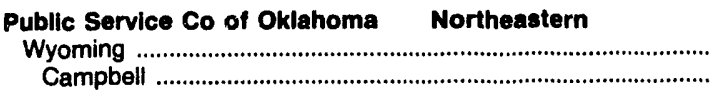 & $\begin{array}{l}2,970 \\
2,970\end{array}$ & $\begin{array}{l}8,712 \\
8,712\end{array}$ & $\begin{array}{r}0.45 \\
.45\end{array}$ & $\begin{array}{l}5.87 \\
5.87\end{array}$ & $\begin{array}{l}161.4 \\
161.4\end{array}$ & $\begin{array}{l}28.13 \\
28.13\end{array}$ \\
\hline $\begin{array}{l}\text { Public Service ElectriceGas Co Hudson } \\
\text { Kentucky } \\
\text { Letcher } \\
\text { Perry } \\
\text { Pike } \\
\text { West Virginia } \\
\text { Boone } \\
\text { Mingo } \\
\text { Randolph } \\
\text { Webster }\end{array}$ & $\begin{array}{r}569 \\
189 \\
7 \\
166 \\
16 \\
380 \\
124 \\
64 \\
16 \\
176\end{array}$ & $\begin{array}{l}13,111 \\
13,197 \\
12,677 \\
13,228 \\
13,102 \\
13,069 \\
13,034 \\
13,310 \\
13,044 \\
13,008\end{array}$ & $\begin{array}{l}.82 \\
.83 \\
.79 \\
.83 \\
.83 \\
.82 \\
.85 \\
.68 \\
.87 \\
.85\end{array}$ & $\begin{array}{l}7.12 \\
6.64 \\
6.90 \\
6.59 \\
6.97 \\
7.36 \\
7.07 \\
6.86 \\
7.90 \\
7.69\end{array}$ & $\begin{array}{l}176.5 \\
183.3 \\
195.4 \\
182.4 \\
187.8 \\
173.1 \\
176.4 \\
175.4 \\
181.0 \\
169.1\end{array}$ & $\begin{array}{l}46.28 \\
48.38 \\
49.54 \\
48.25 \\
49.20 \\
45.24 \\
45.98 \\
46.70 \\
47.22 \\
44.00\end{array}$ \\
\hline 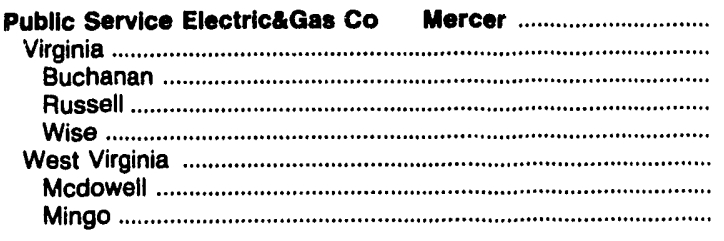 & $\begin{array}{r}841 \\
806 \\
791 \\
6 \\
8 \\
35 \\
35 \\
1\end{array}$ & $\begin{array}{l}14,172 \\
14,185 \\
14,195 \\
13,897 \\
13,477 \\
13,875 \\
13,886 \\
13,331\end{array}$ & $\begin{array}{l}.82 \\
.83 \\
.82 \\
.87 \\
.88 \\
.64 \\
.64 \\
.71\end{array}$ & $\begin{array}{l}4.46 \\
4.40 \\
4.38 \\
6.07 \\
5.20 \\
5.71 \\
5.69 \\
6.61\end{array}$ & $\begin{array}{l}175.7 \\
175.9 \\
175.8 \\
177.0 \\
185.2 \\
170.8 \\
170.9 \\
166.3\end{array}$ & $\begin{array}{l}49.80 \\
49.90 \\
49.91 \\
49.20 \\
49.92 \\
47.40 \\
47.46 \\
44.34\end{array}$ \\
\hline $\begin{array}{l}\text { Rlchmond Clty of } \\
\text { Indiana } \\
\text { Daviess . } \\
\text { Greene } \\
\text { Kentucky } \\
\text { Perry } \\
\text { Unknown } \\
\text { Ohio }\end{array}$ & $\begin{array}{r}293 \\
214 \\
146 \\
68 \\
60 \\
14 \\
46 \\
19 \\
19\end{array}$ & $\begin{array}{l}11,427 \\
11,307 \\
11,345 \\
11,228 \\
11,845 \\
12,035 \\
11,789 \\
11,458 \\
11,458\end{array}$ & $\begin{array}{r}2.02 \\
2.16 \\
2.27 \\
1.94 \\
1.28 \\
.83 \\
1.41 \\
2.82 \\
2.82\end{array}$ & $\begin{array}{r}9.04 \\
8.88 \\
8.67 \\
9.31 \\
9.36 \\
10.43 \\
9.04 \\
9.81 \\
9.81\end{array}$ & $\begin{array}{l}148.7 \\
157.3 \\
155.9 \\
160.1 \\
125.6 \\
124.6 \\
125.9 \\
128.6 \\
128.6\end{array}$ & $\begin{array}{l}33.99 \\
35.57 \\
35.38 \\
35.96 \\
29.76 \\
30.00 \\
29.69 \\
29.46 \\
29.46\end{array}$ \\
\hline 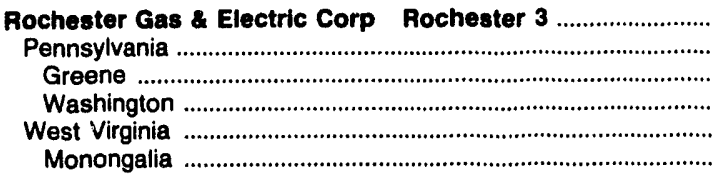 & $\begin{array}{r}202 \\
137 \\
117 \\
20 \\
65 \\
65\end{array}$ & $\begin{array}{l}13,281 \\
13,235 \\
13,214 \\
13,355 \\
13,377 \\
13,377\end{array}$ & $\begin{array}{l}2.04 \\
1.89 \\
1.80 \\
2.38 \\
2.36 \\
2.36\end{array}$ & $\begin{array}{l}6.57 \\
6.67 \\
6.64 \\
6.89 \\
6.34 \\
6.34\end{array}$ & $\begin{array}{l}148.7 \\
149.0 \\
151.6 \\
134.1 \\
148.0 \\
148.0\end{array}$ & $\begin{array}{l}39.49 \\
39.44 \\
40.08 \\
35.82 \\
39.60 \\
39.60\end{array}$ \\
\hline 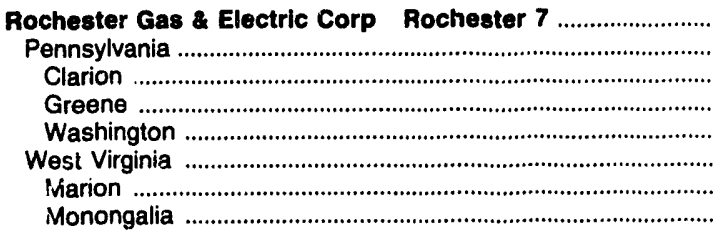 & $\begin{array}{r}639 \\
363 \\
8 \\
203 \\
151 \\
277 \\
42 \\
235\end{array}$ & $\begin{array}{l}13,304 \\
13,235 \\
12,862 \\
13,169 \\
13,343 \\
13,394 \\
13,507 \\
13,374\end{array}$ & $\begin{array}{l}2.13 \\
1.90 \\
1.84 \\
1.70 \\
2.18 \\
2.42 \\
2.69 \\
2.37\end{array}$ & $\begin{array}{l}6.76 \\
6.84 \\
8.00 \\
6.69 \\
6.99 \\
6.65 \\
7.52 \\
6.49\end{array}$ & $\begin{array}{l}144.7 \\
145.7 \\
138.5 \\
152.5 \\
137.0 \\
143.4 \\
134.9 \\
144.9\end{array}$ & $\begin{array}{l}3849 \\
38.56 \\
35.64 \\
40.17 \\
36.55 \\
38.41 \\
36.43 \\
38.76\end{array}$ \\
\hline 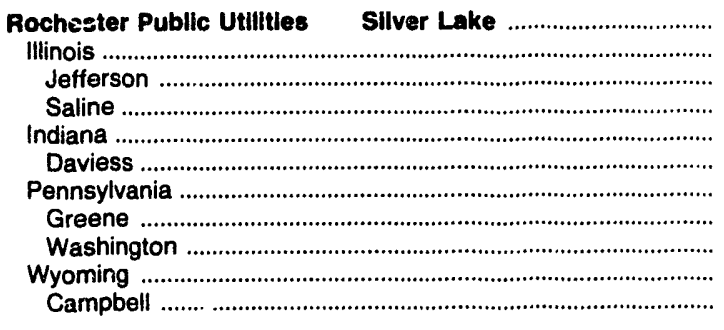 & $\begin{array}{r}80 \\
63 \\
3 \\
60 \\
\vdots \\
11 \\
5 \\
6 \\
6 \\
6\end{array}$ & $\begin{array}{r}11,885 \\
11,836 \\
12,019 \\
11,826 \\
9,940 \\
9,940 \\
13,351 \\
13,376 \\
13,330 \\
9,839 \\
9,839\end{array}$ & $\begin{array}{l}1.82 \\
1.84 \\
1.05 \\
1.88 \\
1.10 \\
1.10 \\
2.04 \\
1.60 \\
2.40 \\
1.26 \\
1.26\end{array}$ & $\begin{array}{r}8.27 \\
8.79 \\
5.34 \\
8.97 \\
11.70 \\
11.70 \\
6.92 \\
6.84 \\
6.99 \\
5.19 \\
5.19\end{array}$ & $\begin{array}{r}156.3 \\
162.0 \\
153.7 \\
162.4 \\
90.5 \\
90.5 \\
142.3 \\
145.6 \\
139.7 \\
121.7 \\
121.7\end{array}$ & $\begin{array}{l}37.16 \\
38.34 \\
36.95 \\
38.41 \\
17.99 \\
17.99 \\
38.00 \\
38.96 \\
37.24 \\
23.94 \\
23.94\end{array}$ \\
\hline $\begin{array}{l}\text { Salt River Prol Ag I \& P Dist Coronado } \\
\text { New Mexico } \\
\text { Mckinley }\end{array}$ & $\begin{array}{l}2,246 \\
2,246 \\
2,246\end{array}$ & $\begin{array}{l}9,915 \\
9,915 \\
9,915\end{array}$ & $\begin{array}{l}.45 \\
.45 \\
.45\end{array}$ & $\begin{array}{l}13.32 \\
13.32 \\
13.32\end{array}$ & $\begin{array}{l}200.9 \\
200.9 \\
200.9\end{array}$ & $\begin{array}{l}39.83 \\
39.83 \\
39.83\end{array}$ \\
\hline 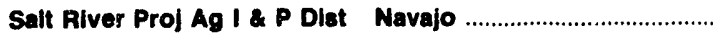 & 7,441 & 11,043 & .52 & 9.00 & 104.8 & 23.14 \\
\hline
\end{tabular}

See footnotes at end of table.

Source: Federal Energy Regulatory Commission, FERC Form 423, "Monthly Report of Cost and Quality of Fuels for Electric Plants." 
Table 24. Origin of Coal Received by Electric Utisity and Plant, 1992 (Continued)

\begin{tabular}{|c|c|c|c|c|c|c|}
\hline \multirow{2}{*}{$\begin{array}{l}\text { Electric Utility Plant } \\
\text { Origin State } \\
\text { County }\end{array}$} & \multirow{2}{*}{$\begin{array}{l}\text { Quantity } \\
\text { (thousand } \\
\text { short tons) }\end{array}$} & \multicolumn{3}{|c|}{ Average Quality } & \multicolumn{2}{|c|}{ Average Delivered Cost } \\
\hline & & $\begin{array}{c}\text { Btu } \\
\text { (per pound) }\end{array}$ & $\begin{array}{l}\text { Sulfur } \\
\text { (percent } \\
\text { by weight) }\end{array}$ & $\begin{array}{l}\text { Ash } \\
\text { (percent } \\
\text { by weight) }\end{array}$ & $\begin{array}{l}\text { (cents per } \\
\text { million Btu) }\end{array}$ & $\begin{array}{l}\text { (dollars per } \\
\text { short ton) }\end{array}$ \\
\hline Salt River Proj Ag I \& P Dist Navajo & & & & & & \\
\hline Arizona Navajo & $\begin{array}{l}7,441 \\
7,441\end{array}$ & $\begin{array}{l}11,043 \\
11,043\end{array}$ & $\begin{array}{r}0.52 \\
.52\end{array}$ & $\begin{array}{l}9.00 \\
9.00\end{array}$ & $\begin{array}{l}104.8 \\
104.8\end{array}$ & $\begin{array}{l}23.14 \\
23.14\end{array}$ \\
\hline 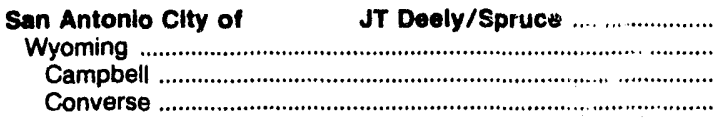 & $\begin{array}{r}3,543 \\
3,543 \\
2,826 \\
716\end{array}$ & $\begin{array}{l}8,489 \\
8,489 \\
8,406 \\
8,819\end{array}$ & $\begin{array}{l}.33 \\
.33 \\
.33 \\
.32\end{array}$ & $\begin{array}{l}5.43 \\
5.43 \\
5.43 \\
5.45\end{array}$ & $\begin{array}{l}127.9 \\
127.9 \\
130.4 \\
118.6\end{array}$ & $\begin{array}{l}21.72 \\
21.72 \\
21.93 \\
20.92\end{array}$ \\
\hline 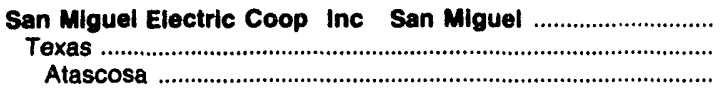 & $\begin{array}{l}2,930 \\
2,930 \\
2,930\end{array}$ & $\begin{array}{l}5,350 \\
5,350 \\
5,350\end{array}$ & $\begin{array}{l}1.98 \\
1.98 \\
1.98\end{array}$ & $\begin{array}{l}25.31 \\
25.31 \\
25.31\end{array}$ & $\begin{array}{l}96.6 \\
96.6 \\
96.6\end{array}$ & $\begin{array}{l}10.34 \\
10.34 \\
10.34\end{array}$ \\
\hline $\begin{array}{l}\text { Savannah Electric a Power Inc Kraft } \\
\text { Kentucky } \\
\text { Harian } \\
\begin{array}{l}\text { Virginia } \\
\text { Wise }\end{array}\end{array}$ & $\begin{array}{r}64 \\
3 \\
3 \\
61 \\
61\end{array}$ & $\begin{array}{l}12,371 \\
11,947 \\
11,947 \\
12,392 \\
12,392\end{array}$ & $\begin{array}{r}1.00 \\
1.36 \\
1.36 \\
.98 \\
.98\end{array}$ & $\begin{array}{l}12.04 \\
13.60 \\
13.60 \\
11.96 \\
11.96\end{array}$ & $\begin{array}{l}14 ? .4 \\
132.2 \\
132.2 \\
148.1 \\
148.1\end{array}$ & $\begin{array}{l}36.46 \\
31.59 \\
31.59 \\
36.71 \\
36.71\end{array}$ \\
\hline $\begin{array}{l}\text { Savannah Electric \& Power Inc Mcintosh } \\
\text { Kentucky } \\
\text { Harlan } \\
\text { Letcher } \\
\text { Perry }\end{array}$ & $\begin{array}{l}92 \\
92 \\
18 \\
38 \\
36\end{array}$ & $\begin{array}{l}12,341 \\
12,341 \\
12,616 \\
12,271 \\
12,278\end{array}$ & $\begin{array}{r}1.29 \\
1.29 \\
.99 \\
1.81 \\
.89\end{array}$ & $\begin{array}{r}9.98 \\
9.98 \\
8.30 \\
11.25 \\
9.47\end{array}$ & $\begin{array}{l}152.5 \\
152.5 \\
149.8 \\
153.6 \\
152.7\end{array}$ & $\begin{array}{l}37.64 \\
37.64 \\
37.80 \\
37.70 \\
37.49\end{array}$ \\
\hline $\begin{array}{l}\text { Seminole Electric Coop Inc } \\
\text { Illinois Seininole } \\
\text { Jefferson . } \\
\text { White } \\
\text { Kentucky } \\
\text { Breathitt } \\
\text { Clay } \\
\text { Harlan } \\
\text { Union }\end{array}$ & $\begin{array}{r}3,539 \\
1,622 \\
25 \\
1,597 \\
1,917 \\
77 \\
81 \\
345 \\
249 \\
1,165\end{array}$ & $\begin{array}{l}12,133 \\
11,640 \\
11,736 \\
11,639 \\
12,551 \\
12,572 \\
13,011 \\
12,736 \\
12,133 \\
12,551\end{array}$ & $\begin{array}{r}2.60 \\
2.75 \\
1.71 \\
2.76 \\
2.48 \\
.93 \\
1.00 \\
1.26 \\
2.99 \\
2.93\end{array}$ & $\begin{array}{l}8.28 \\
7.79 \\
7.90 \\
7.79 \\
8.69 \\
8.19 \\
8.40 \\
9.37 \\
8.42 \\
8.61\end{array}$ & $\begin{array}{l}194.3 \\
203.4 \\
153.2 \\
204.2 \\
107.2 \\
156.4 \\
154.2 \\
153.8 \\
159.2 \\
207.5\end{array}$ & $\begin{array}{l}47.16 \\
47.35 \\
35.96 \\
47.53 \\
47.00 \\
39.32 \\
40.14 \\
39.17 \\
38.64 \\
52.09\end{array}$ \\
\hline 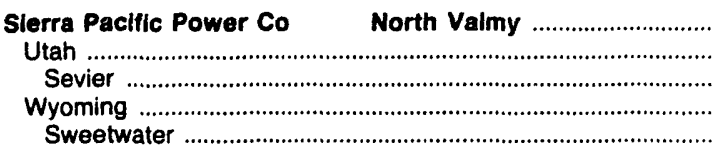 & $\begin{array}{r}1,545 \\
745 \\
745 \\
800 \\
800\end{array}$ & $\begin{array}{r}10,518 \\
11,370 \\
11,370 \\
9,724 \\
9,724\end{array}$ & $\begin{array}{l}.43 \\
.36 \\
.36 \\
.49 \\
.49\end{array}$ & $\begin{array}{l}8.28 \\
8.41 \\
8.41 \\
8.17 \\
8.17\end{array}$ & $\begin{array}{l}198.6 \\
197.1 \\
197.1 \\
200.2 \\
200.2\end{array}$ & $\begin{array}{l}41.77 \\
44.81 \\
44.81 \\
38.93 \\
38.93\end{array}$ \\
\hline 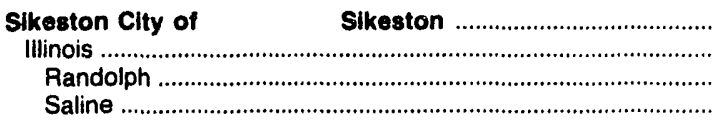 & $\begin{array}{r}587 \\
587 \\
22 \\
565\end{array}$ & $\begin{array}{l}11,735 \\
11,735 \\
10,758 \\
11,773\end{array}$ & $\begin{array}{l}2.49 \\
2.49 \\
3.19 \\
2.46\end{array}$ & $\begin{array}{r}10.03 \\
10.03 \\
12.36 \\
9.94\end{array}$ & $\begin{array}{r}150.7 \\
150.7 \\
92.1 \\
152.7\end{array}$ & $\begin{array}{l}35.36 \\
35.36 \\
19.82 \\
35.96\end{array}$ \\
\hline $\begin{array}{l}\text { South Carolina Electric\&Gas Co } \\
\text { Kentucky } \\
\text { Harlan } \\
\text { Leslie } \\
\text { Perry } \\
\text { Pike } \\
\text { Virginia } \\
\text { Dickenson }\end{array}$ & $\begin{array}{r}663 \\
562 \\
230 \\
254 \\
77 \\
101 \\
101\end{array}$ & $\begin{array}{l}12,819 \\
12,794 \\
12,867 \\
12,709 \\
12,948 \\
12,858 \\
12,955 \\
12,955\end{array}$ & $\begin{array}{r}1.31 \\
1.30 \\
1.30 \\
1.37 \\
.81 \\
1.12 \\
1.32 \\
1.32\end{array}$ & $\begin{array}{l}9.11 \\
9.03 \\
8.46 \\
9.32 \\
6.95 \\
9.74 \\
9.57 \\
9.57\end{array}$ & $\begin{array}{l}158.9 \\
158.6 \\
154.1 \\
165.5 \\
163.8 \\
149.6 \\
160.7 \\
160.7\end{array}$ & $\begin{array}{l}40.74 \\
40.58 \\
39.66 \\
42.07 \\
42.43 \\
38.46 \\
41.63 \\
41.63\end{array}$ \\
\hline $\begin{array}{l}\text { South Carolina ElectricesGas Co } \\
\text { Kentucky } \\
\text { Harlan } \\
\text { Leslie } \\
\text { Letcher } \\
\text { Perry } \\
\text { Pike } \\
\text { Virginia } \\
\text { Dickenson }\end{array}$ & $\begin{array}{r}615 \\
370 \\
103 \\
72 \\
\vdots \\
195 \\
245 \\
245\end{array}$ & $\begin{array}{l}12,870 \\
12,703 \\
12,773 \\
12,664 \\
12,692 \\
13,099 \\
12,681 \\
13,122 \\
13,122\end{array}$ & $\begin{array}{r}1.32 \\
1.24 \\
1.29 \\
1.37 \\
.73 \\
.81 \\
1.16 \\
1.43 \\
1.43\end{array}$ & $\begin{array}{r}9.36 \\
9.71 \\
8.49 \\
9.17 \\
7.80 \\
7.90 \\
10.55 \\
8.83 \\
8.83\end{array}$ & $\begin{array}{l}152.7 \\
151.6 \\
154.3 \\
163.5 \\
157.6 \\
165.1 \\
145.8 \\
154.2 \\
154.2\end{array}$ & $\begin{array}{l}39.30 \\
38.52 \\
39.42 \\
41.40 \\
40.08 \\
43.25 \\
36.98 \\
40.48 \\
40.48\end{array}$ \\
\hline South Carolina Electric\&Gas Co & 500 & 12,914 & 1.26 & 9.45 & 155.1 & 40.05 \\
\hline
\end{tabular}

See footnotes at end of table.

Source: Federal Energy Regulatory Commission, FERC Form 423, "Monthly Report of Cost and Quality of Fuels for Electric Plants." 
Table 24. Origin of Coal Received by Electric Utility and Plant, 1992 (Continued)

\begin{tabular}{|c|c|c|c|c|c|c|}
\hline \multirow{2}{*}{$\begin{array}{l}\text { Electric Utillty Plant } \\
\text { Origin State } \\
\text { County }\end{array}$} & \multirow{2}{*}{$\begin{array}{l}\text { Quantity } \\
\text { (thousand } \\
\text { short tons) }\end{array}$} & \multicolumn{3}{|c|}{ Average Quality } & \multicolumn{2}{|c|}{ Average Delivered Cost } \\
\hline & & $\begin{array}{c}\text { Btu } \\
\text { (per pound) }\end{array}$ & $\begin{array}{l}\text { Sulfur } \\
\text { (percent } \\
\text { by welght) }\end{array}$ & $\begin{array}{l}\text { Ash } \\
\text { (percent } \\
\text { by weight) }\end{array}$ & $\begin{array}{l}\text { (cents per } \\
\text { million Btu) }\end{array}$ & $\begin{array}{l}\text { (dollars per } \\
\text { short ton) }\end{array}$ \\
\hline 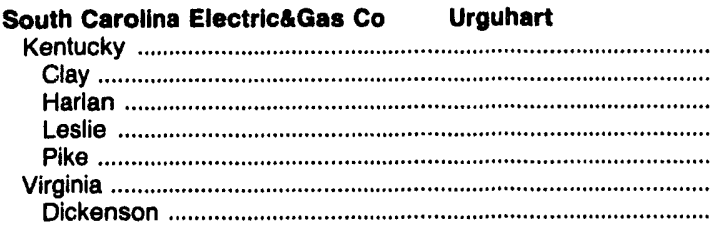 & $\begin{array}{r}335 \\
21 \\
65 \\
64 \\
184 \\
165 \\
165\end{array}$ & $\begin{array}{l}12,843 \\
13,245 \\
12,886 \\
12,776 \\
12,805 \\
13,058 \\
13,058\end{array}$ & $\begin{array}{l}1.27 \\
1.43 \\
1.29 \\
1.38 \\
1.20 \\
1.26 \\
1.26\end{array}$ & $\begin{array}{r}9.50 \\
8.50 \\
8.41 \\
9.03 \\
10.17 \\
9.34 \\
9.34\end{array}$ & $\begin{array}{l}154.3 \\
164.4 \\
154.6 \\
163.5 \\
149.8 \\
156.6 \\
156.6\end{array}$ & $\begin{array}{l}39.63 \\
43.55 \\
39.84 \\
41.78 \\
38.35 \\
40.91 \\
40.91\end{array}$ \\
\hline $\begin{array}{l}\text { South Carolina Electric\&Gas Co } \\
\text { Kentucky } \\
\text { Harlan } \\
\text { Leslie } \\
\text { Letcher } \\
\text { Perry } \\
\text { Pike } \\
\text { Virginia } \\
\text { Dickenson } \\
\text { Wise }\end{array}$ & $\begin{array}{r}1,403 \\
1,092 \\
150 \\
14 \\
35 \\
491 \\
400 \\
312 \\
7 \\
304\end{array}$ & $\begin{array}{l}12,912 \\
12,895 \\
12,798 \\
12,704 \\
12,675 \\
13,107 \\
12,698 \\
12,970 \\
12,727 \\
12,976\end{array}$ & $\begin{array}{r}1.06 \\
.99 \\
1.18 \\
1.33 \\
.80 \\
.84 \\
1.10 \\
1.34 \\
1.31 \\
1.34\end{array}$ & $\begin{array}{r}8.54 \\
8.33 \\
8.68 \\
9.80 \\
8.05 \\
6.92 \\
9.90 \\
9.28 \\
11.10 \\
9.23\end{array}$ & $\begin{array}{l}156.5 \\
158.2 \\
157.1 \\
164.8 \\
158.8 \\
165.8 \\
148.7 \\
150.6 \\
154.8 \\
150.5\end{array}$ & $\begin{array}{l}40.42 \\
40.81 \\
40.20 \\
41.87 \\
40.26 \\
43.47 \\
37.78 \\
39.07 \\
39.40 \\
39.06\end{array}$ \\
\hline $\begin{array}{l}\text { South Carolina ElectriceGas Co } \\
\text { Kentucky } \\
\text { Letcher } \\
\text { Perry } \\
\text { Pike }\end{array}$ & $\begin{array}{r}1,041 \\
1,041 \\
17 \\
871 \\
152\end{array}$ & $\begin{array}{l}12,875 \\
12,875 \\
12,869 \\
12,904 \\
12,712\end{array}$ & $\begin{array}{l}.82 \\
.82 \\
.82 \\
.82 \\
.87\end{array}$ & $\begin{array}{l}7.39 \\
7.39 \\
7.50 \\
7.25 \\
8.21\end{array}$ & $\begin{array}{l}162.7 \\
162.7 \\
159.8 \\
164.0 \\
155.8\end{array}$ & $\begin{array}{l}41.90 \\
41.90 \\
41.13 \\
42.32 \\
39.62\end{array}$ \\
\hline $\begin{array}{l}\text { South Carolina Pub Serv Auth } \\
\text { Kentucky } \\
\text { Breathitt } \\
\text { Harlan } \\
\text { Leslie }\end{array}$ & $\begin{array}{r}1,343 \\
1,343 \\
27 \\
715 \\
582 \\
19\end{array}$ & $\begin{array}{l}12,730 \\
12,730 \\
11,579 \\
12,659 \\
12,862 \\
12,981\end{array}$ & $\begin{array}{r}1.08 \\
1.08 \\
1.31 \\
1.15 \\
.98 \\
1.20\end{array}$ & $\begin{array}{r}8.80 \\
8.80 \\
13.27 \\
8.85 \\
8.58 \\
7.22\end{array}$ & $\begin{array}{l}144.7 \\
144.7 \\
118.7 \\
150.8 \\
138.8 \\
134.1\end{array}$ & $\begin{array}{l}36.85 \\
36.85 \\
27.48 \\
38.18 \\
35.71 \\
34.82\end{array}$ \\
\hline $\begin{array}{l}\text { South Carolina Pub Serv Auth } \\
\text { Kentucky } \\
\text { Breathitt } \\
\text { Pike }\end{array}$ & $\begin{array}{r}99 \\
99 \\
7 \\
92\end{array}$ & $\begin{array}{l}12,923 \\
12,923 \\
11,620 \\
13,025\end{array}$ & $\begin{array}{l}1.85 \\
1.85 \\
1.03 \\
1.91\end{array}$ & $\begin{array}{l}10.84 \\
10.84 \\
14.62 \\
10.54\end{array}$ & $\begin{array}{l}155.0 \\
155.0 \\
148.3 \\
155.4\end{array}$ & $\begin{array}{l}40.05 \\
40.05 \\
34.47 \\
40.49\end{array}$ \\
\hline $\begin{array}{l}\text { South Carollna Pub Serv Auth } \\
\text { Kentucky } \\
\text { Harlan }\end{array}$ & $\begin{array}{r}597 \\
597 \\
35 \\
206 \\
357\end{array}$ & $\begin{array}{l}12,591 \\
12,591 \\
12,529 \\
12,225 \\
12,807\end{array}$ & $\begin{array}{l}1.67 \\
1.67 \\
1.40 \\
1.69 \\
1.68\end{array}$ & $\begin{array}{r}9.36 \\
9.36 \\
10.47 \\
10.85 \\
8.39\end{array}$ & $\begin{array}{l}143.5 \\
143.5 \\
134.1 \\
152.5 \\
139.5\end{array}$ & $\begin{array}{l}36.14 \\
36.14 \\
33.59 \\
37.28 \\
35.73\end{array}$ \\
\hline 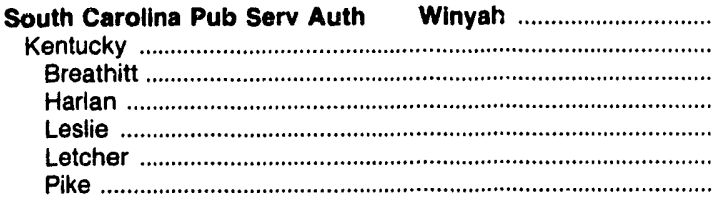 & $\begin{array}{r}2,505 \\
2,505 \\
17 \\
1,776 \\
577 \\
134 \\
1\end{array}$ & $\begin{array}{l}12,889 \\
12,889 \\
12,028 \\
12,976 \\
12,592 \\
13,138 \\
12,519\end{array}$ & $\begin{array}{l}1.13 \\
1.13 \\
1.14 \\
1.14 \\
1.08 \\
1.23 \\
1.23\end{array}$ & $\begin{array}{r}8.80 \\
8.80 \\
12.76 \\
8.37 \\
10.28 \\
7.53 \\
9.67\end{array}$ & $\begin{array}{l}148.2 \\
148.2 \\
117.6 \\
149.7 \\
147.7 \\
135.6 \\
150.8\end{array}$ & $\begin{array}{l}38.22 \\
38.22 \\
28.30 \\
38.84 \\
37.19 \\
35.64 \\
37.75\end{array}$ \\
\hline $\begin{array}{c}\text { South Mississippi El Pwr Assn } \\
\text { Kentucky }\end{array}$ & $\begin{array}{l}757 \\
757 \\
757\end{array}$ & $\begin{array}{l}12,370 \\
12,370 \\
12,370\end{array}$ & $\begin{array}{l}.99 \\
.99 \\
.99\end{array}$ & $\begin{array}{l}9.58 \\
9.58 \\
9.58\end{array}$ & $\begin{array}{l}205.3 \\
205.3 \\
205.3\end{array}$ & $\begin{array}{l}50.80 \\
50.80 \\
50.80\end{array}$ \\
\hline $\begin{array}{l}\text { Southern Callfornia Edison Co Mohave } \\
\text { Arizona } \\
\text { Navajo }\end{array}$ & $\begin{array}{l}4,977 \\
4,977 \\
4,977\end{array}$ & $\begin{array}{l}10,940 \\
10,940 \\
10,940\end{array}$ & $\begin{array}{l}.51 \\
.51 \\
.51\end{array}$ & $\begin{array}{l}10.25 \\
10.25 \\
10.25\end{array}$ & $\begin{array}{l}118.8 \\
118.8 \\
118.8\end{array}$ & $\begin{array}{l}25.99 \\
25.99 \\
25.99\end{array}$ \\
\hline 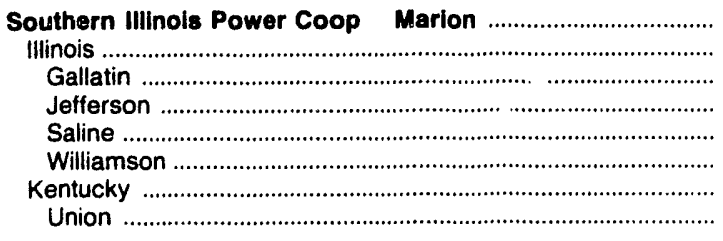 & $\begin{array}{r}490 \\
451 \\
93 \\
38 \\
9 \\
311 \\
39 \\
39\end{array}$ & $\begin{array}{r}10,549 \\
10,532 \\
10,892 \\
8,318 \\
9,075 \\
10,737 \\
10,744 \\
10,744\end{array}$ & $\begin{array}{l}2.79 \\
2.84 \\
3.82 \\
2.07 \\
2.35 \\
2.65 \\
2.24 \\
2.24\end{array}$ & $\begin{array}{l}16.54 \\
17.04 \\
18.40 \\
25.35 \\
22.33 \\
15.46 \\
10.84 \\
10.84\end{array}$ & $\begin{array}{l}91.1 \\
92.9 \\
88.6 \\
51.5 \\
56.4 \\
99.0 \\
70.7 \\
70.7\end{array}$ & $\begin{array}{r}19.21 \\
19.56 \\
19.30 \\
8.57 \\
10.23 \\
21.25 \\
15.18 \\
15.18\end{array}$ \\
\hline Southern Indiana Gas \& Elec Co A B Brown ......................... & 1,123 & 11,554 & 3.53 & 8.18 & 156.8 & 36.23 \\
\hline
\end{tabular}

See footnotes at end of table.

Source: Federal Energy Regulatory Commission, FERC Form 423, "Monthly Report of Cost and Quality of Fuels for Electric Plants." 
Table 24. Origin of Coal Received by Electric Utility and Plant, 1992 (Continued)

\begin{tabular}{|c|c|c|c|c|c|c|}
\hline \multirow[b]{2}{*}{$\begin{array}{l}\text { Electric Utility Plant } \\
\text { Origin State } \\
\text { County }\end{array}$} & \multirow[b]{2}{*}{$\begin{array}{l}\text { Quantity } \\
\text { (thousand } \\
\text { short tons) }\end{array}$} & \multicolumn{3}{|c|}{ Average Quality } & \multicolumn{2}{|c|}{ Average Delivered Cost } \\
\hline & & $\begin{array}{c}\text { Btu } \\
\text { (per pound) }\end{array}$ & $\begin{array}{l}\text { Sulfur } \\
\text { (percent } \\
\text { by weight) }\end{array}$ & $\begin{array}{l}\text { Ash } \\
\text { (percent } \\
\text { by welght) }\end{array}$ & $\begin{array}{l}\text { (cents per } \\
\text { million Btu) }\end{array}$ & $\begin{array}{l}\text { (dollars per } \\
\text { short ton) }\end{array}$ \\
\hline $\begin{array}{l}\text { Southern Indiana Gas \& Elec Co A B Brown } \\
\text { Indiana } \\
\text { Clay }\end{array}$ & $\begin{array}{r}1,123 \\
100 \\
1,023\end{array}$ & $\begin{array}{l}11,554 \\
11,069 \\
11,602\end{array}$ & $\begin{array}{l}3.53 \\
3.82 \\
3.50\end{array}$ & $\begin{array}{r}8.18 \\
10.00 \\
8.00\end{array}$ & $\begin{array}{l}156.8 \\
101.6 \\
161.9\end{array}$ & $\begin{array}{l}36.23 \\
22.49 \\
37.57\end{array}$ \\
\hline 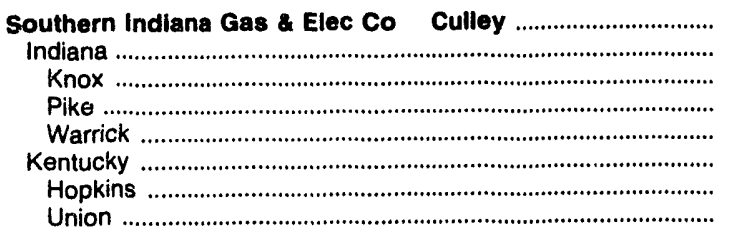 & $\begin{array}{r}1,097 \\
958 \\
270 \\
38 \\
650 \\
140 \\
120 \\
20\end{array}$ & $\begin{array}{l}11,113 \\
10,929 \\
10,895 \\
11,123 \\
10,932 \\
12,378 \\
12,348 \\
12,562\end{array}$ & $\begin{array}{l}2.23 \\
2.35 \\
1.79 \\
1.37 \\
2.34 \\
1.47 \\
1.46 \\
1.49\end{array}$ & $\begin{array}{r}6.83 \\
9.48 \\
10.16 \\
8.35 \\
9.26 \\
4.38 \\
3.79 \\
7.97\end{array}$ & $\begin{array}{l}134.5 \\
134.7 \\
134.4 \\
138.1 \\
134.6 \\
133.0 \\
132.7 \\
134.6\end{array}$ & $\begin{array}{l}29.89 \\
29.44 \\
29.28 \\
30.72 \\
29.44 \\
32.92 \\
32.78 \\
33.81\end{array}$ \\
\hline $\begin{array}{l}\text { Southern Indiana Gas \& Elec Co Warrick } \\
\text { Indiana } \\
\text { Gibson } \\
\text { Pike } \\
\text { Warrick } \\
\text { Kentucky } \\
\text { Henderson }\end{array}$ & $\begin{array}{r}475 \\
422 \\
22 \\
85 \\
315 \\
53 \\
53\end{array}$ & $\begin{array}{l}11,132 \\
11,109 \\
11,077 \\
11,451 \\
11,019 \\
11,315 \\
11,315\end{array}$ & $\begin{array}{l}2.47 \\
2.45 \\
2.47 \\
2.61 \\
2.41 \\
2.60 \\
2.60\end{array}$ & $\begin{array}{r}8.64 \\
8.75 \\
10.10 \\
8.36 \\
8.77 \\
7.71 \\
7.71\end{array}$ & $\begin{array}{r}115.4 \\
116.7 \\
94.3 \\
101.9 \\
122.4 \\
103.2 \\
103.2\end{array}$ & $\begin{array}{l}25.63 \\
25.92 \\
20.90 \\
23.33 \\
26.97 \\
23.35 \\
23.35\end{array}$ \\
\hline 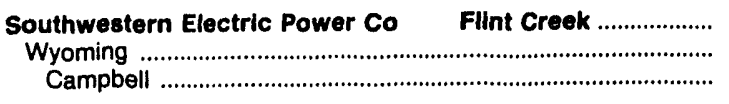 & $\begin{array}{l}1,663 \\
1,663 \\
1,663\end{array}$ & $\begin{array}{l}8,347 \\
8,347 \\
8,347\end{array}$ & $\begin{array}{l}.34 \\
.34 \\
.34\end{array}$ & $\begin{array}{l}4.66 \\
4.66 \\
4.66\end{array}$ & $\begin{array}{l}155.1 \\
155.1 \\
155.1\end{array}$ & $\begin{array}{l}25.89 \\
25.89 \\
25.89\end{array}$ \\
\hline 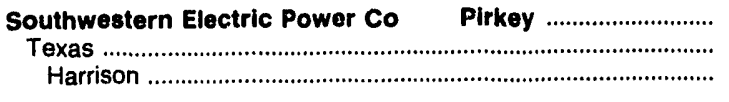 & $\begin{array}{l}2,817 \\
2,817 \\
2,817\end{array}$ & $\begin{array}{l}6,766 \\
6,766 \\
6,766\end{array}$ & $\begin{array}{l}1.33 \\
1.33 \\
1.33\end{array}$ & $\begin{array}{l}12.08 \\
12.08 \\
12.08\end{array}$ & $\begin{array}{l}127.6 \\
127.6 \\
127.6\end{array}$ & $\begin{array}{l}17.26 \\
17.26 \\
17.26\end{array}$ \\
\hline 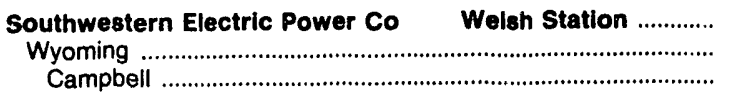 & $\begin{array}{l}4,980 \\
4,980 \\
4,980\end{array}$ & $\begin{array}{l}8,339 \\
8,339 \\
8,339\end{array}$ & $\begin{array}{l}.35 \\
.35 \\
.35\end{array}$ & $\begin{array}{l}4.63 \\
4.63 \\
4.63\end{array}$ & $\begin{array}{l}196.3 \\
196.3 \\
196.3\end{array}$ & $\begin{array}{l}32.74 \\
32.74 \\
32.74\end{array}$ \\
\hline 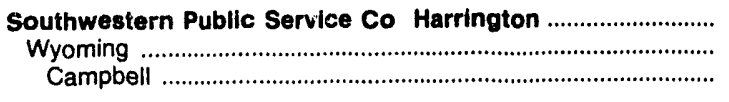 & $\begin{array}{l}4,301 \\
4,301 \\
4,301\end{array}$ & $\begin{array}{l}8,761 \\
8,761 \\
8,761\end{array}$ & $\begin{array}{l}.32 \\
.32 \\
.32\end{array}$ & $\begin{array}{l}4.88 \\
4.88 \\
4.88\end{array}$ & $\begin{array}{l}156.6 \\
156.6 \\
156.6\end{array}$ & $\begin{array}{l}27.44 \\
27.44 \\
27.44\end{array}$ \\
\hline $\begin{array}{c}\text { Southwestern Public Service Co Tolk } \\
\text { Wyoming } \\
\text { Campbell }\end{array}$ & $\begin{array}{l}3,967 \\
3,967 \\
3,967\end{array}$ & $\begin{array}{l}8,759 \\
8,759 \\
8,759\end{array}$ & $\begin{array}{l}.34 \\
.34 \\
.34\end{array}$ & $\begin{array}{l}4.89 \\
4.89 \\
4.89\end{array}$ & $\begin{array}{l}191.3 \\
191.3 \\
191.3\end{array}$ & $\begin{array}{l}33.52 \\
33.52 \\
33.52\end{array}$ \\
\hline 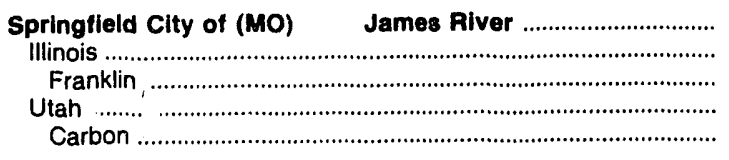 & $\begin{array}{r}271 \\
230 \\
230 \\
41 \\
41\end{array}$ & $\begin{array}{l}11,599 \\
11,574 \\
11,574 \\
11,737 \\
11,737\end{array}$ & $\begin{array}{r}1.74 \\
1.98 \\
1.98 \\
.40 \\
.40\end{array}$ & $\begin{array}{l}7.92 \\
7.91 \\
7.91 \\
8.00 \\
8.00\end{array}$ & $\begin{array}{l}134.4 \\
132.9 \\
132.9 \\
142.5 \\
142.5\end{array}$ & $\begin{array}{l}31.18 \\
30.77 \\
30.77 \\
33.44 \\
33.44\end{array}$ \\
\hline 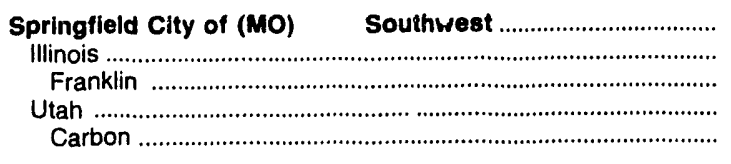 & $\begin{array}{r}477 \\
466 \\
466 \\
11 \\
11\end{array}$ & $\begin{array}{l}11,629 \\
11,621 \\
11,621 \\
11,987 \\
11,987\end{array}$ & $\begin{array}{r}2.09 \\
2.12 \\
2.12 \\
.38 \\
.38\end{array}$ & $\begin{array}{r}8.02 \\
8.02 \\
02 \\
7.210 \\
7.90\end{array}$ & $\begin{array}{l}132.1 \\
132.0 \\
132.0 \\
139.5 \\
139.5\end{array}$ & $\begin{array}{l}30.74 \\
30.67 \\
30.67 \\
33.44 \\
33.44\end{array}$ \\
\hline 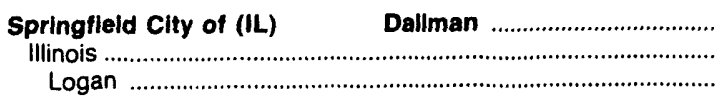 & $\begin{array}{l}827 \\
827 \\
827\end{array}$ & $\begin{array}{l}10,382 \\
10,382 \\
10,382\end{array}$ & $\begin{array}{l}3.04 \\
3.04 \\
3.04\end{array}$ & $\begin{array}{l}9.37 \\
9.37 \\
9.37\end{array}$ & $\begin{array}{l}113.1 \\
113.1 \\
113.1\end{array}$ & $\begin{array}{l}23.48 \\
23.48 \\
23.48\end{array}$ \\
\hline $\begin{array}{c}\text { Springfleid Clty of (IL) } \\
\text { Illinois } \\
\text { Logan }\end{array}$ & $\begin{array}{l}106 \\
106 \\
106\end{array}$ & $\begin{array}{l}10,383 \\
10,383 \\
10,383\end{array}$ & $\begin{array}{l}3.03 \\
3.03 \\
3.03\end{array}$ & $\begin{array}{l}9.33 \\
9.33 \\
9.33\end{array}$ & $\begin{array}{l}113.3 \\
113.3 \\
113.3\end{array}$ & $\begin{array}{l}23.53 \\
23.53 \\
23.53\end{array}$ \\
\hline 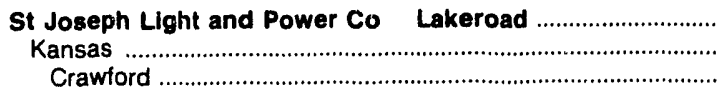 & $\begin{array}{l}135 \\
135 \\
135\end{array}$ & $\begin{array}{l}11,976 \\
11,976 \\
11,976\end{array}$ & $\begin{array}{l}3.72 \\
3.72 \\
3.72\end{array}$ & $\begin{array}{l}12.10 \\
12.10 \\
12.10\end{array}$ & $\begin{array}{l}139.2 \\
139.2 \\
139.2\end{array}$ & $\begin{array}{l}33.35 \\
33.35 \\
33.35\end{array}$ \\
\hline 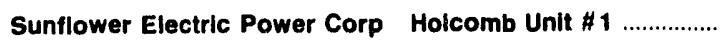 & 1,257 & 8,492 & .38 & 5.11 & 105.3 & 17.88 \\
\hline
\end{tabular}

See footnotes at end of table.

Source: Federal Energy Regulatory Commission, FERC Form 423, "Monthly Report of Cost and Quality of Fuels for Electric Plants." 
Table 24. Origin of Coal Recelved by Electrlc Utility and Plant, 1992 (Continued)

\begin{tabular}{|c|c|c|c|c|c|c|}
\hline \multirow[b]{2}{*}{$\begin{array}{l}\text { Electric Utility Plant } \\
\text { Origin State } \\
\text { County }\end{array}$} & \multirow[b]{2}{*}{$\begin{array}{l}\text { Quantity } \\
\text { (thousand } \\
\text { short tons) }\end{array}$} & \multicolumn{3}{|c|}{ Average Quality } & \multicolumn{2}{|c|}{ Average Dellvered Cost } \\
\hline & & $\begin{array}{c}\text { Btu } \\
\text { (por pound) }\end{array}$ & $\begin{array}{l}\text { Sulfur } \\
\text { (porcent } \\
\text { by woight) }\end{array}$ & $\begin{array}{l}\text { Ash } \\
\text { (percent } \\
\text { by woight) }\end{array}$ & $\begin{array}{l}\text { (cents per } \\
\text { million Btu) }\end{array}$ & $\begin{array}{l}\text { (dollars per } \\
\text { short ton) }\end{array}$ \\
\hline 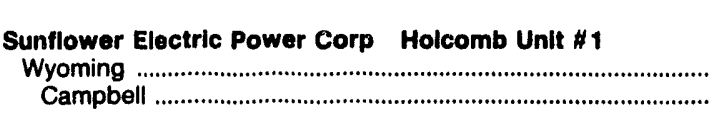 & $\begin{array}{l}1,257 \\
1,257\end{array}$ & $\begin{array}{l}8,492 \\
8,492\end{array}$ & $\begin{array}{r}0.38 \\
.38\end{array}$ & $\begin{array}{l}5.11 \\
5.11\end{array}$ & $\begin{array}{l}105.3 \\
105.3\end{array}$ & $\begin{array}{l}17.88 \\
17.88\end{array}$ \\
\hline $\begin{array}{l}\text { Tacoma Dept of Public Utilitles Steam No. } 2 \\
\text { Montana } \\
\text { Big Horn } \\
\text { Washington } \\
\text { King } \\
\text { Wyoming } \\
\text { Imported }\end{array}$ & $\begin{array}{r}24 \\
4 \\
4 \\
2 \\
2 \\
2 \\
2 \\
15 \\
15\end{array}$ & $\begin{array}{r}10,043 \\
9,492 \\
9,492 \\
12,366 \\
12,366 \\
8,846 \\
8,846 \\
9,993 \\
9,993\end{array}$ & $\begin{array}{l}.43 \\
.40 \\
.40 \\
.72 \\
.72 \\
.22 \\
.22 \\
.42 \\
.42\end{array}$ & $\begin{array}{r}10.87 \\
4.25 \\
4.25 \\
14.03 \\
14.03 \\
4.67 \\
4.67 \\
12.95 \\
12.95\end{array}$ & $\begin{array}{l}197.5 \\
169.0 \\
169.0 \\
154.5 \\
154.5 \\
181.0 \\
181.0 \\
214.7 \\
214.7\end{array}$ & $\begin{array}{l}39.67 \\
32.08 \\
32.08 \\
38.21 \\
38.21 \\
32.02 \\
32.02 \\
42.90 \\
42.90^{2}\end{array}$ \\
\hline 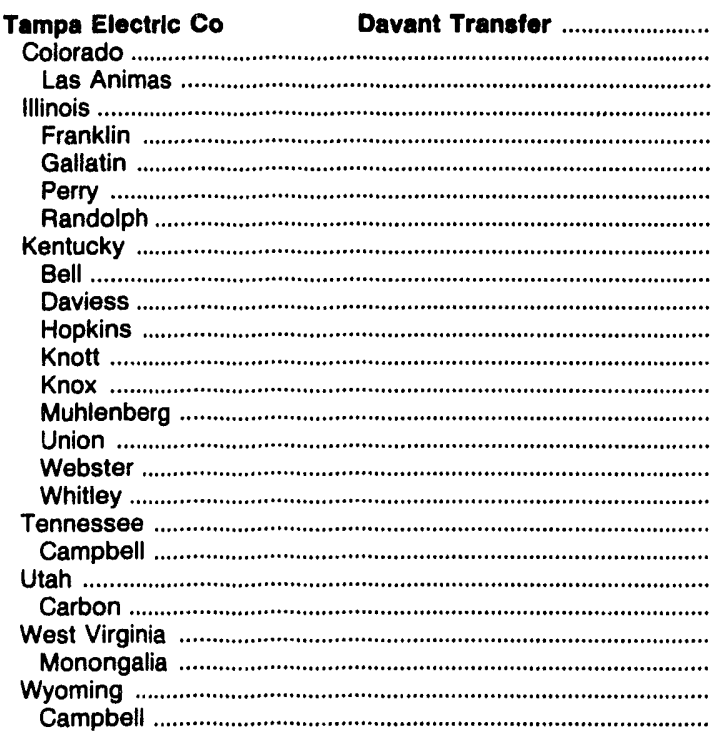 & $\begin{array}{r}5,528 \\
181 \\
181 \\
1,224 \\
48 \\
126 \\
1,018 \\
33 \\
3,359 \\
51 \\
90 \\
104 \\
19 \\
7 \\
488 \\
1,056 \\
516 \\
1,029 \\
269 \\
269 \\
32 \\
32 \\
452 \\
452 \\
12 \\
12\end{array}$ & $\begin{array}{r}12,255 \\
13,092 \\
13,092 \\
11,287 \\
12,213 \\
12,727 \\
11,076 \\
10,945 \\
12,415 \\
12,909 \\
11,629 \\
11,973 \\
12,923 \\
12,967 \\
11,767 \\
12,282 \\
12,599 \\
12,842 \\
12,861 \\
12,861 \\
11,596 \\
11,596 \\
13,137 \\
13,137 \\
8,887 \\
8,887\end{array}$ & $\begin{array}{r}2.30 \\
.45 \\
.45 \\
2.87 \\
1.04 \\
2.79 \\
2.96 \\
2.92 \\
2.30 \\
.62 \\
2.82 \\
3.05 \\
.64 \\
.57 \\
2.75 \\
2.84 \\
2.86 \\
1.27 \\
1.19 \\
1.19 \\
.39 \\
.39 \\
2.38 \\
2.38 \\
.20 \\
.20\end{array}$ & $\begin{array}{r}8.09 \\
10.01 \\
10.01 \\
8.89 \\
5.07 \\
8.73 \\
9.08 \\
9.10 \\
7.91 \\
8.43 \\
9.47 \\
10.25 \\
8.15 \\
8.80 \\
8.51 \\
8.63 \\
8.17 \\
6.36 \\
6.20 \\
6.20 \\
8.20 \\
8.20 \\
7.64 \\
7.64 \\
4.70 \\
4.70\end{array}$ & $\begin{array}{l}182.4 \\
145.5 \\
146.5 \\
181.0 \\
156.0 \\
110.3 \\
194.6 \\
108.9 \\
178.7 \\
167.1 \\
115.4 \\
111.2 \\
167.1 \\
167.1 \\
115.1 \\
171.0 \\
164.8 \\
232.9 \\
217.6 \\
217.6 \\
163.8 \\
163.8 \\
207.1 \\
207.1 \\
142.3 \\
142.3\end{array}$ & $\begin{array}{l}44.70 \\
38.37 \\
38.37 \\
40.86 \\
38.11 \\
28.08 \\
43.11 \\
23.84 \\
44.37 \\
43.14 \\
211.83 \\
26.93 \\
43.11 \\
43.34 \\
27.09 \\
41.99 \\
41.53 \\
59.83 \\
55.98 \\
55.98 \\
37.99 \\
37.99 \\
54.41 \\
54.41 \\
25.29 \\
25.29\end{array}$ \\
\hline 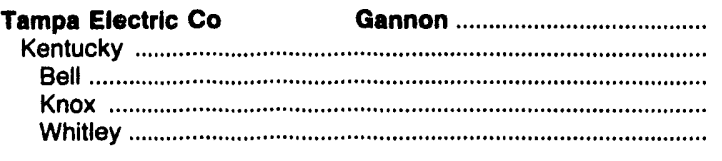 & $\begin{array}{r}728 \\
728 \\
8 \\
8 \\
712\end{array}$ & $\begin{array}{l}12,713 \\
12,713 \\
12,584 \\
12,845 \\
12,713\end{array}$ & $\begin{array}{l}1.21 \\
1.21 \\
1.20 \\
1.35 \\
1.21\end{array}$ & $\begin{array}{l}6.46 \\
6.46 \\
6.60 \\
5.60 \\
6.47\end{array}$ & $\begin{array}{l}233.8 \\
233.8 \\
205.1 \\
205.7 \\
234.4\end{array}$ & $\begin{array}{l}59.45 \\
59.45 \\
51.62 \\
52.84 \\
59.61\end{array}$ \\
\hline $\begin{array}{l}\text { Tennessee Valley Authority Allen } \\
\text { Illinois ..... } \\
\text { Jefferson . } \\
\text { Saline } \\
\text { Williamson } \\
\text { Kentucky } \\
\text { Webster } \\
\text { Pennsylvania } \\
\text { Greene }\end{array}$ & $\begin{array}{r}1,501 \\
1,038 \\
21 \\
726 \\
291 \\
460 \\
460 \\
3 \\
3\end{array}$ & $\begin{array}{l}12,146 \\
11,969 \\
11,500 \\
12,078 \\
11,731 \\
12,537 \\
12,537 \\
13,200 \\
13,200\end{array}$ & $\begin{array}{l}2.14 \\
2.10 \\
2.00 \\
2.06 \\
2.20 \\
2.24 \\
2.24 \\
2.40 \\
2.40\end{array}$ & $\begin{array}{l}8.94 \\
9.11 \\
8.00 \\
9.12 \\
9.15 \\
8.59 \\
8.59 \\
7.40 \\
7.40\end{array}$ & $\begin{array}{l}123.4 \\
119.0 \\
117.7 \\
119.0 \\
119.3 \\
132.9 \\
132.9 \\
120.0 \\
120.0\end{array}$ & $\begin{array}{l}29.98 \\
28.49^{-} \\
27.07 \\
28.74 \\
27.98 \\
33.32 \\
33.32 \\
31.68 \\
31.68\end{array}$ \\
\hline $\begin{array}{l}\text { Tennessee Valley Authority Bull Run } \\
\text { Kentucky } \\
\text { Bell } \\
\text { Clay } \\
\text { Harlan } \\
\text { Leslie } \\
\text { Letcher }\end{array}$ & $\begin{array}{r}2,005 \\
1,833 \\
483 \\
227 \\
1,061 \\
62 \\
1 \\
172 \\
172\end{array}$ & $\begin{array}{l}12,963 \\
12,988 \\
12,655 \\
12,754 \\
13,209 \\
12,644 \\
13,528 \\
12,700 \\
12,700\end{array}$ & $\begin{array}{r}1.07 \\
1.07 \\
1.10 \\
.96 \\
1.09 \\
1.03 \\
.70 \\
1.00 \\
1.00\end{array}$ & $\begin{array}{l}8.03 \\
8.13 \\
8.94 \\
8.71 \\
7.57 \\
9.31 \\
6.70 \\
7.00 \\
700\end{array}$ & $\begin{array}{l}123.8 \\
123.9 \\
126.7 \\
108.3 \\
126.8 \\
108.0 \\
124.4 \\
122.3 \\
122.3\end{array}$ & $\begin{array}{l}32.09 \\
32.19 \\
32.06 \\
27.62 \\
33.51 \\
27.30 \\
33.66 \\
31.07 \\
31.07\end{array}$ \\
\hline 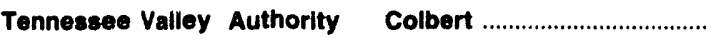 & 2,742 & 11,970 & 1.32 & 10.93 & 129.6 & 31.01 \\
\hline
\end{tabular}

See

Source: val Energy Regulatory Commission, FERC Form 423, "Monthly Report of Cost and Quplity of Fuels for Electric Plants." 
Table 24. Origin of Coal Received by Electric Utility and Plant, 1992 (Continued)

\begin{tabular}{|c|c|c|c|c|c|c|}
\hline \multirow[b]{2}{*}{$\begin{array}{c}\text { Electric Utility Plant } \\
\text { Origin State } \\
\text { County }\end{array}$} & \multirow{2}{*}{$\begin{array}{l}\text { Quantity } \\
\text { (thousand } \\
\text { short tons) }\end{array}$} & \multicolumn{3}{|c|}{ Average Quality } & \multicolumn{2}{|c|}{ Average Delivered Cost } \\
\hline & & $\begin{array}{c}\text { Btu } \\
\text { (per pound) }\end{array}$ & $\begin{array}{c}\text { Sulfur } \\
\text { (percent } \\
\text { by weight) }\end{array}$ & $\begin{array}{c}\text { Ash } \\
\text { (percent } \\
\text { by welght) }\end{array}$ & $\begin{array}{l}\text { (cents per } \\
\text { million Btu) }\end{array}$ & $\begin{array}{l}\text { (dollars per } \\
\text { short ton) }\end{array}$ \\
\hline $\begin{array}{l}\text { Tennessee Valley Authority Colbert } \\
\text { Illinois } \\
\text { Franklin } \\
\text { Kentucky } \\
\text { Breathitt } \\
\text { Daviess . } \\
\text { Floyd } \\
\text { Johnson } \\
\text { Webster } \\
\text { Sennessee } \\
\text { Sequatchie } \\
\text { Boont Virginia } \\
\text { Kanawha } \\
\text { Lincoln } \\
\text { Mingo }\end{array}$ & $\begin{array}{r}850 \\
850 \\
583 \\
80 \\
44 \\
47 \\
324 \\
88 \\
363 \\
363 \\
945 \\
50 \\
666 \\
26 \\
204\end{array}$ & $\begin{array}{l}11,577 \\
11,577 \\
12,108 \\
12,150 \\
12,200 \\
12,200 \\
12,102 \\
12,000 \\
12,377 \\
12,377 \\
12,081 \\
12,287 \\
12,040 \\
12,000 \\
12,174\end{array}$ & $\begin{array}{r}1.88 \\
1.88 \\
1.48 \\
1.30 \\
1.04 \\
1.26 \\
1.40 \\
2.30 \\
.79 \\
.79 \\
.93 \\
.70 \\
.94 \\
.70 \\
.97\end{array}$ & $\begin{array}{r}9.26 \\
9.26 \\
10.72 \\
12.10 \\
12.50 \\
12.50 \\
9.26 \\
13.00 \\
12.53 \\
12.53 \\
11.94 \\
13.95 \\
12.34 \\
11.00 \\
10.24\end{array}$ & $\begin{array}{l}123.7 \\
123.7 \\
124.6 \\
119.4 \\
122.5 \\
123.8 \\
131.1 \\
106.9 \\
127.3 \\
127.3 \\
138.5 \\
118.1 \\
140.8 \\
129.4 \\
137.0\end{array}$ & $\begin{array}{l}28.65 \\
28.65 \\
30.18 \\
29.00 \\
29.89 \\
30.21 \\
31.74 \\
25.65 \\
31.52 \\
31.52 \\
33.46 \\
29.03 \\
33.91 \\
31.05 \\
33.36\end{array}$ \\
\hline 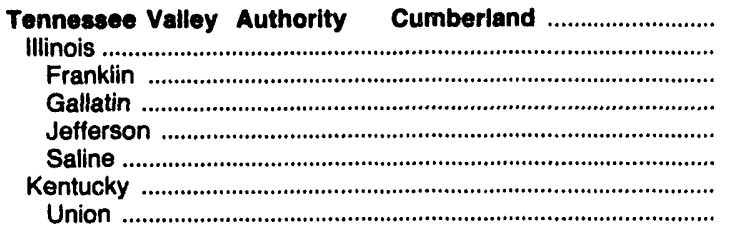 & $\begin{array}{r}6,930 \\
330 \\
283 \\
28 \\
13 \\
6 \\
6,599 \\
6,599\end{array}$ & $\begin{array}{l}11,616 \\
11,751 \\
11,700 \\
12,500 \\
11,500 \\
11,167 \\
11,609 \\
11,609\end{array}$ & $\begin{array}{l}2.77 \\
2.60 \\
2.61 \\
2.95 \\
1.80 \\
2.30 \\
2.78 \\
2.78\end{array}$ & $\begin{array}{r}7.96 \\
9.53 \\
9.53 \\
9.90 \\
7.80 \\
11.30 \\
7.88 \\
7.88\end{array}$ & $\begin{array}{l}129.9 \\
100.7 \\
100.4 \\
100.4 \\
106.0 \\
104.7 \\
131.4 \\
131.4\end{array}$ & $\begin{array}{l}30.18 \\
23.66 \\
23.49 \\
25.10 \\
24.38 \\
23.38 \\
30.50 \\
30.50\end{array}$ \\
\hline 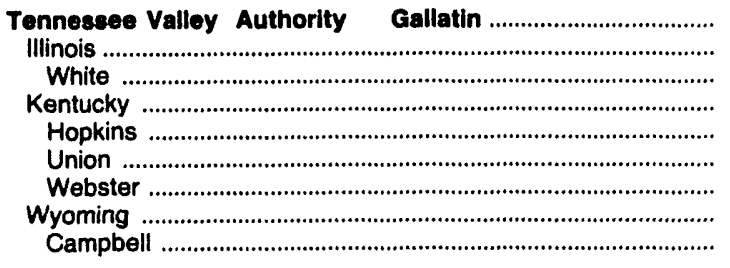 & $\begin{array}{r}2,215 \\
260 \\
260 \\
1,884 \\
1,062 \\
36 \\
786 \\
71 \\
71\end{array}$ & $\begin{array}{r}12,088 \\
11,880 \\
11,880 \\
12,249 \\
12,078 \\
12,509 \\
12,467 \\
8,601 \\
8,601\end{array}$ & $\begin{array}{r}2.54 \\
2.76 \\
2.76 \\
2.59 \\
2.34 \\
2.20 \\
2.95 \\
.50 \\
.50\end{array}$ & $\begin{array}{l}7.79 \\
7.11 \\
7.11 \\
7.87 \\
6.97 \\
8.20 \\
9.08 \\
7.99 \\
7.99\end{array}$ & $\begin{array}{l}125.0 \\
125.7 \\
125.7 \\
124.7 \\
126.7 \\
119.5 \\
122.3 \\
132.1 \\
132.1\end{array}$ & $\begin{array}{l}30.22 \\
29.87 \\
29.87 \\
30.55 \\
30.61 \\
29.89 \\
30.50 \\
22.73 \\
22.73\end{array}$ \\
\hline 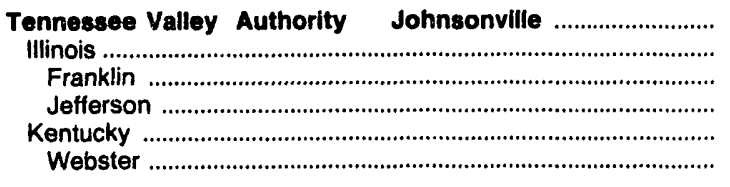 & $\begin{array}{r}2,326 \\
1,203 \\
1,062 \\
29 \\
1,123 \\
1,123\end{array}$ & $\begin{array}{l}11,992 \\
11,681 \\
11,672 \\
11,700 \\
12,325 \\
12,325\end{array}$ & $\begin{array}{l}1.75 \\
1.71 \\
1.72 \\
1.70 \\
1.79 \\
1.79\end{array}$ & $\begin{array}{l}9.12 \\
8.99 \\
9.01 \\
8.50 \\
9.24 \\
9.24\end{array}$ & $\begin{array}{l}\mathbf{1 3 0 . 8} \\
132.9 \\
133.9 \\
120.0 \\
128.6 \\
128.6\end{array}$ & $\begin{array}{l}31.37 \\
31.06 \\
31.26 \\
\quad 8.08 \\
31.71 \\
31.71\end{array}$ \\
\hline $\begin{array}{l}\text { Tennessee Valley Authority KIngston } \\
\text { Kentucky } \\
\text { Bell . } \\
\text { Harlan } \\
\text { Leslie } \\
\text { Perry } \\
\text { Tennessee } \\
\text { Anderson } \\
\text { Campbell } \\
\text { Morgan } \\
\text { Scott } \\
\text { West Virginia. } \\
\text { Lincoln }\end{array}$ & $\begin{array}{r}3,667 \\
2,463 \\
1,829 \\
446 \\
171 \\
17 \\
1,176 \\
90 \\
804 \\
37 \\
244 \\
28 \\
28\end{array}$ & $\begin{array}{l}12,723 \\
12,646 \\
12,668 \\
12,622 \\
12,540 \\
12,000 \\
12,902 \\
12,480 \\
12,738 \\
12,690 \\
13,629 \\
12,000 \\
12,000\end{array}$ & $\begin{array}{r}1.18 \\
1.10 \\
1.11 \\
1.15 \\
.95 \\
.60 \\
1.24 \\
1.17 \\
1.24 \\
1.41 \\
1.71 \\
1.40 \\
1.40\end{array}$ & $\begin{array}{r}8.21 \\
8.30 \\
8.10 \\
8.92 \\
9.00 \\
7.00 \\
7.93 \\
8.46 \\
8.73 \\
10.62 \\
4.67 \\
12.00 \\
12.00\end{array}$ & $\begin{array}{l}124.8 \\
125.6 \\
124.6 \\
129.3 \\
126.6 \\
127.5 \\
123.2 \\
124.2 \\
123.5 \\
104.3 \\
124.8 \\
126.5 \\
126.5\end{array}$ & $\begin{array}{l}31.77 \\
31.77 \\
31.57 \\
32.65 \\
31.74 \\
30.60 \\
31.80 \\
31.00 \\
31.46 \\
26.46 \\
34.03 \\
30.36 \\
30.36\end{array}$ \\
\hline 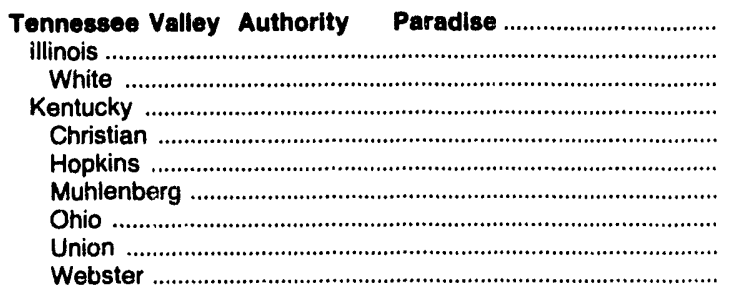 & $\begin{array}{r}6,457 \\
7 \\
7 \\
6,449 \\
61 \\
14 \\
2,700 \\
240 \\
1,340 \\
2,095\end{array}$ & $\begin{array}{l}11,018 \\
11,650 \\
11,650 \\
11,017 \\
11,506 \\
12,000 \\
10,590 \\
11,356 \\
11,108 \\
11,450\end{array}$ & $\begin{array}{l}3.95 \\
2.50 \\
2.50 \\
3.95 \\
2.40 \\
3.10 \\
4.08 \\
2.69 \\
3.79 \\
4.10\end{array}$ & $\begin{array}{r}16.25 \\
10.20 \\
10.20 \\
16.26 \\
11.50 \\
8.20 \\
17.79 \\
11.48 \\
15.95 \\
15.22\end{array}$ & $\begin{array}{r}106.5 \\
110.3 \\
110.3 \\
106.5 \\
89.1 \\
128.2 \\
98.5 \\
87.0 \\
117.8 \\
111.5\end{array}$ & $\begin{array}{l}23.47 \\
25.70 \\
25.70 \\
23.47 \\
20.50 \\
30.77 \\
20.87 \\
19.76 \\
26.17 \\
25.54\end{array}$ \\
\hline Tennessee Valley Authority & 1,728 & 12,803 & 1.52 & 9.25 & 128.5 & 32.92 \\
\hline
\end{tabular}

See footnotes at end of table.

Source: Federal Energy Regulatory Commission, FERC Form 423, "Monthly Report of Cost and Quality of Fuels for Electric Plants." 
Table 24. Origin of Coal Received by Electric Utility and Plant, 1992 (Continued)

\begin{tabular}{|c|c|c|c|c|c|c|}
\hline \multirow{2}{*}{$\begin{array}{c}\text { Electric Utillty Plant } \\
\text { Origin State } \\
\text { County }\end{array}$} & \multirow{2}{*}{$\begin{array}{l}\text { Quantity } \\
\text { (thousand } \\
\text { short tons) }\end{array}$} & \multicolumn{3}{|c|}{ Average Quality } & \multicolumn{2}{|c|}{ Average Delivered Cost } \\
\hline & & $\begin{array}{c}\text { Btu } \\
\text { (per pound) }\end{array}$ & $\begin{array}{l}\text { Sulfur } \\
\text { (percent } \\
\text { by welght) }\end{array}$ & $\begin{array}{c}\text { Ash } \\
\text { (percent } \\
\text { by weight) }\end{array}$ & $\begin{array}{l}\text { (cents per } \\
\text { million Btu) }\end{array}$ & $\begin{array}{l}\text { (dollars per } \\
\text { short ton) }\end{array}$ \\
\hline \multirow{2}{*}{\multicolumn{7}{|c|}{$\begin{array}{l}\text { Tennessee Valley Authority Sevier } \\
\text { Kentucky }\end{array}$}} \\
\hline & 462 & 12,527 & 1.31 & 11.03 & 125.2 & 31.36 \\
\hline 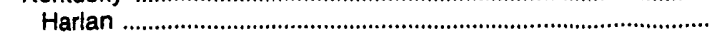 & 210 & 12,574 & 1.34 & 10.83 & 123.6 & 31.09 \\
\hline 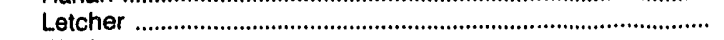 & 242 & 12,487 & 1.25 & 11.20 & 126.8 & 31.67 \\
\hline & 10 & 12,500 & 2.30 & 10.90 & 118.8 & 29.69 \\
\hline 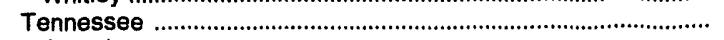 & 47 & 12,000 & 2.10 & 11.00 & 120.7 & 28.98 \\
\hline 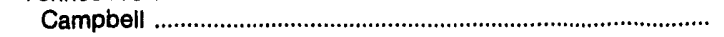 & 47 & 12,000 & 2.10 & 11.00 & 120.7 & 28.98 \\
\hline & 1,220 & 12,939 & 1.57 & 8.51 & 130.1 & 33.66 \\
\hline Le日 & 372 & 12,910 & 1.37 & 9.10 & 121.5 & 31.38 \\
\hline Wise & 847 & 12,952 & 1.66 & 8.25 & 133.8 & 34.66 \\
\hline 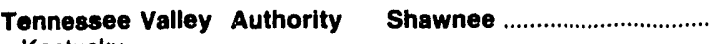 & 2,503 & 12,089 & 1.30 & 10.39 & 129.4 & 31.28 \\
\hline 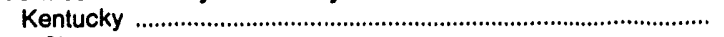 & 1,775 & 12,017 & 1.54 & 9.90 & 129.7 & 31.16 \\
\hline 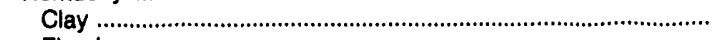 & 13 & 12,000 & .72 & 14.00 & 119.7 & 28.73 \\
\hline Floyd & 10 & 12,100 & .74 & 12.00 & 130.6 & 31.61 \\
\hline 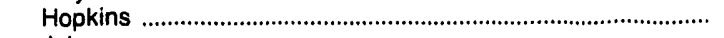 & 327 & 11,479 & 3.67 & 11.56 & 120.3 & 27.61 \\
\hline Johnson & 48 & 11,300 & .70 & 12.10 & 115.1 & 26.02 \\
\hline 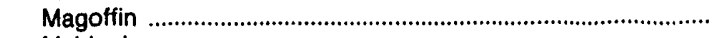 & 107 & 12,000 & .71 & 12.11 & 118.9 & 28.53 \\
\hline Muhlenberg & 272 & 11,613 & 2.52 & 9.40 & 123.8 & 28.75 \\
\hline Perry & 18 & 12,296 & .74 & 10.96 & 147.2 & 36.21 \\
\hline Pike & 966 & 12,331 & .70 & 9.08 & 135.7 & 33.46 \\
\hline 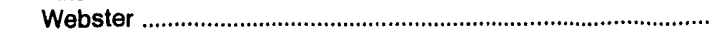 & 14 & 13,000 & 2.25 & 7.00 & 138.2 & 35.94 \\
\hline Tennessee & 13 & 12,500 & .76 & 12.10 & 128.0 & 32.00 \\
\hline Sequatchie & 13 & 12,500 & .76 & 12.10 & 128.0 & 32.00 \\
\hline West Virginia & 715 & 12,260 & .73 & 11.57 & 128.7 & 31.56 \\
\hline Boone & 347 & 12,314 & .72 & 11.35 & 129.5 & 31.89 \\
\hline 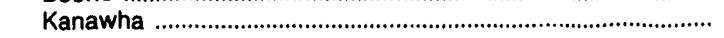 & 128 & 12,209 & .76 & 13.00 & 125.4 & 30.62 \\
\hline Logan & 142 & 12,240 & .72 & 11.36 & 129.4 & 31.68 \\
\hline 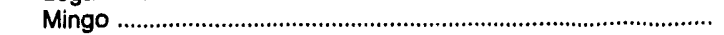 & 79 & 12,203 & .71 & 10.73 & 130.6 & 31.87 \\
\hline 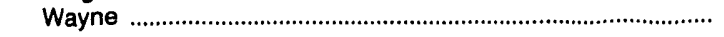 & 20 & 12,000 & .74 & 11.00 & 124.0 & 29.76 \\
\hline Tennessee Valley Authority Widows Creek ......................... & 3,643 & 11,986 & 2.58 & 10.91 & 116.1 & 27.83 \\
\hline Illinois & 106 & 11,586 & 2.63 & 9.62 & 106.2 & 24.62 \\
\hline 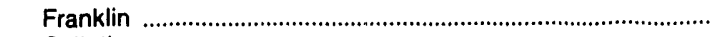 & 102 & 11,554 & 2.62 & 9.61 & 106.1 & 24.51 \\
\hline Gallatin & 4 & 12,500 & 2.80 & 9.90 & 110.9 & 27.72 \\
\hline 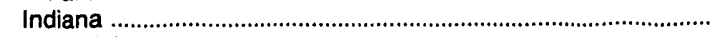 & 19 & 11,296 & 3.45 & 10.98 & 101.5 & 22.92 \\
\hline 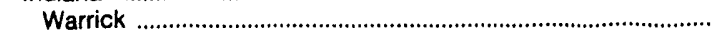 & 19 & 11,296 & 3.45 & 10.98 & 101.5 & 22.92 \\
\hline 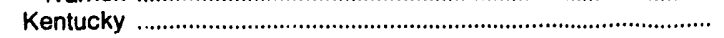 & 3,064 & 11,929 & 2.84 & 10.80 & 114.0 & 27.19 \\
\hline 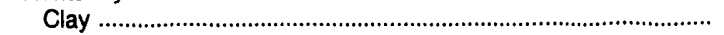 & 134 & 12,500 & .80 & 8.50 & 120.9 & 30.22 \\
\hline 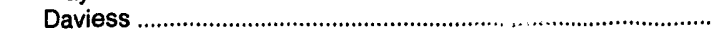 & 7 & 11,000 & 3.40 & 13.00 & 101.1 & 22.24 \\
\hline 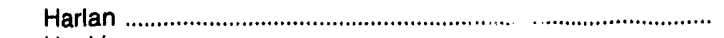 & 45 & 12,790 & .80 & 8.30 & 136.1 & 34.82 \\
\hline 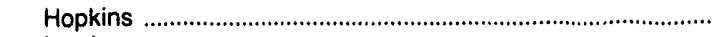 & 1,025 & 11,599 & 3.69 & 11.46 & 107.1 & 24.84 \\
\hline Letcher & 333 & 12,500 & .90 & 10.60 & 126.0 & 31.50 \\
\hline 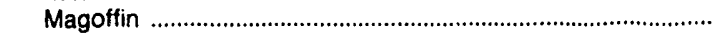 & 9 & 12,000 & .90 & 12.00 & 123.5 & 29.64 \\
\hline Ohio & 145 & 11,600 & 3.30 & 10.10 & 104.7 & 24.29 \\
\hline 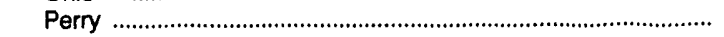 & 133 & 12,528 & .84 & 8.57 & 130.2 & 32.62 \\
\hline 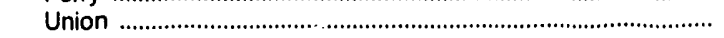 & 68 & 11,800 & 3.38 & 11.63 & 123.8 & 29.22 \\
\hline 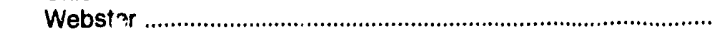 & 1,165 & 11,941 & 3.10 & 10.90 & 113.2 & 27.02 \\
\hline Tenness & 454 & 12,493 & .81 & 11.95 & $132 . ?$ & 33.06 \\
\hline Sequatchie & 454 & 12,493 & .81 & 11.95 & $i 32.3$ & 33.06 \\
\hline Texas Municipal Power Agency Glbbons Creek ..................... & 3,277 & 4,941 & 1.40 & 20.68 & 158.5 & 15.66 \\
\hline Texas & 3,277 & 4,941 & 1.40 & 20.58 & 158.5 & 15.66 \\
\hline 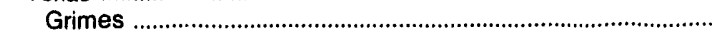 & 3,094 & 4,833 & 1.42 & 20.89 & 160.7 & 15.53 \\
\hline Robertson & 184 & 6,765 & 1.06 & 15.43 & 131.8 & 17.83 \\
\hline 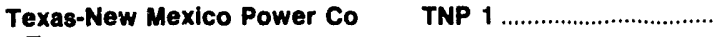 & 1,668 & 6,730 & 1.03 & 15.72 & 1.3 .2 & 20.62 \\
\hline 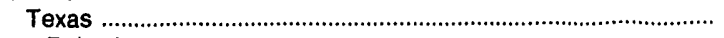 & 1,668 & 6,730 & 1.03 & 15.72 & 153.2 & 20.62 \\
\hline Robertson & 1,668 & 6,730 & 1.03 & 15.72 & 153.2 & 20.62 \\
\hline 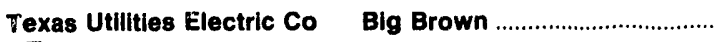 & 5,203 & 6,408 & .80 & 17.71 & 111.4 & 14.27 \\
\hline 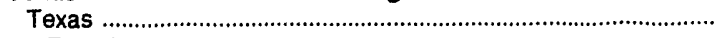 & 5,203 & 6,408 & .80 & 17.71 & 111.4 & 14.27 \\
\hline Freestone & 5,203 & 6,408 & .80 & 17.71 & 111.4 & 14.27 \\
\hline 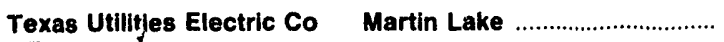 & 13,830 & 6,612 & 1.13 & 12.88 & 95.1 & 12.57 \\
\hline Texas & 13,830 & 6,612 & 1.13 & 12.88 & 95.1 & 12.57 \\
\hline 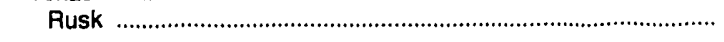 & 13,830 & 6,612 & 1.13 & 12.88 & 95.1 & 12.57 \\
\hline Monticello .................................... & 10,971 & 5,826 & .49 & 20.39 & 112.8 & 13.14 \\
\hline
\end{tabular}

See footnotes at end of table.

Source: Federal Energy Regulatory Commission, FERC Form 423, "Monthly Report of Cost and Quality of Fuels for Electric Plants." 
Table 24. Origin of Coal Received by Electric Utility and Plant, 1992 (Continued)

\begin{tabular}{|c|c|c|c|c|c|c|}
\hline \multirow{2}{*}{$\begin{array}{l}\text { Electric Utility Plant } \\
\text { Origin State } \\
\text { County }\end{array}$} & \multirow{2}{*}{$\begin{array}{l}\text { Quantity } \\
\text { (thousand } \\
\text { short tons) }\end{array}$} & \multicolumn{3}{|c|}{ Average Quality } & \multicolumn{2}{|c|}{ Average Delivered Cost } \\
\hline & & $\begin{array}{c}\text { Btu } \\
\text { (par pound) }\end{array}$ & $\begin{array}{c}\text { Sulfur } \\
\text { (percent } \\
\text { by weight) }\end{array}$ & $\begin{array}{c}\text { Ash } \\
\text { (percent } \\
\text { by weight) }\end{array}$ & $\begin{array}{l}\text { (cents per } \\
\text { million Btu) }\end{array}$ & $\begin{array}{l}\text { (doliars per } \\
\text { short ton) }\end{array}$ \\
\hline 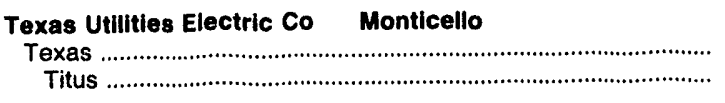 & $\begin{array}{l}10,971 \\
10,971\end{array}$ & $\begin{array}{l}5,826 \\
5,826\end{array}$ & $\begin{array}{r}0.49 \\
.49\end{array}$ & $\begin{array}{l}20.39 \\
20.39\end{array}$ & $\begin{array}{l}112.8 \\
112.8\end{array}$ & $\begin{array}{l}13.14 \\
13.14\end{array}$ \\
\hline 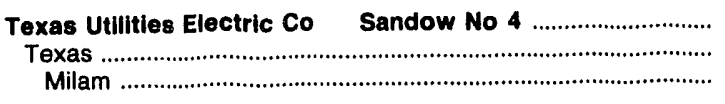 & $\begin{array}{l}3,464 \\
3,464 \\
3,464\end{array}$ & $\begin{array}{l}6,308 \\
6,308 \\
6,308\end{array}$ & $\begin{array}{l}1.10 \\
1.10 \\
1.10\end{array}$ & $\begin{array}{l}20.83 \\
20.83 \\
20.83\end{array}$ & $\begin{array}{l}107.0 \\
107.0 \\
107.0\end{array}$ & $\begin{array}{l}13.49 \\
13.49 \\
13.49\end{array}$ \\
\hline $\begin{array}{l}\text { Toledo Edison Co } \\
\text { West Virginia } \\
\text { Mingo }\end{array}$ & $\begin{array}{l}57 \\
57 \\
57\end{array}$ & $\begin{array}{l}12,721 \\
12,721 \\
12,721\end{array}$ & $\begin{array}{l}.66 \\
.66 \\
.66\end{array}$ & $\begin{array}{l}8.81 \\
8.81 \\
8.81\end{array}$ & $\begin{array}{l}178.0 \\
178.0 \\
178.0\end{array}$ & $\begin{array}{l}45.29 \\
45.29 \\
45.29\end{array}$ \\
\hline 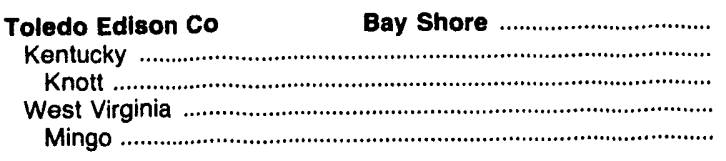 & $\begin{array}{r}1,195 \\
30 \\
30 \\
1,165 \\
1,165\end{array}$ & $\begin{array}{l}12,933 \\
12,681 \\
12,681 \\
12,939 \\
12,939\end{array}$ & $\begin{array}{r}1.14 \\
.84 \\
.84 \\
1.14 \\
1.14\end{array}$ & $\begin{array}{l}7.99 \\
8.00 \\
8.00 \\
7.99 \\
7.99\end{array}$ & $\begin{array}{l}202.6 \\
141.9 \\
141.9 \\
204.1 \\
204.1\end{array}$ & $\begin{array}{l}52.41 \\
35.99 \\
35.99 \\
52.83 \\
52.83\end{array}$ \\
\hline $\begin{array}{l}\text { Tri-State G \& T Assn, Inc. Craig } \\
\text { Colorado } \\
\text { Moffat } \\
\text { Routt }\end{array}$ & $\begin{array}{r}4,493 \\
4,493 \\
4,278 \\
214\end{array}$ & $\begin{array}{l}10,220 \\
10,220 \\
10,203 \\
10,575\end{array}$ & $\begin{array}{l}.37 \\
.37 \\
.36 \\
.51\end{array}$ & $\begin{array}{l}6.49 \\
6.49 \\
6.42 \\
7.97\end{array}$ & $\begin{array}{r}111.6 \\
111.6 \\
113.6 \\
71.9\end{array}$ & $\begin{array}{l}22.81 \\
22.81 \\
23.19 \\
15.20\end{array}$ \\
\hline $\begin{array}{l}\text { Tri-State G \& T Assn, Inc. Nucla } \\
\text { Colorado } \\
\text { Garfield } \\
\text { Montrose }\end{array}$ & $\begin{array}{r}240 \\
240 \\
8 \\
232\end{array}$ & $\begin{array}{r}8,409 \\
8,409 \\
10,004 \\
8,354\end{array}$ & $\begin{array}{l}.81 \\
.81 \\
.43 \\
.83\end{array}$ & $\begin{array}{l}24.79 \\
24.79 \\
17.67 \\
25.03\end{array}$ & $\begin{array}{r}94.1 \\
94.1 \\
124.4 \\
92.8\end{array}$ & $\begin{array}{l}15.82 \\
15.82 \\
24.89 \\
15.51\end{array}$ \\
\hline $\begin{array}{l}\text { Tucson Electric Power Co Irvington } \\
\text { New Mexico } \\
\text { Mckinley }\end{array}$ & $\begin{array}{l}199 \\
199 \\
199\end{array}$ & $\begin{array}{l}10,060 \\
10,060 \\
10,060\end{array}$ & $\begin{array}{l}.45 \\
.45 \\
.45\end{array}$ & $\begin{array}{l}12.61 \\
12.61 \\
12.61\end{array}$ & $\begin{array}{l}234.1 \\
234.1 \\
234.1\end{array}$ & $\begin{array}{l}47.11 \\
47.11 \\
47.11\end{array}$ \\
\hline 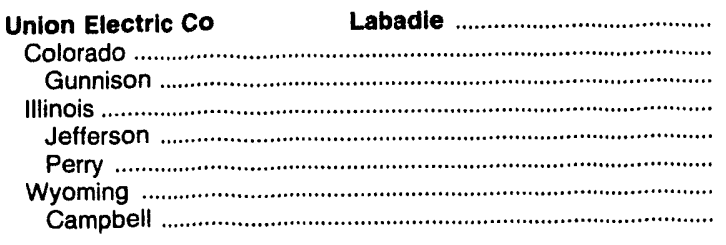 & $\begin{array}{r}5,468 \\
487 \\
487 \\
2,480 \\
9 \\
2,471 \\
2,501 \\
2,501\end{array}$ & $\begin{array}{r}10,151 \\
11,750 \\
11,750 \\
11,202 \\
11,800 \\
11,200 \\
8,798 \\
8,798\end{array}$ & $\begin{array}{r}1.55 \\
.47 \\
.47 \\
3.09 \\
1.30 \\
3.10 \\
.22 \\
.22\end{array}$ & $\begin{array}{r}7.50 \\
9.60 \\
9.60 \\
10.09 \\
7.30 \\
10.10 \\
4.52 \\
4.52\end{array}$ & $\begin{array}{r}116.0 \\
161.0 \\
161.0 \\
128.6 \\
214.2 \\
128.3 \\
88.3 \\
88.3\end{array}$ & $\begin{array}{l}23.54 \\
37.84 \\
37.84 \\
28.82 \\
50.55 \\
28.74 \\
15.53 \\
15.53\end{array}$ \\
\hline $\begin{array}{l}\text { Union Electric Co } \\
\text { Illinois } \\
\text { Jefferson } \\
\text { Saline }\end{array}$ & $\begin{array}{l}773 \\
773 \\
201 \\
572\end{array}$ & $\begin{array}{l}11,648 \\
11,648 \\
11,500 \\
11,700\end{array}$ & $\begin{array}{l}1.28 \\
1.28 \\
1.27 \\
1.28\end{array}$ & $\begin{array}{r}8.37 \\
8.37 \\
12.00 \\
7.10\end{array}$ & $\begin{array}{l}200.1 \\
200.1 \\
142.3 \\
220.1\end{array}$ & $\begin{array}{l}46.61 \\
46.61 \\
32.73 \\
51.49\end{array}$ \\
\hline 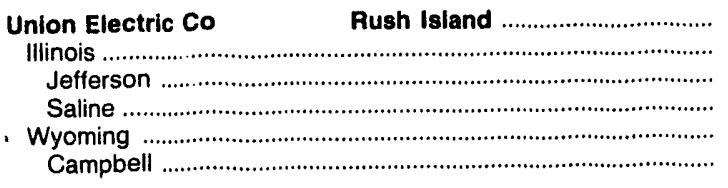 & $\begin{array}{r}2,541 \\
2,042 \\
1,386 \\
656 \\
499 \\
499\end{array}$ & $\begin{array}{r}11,102 \\
11,692 \\
11,689 \\
11,700 \\
8,685 \\
8,685\end{array}$ & $\begin{array}{r}1.12 \\
1.29 \\
1.29 \\
1.28 \\
.45 \\
.45\end{array}$ & $\begin{array}{l}7.83 \\
8.42 \\
9.05 \\
7.10 \\
5.42 \\
5.42\end{array}$ & $\begin{array}{l}178.9 \\
192.8 \\
193.2 \\
191.9 \\
102.2 \\
102.2\end{array}$ & $\begin{array}{l}39.71 \\
45.08 \\
45.16 \\
44.91 \\
17.76 \\
17.76\end{array}$ \\
\hline 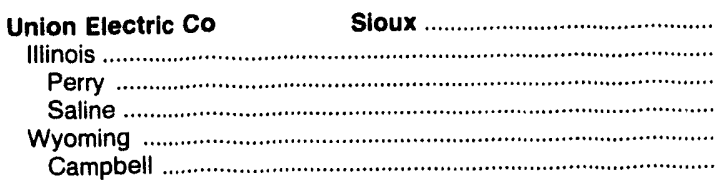 & $\begin{array}{r}1,845 \\
1,714 \\
483 \\
1,231 \\
131 \\
131\end{array}$ & $\begin{array}{r}11,317 \\
11,521 \\
11,321 \\
11,600 \\
8,650 \\
8,650\end{array}$ & $\begin{array}{r}2.39 \\
2.54 \\
2.89 \\
2.40 \\
.52 \\
.52\end{array}$ & $\begin{array}{l}8.22 \\
8.41 \\
9.47 \\
8.00 \\
5.70 \\
5.70\end{array}$ & $\begin{array}{l}174.8 \\
178.9 \\
155.3 \\
188.0 \\
102.0 \\
102.0\end{array}$ & $\begin{array}{l}39.56 \\
41.23 \\
35.17 \\
43.61 \\
17.65 \\
17.65\end{array}$ \\
\hline 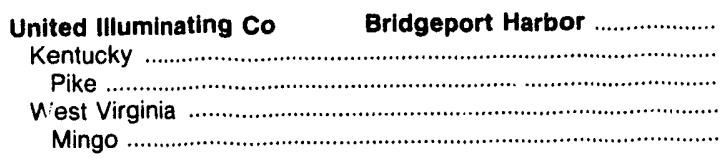 & $\begin{array}{r}793 \\
772 \\
772 \\
21 \\
21\end{array}$ & $\begin{array}{l}13,167 \\
13,162 \\
13,162 \\
13,351 \\
13,351\end{array}$ & $\begin{array}{l}.55 \\
.55 \\
.55 \\
.67 \\
.67\end{array}$ & $\begin{array}{l}6.25 \\
6.25 \\
6.25 \\
6.20 \\
6.20\end{array}$ & $\begin{array}{l}1948 \\
195.5 \\
195.5 \\
168.9 \\
168.9\end{array}$ & $\begin{array}{l}51.30 \\
51.47 \\
51.47 \\
45.10 \\
45.10\end{array}$ \\
\hline Stanton & 1,067 & 6,744 & .71 & 8.66 & 68.5 & 9.23 \\
\hline
\end{tabular}

See footnotes at end of table.

Source: Federal Energy Regulatory Commission, FERC Form 423, "Monthly Report of Cost and Quality of Fuels for Electric Plants." 
Table 24. Origin of Coal Recelved by Electric Utillty and Plant, 1992 (Continued)

\begin{tabular}{|c|c|c|c|c|c|c|}
\hline \multirow[b]{2}{*}{$\begin{array}{c}\text { Electric Utillty Plant } \\
\text { Orlgin State } \\
\text { County }\end{array}$} & \multirow{2}{*}{$\begin{array}{l}\text { Quantity } \\
\text { (thousand } \\
\text { short tons) }\end{array}$} & \multicolumn{3}{|c|}{ Average Quality } & \multicolumn{2}{|c|}{ Average Delivered Cost } \\
\hline & & $\begin{array}{c}\text { Btu } \\
\text { (per pound) }\end{array}$ & $\begin{array}{l}\text { Sulfur } \\
\text { (percent } \\
\text { by weight) }\end{array}$ & $\begin{array}{c}\text { Ash } \\
\text { (percent } \\
\text { by weight) }\end{array}$ & $\begin{array}{l}\text { (cents per } \\
\text { million Btu) }\end{array}$ & $\begin{array}{l}\text { (dollars per } \\
\text { short ton) }\end{array}$ \\
\hline $\begin{array}{l}\text { United Power Assn } \\
\text { North Dakota }\end{array}$ & $\begin{array}{r}1,062 \\
1,062 \\
5 \\
5\end{array}$ & $\begin{array}{l}6,732 \\
6,732 \\
9,276 \\
9,276\end{array}$ & $\begin{array}{r}0.71 \\
.71 \\
.52 \\
.52\end{array}$ & $\begin{array}{l}8.69 \\
8.69 \\
4.30 \\
4.30\end{array}$ & $\begin{array}{l}68.5 \\
68.5 \\
67.8 \\
67.8\end{array}$ & $\begin{array}{r}9.22 \\
9.22 \\
12.58 \\
12.58\end{array}$ \\
\hline 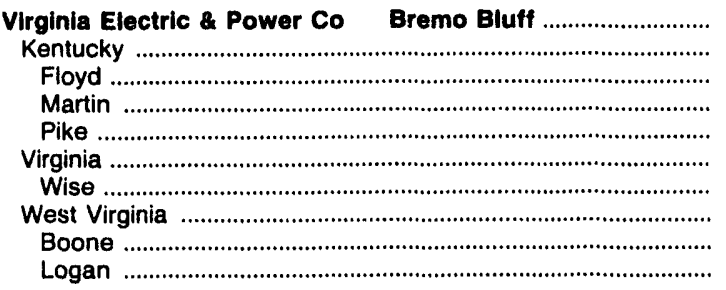 & $\begin{array}{r}463 \\
63 \\
7 \\
15 \\
41 \\
36 \\
36 \\
365 \\
233 \\
131\end{array}$ & $\begin{array}{l}12,653 \\
12,788 \\
12,639 \\
12,366 \\
12,970 \\
12,875 \\
12,875 \\
12,607 \\
12,616 \\
12,593\end{array}$ & $\begin{array}{r}.83 \\
.89 \\
.86 \\
.73 \\
.96 \\
1.14 \\
1.14 \\
.79 \\
.83 \\
.72\end{array}$ & $\begin{array}{l}9.39 \\
7.91 \\
6.90 \\
7.60 \\
8.20 \\
9.36 \\
9.36 \\
9.64 \\
9.56 \\
9.80\end{array}$ & $\begin{array}{l}150.0 \\
147.9 \\
147.3 \\
138.0 \\
151.6 \\
149.1 \\
149.1 \\
150.5 \\
154.1 \\
144.0\end{array}$ & $\begin{array}{l}37.97 \\
37.84 \\
37.23 \\
34.13 \\
39.33 \\
38.39 \\
38.39 \\
37.95 \\
38.89 \\
36.28\end{array}$ \\
\hline 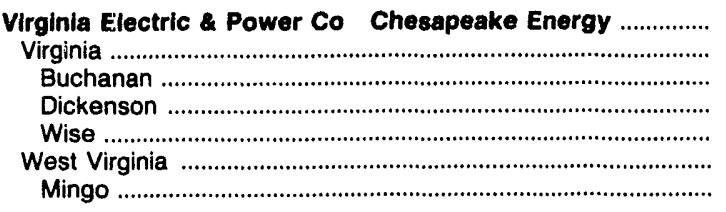 & $\begin{array}{r}1,125 \\
987 \\
410 \\
181 \\
395 \\
138 \\
138\end{array}$ & $\begin{array}{l}13,062 \\
13,109 \\
13,122 \\
13,169 \\
13,068 \\
12,724 \\
12,724\end{array}$ & $\begin{array}{r}1.10 \\
1.13 \\
1.27 \\
.84 \\
1.11 \\
.87 \\
.87\end{array}$ & $\begin{array}{l}8.61 \\
8.49 \\
8.65 \\
8.88 \\
8.16 \\
9.42 \\
9.42\end{array}$ & $\begin{array}{l}150.4 \\
150.7 \\
149.6 \\
152.4 \\
151.0 \\
147.9 \\
147.9\end{array}$ & $\begin{array}{l}39.28 \\
39.51 \\
39.27 \\
40.14 \\
39.46 \\
37.64 \\
37.64\end{array}$ \\
\hline $\begin{array}{l}\text { Virginia Electric \& Power Co Chesterfleld } \\
\text { Kentucky } \\
\text { Breathitt . } \\
\text { Harlan } \\
\text { Knott } \\
\text { Letcher } \\
\text { Pike } \\
\text { Virginia } \\
\text { Buchanan } \\
\text { Dickenson } \\
\text { Lee } \\
\text { West Virginia } \\
\text { Boone } \\
\text { Logan } \\
\text { Mingo . }\end{array}$ & $\begin{array}{r}2,968 \\
1,680 \\
61 \\
50 \\
344 \\
82 \\
1,142 \\
621 \\
258 \\
39 \\
16 \\
308 \\
667 \\
609 \\
23 \\
34\end{array}$ & $\begin{array}{l}12,841 \\
12,721 \\
12,443 \\
12,769 \\
12,653 \\
12,825 \\
12,746 \\
13,012 \\
13,036 \\
13,065 \\
13,089 \\
12,982 \\
12,984 \\
13,023 \\
12,693 \\
12,487\end{array}$ & $\begin{array}{r}1.13 \\
1.08 \\
1.06 \\
1.04 \\
.92 \\
1.11 \\
1.12 \\
1.13 \\
1.25 \\
.81 \\
.94 \\
1.08 \\
1.26 \\
1.29 \\
.80 \\
.97\end{array}$ & $\begin{array}{r}8.72 \\
8.79 \\
8.52 \\
7.85 \\
8.40 \\
7.92 \\
9.03 \\
8.56 \\
8.88 \\
8.58 \\
6.07 \\
8.41 \\
8.70 \\
8.59 \\
8.31 \\
10.87\end{array}$ & $\begin{array}{l}146.7 \\
146.5 \\
148.9 \\
145.1 \\
146.1 \\
141.6 \\
146.9 \\
147.2 \\
146.9 \\
160.7 \\
145.9 \\
145.7 \\
146.7 \\
146.4 \\
145.8 \\
151.4\end{array}$ & $\begin{array}{l}37.67 \\
37.27 \\
37.07 \\
37.06 \\
36.97 \\
36.31 \\
37.44 \\
38.30 \\
38.30 \\
41.98 \\
38.19 \\
37.84 \\
38.09 \\
38.14 \\
37.02 \\
37.80\end{array}$ \\
\hline $\begin{array}{l}\text { Virginia Electric \& Power Co Mount Storm } \\
\text { Maryland ... } \\
\text { Allegany } \\
\text { Garrett . } \\
\text { Pennsylvania . } \\
\text { Somerset } \\
\text { West Virginia } \\
\text { Barbour } \\
\text { Grant } \\
\text { Mineral } \\
\text { Preston } \\
\text { Randolph } \\
\text { Upshur . }\end{array}$ & $\begin{array}{r}4,541 \\
1,531 \\
240 \\
1,291 \\
48 \\
48 \\
2,962 \\
178 \\
2,447 \\
248 \\
68 \\
6 \\
14\end{array}$ & $\begin{array}{l}12,273 \\
12,375 \\
11,803 \\
12,482 \\
11,715 \\
11,715 \\
12,229 \\
11,796 \\
12,314 \\
11,709 \\
12,334 \\
11,784 \\
11,758\end{array}$ & $\begin{array}{l}1.78 \\
1.79 \\
1.79 \\
1.79 \\
1.79 \\
1.79 \\
1.77 \\
1.91 \\
1.77 \\
1.75 \\
1.69 \\
1.48 \\
1.72\end{array}$ & $\begin{array}{l}14.33 \\
14.16 \\
16.87 \\
13.66 \\
17.32 \\
17.32 \\
14.37 \\
17.79 \\
13.80 \\
17.38 \\
14.24 \\
17.66 \\
17.10\end{array}$ & $\begin{array}{l}139.1 \\
118.5 \\
112.0 \\
119.6 \\
108.3 \\
108.3 \\
150.3 \\
113.9 \\
157.8 \\
113.6 \\
111.5 \\
111.6 \\
110.0\end{array}$ & $\begin{array}{l}34.14 \\
29.32 \\
26.43 \\
29.85 \\
25.38 \\
25.38 \\
36.77 \\
26.87 \\
38.87 \\
26.59 \\
27.5 n \\
26.21 \\
25.86\end{array}$ \\
\hline 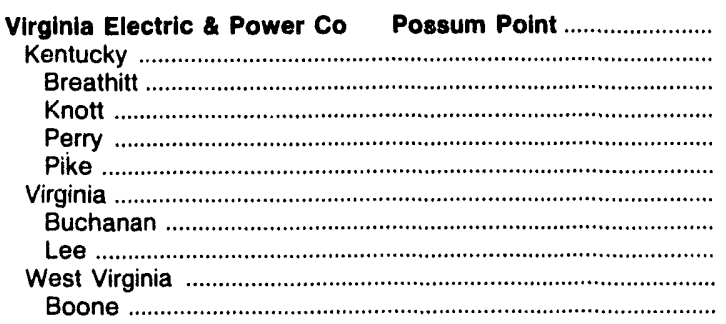 & $\begin{array}{r}743 \\
610 \\
7 \\
40 \\
44 \\
519 \\
49 \\
7 \\
42 \\
83 \\
83\end{array}$ & $\begin{array}{l}12,717 \\
12,696 \\
12,628 \\
12,675 \\
13,153 \\
12,660 \\
13,003 \\
12,634 \\
13,066 \\
12,704 \\
12,704\end{array}$ & $\begin{array}{r}1.07 \\
1.10 \\
1.11 \\
.91 \\
.87 \\
1.13 \\
1.05 \\
1.18 \\
1.02 \\
.83 \\
.83\end{array}$ & $\begin{array}{r}8.43 \\
8.47 \\
9.30 \\
8.03 \\
7.23 \\
8.60 \\
7.52 \\
10.70 \\
6.96 \\
8.65 \\
8.65\end{array}$ & $\begin{array}{l}153.2 \\
153.1 \\
160.1 \\
152.0 \\
145.6 \\
153.8 \\
147.4 \\
147.1 \\
147.4 \\
157.4 \\
157.4\end{array}$ & $\begin{array}{l}38.97 \\
38.88 \\
40.43 \\
38.54 \\
38.30 \\
38.93 \\
38.32 \\
37.17 \\
38.52 \\
40.00 \\
40.00\end{array}$ \\
\hline 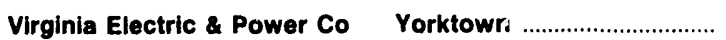 & 676 & 13,135 & 1.57 & 8.61 & 156.4 & 41.10 \\
\hline
\end{tabular}

See footnotes at end of table.

Source: Federal Energy Regulatory Commission, FERC Form 423, "Monthly Report of Cost and Quality of Fuels for Electric Plants." 
Table 24. Origin of Coal Received by Electric Utility and Plant, 1992 (Continued)

\begin{tabular}{|c|c|c|c|c|c|c|}
\hline \multirow{2}{*}{$\begin{array}{l}\text { Electric Utility Plant } \\
\text { Origin State } \\
\text { County }\end{array}$} & \multirow{2}{*}{$\begin{array}{l}\text { Quantity } \\
\text { (thousand } \\
\text { short tons) }\end{array}$} & \multicolumn{3}{|c|}{ Average Quality } & \multicolumn{2}{|c|}{ Average Delivered Cost } \\
\hline & & $\begin{array}{c}\text { Btu } \\
\text { (per pound) }\end{array}$ & $\begin{array}{l}\text { Sulfur } \\
\text { (percent } \\
\text { by weight) }\end{array}$ & $\begin{array}{l}\text { Ash } \\
\text { (percent } \\
\text { by welght) }\end{array}$ & $\begin{array}{l}\text { (cents per } \\
\text { million Btu) }\end{array}$ & $\begin{array}{l}\text { (dollars per } \\
\text { short ton) }\end{array}$ \\
\hline $\begin{array}{l}\text { Virginia Electric \& Power Co Yorktown } \\
\text { Kentucky } \\
\text { Harlan ...... } \\
\text { Pike . } \\
\text { Virginia } \\
\text { Buchanan } \\
\text { Dickenson }\end{array}$ & $\begin{array}{r}132 \\
14 \\
118 \\
285 \\
87 \\
158 \\
7 \\
34 \\
259 \\
94 \\
165\end{array}$ & $\begin{array}{l}12,906 \\
12,740 \\
12,926 \\
13,110 \\
13,176 \\
13,083 \\
13,027 \\
13,083 \\
13,280 \\
13,142 \\
13,358\end{array}$ & $\begin{array}{l}1.28 \\
1.26 \\
1.28 \\
1.36 \\
1.29 \\
1.43 \\
1.13 \\
1.25 \\
1.96 \\
1.41 \\
2.27\end{array}$ & $\begin{array}{r}8.23 \\
9.35 \\
8.10 \\
9.47 \\
9.19 \\
9.63 \\
6.30 \\
10.05 \\
7.87 \\
8.64 \\
7.43\end{array}$ & $\begin{array}{l}155.5 \\
144.4 \\
156.9 \\
147.8 \\
147.9 \\
148.1 \\
147.3 \\
146.4 \\
166.2 \\
146.3 \\
177.3\end{array}$ & $\begin{array}{l}40.15 \\
36.78 \\
40.55 \\
38.76 \\
38.98 \\
38.76 \\
38.38 \\
38.30 \\
44.15 \\
38.46 \\
47.38\end{array}$ \\
\hline $\begin{array}{l}\text { West Penn Power Co } \\
\text { Pennsylvania ... Armstrong } \\
\text { Armstrong } \\
\text { Butler . } \\
\text { Greene } \\
\text { Jefferson } \\
\text { Unknown }\end{array}$ & $\begin{array}{r}970 \\
970 \\
430 \\
24 \\
60 \\
456 \\
1\end{array}$ & $\begin{array}{l}12,430 \\
12,430 \\
12,121 \\
11,885 \\
13,072 \\
12,666 \\
11,630\end{array}$ & $\begin{array}{l}1.96 \\
1.96 \\
2.02 \\
2.11 \\
2.21 \\
1.86 \\
2.08\end{array}$ & $\begin{array}{r}11.16 \\
11.16 \\
12.41 \\
12.64 \\
7.56 \\
10.36 \\
14.80\end{array}$ & $\begin{array}{r}117.5 \\
117.5 \\
100.4 \\
94.4 \\
99.8 \\
136.5 \\
89.5\end{array}$ & $\begin{array}{l}29.21 \\
29.21 \\
24.33 \\
22.45 \\
26.10 \\
34.57 \\
20.82\end{array}$ \\
\hline 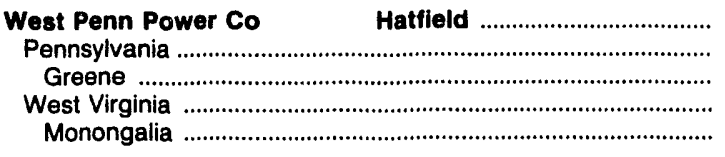 & $\begin{array}{r}3,822 \\
35 \\
35 \\
3,787 \\
3,787\end{array}$ & $\begin{array}{l}12,924 \\
13,194 \\
13,194 \\
12,921 \\
12,921\end{array}$ & $\begin{array}{l}2.22 \\
1.70 \\
1.70 \\
2.22 \\
2.22\end{array}$ & $\begin{array}{l}9.29 \\
7.75 \\
7.75 \\
9.30 \\
9.30\end{array}$ & $\begin{array}{l}153.3 \\
156.1 \\
156.1 \\
153.2 \\
153.2\end{array}$ & $\begin{array}{l}39.61 \\
41.20 \\
41.20 \\
39.60 \\
39.60\end{array}$ \\
\hline $\begin{array}{l}\text { West Penn Power Co } \\
\text { West Virginia } \\
\text { Monongalia }\end{array}$ & $\begin{array}{l}655 \\
655 \\
655\end{array}$ & $\begin{array}{l}12,365 \\
12,365 \\
12,365\end{array}$ & $\begin{array}{l}2.63 \\
2.63 \\
2.63\end{array}$ & $\begin{array}{l}12.46 \\
12.46 \\
12.46\end{array}$ & $\begin{array}{l}130.9 \\
130.9 \\
130.9\end{array}$ & $\begin{array}{l}32.38 \\
32.38 \\
32.38\end{array}$ \\
\hline $\begin{array}{c}\text { West Texas Utilities Co } \quad \text { Oklaunion } \\
\text { Wyoming } \\
\text { Campbell }\end{array}$ & $\begin{array}{l}2,878 \\
2,878 \\
2,878\end{array}$ & $\begin{array}{l}8,376 \\
8,376 \\
8,376\end{array}$ & $\begin{array}{l}.35 \\
.35 \\
.35\end{array}$ & $\begin{array}{l}4.84 \\
4.84 \\
4.84\end{array}$ & $\begin{array}{l}152.7 \\
152.7 \\
152.7\end{array}$ & $\begin{array}{l}25.59 \\
25.59 \\
25.59\end{array}$ \\
\hline $\begin{array}{l}\text { Western Farmers Elec Coop Inc Hugo } \\
\text { Oklahorna } \\
\text { Haskell } \\
\text { Wagoner } \\
\text { Wyoming } \\
\text { Campbell }\end{array}$ & $\begin{array}{r}1,426 \\
6 \\
4 \\
2 \\
1,420 \\
1,420\end{array}$ & $\begin{array}{r}8,407 \\
12,676 \\
12,541 \\
12,938 \\
8,389 \\
8,389\end{array}$ & $\begin{array}{l}.44 \\
.62 \\
.71 \\
.45 \\
.44 \\
.44\end{array}$ & $\begin{array}{r}5.20 \\
9.47 \\
11.36 \\
5.80 \\
5.18 \\
5.18\end{array}$ & $\begin{array}{l}178.1 \\
177.0 \\
177.0 \\
177.0 \\
178.2 \\
178.2\end{array}$ & $\begin{array}{l}29.95 \\
44.87 \\
44.39 \\
45.80 \\
29.89 \\
29.89\end{array}$ \\
\hline 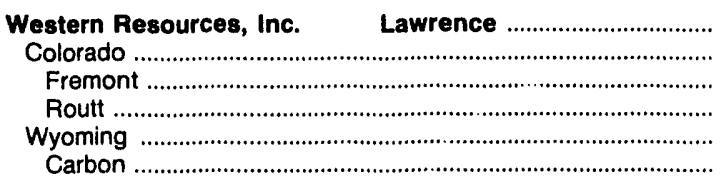 & $\begin{array}{r}1,122 \\
240 \\
34 \\
206 \\
882 \\
882\end{array}$ & $\begin{array}{l}10,574 \\
11,181 \\
11,030 \\
11,206 \\
10,408 \\
10,408\end{array}$ & $\begin{array}{l}.43 \\
.46 \\
.74 \\
.41 \\
.42 \\
.42\end{array}$ & $\begin{array}{l}9.04 \\
9.56 \\
8.20 \\
9.78 \\
8.89 \\
8.89\end{array}$ & $\begin{array}{l}122.8 \\
112.3 \\
118.0 \\
111.4 \\
125.9 \\
125.9\end{array}$ & $\begin{array}{l}25.97 \\
25.12 \\
26.03 \\
24.96 \\
26.21 \\
26.21\end{array}$ \\
\hline 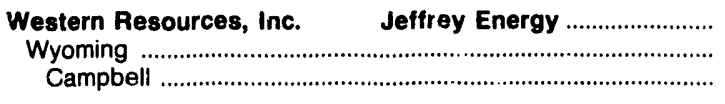 & $\begin{array}{l}5,818 \\
5,818 \\
5,818\end{array}$ & $\begin{array}{l}8,345 \\
8,345 \\
8,345\end{array}$ & $\begin{array}{l}.32 \\
32 \\
.32\end{array}$ & $\begin{array}{l}4.88 \\
4.88 \\
4.88\end{array}$ & $\begin{array}{l}132.4 \\
132.4 \\
132.4\end{array}$ & $\begin{array}{l}22.09 \\
22.09 \\
22.09\end{array}$ \\
\hline 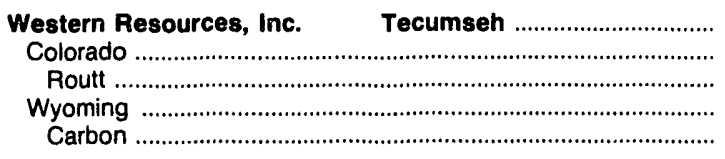 & $\begin{array}{r}409 \\
88 \\
88 \\
321 \\
321\end{array}$ & $\begin{array}{l}10,585 \\
11,226 \\
11,226 \\
10,409 \\
10,409\end{array}$ & $\begin{array}{l}.42 \\
.41 \\
.41 \\
.43 \\
.43\end{array}$ & $\begin{array}{l}9.18 \\
9.82 \\
9.82 \\
9.00 \\
9.00\end{array}$ & $\begin{array}{l}122.5 \\
111.9 \\
111.9 \\
125.6 \\
125.6\end{array}$ & $\begin{array}{l}25.93 \\
25.12 \\
25.12 \\
26.15 \\
26.15\end{array}$ \\
\hline $\begin{array}{l}\text { Wisconsin Electric Power Co Oak Creek } \\
\text { Illinois .... } \\
\text { Franklin . } \\
\text { New Mexico } \\
\text { Colfax } \\
\text { Pennsylvania } \\
\text { Greene }\end{array}$ & $\begin{array}{r}1,758 \\
304 \\
304 \\
578 \\
578 \\
876 \\
876\end{array}$ & $\begin{array}{l}12,752 \\
11,935 \\
11,935 \\
12,394 \\
12,394 \\
13,271 \\
13,271\end{array}$ & $\begin{array}{r}1.30 \\
1.77 \\
1.77 \\
.55 \\
.55 \\
1.63 \\
1.63\end{array}$ & $\begin{array}{r}8.46 \\
7.60 \\
7.60 \\
12.49 \\
12.49 \\
6.11 \\
6.11\end{array}$ & $\begin{array}{l}152.0 \\
155.2 \\
155.2 \\
150.7 \\
150.7 \\
151.9 \\
151.9\end{array}$ & $\begin{array}{l}38.78 \\
37.05 \\
37.05 \\
37.36 \\
37.36 \\
40.31 \\
40.31\end{array}$ \\
\hline Wisconsin Electric Power Co Pleasant Prairle ................... & 4,438 & 8,500 & .38 & 5.06 & 90.3 & 15.36 \\
\hline
\end{tabular}

See footnotes at end of table.

Source: Federal Energy Regulatory Commission, FERC Form 423, "Monthly Report of Cost and Quality of Fuels for Electric Plants." 
Table 24. Origin of Coal Received by Electric Utility and Planit, 1992 (Continued)

\begin{tabular}{|c|c|c|c|c|c|c|}
\hline \multirow{2}{*}{$\begin{array}{l}\text { Eloctric Utillty Piant } \\
\text { Origin State } \\
\text { County }\end{array}$} & \multirow{2}{*}{$\begin{array}{l}\text { Quantity } \\
\text { (thousand } \\
\text { short tons) }\end{array}$} & \multicolumn{3}{|c|}{ Average Quality } & \multicolumn{2}{|c|}{ Avergas: Delivered Cost } \\
\hline & & $\begin{array}{c}\text { Btu } \\
\text { (per pound) }\end{array}$ & $\begin{array}{l}\text { Sulfur } \\
\text { (percent }\end{array}$ & $\begin{array}{c}\text { Ash } \\
\text { (percent }\end{array}$ & $\begin{array}{l}\text { (cents per } \\
\text { million Btu) }\end{array}$ & (dollars per \\
\hline $\begin{array}{c}\text { Wisconsin Electric Power Co Pleasant Pralrie } \\
\text { Wyoming } \\
\text { Campbell }\end{array}$ & $\begin{array}{l}4,438 \\
4,438\end{array}$ & $\begin{array}{l}8.500 \\
8.500\end{array}$ & $\begin{array}{r}0.38 \\
.38\end{array}$ & $\begin{array}{l}5.06 \\
5.06\end{array}$ & $\begin{array}{l}90.3 \\
90.3\end{array}$ & $\begin{array}{l}15.36 \\
15.36\end{array}$ \\
\hline $\begin{array}{c}\text { Wleconain Electric Power Co Port Washington } \\
\text { Pennsylvania } \\
\text { Greene }\end{array}$ & $\begin{array}{l}138 \\
138 \\
138\end{array}$ & $\begin{array}{l}13,243 \\
13,243 \\
13,243\end{array}$ & $\begin{array}{l}1.44 \\
1.44 \\
1.44\end{array}$ & $\begin{array}{l}6.21 \\
6.21 \\
6.21\end{array}$ & $\begin{array}{l}154.0 \\
154.0 \\
154.0\end{array}$ & $\begin{array}{l}40.78 \\
40.78 \\
40.78\end{array}$ \\
\hline 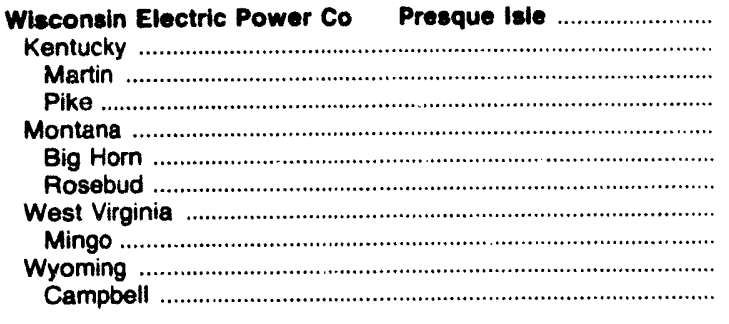 & $\begin{array}{r}1,423 \\
262 \\
138 \\
124 \\
859 \\
630 \\
228 \\
277 \\
277 \\
25 \\
25\end{array}$ & $\begin{array}{r}10,425 \\
12,986 \\
12,989 \\
12,984 \\
8,875 \\
8,873 \\
8,879 \\
12,984 \\
12,984 \\
8,538 \\
8,538\end{array}$ & $\begin{array}{l}.62 \\
.74 \\
.74 \\
.74 \\
.56 \\
.55 \\
.56 \\
.73 \\
.73 \\
.42 \\
.42\end{array}$ & $\begin{array}{l}7.14 \\
7.74 \\
7.77 \\
7.71 \\
6.83 \\
6.83 \\
6.84 \\
7.69 \\
7.69 \\
5.30 \\
5.30\end{array}$ & $\begin{array}{l}164.6 \\
145.8 \\
143.3 \\
148.6 \\
182.5 \\
184.7 \\
176.2 \\
147.1 \\
147.1 \\
125.3 \\
125.3\end{array}$ & $\begin{array}{l}34.33 \\
37.87 \\
37.22 \\
38.58 \\
32.38 \\
32.78 \\
31.28 \\
38.19 \\
38.19 \\
21.40 \\
21.40\end{array}$ \\
\hline 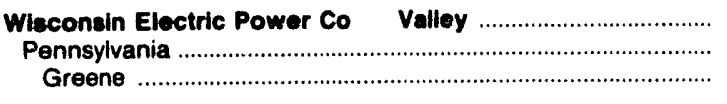 & $\begin{array}{l}520 \\
52 C \\
520\end{array}$ & $\begin{array}{l}13,229 \\
13,229 \\
13,229\end{array}$ & $\begin{array}{l}1.55 \\
1.55 \\
1.55\end{array}$ & $\begin{array}{l}6.32 \\
6.32 \\
6.32\end{array}$ & $\begin{array}{l}166.8 \\
166.8 \\
166.8\end{array}$ & $\begin{array}{l}44.13 \\
44.13 \\
44.13\end{array}$ \\
\hline 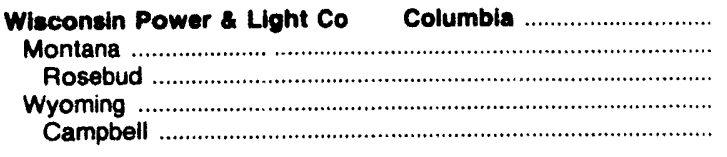 & $\begin{array}{l}3,558 \\
1,604 \\
1,604 \\
1,954 \\
1,954\end{array}$ & $\begin{array}{l}8,717 \\
8,693 \\
8,693 \\
8,737 \\
8,737\end{array}$ & $\begin{array}{l}.46 \\
.73 \\
.73 \\
.25 \\
.25\end{array}$ & $\begin{array}{l}6.54 \\
8.76 \\
8.76 \\
4.71 \\
4.71\end{array}$ & $\begin{array}{l}129.3 \\
161.5 \\
161.5 \\
103.0 \\
103.0\end{array}$ & $\begin{array}{l}22.55 \\
28.09 \\
28.09 \\
18.01 \\
18.01\end{array}$ \\
\hline 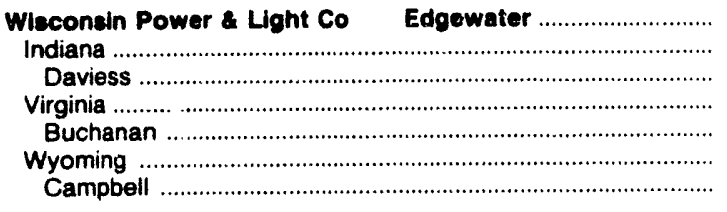 & $\begin{array}{r}2,136 \\
803 \\
803 \\
10 \\
10 \\
1,323 \\
1,323\end{array}$ & $\begin{array}{r}9,730 \\
11,209 \\
11,209 \\
14,190 \\
14,190 \\
8,798 \\
8,798\end{array}$ & $\begin{array}{r}1.05 \\
2.23 \\
2.23 \\
.70 \\
.70 \\
.33 \\
.33\end{array}$ & $\begin{array}{l}6.44 \\
9.04 \\
9.04 \\
3.92 \\
3.92 \\
4.89 \\
4.89\end{array}$ & $\begin{array}{l}150.2 \\
188.0 \\
188.0 \\
174.3 \\
174.3 \\
120.8 \\
120.8\end{array}$ & $\begin{array}{l}29.23 \\
42.14 \\
42.14 \\
49.47 \\
49.47 \\
21.25 \\
21.25\end{array}$ \\
\hline 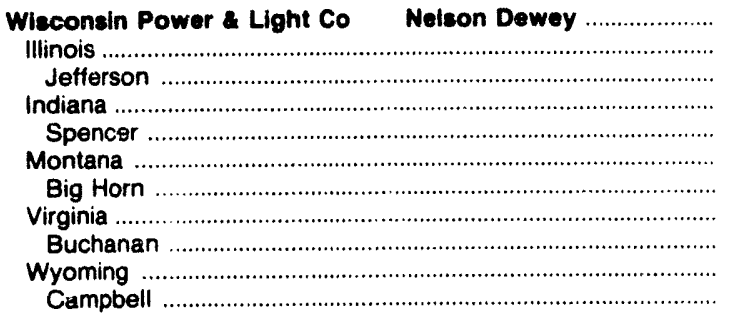 & $\begin{array}{r}447 \\
11 \\
11 \\
86 \\
86 \\
243 \\
243 \\
52 \\
52 \\
55 \\
55\end{array}$ & $\begin{array}{r}10,386 \\
12,246 \\
12,246 \\
11,596 \\
11,596 \\
9,431 \\
9,431 \\
14,109 \\
14,109 \\
8,810 \\
8,810\end{array}$ & $\begin{array}{r}.58 \\
1.04 \\
1.04 \\
1.44 \\
144 \\
.31 \\
.31 \\
.67 \\
.67 \\
.20 \\
.20\end{array}$ & $\begin{array}{l}4.40 \\
5.12 \\
5.12 \\
5.81 \\
5.81 \\
3.80 \\
3.80 \\
4.25 \\
4.25 \\
4.80 \\
4.80\end{array}$ & $\begin{array}{l}127.6 \\
136.7 \\
136.7 \\
146.7 \\
146.7 \\
115.3 \\
115.3 \\
150.7 \\
150.7 \\
108.9 \\
108.9\end{array}$ & $\begin{array}{l}26.51 \\
33.48 \\
33.48 \\
34.02 \\
34.02 \\
21.76 \\
21.76 \\
42.52 \\
42.52 \\
19.19 \\
19.19\end{array}$ \\
\hline 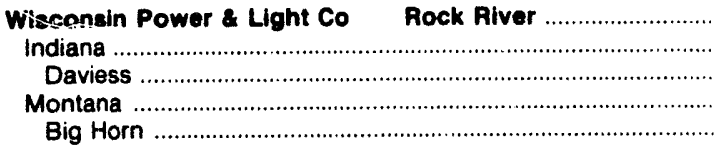 & $\begin{array}{r}191 \\
180 \\
180 \\
11 \\
11\end{array}$ & $\begin{array}{r}11,089 \\
11,186 \\
11,186 \\
9,502 \\
9,502\end{array}$ & $\begin{array}{r}1.92 \\
2.02 \\
2.02 \\
.34 \\
.34\end{array}$ & $\begin{array}{l}8.75 \\
9.05 \\
9.05 \\
3.87 \\
3.87\end{array}$ & $\begin{array}{l}195.5 \\
198.9 \\
198.9 \\
130.6 \\
130.6\end{array}$ & $\begin{array}{l}43.37 \\
44.50 \\
44.50 \\
24.82 \\
24.82\end{array}$ \\
\hline 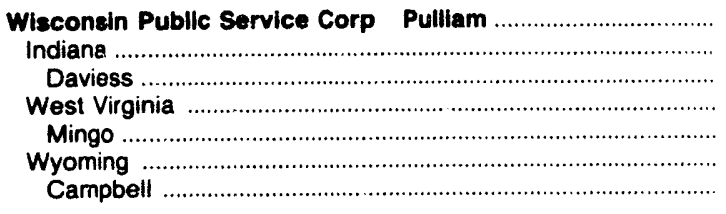 & $\begin{array}{l}594 \\
236 \\
236 \\
185 \\
185 \\
173 \\
173\end{array}$ & $\begin{array}{r}11,084 \\
11,066 \\
11,066 \\
13,236 \\
13,236 \\
8,809 \\
8,809\end{array}$ & $\begin{array}{r}1.25 \\
2.35 \\
2.35 \\
.67 \\
.67 \\
.38 \\
.38\end{array}$ & $\begin{array}{l}7.58 \\
9.92 \\
9.92 \\
7.09 \\
7.09 \\
4.93 \\
4.93\end{array}$ & $\begin{array}{l}177.1 \\
218.9 \\
218.9 \\
173.0 \\
173.0 \\
112.1 \\
112.1\end{array}$ & $\begin{array}{l}39.27 \\
48.45 \\
48.45 \\
45.81 \\
45.81 \\
19.74 \\
19.74\end{array}$ \\
\hline 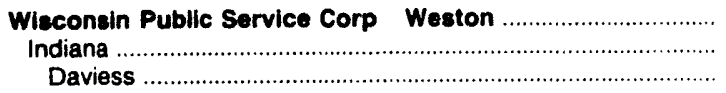 & $\begin{array}{r}1,606 \\
97 \\
97\end{array}$ & $\begin{array}{r}8,987 \\
11,029 \\
11,029\end{array}$ & $\begin{array}{r}.43 \\
1.15 \\
1.15\end{array}$ & $\begin{array}{l}5.29 \\
9.49 \\
9.49\end{array}$ & $\begin{array}{l}140.0 \\
214.8 \\
214.8\end{array}$ & $\begin{array}{l}25.17 \\
47.39 \\
47.39\end{array}$ \\
\hline
\end{tabular}

See footnotes at end of table.

Source: Federal Energy Regulatory Commission, FERC Form 423, "Monthly Report of Cost and Quality of Fuels for Electric Plants." 
Table 24. Origin of Coal Recelved by Electric Utility and Plant, 1992 (Continued)

\begin{tabular}{|c|c|c|c|c|c|c|}
\hline \multirow[b]{2}{*}{$\begin{array}{l}\text { Electric Utility Piant } \\
\text { Origin State } \\
\text { County }\end{array}$} & \multirow[b]{2}{*}{$\begin{array}{l}\text { Quantity } \\
\text { (thousand } \\
\text { short tons) }\end{array}$} & \multicolumn{3}{|c|}{ Average Quallty } & \multicolumn{2}{|c|}{ Average Dellvered Cost } \\
\hline & & $\begin{array}{l}\text { Btu } \\
\text { (per pound) }\end{array}$ & $\begin{array}{l}\text { Sul.ur } \\
\text { (percent } \\
\text { by wolght) }\end{array}$ & $\begin{array}{l}\text { Ash } \\
\text { (percont } \\
\text { by welght) }\end{array}$ & $\begin{array}{l}\text { (cents per } \\
\text { million Btu) }\end{array}$ & $\begin{array}{l}\text { (dollars per } \\
\text { short ton) }\end{array}$ \\
\hline \\
\hline $\begin{array}{l}\text { West Virginia } \\
\text { Mingo . } \\
\text { Wyoming } \\
\text { Campbell }\end{array}$ & $\begin{array}{r}19 \\
19 \\
1,490 \\
1,490\end{array}$ & $\begin{array}{r}13,331 \\
13,331 \\
8,799 \\
8,799\end{array}$ & $\begin{array}{r}0.67 \\
.67 \\
.38 \\
.38\end{array}$ & $\begin{array}{l}6.85 \\
6.85 \\
5.00 \\
5.00\end{array}$ & $\begin{array}{l}169.2 \\
169.2 \\
133.4 \\
133.4\end{array}$ & $\begin{array}{l}45.12 \\
45.12 \\
23.47 \\
23.47\end{array}$ \\
\hline 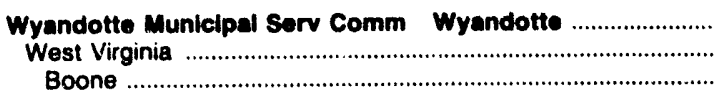 & $\begin{array}{l}104 \\
104 \\
104\end{array}$ & $\begin{array}{l}13,209 \\
13,289 \\
13,289\end{array}$ & $\begin{array}{l}.88 \\
.88 \\
.88\end{array}$ & $\begin{array}{l}5.65 \\
5.65 \\
5.65\end{array}$ & $\begin{array}{l}187.2 \\
187.2 \\
187.2\end{array}$ & $\begin{array}{l}49.75 \\
49.75 \\
49.75\end{array}$ \\
\hline Total & 775,863 & 10,305 & 1.29 & 9.71 & 141.2 & 29.36 \\
\hline
\end{tabular}

- Number less than 0.5 .

Notes: - Totals may not equal sum of components because of independent rounding. - Data are for electric generating plants with a total steam-electric and combined-cycle nameplate capacity of 50 or more megawatts.

Source: Federal Energy Regulatory Commission, FERC Form 423, "Monthly Report of Cost and Quality of Fuels for Electric Plants." 


\section{Fossil-Fuel Data at the Electric Utility and Plant Level}

This chapter provides 1992 data on the quantity, quality, and cost of fossil fuels received at the plant and electric utility level (Table 31). The fuels received by these plants are described by quantity (thousand short tons, thousand barrels, or thousand cubic feet) and cost (cents per million Btu and dollars per short ton, barrel, or thousand cubic feet). The costs reported by electric utilities include all costs incurred (including transportation, taxes, etc.) for delivery of fuel to the electric plant. In addition, coal and petroleum are described by their quality, referring to the average percentage of sulfur and ash content and the average Btu content.

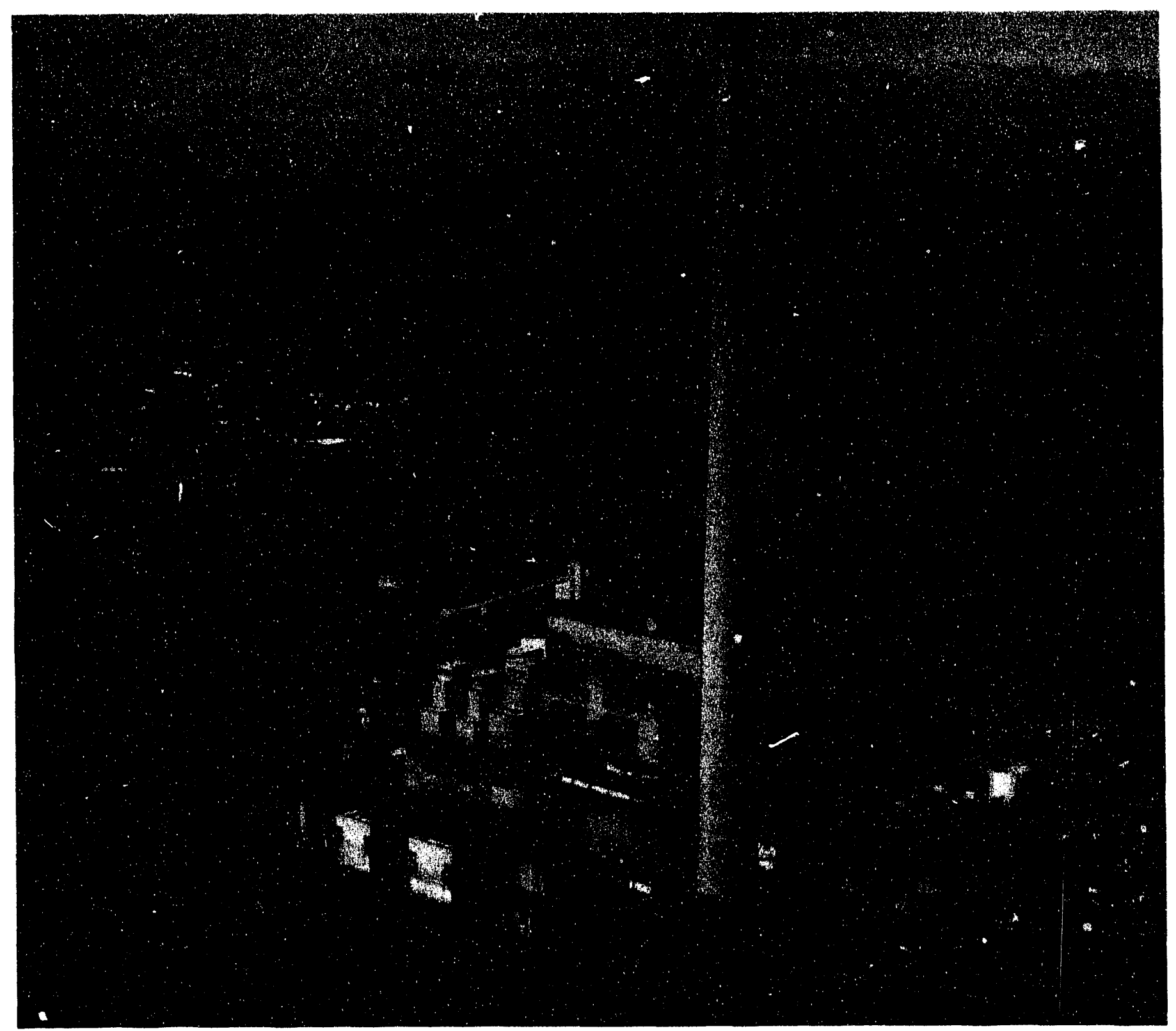

The Ohio Edison Company's R. E. Burger Station entered commercial operation in 1944. This 5-unit coal-fired plant, located on the Ohio River, has a generator nameplate capacity of 518 megawatts and burns primarily high-sulfur Ohio coal. 
Top Electric Utilities, Ranked by Receipts

Coa!

The Tennessee Valley Authority (TVA) reported the highest quantity of coal receipts of any electric utility in the Nation (Table 25). In 1992, the TVA, which operates coal-fired plants in Alabama, Kentucky, and Tennessee, received 36 million short tons of coal, an increase of 3 million short tons from 1991.

The Texas Utilities Electric Company (TU) reported the second highest quantity of coal receipts, with 33 million short tons of lignite delivered to four generating plants in Texas. Since the Btu content of lignite is approximately half that of bituminous coal, the amount of electricity that the company generated is equivalent to the generation produced from 15 to 20 million short tons of bituminous coal.

PacifiCorp ranked third in total coal receipts, with 30 million short tons received in 1992. PacifiCorp (formed by the merger of the Pacific Power \& Light Company and the Utah Power \& Light Company) operates coalfired plants in Utah, Washington, and Wyoming. PacifiCorp's plants in Utah receive mostly in-State high-Btu bituminous coal, while its Wyoming plants primarily receive subbituminous coal from Wyoming. The Georgia Power Company and the Detroit Edison Company ranked fourth and fifth, respectively, in total coal receipts.

\section{Petroleum}

Electric utilities located in Florida and New York led the list of the top 20 companies, ranked by total receipts of petroleum (Table 26). Number 6 fuel oil is the primary grade of petroleum consumed in large quantities by these electric utilities. The Florida Power \& Light Company (FP\&L) reported the highest total receipts of petroleum, 29 million barrels in 1992. The Florida Power Corporation ranked second in petroleum receipts with 11 million barrels. The Long Island Lighting Company (LILCO) ranked third with nearly 11 million barrels, its lowest total since the FERC Form 423 data collection began. Ranked fourth in terms of petroleum receipts was the Canal Electric Company (Massachusetts) at 10 million barrels. The Consolidated Edison Company of New York (ConEd) ranked fifth in total petroleum receipts, with 9 million barrels received in 1992. This is the lowest amount of petroleum received by ConEd since data collection on the FERC Form 423 began in 1972.

\section{Gas}

The top 20 electric utilities in 1992, ranked according to receipts of gas, show TU first with a level of 301 billion cubic feet (Table 27). The Pacific Gas \& Electric Company (PG\&E) ranked second in receipts of gas with 266 billion cubic feet. The Houston Lighting \& Power Company (HL\&P) ranked third with 217 billion cubic feet; The Southern California Edison Company ranked fourth; Gulf States Utilities ranked fifth with 189 billion cubic feet and 187 billion cubic feet, respectively.

Table 25. The Top 20 Electric Utilities Ranked by Receipts of Coal, 1992

\begin{tabular}{|c|c|c|c|c|}
\hline \multirow[b]{2}{*}{ Electric Utility } & \multirow{2}{*}{$\begin{array}{l}\text { Recelpts } \\
\text { (thousand } \\
\text { short tons) }\end{array}$} & \multicolumn{2}{|c|}{ Average Dellvered Cost } & \multirow{2}{*}{$\begin{array}{c}\text { Total } \\
\text { Coal Blll } \\
\text { (million dollars) }\end{array}$} \\
\hline & & $\begin{array}{l}\text { (cents per } \\
\text { million Btu) }\end{array}$ & $\begin{array}{l}\text { (dollars per } \\
\text { short ton) }\end{array}$ & \\
\hline 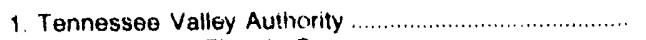 & 35,717 & 123.0 & 29.34 & $1,048.0$ \\
\hline 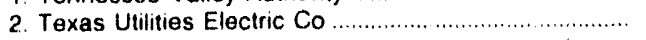 & 33,468 & 104.3 & 13.12 & 439.0 \\
\hline 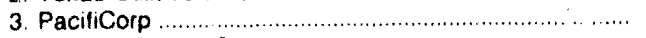 & 30,124 & 93.8 & 17.69 & 532.8 \\
\hline 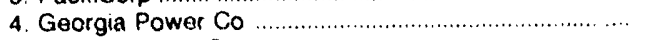 & 22,695 & 180.3 & 43.40 & 985.1 \\
\hline 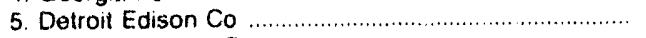 & 18,001 & 150.2 & 31.62 & 569.1 \\
\hline 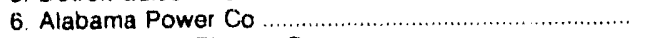 & 17,106 & 193.6 & 46.78 & 800.1 \\
\hline 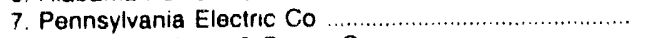 & 16.890 & 131.0 & 32.02 & 540.8 \\
\hline 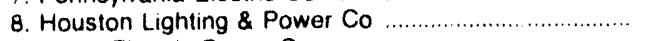 & 16.695 & 202.8 & 31.00 & 517.6 \\
\hline 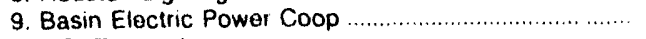 & 15,155 & 67.1 & 9.80 & 148.5 \\
\hline 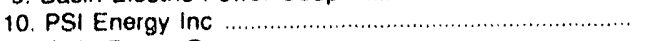 & 13,834 & 144.2 & 31.95 & 442.0 \\
\hline 11. Onio Power Co & 13,195 & 158.9 & 37.06 & 489.0 \\
\hline 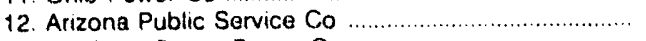 & 12.665 & 118.8 & 21.63 & 274.0 \\
\hline 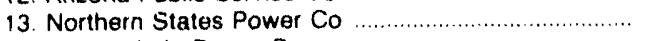 & 11,687 & 118.1 & 20.72 & 242.1 \\
\hline 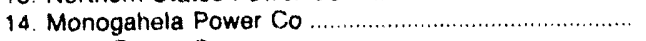 & 11,586 & 127.9 & 32.72 & 379.1 \\
\hline 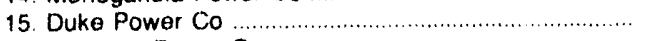 & 10,746 & 172.2 & 43.03 & 462.4 \\
\hline 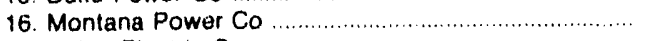 & 10,683 & 70.3 & 12.11 & 129.3 \\
\hline 17. Union Electric Co & 10.627 & 149.1 & 31.87 & 338.7 \\
\hline 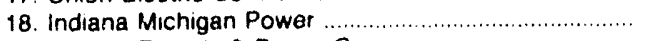 & 10,598 & 119.6 & 21.50 & 227.9 \\
\hline 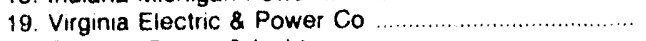 & 10,516 & 145.2 & 36.64 & 385.3 \\
\hline 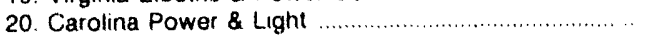 & 10,403 & 172.6 & 42.86 & 445.9 \\
\hline
\end{tabular}

Note: Data are for electric generating plants with a total steam-electric and combined-cycle nameplate capacity of 50 or more megawatts Source: Federal Energy Regulatory Commission. FERC, Form 423, "Monthly Report of Cost and Quality of Fuels for Electric Plants." 
Table 26. The Top 20 Electric Utilities Ranked by Receipts of Petroleum, 1992

\begin{tabular}{|c|c|c|c|c|}
\hline \multirow[b]{2}{*}{ Electric Utility } & \multirow{2}{*}{$\begin{array}{c}\text { Receipts } \\
\text { (thousand barrels) }\end{array}$} & \multicolumn{2}{|c|}{ Average Delivered Cost } & \multirow{2}{*}{$\begin{array}{c}\text { Total } \\
\text { Petroleum BIII } \\
\text { (million dollars) }\end{array}$} \\
\hline & & $\begin{array}{l}\text { (cents per } \\
\text { million Btu) }\end{array}$ & $\begin{array}{l}\text { (dollars per } \\
\text { barrel) }\end{array}$ & \\
\hline 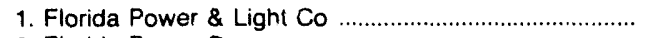 & 28,745 & 244.7 & 15.58 & 447.7 \\
\hline 2. Florida Power Corp & 10,960 & 236.6 & 15.07 & 165.1 \\
\hline 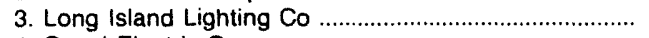 & 10,542 & 281.0 & 17.93 & 189.0 \\
\hline 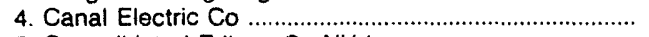 & 9,789 & 198.2 & 12.59 & 123.3 \\
\hline 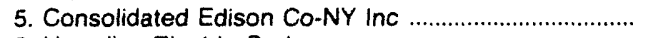 & 8,949 & 277.6 & 17.35 & 155.3 \\
\hline 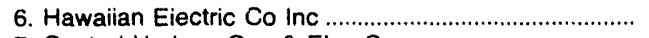 & 8,324 & 292.1 & 18.32 & 152.5 \\
\hline 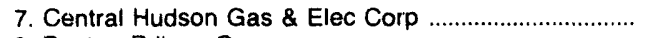 & 6,618 & 226.3 & 14.47 & 95.8 \\
\hline 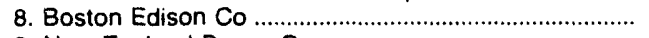 & 6,377 & 235.1 & 14.96 & 95.4 \\
\hline 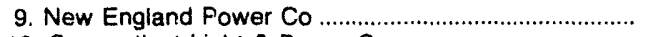 & 5,151 & 306.5 & 19.53 & 100.6 \\
\hline 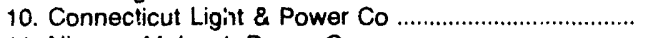 & 5,079 & 245.6 & 15.48 & 78.6 \\
\hline 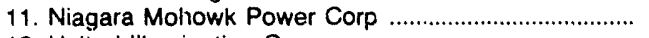 & 4,338 & 251.1 & 15.96 & 69.2 \\
\hline 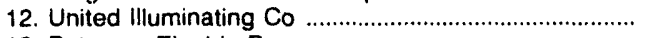 & 4,029 & 235.2 & 15.00 & 60.4 \\
\hline 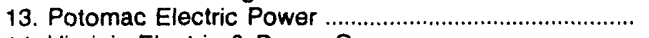 & 3,783 & 241.7 & 15.22 & 57.6 \\
\hline 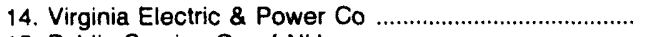 & 2,764 & 245.0 & 15.34 & 42.4 \\
\hline 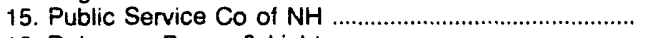 & 2,605 & 185.8 & 12.23 & 31.9 \\
\hline 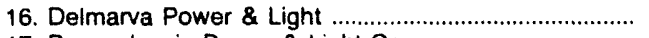 & 2,563 & 228.1 & 14.47 & 37.1 \\
\hline 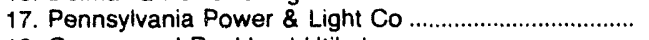 & 2,365 & 244.6 & 15.54 & 36.7 \\
\hline 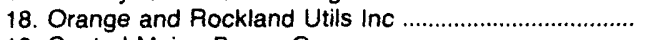 & 2,219 & 268.7 & 16.86 & 37.4 \\
\hline 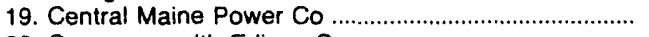 & 2,178 & 228.0 & 14.43 & 31.4 \\
\hline 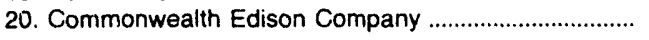 & 2,102 & 297.0 & 18.85 & 39.6 \\
\hline
\end{tabular}

Note: Data are for electric generating plants with a total steam-electric and combined-cycle nameplate capacity of 50 or more megawatts.

Source: Federal Energy Regulatory Commission, FERC Form 423. "Monthly Report of Cost and Quality of Fuels for Electric Plants."

Table 27. The Top 20 Electric Utilities Ranked by Receipts of Gas, 1992

\begin{tabular}{|c|c|c|c|c|}
\hline \multirow[b]{2}{*}{ Electric Utility } & \multirow{2}{*}{$\begin{array}{c}\text { Receipts } \\
\text { (thousand Mcf) }\end{array}$} & \multicolumn{2}{|c|}{ Average Dellvered Cost } & \multirow{2}{*}{$\begin{array}{c}\text { Total } \\
\text { Gas Bill } \\
\text { (million doliars) }\end{array}$} \\
\hline & & $\begin{array}{l}\text { (cents per } \\
\text { million Btu) }\end{array}$ & $\begin{array}{c}\text { (dollars per } \\
\text { Mcf) }\end{array}$ & \\
\hline 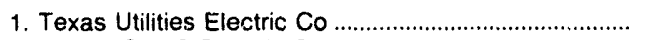 & 300,881 & 269.1 & 2.78 & 835.3 \\
\hline 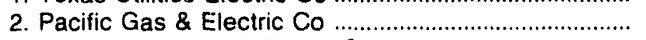 & 266,457 & 252.8 & 2.59 & 689.6 \\
\hline 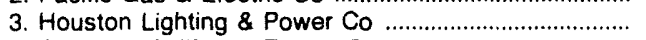 & 217,470 & 186.4 & 1.91 & 415.2 \\
\hline 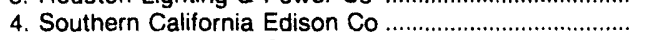 & 188,582 & 282.2 & 2.95 & 556.7 \\
\hline 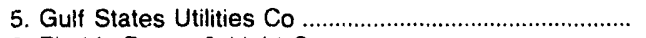 & 187,379 & 193.7 & 2.01 & 375.8 \\
\hline 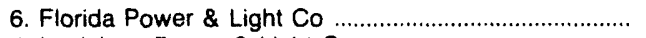 & 124,153 & 224.9 & 2.25 & 279.2 \\
\hline 7. Louisiana Power \& Light Co & 111,426 & 174.1 & 1.82 & 202.3 \\
\hline 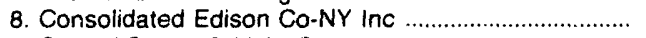 & 86,468 & 228.3 & 2.36 & 203.7 \\
\hline 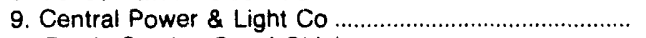 & 85,938 & 209.8 & 2.17 & 186.9 \\
\hline 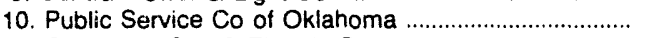 & 67,103 & 303.1 & 3.15 & 211.7 \\
\hline 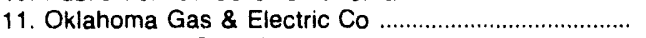 & 64.194 & 341.3 & 3.54 & 227.2 \\
\hline 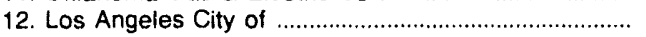 & 53.593 & 304.4 & 3.16 & 169.4 \\
\hline 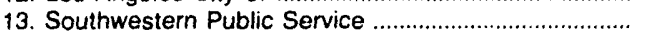 & 48,951 & 175.3 & 1.77 & 86.7 \\
\hline 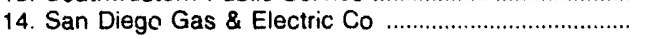 & 47,131 & 290.0 & 2.99 & 140.8 \\
\hline 15. West Texas Utilities Co & 38,846 & 200.3 & 2.03 & 78.9 \\
\hline 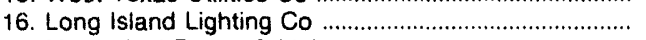 & 32,681 & 218.3 & 2.25 & 73.5 \\
\hline 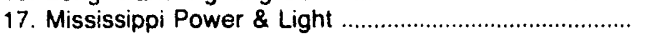 & 31,721 & 179.3 & 1.85 & 58.7 \\
\hline 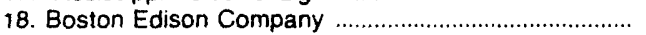 & 29,129 & 252.8 & 2.61 & 76.1 \\
\hline 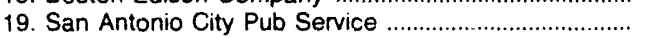 & 28,975 & 194.5 & 1.98 & 57.4 \\
\hline 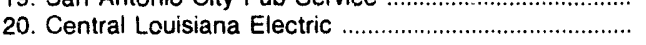 & 28,234 & 204.6 & 2.13 & 60.1 \\
\hline
\end{tabular}

Notes: - Data are for electric generating plants with a total steam-electric and combined-cycle nameplate capacity of 50 or more megawatts. - Mcf $=$ thousand cubic feet.

Source: Federal Energy Regulatory Commission, FERC Form 423, "Monthly Report of Cost and Quality of Fuels for Electric Plants." 


\section{Electric Utilities With Unique Situations}

The following Electric Utilities have unique situations that affect the quantity or cost of fuel reported on the FERC Form 423.

Alabama Power Company. All coal delivered to the Gorgas Transshipping Facility is reported as receipts to the Gorgas Plant. Large quantities of this coal are then shipped to the Barry Plant, approximately 250 miles to the south. Transportation costs for coal shipped from the Gorgas Plant to the Barry Plant are not included in this report.

Baltimore Gas \& Electric. Coal receipts for the Brandon Shores Plant are reported when received at the Newport News Virginia dock facility. Transportation costs from Newport News to the Brandon Shores Plant are included in the cost data shown in this report.

Consolidated Edison of New York. Its storage facilities 5 and 8 are located in New Jersey; facilities 3, 4, 6, and 7 are located in New York.

Atlantic City Electric Company. Coal receipts are reported only for the coal-fired unit at the Deepwater Plant that is owned by the company. Data on units owned by the Dupont Chemical Company, which is not an electric utility, are not included in this report.
Delmarva Power \& Light Company. Only the fuel receipts for Unit 3 at the Delaware City Plant are reported. Data are not reported for Units 1, 2, and 4 since they are owned by Texaco, which is not an electric utility.

Detroit Edison. The company's low cost for gas results from its purchase of large quantities of blast-furnace gas.

Florida Power Corporation. Coal shown as delivered to TTI Transfer (Kentucky), and IMT Transfer (Louisiana) is coal destined for the Crystal River plant located in Florida. Transportation costs included are only from the mine to these transfer facilities. The company incurs additional transportation costs to deliver the coal from the transfer facilities to the Crystal River Plant.

Tampa Electric. Coal destined for the Big Bend electric plant is shown as delivered to the Davant Transfer facility in Louisiana. The company incurs additional transportation cost to deliver the coal from this transfer facility to the Big Bend plant.

Table A1 in Appendix A contains a listing, by State, of the electric utilities that submit the FERC Form 423.

Table 28. Receipts of Petroleum Coke by Electric Utility, 1992

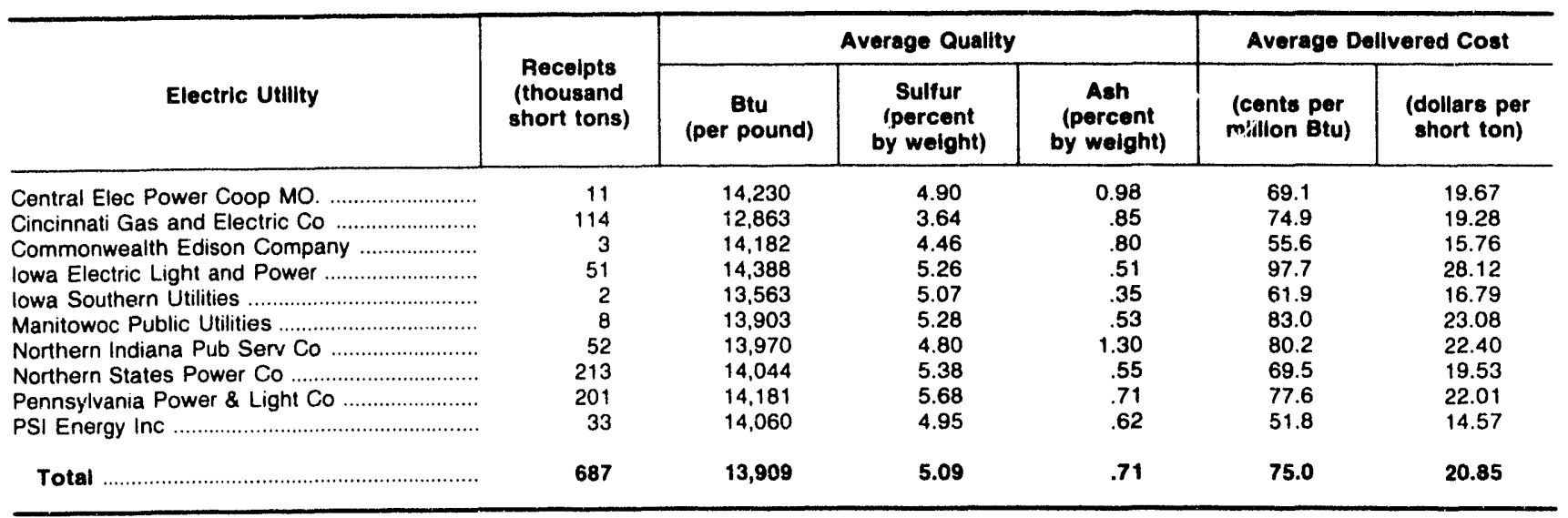

Notes: - Totals may not equal sum of components because of independent rounding. - Data are for electric generating plants with a total steam-electric and combined-cycle nameplate capacity of 50 or more megawatts.

Source: Federal Energy Regulatory Commission, FERC Form 423, "Monthly Report of Cost and Quality of Fuels for Electric Plants." 
Table 29. Recelpts of No. 6 Fuel Oll by Electric Utility, 1992

\begin{tabular}{|c|c|c|c|c|c|}
\hline \multirow[b]{2}{*}{ Company } & \multirow{2}{*}{$\begin{array}{c}\text { Recelpts } \\
\text { (thousand } \\
\text { barrela) }\end{array}$} & \multicolumn{2}{|c|}{ Average Quality } & \multicolumn{2}{|c|}{ Average Delivered Cost } \\
\hline & & $\begin{array}{c}\text { Btu } \\
\text { (per gallon) }\end{array}$ & $\begin{array}{c}\text { Sulfur } \\
\text { (fercent } \\
\text { by welght) }\end{array}$ & $\begin{array}{l}\text { (cents per } \\
\text { million Btu) }\end{array}$ & $\begin{array}{c}\text { (dollars } \\
\text { per barrel) }\end{array}$ \\
\hline Atlantic City Electric Co & 100 & 151,992 & 0.97 & 265.0 & 16.92 \\
\hline Baltimore Gas \& Electric Co ................................ & 710 & 151,183 & .98 & 230.0 & $14.6 !$ \\
\hline 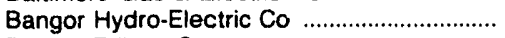 & 19 & 151,907 & .67 & 316.0 & 20.16 \\
\hline 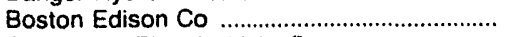 & 6,354 & 151,556 & .79 & 234.4 & 14.92 \\
\hline Cambridge Electric Light Co .............................. & 176 & 151,179 & .48 & 258.8 & 16.43 \\
\hline Canal Electric Co & $9.10 \%$ & 151,267 & 1.91 & 198.2 & 12.59 \\
\hline 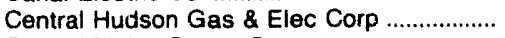 & 6,612 & 152,296 & 1.11 & 226.1 & 14.46 \\
\hline Central Maine Power Co ..................................... & 2,158 & 150,796 & .95 & 226.2 & 14.32 \\
\hline 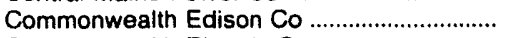 & 1,867 & 152,723 & .69 & 291.2 & 18.03 \\
\hline Commonwealth Electric Co ................................. & 29 & 151,424 & .97 & 221.7 & 14.10 \\
\hline Connecticut Light \& Power Co ........................... & 5,055 & 150,176 & .82 & 244.5 & 15.42 \\
\hline Consolidated Edison Co-NY Inc ........................ & 8,949 & 148,837 & .27 & 277.6 & 17.35 \\
\hline 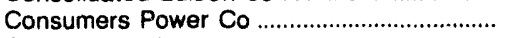 & 476 & 153,462 & .96 & 232.8 & 15.01 \\
\hline 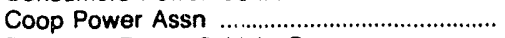 & 4 & 147,000 & 2.50 & 245.5 & 15.16 \\
\hline 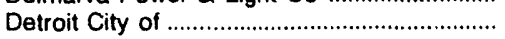 & 181 & 143,423 & .7 & 275.4 & 16.59 \\
\hline 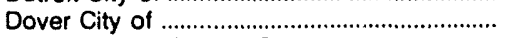 & 439 & 150,212 & 1.4 & 255.8 & 16.14 \\
\hline 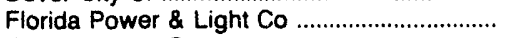 & 28,745 & 151,537 & 1.4 & 244.7 & 15.58 \\
\hline 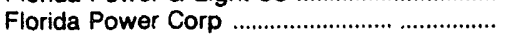 & 10,827 & 151,732 & 1.4 & 234.3 & 14.93 \\
\hline 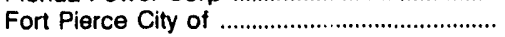 & 1 & 143,184 & .7 & 318.5 & 19.15 \\
\hline 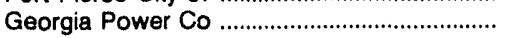 & 40 & 149,500 & 2.1 & 304.9 & 19.14 \\
\hline 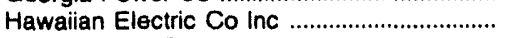 & 8,324 & 149,295 & .4 & 292.1 & 18.32 \\
\hline 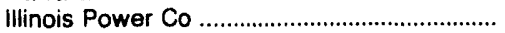 & 63 & 150,000 & .8 & 277.7 & 17.50 \\
\hline Jacksonville Electric Auth ................................. & 1,730 & 151,460 & 1.7 & 197.1 & 12.54 \\
\hline Jersey Central Power\&Light Co ......................... & 96 & 151,206 & .6 & 313.7 & 19.92 \\
\hline Lakeland City of & 101 & 149,559 & 2.2 & 261.3 & 16.41 \\
\hline 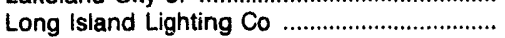 & 10,542 & 151,940 & .9 & 281.0 & 17.93 \\
\hline 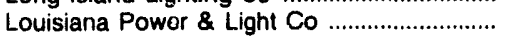 & 14 & 150,602 & 1.0 & 220.0 & 13.91 \\
\hline Mississippi Power \& Light Co .............................. & 572 & 153,458 & 2.9 & 185.0 & 11.93 \\
\hline 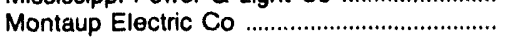 & 93 & 151,601 & 1.1 & 243.6 & 15.51 \\
\hline Nevada Power Co & 17 & 154,762 & .4 & 365.6 & 23.76 \\
\hline 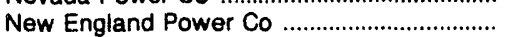 & 5,151 & 151,701 & 2.0 & 306.5 & 19.53 \\
\hline New Orleans Public Service Inc ...................... & 3 & 150,751 & 1.4 & 196.0 & 12.41 \\
\hline Nitigara Mohawk Power Corp .......................... & 4,303 & 151,406 & 1.2 & 249.5 & 15.87 \\
\hline Pennsylvania Power \& Light Co .................... & 2,153 & 152,385 & .8 & 228.5 & 14.63 \\
\hline Philadelphia Electric Co ...................................... & 835 & 152,343 & .4 & 287.8 & 18.42 \\
\hline Potomac Electric Power Co ................................ & 3,282 & 151,393 & 1.5 & 220.1 & 13.99 \\
\hline Power Authority of State of NY ........................ & 905 & 148,647 & .3 & 269.8 & 16.84 \\
\hline Public Service Co of NH ................................ & 2,574 & 156,976 & 1.7 & 183.1 & 12.07 \\
\hline Public Service Electric\&Gas Co ......................... & 1.178 & 148,687 & .3 & 320.2 & 20.00 \\
\hline 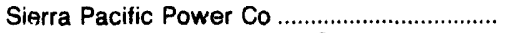 & 352 & 147,964 & .8 & 320.8 & 19.93 \\
\hline Southern California Edison Co ........................... & 1 & 144,857 & $\cdot$ & 217.9 & 13.26 \\
\hline St Joseph Light \& Power Co .............................. & 189 & 154,515 & 2.6 & 145.3 & 9.43 \\
\hline Tampa Electric Co . .......................................... & 564 & 151,961 & 1.0 & 266.9 & 17.04 \\
\hline 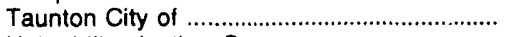 & 89 & 149,148 & 2.0 & 227.9 & 14.28 \\
\hline 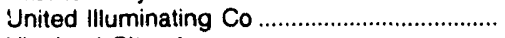 & 4,019 & 151,801 & 1.0 & 234.8 & 14.97 \\
\hline Vineland City of & 131 & 150,907 & .9 & 263.6 & 16.71 \\
\hline Virginia Electric \& Power Co ............................... & 2,622 & 149,539 & 1.0 & 232.9 & 14.63 \\
\hline Western Massachusetts Elec Co ...................... & 192 & 151,653 & 1.0 & 247.7 & 15.78 \\
\hline Total & 138,261 & 151,245 & 1.13 & 247.28 & 15.71 \\
\hline
\end{tabular}

- = Number less than 0.5 .

Notes: - Totals may not equal sum of components because of independent rounding. - Data are for electric generating plants with a total steam-electric and combined-cycle nameplate capacity of 50 or more megawatts.

Source: Federal Energy Regulatory Commission, FERC Form 423, "Monthly Report of Cost and Quality of Fuels for Electric Plants." 
Table 30. Receipts and Average Delivered Cost of Coal by Type of Purchase, Electric, Utility and Plant, 1992

\begin{tabular}{|c|c|c|c|c|c|c|c|c|c|c|c|c|}
\hline \multirow{3}{*}{$\begin{array}{l}\text { Electric Utility } \\
\text { Plant (State) }\end{array}$} & \multicolumn{6}{|c|}{ Contract } & \multicolumn{6}{|c|}{ Spot } \\
\hline & \multirow{2}{*}{$\begin{array}{l}\text { Recelpts } \\
\text { (1000 } \\
\text { short } \\
\text { tons) }\end{array}$} & \multicolumn{3}{|c|}{ Average Quality } & \multicolumn{2}{|c|}{$\begin{array}{c}\text { Average } \\
\text { Delivered Cost }\end{array}$} & \multirow{2}{*}{$\begin{array}{c}\text { Peceipts } \\
\text { (1000 } \\
\text { short } \\
\text { tons) }\end{array}$} & \multicolumn{3}{|c|}{ Average Quality } & \multicolumn{2}{|c|}{$\begin{array}{l}\text { Average } \\
\text { Delivered } \\
\text { Cost }\end{array}$} \\
\hline & & $\begin{array}{c}\text { Btu } \\
\text { (per } \\
\text { pound) }\end{array}$ & $\begin{array}{c}\text { Sulfur } \\
\text { (percent } \\
\text { by } \\
\text { weight) }\end{array}$ & $\begin{array}{c}\text { Ash } \\
\text { (percent } \\
\text { by } \\
\text { weight) }\end{array}$ & $\begin{array}{l}\text { (cents } \\
\text { per } \\
\text { million } \\
\text { Btu) }\end{array}$ & $\begin{array}{c}(\$ \\
\text { per } \\
\text { short } \\
\text { ton) }\end{array}$ & & $\begin{array}{c}\text { Btu } \\
\text { (per } \\
\text { pound) }\end{array}$ & $\begin{array}{c}\text { Sulfur } \\
\text { (percent } \\
\text { by } \\
\text { welght) }\end{array}$ & $\begin{array}{c}\text { Ash } \\
\text { (percent } \\
\text { by } \\
\text { welght) }\end{array}$ & $\begin{array}{c}\text { (cents } \\
\text { per } \\
\text { million } \\
\text { Btu) }\end{array}$ & $\begin{array}{l}\text { (s } \\
\text { per } \\
\text { short } \\
\text { ton) }\end{array}$ \\
\hline $\begin{array}{l}\text { Alabama Electric Coop Inc } \\
\text { Lowman (AL) } \ldots \ldots \ldots \ldots \ldots \ldots \ldots \ldots \ldots \ldots \ldots \ldots \ldots \ldots \ldots\end{array}$ & $\begin{array}{l}787 \\
787\end{array}$ & $\begin{array}{l}12,076 \\
12,076\end{array}$ & $\begin{array}{l}1.41 \\
1.41\end{array}$ & $\begin{array}{l}12.01 \\
12.01\end{array}$ & $\begin{array}{l}152.3 \\
152.3\end{array}$ & $\begin{array}{l}36.79 \\
36.79\end{array}$ & $\begin{array}{l}608 \\
608\end{array}$ & $\begin{array}{l}12,281 \\
12,281\end{array}$ & $\begin{array}{l}1.14 \\
1.14\end{array}$ & $\begin{array}{l}12.24 \\
12.24\end{array}$ & $\begin{array}{l}143.1 \\
143.1\end{array}$ & $\begin{array}{l}35.14 \\
35.14\end{array}$ \\
\hline 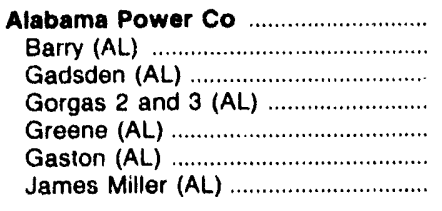 & $\begin{array}{r}15,041 \\
792 \\
135 \\
5,157 \\
1,169 \\
3,782 \\
4,005\end{array}$ & $\begin{array}{l}12,099 \\
12,341 \\
12,530 \\
11,799 \\
12,274 \\
12,059 \\
12,409\end{array}$ & $\begin{array}{r}1.16 \\
.92 \\
1.79 \\
1.18 \\
1.40 \\
1.66 \\
.61\end{array}$ & $\begin{array}{r}12.02 \\
11.25 \\
12.45 \\
13.65 \\
9.00 \\
11.92 \\
11.02\end{array}$ & $\begin{array}{l}202.6 \\
216.5 \\
182.7 \\
186.3 \\
142.0 \\
175.7 \\
263.6\end{array}$ & $\begin{array}{l}49.08 \\
53.43 \\
45.80 \\
43.96 \\
34.86 \\
42.37 \\
65.41\end{array}$ & $\begin{array}{r}2,065 \\
40 \\
-- \\
1,438 \\
176 \\
58 \\
353\end{array}$ & $\begin{array}{r}11,973 \\
11,718 \\
11,932 \\
11,867 \\
12,055 \\
12,207\end{array}$ & $\begin{array}{r}1.63 \\
1.01 \\
- \\
1.87 \\
1.96 \\
1.92 \\
.53\end{array}$ & $\begin{array}{r}12.76 \\
12.24 \\
-- \\
13.00 \\
12.93 \\
12.24 \\
11.85\end{array}$ & $\begin{array}{r}125.2 \\
142.4 \\
121.4 \\
125.5 \\
113.3 \\
140.4\end{array}$ & $\begin{array}{r}29.98 \\
33.37 \\
-- \\
28.96 \\
29.78 \\
27.31 \\
34.27\end{array}$ \\
\hline $\begin{array}{l}\text { American Mun Power Ohio Inc ........ } \\
\text { Gorsuch }(\mathrm{OH})\end{array}$ & $-\infty$ & - & -- & -- & -- & -- & $\begin{array}{l}891 \\
891\end{array}$ & $\begin{array}{l}11,337 \\
11,337\end{array}$ & $\begin{array}{l}4.55 \\
4.55\end{array}$ & $\begin{array}{l}14.59 \\
14.59\end{array}$ & $\begin{array}{l}96.9 \\
96.9\end{array}$ & $\begin{array}{l}21.96 \\
21.96\end{array}$ \\
\hline Ames Clty of & $\begin{array}{l}156 \\
156\end{array}$ & $\begin{array}{l}8,762 \\
8,762\end{array}$ & $\begin{array}{l}.19 \\
.19\end{array}$ & $\begin{array}{l}4.59 \\
4.59\end{array}$ & $\begin{array}{l}132.8 \\
132.8\end{array}$ & $\begin{array}{l}23.28 \\
23.28\end{array}$ & -- & - & - & - & -- & $\overline{--}$ \\
\hline 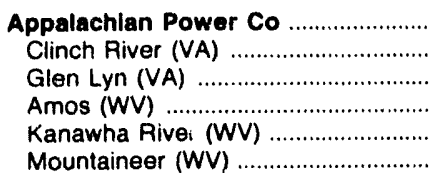 & $\begin{array}{r}8,543 \\
1.194 \\
448 \\
4,244 \\
368 \\
2,289\end{array}$ & $\begin{array}{l}12,488 \\
12,631 \\
12,892 \\
12,378 \\
12,578 \\
12,523\end{array}$ & $\begin{array}{l}.76 \\
.75 \\
.91 \\
.79 \\
.80 \\
.68\end{array}$ & $\begin{array}{l}11.16 \\
12.61 \\
10.12 \\
11.27 \\
11.49 \\
10.37\end{array}$ & $\begin{array}{l}175.4 \\
134.7 \\
138.6 \\
193.5 \\
172.6 \\
171.4\end{array}$ & $\begin{array}{l}43.80 \\
34.02 \\
35.75 \\
47.90 \\
43.41 \\
42.93\end{array}$ & $\begin{array}{r}514 \\
509 \\
4 \\
-- \\
--\end{array}$ & $\begin{array}{r}12,469 \\
12,468 \\
12,530 \\
-- \\
-- \\
--\end{array}$ & $\begin{array}{l}.76 \\
.76 \\
.90 \\
-- \\
-- \\
--\end{array}$ & $\begin{array}{r}13.20 \\
13.22 \\
10.81 \\
-- \\
-- \\
--\end{array}$ & $\begin{array}{r}114.2 \\
114.0 \\
131.1 \\
-- \\
-- \\
--\end{array}$ & $\begin{array}{r}28.47 \\
28.44 \\
32.85 \\
-- \\
-- \\
--\end{array}$ \\
\hline $\begin{array}{l}\text { Arizona Electric Pwr Coop Inc } \ldots \ldots . . . \\
\text { Apache (AZ) }\end{array}$ & $\begin{array}{l}119 \\
119\end{array}$ & $\begin{array}{l}12,158 \\
12,158\end{array}$ & .41 & $\begin{array}{l}15.76 \\
15.76\end{array}$ & $\begin{array}{l}167.5 \\
167.5\end{array}$ & $\begin{array}{l}40.74 \\
40.74\end{array}$ & $\begin{array}{l}86 \\
86\end{array}$ & $\begin{array}{l}9,984 \\
9,984\end{array}$ & $\begin{array}{l}.43 \\
.43\end{array}$ & $\begin{array}{l}12.42 \\
12.42\end{array}$ & $\begin{array}{l}127.7 \\
127.7\end{array}$ & $\begin{array}{l}25.50 \\
25.50\end{array}$ \\
\hline $\begin{array}{l}\text { Arizona Public Service Co } \\
\text { Cholla (AZ) } \\
\text { Four Corners (NM) }\end{array}$ & $\begin{array}{r}11,336 \\
2,401 \\
8,935\end{array}$ & $\begin{array}{l}9,025 \\
9,834 \\
8,808\end{array}$ & $\begin{array}{l}.72 \\
.44 \\
.79\end{array}$ & $\begin{array}{l}20.35 \\
13.68 \\
22.14\end{array}$ & $\begin{array}{l}121.2 \\
169.8 \\
106.7\end{array}$ & $\begin{array}{l}21.88 \\
33.39 \\
18.79\end{array}$ & $\begin{array}{r}1,329 \\
1,329 \\
-\cdots\end{array}$ & $\begin{array}{r}9,786 \\
9,786 \\
--\end{array}$ & $\begin{array}{r}.45 \\
.45 \\
--\end{array}$ & $\begin{array}{r}14.27 \\
14.27 \\
--\end{array}$ & $\begin{array}{r}99.7 \\
99.7 \\
--\end{array}$ & $\begin{array}{r}19.51 \\
19.51 \\
-\end{array}$ \\
\hline 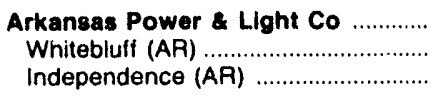 & $\begin{array}{l}9,967 \\
4,953 \\
5,014\end{array}$ & $\begin{array}{l}8,787 \\
8,730 \\
8,843\end{array}$ & $\begin{array}{l}.32 \\
.43 \\
.21\end{array}$ & $\begin{array}{l}5.20 \\
5.70 \\
4.71\end{array}$ & $\begin{array}{l}166.9 \\
173.0 \\
161.0\end{array}$ & $\begin{array}{l}29.33 \\
30.21 \\
28.47\end{array}$ & $\begin{array}{l}-- \\
--\end{array}$ & $\begin{array}{l}-- \\
--\end{array}$ & -- & $\begin{array}{l}-- \\
--\end{array}$ & -- & $\begin{array}{l}-- \\
--\end{array}$ \\
\hline $\begin{array}{l}\text { Associated Electric Coop inc } \\
\text { Madrid (MO) } \\
\text { Hill (MO) }\end{array}$ & $\begin{array}{l}5,238 \\
2,732 \\
2,506\end{array}$ & $\begin{array}{l}10,730 \\
10,890 \\
10,555\end{array}$ & $\begin{array}{l}3.60 \\
3.06 \\
4.19\end{array}$ & $\begin{array}{r}9.96 \\
9.74 \\
10.19\end{array}$ & $\begin{array}{l}138.9 \\
116.0 \\
164.8\end{array}$ & $\begin{array}{l}29.82 \\
25.25 \\
34.79\end{array}$ & $\begin{array}{r}116 \\
-\overline{116}\end{array}$ & $\begin{array}{r}8,844 \\
-\overline{8,844}\end{array}$ & $\frac{.21}{21}$ & $\begin{array}{r}4.57 \\
-\overline{-57}\end{array}$ & $\begin{array}{r}121.8 \\
-\overline{-} \\
121.8\end{array}$ & $\begin{array}{r}21.54 \\
21.54\end{array}$ \\
\hline $\begin{array}{l}\text { Atlantlc Clty Electric Co } \\
\text { England }(\mathrm{N} J) \\
\text { Deepwater }(\mathrm{NJ})\end{array}$ & $\begin{array}{l}765 \\
629 \\
136\end{array}$ & $\begin{array}{l}12,960 \\
13,015 \\
12,707\end{array}$ & $\begin{array}{r}2.13 \\
2.43 \\
.76\end{array}$ & $\begin{array}{r}9.21 \\
8.97 \\
10.30\end{array}$ & $\begin{array}{l}168.3 \\
166.3 \\
177.5\end{array}$ & $\begin{array}{l}43.61 \\
43.29 \\
45.12\end{array}$ & $\begin{array}{r}30 \\
23 \\
7\end{array}$ & $\begin{array}{l}13,246 \\
13,443 \\
12,654\end{array}$ & $\begin{array}{r}2.02 \\
2.39 \\
.91\end{array}$ & $\begin{array}{r}8.05 \\
7.07 \\
11.00\end{array}$ & $\begin{array}{l}153.1 \\
149.4 \\
164.7\end{array}$ & $\begin{array}{l}40.55 \\
40.18 \\
41.68\end{array}$ \\
\hline $\begin{array}{l}\text { Baltimore Gas \& Electric Co } \\
\text { Brandon Shores (MD) } \\
\text { Crane (MD) } \\
\text { Wagner (MD) }\end{array}$ & $\begin{array}{r}3,370 \\
2,093 \\
488 \\
789\end{array}$ & $\begin{array}{l}12,872 \\
12,699 \\
13,377 \\
13,018\end{array}$ & $\begin{array}{r}.94 \\
.68 \\
2.20 \\
.86\end{array}$ & $\begin{array}{l}8.98 \\
9.76 \\
6.61 \\
8.35\end{array}$ & $\begin{array}{l}156.0 \\
155.7 \\
142.6 \\
165.3\end{array}$ & $\begin{array}{l}40.16 \\
39.54 \\
38.16 \\
43.03\end{array}$ & $\begin{array}{r}769 \\
440 \\
237 \\
92\end{array}$ & $\begin{array}{l}13,036 \\
12,768 \\
13,598 \\
12,869\end{array}$ & $\begin{array}{r}1.01 \\
.69 \\
1.67 \\
.82\end{array}$ & $\begin{array}{l}6.38 \\
9.39 \\
6.49 \\
8.42\end{array}$ & $\begin{array}{l}145.3 \\
143.2 \\
148.6 \\
146.3\end{array}$ & $\begin{array}{l}37.89 \\
36.58 \\
40.40 \\
37.66\end{array}$ \\
\hline $\begin{array}{l}\text { Basin Electric Power Coop .............. } \\
\text { Leland Olds (ND) } \\
\text { Laramie River (WY) } \\
\text { Antelope Valley (ND) }\end{array}$ & $\begin{array}{r}15,155 \\
3,047 \\
6,914 \\
5,193\end{array}$ & $\begin{array}{l}7,302 \\
6,427 \\
8,207 \\
6,612\end{array}$ & $\begin{array}{r}.66 \\
.66 \\
.35 \\
1.08\end{array}$ & $\begin{array}{l}7.43 \\
9.13 \\
5.09 \\
9.53\end{array}$ & $\begin{array}{l}67.1 \\
95.9 \\
52.7 \\
74.4\end{array}$ & $\begin{array}{r}9.80 \\
12.33 \\
8.64 \\
9.84\end{array}$ & $\begin{array}{l}-- \\
-- \\
--\end{array}$ & $\begin{array}{l}- \\
-- \\
--\end{array}$ & $\begin{array}{l}-- \\
-- \\
-- \\
--\end{array}$ & $\begin{array}{l}-- \\
-- \\
--\end{array}$ & $\begin{array}{l}-- \\
-- \\
--\end{array}$ & $\begin{array}{l}-- \\
--\end{array}$ \\
\hline 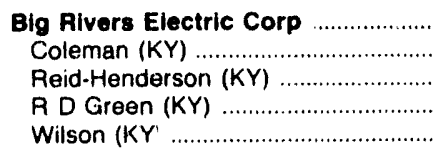 & $\begin{array}{r}4,534 \\
1,133 \\
658 \\
1,482 \\
1,260\end{array}$ & $\begin{array}{l}11,270 \\
11,267 \\
12,210 \\
10,492 \\
11,698\end{array}$ & $\begin{array}{l}3.09 \\
2.54 \\
2.33 \\
3.78 \\
3.17\end{array}$ & $\begin{array}{r}11.72 \\
8.08 \\
9.42 \\
16.15 \\
11.00\end{array}$ & $\begin{array}{r}121.3 \\
97.4 \\
121.4 \\
119.0 \\
144.3\end{array}$ & $\begin{array}{l}27.34 \\
21.95 \\
29.65 \\
24.96 \\
33.77\end{array}$ & $\begin{array}{l}-- \\
-- \\
-- \\
--\end{array}$ & $\begin{array}{l}-- \\
-- \\
-- \\
--\end{array}$ & $\begin{array}{l}-- \\
-- \\
--\end{array}$ & $\begin{array}{l}- \\
- \\
-- \\
--\end{array}$ & $\begin{array}{l}-- \\
-- \\
-- \\
--\end{array}$ & $\begin{array}{l}-- \\
-- \\
-- \\
--\end{array}$ \\
\hline $\begin{array}{c}\text { Cajun Electric Power Coop Inc } \\
\text { Big Cajun No...... }\end{array}$ & $\begin{array}{l}5,344 \\
5,344\end{array}$ & $\begin{array}{l}8,368 \\
8,368\end{array}$ & $\begin{array}{l}.46 \\
.46\end{array}$ & $\begin{array}{l}5.30 \\
5.30\end{array}$ & $\begin{array}{l}147.5 \\
147.5\end{array}$ & $\begin{array}{l}24.69 \\
24.69\end{array}$ & $\overline{--}$ & -- & -- & -- & - & -- \\
\hline $\begin{array}{l}\text { Cardinal Operating Co } \\
\text { Cardinal }(\mathrm{OH})\end{array}$ & $\begin{array}{l}3,887 \\
3,887\end{array}$ & $\begin{array}{l}11,822 \\
11,822\end{array}$ & $\begin{array}{l}2.10 \\
2.10\end{array}$ & $\begin{array}{l}12.95 \\
12.95\end{array}$ & $\begin{array}{l}152.3 \\
152.3\end{array}$ & $\begin{array}{l}36.00 \\
36.00\end{array}$ & $\begin{array}{l}390 \\
390\end{array}$ & $\begin{array}{l}12,045 \\
12,045\end{array}$ & $\begin{array}{l}2.71 \\
2.71\end{array}$ & $\begin{array}{l}\mathbf{1 2 . 1 4} \\
12.14\end{array}$ & $\begin{array}{l}106.3 \\
06.3\end{array}$ & $\begin{array}{l}25.60 \\
25.60\end{array}$ \\
\hline
\end{tabular}

See footnotes at end of table.

Source: Federal Energy Regulatory Commission, FERC Form 423, "Monthly Report of Cost and Quality of Fuels for Electric Plants." 
Table 30. Receipts and Average Delivered Cost of Coal by Type of Purchase, Electric, Utility and Plant, 1992 (Continued)

\begin{tabular}{|c|c|c|c|c|c|c|c|c|c|c|c|c|}
\hline \multirow{3}{*}{$\begin{array}{l}\text { Electric Utility } \\
\text { Plant (State) }\end{array}$} & \multicolumn{6}{|c|}{ Contract } & \multicolumn{6}{|c|}{ Spot } \\
\hline & \multirow{2}{*}{$\begin{array}{l}\text { Receipts } \\
\text { (1000 } \\
\text { short } \\
\text { tons) }\end{array}$} & \multicolumn{3}{|c|}{ Average Quality } & \multicolumn{2}{|c|}{$\begin{array}{c}\text { Average } \\
\text { Dellvered Cost }\end{array}$} & \multirow{2}{*}{$\begin{array}{l}\text { Recelpts } \\
\text { (1000 } \\
\text { short } \\
\text { tons) }\end{array}$} & \multicolumn{3}{|c|}{ Average Quality } & \multicolumn{2}{|c|}{$\begin{array}{c}\text { Average } \\
\text { Delivered } \\
\text { Cost }\end{array}$} \\
\hline & & $\begin{array}{c}\text { Btu } \\
\text { (per } \\
\text { pound) }\end{array}$ & $\begin{array}{c}\text { Sulfur } \\
\text { (percent } \\
\text { by } \\
\text { weight) }\end{array}$ & $\begin{array}{c}\text { Ash } \\
\text { (percent } \\
\text { by } \\
\text { welght) }\end{array}$ & $\begin{array}{l}\text { (cents } \\
\text { per } \\
\text { million } \\
\text { Btu) }\end{array}$ & $\begin{array}{c}\text { (S } \\
\text { per } \\
\text { short } \\
\text { ton) }\end{array}$ & & $\begin{array}{c}\text { Btu } \\
\text { (per } \\
\text { pound) }\end{array}$ & $\begin{array}{c}\text { Sulfur } \\
\text { (percent } \\
\text { by } \\
\text { weight) }\end{array}$ & $\begin{array}{c}\text { Ash } \\
\text { (percent } \\
\text { by } \\
\text { welght) }\end{array}$ & $\begin{array}{c}\text { (cents } \\
\text { per } \\
\text { million } \\
\text { Btu) }\end{array}$ & $\begin{array}{l}\text { (s } \\
\text { per } \\
\text { short } \\
\text { ton) }\end{array}$ \\
\hline Carolina Power \& Light Co .............. & 8,226 & 12,408 & 0.88 & 10.46 & 180.1 & 44.70 & 2,177 & 12,452 & 0.85 & 9.87 & 144.2 & 35.90 \\
\hline Asheville (NC) & 755 & 13,087 & 1.18 & 8.79 & 132.8 & 34.75 & 34 & 12,940 & 1.24 & 9.14 & 139.9 & 36.20 \\
\hline Cape Fear (NC) & 331 & 12,781 & .97 & 8.46 & $2: 1.7$ & 54.11 & 96 & 12,810 & .98 & 9.26 & 146.7 & 37.59 \\
\hline Lee (NC) & 418 & 12,808 & 1.01 & 8.62 & 208.0 & 53.29 & 162 & 12,347 & .91 & 10.41 & 144.8 & 35.76 \\
\hline Roxboro (NC) & 4,932 & 12,339 & .88 & 10.67 & 179.4 & 44.27 & 805 & 12,519 & .73 & 9.22 & 138.2 & 34.59 \\
\hline Sutton (NC) & 168 & 12,451 & .93 & 11.07 & 171.6 & 42.74 & 599 & 12,431 & .92 & 10.16 & 150.4 & 37.40 \\
\hline 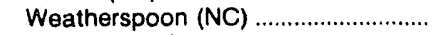 & 86 & 12,694 & .98 & 9.94 & 177.3 & 45.01 & 153 & 12,253 & 1.12 & 9.96 & 153.2 & 37.55 \\
\hline Robinson (SC) & 158 & 12,416 & 1.08 & 9.15 & 184.9 & 45.92 & 113 & 12,494 & 1.00 & 9.18 & 152.5 & 38.11 \\
\hline Mayo (NC) & 1,378 & 12,048 & .64 & 11.77 & 194.6 & 46.88 & 216 & 12,218 & .67 & 11.70 & 137.5 & 33.60 \\
\hline Cedar Falls City of .................................. & -- & - & -- & - & -- & - & 10 & 11,188 & 2.72 & 9.11 & 140.9 & 31.54 \\
\hline 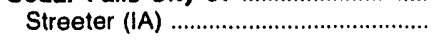 & -- & - & - & -- & -- & -- & 10 & $11.18 \mathrm{R}$ & 2.72 & 9.11 & 140.9 & 31.54 \\
\hline Central Electric Pwr Coop-MO ........ & - & -- & -- & - & -- & -- & 83 & 10,971 & 3.14 & 9.90 & 118.5 & 26.00 \\
\hline Chamois (MO) & -- & -- & -- & -- & -- & -- & 83 & 10,971 & 3.14 & 9.90 & 118.5 & 26.00 \\
\hline Central Hudson Gas \& Elec Corp ... & 701 & 13,034 & .60 & 7.57 & 182.2 & 47.51 & 180 & 12,955 & .58 & 7.22 & 181,4 & 47.00 \\
\hline 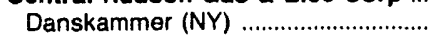 & 701 & 13,034 & .60 & 7.57 & 182.2 & 47.51 & 180 & 12,955 & .58 & 7.22 & 181.4 & 47.00 \\
\hline Central Illinois Light Co ...................... & 1,742 & 11,833 & 2.18 & 7.15 & 173.0 & 40.93 & 525 & 12,361 & 1.38 & 7.03 & 152.7 & 37.75 \\
\hline 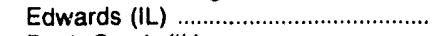 & 804 & 13,118 & .82 & 6.23 & 174.7 & 45.84 & 449 & 12,642 & 1.08 & 6.89 & 160.4 & 40.55 \\
\hline 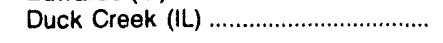 & 938 & 10,733 & 3.33 & 7.94 & 171.1 & 36.73 & 76 & 10,701 & 3.20 & 7.85 & 99.2 & 21.24 \\
\hline Central Illinois Pub Serv Co ............. & 3,867 & 11,056 & 2.81 & 9.25 & 162.3 & 35.90 & 535 & 11,809 & .56 & $\mathbf{8 . 3 8}$ & 142.7 & 33.71 \\
\hline 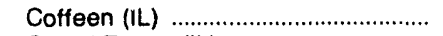 & 1.755 & 10,562 & 3.00 & 8.53 & 155.6 & 32.87 & -- & - & -- & -- & - & - \\
\hline 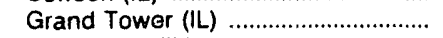 & 180 & 11,543 & 2.82 & 11.63 & 176.5 & 40.75 & -- & - & -- & -- & - & - \\
\hline Hutsonville (IL) ...................................... & 227 & 11,314 & 2.28 & 8.45 & 148.4 & 33.59 & 3 & 11,371 & 1.36 & 7.30 & 136.0 & 30.93 \\
\hline 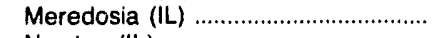 & 463 & 11,540 & 2.95 & 5.77 & 153.1 & 35.34 & 66 & 11,776 & 1.00 & 8.30 & 151.4 & 35.65 \\
\hline 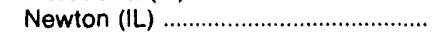 & 1,243 & 11,455 & 2.58 & 11.35 & 175.0 & 40.09 & 467 & 11,816 & .49 & 8.39 & 141.5 & 33.44 \\
\hline Central lowa Power Coop ................... & 85 & 10,747 & 2.93 & 10.46 & 119.6 & 25.70 & 62 & 11,830 & 3.31 & 8.78 & 105.9 & 25.05 \\
\hline Fair Station (IA) & 85 & 10,747 & 2.93 & 10.46 & 119.6 & 25.70 & 62 & 11,830 & 3.31 & 8.78 & 105.9 & 25.05 \\
\hline Central Louisiana Elec Co Inc .......... & 5,082 & 7,605 & .56 & 9.80 & 156.6 & 23.82 & -- & -- & - & -- & -- & - \\
\hline 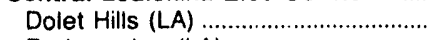 & 3,212 & 6,951 & .62 & 12.14 & 138.3 & 19.22 & $-\cdots$ & -- & - & -- & - & - \\
\hline 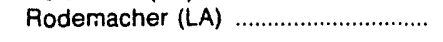 & 1,870 & 8,727 & .45 & 5.79 & 181.7 & 31.71 & -- & -- & -- & -- & -- & -- \\
\hline Central Operating Co ............................ & 1,366 & 12,354 & 1.20 & 11.61 & 165.1 & 40.78 & 1 & 12,216 & 1.37 & 12.50 & 117.3 & 28.66 \\
\hline Sporn (WV) & 1,366 & 12,354 & 1.20 & 11.61 & 165.1 & 40.78 & 1 & 12,216 & 1.37 & 12.50 & 117.3 & 28.66 \\
\hline Centrai Power \& Light Co ................. & 1,207 & 10,548 & .36 & 5.30 & 225.4 & 47.54 & 653 & 11,774 & .49 & 8.33 & 167.3 & 39.39 \\
\hline 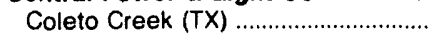 & 1,207 & 10,548 & .36 & 5.30 & 225.4 & 47.54 & 653 & 11,774 & .49 & 8.33 & 167.3 & 39.39 \\
\hline Century Power Corp .............................. & 2,493 & 9,117 & .63 & 17.93 & 170.9 & 31.16 & -- & -- & - & -- & - & -- \\
\hline Springerville $(A Z)$ & 2,493 & 9,117 & .63 & 17.93 & 170.9 & 31.16 & -- & -- & -- & -- & -- & -- \\
\hline & 7,761 & $\begin{array}{l}11,994 \\
11,725\end{array}$ & $\begin{array}{l}2.35 \\
1.71\end{array}$ & $\begin{array}{l}10.94 \\
12.56\end{array}$ & $\begin{array}{l}145.7 \\
170.9\end{array}$ & $\begin{array}{l}34.95 \\
40.07\end{array}$ & $\begin{array}{r}1,561 \\
115\end{array}$ & $\begin{array}{l}12,178 \\
12,062\end{array}$ & 1.98 & 10.94 & 97.8 & 23.82 \\
\hline Beckjord $(\mathrm{OH})$ & $\begin{array}{l}1,236 \\
2,231\end{array}$ & $\begin{array}{l}11,725 \\
12,145\end{array}$ & $\begin{array}{l}1.71 \\
1.29\end{array}$ & $\begin{array}{l}12.56 \\
11.08\end{array}$ & $\begin{array}{l}170.9 \\
170.3\end{array}$ & $\begin{array}{l}40.07 \\
41.37\end{array}$ & $\begin{array}{l}115 \\
270\end{array}$ & 12,062 & 2.36 & 11.39 & 99.5 & 24.00 \\
\hline & $\begin{array}{r}2,231 \\
944\end{array}$ & $\begin{array}{l}12,145 \\
11,793\end{array}$ & 1.61 & 12.96 & $\begin{array}{l}170.3 \\
176.5\end{array}$ & $\begin{array}{l}41.37 \\
41.63\end{array}$ & $\begin{array}{l}270 \\
232\end{array}$ & 12,344 & 1.55 & 10.67 & 108.6 & 26.80 \\
\hline 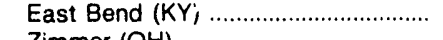 & $\begin{array}{r}944 \\
3349\end{array}$ & $\begin{array}{l}11,793 \\
12,049\end{array}$ & 3.49 & & 176.5 & 41.63 & 232 & 11,675 & 1.12 & 13.85 & 101.0 & 23.58 \\
\hline Zimmer $(\mathrm{OH})$ & 3,349 & 12,049 & 3.49 & 9.68 & 111.7 & 26.91 & 944 & 12,268 & 2.28 & 10.24 & 93.7 & 23.00 \\
\hline Cleveland Electric Illum Co ............... & 2,819 & 12,543 & 3.08 & 9.45 & 165.1 & 41.43 & 1,830 & 13,174 & 1.87 & 7.51 & 132.2 & 34.82 \\
\hline Ashtabula $(\mathrm{OH})$ & 509 & 12,446 & 3.95 & 9.52 & 175.7 & 43.72 & 392 & 13,353 & 2.28 & 7.18 & 120.8 & 32.25 \\
\hline Avon Lake $(\mathrm{OH})$ & 1,345 & 12,444 & 2.49 & 9.76 & 158.3 & 39.41 & 182 & 13,280 & 2.12 & 7.13 & 120.1 & 31.90 \\
\hline 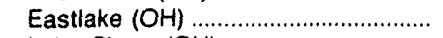 & 921 & 12,716 & 3.58 & 9.08 & 169.1 & 43.01 & 1,108 & 13,089 & 1.84 & 7.79 & 133.8 & 35.04 \\
\hline Lake Shore $(\mathrm{OH})$ & 44 & 13,114 & .62 & 6.76 & 166.0 & 43.54 & 148 & 13,200 & .64 & 6.79 & 165.3 & 43.63 \\
\hline Colorado Springs Clty of ...................... & 1,196 & 10,762 & .37 & 6.03 & 153.8 & 33.10 & 18 & 11,850 & .43 & 8.08 & 94.5 & 22.39 \\
\hline 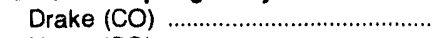 & 604 & 10,646 & .36 & 5.25 & 164.3 & 34.99 & - & - & - & - & - & - \\
\hline 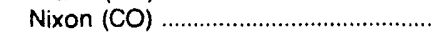 & 592 & 10,881 & .37 & 6.81 & 143.2 & 31.17 & 18 & 11,850 & .43 & 8.08 & 94.5 & 22.39 \\
\hline 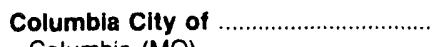 & - & - & -- & -- & -- & - & 37 & 13,975 & .64 & 5.62 & 211.2 & 59.04 \\
\hline 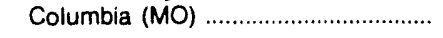 & - & -- & -- & -- & -- & -- & 37 & 13,975 & .64 & 5.62 & 211.2 & 59.04 \\
\hline
\end{tabular}

See footnotes at end of table.

Source: Federal Energy Regulatory Commission, FERC Form 423, "Monthly Report of Cost and Quality of Fuels for Electric Plants." 
Table 30. Receipts and Average Delivered Cost of Coal by Type of Purchase, Electric, Utility and Plant, 1992 (Continued)

\begin{tabular}{|c|c|c|c|c|c|c|c|c|c|c|c|c|}
\hline \multirow{3}{*}{$\begin{array}{l}\text { Electric Utllity } \\
\text { Plant (State) }\end{array}$} & \multicolumn{6}{|c|}{ Contract } & \multicolumn{6}{|c|}{ Spot } \\
\hline & \multirow{2}{*}{$\begin{array}{l}\text { Recelpts } \\
\text { (1000 } \\
\text { short } \\
\text { tons) }\end{array}$} & \multicolumn{3}{|c|}{ Average Quality } & \multicolumn{2}{|c|}{$\begin{array}{c}\text { Average } \\
\text { Dellvered Cost }\end{array}$} & \multirow{2}{*}{$\begin{array}{l}\text { Recelpts } \\
\text { (1000 } \\
\text { short } \\
\text { tons) }\end{array}$} & \multicolumn{3}{|c|}{ Average Quality } & \multicolumn{2}{|c|}{$\begin{array}{l}\text { Average } \\
\text { Dellvered } \\
\text { Cost }\end{array}$} \\
\hline & & $\begin{array}{c}\text { Btu } \\
\text { (per } \\
\text { pound) }\end{array}$ & $\begin{array}{c}\text { Sultur } \\
\text { (percent } \\
\text { by } \\
\text { weight) }\end{array}$ & $\begin{array}{c}\text { Ash } \\
\text { (percent } \\
\text { by } \\
\text { weight) }\end{array}$ & $\begin{array}{l}\text { (cents } \\
\text { per } \\
\text { million } \\
\left.\left.\mathrm{B}^{*} \cdot\right)^{+}\right)\end{array}$ & $\begin{array}{c}(\$ \\
\text { per } \\
\text { short } \\
\text { ton) }\end{array}$ & & $\begin{array}{c}\text { Btu } \\
\text { (per } \\
\text { pound) }\end{array}$ & $\begin{array}{c}\text { Sulfur } \\
\text { (percent } \\
\text { by } \\
\text { weight) }\end{array}$ & $\begin{array}{c}\text { Ash } \\
\text { (percent } \\
\text { by } \\
\text { weight) }\end{array}$ & $\begin{array}{c}\text { (cents } \\
\text { per } \\
\text { million } \\
\text { Btu) }\end{array}$ & $\begin{array}{l}\text { (S } \\
\text { per } \\
\text { short } \\
\text { ton) }\end{array}$ \\
\hline $\begin{array}{l}\text { Columbus Southern Power Co ......... } \\
\text { Conesville }(\mathrm{OH}) \\
\text { Picway }(\mathrm{OH})\end{array}$ & $\begin{array}{r}2,673 \\
2,652 \\
21\end{array}$ & $\begin{array}{l}12,052 \\
12,057 \\
11,490\end{array}$ & $\begin{array}{l}3.24 \\
3.24 \\
2.90\end{array}$ & $\begin{array}{l}7.93 \\
7.92 \\
9.73\end{array}$ & $\begin{array}{l}161.6 \\
161.9 \\
114.7\end{array}$ & $\begin{array}{l}38.95 \\
39.05 \\
26.35\end{array}$ & $\begin{array}{r}1,056 \\
769 \\
286\end{array}$ & $\begin{array}{l}11,809 \\
11,941 \\
11,454\end{array}$ & $\begin{array}{l}3.15 \\
3.18 \\
3.06\end{array}$ & $\begin{array}{l}9.57 \\
9.46 \\
9.87\end{array}$ & $\begin{array}{l}105.9 \\
106.3 \\
104.8\end{array}$ & $\begin{array}{l}25.01 \\
25.39 \\
24.00\end{array}$ \\
\hline $\begin{array}{l}\text { Columbus City of } \\
\text { Solid Waste R F }(\mathrm{OH})\end{array}$ & - & - & - & -- & -- & -- & $\begin{array}{l}29 \\
29\end{array}$ & $\begin{array}{l}12,645 \\
12,645\end{array}$ & $\begin{array}{l}.95 \\
.95\end{array}$ & $\begin{array}{l}8.49 \\
8.49\end{array}$ & $\begin{array}{l}164.4 \\
164.4\end{array}$ & $\begin{array}{l}41.58 \\
41.58\end{array}$ \\
\hline 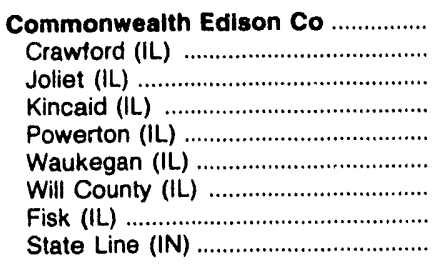 & $\begin{array}{r}8,268 \\
303 \\
1,862 \\
1,611 \\
1,279 \\
825 \\
1,682 \\
253 \\
452\end{array}$ & $\begin{array}{r}9,677 \\
9,392 \\
9,439 \\
10,445 \\
9,583 \\
9,446 \\
9,497 \\
9,463 \\
9,595\end{array}$ & $\begin{array}{r}1.00 \\
.42 \\
.43 \\
3.52 \\
.35 \\
.40 \\
.37 \\
.44 \\
.36\end{array}$ & $\begin{array}{l}6.27 \\
7.24 \\
6.84 \\
8.74 \\
4.03 \\
6.28 \\
5.29 \\
6.87 \\
4.05\end{array}$ & $\begin{array}{l}263.5 \\
314.9 \\
285.4 \\
170.6 \\
267.6 \\
277.0 \\
306.5 \\
315.0 \\
278.5\end{array}$ & $\begin{array}{l}50.99 \\
59.16 \\
53.88 \\
35.63 \\
51.29 \\
52.33 \\
58.21 \\
59.61 \\
53.44\end{array}$ & $\begin{array}{r}285 \\
-\overline{57} \\
105 \\
-- \\
55 \\
\overline{68} \\
--\end{array}$ & $\begin{array}{r}9,827 \\
-- \\
8,771 \\
11,611 \\
8,836 \\
-0 \\
-158 \\
--\end{array}$ & $\begin{array}{r}.69 \\
-\overline{18} \\
.18 \\
1.46 \\
-- \\
.41 \\
-\overline{17} \\
--\end{array}$ & $\begin{array}{r}5.78 \\
-\overline{-} \\
4.46 \\
7.77 \\
-\overline{10} \\
\overline{10} \\
\overline{-39} \\
--\end{array}$ & $\begin{array}{r}112.2 \\
-\overline{2} \\
103.2 \\
115.7 \\
- \\
105.4 \\
-\overline{-} \\
118.0 \\
--\end{array}$ & $\begin{array}{r}22.05 \\
18 \overline{11} \\
26.87 \\
18 . \overline{63} \\
-\overline{66} \\
20 . \overline{--}\end{array}$ \\
\hline 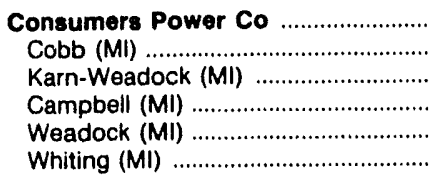 & $\begin{array}{r}4,676 \\
708 \\
934 \\
2,230 \\
538 \\
266\end{array}$ & $\begin{array}{l}12,274 \\
11,283 \\
12,218 \\
12,612 \\
12,227 \\
12,380\end{array}$ & $\begin{array}{l}.75 \\
.64 \\
.85 \\
.72 \\
.83 \\
.84\end{array}$ & $\begin{array}{r}9.94 \\
7.73 \\
11.73 \\
9.45 \\
11.31 \\
10.96\end{array}$ & $\begin{array}{l}170.0 \\
166.2 \\
158.9 \\
179.6 \\
159.3 \\
156.7\end{array}$ & $\begin{array}{l}41.72 \\
37.50 \\
38.83 \\
45.29 \\
38.96 \\
38.81\end{array}$ & $\begin{array}{r}2,250 \\
151 \\
340 \\
836 \\
407 \\
517\end{array}$ & $\begin{array}{r}11,516 \\
10,115 \\
12,097 \\
11,954 \\
9,889 \\
12,116\end{array}$ & $\begin{array}{l}.75 \\
.54 \\
.87 \\
.80 \\
.49 \\
.88\end{array}$ & $\begin{array}{r}10.14 \\
6.82 \\
11.32 \\
11.15 \\
7.18 \\
11.05\end{array}$ & $\begin{array}{l}141.1 \\
134.5 \\
139.7 \\
150.3 \\
131.8 \\
135.0\end{array}$ & $\begin{array}{l}32.51 \\
27.21 \\
33.79 \\
35.94 \\
26.06 \\
32.72\end{array}$ \\
\hline $\begin{array}{c}\text { Coop Power Assn } \\
\text { Coal Creek (ND) }\end{array}$ & $\begin{array}{l}6,949 \\
6,949\end{array}$ & $\begin{array}{l}6,260 \\
6,260\end{array}$ & $\begin{array}{l}.78 \\
.78\end{array}$ & $\begin{array}{l}10.66 \\
10.66\end{array}$ & $\begin{array}{l}74.6 \\
74.6\end{array}$ & $\begin{array}{l}9.35 \\
9.35\end{array}$ & $\begin{array}{l}489 \\
489\end{array}$ & $\begin{array}{l}6,312 \\
6,312\end{array}$ & $\begin{array}{l}.71 \\
.71\end{array}$ & $\begin{array}{l}10.21 \\
10.21\end{array}$ & $\begin{array}{l}44.7 \\
44.7\end{array}$ & $\begin{array}{l}5.65 \\
5.65\end{array}$ \\
\hline $\begin{array}{l}\text { Dairyland Power Coop } \\
\text { Alma-Madgett (WI) } \\
\text { Genoa No.3 (WI) } \\
\text { Stoneman (WI) }\end{array}$ & $\begin{array}{r}950 \\
950 \\
-- \\
--\end{array}$ & $\begin{array}{r}8,519 \\
8,519 \\
-- \\
--\end{array}$ & $\begin{array}{r}.30 \\
.30 \\
-- \\
--\end{array}$ & $\begin{array}{r}4.77 \\
4.77 \\
-- \\
--\end{array}$ & $\begin{array}{r}146.2 \\
146.2 \\
-- \\
--\end{array}$ & $\begin{array}{r}24.90 \\
24.90 \\
-- \\
--\end{array}$ & $\begin{array}{r}1,096 \\
298 \\
773 \\
24\end{array}$ & $\begin{array}{l}11,410 \\
10,583 \\
11,702 \\
12,283\end{array}$ & $\begin{array}{r}1.06 \\
.95 \\
1.10 \\
1.11\end{array}$ & $\begin{array}{l}7.30 \\
6.35 \\
7.72 \\
5.50\end{array}$ & $\begin{array}{l}134.8 \\
133.9 \\
135.1 \\
134.0\end{array}$ & $\begin{array}{l}30.75 \\
28.34 \\
31.62 \\
32.92\end{array}$ \\
\hline $\begin{array}{l}\text { Dayton Power Light Co } \\
\text { Hutchings }(\mathrm{OH}) \\
\text { Stuart }(\mathrm{OH}) \\
\text { Killen }(\mathrm{OH})\end{array}$ & $\begin{array}{r}4,429 \\
-\overline{-} \\
4,003 \\
426\end{array}$ & $\begin{array}{r}11,839 \\
11,801 \\
12,204\end{array}$ & $\begin{array}{r}1.08 \\
1.12 \\
.65\end{array}$ & $\begin{array}{r}13.77 \\
-\overline{13.89} \\
12.70\end{array}$ & $\begin{array}{r}165.0 \\
-- \\
162.7 \\
186.0\end{array}$ & $\begin{array}{r}39.08 \\
-\overline{-.} \\
38.41 \\
45.39\end{array}$ & $\begin{array}{r}2,408 \\
51 \\
1,978 \\
379\end{array}$ & $\begin{array}{l}11,656 \\
12,595 \\
11,551 \\
12,082\end{array}$ & $\begin{array}{r}1.49 \\
.89 \\
1.67 \\
.64\end{array}$ & $\begin{array}{l}13.59 \\
10.34 \\
13.92 \\
12.29\end{array}$ & $\begin{array}{r}98.6 \\
131.3 \\
95.0 \\
111.8\end{array}$ & $\begin{array}{l}22.99 \\
33.06 \\
21.95 \\
27.03\end{array}$ \\
\hline $\begin{array}{l}\text { Delmarva Power \& Light Co ............ } \\
\text { Edgemoor (DE) } \\
\text { Indian River (DE) }\end{array}$ & $\begin{array}{r}1,509 \\
554 \\
956\end{array}$ & $\begin{array}{l}13,065 \\
13,101 \\
13,044\end{array}$ & $\begin{array}{r}1.02 \\
.80 \\
1.15\end{array}$ & $\begin{array}{l}8.82 \\
8.65 \\
8.91\end{array}$ & $\begin{array}{l}173.4 \\
183.4 \\
167.6\end{array}$ & $\begin{array}{l}45.31 \\
48.06 \\
43.72\end{array}$ & $\begin{array}{r}22 \\
22\end{array}$ & $\begin{array}{l}13,012 \\
13,000 \\
13,012\end{array}$ & $\begin{array}{r}1.47 \\
.90 \\
1.47\end{array}$ & $\begin{array}{r}10.09 \\
8.00 \\
10.10\end{array}$ & $\begin{array}{l}174.4 \\
207.0 \\
174.3\end{array}$ & $\begin{array}{l}45.39 \\
53.82 \\
45.35\end{array}$ \\
\hline $\begin{array}{l}\text { Deseret Generation \& Tran Coop .. } \\
\text { Bonanza (UT) }\end{array}$ & $\begin{array}{l}1,517 \\
1,517\end{array}$ & $\begin{array}{l}10,531 \\
10,531\end{array}$ & $\begin{array}{l}.48 \\
.48\end{array}$ & $\begin{array}{l}10.54 \\
10.54\end{array}$ & $\begin{array}{l}201.4 \\
201.4\end{array}$ & $\begin{array}{l}42.42 \\
42.42\end{array}$ & - & - & - & -- & - & $\overline{-}$ \\
\hline 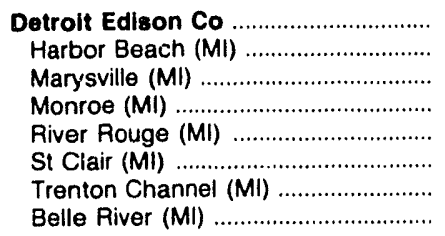 & $\begin{array}{r}15,693 \\
39 \\
61 \\
6,162 \\
644 \\
4,202 \\
1,111 \\
3,474\end{array}$ & $\begin{array}{r}10,532 \\
13,142 \\
13,065 \\
11,371 \\
12,053 \\
9,667 \\
11,241 \\
9,505\end{array}$ & $\begin{array}{l}.63 \\
.85 \\
.85 \\
.87 \\
.62 \\
.50 \\
.59 \\
.35\end{array}$ & $\begin{array}{r}5.30 \\
7.27 \\
7.78 \\
5.95 \\
10.23 \\
4.41 \\
5.81 \\
4.07\end{array}$ & $\begin{array}{l}154.6 \\
162.3 \\
183.2 \\
159.3 \\
158.9 \\
146.2 \\
163.4 \\
150.1\end{array}$ & $\begin{array}{l}32.57 \\
42.66 \\
47.86 \\
36.22 \\
38.31 \\
28.27 \\
36.74 \\
28.53\end{array}$ & $\begin{array}{r}2,308 \\
- \\
- \\
1,658 \\
324 \\
237 \\
89 \\
-\end{array}$ & $\begin{array}{r}10,499 \\
-- \\
-- \\
10,363 \\
11,158 \\
9,613 \\
13,004 \\
--\end{array}$ & $\begin{array}{l}.69 \\
-- \\
-- \\
.69 \\
.54 \\
.87 \\
.69 \\
--\end{array}$ & $\begin{array}{r}6.34 \\
-- \\
-- \\
5.94 \\
8.05 \\
6.26 \\
7.86 \\
--\end{array}$ & $\begin{array}{r}119.6 \\
-- \\
-2 \\
115.0 \\
132.9 \\
120.5 \\
144.7 \\
--\end{array}$ & $\begin{array}{r}25.11 \\
-- \\
-- \\
23.83 \\
29.65 \\
23.16 \\
37.64 \\
--\end{array}$ \\
\hline $\begin{array}{l}\text { Duke Power Co } \\
\text { Allen (NC) } \\
\text { Buck (NC) } \\
\text { Cliffside (NC) } \\
\text { Dan River (NC) } \\
\text { Marshall (NC) } \\
\text { Riverbend (NC) } \\
\text { Lee (SC) } \\
\text { Belews Creek (NC) }\end{array}$ & $\begin{array}{r}7,658 \\
877 \\
45 \\
574 \\
20 \\
2,529 \\
145 \\
- \\
3,468\end{array}$ & $\begin{array}{r}12,486 \\
12,503 \\
12,416 \\
12,651 \\
12,393 \\
12,521 \\
12,661 \\
-- \\
12,424\end{array}$ & $\begin{array}{r}.98 \\
1.07 \\
.82 \\
.97 \\
.87 \\
1.04 \\
1.06 \\
-- \\
.91\end{array}$ & $\begin{array}{r}10.10 \\
11.47 \\
9.16 \\
8.45 \\
9.15 \\
10.94 \\
9.17 \\
-\overline{-} \\
9.46\end{array}$ & $\begin{array}{r}184.9 \\
187.4 \\
202.5 \\
190.8 \\
199.9 \\
186.4 \\
188.6 \\
-\overline{18} \\
181.7\end{array}$ & $\begin{array}{r}46.18 \\
46.85 \\
50.29 \\
48.29 \\
49.54 \\
46.67 \\
47.75 \\
45.16\end{array}$ & $\begin{array}{r}3,088 \\
- \\
216 \\
240 \\
226 \\
1,095 \\
173 \\
218 \\
920\end{array}$ & $\begin{array}{r}12,501 \\
- \\
12,357 \\
12,722 \\
12,466 \\
12,539 \\
12,733 \\
12,287 \\
12,448\end{array}$ & $\begin{array}{r}.91 \\
-. \\
1.05 \\
1.01 \\
.96 \\
.90 \\
1.07 \\
.75 \\
.86\end{array}$ & $\begin{array}{r}9.64 \\
-- \\
10.52 \\
9.44 \\
10.19 \\
9.26 \\
9.00 \\
9.15 \\
10.04\end{array}$ & $\begin{array}{r}140.8 \\
-- \\
150.5 \\
135.3 \\
147.8 \\
139.9 \\
142.1 \\
155.2 \\
135.9\end{array}$ & $\begin{array}{r}35.21 \\
-- \\
37.20 \\
34.43 \\
36.84 \\
35.08 \\
36.18 \\
38.15 \\
33.84\end{array}$ \\
\hline
\end{tabular}

See footnotes at end of table.

Source: Federal Energy Regulatory Commission, FERC Form 423, "Monthly Report of Cost and Quality of Fuels tor Electric Plants." 
Table 30. Recelpts and Average Delivered Cost of Coal by Type of Purchase, Electric, Utility and Plant, 1992 (Continued)

\begin{tabular}{|c|c|c|c|c|c|c|c|c|c|c|c|c|}
\hline \multirow{3}{*}{$\begin{array}{l}\text { Electric Utility } \\
\text { Plant (State) }\end{array}$} & \multicolumn{6}{|c|}{ Contract } & \multicolumn{6}{|c|}{ Spot } \\
\hline & \multirow{2}{*}{$\begin{array}{l}\text { Recelpts } \\
\text { (1000 } \\
\text { short } \\
\text { tons) }\end{array}$} & \multicolumn{3}{|c|}{ Average Quality } & \multicolumn{2}{|c|}{$\begin{array}{c}\text { Average } \\
\text { Dellvered Cost }\end{array}$} & \multirow{2}{*}{$\begin{array}{c}\text { Recelpts } \\
\text { (1000 } \\
\text { short } \\
\text { tons) }\end{array}$} & \multicolumn{3}{|c|}{ Average Quallty } & \multicolumn{2}{|c|}{$\begin{array}{l}\text { Average } \\
\text { Dellvered } \\
\text { Cost }\end{array}$} \\
\hline & & $\begin{array}{c}\text { Btu } \\
\text { (per } \\
\text { pound) }\end{array}$ & $\begin{array}{c}\text { Sulfur } \\
\text { (percent } \\
\text { by } \\
\text { welght) }\end{array}$ & $\begin{array}{c}\text { Ash } \\
\text { (porcent } \\
\text { by } \\
\text { waight) }\end{array}$ & $\begin{array}{l}\text { (cents } \\
\text { per } \\
\text { mililion } \\
\text { Btu) }\end{array}$ & $\begin{array}{c}\text { (\$ } \\
\text { per } \\
\text { short } \\
\text { ton) }\end{array}$ & & $\begin{array}{c}\text { Btu } \\
\text { (per } \\
\text { pound) }\end{array}$ & $\begin{array}{c}\text { Sulfur } \\
\text { (percent } \\
\text { by } \\
\text { weight) }\end{array}$ & $\begin{array}{c}\text { Ash } \\
\text { (percent } \\
\text { by } \\
\text { welght) }\end{array}$ & $\begin{array}{c}\text { (cents } \\
\text { per } \\
\text { million } \\
\text { Btu) }\end{array}$ & $\begin{array}{l}\text { (s } \\
\text { per } \\
\text { short } \\
\text { ton) }\end{array}$ \\
\hline 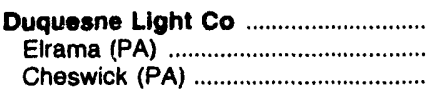 & $\begin{array}{r}1,550 \\
899 \\
651\end{array}$ & $\begin{array}{l}12,537 \\
12,357 \\
12,787\end{array}$ & $\begin{array}{l}1.44 \\
1.54 \\
1.30\end{array}$ & $\begin{array}{l}11.34 \\
12.29 \\
10.02\end{array}$ & $\begin{array}{l}169.6 \\
189.8 \\
142.6\end{array}$ & $\begin{array}{l}42.52 \\
46.90 \\
36.48\end{array}$ & $\begin{array}{l}874 \\
205 \\
669\end{array}$ & $\begin{array}{l}12,937 \\
12,215 \\
13,158\end{array}$ & $\begin{array}{l}2.21 \\
2.27 \\
2.19\end{array}$ & $\begin{array}{r}9.65 \\
12.51 \\
8.77\end{array}$ & $\begin{array}{r}110.8 \\
98.5 \\
114.3\end{array}$ & $\begin{array}{l}28.66 \\
24.07 \\
30.07\end{array}$ \\
\hline 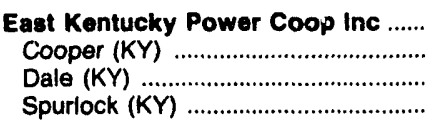 & $\begin{array}{r}1,608 \\
404 \\
-- \\
1,204\end{array}$ & $\begin{array}{r}12,217 \\
12,249 \\
12,207\end{array}$ & $\begin{array}{r}1.48 \\
1.65 \\
1 . \overline{4}\end{array}$ & $\begin{array}{r}10.94 \\
10.84 \\
10 . \overline{97}\end{array}$ & $\begin{array}{r}118.1 \\
118.2 \\
-- \\
118.1\end{array}$ & $\begin{array}{r}28.87 \\
28.95 \\
28 . \overline{4}\end{array}$ & $\begin{array}{l}953 \\
328 \\
287 \\
338\end{array}$ & $\begin{array}{l}12,468 \\
12,499 \\
12,385 \\
12,509\end{array}$ & $\begin{array}{r}1.18 \\
1.58 \\
.84 \\
1.08\end{array}$ & $\begin{array}{l}9.14 \\
9.16 \\
8.22 \\
9.91\end{array}$ & $\begin{array}{l}108.6 \\
106.9 \\
106.8 \\
111.6\end{array}$ & $\begin{array}{l}27.07 \\
26.73 \\
26.47 \\
27.92\end{array}$ \\
\hline $\begin{array}{l}\text { Electric Energy Ine } \\
\text { Joppa (IL) }\end{array}$ & $\begin{array}{l}2,674 \\
2,674\end{array}$ & $\begin{array}{l}10,893 \\
10,893\end{array}$ & $\begin{array}{l}1.45 \\
1.45\end{array}$ & $\begin{array}{l}6.85 \\
6.85\end{array}$ & $\begin{array}{l}104.8 \\
104.8\end{array}$ & $\begin{array}{l}22.83 \\
22.83\end{array}$ & $\begin{array}{l}434 \\
434\end{array}$ & $\begin{array}{l}11,051 \\
11,051\end{array}$ & $\begin{array}{l}2.97 \\
2.97\end{array}$ & $\begin{array}{l}9.40 \\
9.40\end{array}$ & $\begin{array}{l}101.3 \\
101.3\end{array}$ & $\begin{array}{l}22.38 \\
22.38\end{array}$ \\
\hline $\begin{array}{l}\text { Empire District Electric Co } \\
\text { Riverton (KS) } \\
\text { Asbury (MO) }\end{array}$ & $\begin{array}{r}1,118 \\
269 \\
848\end{array}$ & $\begin{array}{r}9,275 \\
10,041 \\
9,031\end{array}$ & $\begin{array}{r}.62 \\
1.18 \\
.44\end{array}$ & $\begin{array}{l}5.45 \\
6.55 \\
5.10\end{array}$ & $\begin{array}{r}99.2 \\
112.7 \\
94.5\end{array}$ & $\begin{array}{l}18.41 \\
22.64 \\
17.06\end{array}$ & - & $\overline{--}$ & - & $\overline{--}$ & $\overline{--}$ & - \\
\hline $\begin{array}{l}\text { Florida Power Corp } \\
\text { Crystal River (FL) }\end{array}$ & $\begin{array}{r}4,971 \\
3,552 \\
316 \\
1,103\end{array}$ & $\begin{array}{l}12,594 \\
12,664 \\
12,338 \\
12,442\end{array}$ & $\begin{array}{l}.82 \\
.81 \\
.93 \\
.82\end{array}$ & $\begin{array}{l}8.68 \\
8.67 \\
7.89 \\
8.92\end{array}$ & $\begin{array}{l}181.2 \\
187.2 \\
140.8 \\
172.9\end{array}$ & $\begin{array}{l}45.63 \\
47.41 \\
34.74 \\
43.04\end{array}$ & $\begin{array}{r}628 \\
352 \\
- \\
276\end{array}$ & $\begin{array}{r}12,582 \\
12,650 \\
12,4 \overline{94}\end{array}$ & $\begin{array}{l}.93 \\
.89 \\
. \\
.97\end{array}$ & $\begin{array}{r}9.42 \\
9.199 \\
9 . \overline{94}\end{array}$ & $\begin{array}{r}160.0 \\
163.0 \\
-\overline{156.1}\end{array}$ & $\begin{array}{r}40.26 \\
41.24 \\
-- \\
39.01\end{array}$ \\
\hline $\begin{array}{l}\text { Fremont Clty of } \\
\text { Wright (NE) }\end{array}$ & $\begin{array}{l}147 \\
147\end{array}$ & $\begin{array}{l}8,705 \\
8,705\end{array}$ & $\begin{array}{l}.32 \\
.32\end{array}$ & $\begin{array}{l}4.84 \\
4.84\end{array}$ & $\begin{array}{l}84.5 \\
84.5\end{array}$ & $\begin{array}{l}14.71 \\
14.71\end{array}$ & $\begin{array}{l}32 \\
32\end{array}$ & $\begin{array}{l}11,117 \\
11,117\end{array}$ & $\begin{array}{l}.61 \\
.61\end{array}$ & $\begin{array}{l}6.63 \\
6.63\end{array}$ & $\begin{array}{l}147.3 \\
147.3\end{array}$ & $\begin{array}{l}32.75 \\
32.75\end{array}$ \\
\hline 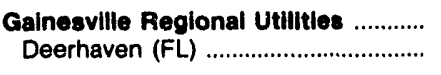 & $\begin{array}{l}496 \\
496\end{array}$ & $\begin{array}{l}13,206 \\
13,206\end{array}$ & $\begin{array}{l}.68 \\
.68\end{array}$ & $\begin{array}{l}7.30 \\
7.30\end{array}$ & $\begin{array}{l}172.9 \\
172.9\end{array}$ & $\begin{array}{l}45.66 \\
45.66\end{array}$ & $\begin{array}{l}27 \\
27\end{array}$ & $\begin{array}{l}12,956 \\
12,956\end{array}$ & $\begin{array}{l}.70 \\
.70\end{array}$ & $\begin{array}{l}8.61 \\
8.61\end{array}$ & $\begin{array}{l}176.9 \\
176.9\end{array}$ & $\begin{array}{l}45.85 \\
45.85\end{array}$ \\
\hline $\begin{array}{l}\text { Georgla Power Co } \\
\text { Arkwright (GA) } \\
\text { Atkinson-Mcdonough (GA) } \\
\text { Bowen (GA) } \\
\text { Hammond (GA) } \\
\text { Harllee Branch (GA) } \\
\text { Mitchell (GA) } \\
\text { Yates (GA) } \\
\text { Wansley (GA) } \\
\text { Scherer (GA) }\end{array}$ & $\begin{array}{r}19,539 \\
30 \\
1,381 \\
7,625 \\
75 ; 6 \\
1,187 \\
154 \\
1,434 \\
4,301 \\
2,041\end{array}$ & $\begin{array}{l}12,033 \\
12,951 \\
11,882 \\
12,157 \\
12,985 \\
12,520 \\
12,697 \\
12,021 \\
11,276 \\
12,420\end{array}$ & $\begin{array}{r}1.79 \\
1.69 \\
1.88 \\
1.57 \\
1.67 \\
1.45 \\
1.32 \\
2.02 \\
2.78 \\
.67\end{array}$ & $\begin{array}{r}10.08 \\
9.61 \\
9.56 \\
10.55 \\
9.85 \\
9.88 \\
8.82 \\
10.20 \\
9.39 \\
10.45\end{array}$ & $\begin{array}{l}185.9 \\
190.4 \\
162.9 \\
163.8 \\
175.4 \\
182.7 \\
185.6 \\
195.0 \\
209.1 \\
237.9\end{array}$ & $\begin{array}{l}44.74 \\
49.32 \\
38.72 \\
39.83 \\
45.55 \\
45.74 \\
47.13 \\
46.88 \\
47.16 \\
59.10\end{array}$ & $\begin{array}{r}3,156 \\
3 \\
457 \\
17 \\
1,350 \\
- \\
142 \\
419 \\
769\end{array}$ & $\begin{array}{r}12,061 \\
- \\
9,595 \\
12,670 \\
12,318 \\
12,166 \\
11,409 \\
10,321 \\
12,586\end{array}$ & $\begin{array}{r}1.04 \\
-. \\
.81 \\
1.02 \\
1.52 \\
1.10 \\
-- \\
1.67 \\
1.29 \\
.67\end{array}$ & $\begin{array}{r}11.55 \\
-- \\
24.70 \\
9.13 \\
10.49 \\
10.08 \\
-\overline{1} \\
15.68 \\
20.25 \\
10.05\end{array}$ & $\begin{array}{r}145.7 \\
-- \\
154.6 \\
132.2 \\
148.5 \\
143.3 \\
-\overline{1} \\
140.3 \\
131.8 \\
164.8\end{array}$ & $\begin{array}{r}35.14 \\
- \\
29.67 \\
33.51 \\
36.57 \\
34.87 \\
- \\
32.02 \\
27.21 \\
41.48\end{array}$ \\
\hline 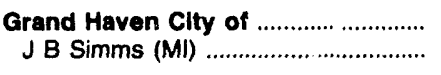 & $\begin{array}{l}80 \\
80\end{array}$ & $\begin{array}{l}11,002 \\
11,0 \cong ?\end{array}$ & $\begin{array}{l}2.54 \\
2.54\end{array}$ & $\begin{array}{l}10.17 \\
10.17\end{array}$ & $\begin{array}{l}161.8 \\
161.8\end{array}$ & $\begin{array}{l}35.61 \\
35.61\end{array}$ & $\begin{array}{l}125 \\
125\end{array}$ & $\begin{array}{l}11,029 \\
11,029\end{array}$ & $\begin{array}{l}2.40 \\
2.40\end{array}$ & $\begin{array}{l}10.01 \\
10.01\end{array}$ & $\begin{array}{l}142.9 \\
142.9\end{array}$ & $\begin{array}{l}31.52 \\
31.52\end{array}$ \\
\hline $\begin{array}{c}\text { Grand island City of } \\
\text { Platte (NE) }\end{array}$ & - & - & - & - & - & - & $\begin{array}{l}275 \\
275\end{array}$ & $\begin{array}{l}8,391 \\
8,391\end{array}$ & $\begin{array}{l}.31 \\
.31\end{array}$ & $\begin{array}{l}\mathbf{5 . 6 2} \\
5.62\end{array}$ & $\begin{array}{l}71.0 \\
71.0\end{array}$ & $\begin{array}{l}11.92 \\
11.92\end{array}$ \\
\hline $\begin{array}{l}\text { Grand Rlver Dam Authority } \\
\text { GRDA No } 1 \text { (OK) }\end{array}$ & $\begin{array}{l}2,959 \\
2,959\end{array}$ & $\begin{array}{l}8,551 \\
8,551\end{array}$ & $\begin{array}{l}.52 \\
.52\end{array}$ & $\begin{array}{l}5.11 \\
5.11\end{array}$ & $\begin{array}{l}91.2 \\
91.2\end{array}$ & $\begin{array}{l}15.60 \\
15.60\end{array}$ & $\begin{array}{l}634 \\
634\end{array}$ & $\begin{array}{l}8,750 \\
8,750\end{array}$ & $\begin{array}{l}.21 \\
.21\end{array}$ & $\begin{array}{l}4.55 \\
4.55\end{array}$ & $\begin{array}{l}89.9 \\
89.9\end{array}$ & $\begin{array}{l}15.73 \\
15.73\end{array}$ \\
\hline $\begin{array}{l}\text { Gult Power Co } \\
\text { Crist (FL) } \\
\text { Scholtz (FL) } \\
\text { Smith (FL) }\end{array}$ & $\begin{array}{r}1,928 \\
1,068 \\
-\overline{860}\end{array}$ & $\begin{array}{r}12,010 \\
12,016 \\
12,002\end{array}$ & $\begin{array}{r}2.77 \\
2.74 \\
-\overline{-} \\
2.81\end{array}$ & $\begin{array}{r}8.52 \\
8.55 \\
-\overline{4}\end{array}$ & $\begin{array}{r}223.2 \\
222.2 \\
-\overline{2} \\
224.5\end{array}$ & $\begin{array}{r}53.61 \\
53.39 \\
53 . \overline{89}\end{array}$ & $\begin{array}{r}1,066 \\
1,009 \\
32 \\
25\end{array}$ & $\begin{array}{l}11,878 \\
11,870 \\
12,192 \\
11,789\end{array}$ & $\begin{array}{l}2.68 \\
2.67 \\
3.06 \\
2.63\end{array}$ & $\begin{array}{l}8.50 \\
8.51 \\
8.84 \\
7.83\end{array}$ & $\begin{array}{l}119.7 \\
118.6 \\
148.7 \\
129.0\end{array}$ & $\begin{array}{l}28.44 \\
28.15 \\
36.27 \\
30.41\end{array}$ \\
\hline 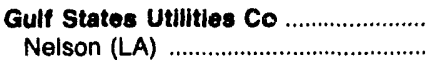 & $\begin{array}{l}2,249 \\
2,249\end{array}$ & $\begin{array}{l}8,706 \\
8,706\end{array}$ & $\begin{array}{l}.45 \\
.45\end{array}$ & $\begin{array}{l}5.86 \\
5.86\end{array}$ & $\begin{array}{l}160.9 \\
160.9\end{array}$ & $\begin{array}{l}28.02 \\
28.02\end{array}$ & - & - & - & - & - & - \\
\hline $\begin{array}{l}\text { Hamilton City of } \\
\text { Hamilton }(\mathrm{OH})\end{array}$ & $\begin{array}{l}26 \\
26\end{array}$ & $\begin{array}{l}12,515 \\
12,515\end{array}$ & $\begin{array}{l}.71 \\
.71\end{array}$ & $\begin{array}{l}8.25 \\
8.25\end{array}$ & $\begin{array}{l}146.6 \\
146.6\end{array}$ & $\begin{array}{l}36.71 \\
36.71\end{array}$ & - & - & - & - & - & - \\
\hline 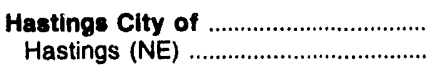 & $\begin{array}{l}145 \\
145\end{array}$ & $\begin{array}{l}8,749 \\
8,749\end{array}$ & $\begin{array}{l}.28 \\
.28\end{array}$ & $\begin{array}{l}4.63 \\
4.63\end{array}$ & $\begin{array}{l}86.7 \\
86.7\end{array}$ & $\begin{array}{l}15.18 \\
15.18\end{array}$ & $\begin{array}{l}17 \\
17\end{array}$ & $\begin{array}{l}8,536 \\
8,536\end{array}$ & $\begin{array}{l}.36 \\
.36\end{array}$ & $\begin{array}{l}4.90 \\
4.90\end{array}$ & $\begin{array}{l}82.8 \\
82.8\end{array}$ & $\begin{array}{l}14.14 \\
14.14\end{array}$ \\
\hline 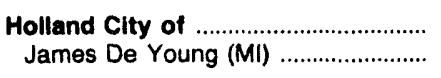 & $\begin{array}{l}153 \\
153\end{array}$ & $\begin{array}{l}13,011 \\
13,011\end{array}$ & $\begin{array}{l}.82 \\
.82\end{array}$ & $\begin{array}{l}6.31 \\
6.31\end{array}$ & $\begin{array}{l}175.0 \\
175.0\end{array}$ & $\begin{array}{l}45.54 \\
45.54\end{array}$ & - & - & - & - & - & - \\
\hline
\end{tabular}

See tootnotes at end of table.

Source: Federal Energy Regulatory Commission, FERC Form 423, "Monthly Report of Cost and Quality of Fuels for Electric Plants." 
Table 30. Recelpts and Average Delivered Cost of Coal by Type of Purchase, Electric, Utility and Plant, 1 :992 (Continued)

\begin{tabular}{|c|c|c|c|c|c|c|c|c|c|c|c|c|}
\hline \multirow{3}{*}{$\begin{array}{l}\text { Electric Utility } \\
\text { Plant (State) }\end{array}$} & \multicolumn{6}{|c|}{ Contract } & \multicolumn{6}{|c|}{ Spot } \\
\hline & \multirow{2}{*}{$\begin{array}{l}\text { Recelpts } \\
\text { (1000 } \\
\text { short } \\
\text { tons) }\end{array}$} & \multicolumn{3}{|c|}{ Average Quality } & \multicolumn{2}{|c|}{$\begin{array}{c}\text { Average } \\
\text { Delivered Cost }\end{array}$} & \multirow{2}{*}{$\begin{array}{l}\text { Receipts } \\
(1000 \\
\text { short } \\
\text { tons) }\end{array}$} & \multicolumn{3}{|c|}{ Average Quality } & \multicolumn{2}{|c|}{$\begin{array}{l}\text { Average } \\
\text { Dellvered } \\
\text { Cost }\end{array}$} \\
\hline & & $\begin{array}{c}\text { Btu } \\
\text { (per } \\
\text { pound) }\end{array}$ & $\begin{array}{c}\text { Sulfur } \\
\text { (percent } \\
\text { by } \\
\text { weight) }\end{array}$ & $\begin{array}{c}\text { Ash } \\
\text { (percent } \\
\text { by } \\
\text { weight) }\end{array}$ & $\begin{array}{l}\text { (cents } \\
\text { per } \\
\text { million } \\
\text { Btu) }\end{array}$ & $\begin{array}{c}\text { (s } \\
\text { per } \\
\text { short } \\
\text { ton) }\end{array}$ & & $\begin{array}{c}\text { Btu } \\
\text { (per } \\
\text { pound) }\end{array}$ & $\begin{array}{c}\text { Sulfur } \\
\text { (percent } \\
\text { by } \\
\text { welght) }\end{array}$ & $\begin{array}{c}\text { Ash } \\
\text { (percent } \\
\text { by } \\
\text { welght) }\end{array}$ & $\begin{array}{c}\text { (cents } \\
\text { per } \\
\text { million } \\
\text { Btu) }\end{array}$ & $\begin{array}{l}\text { (\$ } \\
\text { per } \\
\text { short } \\
\text { ton) }\end{array}$ \\
\hline 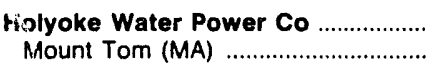 & $\begin{array}{l}277 \\
2.77\end{array}$ & $\begin{array}{l}13,211 \\
13,211\end{array}$ & $\begin{array}{l}1.41 \\
1.41\end{array}$ & $\begin{array}{l}6.19 \\
6.19\end{array}$ & $\begin{array}{l}\mathbf{1 6 8 . 3} \\
168.3\end{array}$ & $\begin{array}{l}44.46 \\
44.46\end{array}$ & $\begin{array}{l}86 \\
86\end{array}$ & $\begin{array}{l}13,266 \\
13,266\end{array}$ & $\begin{array}{l}1.08 \\
1.08\end{array}$ & $\begin{array}{l}6.68 \\
6.68\end{array}$ & $\begin{array}{l}170.6 \\
170.6\end{array}$ & $\begin{array}{l}45.26 \\
45.26\end{array}$ \\
\hline 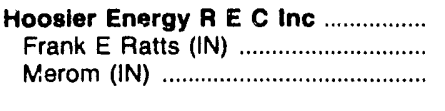 & $\begin{array}{r}2,620 \\
635 \\
1,984\end{array}$ & $\begin{array}{l}11,087 \\
11,240 \\
11,038\end{array}$ & $\begin{array}{l}3.36 \\
2.72 \\
3.56\end{array}$ & $\begin{array}{r}10.86 \\
9.08 \\
11.43\end{array}$ & $\begin{array}{l}132.5 \\
136.8 \\
131.1\end{array}$ & $\begin{array}{l}29.39 \\
30.74 \\
28.95\end{array}$ & $\frac{442}{442}$ & $\begin{array}{r}11,063 \\
11,063\end{array}$ & $\begin{array}{r}3.08 \\
3.08\end{array}$ & $\begin{array}{r}11.21 \\
-\overline{21}\end{array}$ & $\begin{array}{r}83.7 \\
83.7\end{array}$ & $\begin{array}{r}18.52 \\
18 . \overline{52}\end{array}$ \\
\hline 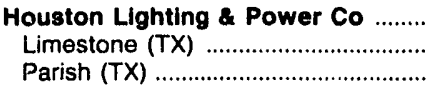 & $\begin{array}{r}16,695 \\
7,156 \\
9,540\end{array}$ & $\begin{array}{l}7,642 \\
6,513 \\
8,490\end{array}$ & $\begin{array}{r}.74 \\
1.23 \\
.38\end{array}$ & $\begin{array}{r}10.51 \\
17.77 \\
5.07\end{array}$ & $\begin{array}{l}202.8 \\
165.3 \\
224.4\end{array}$ & $\begin{array}{l}31.00 \\
21.54 \\
38.10\end{array}$ & $\begin{array}{l}- \\
--\end{array}$ & -- & - & - & - & - \\
\hline $\begin{array}{l}\text { Illinols Power Co } \\
\text { Baldwin (IL) } \\
\text { Havana (IL) } \\
\text { Hennepin (IL) } \\
\text { Vermilion (IL) } \\
\text { Wood River (IL) }\end{array}$ & $\begin{array}{r}5,498 \\
4,216 \\
197 \\
422 \\
162 \\
500\end{array}$ & $\begin{array}{l}11,048 \\
10,834 \\
12,795 \\
10,699 \\
10,750 \\
12,547\end{array}$ & $\begin{array}{r}2.67 \\
2.97 \\
.71 \\
2.92 \\
2.43 \\
.76\end{array}$ & $\begin{array}{r}10.16 \\
10.37 \\
8.09 \\
10.61 \\
10.91 \\
8.58\end{array}$ & $\begin{array}{l}140.7 \\
137.5 \\
168.5 \\
148.9 \\
123.8 \\
151.9\end{array}$ & $\begin{array}{l}31.10 \\
29.80 \\
43.13 \\
31.86 \\
26.61 \\
38.11\end{array}$ & $\begin{array}{r}649 \\
93 \\
189 \\
-- \\
162 \\
204\end{array}$ & $\begin{array}{r}11,203 \\
8,858 \\
11,855 \\
-- \\
11,023 \\
11,811\end{array}$ & $\begin{array}{r}.92 \\
.24 \\
.48 \\
-\overline{19} \\
.63\end{array}$ & $\begin{array}{r}8.36 \\
4.86 \\
8.71 \\
-- \\
9.70 \\
8.57\end{array}$ & $\begin{array}{r}125.7 \\
115.8 \\
129.1 \\
-- \\
128.6 \\
123.5\end{array}$ & $\begin{array}{r}28.16 \\
20.52 \\
30.61 \\
-- \\
28.40 \\
29.18\end{array}$ \\
\hline 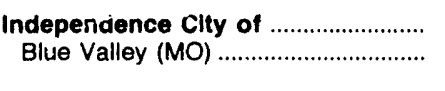 & $\begin{array}{l}44 \\
44\end{array}$ & $\begin{array}{l}12,114 \\
12,114\end{array}$ & $\begin{array}{l}3.23 \\
3.23\end{array}$ & $\begin{array}{l}10.39 \\
10.39\end{array}$ & $\begin{array}{l}127.9 \\
127.9\end{array}$ & $\begin{array}{l}30.99 \\
30.99\end{array}$ & $\overline{--}$ & - & - & - & $\overline{-}$ & - \\
\hline 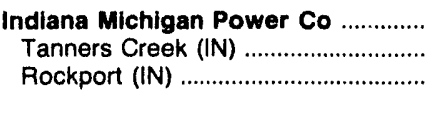 & $\begin{array}{l}9,616 \\
1,323 \\
8,293\end{array}$ & $\begin{array}{r}9,036 \\
11,609 \\
8,626\end{array}$ & $\begin{array}{r}.54 \\
1.88 \\
.32\end{array}$ & $\begin{array}{l}5.47 \\
9.22 \\
4.87\end{array}$ & $\begin{array}{l}120.6 \\
154.1 \\
113.4\end{array}$ & $\begin{array}{l}21.79 \\
35.78 \\
19.56\end{array}$ & $\frac{982}{982}$ & $\begin{array}{r}8,490 \\
8,490\end{array}$ & $\frac{.34}{-34}$ & $\begin{array}{r}4.88 \\
-\overline{4.88}\end{array}$ & $\begin{array}{r}110.1 \\
--\end{array}$ & $18 . \overline{70}$ \\
\hline $\begin{array}{l}\text { Indiana-Kentucky Electric Corp ....... } \\
\text { Clifty Creek (IN) }\end{array}$ & $\begin{array}{l}2,796 \\
2,796\end{array}$ & $\begin{array}{l}11,404 \\
11,404\end{array}$ & $\begin{array}{l}3.29 \\
3.29\end{array}$ & $\begin{array}{l}10.86 \\
10.86\end{array}$ & $\begin{array}{l}106.5 \\
106.5\end{array}$ & $\begin{array}{l}24.29 \\
24.29\end{array}$ & $\begin{array}{l}969 \\
969\end{array}$ & $\begin{array}{l}10,632 \\
10,632\end{array}$ & $\begin{array}{l}1.75 \\
1.75\end{array}$ & $\begin{array}{l}7.55 \\
7.55\end{array}$ & $\begin{array}{l}118.2 \\
118.2\end{array}$ & $\begin{array}{l}25.12 \\
25.12\end{array}$ \\
\hline 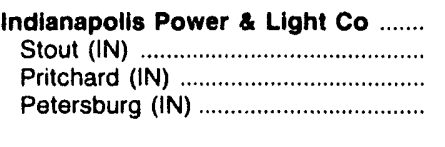 & $\begin{array}{r}4,895 \\
1,069 \\
358 \\
3,468\end{array}$ & $\begin{array}{l}11,167 \\
11,213 \\
11,376 \\
11,131\end{array}$ & $\begin{array}{l}2.30 \\
1.60 \\
1.07 \\
2.65\end{array}$ & $\begin{array}{l}8.31 \\
8.06 \\
6.79 \\
8.54\end{array}$ & $\begin{array}{l}108.4 \\
128.0 \\
121.9 \\
100.9\end{array}$ & $\begin{array}{l}24.20 \\
28.70 \\
27.73 \\
22.45\end{array}$ & $\begin{array}{r}1,187 \\
\overline{--} \\
1,187\end{array}$ & $\begin{array}{r}11,292 \\
-- \\
11,292\end{array}$ & $\begin{array}{r}2.35 \\
-\overline{-} \\
2.35\end{array}$ & $\begin{array}{r}8.05 \\
-- \\
.05\end{array}$ & $\begin{array}{r}95.5 \\
-- \\
\overline{--}\end{array}$ & $\begin{array}{r}21.57 \\
-- \\
21.57\end{array}$ \\
\hline $\begin{array}{l}\text { Interstate Power Co } \\
\text { Dubuque (IA) } \\
\text { Lansing (IA) } \\
\text { Kapp (IA) }\end{array}$ & $\begin{array}{r}1,181 \\
90 \\
590 \\
501\end{array}$ & $\begin{array}{r}9,930 \\
11,038 \\
8,528 \\
11,381\end{array}$ & $\begin{array}{r}1.29 \\
3.00 \\
.40 \\
2.02\end{array}$ & $\begin{array}{l}6.49 \\
9.31 \\
4.78 \\
7.98\end{array}$ & $\begin{array}{l}184.4 \\
200.0 \\
233.8 \\
138.1\end{array}$ & $\begin{array}{l}36.62 \\
44.15 \\
39.87 \\
31.44\end{array}$ & $\begin{array}{l}-- \\
-- \\
--\end{array}$ & $\begin{array}{l}-- \\
-- \\
--\end{array}$ & $\begin{array}{l}- \\
-- \\
--\end{array}$ & $\begin{array}{l}-- \\
-- \\
-\end{array}$ & $\begin{array}{l}- \\
-- \\
--\end{array}$ & 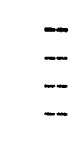 \\
\hline 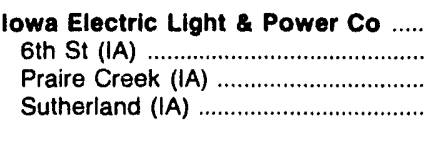 & $\begin{array}{r}510 \\
25 \\
340 \\
145\end{array}$ & $\begin{array}{r}9,758 \\
11,614 \\
10,114 \\
8,605\end{array}$ & $\begin{array}{r}1.49 \\
2.05 \\
1.79 \\
.71\end{array}$ & $\begin{array}{l}7.20 \\
7.82 \\
7.76 \\
5.77\end{array}$ & $\begin{array}{l}126.0 \\
136.7 \\
133.8 \\
102.3\end{array}$ & $\begin{array}{l}24.60 \\
31.75 \\
27.06 \\
17.60\end{array}$ & $\begin{array}{l}99 \\
-- \\
99 \\
--\end{array}$ & $\begin{array}{r}8,556 \\
8 \overline{-} \\
8,556 \\
--\end{array}$ & $\begin{array}{r}.39 \\
. \\
.39 \\
--\end{array}$ & $\begin{array}{r}5.03 \\
-\overline{-} \\
5.03 \\
--\end{array}$ & $\begin{array}{r}110.1 \\
110.1 \\
--\end{array}$ & $\begin{array}{r}18.84 \\
-- \\
18.84 \\
--\end{array}$ \\
\hline 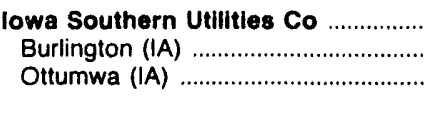 & $\begin{array}{r}1,834 \\
175 \\
1,659\end{array}$ & $\begin{array}{r}8,674 \\
11,464 \\
8,380\end{array}$ & $\begin{array}{r}.58 \\
3.13 \\
.31\end{array}$ & $\begin{array}{l}5.89 \\
8.88 \\
5.58\end{array}$ & 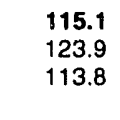 & $\begin{array}{l}19.97 \\
28.42 \\
19.08\end{array}$ & $\begin{array}{l}480 \\
301 \\
179\end{array}$ & $\begin{array}{l}8,341 \\
8,337 \\
8,347\end{array}$ & $\begin{array}{r}.96 \\
1.27 \\
.44\end{array}$ & $\begin{array}{l}6.49 \\
7.27 \\
5.18\end{array}$ & $\begin{array}{l}85.1 \\
88.0 \\
80.1\end{array}$ & $\begin{array}{l}14.19 \\
14.68 \\
13.38\end{array}$ \\
\hline $\begin{array}{l}\text { lowa-IIIInois Gas\&Electric Co } \ldots \ldots \ldots . . . . \\
\text { Riverside (IA) } \\
\text { Louisa (IA) }\end{array}$ & $\begin{array}{r}2,081 \\
281 \\
1,800\end{array}$ & $\begin{array}{r}8,768 \\
11,162 \\
8,394\end{array}$ & $\begin{array}{r}.52 \\
1.85 \\
.31\end{array}$ & $\begin{array}{l}\mathbf{5 . 6 3} \\
7.93 \\
5.27\end{array}$ & $\begin{array}{l}110.9 \\
110.9 \\
110.9\end{array}$ & $\begin{array}{l}19.45 \\
24.76 \\
18.62\end{array}$ & -- & - & - & - & $\begin{array}{l}-- \\
--\end{array}$ & $\overline{--}$ \\
\hline 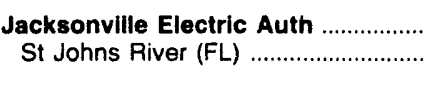 & $\begin{array}{l}2,798 \\
2,798\end{array}$ & $\begin{array}{l}12,272 \\
12,272\end{array}$ & $\begin{array}{l}.93 \\
.93\end{array}$ & $\begin{array}{l}9.06 \\
9.06\end{array}$ & $\begin{array}{l}172.5 \\
172.5\end{array}$ & $\begin{array}{l}42.34 \\
42.34\end{array}$ & $\begin{array}{l}826 \\
826\end{array}$ & $\begin{array}{l}12,522 \\
12,522\end{array}$ & $\begin{array}{l}.94 \\
.94\end{array}$ & $\begin{array}{l}6.89 \\
6.89\end{array}$ & $\begin{array}{l}132.5 \\
132.5\end{array}$ & $\begin{array}{l}33.19 \\
33.19\end{array}$ \\
\hline 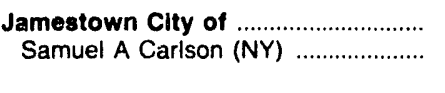 & - & - & - & - & - & -- & $\begin{array}{l}114 \\
114\end{array}$ & $\begin{array}{l}12,656 \\
12,656\end{array}$ & $\begin{array}{l}1.79 \\
1.79\end{array}$ & $\begin{array}{l}10.36 \\
10.36\end{array}$ & $\begin{array}{l}132.6 \\
132.6\end{array}$ & $\begin{array}{l}33.56 \\
33.56\end{array}$ \\
\hline 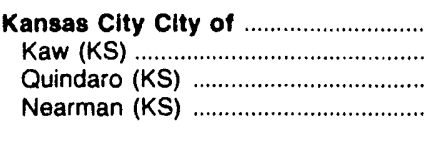 & $\begin{array}{r}1,063 \\
-\overline{192} \\
872\end{array}$ & $\begin{array}{r}8,905 \\
-- \\
11,720 \\
8,287\end{array}$ & $\begin{array}{r}.72 \\
-.43 \\
.34\end{array}$ & $\begin{array}{r}5.77 \\
-\overline{-} \\
10.05 \\
4.83\end{array}$ & $\begin{array}{r}129.8 \\
-- \\
231.3 \\
98.2\end{array}$ & $\begin{array}{r}23.11 \\
-\overline{-} \\
54.21 \\
16.28\end{array}$ & $\begin{array}{r}390 \\
138 \\
164 \\
88\end{array}$ & $\begin{array}{r}9,959 \\
10,366 \\
10,373 \\
8,562\end{array}$ & $\begin{array}{l}.37 \\
.38 \\
.40 \\
.31\end{array}$ & $\begin{array}{l}8.04 \\
9.10 \\
8.66 \\
5.24\end{array}$ & $\begin{array}{r}120.9 \\
127.4 \\
127.5 \\
93.8\end{array}$ & $\begin{array}{l}24.08 \\
26.41 \\
26.46 \\
16.07\end{array}$ \\
\hline Kansas City Power \& Light Co ....... & 3,400 & 8,810 & .32 & 4.93 & 89.3 & 15.73 & 4,961 & 8,916 & .61 & 5.42 & 93.0 & 16.58 \\
\hline
\end{tabular}

See footnotes at end of table.

Source: Federal Energ̣. Figulatory Commission, FERC Form 423, "Monthly Report of Cost and Quality of Fuels for Electric Plants." 
Table 30. Recelpts and Average Delivered Cost of Coal by Type of Purchase, Electric, Utility and Plant, 1992 (Continued)

\begin{tabular}{|c|c|c|c|c|c|c|c|c|c|c|c|c|}
\hline \multirow{3}{*}{$\begin{array}{l}\text { Electric Utilly } \\
\text { Plent (State) }\end{array}$} & \multicolumn{6}{|c|}{ Contract } & \multicolumn{6}{|c|}{ Spot } \\
\hline & \multirow{2}{*}{$\begin{array}{l}\text { Receipts } \\
\text { (1000 } \\
\text { short } \\
\text { tons) }\end{array}$} & \multicolumn{3}{|c|}{ Average Quality } & \multicolumn{2}{|c|}{$\begin{array}{c}\text { Average } \\
\text { Delivered Cost }\end{array}$} & \multirow{2}{*}{$\begin{array}{l}\text { Recelpts } \\
\text { (1000 } \\
\text { short } \\
\text { tons) }\end{array}$} & \multicolumn{3}{|c|}{ Average Quality } & \multicolumn{2}{|c|}{$\begin{array}{c}\text { Average } \\
\text { Dellvered } \\
\text { Cost }\end{array}$} \\
\hline & & $\begin{array}{c}\text { Btu } \\
\text { (per } \\
\text { pound) }\end{array}$ & $\begin{array}{c}\text { Sulfur } \\
\text { (percent } \\
\text { by } \\
\text { wolght) }\end{array}$ & $\begin{array}{c}\text { Ash } \\
\text { (percent } \\
\text { by } \\
\text { welght) }\end{array}$ & $\begin{array}{l}\text { (cents } \\
\text { per } \\
\text { million } \\
\text { Btu) }\end{array}$ & $\begin{array}{c}\text { (5 } \\
\text { per } \\
\text { short } \\
\text { ton) }\end{array}$ & & $\begin{array}{c}\text { Btu } \\
\text { (per } \\
\text { pound) }\end{array}$ & $\begin{array}{c}\text { Sulfur } \\
\text { (percent } \\
\text { by } \\
\text { welght) }\end{array}$ & $\begin{array}{c}\text { Ash } \\
\text { (percent } \\
\text { by } \\
\text { welght) }\end{array}$ & $\begin{array}{c}\text { (cents } \\
\text { per } \\
\text { million } \\
\text { Btu) }\end{array}$ & $\begin{array}{c}\text { (\$ } \\
\text { per } \\
\text { short } \\
\text { ton) }\end{array}$ \\
\hline 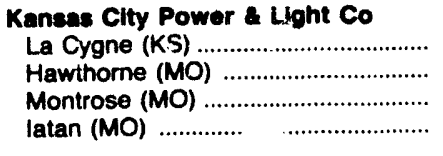 & $\begin{array}{r}12 \\
1,111 \\
-2 \overline{7}\end{array}$ & $\begin{array}{r}8,771 \\
8,862 \\
- \\
8,784\end{array}$ & $\begin{array}{r}0.38 \\
.19 \\
.39\end{array}$ & $\begin{array}{r}5.30 \\
4.58 \\
-- \\
5.10\end{array}$ & $\begin{array}{r}97.8 \\
\dot{5} 6.8 \\
-- \\
85.6\end{array}$ & $\begin{array}{r}17.16 \\
17.15 \\
-\overline{15.03}\end{array}$ & $\begin{array}{r}3,294 \\
148 \\
1,431 \\
88\end{array}$ & $\begin{array}{l}9,036 \\
8,817 \\
8,655 \\
8,832\end{array}$ & $\begin{array}{r}0.75 \\
.22 \\
.34 \\
.26\end{array}$ & $\begin{array}{l}5.58 \\
4.81 \\
5.13 \\
4.83\end{array}$ & $\begin{array}{l}92.7 \\
76.4 \\
97.0 \\
69.4\end{array}$ & $\begin{array}{l}16.74 \\
13.48 \\
16.80 \\
12.25\end{array}$ \\
\hline 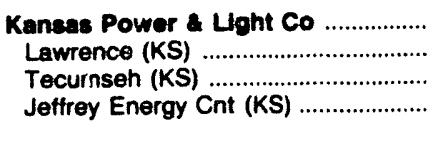 & $\begin{array}{r}7,315 \\
1,088 \\
409 \\
5,818\end{array}$ & $\begin{array}{r}\mathbf{8 , 7 9 9} \\
10,559 \\
10,585 \\
8,345\end{array}$ & $\begin{array}{l}.34 \\
.42 \\
.42 \\
.32\end{array}$ & $\begin{array}{l}5.74 \\
9.06 \\
9.18 \\
4.68\end{array}$ & $\begin{array}{l}130.0 \\
123.0 \\
122.5 \\
132.4\end{array}$ & $\begin{array}{l}22.68 \\
25.97 \\
25.93 \\
22.09\end{array}$ & $\begin{array}{l}34 \\
34 \\
- \\
--\end{array}$ & $\begin{array}{r}11,030 \\
11,030 \\
- \\
-\end{array}$ & $\begin{array}{l}.74 \\
.74 \\
- \\
--\end{array}$ & $\begin{array}{r}8.20 \\
8.20 \\
-- \\
-\end{array}$ & $\begin{array}{r}118.0 \\
118.0 \\
-- \\
--\end{array}$ & $\begin{array}{r}26.03 \\
26.03 \\
- \\
-\end{array}$ \\
\hline $\begin{array}{l}\text { Kentucky Power Co } \\
D_{\text {ig Sandy }}(K Y)\end{array}$ & $\begin{array}{l}1,678 \\
1,678\end{array}$ & $\begin{array}{l}12,039 \\
12,039\end{array}$ & $\begin{array}{l}1.01 \\
1.01\end{array}$ & $\begin{array}{l}11.15 \\
11.15\end{array}$ & $\begin{array}{l}123.8 \\
123.8\end{array}$ & $\begin{array}{l}29.81 \\
29.81\end{array}$ & $\begin{array}{l}839 \\
839\end{array}$ & $\begin{array}{l}12,049 \\
12,049\end{array}$ & $\begin{array}{l}1.11 \\
1.11\end{array}$ & $\begin{array}{l}10.80 \\
10.86\end{array}$ & $\begin{array}{l}104.3 \\
104.3\end{array}$ & $\begin{array}{l}25.13 \\
25.13\end{array}$ \\
\hline 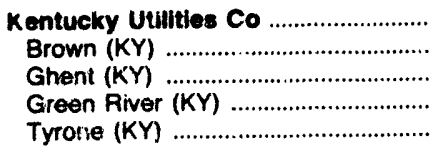 & $\begin{array}{r}3,416 \\
674 \\
2,438 \\
304 \\
-\end{array}$ & $\begin{array}{r}12,165 \\
12,250 \\
12,1,7 \\
11,886 \\
-\end{array}$ & $\begin{array}{r}1.37 \\
2.00 \\
1.07 \\
2.33 \\
--\end{array}$ & $\begin{array}{r}9.69 \\
11.66 \\
9.35 \\
8.08 \\
-\end{array}$ & $\begin{array}{r}123.8 \\
113.2 \\
127.1 \\
109.0 \\
-\end{array}$ & $\begin{array}{r}29.87 \\
27.73 \\
30.96 \\
25.91 \\
--\end{array}$ & $\begin{array}{r}2,516 \\
328 \\
2,157 \\
\overline{31}\end{array}$ & $\begin{array}{r}11,814 \\
11,943 \\
11,789 \\
12,178\end{array}$ & $\begin{array}{r}1.66 \\
1.93 \\
1.53 \\
-92\end{array}$ & $\begin{array}{r}10.23 \\
12.51 \\
9.87 \\
-\overline{10.73}\end{array}$ & $\begin{array}{r}107.2 \\
111.4 \\
106.4 \\
-- \\
115.1\end{array}$ & $\begin{array}{r}25.32 \\
26.61 \\
25.08 \\
-\overline{28.03}\end{array}$ \\
\hline 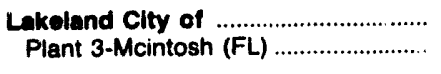 & $\begin{array}{l}749 \\
749\end{array}$ & $\begin{array}{l}13,054 \\
13,054\end{array}$ & $\begin{array}{l}1.04 \\
1.04\end{array}$ & $\begin{array}{l}7.46 \\
7.46\end{array}$ & $\begin{array}{l}165.4 \\
165.4\end{array}$ & $\begin{array}{l}43.18 \\
43.18\end{array}$ & $\begin{array}{l}69 \\
6 r\end{array}$ & $\begin{array}{l}12,404 \\
12,404\end{array}$ & $\begin{array}{l}.96 \\
.96\end{array}$ & $\begin{array}{l}10.38 \\
10.38\end{array}$ & $\begin{array}{l}161.0 \\
161.0\end{array}$ & $\begin{array}{l}39.94 \\
39.94\end{array}$ \\
\hline 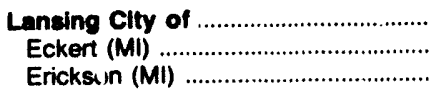 & $\begin{array}{l}681 \\
400 \\
291\end{array}$ & $\begin{array}{l}12,908 \\
12,878 \\
12,945\end{array}$ & $\begin{array}{l}.86 \\
.87 \\
.84\end{array}$ & $\begin{array}{l}7.05 \\
7.31 \\
6.70\end{array}$ & $\begin{array}{l}189.7 \\
194.2 \\
183.6\end{array}$ & $\begin{array}{l}48.97 \\
50.01 \\
47.53\end{array}$ & $\begin{array}{r}19 t \\
63 \\
135\end{array}$ & $\begin{array}{l}12,993 \\
13,098 \\
12,944\end{array}$ & $\begin{array}{l}.87 \\
.86 \\
.87\end{array}$ & $\begin{array}{l}7.65 \\
7.29 \\
7.83\end{array}$ & $\begin{array}{l}164.9 \\
165.4 \\
164.7\end{array}$ & $\begin{array}{l}42.86 \\
43.32 \\
42.65\end{array}$ \\
\hline 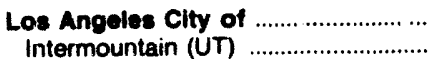 & $\begin{array}{l}3,912 \\
3,912\end{array}$ & $\begin{array}{l}11,834 \\
11,834\end{array}$ & .44 & $\begin{array}{l}8.53 \\
8.53\end{array}$ & $\begin{array}{l}151.8 \\
151.8\end{array}$ & $\begin{array}{l}35.93 \\
35.93\end{array}$ & $\begin{array}{l}366 \\
366\end{array}$ & $\begin{array}{l}12,069 \\
12,069\end{array}$ & $\begin{array}{l}.51 \\
.51\end{array}$ & $\begin{array}{l}7.46 \\
7.46\end{array}$ & $\begin{array}{l}122.7 \\
122.7\end{array}$ & $\begin{array}{l}29.62 \\
29.62\end{array}$ \\
\hline 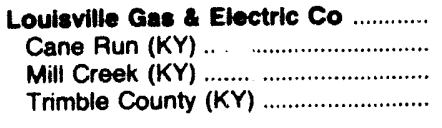 & $\begin{array}{r}4,454 \\
616 \\
2,979 \\
858\end{array}$ & $\begin{array}{l}11,502 \\
11,559 \\
11,520 \\
11,398\end{array}$ & $\begin{array}{l}2.85 \\
2.86 \\
2.84 \\
2.88\end{array}$ & $\begin{array}{l}9.52 \\
9.66 \\
9.66 \\
8.95\end{array}$ & $\begin{array}{l}110.5 \\
114.7 \\
111.4 \\
104.2\end{array}$ & $\begin{array}{l}25.42 \\
26.51 \\
25.68 \\
23.75\end{array}$ & $\begin{array}{r}1,026 \\
183 \\
374 \\
459\end{array}$ & $\begin{array}{l}11,475 \\
11,487 \\
11,668 \\
11,313\end{array}$ & $\begin{array}{l}3.20 \\
3.20 \\
2.97 \\
3.39\end{array}$ & $\begin{array}{l}9.12 \\
8.56 \\
9.28 \\
9.22\end{array}$ & $\begin{array}{r}101.0 \\
91.2 \\
111.0 \\
96.7\end{array}$ & $\begin{array}{l}23.17 \\
20.95 \\
25.90 \\
21.87\end{array}$ \\
\hline $\begin{array}{l}\text { Lower Colorado River Authority .... } \\
\text { S Seymour-Fayette (TX) ...................... }\end{array}$ & $\begin{array}{l}5,227 \\
5,227\end{array}$ & $\begin{array}{l}8,598 \\
8,598\end{array}$ & $\begin{array}{l}.41 \\
.41\end{array}$ & $\begin{array}{l}5.47 \\
5.47\end{array}$ & $\begin{array}{l}135.2 \\
135.2\end{array}$ & $\begin{array}{l}23.25 \\
23.25\end{array}$ & - & - & - & - & - & - \\
\hline 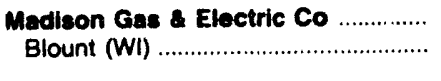 & $\begin{array}{l}18 \\
18\end{array}$ & $\begin{array}{l}11,848 \\
11,8+8\end{array}$ & $\begin{array}{l}2.08 \\
2.08\end{array}$ & $\begin{array}{l}8.18 \\
8.18\end{array}$ & $\begin{array}{l}165.7 \\
165.7\end{array}$ & $\begin{array}{l}39.26 \\
39.26\end{array}$ & - & - & - & - & $\overline{-}$ & - \\
\hline $\begin{array}{l}\text { Manitowoc Public Utilities } \\
\text { Manitowoc (WI) }\end{array}$ & $\overline{-}$ & - & $\overline{-}$ & - & $\overline{-}$ & - & $\begin{array}{l}138 \\
138\end{array}$ & $\begin{array}{l}13,101 \\
13,101\end{array}$ & $\begin{array}{l}.85 \\
.85\end{array}$ & $\begin{array}{l}6.71 \\
6.71\end{array}$ & $\begin{array}{l}174.4 \\
174.4\end{array}$ & $\begin{array}{l}45.69 \\
45.69\end{array}$ \\
\hline 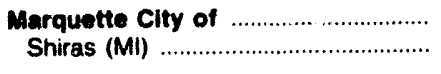 & $\begin{array}{l}123 \\
123\end{array}$ & $\begin{array}{l}8,999 \\
8,999\end{array}$ & $\begin{array}{l}.40 \\
.40\end{array}$ & $\begin{array}{l}6.35 \\
6.35\end{array}$ & $\begin{array}{l}179.0 \\
179.0\end{array}$ & $\begin{array}{l}32.21 \\
32.21\end{array}$ & $\begin{array}{l}10 \\
10\end{array}$ & $\begin{array}{r}12,345 \\
12,345\end{array}$ & $\begin{array}{l}.65 \\
.65\end{array}$ & $\begin{array}{l}9.18 \\
9.18\end{array}$ & $\begin{array}{l}170.5 \\
170.5\end{array}$ & $\begin{array}{l}42.09 \\
42.09\end{array}$ \\
\hline 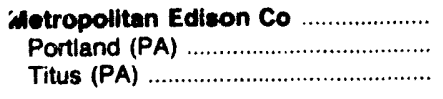 & $\begin{array}{l}348 \\
158 \\
190\end{array}$ & $\begin{array}{l}13,283 \\
13,177 \\
13,371\end{array}$ & $\begin{array}{l}1.51 \\
1.61 \\
1.42\end{array}$ & $\begin{array}{l}6.37 \\
5.99 \\
6.69\end{array}$ & $\begin{array}{l}156.3 \\
153.9 \\
158.4\end{array}$ & $\begin{array}{l}41.53 \\
40.55 \\
42.35\end{array}$ & $\begin{array}{l}762 \\
565 \\
197\end{array}$ & $\begin{array}{l}13,204 \\
13,192 \\
13,241\end{array}$ & $\begin{array}{l}1.67 \\
1.73 \\
1.51\end{array}$ & $\begin{array}{l}7.02 \\
7.24 \\
6.41\end{array}$ & $\begin{array}{l}138.0 \\
136.9 \\
141.2\end{array}$ & $\begin{array}{l}36.44 \\
36.11 \\
37.38\end{array}$ \\
\hline 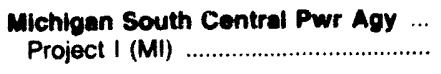 & $\begin{array}{l}40 \\
40\end{array}$ & $\begin{array}{l}12,003 \\
12,003\end{array}$ & $\begin{array}{l}3.35 \\
3.35\end{array}$ & $\begin{array}{l}8.29 \\
8.29\end{array}$ & $\begin{array}{l}223.3 \\
223.3\end{array}$ & $\begin{array}{l}53.60 \\
53.60\end{array}$ & - & - & - & $\overline{--}$ & - & $\overline{-}$ \\
\hline 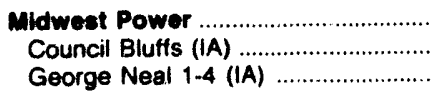 & $\begin{array}{l}4,564 \\
1,709 \\
2,855\end{array}$ & $\begin{array}{l}8,578 \\
8,261 \\
8,768\end{array}$ & $\begin{array}{l}.38 \\
.36 \\
.39\end{array}$ & $\begin{array}{l}5.22 \\
4.60 \\
5.59\end{array}$ & $\begin{array}{l}92.1 \\
99.5 \\
88.0\end{array}$ & $\begin{array}{l}15.81 \\
16.43 \\
15.43\end{array}$ & $\begin{array}{l}3,414 \\
1,150 \\
2,264\end{array}$ & $\begin{array}{l}8,549 \\
8,277 \\
8,698\end{array}$ & $\begin{array}{l}.37 \\
.38 \\
.36\end{array}$ & $\begin{array}{l}5.51 \\
4.68 \\
5.92\end{array}$ & $\begin{array}{l}78.7 \\
73.6 \\
81.2\end{array}$ & $\begin{array}{l}13.46 \\
12.18 \\
14.11\end{array}$ \\
\hline 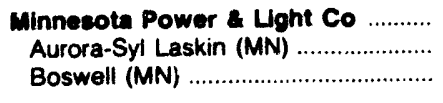 & $\begin{array}{r}2,966 \\
65 \\
2,904\end{array}$ & $\begin{array}{l}9,001 \\
8,854 \\
9,005\end{array}$ & $\begin{array}{l}.55 \\
.65 \\
.55\end{array}$ & $\begin{array}{l}7.01 \\
8.21 \\
6.98\end{array}$ & $\begin{array}{r}120.7 \\
92.1 \\
121.4\end{array}$ & $\begin{array}{l}21.74 \\
16.31 \\
21.86\end{array}$ & $\frac{298}{298}$ & $\begin{array}{r}8,638 \\
-\overline{8,638}\end{array}$ & $\frac{.35}{.35}$ & 5.19 & 98.1 & $\begin{array}{r}16.84 \\
16 . \overline{94}\end{array}$ \\
\hline 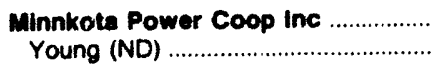 & $\begin{array}{l}4,184 \\
4,184\end{array}$ & $\begin{array}{l}6,831 \\
6,831\end{array}$ & $\begin{array}{l}.86 \\
.86\end{array}$ & $\begin{array}{l}7.58 \\
7.58\end{array}$ & $\begin{array}{l}48.9 \\
48.9\end{array}$ & $\begin{array}{l}6.69 \\
6.69\end{array}$ & $\overline{-}$ & $\overline{-}$ & $\overline{-}$ & $\overline{--}$ & -- & $\overline{-}$ \\
\hline
\end{tabular}

See footnotes at end of table.

Source: Federal Enercy Regulatory Commission, FERC Form 423. "Monthly Report of Cost and Quality of Fuels for Electric Plants." 
Table 30. Receipts and Average Delivered Cost of Coal by Type of Purchase, Electric, Utility and Plant, 1992 (Continued)

\begin{tabular}{|c|c|c|c|c|c|c|c|c|c|c|c|c|}
\hline \multirow{3}{*}{$\begin{array}{l}\text { Electric Utility } \\
\text { Plant (State) }\end{array}$} & \multicolumn{6}{|c|}{ Contract } & \multicolumn{6}{|c|}{ Spot } \\
\hline & \multirow{2}{*}{$\begin{array}{l}\text { Receipts } \\
\text { (1000 } \\
\text { short } \\
\text { tons) }\end{array}$} & \multicolumn{3}{|c|}{ Average Quality } & \multicolumn{2}{|c|}{$\begin{array}{c}\text { Average } \\
\text { Dellvered Cost }\end{array}$} & \multirow{2}{*}{$\begin{array}{l}\text { Recelpts } \\
\text { (1000 } \\
\text { short } \\
\text { tons) }\end{array}$} & \multicolumn{3}{|c|}{ Average Quality } & \multicolumn{2}{|c|}{$\begin{array}{l}\text { Average } \\
\text { Delivered } \\
\text { Cost }\end{array}$} \\
\hline & & $\begin{array}{c}\text { Btu } \\
\text { (per } \\
\text { pound) }\end{array}$ & $\begin{array}{c}\text { Sulfur } \\
\text { (percent } \\
\text { by } \\
\text { weight) }\end{array}$ & $\begin{array}{c}\text { Ash } \\
\text { (percent } \\
\text { by } \\
\text { weight) }\end{array}$ & $\begin{array}{l}\text { (cents } \\
\text { per } \\
\text { million } \\
\text { Btu) }\end{array}$ & $\begin{array}{c}\text { (\$ } \\
\text { por } \\
\text { short } \\
\text { ton) }\end{array}$ & & $\begin{array}{c}\text { Btu } \\
\text { (per } \\
\text { pound) }\end{array}$ & $\begin{array}{c}\text { Sulfur } \\
\text { (percent } \\
\text { by } \\
\text { welght) }\end{array}$ & $\begin{array}{c}\text { Ash } \\
\text { (percent } \\
\text { by } \\
\text { wolght) }\end{array}$ & $\begin{array}{c}\text { (cents } \\
\text { per } \\
\text { million } \\
\text { Btu) }\end{array}$ & $\begin{array}{c}(5 \\
\text { per } \\
\text { short } \\
\text { ton) }\end{array}$ \\
\hline 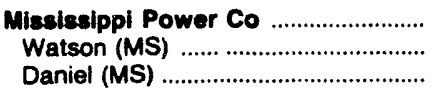 & $\begin{array}{r}1,869 \\
1,058 \\
811\end{array}$ & $\begin{array}{l}12,853 \\
12,750 \\
12,988\end{array}$ & $\begin{array}{r}1.87 \\
2.74 \\
.73\end{array}$ & $\begin{array}{l}8.09 \\
8.75 \\
7.22\end{array}$ & $\begin{array}{l}149.6 \\
133.8 \\
170.0\end{array}$ & $\begin{array}{l}38.46 \\
34.11 \\
44.15\end{array}$ & $\begin{array}{l}582 \\
429 \\
153\end{array}$ & $\begin{array}{r}11,572 \\
12,457 \\
9,095\end{array}$ & $\begin{array}{r}2.00 \\
2.60 \\
.32\end{array}$ & $\begin{array}{l}7.35 \\
8.36 \\
4.51\end{array}$ & $\begin{array}{l}131.9 \\
128.9 \\
143.6\end{array}$ & $\begin{array}{l}30.53 \\
32.11 \\
26.11\end{array}$ \\
\hline $\begin{array}{l}\text { Missouri Public Service Comm ........ } \\
\text { Sibley (MO) }\end{array}$ & $\begin{array}{l}529 \\
529\end{array}$ & $\begin{array}{l}11,032 \\
11,032\end{array}$ & $\begin{array}{l}2.86 \\
2.86\end{array}$ & $\begin{array}{l}9.63 \\
9.63\end{array}$ & $\begin{array}{l}151.6 \\
151.6\end{array}$ & $\begin{array}{l}33.46 \\
33.46\end{array}$ & $\begin{array}{l}455 \\
455\end{array}$ & $\begin{array}{l}11,173 \\
11,173\end{array}$ & $\begin{array}{l}2.36 \\
2.36\end{array}$ & $\begin{array}{l}8.90 \\
8.90\end{array}$ & $\begin{array}{l}113.1 \\
113.1\end{array}$ & $\begin{array}{l}25.28 \\
25.28\end{array}$ \\
\hline $\begin{array}{l}\text { Monongahela Power Co } \\
\text { Albright (WV) } \\
\text { Ft Martin (WV) } \\
\text { Harrison (WV) } \\
\text { Rivesville (WV) } \\
\text { Willow Island (WV) } \\
\text { Pleasants (WV) }\end{array}$ & $\begin{array}{r}7,517 \\
19 \\
2,478 \\
3,774 \\
5 \\
167 \\
1,074\end{array}$ & $\begin{array}{l}12,868 \\
12,897 \\
12,719 \\
13,151 \\
12,011 \\
12,297 \\
12,309\end{array}$ & $\begin{array}{l}2.58 \\
1.57 \\
1.79 \\
3.04 \\
1.04 \\
1.70 \\
2.96\end{array}$ & $\begin{array}{r}9.54 \\
11.49 \\
10.50 \\
7.71 \\
14.30 \\
13.27 \\
13.10\end{array}$ & $\begin{array}{l}145.3 \\
108.1 \\
145.4 \\
150.7 \\
128.3 \\
117.0 \\
129.9\end{array}$ & $\begin{array}{l}37.40 \\
27.89 \\
36.98 \\
39.65 \\
30.82 \\
28.79 \\
31.99\end{array}$ & $\begin{array}{r}4,069 \\
483 \\
-\overline{845} \\
63 \\
95 \\
2,583\end{array}$ & $\begin{array}{r}12,668 \\
12,319 \\
13,190 \\
12,195 \\
12,823 \\
12,567\end{array}$ & $\begin{array}{r}3.20 \\
1.54 \\
-.- \\
3.08 \\
.96 \\
1.48 \\
3.66\end{array}$ & $\begin{array}{r}9.83 \\
12.93 \\
-\overline{-} \\
8.06 \\
10.82 \\
8.07 \\
9.87\end{array}$ & $\begin{array}{r}95.1 \\
100.5 \\
-\overline{100.0} \\
120.2 \\
113.2 \\
91.1\end{array}$ & $\begin{array}{r}24.09 \\
24.77 \\
26 . \overline{39} \\
29.31 \\
29.04 \\
22.90\end{array}$ \\
\hline 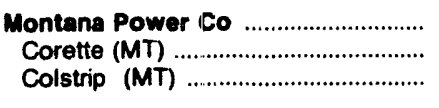 & $\begin{array}{r}10,683 \\
749 \\
9,934\end{array}$ & $\begin{array}{l}8,609 \\
8,782 \\
\overline{0} .596\end{array}$ & $\begin{array}{l}.66 \\
.63 \\
.66\end{array}$ & $\begin{array}{l}8.92 \\
8.11 \\
8.98\end{array}$ & $\begin{array}{l}70.3 \\
69.1 \\
70.4\end{array}$ & $\begin{array}{l}12.11 \\
12.13 \\
12.10\end{array}$ & - & - & - & - & - & - \\
\hline 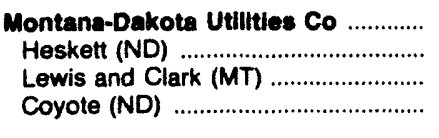 & $\begin{array}{r}2,674 \\
345 \\
177 \\
2,151\end{array}$ & $\begin{array}{l}6,915 \\
7,009 \\
6,542 \\
6,931\end{array}$ & $\begin{array}{r}.99 \\
.82 \\
.51 \\
1.06\end{array}$ & $\begin{array}{l}8.23 \\
8.53 \\
9.04 \\
8.12\end{array}$ & $\begin{array}{r}80.4 \\
105.3 \\
107.8 \\
74.3\end{array}$ & $\begin{array}{l}11.13 \\
14.76 \\
14.10 \\
10.30\end{array}$ & $\begin{array}{l}-- \\
--\end{array}$ & $\overline{-}$ & $\overline{-}$ & $\overline{-}$ & $\overline{-}$ & $\overline{-}$ \\
\hline 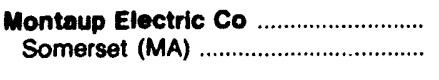 & $\begin{array}{l}413 \\
413\end{array}$ & $\begin{array}{l}12,917 \\
12,917\end{array}$ & $\begin{array}{l}1.03 \\
1.03\end{array}$ & $\begin{array}{l}7.93 \\
7.93\end{array}$ & $\begin{array}{l}176.4 \\
176.4\end{array}$ & $\begin{array}{l}45.58 \\
45.58\end{array}$ & - & - & - & - & - & $\overline{-}$ \\
\hline 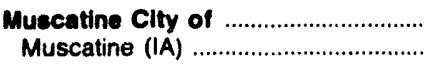 & $\begin{array}{l}536 \\
536\end{array}$ & $\begin{array}{l}11,078 \\
11,078\end{array}$ & $\begin{array}{l}3.16 \\
3.16\end{array}$ & $\begin{array}{l}8.25 \\
8.25\end{array}$ & $\begin{array}{l}223.9 \\
223.9\end{array}$ & $\begin{array}{l}49.60 \\
49.60\end{array}$ & $\begin{array}{l}22 \\
22\end{array}$ & $\begin{array}{l}8,491 \\
8,491\end{array}$ & $\begin{array}{l}.59 \\
.59\end{array}$ & $\begin{array}{l}\mathbf{5 . 5 1} \\
\mathbf{5 . 5 1}\end{array}$ & $\begin{array}{l}100.0 \\
100.0\end{array}$ & $\begin{array}{l}16.98 \\
16.98\end{array}$ \\
\hline 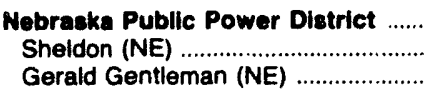 & $\begin{array}{r}3,522 \\
558 \\
2,964\end{array}$ & $\begin{array}{l}8,780 \\
8,779 \\
8,780\end{array}$ & $\begin{array}{l}.38 \\
.38 \\
.38\end{array}$ & $\begin{array}{l}5.07 \\
5.04 \\
5.07\end{array}$ & $\begin{array}{l}84.0 \\
78.1 \\
85.1\end{array}$ & $\begin{array}{l}14.75 \\
13.71 \\
14.94\end{array}$ & $\begin{array}{r}292 \\
\overline{292}\end{array}$ & $\begin{array}{r}8,753 \\
-- \\
8,753\end{array}$ & $\frac{.27}{.27}$ & $\begin{array}{r}4.70 \\
-\overline{-} \\
4.70\end{array}$ & $\begin{array}{r}71.9 \\
71.9\end{array}$ & $\begin{array}{r}12.59 \\
12 . \overline{59}\end{array}$ \\
\hline $\begin{array}{l}\text { Nevada Power Co } \\
\text { Gardner (NV) }\end{array}$ & $\begin{array}{l}1,372 \\
1,372\end{array}$ & $\begin{array}{l}12,058 \\
12,058\end{array}$ & $\begin{array}{l}.50 \\
.50\end{array}$ & $\begin{array}{l}9.11 \\
9.11\end{array}$ & $\begin{array}{l}185.1 \\
185.1\end{array}$ & $\begin{array}{l}44.64 \\
44.64\end{array}$ & - & - & - & - & - & $\overline{-}$ \\
\hline 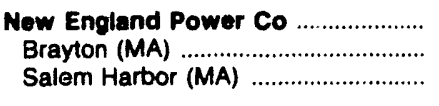 & $\begin{array}{r}3,035 \\
2,314 \\
721\end{array}$ & $\begin{array}{l}13,077 \\
13,061 \\
13,130\end{array}$ & $\begin{array}{l}1.18 \\
1.10 \\
1.46\end{array}$ & $\begin{array}{l}8.59 \\
8.32 \\
9.46\end{array}$ & $\begin{array}{l}168.4 \\
168.7 \\
167.5\end{array}$ & $\begin{array}{l}44.04 \\
44.06 \\
43.98\end{array}$ & $\begin{array}{l}383 \\
233 \\
150\end{array}$ & $\begin{array}{l}13,034 \\
12,934 \\
13,189\end{array}$ & $\begin{array}{r}1.06 \\
.98 \\
1.18\end{array}$ & $\begin{array}{l}7.78 \\
8.28 \\
7.01\end{array}$ & $\begin{array}{l}163.3 \\
165.2 \\
160.4\end{array}$ & $\begin{array}{l}42.57 \\
42.72 \\
42.32\end{array}$ \\
\hline 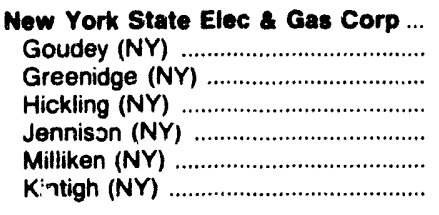 & $\begin{array}{r}2,010 \\
- \\
- \\
- \\
32 \\
1,978\end{array}$ & $\begin{array}{r}13,139 \\
= \\
= \\
-- \\
12,758 \\
13,146\end{array}$ & $\begin{array}{r}1.72 \\
-- \\
-- \\
1.50 \\
1.72\end{array}$ & $\begin{array}{r}6.67 \\
-- \\
-- \\
-- \\
7.08 \\
6.66\end{array}$ & $\begin{array}{r}141.3 \\
- \\
- \\
- \\
138.0 \\
141.3\end{array}$ & $\begin{array}{r}37.13 \\
- \\
- \\
- \\
\overline{-} \\
35.21 \\
37.16\end{array}$ & $\begin{array}{r}2,349 \\
337 \\
510 \\
327 \\
250 \\
822 \\
102\end{array}$ & $\begin{array}{l}12,409 \\
13,116 \\
12,808 \\
10,720 \\
10,753 \\
12,954 \\
13,176\end{array}$ & $\begin{array}{l}1.81 \\
1.83 \\
2.04 \\
1.31 \\
1.14 \\
1.96 \\
2.56\end{array}$ & $\begin{array}{r}11.52 \\
7.48 \\
8.98 \\
21.28 \\
21.72 \\
8.37 \\
6.68\end{array}$ & $\begin{array}{l}137.8 \\
138.4 \\
137.6 \\
130.1 \\
148.6 \\
139.8 \\
121.3\end{array}$ & $\begin{array}{l}34.22 \\
36.30 \\
35.24 \\
27.90 \\
31.96 \\
36.22 \\
31.97\end{array}$ \\
\hline $\begin{array}{l}\text { Nlagara Mohawk Power Corp .......... } \\
\text { Huntley (NY) ..................................... } \\
\text { Dunkirk (NY) }\end{array}$ & $\begin{array}{r}1,950 \\
1,296 \\
654\end{array}$ & $\begin{array}{l}13,122 \\
13,169 \\
13,028\end{array}$ & $\begin{array}{l}1.79 \\
1.74 \\
1.88\end{array}$ & $\begin{array}{l}7.10 \\
6.97 \\
7.35\end{array}$ & $\begin{array}{l}150.1 \\
151.3 \\
147.8\end{array}$ & $\begin{array}{l}39.40 \\
39.84 \\
38.52\end{array}$ & $\begin{array}{r}1,580 \\
713 \\
876\end{array}$ & $\begin{array}{l}13,252 \\
13,208 \\
13,289\end{array}$ & $\begin{array}{l}1.97 \\
1.70 \\
2.20\end{array}$ & $\begin{array}{l}6.83 \\
7.03 \\
6.66\end{array}$ & $\begin{array}{l}133.4 \\
140.9 \\
127.3\end{array}$ & $\begin{array}{l}35.35 \\
37.21 \\
33.84\end{array}$ \\
\hline $\begin{array}{l}\text { Northern Indiana Pub Serv Co } \\
\text { Bailly (IN) } \\
\text { Mitchell (IN) } \\
\text { Michigan City (IN) } \\
\text { Rollin Schahfer (IN) }\end{array}$ & $\begin{array}{r}4,111 \\
914 \\
39 \\
484 \\
2,674\end{array}$ & $\begin{array}{l}11,063 \\
10,945 \\
13,107 \\
11,082 \\
11,071\end{array}$ & $\begin{array}{r}1.98 \\
2.94 \\
.67 \\
1.88 \\
1.68\end{array}$ & $\begin{array}{r}8.05 \\
10.39 \\
7.60 \\
8.67 \\
8.69\end{array}$ & $\begin{array}{l}158.7 \\
148.4 \\
159.2 \\
164.1 \\
161.3\end{array}$ & $\begin{array}{l}35.12 \\
32.48 \\
41.73 \\
36.37 \\
35.70\end{array}$ & $\begin{array}{r}2,947 \\
501 \\
1,040 \\
538 \\
868\end{array}$ & $\begin{array}{r}10,919 \\
11,398 \\
9,851 \\
11,366 \\
11,645\end{array}$ & $\begin{array}{r}1.61 \\
2.70 \\
.43 \\
2.89 \\
1.61\end{array}$ & $\begin{array}{l}7.74 \\
8.77 \\
5.88 \\
8.03 \\
9.19\end{array}$ & $\begin{array}{l}122.6 \\
109.8 \\
121.7 \\
111.2 \\
137.6\end{array}$ & $\begin{array}{l}26.78 \\
25.04 \\
23.98 \\
25.29 \\
32.04\end{array}$ \\
\hline $\begin{array}{l}\text { Northern States Power Co } \\
\text { Black Dog (MN) } \\
\text { High Bridge (MN) } \\
\text { King (MN) }\end{array}$ & $\begin{array}{r}11,571 \\
725 \\
468 \\
1,567\end{array}$ & $\begin{array}{l}8,775 \\
8,836 \\
8,780 \\
8,828\end{array}$ & $\begin{array}{l}.42 \\
.28 \\
.22 \\
.33\end{array}$ & $\begin{array}{l}6.49 \\
5.12 \\
4.58 \\
5.77\end{array}$ & $\begin{array}{l}118.1 \\
114.3 \\
112.7 \\
113.3\end{array}$ & $\begin{array}{l}20.73 \\
20.20 \\
19.79 \\
20.00\end{array}$ & $\begin{array}{r}116 \\
- \\
- \\
-\end{array}$ & $\begin{array}{r}8,808 \\
- \\
- \\
-\end{array}$ & $\begin{array}{c}.68 \\
-- \\
-- \\
--\end{array}$ & $\begin{array}{r}8.55 \\
- \\
- \\
-\end{array}$ & $\begin{array}{r}113.4 \\
- \\
- \\
-\end{array}$ & $\begin{array}{r}19.97 \\
-- \\
- \\
-\end{array}$ \\
\hline
\end{tabular}

See footnotes at end of table.

Source: Federal Energy Regulatory Commission, FERC Form 423, "Monthly Report of Cost and Quality of Fuels for Electric Plants." 
Table 30. Receipts and Average Delivered Cost of Coal by Type of Purchase, Electric, Utility and Plant, 1992 (Continued)

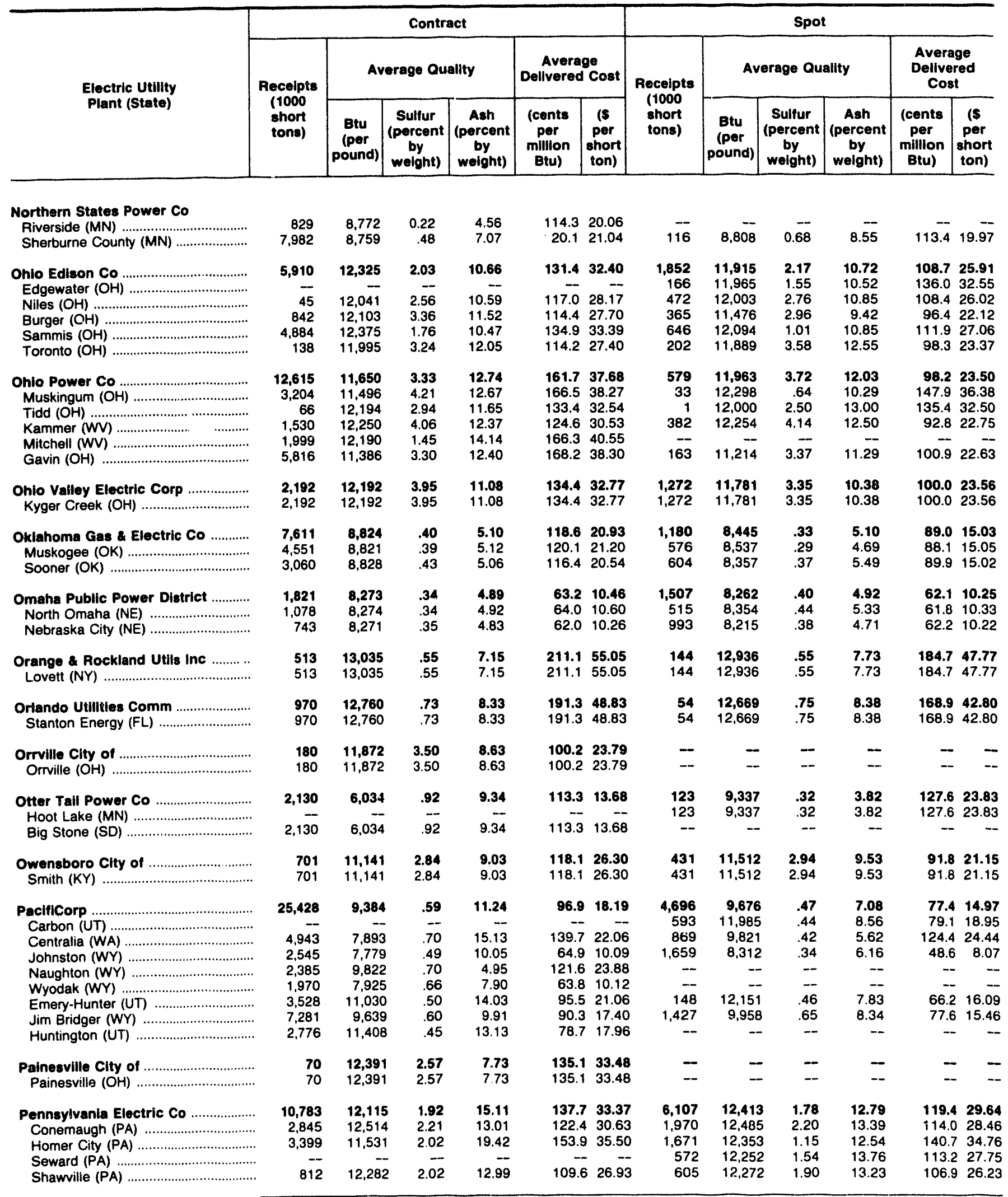

See foutnotes at end of table.

Source: Federal Energy Regulatory Commission. FERC Form 423, "Monthiy Report of Cost and Quality of Fuels for Electric Plants." 
Table 30. Recelpts and Average Delivered Cost of Coal by Type of Purchase, Electric, Utillty and Plant, 1992 (Continued)

\begin{tabular}{|c|c|c|c|c|c|c|c|c|c|c|c|c|}
\hline \multirow{3}{*}{$\begin{array}{l}\text { Electric Utility } \\
\text { Plant (Stato) }\end{array}$} & \multicolumn{6}{|c|}{ Contract } & \multicolumn{6}{|c|}{ Spot } \\
\hline & \multirow{2}{*}{$\begin{array}{l}\text { Pocelple } \\
\text { (1000 } \\
\text { short } \\
\text { tone) }\end{array}$} & \multicolumn{3}{|c|}{ Average Quallity } & \multicolumn{2}{|c|}{$\begin{array}{c}\text { Average } \\
\text { Dellvered Cost }\end{array}$} & \multirow{2}{*}{$\begin{array}{l}\text { Recelpts } \\
\text { (1000 } \\
\text { chort } \\
\text { tons) }\end{array}$} & \multicolumn{3}{|c|}{ Average Quality } & \multicolumn{2}{|c|}{$\begin{array}{l}\text { Average } \\
\text { Dellverod } \\
\text { Cost }\end{array}$} \\
\hline & & $\begin{array}{c}\text { Btu } \\
\text { (por } \\
\text { pound) }\end{array}$ & $\begin{array}{c}\text { Sulfur } \\
\text { (porcent } \\
\text { by } \\
\text { welght) }\end{array}$ & $\begin{array}{c}\text { Ash } \\
\text { (percent } \\
\text { by } \\
\text { welght) }\end{array}$ & $\begin{array}{l}\text { (cents } \\
\text { per } \\
\text { million } \\
\text { Btu) }\end{array}$ & $\begin{array}{c}\text { (\$ } \\
\text { per } \\
\text { whort } \\
\text { ton) }\end{array}$ & & $\begin{array}{c}\text { Btu } \\
\text { (por } \\
\text { pound) }\end{array}$ & $\begin{array}{c}\text { Sulfur } \\
\text { (percent } \\
\text { by } \\
\text { wolght) }\end{array}$ & $\begin{array}{c}\begin{array}{c}\text { Auh } \\
\text { (porcent } \\
\text { by } \\
\text { wolght) }\end{array} \\
\end{array}$ & $\begin{array}{c}\text { (cents } \\
\text { par } \\
\text { million } \\
\text { Btu) }\end{array}$ & $\begin{array}{l}(\$ \\
\text { per } \\
\text { short } \\
\text { ton) }\end{array}$ \\
\hline 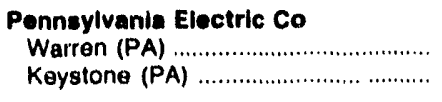 & $3, \overline{727}$ & 12,307 & $1 . \overline{8 B}$ & $13 . \overline{25}$ & $14 \overline{1.9}$ & 34.92 & $\begin{array}{r}217 \\
1.072\end{array}$ & $\begin{array}{l}12,218 \\
12,583\end{array}$ & $\begin{array}{l}1.77 \\
2.06\end{array}$ & $\begin{array}{l}11.09 \\
11.65\end{array}$ & $\begin{array}{l}116.7 \\
107.2\end{array}$ & $\begin{array}{l}28.53 \\
26.98\end{array}$ \\
\hline 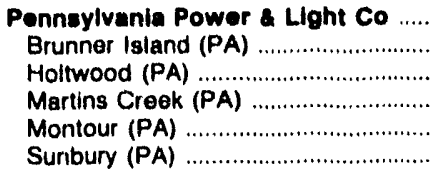 & $\begin{array}{r}7,102 \\
3,471 \\
15 \\
543 \\
2,762 \\
311\end{array}$ & $\begin{array}{r}12,642 \\
12,718 \\
7,080 \\
12,840 \\
12,544 \\
12,426\end{array}$ & $\begin{array}{r}1.86 \\
1.83 \\
.66 \\
1.92 \\
1.92 \\
1.95\end{array}$ & $\begin{array}{r}12.13 \\
11.46 \\
36.49 \\
9.89 \\
13.19 \\
13.07\end{array}$ & $\begin{array}{l}184.4 \\
186.9 \\
107.6 \\
191.7 \\
183.4 \\
154.7\end{array}$ & $\begin{array}{l}46.64 \\
47.53 \\
15.23 \\
49.60 \\
46.02 \\
38.43\end{array}$ & $\begin{array}{r}1,376 \\
178 \\
60 \\
493 \\
645\end{array}$ & $\begin{array}{r}11,054 \\
8,815 \\
13,084 \\
12,646 \\
10,239\end{array}$ & $\begin{array}{r}1.50 \\
-60 \\
1.79 \\
1.94 \\
1.38\end{array}$ & $\begin{array}{r}20.33 \\
29 . \overline{-} \\
9.00 \\
13.01 \\
24.50\end{array}$ & $\begin{array}{r}123.0 \\
-\overline{116.8} \\
140.3 \\
137.4 \\
108.8\end{array}$ & $\begin{array}{r}27.19 \\
20.82 \\
36.71 \\
34.76 \\
22.27\end{array}$ \\
\hline 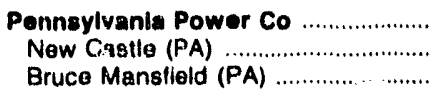 & $\begin{array}{r}6,204 \\
324 \\
4,880\end{array}$ & $\begin{array}{l}12,152 \\
12,344 \\
12,139\end{array}$ & $\begin{array}{l}3.72 \\
1.40 \\
3.88\end{array}$ & $\begin{array}{l}11.60 \\
10.94 \\
11.65\end{array}$ & $\begin{array}{l}168.0 \\
138.1 \\
168.8\end{array}$ & $\begin{array}{l}40.56 \\
34.11 \\
40.98\end{array}$ & $\begin{array}{r}438 \\
438 \\
-\end{array}$ & $\begin{array}{r}12,168 \\
12,168 \\
--\end{array}$ & $\begin{array}{r}1.51 \\
1.51 \\
--\end{array}$ & $\begin{array}{r}9.98 \\
9.98 \\
--\end{array}$ & $\begin{array}{r}119.2 \\
119.2 \\
\cdots\end{array}$ & $\begin{array}{r}29.00 \\
29.00 \\
-\end{array}$ \\
\hline $\begin{array}{l}\text { Philadelphia Electric Co } \\
\text { Cromby (PA) } \\
\text { Eddystone (PA) }\end{array}$ & $\begin{array}{l}320 \\
100 \\
220\end{array}$ & $\begin{array}{l}13,22 b \\
13,427 \\
13,139\end{array}$ & $\begin{array}{l}1.66 \\
1.53 \\
1.71\end{array}$ & $\begin{array}{l}7.39 \\
6.99 \\
7.57\end{array}$ & $\begin{array}{l}167.2 \\
160.8 \\
170.2\end{array}$ & $\begin{array}{l}44.25 \\
43.19 \\
44.73\end{array}$ & $\begin{array}{l}770 \\
188 \\
582\end{array}$ & $\begin{array}{l}13,170 \\
13,238 \\
13,148\end{array}$ & $\begin{array}{l}1.07 \\
1.81 \\
2.02\end{array}$ & $\begin{array}{l}7.32 \\
7.32 \\
7.33\end{array}$ & $\begin{array}{l}151.1 \\
150.6 \\
151.3\end{array}$ & $\begin{array}{l}39.81 \\
39.88 \\
38.78\end{array}$ \\
\hline $\begin{array}{l}\text { Plalna Eluc Genetrans Coop Inc ... } \\
\text { Escalante (NM) }\end{array}$ & $\begin{array}{l}889 \\
889\end{array}$ & $\begin{array}{l}9,070 \\
8,079\end{array}$ & $\begin{array}{l}.65 \\
.65\end{array}$ & $\begin{array}{l}18.58 \\
18.58\end{array}$ & $\begin{array}{l}137.5 \\
137.5\end{array}$ & $\begin{array}{l}24.916 \\
24.816\end{array}$ & - & - & -- & $\overline{-}$ & $-\overline{-}$ & $\overline{--}$ \\
\hline $\begin{array}{l}\text { Platte River Power Authority ........... } \\
\text { Rawhide (CO) }\end{array}$ & $\begin{array}{l}1,009 \\
1,009\end{array}$ & $\begin{array}{l}8,825 \\
8,825\end{array}$ & $\begin{array}{l}.32 \\
.32\end{array}$ & $\begin{array}{l}5.54 \\
5.54\end{array}$ & $\begin{array}{l}74.6 \\
74.6\end{array}$ & $\begin{array}{l}13.17 \\
13.17\end{array}$ & -- & - & - & - & - & - \\
\hline $\begin{array}{l}\text { Portland General Electric Co } \ldots \ldots \ldots \ldots \\
\text { Boardman (OA) }\end{array}$ & $\overline{-}$ & - & - & - & -- & -- & $\begin{array}{l}1,932 \\
1,832\end{array}$ & $\begin{array}{l}9,642 \\
9,642\end{array}$ & $\begin{array}{r}.40 \\
.40\end{array}$ & $\begin{array}{l}4.42 \\
4.42\end{array}$ & $\begin{array}{l}110.1 \\
110.1\end{array}$ & $\begin{array}{l}21.23 \\
21.23\end{array}$ \\
\hline $\begin{array}{l}\text { Potomac Edlson Co } \\
\text { Smith (MD) }\end{array}$ & $\begin{array}{l}3 \\
3\end{array}$ & $\begin{array}{l}13,427 \\
13,427\end{array}$ & $\begin{array}{l}1.09 \\
1.09\end{array}$ & $\begin{array}{l}7.29 \\
7.29\end{array}$ & $\begin{array}{l}158.0 \\
156.0\end{array}$ & $\begin{array}{l}41.89 \\
41.89\end{array}$ & $\begin{array}{l}151 \\
151\end{array}$ & $\begin{array}{l}12,522 \\
12,522\end{array}$ & $\begin{array}{l}.82 \\
.92\end{array}$ & $\begin{array}{l}12.41 \\
12.41\end{array}$ & $\begin{array}{l}133.6 \\
133.6\end{array}$ & $\begin{array}{l}33.45 \\
33.45\end{array}$ \\
\hline $\begin{array}{l}\text { Potomac Eloctric Power Co } \\
\text { Chalk (MD) } \ldots \ldots \ldots \ldots \\
\text { Dickerson (MD) } \\
\text { Morgantown (MD) } \\
\text { Polomac River (VA) }\end{array}$ & $\begin{array}{r}4,194 \\
1.352 \\
838 \\
1,499 \\
505\end{array}$ & $\begin{array}{l}12,638 \\
12,503 \\
12,721 \\
12,618 \\
12,922\end{array}$ & $\begin{array}{r}1.62 \\
1.86 \\
1.42 \\
1.78 \\
.82\end{array}$ & $\begin{array}{r}11.31 \\
12.34 \\
10.04 \\
12.29 \\
7.79\end{array}$ & $\begin{array}{l}171.1 \\
175.8 \\
149.0 \\
176.7 \\
178.7\end{array}$ & $\begin{array}{l}43.25 \\
43.96 \\
37.91 \\
44.60 \\
46.19\end{array}$ & $\begin{array}{r}1,581 \\
282 \\
374 \\
666 \\
279\end{array}$ & $\begin{array}{l}12,764 \\
12,697 \\
12,823 \\
12,705 \\
12,888\end{array}$ & $\begin{array}{r}1.49 \\
1.71 \\
1.44 \\
1.74 \\
.79\end{array}$ & $\begin{array}{r}10.96 \\
11.88 \\
10.06 \\
12.41 \\
7.83\end{array}$ & $\begin{array}{l}153.9 \\
157.8 \\
130.2 \\
159.4 \\
169.0\end{array}$ & $\begin{array}{l}30.29 \\
40.07 \\
33.39 \\
40.51 \\
43.55\end{array}$ \\
\hline $\begin{array}{l}\text { PSI Energy Inc } \\
\text { Cayuga (IN) } \\
\text { Edwardsport (IN) } \\
\text { Noblesville (IN) } \\
\text { Gallagher (iN) } \\
\text { Wabash River (IN) } \\
\text { Gibson Station (IN) }\end{array}$ & $\begin{array}{r}8,275 \\
1,348 \\
- \\
- \\
551 \\
384 \\
5,991\end{array}$ & $\begin{array}{r}10,782 \\
10,898 \\
- \\
10,887 \\
10,880 \\
10,739\end{array}$ & $\begin{array}{r}2.36 \\
1.98 \\
-- \\
-\overline{2.37} \\
1.97 \\
2.47\end{array}$ & $\begin{array}{r}10.36 \\
10.21 \\
-- \\
-\overline{8.76} \\
10.10 \\
1056\end{array}$ & $\begin{array}{r}161.0 \\
129.7 \\
- \\
-\ldots \\
156.5 \\
138.4 \\
170.0\end{array}$ & $\begin{array}{r}34.71 \\
28.26 \\
- \\
-- \\
34.08 \\
30.12 \\
36.52\end{array}$ & $\begin{array}{r}5,659 \\
1,514 \\
71 \\
29 \\
593 \\
1,046 \\
2,306\end{array}$ & $\begin{array}{l}11,515 \\
10,980 \\
11,197 \\
11,045 \\
11,568 \\
11,094 \\
12,059\end{array}$ & $\begin{array}{r}1.51 \\
2.04 \\
2.45 \\
2.37 \\
1.74 \\
2.01 \\
.83\end{array}$ & $\begin{array}{l}9.22 \\
9.67 \\
9.45 \\
9.79 \\
8.68 \\
9.05 \\
9.06\end{array}$ & $\begin{array}{r}120.8 \\
118.8 \\
96.4 \\
145.1 \\
120.3 \\
109.6 \\
127.4\end{array}$ & $\begin{array}{l}27.84 \\
26.10 \\
21.59 \\
32.06 \\
27.82 \\
24.31 \\
30.73\end{array}$ \\
\hline $\begin{array}{l}\text { Publlc Service Co of Colorado } \\
\text { Araphoe (CO) } \\
\text { Cameo (CO) } \\
\text { Cherokee (CO) } \\
\text { Comanche (CO) } \\
\text { Valmont (CO) } \\
\text { Hayden (CO) } \\
\text { Pawnee (CO) }\end{array}$ & $\begin{array}{r}7,628 \\
79 \\
246 \\
1,707 \\
2,064 \\
169 \\
1,501 \\
1,863\end{array}$ & $\begin{array}{r}9,627 \\
11,177 \\
11,315 \\
11,095 \\
8,519 \\
11,167 \\
10.639 \\
8.266\end{array}$ & $\begin{array}{l}.38 \\
.61 \\
.59 \\
.42 \\
.30 \\
.61 \\
.40 \\
.36\end{array}$ & $\begin{array}{l}6.78 \\
7.43 \\
8.76 \\
9.41 \\
4.68 \\
7.48 \\
8.98 \\
4.56\end{array}$ & $\begin{array}{r}105.1 \\
121.4 \\
90.2 \\
110.1 \\
112.7 \\
114.1 \\
91.8 \\
104.8\end{array}$ & $\begin{array}{l}20.24 \\
27.15 \\
20.41 \\
24.44 \\
19.21 \\
25.49 \\
19.55 \\
17.32\end{array}$ & $\begin{array}{r}1,012 \\
383 \\
- \\
228 \\
-- \\
401 \\
-- \\
--\end{array}$ & $\begin{array}{r}11,212 \\
11,235 \\
11,110 \\
11,248 \\
-\ldots \\
-\cdots\end{array}$ & $\begin{array}{c}.44 \\
.44 \\
. . \\
.42 \\
.- \\
.45 \\
-. \\
--\end{array}$ & $\begin{array}{r}9.39 \\
8.44 \\
-\overline{-} \\
9.67 \\
-- \\
9.19 \\
-- \\
-\end{array}$ & $\begin{array}{r}105.4 \\
112.2 \\
-\ldots \\
94.1 \\
- \\
105.3 \\
- \\
-\end{array}$ & $\begin{array}{r}23.64 \\
25.22 \\
\ldots . \\
20.91 \\
23.69 \\
-- \\
-\end{array}$ \\
\hline $\begin{array}{l}\text { Public Service Co of NH } \ldots \ldots \ldots \ldots \ldots \ldots \\
\text { Merrimack }(\mathrm{NH}) \\
\text { Schiller }(\mathrm{NH})\end{array}$ & $\begin{array}{r}1,076 \\
864 \\
112\end{array}$ & $\begin{array}{l}13,289 \\
13,312 \\
13,095\end{array}$ & $\begin{array}{r}1.67 \\
1.79 \\
.64\end{array}$ & $\begin{array}{l}6.53 \\
6.52 \\
6.61\end{array}$ & $\begin{array}{l}168.9 \\
168.4 \\
173.3\end{array}$ & $\begin{array}{l}44.89 \\
44.83 \\
45.39\end{array}$ & $\begin{array}{r}151 \\
39 \\
111\end{array}$ & $\begin{array}{l}13,052 \\
13,412 \\
12,925\end{array}$ & $\begin{array}{r}1.18 \\
2.18 \\
.83\end{array}$ & $\begin{array}{l}6.44 \\
6.25 \\
6.51\end{array}$ & $\begin{array}{l}165.8 \\
161.7 \\
167.2\end{array}$ & $\begin{array}{l}43.27 \\
43.39 \\
43.23\end{array}$ \\
\hline $\begin{array}{l}\text { Public Service Co of NM } \\
\text { San Juan (NM) }\end{array}$ & $\begin{array}{l}5,105 \\
5,105\end{array}$ & $\begin{array}{l}9,360 \\
\theta, 360\end{array}$ & $\begin{array}{l}.87 \\
.87\end{array}$ & $\begin{array}{l}23.78 \\
23.78\end{array}$ & $\begin{array}{l}173.4 \\
173.4\end{array}$ & $\begin{array}{l}32.46 \\
32.46\end{array}$ & - & - & - & - & - & $m$ \\
\hline $\begin{array}{l}\text { Public Service Co of Okiahoma ....... } \\
\text { Northeastern (OK) }\end{array}$ & $\begin{array}{l}2,870 \\
2,970\end{array}$ & $\begin{array}{l}8,712 \\
8,712\end{array}$ & $\begin{array}{r}.45 \\
.45\end{array}$ & $\begin{array}{l}\mathbf{5 . 8 7} \\
\mathbf{5 . 8 7}\end{array}$ & $\begin{array}{l}161.4 \\
161.4\end{array}$ & $\begin{array}{l}28.13 \\
28.13\end{array}$ & $\begin{array}{l}60 \\
60\end{array}$ & $\begin{array}{l}11,227 \\
11,227\end{array}$ & $\begin{array}{l}.46 \\
.46\end{array}$ & $\begin{array}{l}10.94 \\
10.94\end{array}$ & $\begin{array}{l}149.0 \\
149.0\end{array}$ & $\begin{array}{l}33.46 \\
33.46\end{array}$ \\
\hline
\end{tabular}

See footnotes at end of table.

Source: Fec'sral Energy Regulatory Commission, FERC Form 423, "Monthly Report of Cost and Quality of Fuels for Electric Plants." 
Table 30. Receipts and Average Delivered Cost of Coal by Type of Purchase, Electric, Utility and Plant, 1992 (Continued)

\begin{tabular}{|c|c|c|c|c|c|c|c|c|c|c|c|c|}
\hline \multirow{3}{*}{$\begin{array}{l}\text { Electric Utility } \\
\text { Plant (State) }\end{array}$} & \multicolumn{6}{|c|}{ Contract } & \multicolumn{6}{|c|}{ Spot } \\
\hline & \multirow{2}{*}{$\begin{array}{l}\text { Receipts } \\
\text { (1000 } \\
\text { short } \\
\text { tons) }\end{array}$} & \multicolumn{3}{|c|}{ Average Quality } & \multicolumn{2}{|c|}{\begin{tabular}{c|} 
Average \\
Delivered Cost
\end{tabular}} & \multirow{2}{*}{$\begin{array}{l}\text { Recelpts } \\
\text { (1000 } \\
\text { short } \\
\text { tons) }\end{array}$} & \multicolumn{3}{|c|}{ Average Quality } & \multicolumn{2}{|c|}{$\begin{array}{l}\text { Average } \\
\text { Delivered } \\
\text { Cost }\end{array}$} \\
\hline & & $\begin{array}{c}\text { Btu } \\
\text { (per } \\
\text { pound) }\end{array}$ & $\begin{array}{c}\text { Sulfur } \\
\text { (percent } \\
\text { by } \\
\text { weight) }\end{array}$ & $\begin{array}{c}\text { Ash } \\
\text { (percent } \\
\text { by } \\
\text { welght) }\end{array}$ & $\begin{array}{c}\text { (cents } \\
\text { per } \\
\text { million } \\
\text { Btu) }\end{array}$ & $\begin{array}{c}\text { (\$ } \\
\text { per } \\
\text { short } \\
\text { ton) }\end{array}$ & & $\begin{array}{c}\text { Btu } \\
\text { (per } \\
\text { pound) }\end{array}$ & $\begin{array}{c}\text { Sulfur } \\
\text { (percent } \\
\text { by } \\
\text { welght) }\end{array}$ & $\begin{array}{c}\text { Ash } \\
\text { (percent } \\
\text { by } \\
\text { weight) }\end{array}$ & $\begin{array}{c}\text { (cents } \\
\text { per } \\
\text { million } \\
\text { Btu) }\end{array}$ & $\begin{array}{l}\text { (s } \\
\text { per } \\
\text { short } \\
\text { ton) }\end{array}$ \\
\hline Public Service Electric\&Gas Co ...... & 1,290 & 13,810 & 0.82 & 5.33 & 177.1 & 48.91 & 120 & 13,034 & 0.85 & 7.70 & 163.7 & 42.66 \\
\hline $\begin{array}{l}\text { Hudson (NJ) } \\
\text { Mercer (NJ) }\end{array}$ & 460 & 13,143 & .81 & 6.92 & 180.0 & 47.31 & 109 & 12,978 & .85 & 7.93 & 161.7 & 41.97 \\
\hline 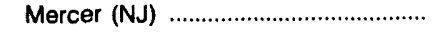 & 830 & 14,180 & .82 & 4.45 & 175.6 & 49.80 & 11 & 13,597 & .87 & 5.34 & 182.5 & 49.63 \\
\hline Aichmond City of & 199 & 11,276 & 2.18 & 8.98 & 159.5 & 35.96 & 93 & 11,749 & 1.70 & 9.16 & 126.8 & 29.79 \\
\hline 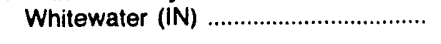 & 199 & 11,276 & 2.18 & 8.98 & 159.5 & 35.96 & 93 & 11,749 & 1.70 & 9.16 & 126.8 & 29.79 \\
\hline Rochester Gas \& Electric Corp ....... & 564 & 13,273 & 1.91 & 6.60 & 152.0 & 40.34 & 277 & 13,349 & 2.49 & 6.96 & 132.8 & 35.46 \\
\hline 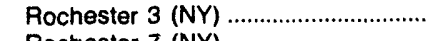 & 164 & 13,269 & 1.94 & 6.57 & 152.6 & 40.50 & 38 & 13,332 & 2.45 & 6.57 & 131.6 & 35.08 \\
\hline 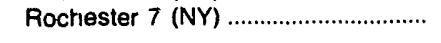 & 400 & 13,275 & 1.90 & 6.61 & 151.7 & 40.28 & 239 & 13,351 & 2.50 & 7.02 & 133.0 & 35.51 \\
\hline Rochester Public Utilities ...................... & 27 & 11,471 & 1.93 & 7.85 & 152.2 & 34.92 & 53 & 12,095 & 1.77 & 8.48 & 158.3 & 38.29 \\
\hline Silver Lake (MN) ...................................... & 27 & 11,471 & 1.93 & 7.85 & 152.2 & 34.92 & 53 & 12,095 & 1.77 & 8.48 & 158.3 & 38.29 \\
\hline Salt River Prol Ag I \& P Dist ............. & 9,521 & 10,800 & .51 & 9.93 & 125.4 & 27.08 & 166 & $\mathbf{9 , 7 0 2}$ & .45 & 13.95 & 117.8 & 22.85 \\
\hline Navajo (AZ) & 7.441 & 11.043 & .52 & 9.00 & 104.8 & 23.14 & -- & -- & -- & -- & - & $\overline{-}$ \\
\hline 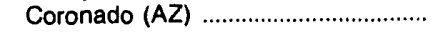 & 2,080 & 9,932 & .45 & 13.26 & 207.3 & 41.19 & 166 & 9,702 & .45 & 13.95 & 117.8 & 22.85 \\
\hline 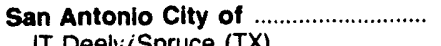 & 2,659 & 8,408 & .32 & 5.44 & 131.8 & 22.16 & 884 & 8,735 & .35 & 5.40 & 116.9 & 20.42 \\
\hline 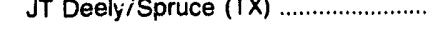 & 2,659 & 8.408 & .32 & 5.44 & 131.8 & 22.16 & 884 & 8,735 & .35 & 5.40 & 116.9 & 20.42 \\
\hline San Miguel Electric Coop Inc ........... & 2,930 & $\mathbf{5 , 3 5 0}$ & 1.98 & 25.31 & 96.6 & 10.34 & - & - & -- & - & - & - \\
\hline & 2,930 & 5,350 & 1.98 & 25.31 & 96.6 & 10.34 & - & -- & - & - & - & - \\
\hline Savannah Electric \& Power Co ........ & - & - & - & -- & - & - & 156 & 12,353 & 1.17 & 10.82 & 150.4 & 37.16 \\
\hline Kraft (GA) & -- & - & - & - & - & - & 64 & 12,371 & 1.00 & 12.04 & 147.4 & 36.46 \\
\hline McIntosh (GA) & -- & - & -- & -- & -- & - & 92 & 12,341 & 1.29 & 9.98 & 152.5 & 37.64 \\
\hline Seminole Electric Coop Inc .............. & 2,249 & 12,115 & 2.85 & 8.20 & 214.2 & 51.91 & 1,290 & 12,165 & 2.16 & 8.42 & 159.8 & 38.88 \\
\hline 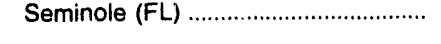 & 2,249 & 12,115 & 2.85 & 8.20 & 214.2 & 51.91 & 1,290 & 12,165 & 2.16 & 8.42 & 159.8 & 38.88 \\
\hline Sierra Pacific Power Co ........................ & 1,545 & 10,518 & .43 & 8.28 & 198.6 & 41.77 & - & - & - & - & - & - \\
\hline North Valmy (NV) ..................................... & 1,545 & 10,518 & .43 & 8.28 & 198.6 & 41.77 & -- & -- & - & -- & - & -- \\
\hline & 400 & 11,774 & 2.45 & 9.92 & 174.4 & 41.06 & 187 & 11,651 & 2.56 & 10.26 & 99.6 & 23.20 \\
\hline 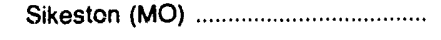 & 400 & 11,774 & 2.45 & 9.92 & 174.4 & 41.06 & 187 & 11,651 & 2.56 & 10.26 & 99.6 & 23.20 \\
\hline South Carolina Electric\&Gas Co ..... & $\mathbf{3 , 4 4 4}$ & 12,911 & 1.09 & 8.27 & 159.8 & 41.26 & 777 & 12,757 & 1.15 & 9.91 & 148.4 & 37.86 \\
\hline Canadys (SC) & 523 & 12.796 & 1.34 & 9.14 & 161.5 & 41.34 & 140 & 12,903 & 1.20 & 8.99 & 149.2 & 38.51 \\
\hline 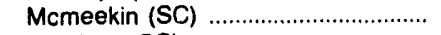 & 405 & 12,968 & 1.39 & 8.82 & 156.1 & 40.49 & 210 & 12,683 & 1.1 & 10.41 & 145.9 & 37.00 \\
\hline 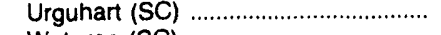 & 309 & 12,976 & 1.30 & 9.06 & 158.4 & 41.11 & 191 & 12,814 & 1.20 & 10.08 & 149.6 & 38.35 \\
\hline Wateree (SC) & 1,184 & 12,956 & 1.06 & 8.26 & 158.0 & 40.94 & 219 & 12,677 & 1.09 & 10.06 & 48.3 & 37.60 \\
\hline 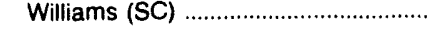 & 1.024 & 12,875 & .82 & 7.39 & 162.8 & 41.92 & 17 & 12,869 & .82 & 7.50 & 59.8 & 41.13 \\
\hline South Carolina Pub Serv Auth ........ & $\begin{array}{r}1,912 \\
497\end{array}$ & 12,553 & 1.26 & 9.97 & 155.4 & 39.01 & 2,633 & 12,986 & 1.16 & 8.15 & 140.7 & 36.54 \\
\hline Cross (SC) & 497 & 12,375 & 1.18 & 10.01 & 154.6 & 38.25 & 847 & 12,938 & 1.0 & 8.09 & 139.2 & 36.02 \\
\hline Grainger (SC) & $\overline{0}$ & & $\overline{0}$ & $\overline{0}$ & $-\bar{r}$ & $\bar{x}$ & 99 & 12,923 & 1.85 & 10.84 & 155.0 & 40.05 \\
\hline Jefferies (SC) & 206 & 12,225 & 1.69 & 10.85 & 152.5 & 37.28 & 392 & 12,783 & 1.65 & 8.57 & 139.0 & 35.54 \\
\hline 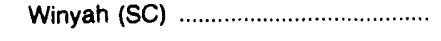 & 1,210 & 12,681 & 1.22 & 9.80 & 156.2 & 39.61 & 1,296 & 13,083 & 1.05 & 7.86 & 141.1 & 36.91 \\
\hline South Mississippl El Pwr Assn ........ & 757 & 12,370 & .99 & 9.58 & 205.3 & 50.80 & - & - & - & - & - & - \\
\hline 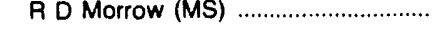 & 757 & 12,370 & .99 & 9.58 & 205.3 & 50.80 & - & - & -- & - & - & - \\
\hline Southern California Edison Co ........ & 4,977 & 10,940 & .51 & 10.25 & 118.8 & 25.99 & - & - & - & - & - & - \\
\hline 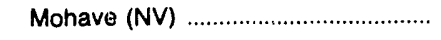 & 4,977 & 10,940 & .51 & 10.25 & 118.8 & 325.99 & - & - & -- & -- & & -- \\
\hline Southern Illinols Power Coop .......... & 200 & 11,382 & 2.86 & 13.33 & 113.5 & 25.83 & 290 & 9,974 & 2.74 & 18.76 & 73.4 & 14.65 \\
\hline 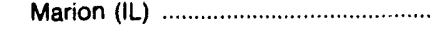 & 200 & 11,382 & 2.86 & 13.33 & 113.5 & 25.83 & 290 & 9,974 & 2.74 & 18.76 & 73.4 & 14.65 \\
\hline Southern Indiana Gas Elec Co .... & 1,882 & 11,289 & 3.09 & 8.58 & 149.8 & 33.82 & 813 & 11,327 & 2.17 & $\mathbf{8 . 4 0}$ & 119.4 & 27.05 \\
\hline 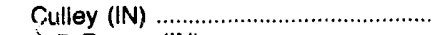 & 631 & 10,929 & 2.68 & 9.32 & 134.6 & 29.42 & 466 & 11,362 & 1.63 & 8.18 & 134.3 & 30.51 \\
\hline A B Brown (IN) & 1,001 & 11,598 & 3.50 & 8.01 & 163.6 & 37.95 & 121 & 11,193 & 3.73 & 9.61 & 98.2 & 21.99 \\
\hline Warrick (IN) & 250 & 10,957 & 2.50 & 9.02 & 129.5 & 28.37 & 225 & 11,327 & 2.43 & 8.21 & 99.7 & 22.58 \\
\hline
\end{tabular}

See footnotes at end of table.

Source: Federal Energy Regulatory Commission, FERC Form 423, "Monthly Report of Cost and Quality of Fuels for Electric Plants." 
Table 30. Recelpts and Average Delivered Cost of Coal by Type of Purchase, Electric, Utility and Plant, 1992 (Continued)

\begin{tabular}{|c|c|c|c|c|c|c|c|c|c|c|c|c|}
\hline \multirow{3}{*}{$\begin{array}{l}\text { Electric Utillty } \\
\text { Plant (Stato) }\end{array}$} & \multicolumn{6}{|c|}{ Contract } & \multicolumn{6}{|c|}{ Spot } \\
\hline & \multirow{2}{*}{$\begin{array}{l}\text { Recelpts } \\
\text { (1000 } \\
\text { short } \\
\text { tons) }\end{array}$} & \multicolumn{3}{|c|}{ Averas $\bullet$ Quallity } & \multicolumn{2}{|c|}{$\begin{array}{c}\text { Average } \\
\text { Dellvered Cost }\end{array}$} & \multirow{2}{*}{$\begin{array}{l}\text { Recelpts } \\
\text { (1000 } \\
\text { short } \\
\text { tons) }\end{array}$} & \multicolumn{3}{|c|}{ Average Quality } & \multicolumn{2}{|c|}{$\begin{array}{l}\text { Average } \\
\text { Dellvered } \\
\text { Cost }\end{array}$} \\
\hline & & $\begin{array}{c}\text { Btu } \\
\text { (per } \\
\text { pound) }\end{array}$ & $\begin{array}{c}\text { Sulfur } \\
\text { (percent } \\
\text { by } \\
\text { wolght) }\end{array}$ & $\begin{array}{c}\text { Ash } \\
\text { ipercent } \\
\text { by } \\
\text { weight) }\end{array}$ & $\begin{array}{c}\text { (cents } \\
\text { per } \\
\text { million } \\
\text { Btu) }\end{array}$ & $\begin{array}{c}(\$ \\
\text { per } \\
\text { short } \\
\text { ton) }\end{array}$ & & $\left|\begin{array}{c}\text { Btu } \\
\text { (por } \\
\text { pound) }\end{array}\right|$ & $\begin{array}{c}\text { Sulfur } \\
\text { (percent } \\
\text { by } \\
\text { weight) }\end{array}$ & $\begin{array}{c}\text { Ash } \\
\text { (percent } \\
\text { by } \\
\text { welght) }\end{array}$ & $\begin{array}{c}\text { (cents } \\
\text { per } \\
\text { million } \\
\text { Btu) }\end{array}$ & $\begin{array}{l}\text { (s } \\
\text { per } \\
\text { short } \\
\text { ton) }\end{array}$ \\
\hline 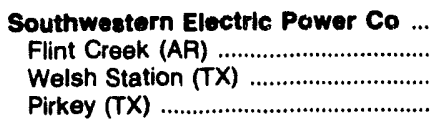 & $\begin{array}{l}7,679 \\
1,189 \\
3,673 \\
2,817\end{array}$ & $\begin{array}{l}7,756 \\
8,322 \\
8,332 \\
6,766\end{array}$ & $\begin{array}{r}0.71 \\
.34 \\
.35 \\
1.33\end{array}$ & $\begin{array}{r}7.36 \\
4.62 \\
4.63 \\
12.08\end{array}$ & $\begin{array}{l}173.6 \\
166.8 \\
204.5 \\
127.6\end{array}$ & $\begin{array}{l}26.93 \\
27.76 \\
34.07 \\
17.26\end{array}$ & $\begin{array}{r}1,781 \\
474 \\
1,307 \\
-\end{array}$ & $\begin{array}{r}8,371 \\
8,411 \\
8,356 \\
--\end{array}$ & $\begin{array}{r}0.34 \\
.34 \\
.34 \\
-\end{array}$ & $\begin{array}{r}4.67 \\
4.75 \\
4.64 \\
-\end{array}$ & $\begin{array}{r}160.7 \\
125.9 \\
173.4 \\
--\end{array}$ & $\begin{array}{r}26.91 \\
21.19 \\
28.98 \\
--\end{array}$ \\
\hline 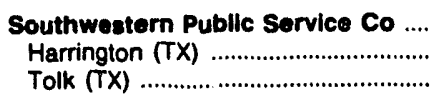 & $\begin{array}{l}7,656 \\
4,301 \\
3,355\end{array}$ & $\begin{array}{l}8,761 \\
8,761 \\
8,761\end{array}$ & $\begin{array}{l}.33 \\
.32 \\
.34\end{array}$ & $\begin{array}{l}4.88 \\
4.88 \\
4.90\end{array}$ & $\begin{array}{l}178.3 \\
156.6 \\
206.2\end{array}$ & $\begin{array}{l}31.25 \\
27.44 \\
36.13\end{array}$ & $\frac{612}{612}$ & $\begin{array}{l}8,751 \\
-7, \overline{751}\end{array}$ & $\overline{.34}$ & $\begin{array}{r}4.89 \\
4 . \overline{89}\end{array}$ & $\begin{array}{r}109.9 \\
\overline{-} \\
109.9\end{array}$ & $\begin{array}{r}19.23 \\
19 . \overline{23}\end{array}$ \\
\hline 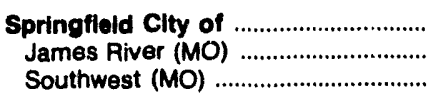 & $\begin{array}{l}696 \\
230 \\
466\end{array}$ & $\begin{array}{l}11,606 \\
11,574 \\
11,621\end{array}$ & $\begin{array}{l}2.08 \\
1.98 \\
2.12\end{array}$ & $\begin{array}{l}7.98 \\
7.91 \\
8.02\end{array}$ & $\begin{array}{l}132.3 \\
132.9 \\
132.0\end{array}$ & $\begin{array}{l}30.71 \\
30.77 \\
30.67\end{array}$ & $\begin{array}{l}52 \\
41 \\
11\end{array}$ & $\begin{array}{l}11,788 \\
11,737 \\
11,987\end{array}$ & $\begin{array}{l}.39 \\
.40 \\
.38\end{array}$ & $\begin{array}{l}7.98 \\
8.00 \\
7.90\end{array}$ & $\begin{array}{l}141.8 \\
142.5 \\
139.5\end{array}$ & $\begin{array}{l}33.44 \\
33.44 \\
33.44\end{array}$ \\
\hline $\begin{array}{l}\text { Springfleld City of } \\
\text { Dallman (IL) } \\
\text { Lakeside (IL) }\end{array}$ & $\begin{array}{l}933 \\
827 \\
106\end{array}$ & $\begin{array}{l}10,382 \\
10,382 \\
10,383\end{array}$ & $\begin{array}{l}3.04 \\
3.04 \\
3.03\end{array}$ & $\begin{array}{l}9.36 \\
9.37 \\
9.33\end{array}$ & $\begin{array}{l}113.1 \\
113.1 \\
113.3\end{array}$ & $\begin{array}{l}23.49 \\
23.48 \\
23.53\end{array}$ & $\overline{-}$ & $\bar{z}$ & $\bar{z}$ & $\begin{array}{l}- \\
-\end{array}$ & $\begin{array}{l}- \\
-\end{array}$ & $\overline{-}$ \\
\hline 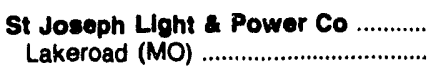 & $\overline{-}$ & $\overline{-}$ & $\overline{-}$ & $\overline{-}$ & $\overline{-}$ & $\overline{-}$ & $\begin{array}{l}135 \\
135\end{array}$ & $\begin{array}{l}11,976 \\
11,976\end{array}$ & $\begin{array}{l}3.72 \\
3.72\end{array}$ & $\begin{array}{l}12.10 \\
12.10\end{array}$ & $\begin{array}{l}139.2 \\
139.2\end{array}$ & $\begin{array}{l}33.35 \\
33.35\end{array}$ \\
\hline $\begin{array}{l}\text { Sunflower Eloctric Power Corp ....... } \\
\text { Holcomb (KS) ....................................... }\end{array}$ & $\begin{array}{l}1,257 \\
1,257\end{array}$ & $\begin{array}{l}8,492 \\
8,492\end{array}$ & $\begin{array}{l}.38 \\
.38\end{array}$ & $\begin{array}{l}5.11 \\
5.11\end{array}$ & $\begin{array}{l}105.3 \\
105.3\end{array}$ & $\begin{array}{l}17.88 \\
17.88\end{array}$ & $\overline{-}$ & $\overline{-}$ & $\overline{-}$ & $\overline{-}$ & $\overline{-}$ & $\overline{-}$ \\
\hline $\begin{array}{l}\text { Tacoma Public Utilities } \\
\text { Steam No.2 (WA) }\end{array}$ & $\overline{-}$ & $\overline{-}$ & $\overline{-}$ & $\overline{-}$ & $\overline{-}$ & $\overline{-}$ & $\begin{array}{l}24 \\
24\end{array}$ & $\begin{array}{l}10,043 \\
10,043\end{array}$ & $\begin{array}{l}.43 \\
.43\end{array}$ & $\begin{array}{l}10.87 \\
10.87\end{array}$ & $\begin{array}{l}197.5 \\
197.5\end{array}$ & $\begin{array}{l}39.67 \\
39.67\end{array}$ \\
\hline $\begin{array}{l}\text { Tampa Electric Co } \\
\text { Gannon (FL) } \\
\text { Davant Transfer (LA) }\end{array}$ & $\begin{array}{r}4,666 \\
712 \\
3,954\end{array}$ & $\begin{array}{l}12,361 \\
12,713 \\
12,297\end{array}$ & $\begin{array}{l}2.14 \\
1.21 \\
2.30\end{array}$ & $\begin{array}{l}7.62 \\
6.47 \\
7.83\end{array}$ & $\begin{array}{l}210.6 \\
234.4 \\
206.1\end{array}$ & $\begin{array}{l}52.06 \\
59.61 \\
50.70\end{array}$ & $\begin{array}{r}1,590 \\
16 \\
1,574\end{array}$ & $\begin{array}{l}12,156 \\
12,714 \\
12,150\end{array}$ & $\begin{array}{l}2.29 \\
1.27 \\
2.30\end{array}$ & $\begin{array}{l}8.69 \\
6.10 \\
8.72\end{array}$ & $\begin{array}{l}122.8 \\
205.4 \\
122.0\end{array}$ & $\begin{array}{l}29.87 \\
52.23 \\
29.64\end{array}$ \\
\hline 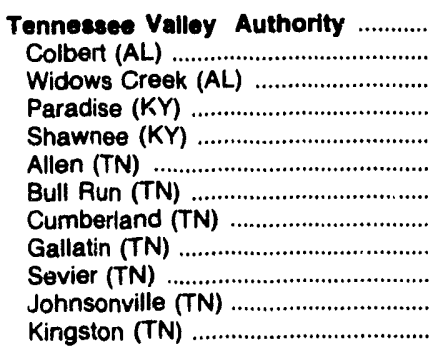 & $\begin{array}{r}31,753 \\
2,469 \\
2,876 \\
5,597 \\
1,753 \\
1,195 \\
1,917 \\
6,598 \\
1,944 \\
1,643 \\
2,297 \\
3,462\end{array}$ & $\begin{array}{l}11,937 \\
11,955 \\
11,930 \\
11,008 \\
12,069 \\
12,144 \\
12,977 \\
11,608 \\
12,190 \\
12,835 \\
11,995 \\
12,739\end{array}$ & $\begin{array}{l}2.38 \\
1.28 \\
2.84 \\
4.13 \\
1.43 \\
2.11 \\
1.06 \\
2.78 \\
2.58 \\
1.49 \\
1.75 \\
1.17\end{array}$ & $\begin{array}{r}10.26 \\
10.83 \\
11.14 \\
16.59 \\
10.07 \\
8.83 \\
7.95 \\
7.89 \\
7.49 \\
9.15 \\
9.12 \\
8.10\end{array}$ & $\begin{array}{l}123.8 \\
130.8 \\
115.5 \\
106.3 \\
130.4 \\
125.2 \\
124.4 \\
131.3 \\
125.5 \\
129.0 \\
130.9 \\
125.2\end{array}$ & $\begin{array}{l}29.56 \\
31.28 \\
27.57 \\
23.39 \\
31.47 \\
30.40 \\
32.30 \\
30.47 \\
30.60 \\
33.12 \\
31.41 \\
31.90\end{array}$ & $\begin{array}{r}3,965 \\
273 \\
767 \\
859 \\
750 \\
306 \\
88 \\
331 \\
271 \\
86 \\
29 \\
205\end{array}$ & $\begin{array}{l}11,861 \\
12,104 \\
12,194 \\
11,083 \\
12,135 \\
12,152 \\
12,658 \\
11,773 \\
11,362 \\
12,198 \\
11,700 \\
12,454\end{array}$ & $\begin{array}{l}1.91 \\
1.67 \\
1.61 \\
2.77 \\
1.00 \\
2.28 \\
1.19 \\
2.59 \\
2.27 \\
1.99 \\
1.70 \\
1.32\end{array}$ & $\begin{array}{r}11.13 \\
11.80 \\
10.02 \\
14.06 \\
11.13 \\
9.38 \\
9.86 \\
9.34 \\
9.95 \\
11.28 \\
8.50 \\
10.00\end{array}$ & $\begin{array}{l}116.5 \\
118.2 \\
118.1 \\
108.1 \\
127.1 \\
116.6 \\
109.1 \\
103.0 \\
121.1 \\
119.0 \\
120.0 \\
118.6\end{array}$ & $\begin{array}{l}27.63 \\
28.62 \\
28.79 \\
23.96 \\
30.84 \\
28.33 \\
27.62 \\
24.26 \\
27.52 \\
29.03 \\
28.08 \\
29.54\end{array}$ \\
\hline $\begin{array}{l}\text { Texas Municipal Power Agoncy ...... } \\
\text { Gibbons Creek (TX) }\end{array}$ & $\begin{array}{l}3,094 \\
3,094\end{array}$ & $\begin{array}{l}4,833 \\
4,833\end{array}$ & $\begin{array}{l}1.42 \\
1.42\end{array}$ & $\begin{array}{l}20.89 \\
20.89\end{array}$ & $\begin{array}{l}160.7 \\
160.7\end{array}$ & $\begin{array}{l}115.53 \\
15.53\end{array}$ & $\begin{array}{l}184 \\
184\end{array}$ & $\begin{array}{l}6,765 \\
6,765\end{array}$ & $\begin{array}{l}1.06 \\
1.06\end{array}$ & $\begin{array}{l}15.43 \\
15.43\end{array}$ & $\begin{array}{l}131.8 \\
131.8\end{array}$ & $\begin{array}{l}17.83 \\
17.83\end{array}$ \\
\hline $\begin{array}{l}\text { Toxas- New Mexico Power Co } \\
\text { TNP One }\left(T_{x}\right)\end{array}$ & $\begin{array}{l}1,668 \\
1,668\end{array}$ & $\begin{array}{l}6,730 \\
6,730\end{array}$ & $\begin{array}{l}1.03 \\
1.03\end{array}$ & $\begin{array}{l}15.72 \\
15.72\end{array}$ & $\begin{array}{l}153.2 \\
153.2\end{array}$ & $\begin{array}{l}20.62 \\
20.62\end{array}$ & $\overline{-}$ & - & $\overline{-}$ & - & $\overline{-}$ & $\overline{-}$ \\
\hline 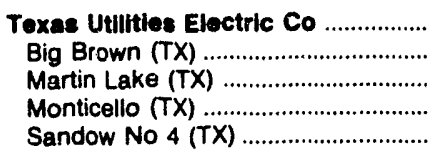 & $\begin{array}{r}33,468 \\
5,203 \\
13,830 \\
10,971 \\
3,464\end{array}$ & $\begin{array}{l}6,291 \\
6,408 \\
6,612 \\
5,826 \\
6,308\end{array}$ & $\begin{array}{r}.87 \\
.80 \\
1.13 \\
.49 \\
1.10\end{array}$ & $\begin{array}{l}16.92 \\
17.71 \\
12.88 \\
20.39 \\
20.83\end{array}$ & $\begin{array}{r}104.3 \\
111.4 \\
95.1 \\
112.8 \\
107.0\end{array}$ & $\begin{array}{l}13.12 \\
14.27 \\
12.57 \\
13.14 \\
13.49\end{array}$ & $\begin{array}{l}\overline{-} \\
\bar{z} \\
\overline{-}\end{array}$ & $\begin{array}{l}- \\
\overline{-} \\
\overline{-}\end{array}$ & $\begin{array}{l}- \\
\overline{-} \\
\overline{-} \\
-\end{array}$ & $\begin{array}{l}- \\
\bar{z} \\
\overline{-}\end{array}$ & $\begin{array}{l}\overline{-} \\
\bar{z} \\
\overline{-}\end{array}$ & $\begin{array}{l}- \\
\overline{-} \\
-\end{array}$ \\
\hline $\begin{array}{l}\text { Toledo Edison Co } \\
\text { Acme (OH) } \\
\text { Bay Shore (OH) }\end{array}$ & $\begin{array}{r}1,222 \\
57 \\
1,165\end{array}$ & $\begin{array}{l}12,929 \\
12,721 \\
12,939\end{array}$ & $\begin{array}{r}1.12 \\
.66 \\
1.14\end{array}$ & $\begin{array}{l}8.03 \\
8.81 \\
7.99\end{array}$ & $\begin{array}{l}202.9 \\
178.0 \\
204.1\end{array}$ & $\begin{array}{l}52.48 \\
45.29 \\
52.83\end{array}$ & $\frac{30}{30}$ & $\begin{array}{r}12,681 \\
-\overline{12,681}\end{array}$ & $\frac{.84}{-84}$ & $\begin{array}{r}8.00 \\
\overline{8.00}\end{array}$ & 141.9 & $35 . \overline{-}$ \\
\hline $\begin{array}{l}\text { Tri-state G \& T Asan Inc } \\
\text { Nucla (CO) } \\
\text { Craig (CO) }\end{array}$ & $\begin{array}{r}3,830 \\
7 \\
3,822\end{array}$ & $\begin{array}{l}10,164 \\
10,045 \\
10,164\end{array}$ & $\begin{array}{l}.36 \\
.43 \\
.36\end{array}$ & $\begin{array}{r}6.50 \\
17.50 \\
6.48\end{array}$ & $\begin{array}{l}115.4 \\
126.2 \\
115.4\end{array}$ & $\begin{array}{l}23.47 \\
25.35 \\
23.46\end{array}$ & $\begin{array}{l}903 \\
232 \\
671\end{array}$ & $\begin{array}{r}9,980 \\
8,357 \\
10,542\end{array}$ & $\begin{array}{l}.52 \\
.83 \\
.42\end{array}$ & $\begin{array}{r}11.32 \\
25.02 \\
6.58\end{array}$ & $\begin{array}{l}91.0 \\
92.8 \\
90.5\end{array}$ & $\begin{array}{l}18.16 \\
15.52 \\
19.08\end{array}$ \\
\hline
\end{tabular}

See footnotes at end of table.

Source: Federal Energy Regulatory Commission, FERC Form 423, "Monthly Report of Cost and Quality of Fuels for Electric Plants." 
Table 30. Receipts and Average Delivered Cost: of Coal by Type of Purchase, Electric, Utility and Plant, 1992 (Continued)

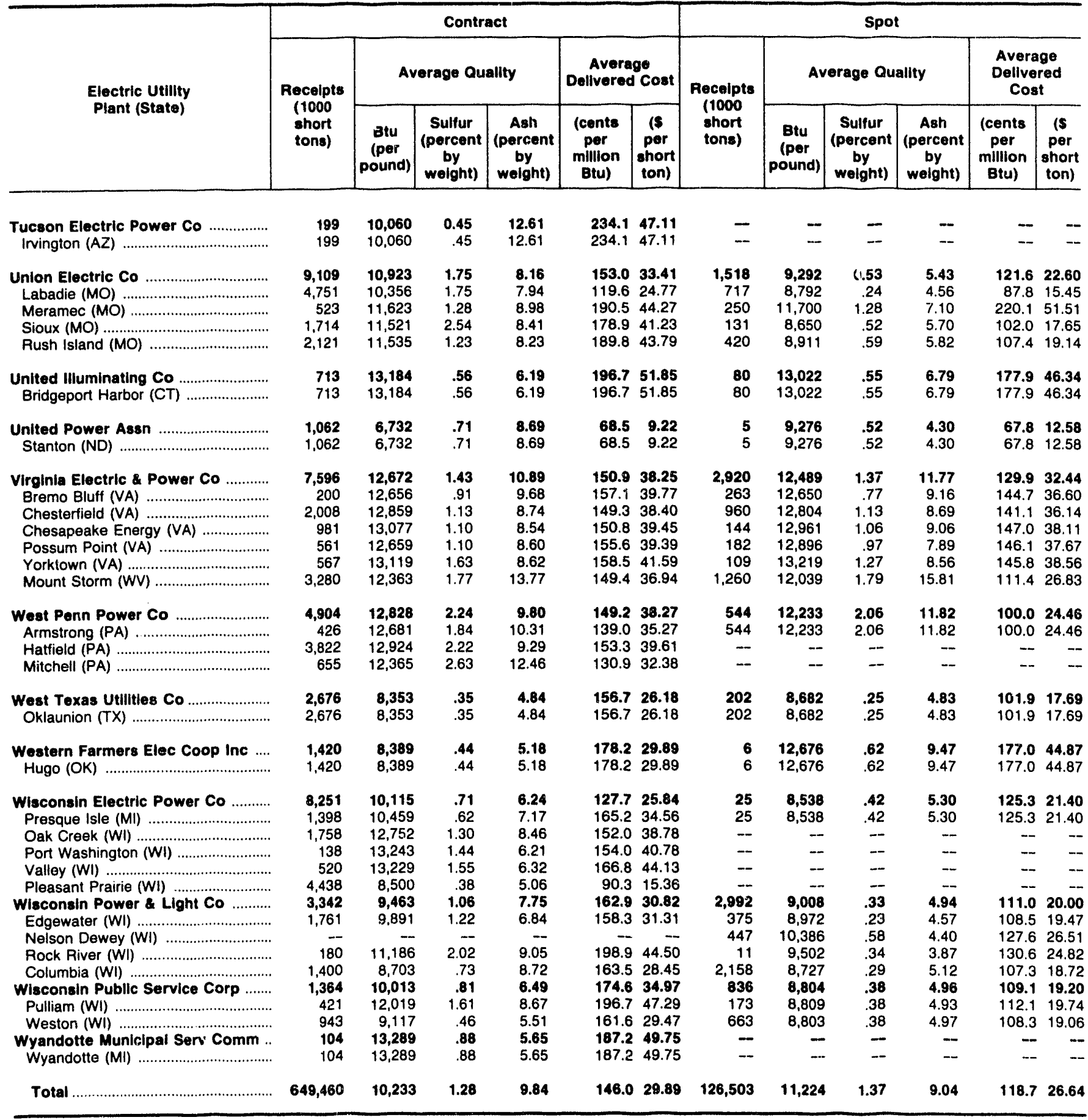

- Number less than 0.5 .

Notes: - Totals may not equal sum of components because of independent rounding. - Data are for electric generating plants with a total steamelectric and combined-cycle nameplate capacity of 50 or more megawatts.

Source: Federal Energy Regulatory Commission, FERC Form 423, "Monthly Report of Cost and Quality of Fuels for Electric Plants." 
Table 31. Receipts, Average Delivered Cost, and Quality of Fossil-Fuels by Electric Utility and Plant, 1992

\begin{tabular}{|c|c|c|c|c|c|c|c|c|c|c|c|c|c|c|}
\hline \multirow[b]{2}{*}{$\begin{array}{l}\text { Electric Utllity } \\
\text { Plant (State) }\end{array}$} & \multicolumn{4}{|c|}{ Coal } & \multicolumn{4}{|c|}{ Petroleum ${ }^{1}$} & \multicolumn{3}{|c|}{ Gas } & \multicolumn{3}{|c|}{$\begin{array}{c}\% \text { of Total } \\
\text { Btu }\end{array}$} \\
\hline & $\begin{array}{l}\text { Receipts } \\
(1,000 \\
\text { Short } \\
\text { Tons) }\end{array}$ & $\begin{array}{l}\text { (Cents } \\
\text { per } \\
\text { 10 } \\
\text { Btu) }\end{array}$ & $\begin{array}{l}\text { (S per } \\
\text { Short } \\
\text { Ton) }\end{array}$ & $\begin{array}{l}\text { ( } \% \\
\text { Avg. } \\
\text { Sulfur) }\end{array}$ & $\begin{array}{l}\text { Recelpts } \\
(1,000 \\
\text { bbls })\end{array}$ & $\begin{array}{c}\text { (Cents } \\
\text { per } \\
10^{6} \\
\text { Btu) }\end{array}$ & $\begin{array}{l}\text { (\$ } \\
\text { per } \\
\text { bbl) }\end{array}$ & $\begin{array}{l}\text { (\% } \\
\text { Avg. } \\
\text { Sulfur) }\end{array}$ & $\begin{array}{l}\text { Receipts } \\
(1,000 \\
\text { Mcf })\end{array}$ & $\begin{array}{c}\text { (Cents } \\
\text { per } \\
10^{6} \\
\text { Btu) }\end{array}$ & $\begin{array}{c}(\$ \\
\text { per } \\
\text { Mcf })\end{array}$ & \begin{tabular}{l|l} 
c & $\mathbf{F}$ \\
0 & \\
$a$ & 1 \\
1 &
\end{tabular} & $\begin{array}{l}\text { Pe- } \\
\text { tr- } \\
0- \\
\text { le- } \\
\text { um }\end{array}$ & $\begin{array}{l}\mathbf{G} \\
\mathbf{a} \\
\mathbf{8}\end{array}$ \\
\hline $\begin{array}{l}\text { Alabama Electric Coop Inc } \ldots \ldots \ldots \ldots \\
\text { Lowman }(A L)\end{array}$ & $\begin{array}{l}1,395 \\
1,395\end{array}$ & $\begin{array}{l}148.3 \\
148.3\end{array}$ & $\begin{array}{l}36.07 \\
36.07\end{array}$ & $\begin{array}{l}1.29 \\
1.29\end{array}$ & $\begin{array}{l}5 \\
5\end{array}$ & $\begin{array}{l}469.3 \\
469.3\end{array}$ & $\begin{array}{l}25.72 \\
25.72\end{array}$ & $\begin{array}{r}0.10 \\
.10\end{array}$ & - & - & & $\begin{array}{l}100 \\
100\end{array}$ & 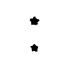 & $\overline{-}$ \\
\hline 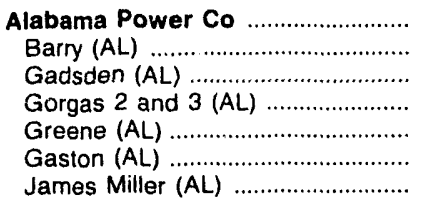 & $\begin{array}{r}17,106 \\
832 \\
135 \\
6,595 \\
1,345 \\
3,840 \\
4,359\end{array}$ & $\begin{array}{l}193.6 \\
213.1 \\
182.7 \\
172.0 \\
139.9 \\
174.7 \\
253.7\end{array}$ & $\begin{array}{l}46.78 \\
52.46 \\
45.80 \\
40.69 \\
34.20 \\
42.14 \\
62.88\end{array}$ & $\begin{array}{r}1.22 \\
.93 \\
1.79 \\
1.33 \\
1.47 \\
1.67 \\
.60\end{array}$ & $\begin{array}{r}72 \\
11 \\
1 \\
19 \\
10 \\
28 \\
4\end{array}$ & $\begin{array}{l}434.7 \\
410.8 \\
437.9 \\
445.4 \\
433.4 \\
440.2 \\
409.9\end{array}$ & $\begin{array}{l}25.24 \\
23.68 \\
25.27 \\
25.79 \\
25.17 \\
25.65 \\
23.96\end{array}$ & $\begin{array}{l}.00 \\
.00 \\
.00 \\
.00 \\
.00 \\
.00 \\
.00\end{array}$ & $\begin{array}{r}2,923 \\
448 \\
83 \\
-- \\
-- \\
-- \\
2,392\end{array}$ & $\begin{array}{r}222.9 \\
232.4 \\
211.1 \\
-- \\
-- \\
221.4\end{array}$ & $\begin{array}{r}2.28 \\
2.48 \\
2.15 \\
-- \\
-- \\
-\overline{-} \\
2.24\end{array}$ & $\begin{array}{r}99 \\
97 \\
97 \\
100 \\
100 \\
100 \\
98\end{array}$ & $\begin{array}{l}: \\
: \\
: \\
:\end{array}$ & $\begin{array}{r}1 \\
2 \\
2 \\
-- \\
-- \\
-2\end{array}$ \\
\hline 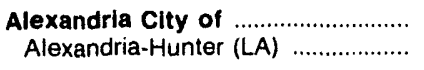 & - & - & -- & - & $\overline{--}$ & - & -- & - & $\begin{array}{l}126 \\
126\end{array}$ & $\begin{array}{l}235.8 \\
235.8\end{array}$ & $\begin{array}{l}2.40 \\
2.40\end{array}$ & - & & $\begin{array}{l}100 \\
100\end{array}$ \\
\hline $\begin{array}{l}\text { American Mun Power Ohio Inc .... } \\
\text { Gorsuch }(\mathrm{OH})\end{array}$ & $\begin{array}{l}891 \\
891\end{array}$ & $\begin{array}{l}96.9 \\
96.9\end{array}$ & $\begin{array}{l}21.96 \\
21.96\end{array}$ & $\begin{array}{l}4.55 \\
4.55\end{array}$ & - & -- & - & - & $\begin{array}{l}120 \\
120\end{array}$ & $\begin{array}{l}385.6 \\
385.6\end{array}$ & $\begin{array}{l}4.01 \\
4.01\end{array}$ & $\begin{array}{l}99 \\
99\end{array}$ & - & $\begin{array}{l}1 \\
1\end{array}$ \\
\hline $\begin{array}{l}\text { Ames Clty of } \\
\text { Ames (IA) }\end{array}$ & $\begin{array}{l}156 \\
156\end{array}$ & $\begin{array}{l}132.8 \\
132.8\end{array}$ & $\begin{array}{l}23.28 \\
23.28\end{array}$ & $\begin{array}{l}.19 \\
.19\end{array}$ & $\begin{array}{l}4 \\
4\end{array}$ & $\begin{array}{l}394.1 \\
394.1\end{array}$ & $\begin{array}{l}23.44 \\
23.44\end{array}$ & $\begin{array}{l}.30 \\
.30\end{array}$ & - & - & - & $\begin{array}{l}99 \\
99\end{array}$ & $\begin{array}{l}1 \\
1\end{array}$ & - \\
\hline 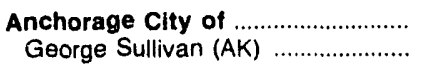 & - & - & - & - & -- & - & -- & -- & $\begin{array}{l}6,389 \\
6,389\end{array}$ & $\begin{array}{l}227.9 \\
227.9\end{array}$ & $\begin{array}{l}2.28 \\
2.28\end{array}$ & - & & $\begin{array}{l}100 \\
100\end{array}$ \\
\hline 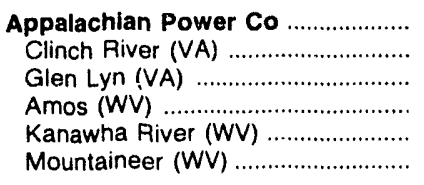 & $\begin{array}{r}9,057 \\
1,703 \\
452 \\
4,244 \\
368 \\
2,289\end{array}$ & $\begin{array}{l}171.9 \\
128.6 \\
138.6 \\
193.5 \\
172.6 \\
171.4\end{array}$ & $\begin{array}{l}\mathbf{4 2 . 9 3} \\
32.35 \\
35.72 \\
47.90 \\
43.41 \\
42.93\end{array}$ & $\begin{array}{l}.76 \\
.75 \\
.91 \\
.79 \\
.80 \\
.68\end{array}$ & $\begin{array}{r}166 \\
7 \\
17 \\
77 \\
5 \\
59\end{array}$ & $\begin{array}{r}479.9 \\
468.1 \\
467.8 \\
2481.0 \\
493.1 \\
2482.2\end{array}$ & $\begin{array}{l}28.04 \\
27.55 \\
27.22 \\
28.32 \\
28.76 \\
27.91\end{array}$ & $\begin{array}{l}.00 \\
.00 \\
.00 \\
.00 \\
.00 \\
.00\end{array}$ & $\begin{array}{l}-- \\
-- \\
-- \\
-- \\
--\end{array}$ & $\begin{array}{l}- \\
- \\
- \\
-- \\
--\end{array}$ & $\begin{array}{l}-- \\
-- \\
-- \\
-- \\
--\end{array}$ & $\begin{array}{r}100 \\
100 \\
99 \\
100 \\
100 \\
99\end{array}$ & $\begin{array}{l}\star \\
1 \\
* \\
1\end{array}$ & $\begin{array}{l}-- \\
-- \\
-- \\
--\end{array}$ \\
\hline $\begin{array}{l}\text { Arizona Electric Pwr Coop Inc ..... } \\
\text { Apache (AZ) }\end{array}$ & $\begin{array}{l}205 \\
205\end{array}$ & $\begin{array}{l}152.8 \\
152.8\end{array}$ & $\begin{array}{l}34.37 \\
34.37\end{array}$ & $\begin{array}{l}.42 \\
.42\end{array}$ & -- & - & - & -- & $\begin{array}{l}14,425 \\
14,425\end{array}$ & $\begin{array}{l}165.0 \\
165.0\end{array}$ & $\begin{array}{l}1.70 \\
1.70\end{array}$ & $\begin{array}{l}24 \\
24\end{array}$ & - & $\begin{array}{l}76 \\
76\end{array}$ \\
\hline 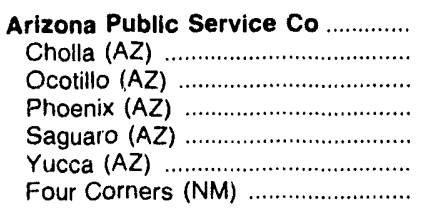 & $\begin{array}{r}12,665 \\
3,730 \\
-- \\
-- \\
-- \\
8,935\end{array}$ & $\begin{array}{r}118.8 \\
144.9 \\
-- \\
-- \\
-- \\
- \\
106.7\end{array}$ & $\begin{array}{r}21.63 \\
28.44 \\
-- \\
-- \\
-- \\
18 . \overline{79}\end{array}$ & $\begin{array}{l}.69 \\
.44 \\
-- \\
-- \\
-- \\
-- \\
.79\end{array}$ & $\begin{array}{r}64 \\
14 \\
7 \\
43 \\
-- \\
--\end{array}$ & $\begin{array}{r}438.0 \\
513.5 \\
494.9 \\
404.2 \\
- \\
-- \\
--\end{array}$ & $\begin{array}{r}25.36 \\
29.53 \\
29.03 \\
23.41 \\
-- \\
-- \\
--\end{array}$ & $\begin{array}{l}.26 \\
.21 \\
.32 \\
.27 \\
-- \\
-- \\
--\end{array}$ & $\begin{array}{r}9,708 \\
57 \\
2,130 \\
5,143 \\
1,004 \\
748 \\
626\end{array}$ & $\begin{array}{l}280.1 \\
313.8 \\
280.2 \\
279.4 \\
285.1 \\
243.4 \\
319.6\end{array}$ & $\begin{array}{l}2.87 \\
3.21 \\
2.90 \\
2.85 \\
2.94 \\
2.54 \\
3.25\end{array}$ & $\begin{array}{r}96 \\
100 \\
-- \\
-- \\
-- \\
-\end{array}$ & $\begin{array}{l}: \\
2 \\
5 \\
--1 \\
-1 \\
--\end{array}$ & $\begin{array}{r}4 \\
98 \\
95 \\
100 \\
100 \\
\end{array}$ \\
\hline 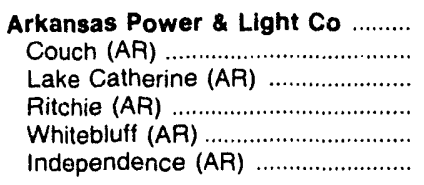 & $\begin{array}{r}9,967 \\
-- \\
-- \\
-\overline{3} \\
5,014\end{array}$ & $\begin{array}{r}166.9 \\
- \\
-- \\
-- \\
173.0 \\
161.0\end{array}$ & $\begin{array}{r}29.33 \\
- \\
-- \\
-- \\
30.21 \\
28.47\end{array}$ & $\begin{array}{l}.32 \\
-- \\
-- \\
- \\
.43 \\
.21\end{array}$ & $\begin{array}{l}85 \\
-- \\
-- \\
-- \\
45 \\
39\end{array}$ & $\begin{array}{r}490.2 \\
- \\
- \\
484.1 \\
497.3\end{array}$ & $\begin{array}{r}28.17 \\
-- \\
-- \\
-- \\
27.82 \\
28.58\end{array}$ & $\begin{array}{c}.30 \\
-- \\
-- \\
-- \\
.30 \\
.30\end{array}$ & $\begin{array}{r}27,137 \\
3,458 \\
8,185 \\
15,495 \\
-- \\
--\end{array}$ & $\begin{array}{r}153.2 \\
119.0 \\
173.8 \\
150.7 \\
--\end{array}$ & $\begin{array}{r}1.57 \\
1.33 \\
1.77 \\
1.52 \\
-- \\
--\end{array}$ & $\begin{array}{r}86 \\
-- \\
-- \\
\overline{1} \\
100 \\
100\end{array}$ & $\begin{array}{l}: \\
-1 \\
--1 \\
-1 \\
:\end{array}$ & $\begin{array}{r}14 \\
100 \\
100 \\
100 \\
-- \\
-\end{array}$ \\
\hline $\begin{array}{l}\text { Associated Electric Coop Inc ........ } \\
\text { Madrid }(\mathrm{MO}) \\
\text { Hill }(\mathrm{MO})\end{array}$ & $\begin{array}{l}5,354 \\
2,732 \\
2,622\end{array}$ & $\begin{array}{l}138.6 \\
116.0 \\
163.2\end{array}$ & $\begin{array}{l}29.64 \\
25.25 \\
34.20\end{array}$ & $\begin{array}{l}3.53 \\
3.06 \\
4.01\end{array}$ & $\cdots$ & -- & - & - & - & - & - & $\begin{array}{l}100 \\
100 \\
100\end{array}$ & - & +- \\
\hline $\begin{array}{l}\text { Atlantic City Electric Co } \ldots \ldots \ldots \ldots \ldots \\
\text { England }(\mathrm{NJ}) \\
\text { Deepwater }(\mathrm{NJ})\end{array}$ & $\begin{array}{l}795 \\
652 \\
143\end{array}$ & $\begin{array}{l}167.7 \\
165.7 \\
176.9\end{array}$ & $\begin{array}{l}43.50 \\
43.18 \\
44.94\end{array}$ & $\begin{array}{r}2.13 \\
2.42 \\
.77\end{array}$ & $\begin{array}{r}110 \\
109 \\
1\end{array}$ & $\begin{array}{l}284.0 \\
281.9 \\
461.3\end{array}$ & $\begin{array}{l}17.96 \\
17.85 \\
26.51\end{array}$ & $\begin{array}{l}.89 \\
.90 \\
.11\end{array}$ & $\begin{array}{r}1,405 \\
1,405\end{array}$ & $\begin{array}{r}197.4 \\
-- \\
197.4\end{array}$ & $\begin{array}{r}2.06 \\
-\overline{-} \\
2.06\end{array}$ & $\begin{array}{l}91 \\
96 \\
71\end{array}$ & $\begin{array}{l}3 \\
4 \\
*\end{array}$ & $\begin{array}{r}6 \\
-29\end{array}$ \\
\hline 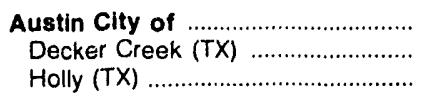 & - & $\begin{array}{l}-- \\
--\end{array}$ & $\overline{-}$ & -- & - & -- & -- & $\begin{array}{l}-- \\
-- \\
--\end{array}$ & $\begin{array}{r}15,328 \\
10,601 \\
4,727\end{array}$ & $\begin{array}{l}230.6 \\
238.3 \\
213.7\end{array}$ & $\begin{array}{l}2.37 \\
2.43 \\
2.24\end{array}$ & $\begin{array}{l}-- \\
--\end{array}$ & $\begin{array}{l}- \\
--1 \\
-\end{array}$ & $\begin{array}{l}100 \\
100 \\
100\end{array}$ \\
\hline $\begin{array}{l}\text { Baltimore Gas \& Electric Co } \ldots \ldots \ldots \\
\text { Brandon Shores (MD) } \\
\text { Crane (MD) } \\
\text { Gould St (MD) } \\
\text { Wagner (MD) }\end{array}$ & $\begin{array}{r}4,139 \\
2,533 \\
725 \\
- \\
881\end{array}$ & $\begin{array}{r}154.0 \\
153.5 \\
144.6 \\
-- \\
163.3\end{array}$ & $\begin{array}{r}39.74 \\
39.03 \\
38.89 \\
-\overline{42.47}\end{array}$ & $\begin{array}{r}.96 \\
.68 \\
2.03 \\
-- \\
.85\end{array}$ & $\begin{array}{r}770 \\
53 \\
7 \\
152 \\
319\end{array}$ & $\begin{array}{l}243.6 \\
420.5 \\
407.1 \\
243.4 \\
218.5\end{array}$ & $\begin{array}{l}15.37 \\
24.46 \\
23.63 \\
15.47 \\
13.85\end{array}$ & $\begin{array}{l}.92 \\
.18 \\
.18 \\
.99 \\
.98\end{array}$ & $\begin{array}{r}3,341 \\
- \\
-- \\
2,487\end{array}$ & $\begin{array}{r}287.4 \\
-- \\
-- \\
288.2\end{array}$ & $\begin{array}{r}2.99 \\
-- \\
-- \\
3.00\end{array}$ & $\begin{array}{c}93 \\
100 \\
100 \\
--1 \\
83\end{array}$ & $\begin{array}{r}4 \\
* \\
100 \\
7\end{array}$ & $\begin{array}{r}3 \\
-- \\
--\end{array}$ \\
\hline
\end{tabular}

See footnotes at end of table.

Source: Federal Energy Regulatory Commission, FERC Form 423, "Monthly Report of Cost and Quality of Fuels for Electric Plants." 
Table 31. Receipts, Average Delivered Cost, and Quality of Fossil-Fuels by Electric Utility and Plant, 1992 (Continued)

\begin{tabular}{|c|c|c|c|c|c|c|c|c|c|c|c|c|c|c|}
\hline \multirow[b]{2}{*}{$\begin{array}{l}\text { Electric Utility } \\
\text { Plant (State) }\end{array}$} & \multicolumn{4}{|c|}{ Coal } & \multicolumn{4}{|c|}{ Petroleum' } & \multicolumn{3}{|c|}{ Gas } & \multicolumn{3}{|c|}{$\begin{array}{c}\% \text { of Total } \\
\text { Btu }\end{array}$} \\
\hline & $\begin{array}{c}\text { Receipts } \\
\text { (1,000 } \\
\text { Short } \\
\text { Tons) }\end{array}$ & $\begin{array}{c}\text { (Cents } \\
\text { per } \\
10^{\circ} \\
\text { Btu) }\end{array}$ & $\begin{array}{l}\text { (S per } \\
\text { Short } \\
\text { Ton) }\end{array}$ & $\begin{array}{c}\text { (\% } \\
\text { Avg. } \\
\text { Sulfur) }\end{array}$ & $\begin{array}{c}\text { Receipts } \\
(1,000 \\
\text { bbls })\end{array}$ & $\begin{array}{c}\text { (Cents } \\
\text { per } \\
10^{6} \\
\text { Btu) }\end{array}$ & $\begin{array}{l}\text { (\$ } \\
\text { per } \\
\text { bbl) }\end{array}$ & $\begin{array}{c}\text { (\% } \\
\text { Avg. } \\
\text { Sulfur) }\end{array}$ & $\begin{array}{c}\text { Recelpts } \\
\text { (1,000 } \\
\text { Mcf) }\end{array}$ & $\begin{array}{c}\text { (Cents } \\
\text { per } \\
10^{6} \\
\text { Btu) }\end{array}$ & $\begin{array}{c}\text { (S } \\
\text { per } \\
\text { Mct) }\end{array}$ & $\begin{array}{l}c \\
0 \\
a \\
1\end{array}$ & $\begin{array}{l}\text { Pe- } \\
\text { tr- } \\
0- \\
\text { le- } \\
\text { um }\end{array}$ & $\begin{array}{l}\mathbf{G} \\
\mathbf{a} \\
\mathbf{8}\end{array}$ \\
\hline \multicolumn{15}{|l|}{ Baltimore Gas Electric Co } \\
\hline Riverside (MD) & -- & - & -- & -- & 139 & 228.0 & 14.48 & 0.98 & 854 & 285.0 & 2.96 & -- & 50 & 50 \\
\hline 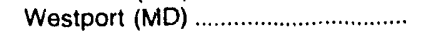 & -- & -- & -- & - & 100 & 249.2 & 15.87 & .99 & -- & -- & -- & & 100 & - \\
\hline Bangor Hydro-Electric Co .............. & -- & - & -- & -- & 19 & 316.0 & 20.16 & .67 & - & - & - & & 100 & - \\
\hline Graham (ME) & -- & -- & $\sim$ & -- & 19 & 316.0 & 20.16 & .67 & - & -- & - & & 100 & - \\
\hline Basin Electric Power Coop ............ & 15,155 & 67.1 & 9.80 & 0.66 & 60 & 494.2 & 28.62 & .34 & - & - & & 100 & * & - \\
\hline 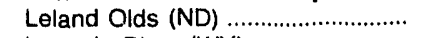 & 3,047 & 95.9 & 12.33 & .66 & 7 & 475.8 & 27.55 & .34 & - & -- & & 100 & * & - \\
\hline 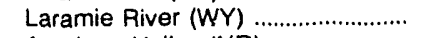 & 6,914 & 52.7 & 8.64 & .35 & 46 & 497.0 & 28.78 & .34 & -- & -- & --1 & 100 & * & -- \\
\hline Antelope Valley (ND) & 5,193 & 74.4 & 9.84 & 1.08 & 8 & 495.6 & 28.70 & .34 & -- & - & & 100 & * & - \\
\hline Big Rivers Electric Corp .................... & 4,534 & 121.3 & 27.34 & 3.09 & 25 & 437.9 & 25.38 & .00 & 52 & 298.6 & 2.99 & 100 & * & " \\
\hline Coleman $(\mathrm{KY})$ & 1,133 & 97.4 & 21.95 & 2.54 & $-\overline{-}$ & -- & -- & -- & 52 & 298.6 & 2.99 & 100 & * & * \\
\hline 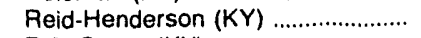 & 658 & 121.4 & 29.65 & 2.33 & 17 & 442.9 & 25.67 & .00 & - & - & - & 99 & 1 & - \\
\hline 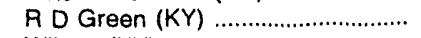 & 1,482 & 119.0 & 24.96 & 3.78 & -- & - & - & -- & -- & - & --1 & 100 & - & - \\
\hline 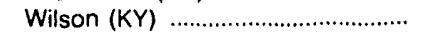 & 1,260 & 144.3 & 33.77 & 3.17 & 8 & 427.2 & 24.76 & .00 & - & -- & -- & 100 & * & - \\
\hline 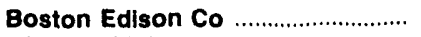 & - & -- & - & - & 6,377 & 235.1 & 14.96 & .79 & 29,129 & 252.8 & 2.61 & - & 57 & 43 \\
\hline 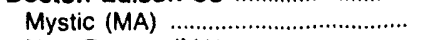 & - & - & -- & - & 4,349 & 231.7 & 14.80 & .95 & 1,982 & 244.2 & 2.64 & - & 93 & 7 \\
\hline 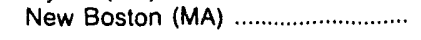 & -- & -- & -- & -- & 2,028 & 242.5 & 15.31 & .45 & 27.146 & 253.5 & 2.61 & -- & 31 & 69 \\
\hline Braintree City of ................................. & - & $-\infty$ & -- & - & -- & - & -- & - & 540 & 229.6 & 2.37 & -- & & 100 \\
\hline 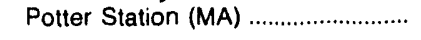 &.- & -- & -- & - & -- & -- & -- & -- & 540 & 229.6 & 2.37 & -- & & 100 \\
\hline Brazos Electric Power Coop Inc. & -- & -- & -- & - & - & - & -- & -- & 17,671 & 186.1 & 1.89 & - & & 100 \\
\hline 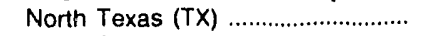 & -- & -- & -- & - & -- & -- & -- & -- & 917 & 194.8 & 2.10 & - & & 100 \\
\hline 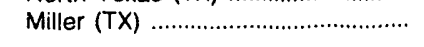 & -- & -- & -- & -- & -- & -- & -- & -- & 16,754 & 185.6 & 1.88 & -- & --1 & 100 \\
\hline 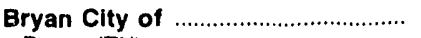 & $-\infty$ & -- & $-\infty$ & -- & -- & -- & -- & -- & 6,592 & 181.6 & 1.85 & - & & 100 \\
\hline 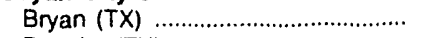 & - & -- & -- & -- & -- & -- & -- & -- & 1,425 & 185.8 & 1.96 & -- & & 100 \\
\hline 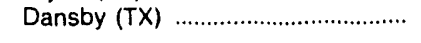 & -- & - & -- & -- & -- & -- & -- & -- & 5,167 & 180.4 & 1.94 & - & & 100 \\
\hline 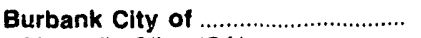 & -- & -- & -- & -- & -- & -- & -- & -- & 2,266 & 301.4 & 3.11 & - & & 100 \\
\hline Magnolia-Olive (CA) ........................... & -- & -- & -- & -- & -- & - & -- & -- & 2,266 & 301.4 & 3.11 & -- & & 100 \\
\hline 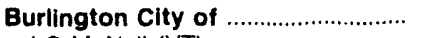 & - & -- & - & -- & -- & $\rightarrow$ & -- & -- & 800 & 202.4 & 2.00 & 64 & - & 36 \\
\hline 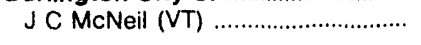 & -- & -- & -- & -- & -- & -- & -- & -- & 800 & 202.4 & 2.00 & 64 & -- & 36 \\
\hline Cajun Electric Power Coop Inc .... & 5,344 & 147.5 & 24.69 & .46 & 47 & 418.2 & 24.59 & .00 & 5,465 & 186.7 & 1.94 & 94 & " & 6 \\
\hline 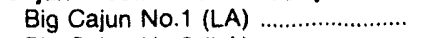 & - & -- & -- & -- & - & -- & $-\overline{-}$ & -- & 5,465 & 186.7 & 1.94 & - & --1 & 100 \\
\hline 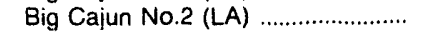 & 5,344 & $1 .+7.5$ & 24.69 & .46 & 47 & 418.2 & 24.59 & .00 & - & -- & --1 & 100 & * & - \\
\hline Cambridge Electric Light Co ........ & $\cdots$ & - & -- & - & 176 & 258.8 & 16.43 & .48 & 630 & 268.3 & 2.68 & - & 64 & 36 \\
\hline Kendall Square (MA) ......................... & -- & -- & -- & -- & 176 & 258.8 & 16.43 & .48 & 630 & 268.3 & 2.68 & -- & 64 & 36 \\
\hline 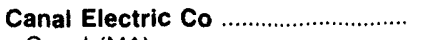 & - & -- & -- & -- & 9,789 & 198.2 & 12.59 & 1.91 & - & - & -- & --1 & 100 & -- \\
\hline Canal (MA) & - & -- & - & -- & 9,789 & 198.é & 12.59 & 1.91 & $\cdots$ & -- & -- & --1 & 100 & - \\
\hline Cardinal Operating Co ...................... & 4,277 & 148.0 & 35.06 & 2.16 & 33 & 459.8! & 26.79 & .00 & $\rightarrow$ & - & & 100 & $\star$ & - \\
\hline Cardinal $(\mathrm{OH})$ & 4,277 & 148.0 & 35.06 & 2.16 & 33 & 459.2. & 26.79 & .00 & -- & - & & 100 & - & - \\
\hline Carolina Power \& Light Co ........... & 10,403 & 172.6 & 42.86 & .88 & 98 & 444.0 & 25.73 & .20 & - & - & & 100 & $\bullet$ & - \\
\hline 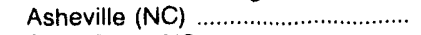 & 789 & 133.1 & 34.82 & 1.18 & 7 & 436.3 & 25.29 & .20 & -- & -- & & 100 & - & - \\
\hline 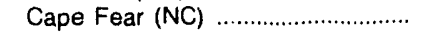 & 427 & 197.1 & 50.40 & .97 & $\bullet$ & 377.6 & 21.89 & .20 & - & -- & & 100 & $\cdot$ & - \\
\hline Lee (NC) & 580 & 190.9 & 48.40 & .98 & $-\overline{-}$ & -- & - & -- & -- & - & & 100 & -- & - \\
\hline Roxboro (NC) & 5,737 & 173.5 & 42.92 & .86 & 59 & 439.6 & 25.48 & .20 & - & -- & & 100 & " & -- \\
\hline Sutton (NC) & $76 \%$ & 155.1 & 38.57 & .93 & 4 & 453.4 & 26.28 & .20 & - & -- & & 100 & * & -- \\
\hline 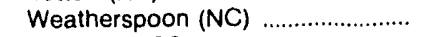 & 238 & 162.1 & 40.23 & 1.07 & * & 472.13 & 27.40 & .20 & -- & -- & & 100 & $\star$ & -- \\
\hline 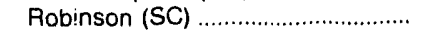 & 271 & 171.4 & 42.67 & 1.05 & 3 & 477.6 & 27.68 & .20 & - & -- & & 100 & $*$ & -- \\
\hline 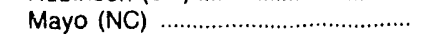 & 1,595 & 186.7 & 45.08 & .64 & 26 & 450.8 & 26.13 & .20 & -- & -- & & 100 & * & - \\
\hline 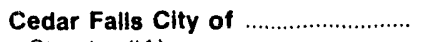 & 10 & 140.9 & 31.54 & 2.72 & -- & - & - & - & 25 & 244.4 & 2.46 & 90 & - & 10 \\
\hline 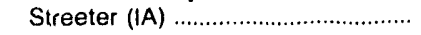 & 10 & 140.9 & 31.54 & 2.72 & -- & -- & - & -- & 25 & 244.4 & 2.46 & 90 & -- & 10 \\
\hline
\end{tabular}

See footnotes at end of table.

Source: Federal Energy Regulatory Commission, FERC Form 423, "Monthly Report of Cost and Quality of Fuels for Electric Plants." 
Table 31. Receipts, Average Delivered Cost, and Quality of Fossil-Fuels by Electric Utility and Plant, 1992 (Continued)

\begin{tabular}{|c|c|c|c|c|c|c|c|c|c|c|c|c|c|c|}
\hline \multirow[b]{2}{*}{$\begin{array}{l}\text { Electric Utility } \\
\text { Plant (State) }\end{array}$} & \multicolumn{4}{|c|}{ Coal } & \multicolumn{4}{|c|}{ Petroleum' } & \multicolumn{3}{|c|}{ Gas } & \multicolumn{3}{|c|}{$\begin{array}{c}\% \text { of Total } \\
\text { Btu }\end{array}$} \\
\hline & $\begin{array}{c}\text { Receipts } \\
(1,000 \\
\text { Short } \\
\text { Tons) }\end{array}$ & $\begin{array}{c}\text { (Cents } \\
\text { per } \\
10^{6} \\
\text { Btu) }\end{array}$ & $\begin{array}{l}\text { (\$ per } \\
\text { Short } \\
\text { Ton) }\end{array}$ & $\begin{array}{c}\text { (\% } \\
\text { Avg. } \\
\text { Sulfur) }\end{array}$ & $\begin{array}{c}\text { Recelpts } \\
\text { (1,000 } \\
\text { bbls) }\end{array}$ & $\begin{array}{c}\text { (Cents } \\
\text { per } \\
10^{8} \\
\text { Btu) }\end{array}$ & $\begin{array}{l}\text { (s } \\
\text { per } \\
\text { bbl) }\end{array}$ & $\begin{array}{c}\text { (\% } \\
\text { Avg. } \\
\text { Sulfur) }\end{array}$ & $\begin{array}{c}\text { Recelpts } \\
(1,000 \\
\text { Mct) }\end{array}$ & $\begin{array}{c}\text { (Cents } \\
\text { per } \\
10^{6} \\
\text { Btu) }\end{array}$ & $\begin{array}{c}(\$ \\
\text { per } \\
\text { Mcf })\end{array}$ & $\begin{array}{l}c \\
0 \\
a \\
1\end{array}$ & $\begin{array}{c}\text { Pe- } \\
\text { tr- } \\
0- \\
\text { le- } \\
\text { um }\end{array}$ & $\begin{array}{l}\mathbf{G} \\
\mathbf{a} \\
\mathbf{8}\end{array}$ \\
\hline Central Electric Pwr Coop-MO ..... & 83 & 118.5 & 26.00 & 3.14 & - & -- & -- & -- & - & - & & 100 & $-\infty$ & - \\
\hline Chamois (MO) & 83 & 118.5 & 26.00 & 3.14 & - & - & -- & - & -- & -- & --1 & 100 & -- & -- \\
\hline Central Hudson Gas \& Elec Corp & 881 & 182.1 & 47.40 & .59 & 6,618 & 226.3 & 14.47 & 1.11 & 16,452 & 244.5 & 2.49 & 28 & 52 & 20 \\
\hline 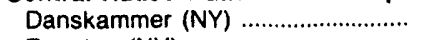 & 881 & 182.1 & 47.40 & .59 & 99 & 261.7 & 16.73 & .94 & 2,788 & 249.9 & 2.55 & 87 & 2 & 11 \\
\hline 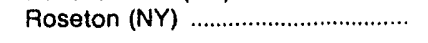 & - & -- & -- & -- & 6,519 & 225.7 & 14.44 & 1.11 & 13,664 & 243.5 & 2.48 & -- & 75 & 25 \\
\hline Central Illinols Light Co ................. & 2,267 & 168.1 & 40.20 & 1.99 & 12 & 459.4 & 26.60 & .23 & - & - & & 100 & $\star$ & - \\
\hline 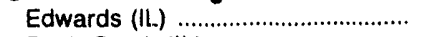 & 1,253 & 169.7 & 43.94 & .91 & 7 & 455.1 & 26.35 & .22 & -- & - & & 100 & * & - \\
\hline 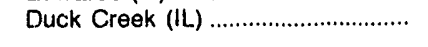 & 1,014 & 165.7 & 35.57 & 3.32 & 5 & 464.8 & 26.90 & .24 & -- & - & & 100 & * & - \\
\hline Central Illinois Pub Serv Co ........... & 4,403 & 159.8 & 35.63 & 2.54 & 67 & 457.7 & 26.46 & .18 & $-\infty$ & -- & & 100 & $\star$ & - \\
\hline 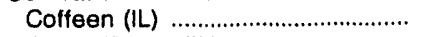 & 1,755 & 155.6 & 32.87 & 3.00 & 16 & 464.5 & 26.76 & .14 & - & -- & --1 & 100 & * & -- \\
\hline 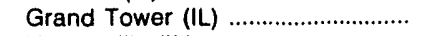 & 180 & 176.5 & 40.75 & 2.82 & 5 & 457.0 & 26.60 & .25 & - & - & -- & 99 & 1 & -- \\
\hline Hutsonville (IL) . & 229 & 148.3 & 33.56 & 2.27 & 9 & 463.1 & 26.74 & .17 & -- & - & -- & 99 & 1 & - \\
\hline 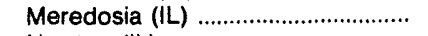 & 529 & 152.9 & 35.38 & 2.71 & 11 & 453.3 & 26.32 & .15 & -- & -- & -- & 99 & 1 & - \\
\hline 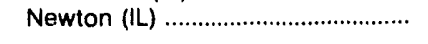 & 1,709 & 165.7 & 38.28 & 2.01 & 25 & 453.6 & 26.20 & .21 & -- & -- & -1 & 100 & * & - \\
\hline Central lowa Power Coop .............. & 148 & 113.4 & 25.42 & 3.09 & 1 & 565.0 & 32.27 & .35 & 8 & 348.6 & 3.551 & 100 & $*$ & $\bullet$ \\
\hline 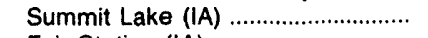 & - & - & $-\overline{-1}$ & $\overline{--}$ & 1 & 565.0 & 32.27 & .35 & $-\overline{0}$ & $-\overline{-}$ & $\overline{-1}$ & --1 & 100 & - \\
\hline 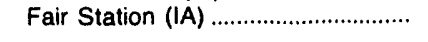 & 148 & 113.4 & 25.42 & 3.09 & -- & - & - & - & 8 & 348.6 & 3.551 & 100 & -- & $\cdot$ \\
\hline Central Louisiana Elec Co Inc ...... & 5,082 & 156.6 & 23.82 & .56 & - & - & - & -- & 28,234 & 204.6 & 2.13 & 72 & - & 28 \\
\hline 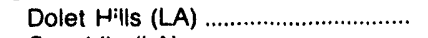 & 3,212 & 138.3 & 19.22 & .62 & -- & -- & -- & -- & 167 & 204.2 & 2.101 & 100 & -- & $*$ \\
\hline 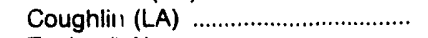 & - & -- & -- & - & -- & -- & -- & -- & 4,392 & 199.9 & 2.12 & - & & 100 \\
\hline 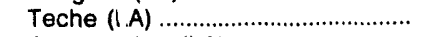 & -- & -- & -- & $\bar{m}$ & -- & -- & -- & -- & 12,239 & 193.3 & 2.02 & -- & & 100 \\
\hline 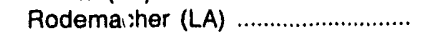 & 1,870 & 181.7 & 31.71 & .45 & $-\infty$ & -- & -- & -- & 11,436 & 218.6 & 2.25 & 73 & -- & 27 \\
\hline Central Maine Power Co .................. & -- & -- & -- & - & 2,178 & 228.0 & 14.43 & .95 & - & - & $-\infty$ & -1 & 100 & - \\
\hline Wyman (ME) & $-\infty$ & -- & -- & -- & 2,178 & 228.0 & 14.43 & .95 & -- & -- & -- & --1 & 100 & - \\
\hline Central Nebraska Pub P\&l Dist .... & - & - & - & - & -- & -- & $-\infty$ & $-\infty$ & 10 & 433.3 & 4.03 & -- & & 100 \\
\hline 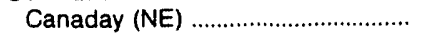 & -- & -- & -- & - & -- & - & - & -- & 10 & 433.3 & 4.03 & -- & -- & 100 \\
\hline Central Operating Co ......................... & 1,367 & 165.0 & 40.77 & 1.20 & 32 & 2478.6 & 27.49 & .00 & - & - & - & 99 & 1 & - \\
\hline Sporn (WV) & 1,367 & 165.0 & 40.77 & 1.20 & 32 & 2478.6 & 27.49 & .00 & -- & -- & -- & 99 & 1 & -- \\
\hline Central Power \& Light Co .............. & 1,860 & 203.5 & 44.68 & .40 & 6 & 436.3 & 25.40 & .34 & 85,938 & 209.8 & 2.17 & 31 & $\cdot$ & 69 \\
\hline 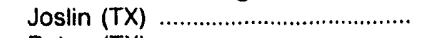 & - & -- & -- & -- & -- & -- & -- & -- & 4,617 & 235.5 & 2.45 & -- & & 100 \\
\hline Bates (TX) & -- & -- & -- & $-\infty$ & -- & - & -- & -- & 7,511 & 201.3 & 2.09 & - & -- & 100 \\
\hline 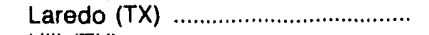 & -- & -- & -- & -- & -- & - & - & -- & 7,243 & 245.2 & 2.58 & -- & & 100 \\
\hline 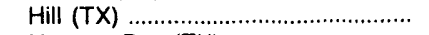 & -- & - & - & -- & -- & -- & - & -- & 15,094 & 203.1 & 2.12 & -- & & 100 \\
\hline 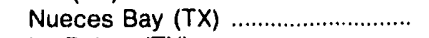 & -- & - & -- & -- & -- & -- & - & -- & 11,717 & 205.8 & 2.12 & - & & 100 \\
\hline 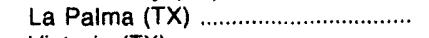 & -- & -- & -- & -- & - & - & - & -- & 8,493 & 207.0 & 2.19 & -- & -- & 100 \\
\hline 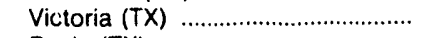 & -- & -- & -- & - & -- & - & -- & -- & 3,796 & 187.3 & 1.98 & -- & -- & 100 \\
\hline 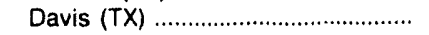 & -- & - & -- & - & -- & -- & $-\overline{0}$ & -- & 27,468 & 207.9 & 2.12 & -- & -- & 100 \\
\hline Coleto Creek (TX) ............................. & 1,860 & 203.5 & 44.68 & .40 & 6 & 436.3 & 25.40 & .34 & - & -- & & 100 & * & - \\
\hline Century Power Corp ............................ & 2,493 & 170.9 & 31.16 & .63 & 12 & 508.4 & 30.56 & .13 & -- & - & & 100 & * & - \\
\hline Springerville $(A Z)$ & 2,493 & 170.9 & 31.16 & .63 & 12 & 508.4 & 30.56 & .13 & -- & -- & & 100 & * & -- \\
\hline Chugach Electric Assn Inc ............ & - & - & - & - & -- & - & -- & - & 11,698 & 57.3 & .57 & - & & 100 \\
\hline 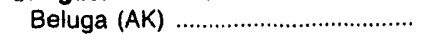 & -- & -- & -- & -- & -- & -- & - & -- & 11,698 & 57.3 & .57 & -- & & 100 \\
\hline Cincinnatl Gas \& Electric Co ......... & 9,322 & 137.6 & 33.09 & 2.28 & 78 & 436.6 & 24.94 & .38 & $-\infty$ & - & -- & 100 & * & - \\
\hline Beckjord $(\mathrm{OH})$ & 1,351 & 164.7 & 38.71 & 1.76 & 22 & 427.2 & 24.64 & .41 & -- & - & & 100 & * & - \\
\hline Miami Fort $(\mathrm{OH})$ & 2,501 & 163.5 & 39.79 & 1.32 & 20 & 453.3 & 25.43 & .26 & -- & -- & & 100 & " & -- \\
\hline 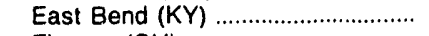 & 1,176 & 161.7 & 38.07 & 1.51 & 12 & 443.0 & 25.42 & .43 & - & - & & 100 & * & -- \\
\hline Zimmer $(\mathrm{OH})$ & 4,294 & 107.7 & 26.05 & 3.22 & 24 & 428.5 & 24.57 & .43 & -- & -- & --1 & 100 & - & - \\
\hline Cleveland Electric Illum Co ........... & 4,649 & 151.8 & 38.83 & 2.60 & 64 & 450.0 & 26.19 & .29 & - & - & & 100 & * & - \\
\hline Ashtabula $(\mathrm{OH})$ & 901 & 150.8 & 38.73 & 3.22 & 13 & 447.8 & 26.01 & .30 & - & -- & & 100 & : & - \\
\hline Avon Lake $(\mathrm{OH})$ & 1,527 & 153.5 & 38.51 & 2.45 & 17 & 451.7 & 26.34 & .28 & -- & -- & & 100 & 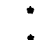 & - \\
\hline Eastlake $(\mathrm{OH})$ & 2,029 & 149.6 & 38.66 & 2.63 & 27 & 448.4 & 26.10 & .29 & -- & - & & 100 & * & - \\
\hline 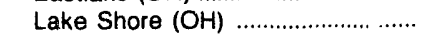 & 192 & 165.4 & 43.61 & .64 & 7 & 456.1 & 26.45 & .29 & - & -- & - & 99 & 1 & - \\
\hline
\end{tabular}

See footnotes at end of table.

Source: Federal Energy Regulatory Commission, FERC Form 423, "Monthly Report of Cost and Quality of Fuels for Electric Plants." 
Table 31. Receipts, Average Delivered Cost, and Quality of Fossil-Fuels by Electric Utility and Plant, 1992 (Continued)

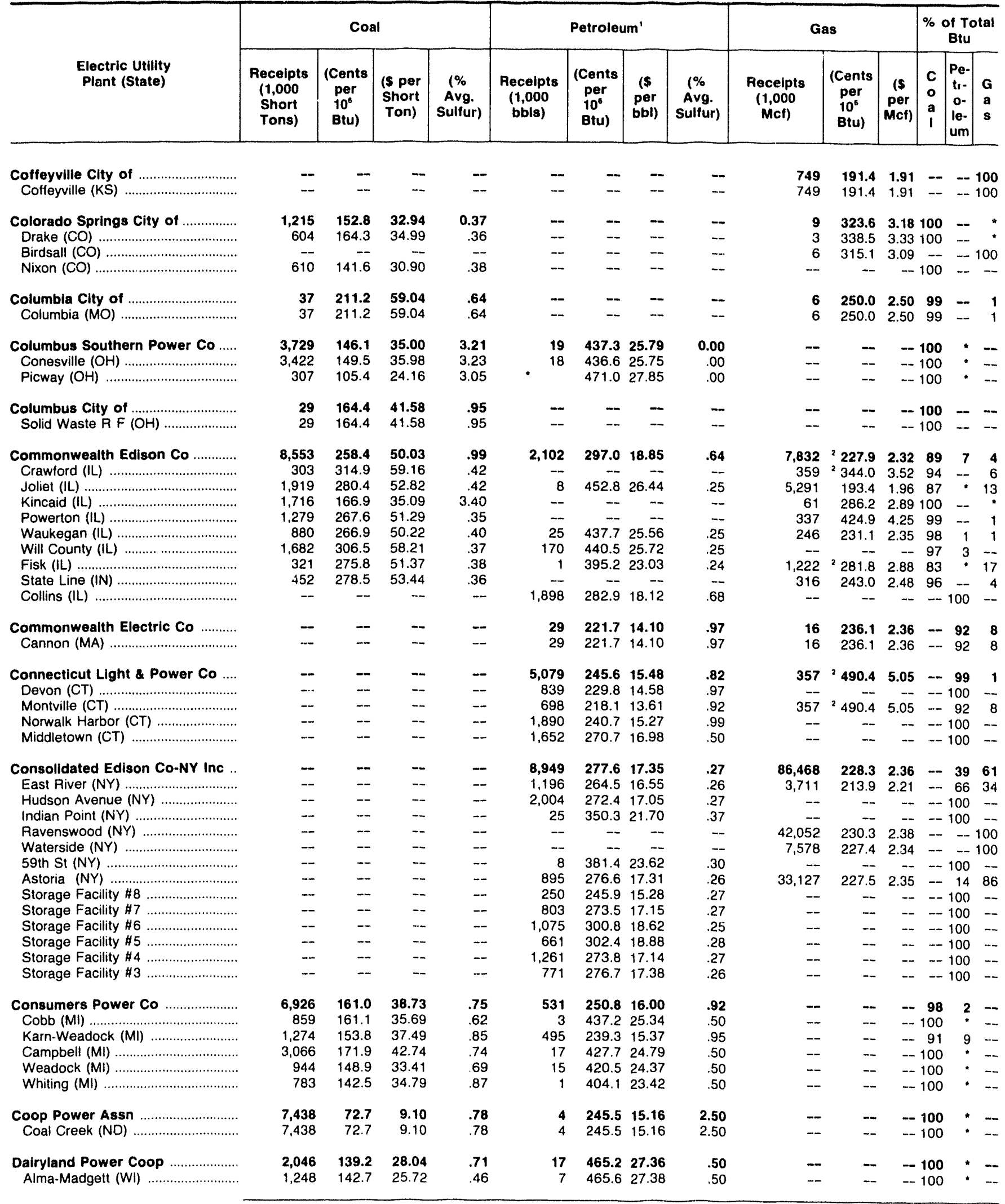

See footnotes at end of table.

Source: Federal Energy Reguiatory Commission, FERC Form 423, "Monthly Report of Cost and Quality of Fuels for Electric Plants." 
Table 31. Recelpts, Average Delivered Cost, and Quality of Fossil-Fuels by Electric Utility and Plant, 1992 (Continued)

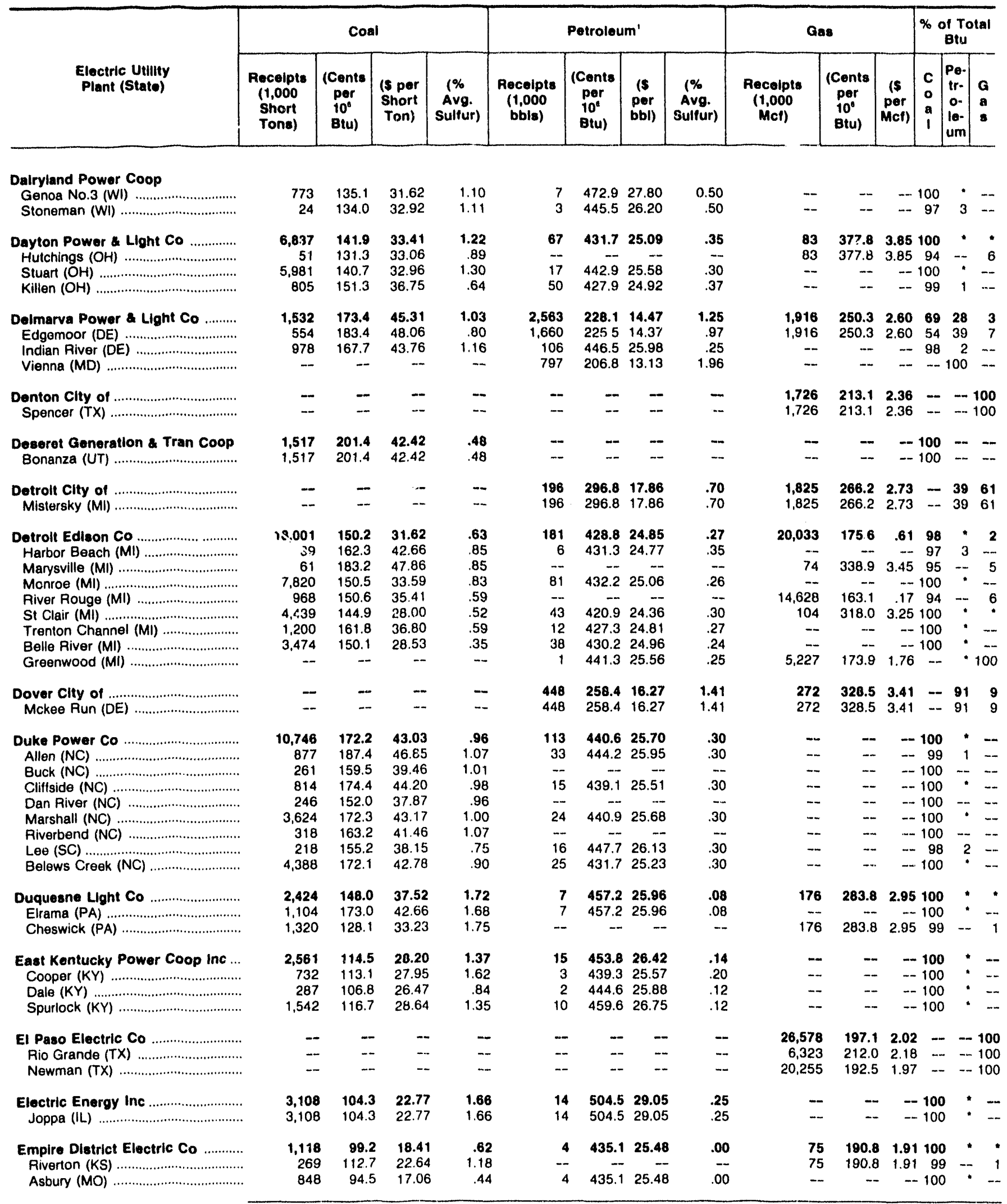

See footnotes at end of table.

Source: Federal Energy Regulatory Commission, FERC Form 423, "Monthly Report of Cost and Quality of Fuels for Electric Plants." 
Table 31. Receipts, Average Delivered Cost, and Quality of Fossil-Fuels by Electric Utility and Plant, 1992 (Continued)

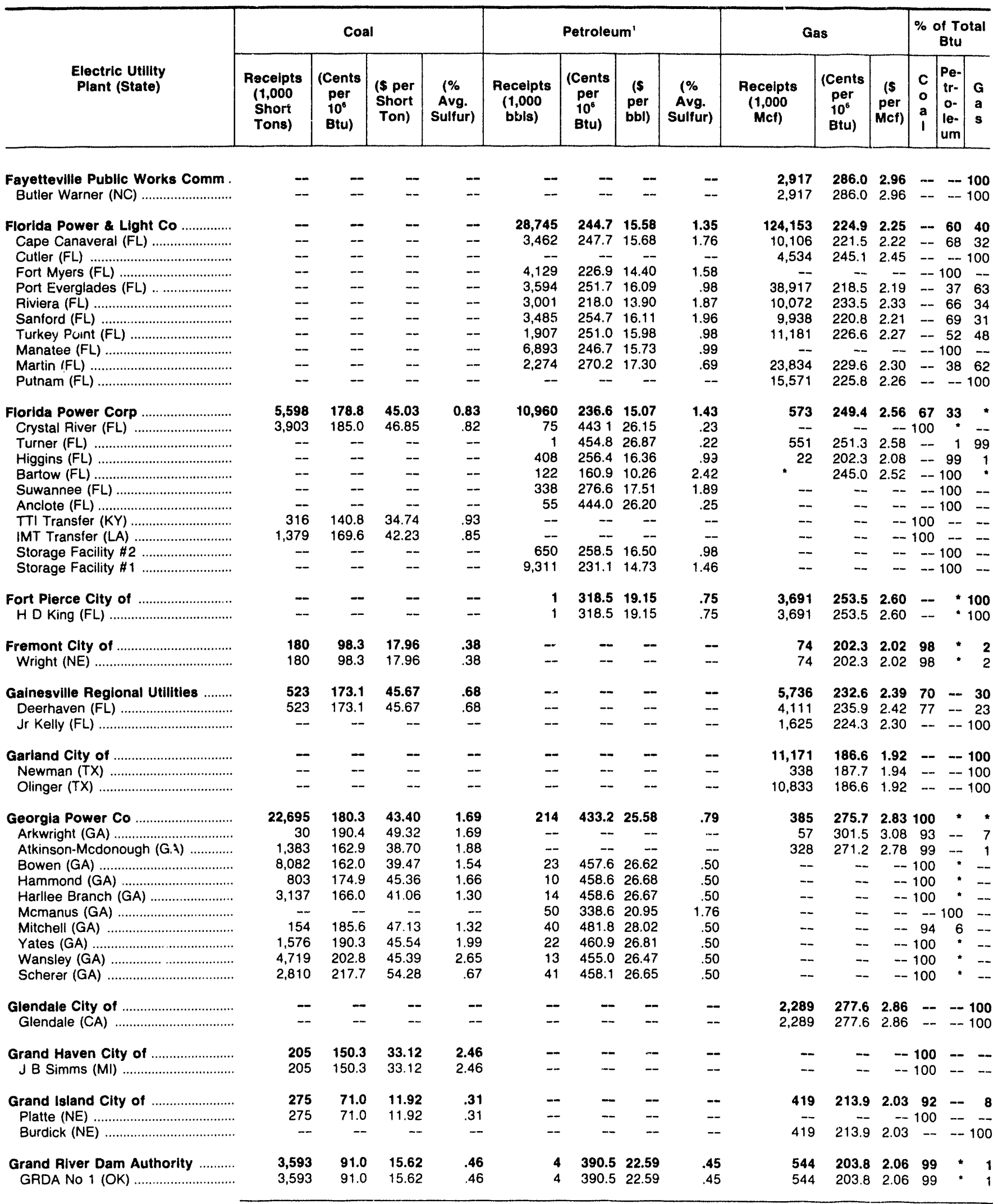

See footnotes at end of table.

Source: Federal Energy Regulatory Commission, FERC Form 423, "Monthly Report of Cost and Quality of Fuels for Electric Plants." 
Table 31. Receipts, Average Dellvered Cost, and Quality of Fossil-Fuels by Electric Utility and Plant, 1992 (Continued)

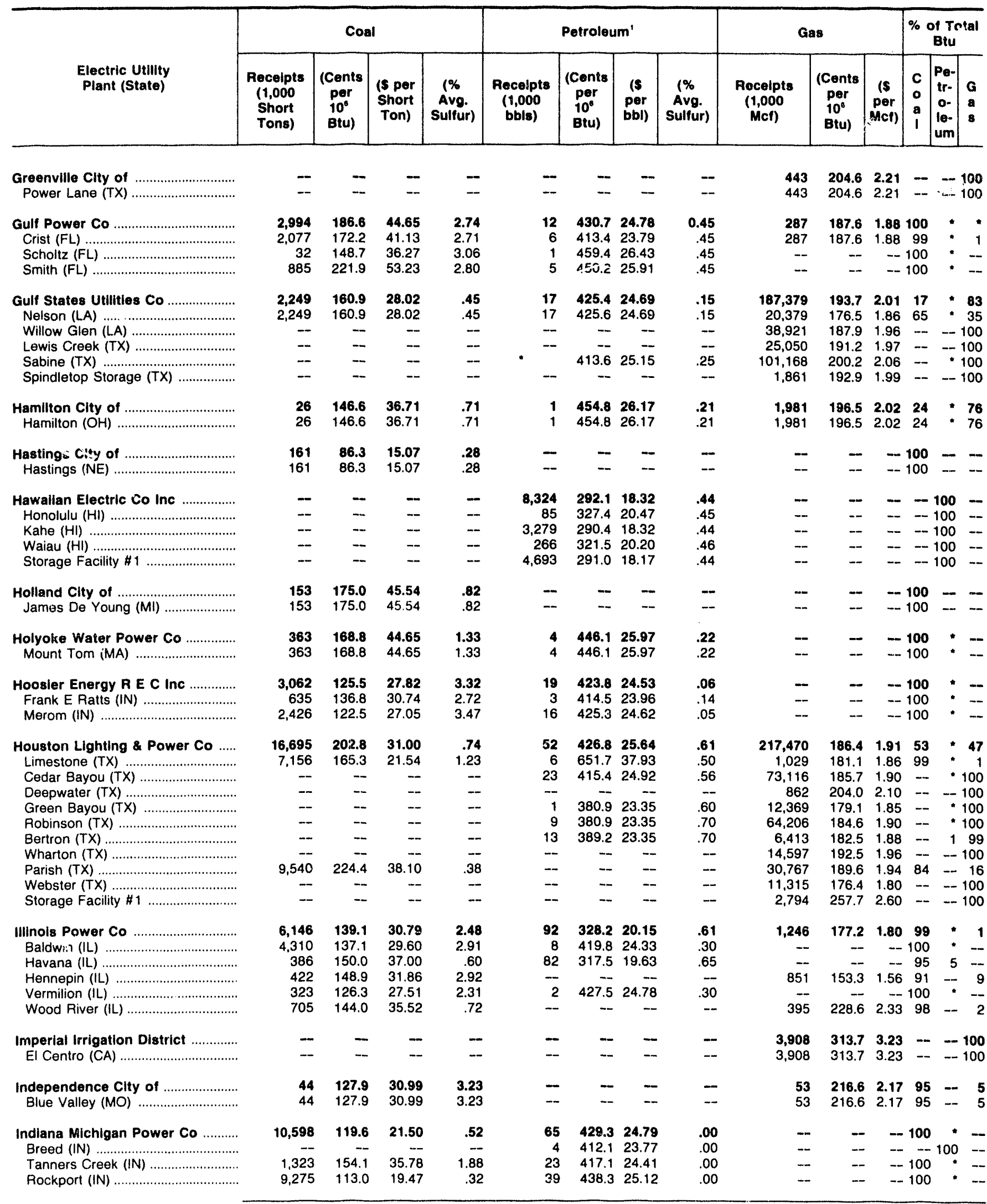

See footnotes at end of table.

Source: Federal Energy Regulatory Commission, FERC Form 423, "Monthly Report of Cost and Quality of Fuels for Electric Plants." 
Table 31. Recelpts, Average Delivered Cost, and Qusality of Fossill-Fuels by Electric Utillty and Plant, 1992 (Gontinued)

\begin{tabular}{|c|c|c|c|c|c|c|c|c|c|c|c|c|c|}
\hline \multirow[b]{2}{*}{$\begin{array}{l}\text { Electric Utility } \\
\text { Plant (State) }\end{array}$} & \multicolumn{4}{|c|}{ Cond } & \multicolumn{4}{|c|}{ Petroleum' } & \multicolumn{3}{|c|}{ Gas } & \multicolumn{2}{|c|}{$\begin{array}{c}\text { \% of Total } \\
\text { Btu }\end{array}$} \\
\hline & $\begin{array}{c}\text { Recelpts } \\
\text { (1,000 } \\
\text { Short } \\
\text { Tons) }\end{array}$ & $\begin{array}{c}\text { (Cents } \\
\text { per } \\
10^{6} \\
\text { Btu) }\end{array}$ & $\begin{array}{l}\text { (S per } \\
\text { Short } \\
\text { Ton) }\end{array}$ & $\begin{array}{l}\text { (\% } \\
\text { Avg. } \\
\text { Sulfur) }\end{array}$ & $\begin{array}{c}\text { Rocelpts } \\
\text { (1,000 } \\
\text { bbls) }\end{array}$ & $\begin{array}{c}\text { (Conts } \\
\text { per } \\
10^{8} \\
\text { Btu) }\end{array}$ & 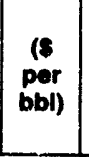 & $\begin{array}{l}\text { (\% } \\
\text { Avg. } \\
\text { Sulfur) }\end{array}$ & $\begin{array}{l}\text { Rocelpts } \\
(1,000 \\
\text { Mof) }\end{array}$ & $\begin{array}{c}\text { (Cents } \\
\text { per } \\
10^{\circ} \\
\text { Btu) }\end{array}$ & $\begin{array}{c}(s \\
\text { per } \\
\text { Mct) }\end{array}$ & \begin{tabular}{l|l}
$c$ & $p$ \\
0 & $t$ \\
$a$ & $c$ \\
1 & 1 \\
& $u$
\end{tabular} & $\begin{array}{ll}\text { Po-n } & \\
\text { tr- } & G \\
0- & a \\
\text { le- } & \text { a } \\
\text { um } & \end{array}$ \\
\hline $\begin{array}{l}\text { Indiana-Kentucky Electric Corp ... } \\
\text { Clifty Creek (IN) }\end{array}$ & $\begin{array}{l}3,765 \\
3,765\end{array}$ & $\begin{array}{l}109.3 \\
109.3\end{array}$ & $\begin{array}{l}24.50 \\
24.50\end{array}$ & $\begin{array}{l}2.90 \\
2.90\end{array}$ & $\begin{array}{l}5 \\
5\end{array}$ & $\begin{array}{l}5 \mathrm{si1.8} \\
501.8\end{array}$ & $\begin{array}{l}28.03 \\
29.03\end{array}$ & $\begin{array}{r}0.28 \\
.28\end{array}$ & $\overline{-}$ & $\overline{-}$ & & $\begin{array}{l}100 \\
100\end{array}$ & :- \\
\hline 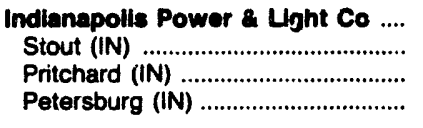 & $\begin{array}{r}6,092 \\
1,069 \\
358 \\
4,655\end{array}$ & $\begin{array}{r}105.8 \\
128.0 \\
121.9 \\
99.5\end{array}$ & $\begin{array}{l}23.69 \\
28.70 \\
27.73 \\
22.23\end{array}$ & $\begin{array}{l}2.31 \\
1.60 \\
1.07 \\
2.57\end{array}$ & $\begin{array}{r}39 \\
8 \\
14 \\
18\end{array}$ & $\begin{array}{l}458.9 \\
487.3 \\
459.4 \\
445.7\end{array}$ & $\begin{array}{l}26.60 \\
27.99 \\
26.77 \\
25.83\end{array}$ & $\begin{array}{l}.28 \\
.29 \\
.30 \\
.26\end{array}$ & $\bar{z}$ & $\begin{array}{l}\bar{z} \\
\bar{z}\end{array}$ & $\begin{array}{l}-1 \\
-1 \\
-1 \\
-1\end{array}$ & $\begin{array}{r}100 \\
100 \\
99 \\
100\end{array}$ & $:=$ \\
\hline 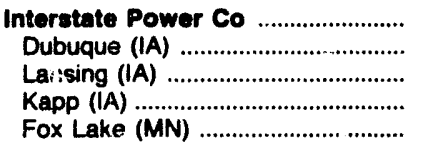 & $\begin{array}{r}1,181 \\
90 \\
590 \\
501 \\
-\end{array}$ & $\begin{array}{r}184.4 \\
200.0 \\
233.8 \\
138.1 \\
-\end{array}$ & $\begin{array}{r}36.62 \\
44.15 \\
39.87 \\
31.44 \\
-\end{array}$ & $\begin{array}{r}1.29 \\
3.00 \\
.40 \\
2.02 \\
-\end{array}$ & $\frac{9}{9}$ & $\begin{array}{r}437.4 \\
-- \\
437.4 \\
--\end{array}$ & $\begin{array}{r}25.72 \\
25.72 \\
- \\
-\end{array}$ & $\frac{.00}{.00}$ & $\begin{array}{r}2,008 \\
26 \\
-- \\
57 \\
1,925\end{array}$ & $\begin{array}{r}174.8 \\
251.5 \\
\overline{314.9} \\
169.5\end{array}$ & $\begin{array}{l}1.75 \\
2.52 \\
-\overline{3} \\
3.18 \\
1.70\end{array}$ & $\begin{array}{l}92 \\
99 \\
99 \\
99 \\
-\end{array}$ & $\begin{array}{lr}* & 8 \\
- & 1 \\
1 & - \\
- & 1 \\
-100\end{array}$ \\
\hline 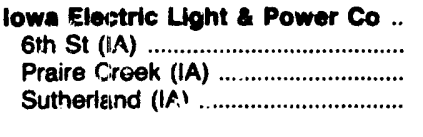 & $\begin{array}{r}609 \\
25 \\
439 \\
145\end{array}$ & $\begin{array}{l}123.7 \\
136.7 \\
129.1 \\
102.3\end{array}$ & $\begin{array}{l}23.66 \\
31.75 \\
25.21 \\
17.60\end{array}$ & $\begin{array}{r}1.31 \\
2.05 \\
1.47 \\
.71\end{array}$ & $\frac{5}{5}$ & $\begin{array}{r}457.5 \\
4575 \\
-5\end{array}$ & $\frac{26.61}{-6.61}$ & $\begin{array}{c}.00 \\
.00 \\
-\end{array}$ & $\begin{array}{r}948 \\
556 \\
63 \\
329\end{array}$ & $\begin{array}{l}277.0 \\
269.2 \\
283.6 \\
289.1\end{array}$ & $\begin{array}{l}2.77 \\
2.69 \\
2.84 \\
2.89\end{array}$ & $\begin{array}{l}93 \\
51 \\
95 \\
92\end{array}$ & $\begin{array}{r}-7 \\
-\quad 49 \\
-\quad 1 \\
-\quad 6\end{array}$ \\
\hline 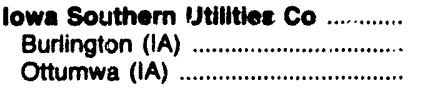 & $\begin{array}{r}2,344 \\
476 \\
1,838\end{array}$ & $\begin{array}{l}109.1 \\
104.0 \\
110.6\end{array}$ & $\begin{array}{l}18.77 \\
19.74 \\
18.52\end{array}$ & $\begin{array}{r}.66 \\
1.95 \\
.32\end{array}$ & $\begin{array}{l}8 \\
3 \\
5\end{array}$ & $\begin{array}{l}439.6 \\
455.1 \\
430.8\end{array}$ & $\begin{array}{l}25.46 \\
26.36 \\
24.95\end{array}$ & $\begin{array}{l}.04 \\
.04 \\
.04\end{array}$ & $\bar{z}$ & $\overline{-}$ & & $\begin{array}{l}100 \\
100 \\
100\end{array}$ & $:=$ \\
\hline 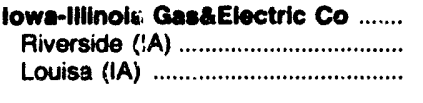 & $\begin{array}{r}2,081 \\
281 \\
1,800\end{array}$ & $\begin{array}{l}110.9 \\
110.9 \\
110.9\end{array}$ & $\begin{array}{l}19.45 \\
24.76 \\
18.62\end{array}$ & $\begin{array}{r}.52 \\
1.85 \\
.31\end{array}$ & $\bar{z}$ & $\bar{z}$ & $\bar{z}$ & $\bar{z}$ & $\begin{array}{l}453 \\
330 \\
123\end{array}$ & $\begin{array}{l}311.4 \\
323.5 \\
278.9\end{array}$ & $\begin{array}{l}3.16 \\
3.29 \\
2.821\end{array}$ & $\begin{array}{r}99 \\
95 \\
100\end{array}$ & $\begin{array}{l}=1 \\
=\quad 5 \\
-\quad 1\end{array}$ \\
\hline 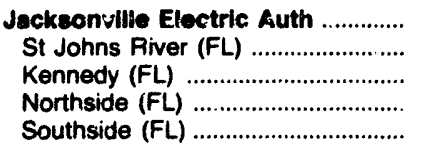 & $\begin{array}{r}3,624 \\
3,624 \\
= \\
-\end{array}$ & $\begin{array}{r}163.2 \\
163.2 \\
= \\
=\end{array}$ & $\begin{array}{r}40.25 \\
40.25 \\
= \\
-\end{array}$ & $\begin{array}{l}.93 \\
.93 \\
- \\
-\end{array}$ & $\begin{array}{r}1,760 \\
30 \\
1,730 \\
-\end{array}$ & $\begin{array}{r}201.0 \\
445.6 \\
-- \\
197.1 \\
--\end{array}$ & $\begin{array}{r}12.77 \\
26.01 \\
\overline{12.54} \\
-\end{array}$ & $\begin{array}{r}1.70 \\
.35 \\
1 . \overline{2} \\
-\end{array}$ & $\begin{array}{r}16,998 \\
- \\
498 \\
15,202 \\
1,297\end{array}$ & $\begin{array}{r}228.0 \\
-- \\
251.2 \\
225.9 \\
244.5\end{array}$ & $\begin{array}{l}2.38 \\
2.61 \\
2.36 \\
2.55\end{array}$ & $\begin{array}{r}76 \\
100 \\
- \\
- \\
-\end{array}$ & $\begin{array}{r}915 \\
-100 \\
-1159 \\
-100\end{array}$ \\
\hline 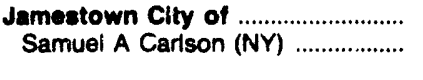 & $\begin{array}{l}114 \\
114\end{array}$ & $\begin{array}{l}132.6 \\
132.6\end{array}$ & $\begin{array}{l}33.56 \\
33.56\end{array}$ & $\begin{array}{l}1.79 \\
1.79\end{array}$ & $\overline{-}$ & $\overline{-}$ & $\overline{-}$ & $\overline{-}$ & $\overline{-}$ & $\overline{-}$ & & $\begin{array}{l}100 \\
100\end{array}$ & $\overline{-}-$ \\
\hline 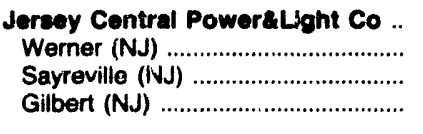 & $\bar{z}$ & $\bar{z}$ & $\bar{z}$ & $\bar{z}$ & $\begin{array}{r}102 \\
19 \\
33 \\
50\end{array}$ & $\begin{array}{l}320.3 \\
311.0 \\
349.2 \\
305.6\end{array}$ & $\begin{array}{l}20.22 \\
19.48 \\
21.63 \\
19.60\end{array}$ & $\begin{array}{l}.60 \\
.30 \\
.26 \\
.93\end{array}$ & $\begin{array}{r}3,777 \\
\overline{1} \\
1,413 \\
2,364\end{array}$ & $\begin{array}{r}253.1 \\
\overline{2} \\
255 . \overline{7} \\
257.6\end{array}$ & $\begin{array}{l}2.61 \\
2 . \overline{53} \\
2.66\end{array}$ & $\begin{array}{l}-1 \\
-10 \\
-1 \\
-1\end{array}$ & $\begin{array}{ll}14 & 86 \\
100 & - \\
12 & 88 \\
12 & 88\end{array}$ \\
\hline 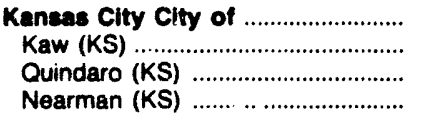 & $\begin{array}{r}1,453 \\
138 \\
355 \\
360\end{array}$ & $\begin{array}{r}127.2 \\
127.4 \\
186.6 \\
97.8\end{array}$ & $\begin{array}{l}23.37 \\
26.41 \\
41.43 \\
16.26\end{array}$ & $\begin{array}{r}.62 \\
.38 \\
1.49 \\
.34\end{array}$ & $\begin{array}{l}10 \\
: \quad 10\end{array}$ & $\begin{array}{l}457.1 \\
481.9 \\
446.8 \\
457.0\end{array}$ & $\begin{array}{l}26.49 \\
27.93 \\
25.90 \\
26.49\end{array}$ & $\begin{array}{l}.00 \\
.00 \\
.00 \\
.00\end{array}$ & $\begin{array}{r}637 \\
213 \\
423 \\
-\end{array}$ & $\begin{array}{r}248.2 \\
240.3 \\
252.3 \\
-\end{array}$ & $\begin{array}{l}2.50 \\
2.42 \\
2.54 \\
-1\end{array}$ & $\begin{array}{r}97 \\
93 \\
95 \\
100\end{array}$ & $\begin{array}{r}2 \\
: \quad 7 \\
: \quad 5 \\
--\end{array}$ \\
\hline 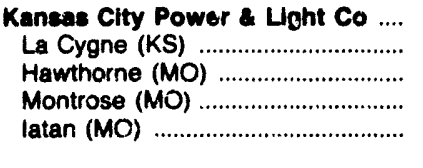 & $\begin{array}{l}8,361 \\
3,306 \\
1,259 \\
1,431 \\
2,365\end{array}$ & $\begin{array}{l}81.5 \\
92.7 \\
94.4 \\
97.0 \\
85.0\end{array}$ & $\begin{array}{l}16.24 \\
16.75 \\
16.72 \\
16.80 \\
14.93\end{array}$ & $\begin{array}{l}.49 \\
.75 \\
.20 \\
.34 \\
.38\end{array}$ & $\begin{array}{r}45 \\
23 \\
9 \\
13\end{array}$ & $\begin{array}{r}445.7 \\
461.8 \\
-\overline{-} \\
434.7 \\
424.7\end{array}$ & $\begin{array}{l}25.80 \\
26.82 \\
25 . \overline{22} \\
24.72\end{array}$ & $\begin{array}{l}.17 \\
.15 \\
.18 \\
.20\end{array}$ & $\begin{array}{r}249 \\
249 \\
--\end{array}$ & $\begin{array}{r}253.1 \\
-. . \\
253.1 \\
-- \\
--\end{array}$ & $\begin{array}{r}2.511 \\
2.51 \\
-1 \\
-1\end{array}$ & $\begin{array}{r}100 \\
100 \\
99 \\
100 \\
100\end{array}$ & 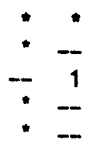 \\
\hline $\begin{array}{l}\text { Kancas Gas E Electric Co } \\
\text { Evans (KS) } \\
\text { Gill (KS) }\end{array}$ & $\bar{z}$ & $\ddot{-}$ & $\bar{z}$ & $\bar{z}$ & $\bar{m}$ & $\bar{z}$ & $\bar{z}$ & $\bar{m}$ & $\begin{array}{l}6,160 \\
2,594 \\
3,566\end{array}$ & $\begin{array}{l}196.5 \\
185.6 \\
204.5\end{array}$ & $\begin{array}{l}1.88 \\
1.76 \\
1.96\end{array}$ & $\bar{z}$ & $\begin{array}{l}-100 \\
-100 \\
-100\end{array}$ \\
\hline 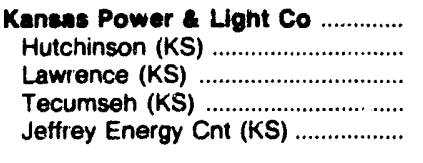 & $\begin{array}{r}7,349 \\
1,122 \\
409 \\
5,818\end{array}$ & $\begin{array}{r}130.0 \\
\overline{122.8} \\
122.5 \\
132.4\end{array}$ & $\begin{array}{l}22.90 \\
\overline{25.97} \\
25.93 \\
22.09\end{array}$ & $\begin{array}{l}.34 \\
.43 \\
.42 \\
.32\end{array}$ & $\frac{17}{\overline{17}}$ & $\begin{array}{r}394.0 \\
\overline{-} \\
394.0\end{array}$ & $\begin{array}{r}23.33 \\
\overline{-} \\
23.33\end{array}$ & $\begin{array}{l}.13 \\
\overline{-} \\
\overline{.13}\end{array}$ & $\begin{array}{r}790 \\
249 \\
336 \\
205 \\
--\end{array}$ & $\begin{array}{r}217.4 \\
236.8 \\
210.4 \\
205.3 \\
--\end{array}$ & $\begin{array}{l}2.15 \\
2.35 \\
2.08 \\
2.04 \\
-1\end{array}$ & $\begin{array}{r}99 \\
99 \\
98 \\
98\end{array}$ & $\begin{array}{l}\because \\
-100 \\
-\quad 1 \\
-\quad 2 \\
-\quad-\end{array}$ \\
\hline 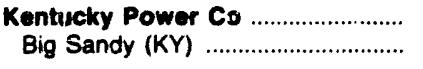 & $\begin{array}{l}2,517 \\
2,517\end{array}$ & $\begin{array}{l}117.3 \\
117.3\end{array}$ & $\begin{array}{l}28.25 \\
28.25\end{array}$ & $\begin{array}{l}1.04 \\
1.04\end{array}$ & $\begin{array}{l}20 \\
20\end{array}$ & $\begin{array}{l}439.0 \\
439.0\end{array}$ & $\begin{array}{l}25.65 \\
25.65\end{array}$ & $\begin{array}{l}.00 \\
.00\end{array}$ & $\overline{-}$ & $\overline{-}$ & & $\begin{array}{l}100 \\
100\end{array}$ & :- \\
\hline
\end{tabular}

See tootnotes at end of table.

Source: Federal Energy Regulatory Commission, FERC Form 423, "Monthly Report of Cost and Quality of Fuels for Electric Plants." 
Table 31. Recelpts, Average Delivered Cost, and Quality of Fossil-Fuels by Electric Utility and Plant, 1992 (Continued)

\begin{tabular}{|c|c|c|c|c|c|c|c|c|c|c|c|c|c|c|}
\hline \multirow[b]{2}{*}{$\begin{array}{l}\text { Electric Utillty } \\
\text { Plant (State) }\end{array}$} & \multicolumn{4}{|c|}{ Coal } & \multicolumn{4}{|c|}{ Petroleum' } & \multicolumn{3}{|c|}{ Gas } & \multicolumn{3}{|c|}{$\begin{array}{c}\text { \% of Total } \\
\text { Btu }\end{array}$} \\
\hline & $\begin{array}{l}\text { Receipts } \\
(1,000 \\
\text { Short } \\
\text { Tons) }\end{array}$ & $\begin{array}{l}\text { (Cents } \\
\text { per } \\
10^{\circ} \\
\text { Btu) }\end{array}$ & $\begin{array}{l}\text { (S por } \\
\text { Short } \\
\text { Ton) }\end{array}$ & $\begin{array}{l}\text { ( } \% \\
\text { Avg. } \\
\text { Sulfur) }\end{array}$ & $\begin{array}{l}\text { Recelpts } \\
\text { (1,000 } \\
\text { bbls) }\end{array}$ & $\begin{array}{l}\text { (Cents } \\
\text { per } \\
10^{6} \\
\text { Btu) }\end{array}$ & $\begin{array}{l}\text { (s } \\
\text { per } \\
\text { bbl) }\end{array}$ & $\begin{array}{c}(\% \\
\text { Avg. } \\
\text { Sulfur) }\end{array}$ & $\begin{array}{l}\text { Receipts } \\
(1,000 \\
\text { Mcf })\end{array}$ & $\begin{array}{c}\text { (Cents } \\
\text { per } \\
10^{6} \\
\text { Btu) }\end{array}$ & $\begin{array}{c}(\$ \\
\text { per } \\
\text { Mcf }\end{array}$ & $\begin{array}{l}\mathbf{C} \\
\mathbf{0} \\
\mathbf{a} \\
\mathbf{1}\end{array}$ & $\mid \begin{array}{c}\text { Pe- } \\
\text { tr- } \\
0- \\
\text { le- } \\
\text { um }\end{array}$ & $\begin{array}{l}\mathbf{G} \\
\mathbf{a} \\
\mathbf{8}\end{array}$ \\
\hline 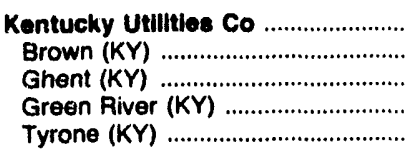 & $\begin{array}{r}5,932 \\
1,002 \\
4,595 \\
304 \\
31\end{array}$ & $\begin{array}{l}116.3 \\
112.6 \\
117.6 \\
109.0 \\
115.1\end{array}$ & $\begin{array}{l}27.94 \\
27.36 \\
28.20 \\
25.91 \\
28.03\end{array}$ & $\begin{array}{r}1.49 \\
1.98 \\
1.34 \\
2.33 \\
.92\end{array}$ & $\begin{array}{r}40 \\
12 \\
25 \\
2 \\
2\end{array}$ & $\begin{array}{l}525.6 \\
523.5 \\
525.0 \\
542.1 \\
533.9\end{array}$ & $\begin{array}{l}30.91 \\
30.78 \\
30.87 \\
31.88 \\
31.39\end{array}$ & $\begin{array}{r}0.40 \\
.40 \\
.40 \\
.40 \\
.40\end{array}$ & $\begin{array}{l}-- \\
-- \\
-- \\
--\end{array}$ & $\begin{array}{l}- \\
-- \\
--\end{array}$ & $\begin{array}{l}- \\
-- \\
-- \\
--\end{array}$ & $\begin{array}{r}100 \\
100 \\
100 \\
100 \\
99\end{array}$ & $:$ & $\begin{array}{l}-- \\
-- \\
-- \\
--\end{array}$ \\
\hline 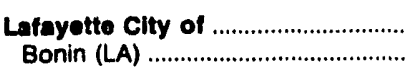 & - & - & - & - & $-\overline{-}$ & - & - & $\overline{-}$ & $\begin{array}{l}3,881 \\
3,881\end{array}$ & $\begin{array}{l}185.9 \\
185.9\end{array}$ & $\begin{array}{l}1.94 \\
1.94\end{array}$ & -- & & $\begin{array}{l}100 \\
100\end{array}$ \\
\hline 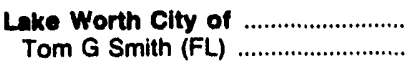 & - & - & - & - & $\begin{array}{l}5 \\
5\end{array}$ & $\begin{array}{l}501.0 \\
501.0\end{array}$ & $\begin{array}{l}29.40 \\
29.40\end{array}$ & $\begin{array}{l}.14 \\
.14\end{array}$ & $\begin{array}{l}1,627 \\
1,827\end{array}$ & $\begin{array}{l}265.9 \\
265.9\end{array}$ & $\begin{array}{l}2.73 \\
2.73\end{array}$ & $\overline{-}$ & $\begin{array}{l}1 \\
1\end{array}$ & $\begin{array}{l}89 \\
99\end{array}$ \\
\hline 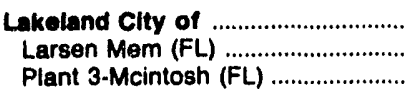 & $\begin{array}{r}818 \\
-\overline{818}\end{array}$ & $\begin{array}{r}165.0 \\
165.0\end{array}$ & 42.90 & $\begin{array}{r}1.04 \\
1.04\end{array}$ & $\begin{array}{r}131 \\
38 \\
93\end{array}$ & $\begin{array}{l}304.2 \\
356.3 \\
283.4\end{array}$ & $\begin{array}{l}18.79 \\
21.69 \\
17.61\end{array}$ & $\begin{array}{l}1.75 \\
1.13 \\
2.00\end{array}$ & $\begin{array}{r}5,965 \\
883 \\
5,082\end{array}$ & $\begin{array}{l}216.7 \\
248.7 \\
211.1\end{array}$ & $\begin{array}{l}2.22 \\
2.56 \\
2.17\end{array}$ & $\overline{75}$ & $\begin{array}{r}3 \\
20 \\
2\end{array}$ & $\begin{array}{l}22 \\
80 \\
19\end{array}$ \\
\hline 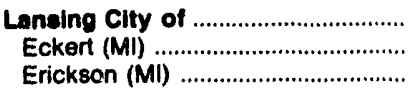 & $\begin{array}{l}889 \\
463 \\
426\end{array}$ & $\begin{array}{l}184.2 \\
190.2 \\
177.6\end{array}$ & $\begin{array}{l}47.60 \\
49.10 \\
45.98\end{array}$ & $\begin{array}{l}.86 \\
.87 \\
.85\end{array}$ & $\begin{array}{l}9 \\
8 \\
1\end{array}$ & $\begin{array}{l}445.5 \\
448.3 \\
428.3\end{array}$ & $\begin{array}{l}25.82 \\
25.98 \\
24.83\end{array}$ & $\begin{array}{l}.26 \\
.26 \\
.29\end{array}$ & - & - & & $\begin{array}{l}100 \\
100 \\
100\end{array}$ & 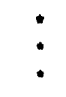 & - \\
\hline 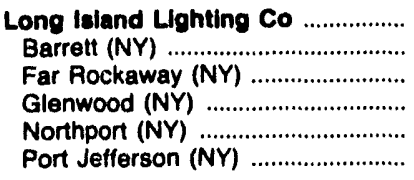 & $\begin{array}{l}-- \\
-- \\
-- \\
--\end{array}$ & $\begin{array}{l}- \\
-- \\
-- \\
-\end{array}$ & $\begin{array}{l}-- \\
-- \\
-- \\
--\end{array}$ & $\begin{array}{l}- \\
-- \\
-- \\
--\end{array}$ & $\begin{array}{r}10,542 \\
149 \\
39 \\
-- \\
8,151 \\
2,203\end{array}$ & $\begin{array}{r}281.0 \\
318.8 \\
311.3 \\
-. \\
279.1 \\
285.1\end{array}$ & $\begin{array}{r}17.93 \\
20.00 \\
19.59 \\
-- \\
17.80 \\
18.23\end{array}$ & $\begin{array}{l}.90 \\
.36 \\
.29 \\
.90 \\
.97\end{array}$ & $\begin{array}{r}32,681 \\
22,262 \\
3,422 \\
6,997 \\
-- \\
--\end{array}$ & $\begin{array}{r}218.3 \\
218.3 \\
213.0 \\
220.9 \\
-- \\
--\end{array}$ & $\begin{array}{r}2.25 \\
2.26 \\
2.19 \\
2.25 \\
-- \\
--\end{array}$ & $\begin{array}{l}- \\
-- \\
-- \\
--\end{array}$ & $\begin{array}{r}67 \\
4 \\
7 \\
-1 \\
100 \\
100\end{array}$ & $\begin{array}{r}33 \\
96 \\
93 \\
100 \\
- \\
-\end{array}$ \\
\hline 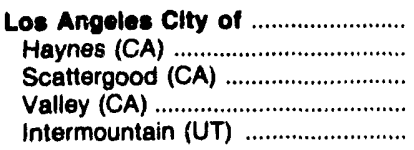 & $\begin{array}{r}4,278 \\
-- \\
-- \\
-- \\
4,278\end{array}$ & $\begin{array}{r}149.3 \\
-- \\
-- \\
149.3\end{array}$ & $\begin{array}{r}35.39 \\
-- \\
-- \\
35.39\end{array}$ & $\begin{array}{r}.45 \\
-- \\
-- \\
-. \\
.45\end{array}$ & $\begin{array}{l}- \\
-- \\
-- \\
--\end{array}$ & $\begin{array}{l}-- \\
-- \\
--\end{array}$ & $\begin{array}{l}-- \\
-- \\
--\end{array}$ & $\begin{array}{l}-- \\
-- \\
-- \\
--\end{array}$ & $\begin{array}{r}53,593 \\
33,572 \\
18,849 \\
1,172 \\
--\end{array}$ & $\begin{array}{r}304.4 \\
303.7 \\
306.8 \\
287.6 \\
--\end{array}$ & $\begin{array}{r}3.16 \\
3.16 \\
3.18 \\
2.97 \\
--\end{array}$ & $\begin{array}{r}65 \\
-- \\
-- \\
100\end{array}$ & $\begin{array}{l}-1 \\
-1 \\
-1 \\
-1 \\
--\end{array}$ & $\begin{array}{r}35 \\
100 \\
100 \\
100 \\
-\end{array}$ \\
\hline 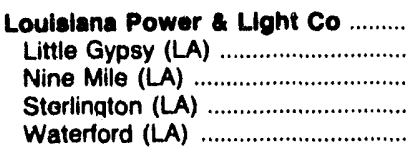 & $\begin{array}{l}- \\
-- \\
-- \\
--\end{array}$ & $\begin{array}{l}- \\
-- \\
- \\
-\end{array}$ & $\begin{array}{l}- \\
-- \\
-- \\
--\end{array}$ & $\begin{array}{l}- \\
-- \\
--\end{array}$ & $\begin{array}{r}25 \\
3 \\
5 \\
2 \\
14\end{array}$ & $\begin{array}{l}328.8 \\
488.7 \\
490.7 \\
501.6 \\
220.0\end{array}$ & $\begin{array}{l}20.41 \\
28.92 \\
30.13 \\
28.83 \\
13.91\end{array}$ & $\begin{array}{r}.64 \\
.25 \\
.02 \\
.25 \\
1.00\end{array}$ & $\begin{array}{r}111,426 \\
29,219 \\
55,530 \\
1,192 \\
25,465\end{array}$ & $\begin{array}{l}174.1 \\
178.6 \\
165.8 \\
194.9 \\
185.9\end{array}$ & $\begin{array}{l}1.82 \\
1.86 \\
1.73 \\
2.03 \\
1.94\end{array}$ & - & $\begin{array}{l}1 \\
1 \\
1 \\
1 \\
1 \\
01\end{array}$ & $\begin{array}{r}100 \\
100 \\
100 \\
99 \\
100\end{array}$ \\
\hline 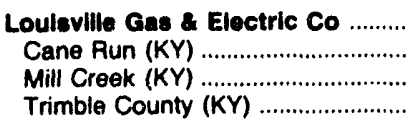 & $\begin{array}{r}5,480 \\
809 \\
3,353 \\
1,317\end{array}$ & $\begin{array}{l}108.7 \\
109.1 \\
111.4 \\
101.6\end{array}$ & $\begin{array}{l}25.00 \\
25.18 \\
25.70 \\
23.10\end{array}$ & $\begin{array}{l}2.92 \\
2.94 \\
2.86 \\
3.06\end{array}$ & $\begin{array}{r}60 \\
1 \\
50 \\
9\end{array}$ & $\begin{array}{l}508.6 \\
480.3 \\
508.7 \\
510.5\end{array}$ & $\begin{array}{l}29.91 \\
28.24 \\
29.91 \\
30.02\end{array}$ & $\begin{array}{l}.18 \\
.18 \\
.20 \\
.14\end{array}$ & $\begin{array}{r}188 \\
100 \\
88 \\
--\end{array}$ & $\begin{array}{r}264.3 \\
259.3 \\
269.9 \\
--\end{array}$ & $\begin{array}{r}2.71 \\
2.66 \\
2.77 \\
--\end{array}$ & $\begin{array}{r}100 \\
99 \\
100 \\
100\end{array}$ & $\ddot{:}$ & $\dot{1}$ \\
\hline 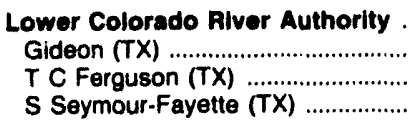 & $\begin{array}{r}5,227 \\
-- \\
5,227\end{array}$ & 135.2 & 23.25 & .41 & $\begin{array}{l}38 \\
26 \\
-- \\
12\end{array}$ & $\begin{array}{r}341.2 \\
304.9 \\
419.7\end{array}$ & $\begin{array}{r}20.21 \\
18.06 \\
24 . \overline{86}\end{array}$ & $\begin{array}{l}.00 \\
.00 \\
.00\end{array}$ & $\begin{array}{r}20,854 \\
9,618 \\
11,236 \\
--\end{array}$ & $\begin{array}{r}185.6 \\
188.3 \\
183.4 \\
--\end{array}$ & $\begin{array}{r}1.91 \\
1.94 \\
1.88 \\
--\end{array}$ & $\begin{array}{r}81 \\
-- \\
100\end{array}$ & 2 & $\begin{array}{r}18 \\
98 \\
100 \\
-\end{array}$ \\
\hline 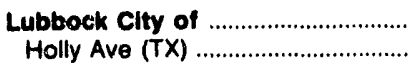 & - & - & - & - & - & - & - & - & $\begin{array}{l}5,480 \\
5,480\end{array}$ & $\begin{array}{l}226.7 \\
226.7\end{array}$ & $\begin{array}{l}2.33 \\
2.33\end{array}$ & - & & $\begin{array}{l}100 \\
100\end{array}$ \\
\hline 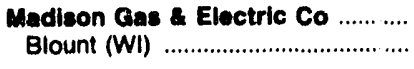 & $\begin{array}{l}18 \\
18\end{array}$ & $\begin{array}{l}165.7 \\
165.7\end{array}$ & $\begin{array}{l}39.26 \\
39.26\end{array}$ & $\begin{array}{l}2.08 \\
2.08\end{array}$ & - & - & - & - & $\begin{array}{l}1,412 \\
1,412\end{array}$ & $\begin{array}{l}207.9 \\
207.9\end{array}$ & $\begin{array}{l}2.09 \\
2.09\end{array}$ & $\begin{array}{l}24 \\
24\end{array}$ & - & $\begin{array}{l}76 \\
76\end{array}$ \\
\hline 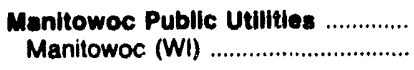 & $\begin{array}{l}138 \\
138\end{array}$ & $\begin{array}{l}174.4 \\
174.4\end{array}$ & $\begin{array}{l}45.69 \\
45.69\end{array}$ & $\begin{array}{l}.85 \\
.85\end{array}$ & - & - & - & - & - & - & & & - & - \\
\hline 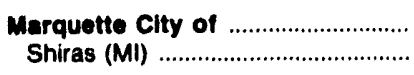 & $\begin{array}{l}134 \\
134\end{array}$ & $\begin{array}{r}78.1 \\
178.1\end{array}$ & $\begin{array}{l}32.98 \\
32.98\end{array}$ & $\begin{array}{l}.42 \\
.42\end{array}$ & -- & $\overline{--}$ & - & - & - & - & - & $\begin{array}{l}100 \\
100\end{array}$ & - & - \\
\hline 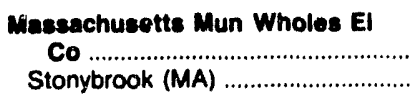 & - & - & - & - & - & $\overline{-}$ & $\overline{-}$ & - & $\begin{array}{l}2,993 \\
2,993\end{array}$ & $\begin{array}{l}232.5 \\
232.5\end{array}$ & $\begin{array}{l}2.38 \\
2.38\end{array}$ & - & $\begin{array}{l}--1 \\
--1\end{array}$ & $\begin{array}{l}100 \\
100\end{array}$ \\
\hline
\end{tabular}

See footnotes at end of table.

Source: Federal Energy Regulatory Commission, FERC Form 423, "Monthly Report of Cost and Quality of Fuels for Electric Plants." 
Table 31. Receipts, Average Delivered Cost, and Quality of Fossll-Fuels by Electric Utility and Plant, 1992 (Continued)

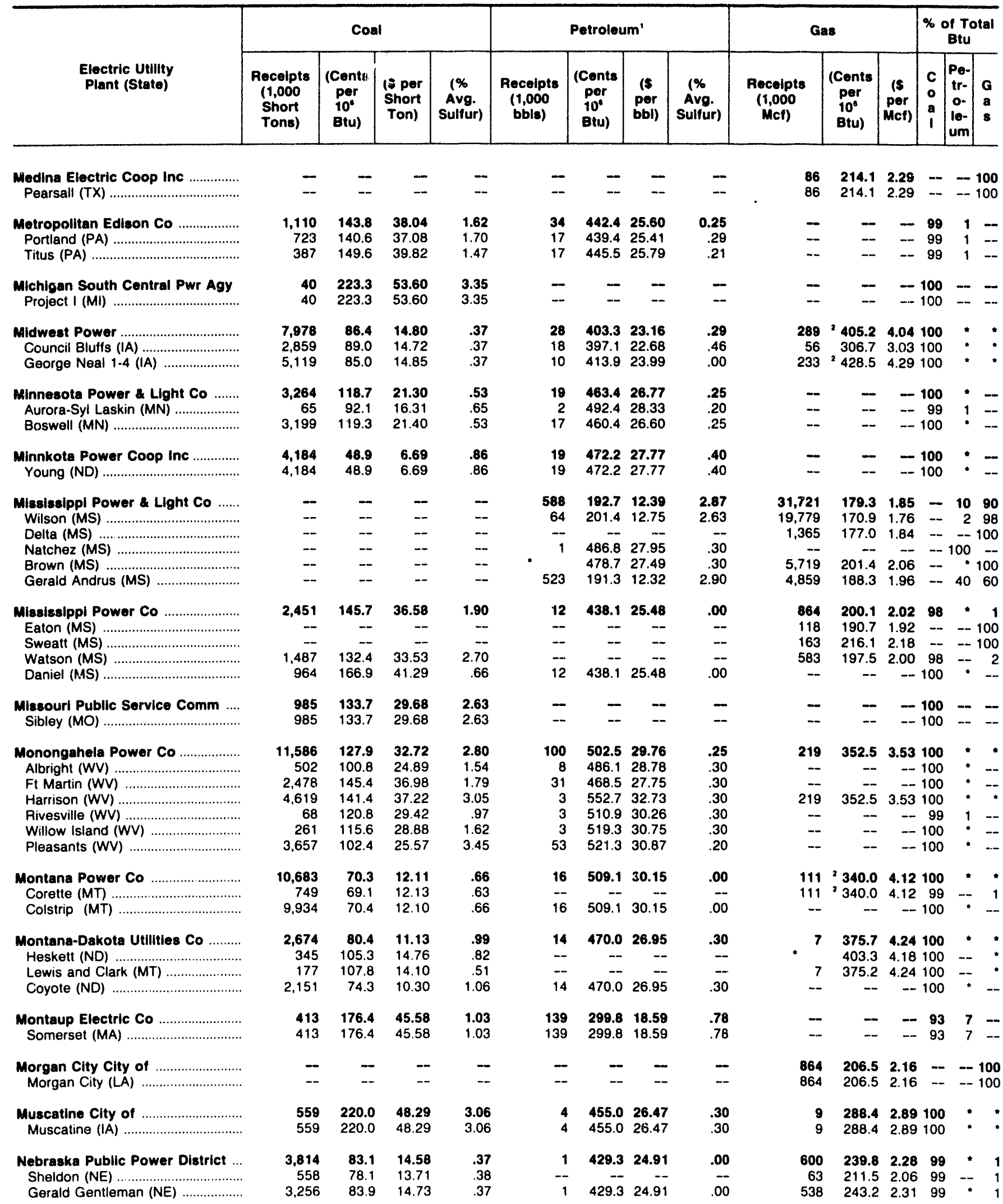

See footnotes at end of table.

Source: Federal Energy Regulatory Commission, FERC Form 423, "Monthly Report of Cost and Quality of Fuels for Electric Plants." 
Table 31. Recelpts, Average Dellvered Cost, and Quality of Fossil-Fuels by Electric Utility and Plant, 1992 (Continued)

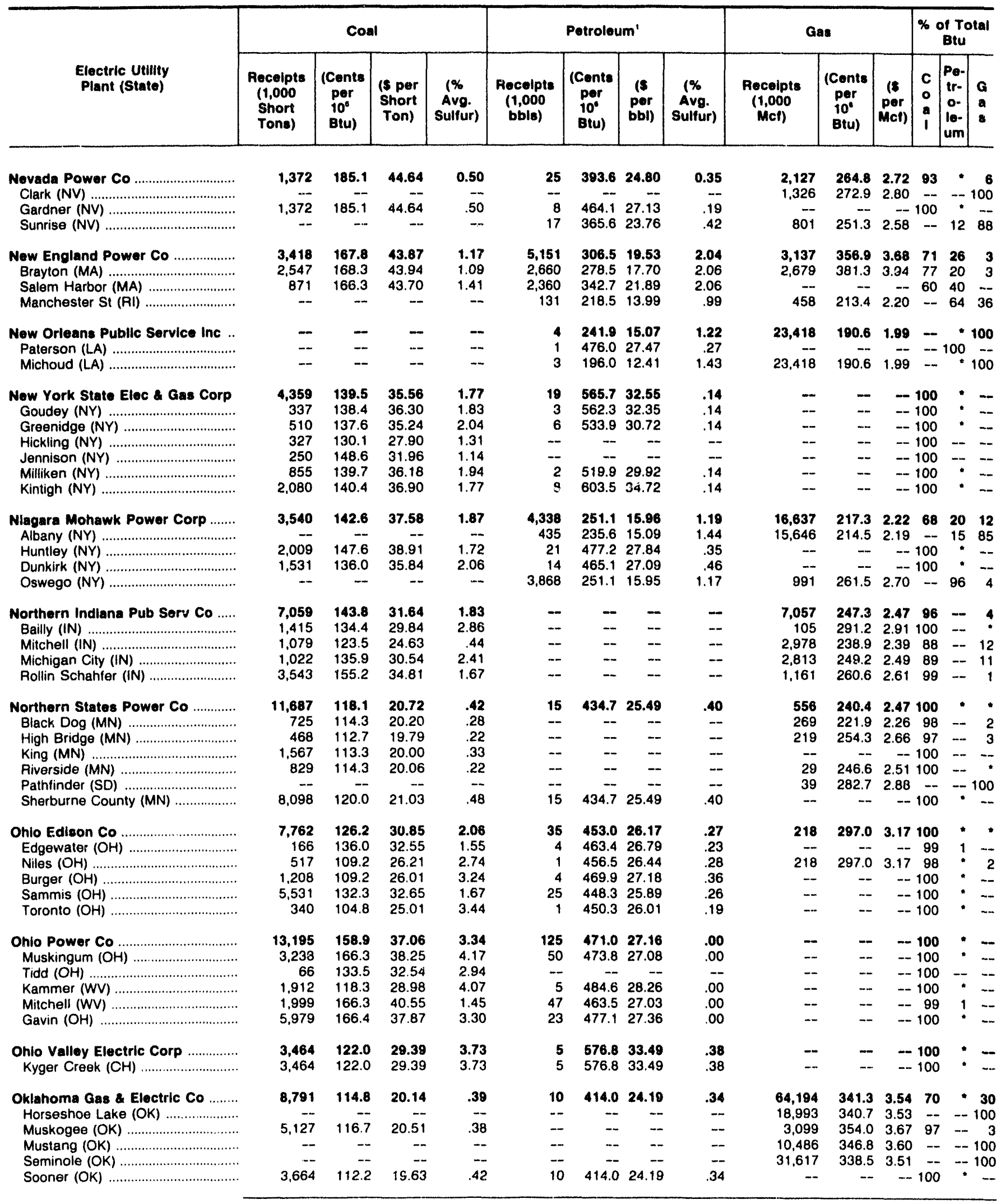

See footnotes at end of table.

Source: Federal Energy Regulatory Commission, FERC Form 423, "Monthly Report of Cost and Quality of Fuels for Electric Plants." 
Table 31. Recelpts, Average Delivered Cost, and Quality of Fossil-Fuels by Electric Utility and Plant, 1992 (Continued)

\begin{tabular}{|c|c|c|c|c|c|c|c|c|c|c|c|c|c|c|}
\hline \multirow[b]{2}{*}{$\begin{array}{l}\text { Electric Utillty } \\
\text { Plant (State) }\end{array}$} & \multicolumn{4}{|c|}{ Coal } & \multicolumn{4}{|c|}{ Petroleum' } & \multicolumn{3}{|c|}{ Gas } & \multicolumn{3}{|c|}{$\begin{array}{c}\% \text { of Total } \\
\text { Btu }\end{array}$} \\
\hline & $\begin{array}{c}\text { Aecelpts } \\
\text { (1,000 } \\
\text { Short } \\
\text { Tons) }\end{array}$ & $\begin{array}{c}\text { (Cents } \\
\text { per } \\
10^{\circ} \\
\text { Btu) }\end{array}$ & $\begin{array}{l}\text { (S per } \\
\text { Short } \\
\text { Ton) }\end{array}$ & $\begin{array}{c}\text { (\%) } \\
\text { Avg. } \\
\text { Sulfur) }\end{array}$ & $\begin{array}{c}\text { Recelpts } \\
\text { (1,000 } \\
\text { bbis) }\end{array}$ & $\begin{array}{c}\text { (Cents } \\
\text { per } \\
10^{6} \\
\text { Btu) }\end{array}$ & $\begin{array}{l}\text { (s } \\
\text { per } \\
\text { bbl) }\end{array}$ & $\begin{array}{c}\text { (\% } \\
\text { Avg. } \\
\text { Sulfur) }\end{array}$ & $\begin{array}{c}\text { Recelpts } \\
(1,000 \\
\text { Mct })\end{array}$ & $\begin{array}{c}\text { (Cents } \\
\text { per } \\
10^{\circ} \\
\text { Btu) }\end{array}$ & $\begin{array}{c}(s \\
\text { per } \\
\text { Mct) }\end{array}$ & $\begin{array}{l}c \\
0 \\
a \\
1\end{array}$ & $\begin{array}{l}\text { Pe- } \\
\text { tr- } \\
0- \\
\text { le- } \\
\text { um }\end{array}$ & $\begin{array}{l}\mathbf{G} \\
\mathbf{a} \\
\mathbf{8}\end{array}$ \\
\hline Omaha Public Power District ........ & 3,328 & 62.7 & 10.37 & 0.37 & 7 & 470.4 & 27.17 & 0.20 & 206 & 285.5 & \multicolumn{2}{|c|}{2.81100} & * & $\bullet$ \\
\hline 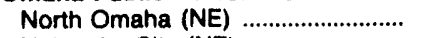 & 1,592 & 63.3 & 10.51 & .37 & - & - & - & -- & 206 & 285.5 & \multirow{2}{*}{\multicolumn{2}{|c|}{$\begin{array}{r}2.81 \\
--100\end{array}$}} & -- & 1 \\
\hline 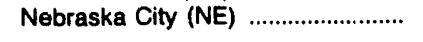 & 1,736 & 62.1 & 10.24 & .37 & 7 & 470.4 & 27.17 & .20 & - & - & & & $\cdot$ & - \\
\hline Orange \& Rockiand Utils Inc ........ & 657 & 205.4 & 53.45 & .55 & 2,219 & 268.7 & 16.86 & .33 & 24,024 & 272.1 & 2.81 & 31 & 25 & 44 \\
\hline 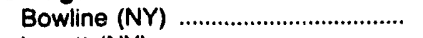 & $\overline{-1}$ & - & $\overline{-1}$ & $\bar{m}$ & 2,219 & 268.7 & 16.86 & .33 & 21,815 & 272.1 & 2.81 & -- & 38 & 62 \\
\hline 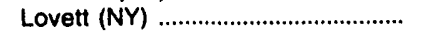 & 657 & 205.4 & 53.45 & .55 & -- & -- & -- & -- & 2,209 & 272.5 & 2.81 & 88 & -- & 12 \\
\hline Orlando Utilitles Comm ..................... & 1,024 & 190.1 & 48.51 & .73 & 984 & 227.8 & 14.47 & 1.08 & 13,151 & 221.0 & 2.27 & 57 & 14 & 29 \\
\hline 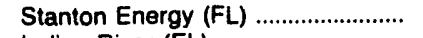 & 1,024 & 190.1 & 48.51 & .73 & 9 & 374.9 & 22.69 & .58 & - & -- & --1 & 100 & $\cdot$ & - \\
\hline 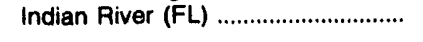 & - & -- & - & -- & 975 & 226.5 & 14.39 & 1.09 & 13,151 & 221.0 & 2.27 & -- & 31 & 69 \\
\hline Orrvilie City of .................................... & 180 & 100.2 & 23.79 & 3.50 & - & - & - & - & - & - & & 100 & - & - \\
\hline Orrville $(\mathrm{OH})$ & 180 & 100.2 & 23.79 & 3.50 & -- & -- & -- & -- & - & - & & 100 & - & - \\
\hline & $\begin{array}{r}2,253 \\
123\end{array}$ & 114.5 & 14.23 & $\begin{array}{r}.88 \\
32\end{array}$ & 3 & 455.3 & 26.77 & .31 & - & - & & 100 & 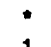 & - \\
\hline $\begin{array}{l}\text { Hoot Lake (MN) } \\
\text { Big Stone (SD) }\end{array}$ & $\begin{array}{r}123 \\
2,130\end{array}$ & $\begin{array}{l}127.6 \\
113.3\end{array}$ & $\begin{array}{l}23.83 \\
13.68\end{array}$ & $\begin{array}{l}.32 \\
.92\end{array}$ & -3 & $\begin{array}{r}455.3 \\
--\end{array}$ & $\begin{array}{r}26.77 \\
--\end{array}$ & $\begin{array}{l}.31 \\
--\end{array}$ & $-\infty$ & - & & $\begin{array}{r}99 \\
100\end{array}$ & 1 & - \\
\hline & & & & & & & & & & & & & & \\
\hline & 1,132 & 107.9 & 24.34 & 2.86 & 4 & 441.7 & 25.60 & .38 & - & -- & -1 & 100 & $\because$ & - \\
\hline 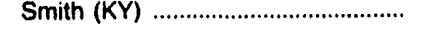 & 1,132 & 107.9 & 24.34 & 2.88 & 4 & 441.7 & 25.60 & .38 & - & - & & 100 & * & - \\
\hline Pacific Gas \& Eloctric Co ................. & - & - & - & - & - & - & - & - & 268,457 & 252.8 & 2.59 & - & -1 & \\
\hline 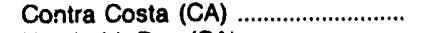 & - & - & - & - & -- & - & -- & - & 33,159 & 258.0 & 2.65 & -- & & 100 \\
\hline 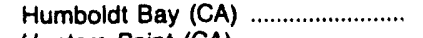 & -- & - & -- & - & - & - & -- & - & 2,002 & 250.4 & 2.57 & -- & --1 & 100 \\
\hline 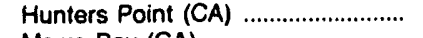 & - & - & - & - & - & - & - & -- & 16,133 & 248.0 & 2.52 & -- & -1 & 100 \\
\hline 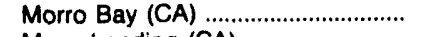 & - & -- & - & - & - & - & -- & -- & 31,760 & 251.7 & 2.58 & $-\infty$ & -1 & 100 \\
\hline 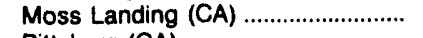 & - & - & - & -- & - & - & - & - & 87,455 & 247.7 & 2.54 & -- & --1 & 100 \\
\hline Pittsburg (CA) & - & - & - & -- & - & - & -- & $r$ & 85,121 & 256.7 & 2.63 & -- & --1 & 100 \\
\hline 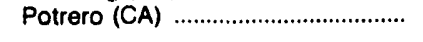 & - & - & - & - & - & -- & - & -- & 10,825 & 257.7 & 2.62 & - & --1 & 100 \\
\hline Pacificorp & 30,124 & 93.8 & 17.69 & .57 & 111 & 471.0 & 27.70 & .30 & 4,967 & 176.8 & 1.90 & 99 & $\bullet$ & 1 \\
\hline 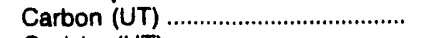 & 593 & 79.1 & 18.95 & .44 & - & - & - & - & - & -- & -1 & 100 & -- & - \\
\hline 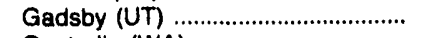 & $-\overline{10}$ & $-\overline{0}$ & - & - & - & $-\overline{7}$ & $-\overline{0}$ & $\overline{0}$ & 4,884 & 174.5 & 1.87 & - & --1 & 100 \\
\hline 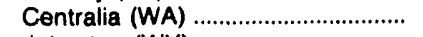 & 5,812 & 137.0 & 22.41 & .66 & 14 & 460.7 & 27.09 & .30 & -- & - & -1 & 100 & $\cdot$ & - \\
\hline 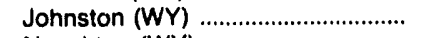 & 4,204 & 58.2 & 9.29 & .43 & 14 & 484.7 & 28.50 & .30 & - & - & -1 & 100 & - & -- \\
\hline 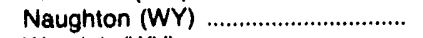 & 2,385 & 121.6 & 23.88 & .70 & 6 & 506.9 & 29.81 & .30 & 83 & 320.1 & 3.331 & 100 & - & • \\
\hline 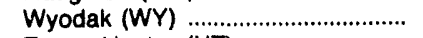 & 1,970 & 63.8 & 10.12 & .66 & 5 & 549.6 & 32.32 & .30 & -- & -- & -1 & 100 & * & -- \\
\hline 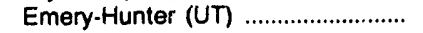 & 3,676 & 94.2 & 20.86 & .50 & 20 & 481.7 & 28.32 & .30 & -- & -- & -1 & 100 & • & - \\
\hline 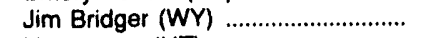 & 8,708 & 88.1 & 17.08 & .61 & 43 & 447.0 & 26.28 & .30 & - & -- & -1 & 100 & * & - \\
\hline 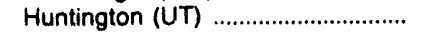 & 2,776 & 78.7 & 17.96 & .45 & 9 & 489.5 & 28.78 & .30 & -- & -- & -1 & 100 & • & -- \\
\hline Painesville City of .............................. & 70 & 135.1 & 33.48 & 2.57 & - & - & - & - & 50 & 302.1 & 3.02 & 97 & - & 3 \\
\hline Painesville $(\mathrm{OH})$ & 70 & 135.1 & 33.48 & 2.57 & -- & -- & -- & - & 50 & 302.1 & 3.02 & 97 & -- & 3 \\
\hline Pasadena Clty of ................................. & - & - & - & - & - & - & - & - & 3,542 & 328.9 & 3.39 & - & & 100 \\
\hline 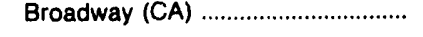 & - & $\cdots$ & - & -- & - & -- & - & - & 3,542 & 328.9 & 3.39 & -- & & 100 \\
\hline Pennsylvania Electric Co ................. & 16,890 & 131.0 & 32.02 & 1.87 & 174 & $\begin{array}{l}440.1 \\
4487\end{array}$ & $\begin{array}{l}25.66 \\
26.16\end{array}$ & .05 & 86 & 302.2 & 3.11 & 100 & & \\
\hline 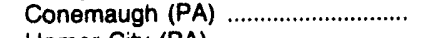 & 4,815 & 118.9 & $\begin{array}{l}29.74 \\
35.26\end{array}$ & $\begin{array}{l}2.20 \\
1.73\end{array}$ & $\begin{array}{l}34 \\
49\end{array}$ & $\begin{array}{l}448.7 \\
438.8\end{array}$ & $\begin{array}{l}26.16 \\
25.58\end{array}$ & .05 & 86 & 302.2 & 3.111 & 100 & • & \\
\hline 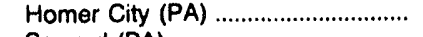 & 5,070 & 149.4 & $\begin{array}{l}35.26 \\
27.75\end{array}$ & 1.73 & 49 & 438.8 & 25.58 & .05 & -- & -- & --1 & 100 & * & - \\
\hline Seward (PA) & 572 & 113.2 & 27.75 & 1.54 & 13 & 443.9 & 25.88 & .05 & -- & - & -- & 99 & 1 & - \\
\hline 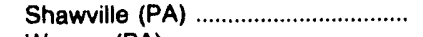 & 1,417 & 108.5 & 26.63 & 1.97 & 38 & 440.0 & 25.65 & .05 & -- & -- & -- & 99 & 1 & - \\
\hline 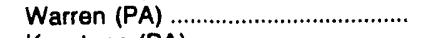 & 217 & 116.7 & 28.53 & 1.77 & 3 & 394.1 & 22.97 & .05 & - & -- & --1 & 100 & : & -- \\
\hline 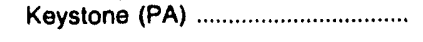 & 4,799 & 134.0 & 33.15 & 1.68 & 37 & 436.4 & 25.44 & .05 & -- & - & -1 & 100 & • & - \\
\hline Pennaylvania Power Light Co .. & 8,478 & 175.5 & 43.48 & 1.81 & 2,365 & 244.6 & 15.54 & .78 & - & - & - & 93 & 7 & -- \\
\hline Brunner Island (PA) ............................. & 3,471 & 1869 & 47.53 & 1.83 & 42 & 427.1 & 24.92 & .11 & - & - & & 100 & $\cdot$ & - \\
\hline Holtwood (PA) & 193 & $116 . \dot{2}$ & 20.39 & .60 & -- & -- & -- & - & - & - & --1 & 100 & -- & - \\
\hline Martins Creek (PA) ............................ & 603 & 186.5 & 48.32 & 1.91 & $\overline{-}$ & - & $-\overline{0}$ & - & - & -- & --1 & 100 & - & - \\
\hline 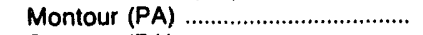 & 3,255 & 176.4 & 44.32 & 1.92 & 66 & 429.5 & 25.09 & .11 & -- & -- & --1 & 100 & : & - \\
\hline 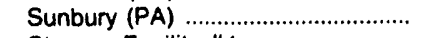 & 956 & 125.7 & 27.53 & 1.57 & 4 & 441.2 & 25.74 & .11 & -- & - & --1 & 100 & • & - \\
\hline Storage Facility $\$ 1$............................. & - & - & -- & - & 2,253 & 236.2 & 15.06 & .81 & - & -- & -- & --1 & 100 & -- \\
\hline Pennsylvania Power Co ................... & 5,642 & 163.2 & 39.67 & 3.55 & 99 & 430.6 & 24.80 & .27 & - & -- & -- & 100 & • & - \\
\hline
\end{tabular}

See fontnotes at end of table.

Source: Federal Energy Regulatory Commission. FERC Form 423, "Monthly Report of Cost and Quality of Fuels for Electric Plants." 
Table 31. Receipts, Average Delivered Cost, and Quality of Fossil-Fuels by Electric Utility and Plant, 1992 (Continued)

\begin{tabular}{|c|c|c|c|c|c|c|c|c|c|c|c|c|c|c|}
\hline \multirow[b]{2}{*}{$\begin{array}{l}\text { Electric Utility } \\
\text { Plant (State) }\end{array}$} & \multicolumn{4}{|c|}{ Coal } & \multicolumn{4}{|c|}{ Petroleum' } & \multicolumn{3}{|c|}{ Gas } & \multicolumn{3}{|c|}{$\begin{array}{l}\% \text { of Total } \\
\text { Btu }\end{array}$} \\
\hline & $\begin{array}{l}\text { Recelpts } \\
\text { (1,000 } \\
\text { Short } \\
\text { Tons) }\end{array}$ & $\begin{array}{c}\text { (Cents } \\
\text { per } \\
10^{6} \\
\text { Btu) }\end{array}$ & $\begin{array}{l}\text { (S per } \\
\text { Short } \\
\text { Ton) }\end{array}$ & $\begin{array}{l}(\% \\
\text { Avg. } \\
\text { Sulfur) }\end{array}$ & $\begin{array}{l}\text { Recelpts } \\
\text { (1,000 } \\
\text { bbls) }\end{array}$ & $\begin{array}{c}\text { (Cents } \\
\text { per } \\
10^{6} \\
\text { Btu) }\end{array}$ & $\begin{array}{l}(\$ \\
\text { per } \\
\text { bbl) }\end{array}$ & $\begin{array}{c}\text { (\% } \\
\text { Avg. } \\
\text { Sulfur) }\end{array}$ & $\begin{array}{l}\text { Recelpts } \\
(1,000 \\
\text { Mcf) }\end{array}$ & $\begin{array}{c}\text { (Cents } \\
\text { per } \\
10^{6} \\
\text { Btu) }\end{array}$ & $\begin{array}{c}(\$ \\
\text { per } \\
\text { Mcf) }\end{array}$ & $\begin{array}{l}\mathbf{C} \\
0 \\
\mathbf{a} \\
1\end{array}$ & $\begin{array}{l}\text { Pe- } \\
\text { tr- } \\
0- \\
\text { le- } \\
\text { um }\end{array}$ & $\begin{array}{l}\mathbf{G} \\
\mathbf{a} \\
\mathbf{8}\end{array}$ \\
\hline 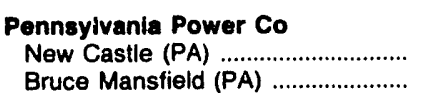 & $\begin{array}{r}762 \\
4,880\end{array}$ & $\begin{array}{l}127.3 \\
168.8\end{array}$ & $\begin{array}{l}31.17 \\
40.99\end{array}$ & $\begin{array}{l}1.46 \\
3.88\end{array}$ & $\begin{array}{r}2 \\
97\end{array}$ & $\begin{array}{l}468.7 \\
429.9\end{array}$ & $\begin{array}{l}27.07 \\
24.75\end{array}$ & $\begin{array}{r}0.25 \\
.27\end{array}$ & -- & -- & & $\begin{array}{l}100 \\
100\end{array}$ & : & - \\
\hline $\begin{array}{l}\text { Philadelphia Electric Co } \\
\text { Cromby (PA) } \\
\text { Delaware (PA) } \\
\text { Eddystone (PA) } \\
\text { Schuylkill (PA) }\end{array}$ & $\begin{array}{r}1,090 \\
288 \\
-\overline{802} \\
--\end{array}$ & $\begin{array}{r}155.9 \\
154.2 \\
-\overline{-} \\
156.5 \\
--\end{array}$ & $\begin{array}{r}41.11 \\
41.03 \\
-\overline{4} \\
41.14 \\
--\end{array}$ & $\begin{array}{r}1.88 \\
1.72 \\
1.94 \\
--\end{array}$ & $\begin{array}{r}919 \\
39 \\
249 \\
500 \\
131\end{array}$ & $\begin{array}{l}299.5 \\
365.3 \\
320.7 \\
289.0 \\
281.1\end{array}$ & $\begin{array}{l}19.02 \\
22.07 \\
20.33 \\
18.46 \\
17.75\end{array}$ & $\begin{array}{l}.33 \\
.29 \\
.35 \\
.32 \\
.32\end{array}$ & $\begin{array}{r}1,641 \\
1,641 \\
-- \\
--\end{array}$ & $\begin{array}{r}296.7 \\
296.7 \\
-- \\
--\end{array}$ & $\begin{array}{r}3.06 \\
3.06 \\
-- \\
-- \\
--\end{array}$ & $\begin{array}{l}79 \\
80 \\
--1 \\
87 \\
--1\end{array}$ & $\begin{array}{r}16 \\
2 \\
100 \\
13 \\
100\end{array}$ & $\begin{array}{r}5 \\
18 \\
-- \\
-- \\
--\end{array}$ \\
\hline $\begin{array}{l}\text { Plains Elec Gen\&Trans Coop Inc } \\
\text { Escalante (NM) }\end{array}$ & $\begin{array}{l}889 \\
889\end{array}$ & $\begin{array}{l}137.5 \\
137.5\end{array}$ & $\begin{array}{l}24.96 \\
24.96\end{array}$ & $\begin{array}{l}.65 \\
.65\end{array}$ & - & - & -- & - & $\begin{array}{l}34 \\
34\end{array}$ & $\begin{array}{l}334.5 \\
334.5\end{array}$ & $\begin{array}{l}2.871 \\
2.871\end{array}$ & $\begin{array}{l}100 \\
100\end{array}$ & - & : \\
\hline $\begin{array}{l}\text { Platte River Power Authority ........ } \\
\text { Rawhide (CO) }\end{array}$ & $\begin{array}{l}1,009 \\
1,009\end{array}$ & $\begin{array}{l}74.6 \\
74.6\end{array}$ & $\begin{array}{l}13.17 \\
13.17\end{array}$ & $\begin{array}{l}.32 \\
.32\end{array}$ & - & - & - & - & - & - & & $\begin{array}{l}100 \\
100\end{array}$ & - & - \\
\hline $\begin{array}{l}\text { Portland General Electric Co ......... } \\
\text { Boardman (OR) } \\
\text { Beaver (OR) }\end{array}$ & $\begin{array}{r}1,932 \\
1,932 \\
--\end{array}$ & $\begin{array}{r}110.1 \\
110.1 \\
--\end{array}$ & $\begin{array}{r}21.23 \\
21.23 \\
--\end{array}$ & $\begin{array}{l}.40 \\
.40 \\
--\end{array}$ & $\begin{array}{l}19 \\
19 \\
-\end{array}$ & $\begin{array}{r}449.2 \\
449.2 \\
--\end{array}$ & $\begin{array}{r}26.44 \\
26.44 \\
--\end{array}$ & $\begin{array}{r}.32 \\
.32 \\
--\end{array}$ & $\begin{array}{r}14,684 \\
14,684\end{array}$ & $\begin{array}{r}193.7 \\
-\overline{-} \\
193.7\end{array}$ & $\frac{1.96}{1.96}$ & $\begin{array}{r}71 \\
100 \\
--\end{array}$ & * & $\begin{array}{r}28 \\
100\end{array}$ \\
\hline $\begin{array}{l}\text { Potomac Edison Co } \\
\text { Smith (MD) }\end{array}$ & $\begin{array}{l}154 \\
154\end{array}$ & $\begin{array}{l}134.0 \\
134.0\end{array}$ & $\begin{array}{l}33.61 \\
33.61\end{array}$ & $\begin{array}{l}.92 \\
.92\end{array}$ & $\begin{array}{l}4 \\
4\end{array}$ & $\begin{array}{l}441.5 \\
441.5\end{array}$ & $\begin{array}{l}26.14 \\
26.14\end{array}$ & $\begin{array}{l}.30 \\
.30\end{array}$ & - & - & $\overline{-}$ & $\begin{array}{l}99 \\
99\end{array}$ & $\begin{array}{l}1 \\
1\end{array}$ & - \\
\hline 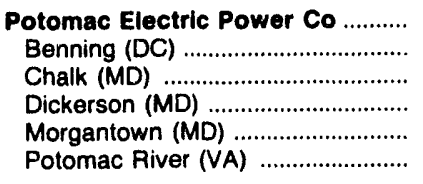 & $\begin{array}{r}5,775 \\
-- \\
1,615 \\
1,212 \\
2,165 \\
784\end{array}$ & $\begin{array}{r}166.4 \\
-\overline{-} \\
172.8 \\
143.2 \\
171.4 \\
175.2\end{array}$ & $\begin{array}{r}42.16 \\
-- \\
43.33 \\
36.52 \\
43.34 \\
45.25\end{array}$ & $\begin{array}{r}1.59 \\
-\overline{1.83} \\
1.43 \\
1.77 \\
.81\end{array}$ & $\begin{array}{r}3,783 \\
231 \\
3,014 \\
28 \\
463 \\
47\end{array}$ & $\begin{array}{l}241.7 \\
350.4 \\
238.5 \\
445.5 \\
181.2 \\
434.0\end{array}$ & $\begin{array}{l}15.22 \\
21.03 \\
15.10 \\
25.86 \\
11.42 \\
25.10\end{array}$ & $\begin{array}{r}1.35 \\
.82 \\
1.34 \\
.20 \\
1.85 \\
.20\end{array}$ & $\begin{array}{r}5,243 \\
- \\
5,052 \\
191 \\
-- \\
--\end{array}$ & $\begin{array}{r}234.5 \\
-- \\
236.4 \\
183.1 \\
-- \\
--\end{array}$ & $\begin{array}{r}2.46 \\
- \\
2.48 \\
1.89 \\
-- \\
-\end{array}$ & $\begin{array}{l}83 \\
--1 \\
62 \\
99 \\
95 \\
99\end{array}$ & $\begin{array}{r}14 \\
100 \\
29 \\
1 \\
5 \\
1\end{array}$ & $\begin{array}{r}3 \\
-8 \\
1 \\
--\end{array}$ \\
\hline 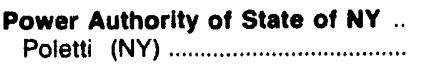 & - & - & -- & - & $\begin{array}{l}905 \\
905\end{array}$ & $\begin{array}{l}269.8 \\
269.8\end{array}$ & $\begin{array}{l}16.84 \\
16.84\end{array}$ & $\begin{array}{l}.28 \\
.28\end{array}$ & $\begin{array}{c}19,213 \\
19,213\end{array}$ & $\begin{array}{l}317.1 \\
317.1\end{array}$ & $\begin{array}{l}3.27 \\
3.27\end{array}$ & $\overline{-}$ & $\begin{array}{l}22 \\
22\end{array}$ & $\begin{array}{l}78 \\
78\end{array}$ \\
\hline 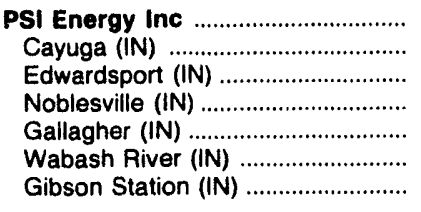 & $\begin{array}{r}13,834 \\
2,863 \\
71 \\
29 \\
1,144 \\
1,430 \\
8,297\end{array}$ & $\begin{array}{r}144.2 \\
12.9 .9 \\
96.4 \\
145.1 \\
137.2 \\
117.2 \\
157.2\end{array}$ & $\begin{array}{l}31.95 \\
27.12 \\
21.59 \\
32.06 \\
30.84 \\
25.87 \\
34.91\end{array}$ & $\begin{array}{l}2.02 \\
2.01 \\
2.45 \\
2.37 \\
2.04 \\
2.00 \\
2.01\end{array}$ & $\begin{array}{r}141 \\
14 \\
2 \\
4 \\
32 \\
34 \\
55\end{array}$ & $\begin{array}{l}445.4 \\
453.2 \\
484.8 \\
422.7 \\
452.8 \\
443.9 \\
440.3\end{array}$ & $\begin{array}{l}25.63 \\
26.07 \\
27.90 \\
24.32 \\
26.05 \\
25.54 \\
25.34\end{array}$ & $\begin{array}{l}.30 \\
.30 \\
.30 \\
.30 \\
.30 \\
.30 \\
.30\end{array}$ & $\begin{array}{l}- \\
-- \\
-- \\
- \\
- \\
-\end{array}$ & $\begin{array}{l}- \\
-- \\
-- \\
- \\
- \\
--\end{array}$ & $\begin{array}{l}-1 \\
--1 \\
- \\
-- \\
-- \\
-- \\
--1\end{array}$ & $\begin{array}{r}100 \\
100 \\
99 \\
97 \\
99 \\
99 \\
100\end{array}$ & $\begin{array}{l}* \\
1 \\
3 \\
1 \\
1 \\
\text { ? }\end{array}$ & $\begin{array}{l}- \\
-- \\
-- \\
-- \\
-\end{array}$ \\
\hline $\begin{array}{l}\text { Public Service Co of Colorado } \\
\text { Araphoe (CO) } \\
\text { Cameo (CO) } \\
\text { Cherokee (CO) } \\
\text { Comanche (CO) } \\
\text { Valmont (CO) } \\
\text { Zuni (CO) } \\
\text { Hayden (CO) } \\
\text { Pawnee (CO) }\end{array}$ & $\begin{array}{r}8,640 \\
462 \\
246 \\
1,935 \\
2,064 \\
570 \\
-- \\
1,501 \\
1,863\end{array}$ & $\begin{array}{r}105.2 \\
113.8 \\
90.2 \\
108.2 \\
112.7 \\
107.9 \\
\overline{91.9} \\
104.8\end{array}$ & $\begin{array}{r}20.64 \\
25.55 \\
20.41 \\
24.02 \\
19.21 \\
24.22 \\
-\overline{-} \\
19.55 \\
17.32\end{array}$ & $\begin{array}{l}.39 \\
.47 \\
.59 \\
.42 \\
.30 \\
.50 \\
-.- \\
.40 \\
.36\end{array}$ & $\begin{array}{l}14 \\
-- \\
-- \\
-- \\
11 \\
-- \\
- \\
-\end{array}$ & $\begin{array}{r}438.2 \\
-- \\
- \\
436.0 \\
-- \\
-\overline{-} \\
449.4\end{array}$ & $\begin{array}{r}25.14 \\
\overline{--} \\
25 . \overline{-} \\
\overline{--} \\
25 . \overline{-} \\
-\end{array}$ & $\begin{array}{c}.23 \\
-- \\
-- \\
-- \\
.26 \\
-- \\
-- \\
.10 \\
-.\end{array}$ & $\begin{array}{r}1,370 \\
71 \\
80 \\
765 \\
26 \\
78 \\
232 \\
23 \\
93\end{array}$ & $\begin{array}{r}212.9 \\
211.0 \\
326.8 \\
195.2 \\
209.1 \\
248.5 \\
197.2 \\
218.4 \\
259.8\end{array}$ & $\begin{array}{l}2.12 \\
2.07 \\
3.39 \\
1.92 \\
2.071 \\
2.46 \\
1.94 \\
2.401 \\
2.821\end{array}$ & $\begin{array}{r}99 \\
99 \\
99 \\
98 \\
100 \\
99 \\
-- \\
100 \\
100\end{array}$ & $\begin{array}{c}" \\
-- \\
-- \\
-- \\
-- \\
--\end{array}$ & $\begin{array}{r}1 \\
1 \\
1 \\
2 \\
\vdots \\
1 \\
100 \\
\vdots\end{array}$ \\
\hline 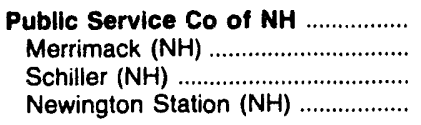 & $\begin{array}{r}1,226 \\
1,003 \\
223 \\
--\end{array}$ & $\begin{array}{r}168.5 \\
168.1 \\
170.3 \\
--\end{array}$ & $\begin{array}{r}44.69 \\
44.77 \\
44.31 \\
--\end{array}$ & $\begin{array}{r}1.61 \\
1.80 \\
.73 \\
--\end{array}$ & $\begin{array}{r}2,605 \\
2 \\
-\overline{-} \\
2,602\end{array}$ & $\begin{array}{r}185.8 \\
451.5 \\
-\overline{-} \\
185.6\end{array}$ & $\begin{array}{r}12.23 \\
26.45 \\
-\overline{12.22}\end{array}$ & $\begin{array}{r}1.72 \\
.26 \\
1 . \overrightarrow{72}\end{array}$ & $\begin{array}{r}916 \\
-- \\
-\overline{916}\end{array}$ & $\begin{array}{r}205.9 \\
-- \\
205.9\end{array}$ & $\begin{array}{r}2.10 \\
-1 \\
-\overline{1} \\
2.1\end{array}$ & $\begin{array}{r}64 \\
100 \\
100 \\
--\end{array}$ & $\frac{34}{95}$ & $\begin{array}{r}2 \\
-- \\
5\end{array}$ \\
\hline 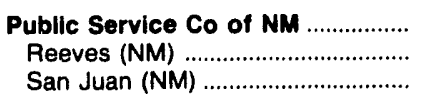 & $\begin{array}{r}5,105 \\
5,105\end{array}$ & $\begin{array}{r}173.4 \\
-- \\
173.4\end{array}$ & $\begin{array}{r}32.46 \\
-- \\
32.46\end{array}$ & $\begin{array}{r}.87 \\
-87\end{array}$ & $\begin{array}{l}74 \\
-24\end{array}$ & $\begin{array}{r}515.5 \\
-- \\
515.5\end{array}$ & $\begin{array}{r}29.38 \\
-\overline{29.38}\end{array}$ & $\begin{array}{r}.90 \\
-- \\
.90\end{array}$ & $\begin{array}{r}305 \\
305 \\
--\end{array}$ & $\begin{array}{r}199.1 \\
199.1 \\
--\end{array}$ & $\begin{array}{c}2.05 \\
2.05 \\
-\end{array}$ & $\begin{array}{r}99 \\
\overline{100}\end{array}$ & $\ddot{-}$ & $\begin{array}{r}100 \\
-\end{array}$ \\
\hline 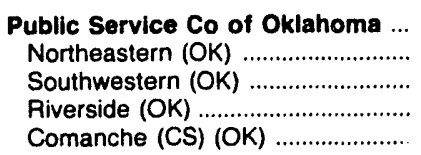 & $\begin{array}{r}3,030 \\
3,030 \\
-- \\
--\end{array}$ & $\begin{array}{r}161.1 \\
161.1 \\
-- \\
-- \\
--\end{array}$ & $\begin{array}{r}28.24 \\
28.24 \\
-- \\
-- \\
--\end{array}$ & $\begin{array}{r}.45 \\
.45 \\
-- \\
-- \\
--\end{array}$ & $\frac{100}{\overline{100}}$ & $\begin{array}{r}439.7 \\
-\overline{-} \\
439 . \overline{7} \\
--\end{array}$ & $\begin{array}{r}25.56 \\
-- \\
25.56 \\
--\end{array}$ & $\begin{array}{l}.31 \\
-- \\
-- \\
.31 \\
--\end{array}$ & $\begin{array}{r}67,103 \\
23,644 \\
7,979 \\
23,546 \\
11,934\end{array}$ & $\begin{array}{l}303.1 \\
301.4 \\
294.7 \\
309.6 \\
299.6\end{array}$ & $\begin{array}{l}3.15 \\
3.09 \\
3.14 \\
3.17 \\
3.26\end{array}$ & $\begin{array}{c}43 \\
69 \\
-- \\
-- \\
--\end{array}$ & $\begin{array}{r}\cdot \\
-- \\
-- \\
--\end{array}$ & $\begin{array}{r}57 \\
31 \\
100 \\
98 \\
100\end{array}$ \\
\hline
\end{tabular}

See footnotes at end of table.

Source: Federal Energy Regulatory Commission, FERC Form 423, "Monthly Report of Cost and Quality of Fuels for Electric Plants." 
Table 31. Receipts, Average Dellvered Cost, and Quality of Fossil-Fuels by Electric Utility and Plant, 1992 (Continued)

\begin{tabular}{|c|c|c|c|c|c|c|c|c|c|c|c|c|c|c|}
\hline \multirow[b]{2}{*}{$\begin{array}{l}\text { Electric Utillty } \\
\text { Plant (State) }\end{array}$} & \multicolumn{4}{|c|}{ Coal } & \multicolumn{4}{|c|}{ Petroleum' } & \multicolumn{3}{|c|}{ Gas } & \multicolumn{3}{|c|}{$\begin{array}{c}\% \text { of Total } \\
\text { Btu }\end{array}$} \\
\hline & $\begin{array}{c}\text { Recelpts } \\
\text { (1,000 } \\
\text { Short } \\
\text { Tons) }\end{array}$ & $\begin{array}{c}\text { (Cents } \\
\text { per } \\
10^{\circ} \\
\text { Btu) }\end{array}$ & $\begin{array}{l}\text { (S per } \\
\text { Short } \\
\text { Ton) }\end{array}$ & $\begin{array}{c}\text { (\% } \\
\text { Avg. } \\
\text { Sultur) }\end{array}$ & $\begin{array}{c}\text { Recelpts } \\
(1,000 \\
\text { bbls) }\end{array}$ & \begin{tabular}{|c} 
(Cents \\
per \\
$10^{\circ}$ \\
Btu)
\end{tabular} & $\begin{array}{l}\text { (\$ } \\
\text { per } \\
\text { bbl) }\end{array}$ & $\begin{array}{c}(\% \\
\text { Avg. } \\
\text { Sulfur) }\end{array}$ & $\begin{array}{c}\text { Recelpts } \\
(1,000 \\
\text { Mcf })\end{array}$ & $\begin{array}{c}\text { (Cents } \\
\text { per } \\
10^{8} \\
\text { Btu) }\end{array}$ & $\begin{array}{c}\text { (S } \\
\text { per } \\
\text { Mcf) }\end{array}$ & $\begin{array}{l}\text { C } \\
0 \\
\text { a } \\
\text { l }\end{array}$ & $\mid$\begin{tabular}{c|} 
Pe- \\
tr- \\
$0-$ \\
le- \\
Ie- \\
um
\end{tabular} & $\begin{array}{l}G \\
8 \\
8\end{array}$ \\
\hline Public Service Electric\&Gas Co ... & 1,410 & 176.0 & 48.38 & 0.82 & 1,178 & 320.2 & 20.00 & 0.30 & 27,123 & 205.8 & 2.13 & 52 & 103 & 38 \\
\hline 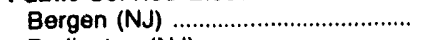 & - & -- & -- & -- & - & -- & -- & -- & 7,031 & 204.5 & 2.12 & -- & --10 & \\
\hline Burlington (NJ) & -- & - & -- & - & 42 & 307.3 & 19.41 & .49 & - & -- & - & - & $100-$ & -- \\
\hline 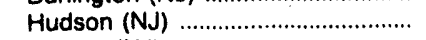 & 569 & 176.5 & 46.28 & .82 & 49 & 342.0 & 21.38 & .29 & 11,633 & 209.7 & 2.17 & 55 & 14 & 44 \\
\hline 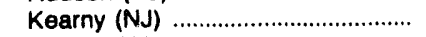 & - & -- & - & -- & 83 & 312.4 & 19.49 & .29 & - & - & - & & 100 & - \\
\hline 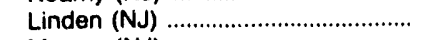 & - & - & - & -- & 1,005 & 320.4 & 20.00 & .29 & -- & - & -- & -- & 100 & - \\
\hline 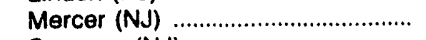 & 841 & 175.7 & 49.80 & .82 & - & - & - & - & 4,440 & 210.4 & 2.18 & 84 & -1 & 16 \\
\hline 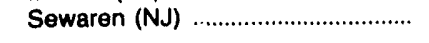 & - & -- & -- & -- & - & - & - & - & 4,018 & 191.5 & 1.98 & - & & 00 \\
\hline 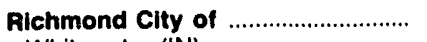 & 293 & 148.7 & 33.98 & 2.02 & - & - & -- & - & - & - & - & 100 & $-m$ & - \\
\hline 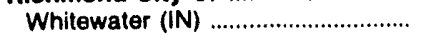 & 293 & 148.7 & 33.99 & 2.02 & -- & - & - & -- & -- & - & -- & 100 & -- & - \\
\hline Rochestor Gas \& Electric Corp ... & 841 & 145.6 & 38.73 & 2.10 & - & - & - & - & - & - & - & 100 & - & - \\
\hline 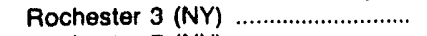 & 202 & 148.7 & 39.49 & 2.04 & -- & -- & - & - & -- & - & -- & 100 & - & - \\
\hline 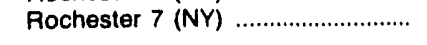 & 639 & 144.7 & 38.49 & 2.13 & - & - & - & -- & -- & -- & -- & 100 & - & - \\
\hline Rochester Public Utilities ................ & 60 & 156.3 & 37.16 & 1.82 & - & - & - & - & 567 & 181.4 & 1.84 & 77 & - & 23 \\
\hline 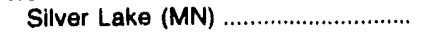 & 80 & 156.3 & 37.16 & 1.82 & - & - & - & $\cdots$ & 567 & 181.4 & 1.84 & 77 & -- & 23 \\
\hline 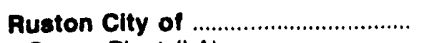 & - & - & - & - & - & - & - & -- & 1,796 & 191.7 & 2.03 & - & -10 & \\
\hline 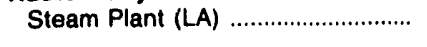 & -- & - & - & - & - & -- & - & -- & 1,796 & 191.7 & 2.03 & - & --10 & 00 \\
\hline Salt River Proj Ag I \& P Dist ......... & 9,687 & 125.2 & 27.01 & .50 & 64 & 486.1 & 28.06 & .53 & 4,166 & 290.7 & 3.00 & 98 & $\bullet$ & 2 \\
\hline 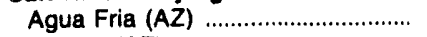 & -- & -- & - & -- & - & -- & - & -- & 2,229 & 282.5 & 2.91 & - & & 00 \\
\hline Kyrene (AZ) & -- & - & - & $\bar{c}$ & $\overline{c-}$ & -- & $\overline{--}$ & $\overline{-1}$ & 160 & ${ }^{2} 533.9$ & 5.48 & $-\bar{m}$ & -10 & 00 \\
\hline 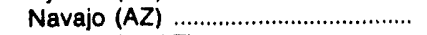 & 7,441 & 104.8 & 23.14 & .52 & 64 & 486.1 & 29.06 & .53 & - & -- & -- & 100 & $\cdot-$ & -- \\
\hline 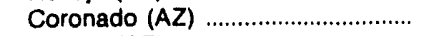 & 2,246 & 200.9 & 39.83 & .45 & - & -- & - & -- & $\ddot{-m}$ & -3 & $\cdots$ & 100 & -- & -- \\
\hline Santan $(A Z)$ & - & - & - & - & - & -- & -- & - & 1,778 & ${ }^{2} 279.1$ & 2.88 & - & --10 & 00 \\
\hline San Antonio City of .......................... & 3,543 & 127.9 & 21.72 & .33 & - & -- & - & $\infty$ & 28,975 & 194.5 & 1.98 & 67 & -3 & 33 \\
\hline Sommers (TX) & - & -- & -- & - & - & -- & -- & $\cdots$ & 17,468 & 197.6 & 2.01 & - & -10 & \\
\hline 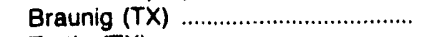 & - & - & - & -- & - & - & - & - & 10,715 & 189.2 & 1.93 & - & -10 & \\
\hline 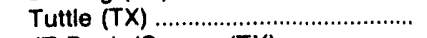 & $-\overline{0}$ & -- & 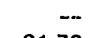 & $\overline{0-}$ & - & -- & -- & - & 361 & 190.9 & 1.97 & -- & -10 & 00 \\
\hline 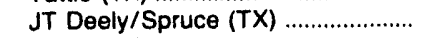 & 3,543 & 127.9 & 21.72 & .33 & -- & -- & - & -- & 242 & 233.1 & 2.38 & 100 & -- & - \\
\hline Spruce $(T x)$ & - & - & $-\cdots$ & - & - & - & -- & -- & 189 & 165.9 & 1.69 & -- & --10 & 00 \\
\hline San Diego Gas \& Electric Co ........ & - & - & - & -- & - & - & -- & - & 47,131 & 290.0 & 2.99 & - & -10 & \\
\hline 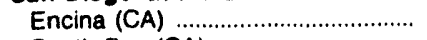 & - & - & -- & -- & -- & -- & -- & - & 23,296 & 289.7 & 2.99 & - & --10 & 00 \\
\hline 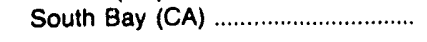 & - & - & -- & -- & - & - & -- & - & 23,835 & 290.2 & 2.99 & -- & --10 & 00 \\
\hline San Miguel Electric Coop Inc ........ & 2,930 & 96.6 & 10.34 & 1.98 & 28 & 380.6 & 22.08 & .66 & - & -- & - & 98 & 1 & - \\
\hline 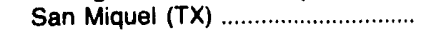 & 2,930 & 96.6 & 10.34 & 1.98 & 28 & 380.6 & 22.08 & .66 & -- & - & - & 99 & 1 & - \\
\hline Savannah Electric \& Power Co .... & 156 & 150.4 & 37.16 & 1.17 & 4 & 503.2 & 29.17 & .50 & 813 & 285.3 & 2.92 & 82 & * & \\
\hline 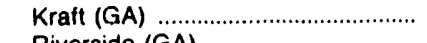 & 64 & 147.4 & 36.46 & 1.00 & -- & - & - & - & 594 & $\begin{array}{l}271.1 \\
3236\end{array}$ & 2.78 & 72 & --2 & 28 \\
\hline Piverside (GA) & $-\overrightarrow{0}$ & - & - & -- & - & -- & - & -- & 220 & 323.6 & 3.31 & -- & --10 & 100 \\
\hline 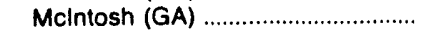 & 92 & 152.5 & 37.64 & 1.29 & 4 & 503.2 & 29.17 & .50 & - & -- & - & 99 & 1 & -- \\
\hline $\begin{array}{l}\text { Seminole Electric Coop Inc } \ldots \ldots \ldots \ldots \\
\text { Seminole (FL) }\end{array}$ & 3,539 & 194.3 & 47.16 & 2.60 & 39 & 442.1 & 26.01 & .23 & - & - & - & 100 & $:$ & - \\
\hline Seminole (FL) & 3,539 & 194.3 & 47.16 & 2.60 & 39 & 442.1 & 26.01 & .23 & - & - & & 100 & 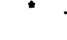 & $\rightarrow$ \\
\hline Slerra Pacific Power Co ................... & 1,545 & 188.6 & 41.77 & .43 & 365 & 325.9 & 20.27 & .72 & 18,528 & 168.6 & 1.73 & 60 & 4 & 35 \\
\hline 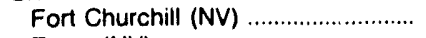 & - & -- & -- & - & 196 & 320.9 & 19.89 & .75 & 9,610 & 166.7 & 1.71 & -- & 11 & 89 \\
\hline 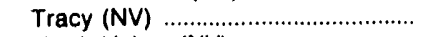 & $-\overline{-}$ & - & -- & -- & 156 & 320.6 & 19.99 & .75 & 8,918 & 170.8 & 1.75 & -- & 10 & 90 \\
\hline 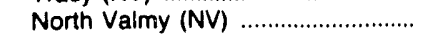 & 1,545 & 198.6 & 41.77 & .43 & 13 & 505.6 & 29.41 & .00 & - & - & & 100 & $\bullet$ & - \\
\hline 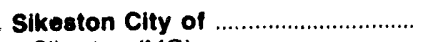 & 587 & 150.7 & 35.36 & 2.49 & 4 & 422.7 & 25.03 & .26 & - & - & & 100 & $\because$ & -- \\
\hline Sikeston $(\mathrm{MO})$ & 587 & 150.7 & 35.36 & 2.49 & 4 & 422.7 & 25.03 & .26 & - & - & & 100 & $\cdot$ & -- \\
\hline South Carolina Electric\&Gas Co .. & 4,222 & 157.7 & 40.63 & 1.10 & 65 & 464.4 & 26.92 & .20 & 1,315 & 169.0 & 1.73 & 98 & • & 1 \\
\hline Canadys (SC) & 663 & 158.9 & 40.74 & 1.31 & - & - & -- & -- & 170 & 237.7 & 2.43 & 99 & - & 1 \\
\hline Hagood (SC) & -- & - & - & -- & 3 & 442.5 & 25.65 & .20 & 239 & 196.8 & 2.01 & - & 6 & 94 \\
\hline 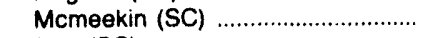 & 615 & 152.7 & 39.30 & 1.32 & -- & - & -- & -- & 496 & 144.6 & 1.48 & 97 & - & 3 \\
\hline 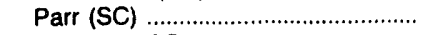 & -- & -- & -- & - & $-\infty$ & - & -- & -- & 11 & 256.2 & 2.62 & -- & $-\cdots-10$ & \\
\hline 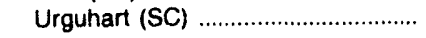 & 500 & 155.1 & 40.05 & 1.26 & 1 & 466.8 & 27.05 & .20 & 399 & 150.9 & 1.54 & 97 & & 3 \\
\hline
\end{tabular}

See footnotes at end of table.

Source: Federal Energy Regulatory Commission, FERC Form 423, "Monthly Report of Cost and Quality of Fuels for Electric Plants." 
Table 31. Receipts, Average Dellvered Cost, and Quality of Fossil-Fuels by Electric Utillty and Plant, 1992 (Continued)

\begin{tabular}{|c|c|c|c|c|c|c|c|c|c|c|c|c|c|c|}
\hline \multirow[b]{2}{*}{$\begin{array}{l}\text { Electric Utility } \\
\text { Plant (State) }\end{array}$} & \multicolumn{4}{|c|}{ Coal } & \multicolumn{4}{|c|}{ Potrolnum } & \multicolumn{3}{|c|}{ Gas } & \multicolumn{3}{|c|}{$\begin{array}{c}\text { \% of Total } \\
\text { Etu }\end{array}$} \\
\hline & $\begin{array}{c}\text { Recelpts } \\
\text { (1,000 } \\
\text { Short } \\
\text { Tons) }\end{array}$ & $\begin{array}{c}\text { (Conte } \\
\text { per } \\
10^{\circ} \\
\text { Btu) }\end{array}$ & $\begin{array}{l}\text { (S por } \\
\text { short } \\
\text { Ton) }\end{array}$ & $\begin{array}{c}\text { (\% } \\
\text { Avg. } \\
\text { Sullur) }\end{array}$ & $\begin{array}{c}\text { Recelpte } \\
(1,000 \\
\text { bble) }\end{array}$ & $\begin{array}{c}\text { (Conts } \\
\text { per } \\
10^{\circ} \\
\text { Btu) }\end{array}$ & $\begin{array}{l}(10 \\
\text { (not) }\end{array}$ & $\begin{array}{c}\text { (\% } \\
\text { Avo. } \\
\text { sulfur) }\end{array}$ & $\begin{array}{c}\text { Aecelpte } \\
(1,000 \\
\text { Mci) }\end{array}$ & $\begin{array}{c}\text { (Cents } \\
\text { per } \\
10^{\circ} \\
\text { Btu) }\end{array}$ & $\begin{array}{c}(5 \\
\text { par } \\
\text { Mcf) }\end{array}$ & $\begin{array}{l}c \\
0 \\
a \\
1\end{array}$ & $\begin{array}{c}P e- \\
\text { tr- } \\
0- \\
10- \\
\text { um }\end{array}$ & $a$ \\
\hline \multicolumn{15}{|l|}{ South Carolina ElectricaGes Co } \\
\hline Wateree (SC) & 1,403 & 156.5 & 40.42 & 1.06 & 51 & 463.2 & 26.85 & 0.20 & - & -- & -- & 99 & 1 & - \\
\hline 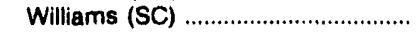 & 1,041 & 162.7 & 41.80 & .82 & 10 & 475.7 & 27.57 & .20 & - & - & - & 100 & : & - \\
\hline South Carolina Pub Sorv Auth ..... & 4,545 & 146.7 & 37.58 & 1.20 & - & - & - & - & -- & - & 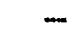 & 100 & - & - \\
\hline Cross (SC) & 1,343 & 144.7 & 36.85 & 1.08 & - & -- & - & - & - & -- & - & 100 & - & - \\
\hline 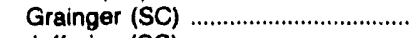 & 89 & 155.0 & 40.05 & 1.85 & - & - & $\sim$ & - & - & -- & & 100 & -- & - \\
\hline 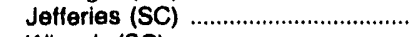 & 597 & 143.5 & 36.14 & 1.67 & - & - & - & - & -- & - & - & 100 & - & $-\infty$ \\
\hline 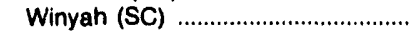 & 2,505 & 148.2 & 38.22 & 1.13 & - & - & -- & - & -- & -- & - & 100 & - & - \\
\hline South Mlsalealppl EI Pwr Asan ..... & 757 & 205.3 & 50.80 & .90 & 7 & 440.5 & 26.10 & .30 & 5,923 & 178.9 & 1.81 & 76 & - & 24 \\
\hline 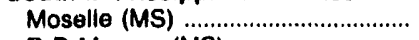 & - & $\overline{-}$ & -- & -- & $\overline{-}$ & - & - & - & 5,923 & 178.9 & 1.81 & -- & & 100 \\
\hline 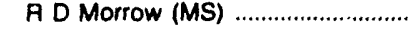 & 757 & 205.3 & 50.80 & .89 & 7 & 449.5 & 26.10 & .30 & -- & - & - & 100 & * & - \\
\hline Southern Callfornia Edison Co .... & 4,977 & 118.8 & 25.99 & .51 & 1 & 217.0 & 13.26 & .03 & 188,582 & 282.2 & 2.95 & 36 & - & 64 \\
\hline Alamitos (CA) & - & - & - & - & -- & - & - & - & 40,264 & 288.4 & 3.00 & - & & \\
\hline 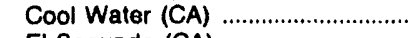 & - & - & - & - & - & - & - & -- & 12,208 & 220.8 & 2.29 & - & & 100 \\
\hline 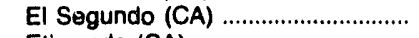 & -- & - & - & - & - & - & - & - & 19,796 & 284.3 & 2.98 & - & - & 100 \\
\hline 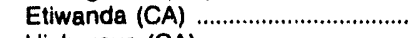 & - & - & -+ & - & - & - & -- & - & 16,467 & 286.3 & 2.95 & - & -- & 100 \\
\hline 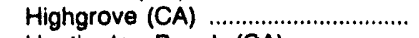 & - & - & - & - & - & - & - & - & 23 & 290.4 & 2.98 & - & & 100 \\
\hline Huntington Beach (CA) .................... & -- & - & - & - & - & - & $\cdots$ & -- & 11,584 & 277.1 & 2.89 & - & & 100 \\
\hline 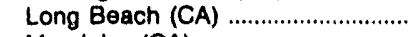 & - & - & - & - & - & - & - & -- & 3,708 & 277.1 & 2.87 & - & & 100 \\
\hline Mandalay (CA) ............................ & - & -- & - & - & - & - & -- & $-\infty$ & 13.759 & 282.4 & 3.02 & - & & 100 \\
\hline 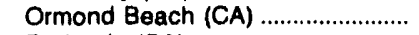 & - & - & - & - & - & - & - & -- & 30,639 & 292.6 & 3.09 & - & & 100 \\
\hline 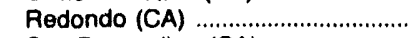 & - & - & - & - & - & - & - & - & 37,888 & 286.8 & 3.01 & - & - & 100 \\
\hline 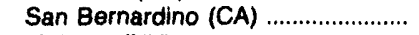 & - & - & - & - & - & $\ldots$ & - & - & 88 & 276.1 & 2.83 & - & - & 100 \\
\hline 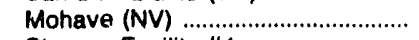 & 4,977 & 118.8 & 25.99 & .51 & - & $\cdots$ & - & - & 2,149 & 264.8 & 2.71 & 98 & - & 2 \\
\hline 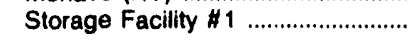 & - & - & - & - & 1 & 217.9 & 13.26 & .03 & - & $-\infty$ & - & - & 100 & - \\
\hline Southern Illinols Power Coop ....... & 490 & 91.1 & 19.21 & 2.79 & 11 & 468.5 & 26.70 & .00 & - & $\sim$ & - & 99 & 1 & - \\
\hline 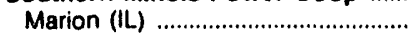 & 490 & 91.1 & 19.21 & 2.79 & 11 & 468.5 & 26.70 & .00 & - & - & $\cdots$ & 99 & 1 & - \\
\hline Southern Indiana Gas Elec Co. & 2,694 & 140.6 & 31.78 & 2.81 & 2 & 494.9 & 28.80 & .39 & 94 & 289.7 & 2.98 & 100 & $\cdot$ & - \\
\hline 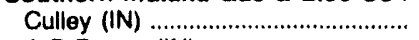 & 1.097 & 134.5 & 29.89 & 2.23 & 2 & 494.9 & 28.89 & .39 & 15 & 289.7 & 2.96 & 100 & • & - \\
\hline A B Brown (IN) & 1,123 & 156.8 & 36.23 & 3.53 & - & - & - & - & 64 & 289.7 & 2.96 & 100 & - & - \\
\hline 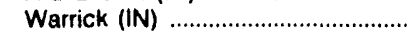 & 475 & 115.1 & 25.63 & 2.47 & - & - & - & - & 15 & 289.8 & 2.97 & 100 & - & - \\
\hline Southwestern Electric Power Co & 9,460 & 171.0 & 26.92 & .84 & 20 & 397.1 & 23.35 & .04 & 20,083 & 285.8 & 2.69 & 89 & $\cdot$ & 11 \\
\hline 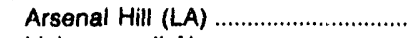 & - & - & - & - & - & - & - & - & 408 & 173.9 & 1.86 & - & & 100 \\
\hline 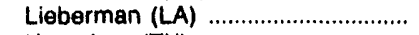 & - & -- & -- & - & - & - & -- & - & 1,471 & 179.5 & 1.86 & - & - & 100 \\
\hline 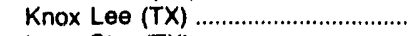 & - & - & - & - & - & -- & -- & - & 3,418 & 169.3 & 1.79 & - & - & 100 \\
\hline 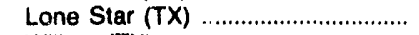 & - & -- & - & - & - & - & -- & - & 1,393 & 722.5 & 5.90 & - & - & 100 \\
\hline 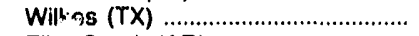 & - & -- & -- & - & - & - & - & -- & 13,318 & 297.0 & 2.70 & -- & - & 100 \\
\hline Flint Creek (AR) & 1,663 & 155.1 & 25.89 & .34 & 12 & 415.5 & 24.43 & .07 & - & - & - & 100 & • & - \\
\hline 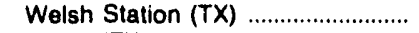 & 4,980 & 196.3 & 32.74 & .35 & 8 & 369.6 & 21.73 & .00 & -- & -- & - & 100 & - & -- \\
\hline 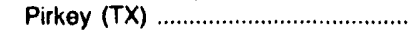 & 2,817 & 127.6 & 17.26 & 1.33 & -- & - & - & - & 75 & 268.2 & 2.89 & 100 & - & • \\
\hline Southwestern Public Service Co . & 8,288 & $\$ 73.3$ & 30.36 & .33 & - & - & - & - & 48,851 & 175.3 & 1.77 & 75 & - & 25 \\
\hline 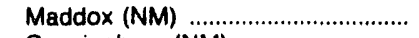 & - & - & -- & - & - & - & - & - & 3,853 & 184.5 & 1.89 & - & & 100 \\
\hline 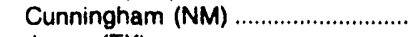 & - & - & - & - & - & - & - & - & 10,520 & 181.3 & 1.83 & - & & 100 \\
\hline 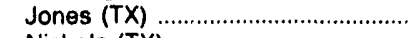 & - & - & - & - & - & - & - & -- & 18,113 & 175.4 & 1.79 & - & & 100 \\
\hline Nichols (TX) & -- & -- & - & - & - & - & - & - & 14,142 & 165.7 & 1.65 & - & & 100 \\
\hline Plant $X(T X)$ & -- & - & - & - & - & - & - & - & 2,185 & 188.4 & 1.91 & - & -- & 100 \\
\hline 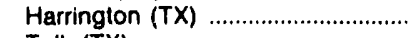 & 4,301 & 156.6 & 27.44 & .32 & - & - & - & - & 85 & 199.7 & 1.98 & 100 & - & 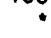 \\
\hline Tolk (TX) & 3,867 & 191.3 & 33.52 & .34 & - & - & -- & -- & 43 & 222.7 & 2.25 & 100 & - & - \\
\hline Springfield Clty of .......................... & 748 & 133.0 & 30.90 & 1.86 & - & - & - & - & 903 & 150.1 & 1.52 & 95 & - & $\mathbf{5}$ \\
\hline 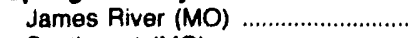 & 271 & 134.4 & 31.18 & 1.74 & - & - & - & -- & 858 & 147.7 & 1.49 & 88 & - & 12 \\
\hline 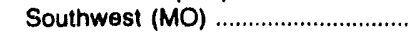 & 477 & 132.1 & 30.74 & 2.00 & - & - & - & - & 45 & 194.5 & 1.87 & 100 & - & $\bullet$ \\
\hline 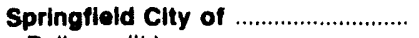 & 933 & 113.1 & 23.40 & 3.04 & 1 & 365.2 & 21.17 & .20 & - & - & - & 100 & - & - \\
\hline 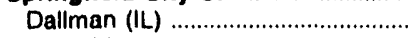 & 827 & 113.1 & 23.48 & 3.04 & $i$ & 365.2 & 21.17 & .20 &.- & - & - & 100 & • & - \\
\hline 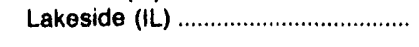 & 106 & 113.3 & 23.53 & 3.03 & - & $\ldots$ & - & - & - & - & - & 100 & - & - \\
\hline $\begin{array}{l}\text { St Joseph Light \& Power Co } \\
\text { Lakeroad (MO) }\end{array}$ & $\begin{array}{l}135 \\
135\end{array}$ & $\begin{array}{l}139.2 \\
139.2\end{array}$ & $\begin{array}{l}33.35 \\
33.35\end{array}$ & $\begin{array}{l}3.72 \\
3.72\end{array}$ & $\begin{array}{l}189 \\
189\end{array}$ & $\begin{array}{l}145.3 \\
145.3\end{array}$ & $\begin{array}{l}9.43 \\
9.43\end{array}$ & $\begin{array}{l}2.55 \\
2.55\end{array}$ & $\begin{array}{l}199 \\
199\end{array}$ & $\begin{array}{l}235.9 \\
235.9\end{array}$ & $\begin{array}{l}2.37 \\
2.37\end{array}$ & $\begin{array}{l}69 \\
69\end{array}$ & $\begin{array}{l}26 \\
26\end{array}$ & 4 \\
\hline
\end{tabular}

See footnotes at end of table.

Source: Federal Energy Regulatory Commission, FERC Form 423. "Monthly Report of Cost and Quality of Fuels for Electric Plants." 
Table 31. Receipts, Average Delivered Cost, and Quality of Fossil-Fuels by Electric Utility and Plant, 1992 (Continued)

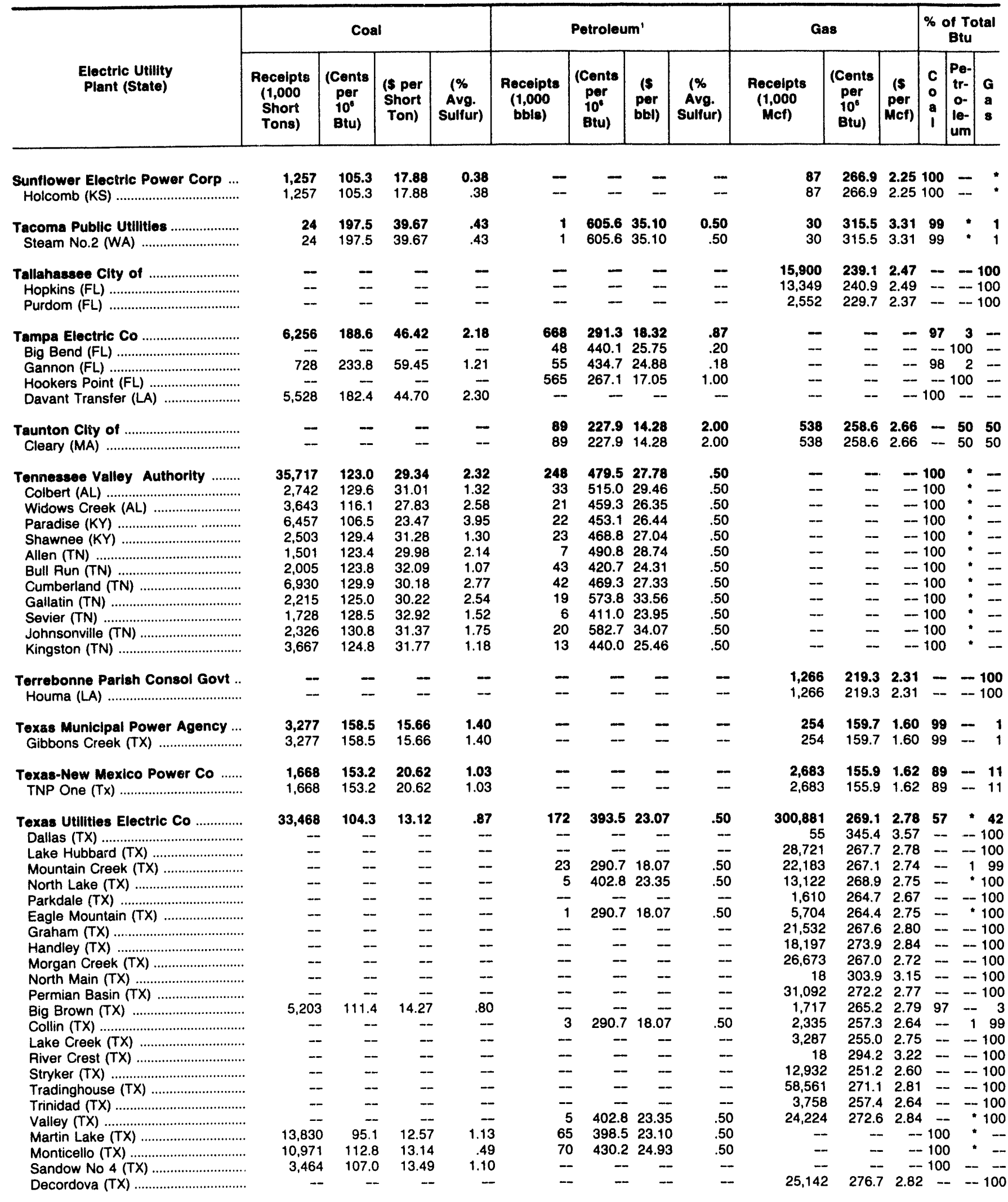

See footnotes at end of table.

Source: Federal Energy Regulatory Commission, FERC Form 423, "Monthly Report of Cost and Quality of Fuels for Electric Plants." 
Table 31. Receipts, Average Delivered Cost, and Quality of Fossil-Fuels by Electric Utility and Plant, 1992 (Continued)

\begin{tabular}{|c|c|c|c|c|c|c|c|c|c|c|c|c|c|c|}
\hline \multirow[b]{2}{*}{$\begin{array}{l}\text { Electric Utility } \\
\text { Plant (State) }\end{array}$} & \multicolumn{4}{|c|}{ Coal } & \multicolumn{4}{|c|}{ Petroleum' } & \multicolumn{3}{|c|}{ Gas } & \multicolumn{3}{|c|}{$\begin{array}{c}\% \text { of Total } \\
\text { Btu }\end{array}$} \\
\hline & $\begin{array}{c}\text { Recelpts } \\
\text { (1,000 } \\
\text { Short } \\
\text { Tnns) }\end{array}$ & $\begin{array}{c}\text { (Cents } \\
\text { per } \\
10^{6} \\
\text { Btu) }\end{array}$ & $\begin{array}{l}\text { (\$ per } \\
\text { Short } \\
\text { Ton) }\end{array}$ & $\begin{array}{c}\text { (\% } \\
\text { Avg. } \\
\text { Sulfur) }\end{array}$ & $\begin{array}{c}\text { Recelpts } \\
(1,000 \\
\text { bbls })\end{array}$ & $\begin{array}{c}\text { (Cents } \\
\text { per } \\
10^{6} \\
\text { Btu) }\end{array}$ & $\begin{array}{l}\text { (\$ } \\
\text { per } \\
\text { bbl) }\end{array}$ & $\begin{array}{c}(\% \\
\text { Avg. } \\
\text { Sulfur })\end{array}$ & $\begin{array}{c}\text { Receipts } \\
\text { (1,000 } \\
\text { Mcf) }\end{array}$ & $\begin{array}{c}\text { (Cents } \\
\text { per } \\
10^{6} \\
\text { Btu) }\end{array}$ & $\begin{array}{c}\text { (s } \\
\text { per } \\
\text { Mct) }\end{array}$ & $\begin{array}{l}c \\
0 \\
a \\
1\end{array}$ & $\begin{array}{l}\text { Pe- } \\
\text { tr- } \\
0- \\
\text { le- } \\
\text { um }\end{array}$ & $\begin{array}{l}\mathbf{G} \\
\mathbf{a} \\
\mathbf{8}\end{array}$ \\
\hline 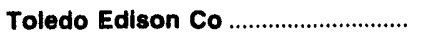 & 1,252 & 201.5 & 52.08 & 1.12 & 6 & 455.7 & 26.41 & 0.31 & 6 & 473.0 & 4.85 & 100 & * & $\cdot$ \\
\hline Acme $(\mathrm{OH})$ & 57 & 178.0 & 45.29 & .66 & -- & $-\overline{-}$ & - & - & 6 & 473.0 & 4.85 & 94 & 5 & * \\
\hline Bay Shore $(\mathrm{OH})$ & 1,195 & 202.6 & 52.41 & 1.14 & 6 & 455.7 & 26.41 & .31 & -- & -- & -- & 100 & 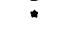 & - \\
\hline Tri-State G T Assn Inc .................. & 4,733 & 110.8 & 22.45 & .39 & 13 & $\mathbf{5 2 3 . 0}$ & 29.46 & .12 & 143 & 217.6 & 2.29 & 100 & * & $*$ \\
\hline Nucla $(\mathrm{CO})$ & 240 & 94.1 & 15.82 & .81 & -- & - & -- & -- & - & - & - & 99 & 1 & - \\
\hline 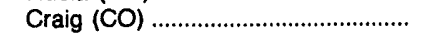 & 4,493 & 111.6 & 22.81 & .37 & 13 & 523.0 & 29.46 & .12 & 143 & 217.6 & 2.29 & 100 & * & • \\
\hline Tucson Electric Power Co ............. & 199 & 234.1 & 47.11 & .45 & - & - & -- & - & 1,746 & 231.3 & 2.39 & 69 & -- & 31 \\
\hline Irvington $(A Z)$ & 199 & 234.1 & 47.11 & .45 & - & -- & -- & -- & 1,746 & 231.3 & 2.39 & 69 & - & 31 \\
\hline Union Electric Co ................................. & 10,627 & 149.1 & 31.87 & 1.57 & 69 & 424.9 & 24.45 & .29 & 373 & 217.7 & 2.22 & 100 & $\star$ & - \\
\hline 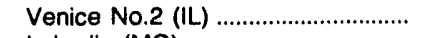 & & - & & - & - & -- & -- & -- & 190 & 216.1 & 2.20 & -- & -1 & 100 \\
\hline 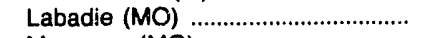 & 5,468 & 116.0 & 23.54 & 1.55 & 49 & 418.4 & 24.08 & .29 & -- & -- & - & 100 & * & - \\
\hline Meramec (MO) & 773 & 200.1 & 46.61 & 1.28 & -- & - & - & -- & 183 & 219.3 & 2.23 & 99 & - & 1 \\
\hline Sioux $(M O)$ & 1,845 & 174.8 & 39.56 & 2.39 & 12 & 454.7 & 26.16 & .29 & - & -- & -- & 100 & * & - \\
\hline Rush Island $(\mathrm{MO})$ & 2,541 & 178.9 & 39.71 & 1.12 & 8 & 420.2 & 24.18 & .29 & -- & -- & -- & 100 & * & - \\
\hline United Illuminating Co ..................... & 793 & 194.8 & 51.30 & .55 & 4,029 & 235.2 & 15.00 & .97 & 1,643 & 217.2 & 2.24 & 43 & 53 & 4 \\
\hline 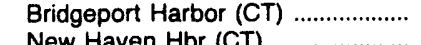 & 793 & 194.8 & 51.30 & .55 & 1,078 & 237.3 & 15.10 & .93 & -- & -- & $\bar{n}$ & 75 & 25 & $-\bar{c}$ \\
\hline New Haven Hbr (CT) ....................... & - & - & - & - & 2,951 & 234.5 & 14.96 & .98 & 1,643 & 217.2 & 2.24 & -- & 92 & 8 \\
\hline United Power Assn .......................... & 1,067 & 68.5 & 9.23 & .71 & 1 & 504.4 & 29.02 & .40 & -- & - & -- & 100 & * & - \\
\hline Stanton (ND) & 1,067 & 68.5 & 9.23 & .71 & 1 & 504.4 & 29.02 & .40 & -- & - & -- & 100 & $\cdot$ & - \\
\hline Vero Beach Clty of ............................ & -- & - & - & - & 7 & 508.3 & 29.46 & .00 & 2,840 & 269.0 & 2.76 & - & 1 & 99 \\
\hline 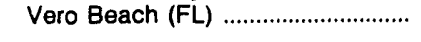 & -- & -- & - & - & 7 & 508.3 & 29.46 & .00 & 2,840 & 269.0 & 2.76 & -- & 1 & 99 \\
\hline 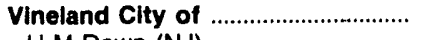 & - & - & - & - & 136 & 269.5 & 17.03 & .87 & -- & - & - & -1 & 100 & - \\
\hline 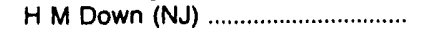 & -- & -- & -- & -- & 136 & 269.5 & 17.03 & .87 & -- & - & -- & -1 & 100 & -- \\
\hline Virginia Electric \& Fower Co ........ & 10,516 & 145.2 & 36.64 & 1.42 & 2,764 & 245.0 & 15.34 & .96 & 10,433 & ${ }^{2} 237.2$ & 2.48 & 90 & 6 & 4 \\
\hline 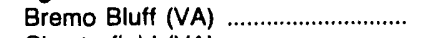 & 463 & 150.0 & 37.97 & .83 & 5 & 520.8 & 30.63 & .20 & - & -- & -1 & 100 & * & - \\
\hline Chesterfield (VA) & 2,968 & 146.7 & 37.67 & 1.13 & 44 & 486.2 & 28.59 & .20 & 9,334 & 240.9 & 2.52 & 88 & - & 11 \\
\hline Chesapeake Energy (VA) ............... & 1,125 & 150.4 & 39.28 & 1.10 & 30 & 468.6 & 27.55 & .20 & $*$ & 2777.3 & 8.16 & 99 & 1 & • \\
\hline 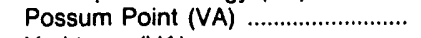 & 743 & 153.2 & 38.97 & 1.07 & 618 & 278.4 & 17.50 & .69 & -- & -- & - & 83 & 17 & - \\
\hline 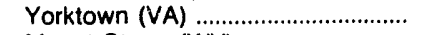 & 676 & 156.4 & 41.10 & 1.57 & 14 & 524.1 & 30.82 & .20 & 1,099 & ${ }^{2} 205.6$ & 2.13 & 94 & * & 6 \\
\hline 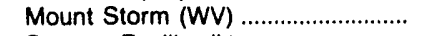 & 4.541 & 139.1 & 34.14 & 1.78 & 35 & 469.5 & 27.61 & .20 & - & -- & -- & 100 & * & - \\
\hline 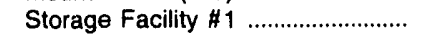 & - & - & - & -- & 2,019 & 220.7 & 13.85 & 1.09 & -- & -- & -- & -1 & 100 & - \\
\hline West Penn Power Co ......................... & 5,448 & 144.5 & 36.89 & 2.22 & 25 & 431.9 & 25.58 & .27 & 26 & 407.8 & 4.08 & 100 & & * \\
\hline Armstrong (PA) & 970 & 117.5 & 29.21 & 1.96 & 4 & 453.6 & 26.86 & .27 & -- & - & -- & 100 & $\bullet$ & -- \\
\hline 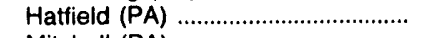 & 3,822 & 153.3 & 39.61 & 2.22 & 15 & 442.8 & 26.22 & .27 & - & - & -- & 100 & * & - \\
\hline Mitchell (PA) ...................................... & 655 & 130.9 & 32.38 & 2.63 & * & 532.4 & 31.53 & .27 & 26 & 407.8 & 4.08 & 100 & * & $\star$ \\
\hline 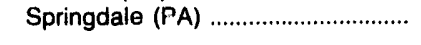 & -- & -- & -- & - & 6 & 383.9 & 22.74 & .27 & - & -- & -- & --1 & 100 & -- \\
\hline 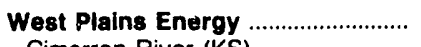 & - & - & -- & - & -- & - & - & - & 1,940 & 2187.9 & 1.86 & - & & 100 \\
\hline Cimarron River (KS) ............................ & -- & -- & -- & - & -- & -- & -- & -- & 565 & 236.4 & 2.59 & -- & & 100 \\
\hline 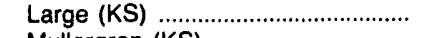 & -- & - & -- & - & -- & -- & -- & -- & 1,229 & 167.3 & 1.58 & -- & --1 & 100 \\
\hline 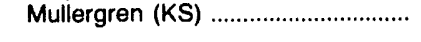 & -- & -- & -- & - & -- & -- & -- & -- & 146 & ${ }^{2} 146.7$ & 1.46 & -- & --1 & 100 \\
\hline West Texas Utilities Co ................... & 2,878 & 152.7 & 25.59 & .35 & 19 & 512.3 & 29.88 & .37 & 38,846 & ${ }^{2} 200.3$ & 2.03 & 55 & & 45 \\
\hline 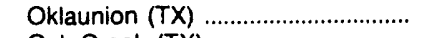 & 2,878 & 152.7 & 25.59 & .35 & 12 & 548.4 & 32.01 & .40 & - & -- & -- & 100 & • & - \\
\hline Oak Creek (TX) & - & -- & -- & -- & - & $\overline{-1}$ & $\overline{n-\infty}$ & $-\overline{7}$ & 4,210 & 184.3 & 1.86 & - & -1 & 100 \\
\hline 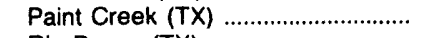 & - & -- & -- & - & 2 & 427.0 & 24.94 & .27 & 2,315 & ${ }^{2} 198.0$ & 1.99 & - & 1 & 99 \\
\hline Rio Pecos (TX) & - & - & -- & -- & 3 & 471.0 & 27.30 & .36 & 9,869 & 160.8 & 1.55 & - & & 100 \\
\hline 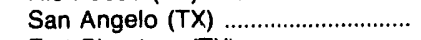 & -- & -- & -- & - & 2 & 434.0 & 25.34 & .27 & 6,114 & 315.0 & 3.56 & -- & & 100 \\
\hline 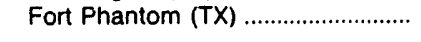 & -- & - & -- & -- & - & - & - & -- & 16,338 & 179.4 & 1.80 & - & & 100 \\
\hline Western Farmers Elec Coop Inc. & 1,426 & 178.1 & 29.95 & .44 & - & - & - & - & 13,574 & 179.6 & 1.84 & 63 & - & 37 \\
\hline 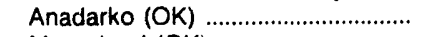 & - & - & - & - & - & - & - & -- & 11,008 & 183.5 & 1.88 & - & & 100 \\
\hline 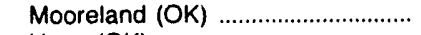 & -- & - & -- & - & - & -- & - & -- & 2,566 & 162.8 & 1.66 & - & & 100 \\
\hline 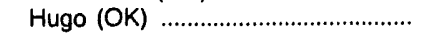 & 1,426 & 178.1 & 29.95 & .44 & - & - & - & - & -- & - & -- & 100 & -- & - \\
\hline $\begin{array}{l}\text { Western Massachusetts Elec Co } . \\
\text { West Sorinafield (MA) }\end{array}$ & - & - & $-\infty$ & - & $\begin{array}{l}198 \\
198\end{array}$ & $\begin{array}{l}252.5 \\
2525\end{array}$ & 16.04 & .96 & 1,389 & 224.1 & 2.28 & - & 47 & 53 \\
\hline West Springfield (MA) ......................... & -- & -- & & -- & & 252.5 & 16.04 & .96 & 1,389 & 224.1 & 2.29 & -- & 47 & 53 \\
\hline
\end{tabular}

See footnotes at end of table.

Source: Federal Energy Regulatory Commission, FERC Form 423, "Monthly Report of Cost and Quality of Fuels for Electric Plants." 
Table 31. Receipts, Average Delivered Cost, and Quality of Fossil-Fuels by Electric Utillty and Plant, 1992 (Continued)

\begin{tabular}{|c|c|c|c|c|c|c|c|c|c|c|c|c|c|c|}
\hline \multirow[b]{2}{*}{$\begin{array}{l}\text { Electric Utillty } \\
\text { Plant (State) }\end{array}$} & \multicolumn{4}{|c|}{ Coal } & \multicolumn{4}{|c|}{ Petroleum' } & \multicolumn{3}{|c|}{ Gas } & \multicolumn{3}{|c|}{$\begin{array}{c}\% \text { of Total } \\
\text { Btu }\end{array}$} \\
\hline & $\begin{array}{c}\text { Recelpts } \\
\text { (1,000 } \\
\text { Short } \\
\text { Tons) }\end{array}$ & $\begin{array}{c}\text { (Cents } \\
\text { per } \\
10^{6} \\
\text { Btu) }\end{array}$ & $\begin{array}{l}\text { (5 per } \\
\text { Short } \\
\text { Ton) }\end{array}$ & $\begin{array}{c}\text { (\% } \\
\text { Avg. } \\
\text { Sulfur) }\end{array}$ & $\begin{array}{c}\text { Recelpts } \\
(1,000 \\
\text { bbls })\end{array}$ & $\begin{array}{c}\text { (Cents } \\
\text { per } \\
10^{\circ} \\
\text { Btu) }\end{array}$ & $\begin{array}{c}\text { (s } \\
\text { per } \\
\text { bbl) }\end{array}$ & $\begin{array}{c}(\% \\
\text { Avg. } \\
\text { Sulfur) }\end{array}$ & $\begin{array}{c}\text { Recelpts } \\
\text { (1,000 } \\
\text { Mct) }\end{array}$ & $\begin{array}{c}\text { (Cents } \\
\text { per } \\
10^{\circ} \\
\text { Btu) }\end{array}$ & $\begin{array}{c}\text { (\$ } \\
\text { per } \\
\text { Mct) }\end{array}$ & $\begin{array}{l}\mathbf{C} \\
\mathbf{0} \\
\mathbf{a} \\
\mathbf{1}\end{array}$ & $\begin{array}{l}\text { Pe- } \\
\text { tr- } \\
0- \\
\text { lo- } \\
\text { um }\end{array}$ & $\begin{array}{l}\mathbf{G} \\
\mathbf{a} \\
\mathbf{B}\end{array}$ \\
\hline Wisconsin Electric Power Co ....... & 8,276 & 127.7 & 25.82 & 0.71 & 26 & 472.0 & 27.59 & 0.28 & 628 & 267.3 & 2.70 & 100 & & \\
\hline 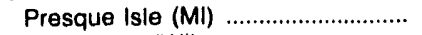 & 1,423 & 164.6 & 34.33 & .62 & 11 & 443.2 & 25.90 & .28 & -- & -- & - & 100 & $\bullet$ & - \\
\hline Oak Creek (WI) & 1,758 & 152.0 & 38.78 & 1.30 & - & -- & -- & -- & 366 & 265.6 & 2.69 & 99 & -- & 1 \\
\hline 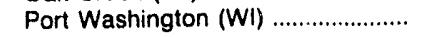 & 138 & 154.0 & 40.78 & 1.44 & -- & -- & -- & -- & $\overline{0}$ & - & -- & 100 & -- & - \\
\hline 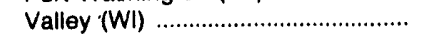 & 520 & 166.8 & 44.13 & 1.55 & - & -- & -- & -- & 62 & 306.2 & 3.09 & 100 & - & • \\
\hline Pleasant Prairie (WI) ........................... & 4,438 & 90.3 & 15.36 & .38 & $\overline{-}$ & $-\bar{x}$ & $\overline{-2}$ & $-\overline{0}$ & 201 & 258.3 & 2.62 & 100 & $-\overline{-}$ & * \\
\hline Storage Facility $\# 1$.......................... & - & - & -- & -- & 15 & 492.5 & 28.79 & .28 & -- & - & - & --1 & 100 & - \\
\hline Wisconsin Power L Light Co ....... & 6,333 & 139.0 & 25.71 & .71 & 18 & 428.0 & 25.23 & .00 & 24 & 279.5 & 2.81 & 100 & * & $\bullet$ \\
\hline 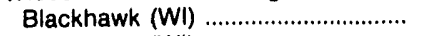 & -- & -- & -- & -- & - & -- & - & - & 24 & 279.5 & 2.81 & -- & & 100 \\
\hline 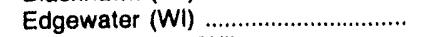 & 2,136 & 150.2 & 29.23 & 1.05 & 8 & 427.4 & 25.13 & .00 & -- & - & -- & 100 & $\because$ & $-\infty$ \\
\hline 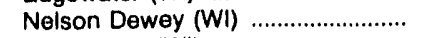 & 447 & 127.6 & 26.51 & .58 & 2 & 451.9 & 26.57 & .00 & -- & -- & -- & 100 & : & -- \\
\hline 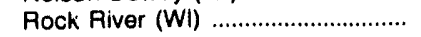 & 191 & 195.5 & 43.37 & 1.92 & 1 & 459.7 & 27.03 & .00 & - & $\cdots$ & -- & 100 & : & - \\
\hline 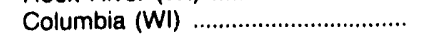 & 3,558 & 129.3 & 22.55 & .46 & 7 & 419.5 & 24.67 & .00 & -- & - & -- & 100 & - & - \\
\hline Wisconsin Publlc Service Corp .... & 2,200 & 151.7 & 28.98 & .65 & 4 & 507.9 & 29.44 & .22 & 235 & 355.4 & 3.60 & 99 & $\bullet$ & 1 \\
\hline 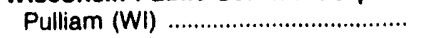 & 594 & 177.1 & 39.27 & 1.25 & - & -- & -- & - & 220 & 361.8 & 3.66 & 98 & -- & 2 \\
\hline Weston (WI) & 1,606 & 140.0 & 25.17 & .43 & 4 & 507.9 & 29.44 & .22 & 15 & 261.5 & 2.65 & 100 & • & - \\
\hline Wyandotte Municlpal Serv Comm & 104 & 187.2 & 49.75 & .88 & - & -- & - & - & 364 & 210.0 & 2.10 & 88 & - & 12 \\
\hline Wyandotte (MI) & 104 & 187.2 & 49.75 & .88 & - & -- & - & - & 364 & 210.0 & 2.10 & 88 & -- & 12 \\
\hline 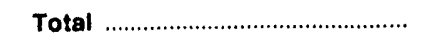 & 775,963 & 141.2 & 29.36 & 1.29 & 144,390 & 255.1 & 16.15 & 1.10 & $2,637,678$ & 232.8 & 2.38 & 82 & 5 & 14 \\
\hline
\end{tabular}

1 The 1992 petroleum coke receipts were 687,000 short tons and the cost was 75.0 cents per million Btu.

2 Includes at least one delivery at a price of 1,000 cents per million Btu or greater. High price is frequently caused when fixed costs are averaged into a small quantity.

" Number less than 0.5 .

Notes: - Totals may not equal sum of components because of independent rounding. - Data are for electric generating plants with a total steamelectric and combined-cycle nameplate capacity of 50 or more megawatts. $-M c f=$ thousand cubic feet.

Source: Federal Energy Regulatory Commission, FERC Form 423, "Monthly Report of Cost and Quality of Fuels for Electric Plants." 
Appendix A

Electric Utilities

Reporting on the

FERC Form 423 


\section{Appendix A}

\section{Electric Utilities Reporting on the FERC Form 423}

This appendix contains a list of the electric utilities that reported on the Federa! Energy Regulatory Commis- sion (FERC) Form 423, "Monthly Report of Cost and Quality of Fuels for Electric Plants," during 1992. 
Table A1. Electric Utilities Reporting on the FERC Form 423 by State

\begin{tabular}{|c|c|c|c|}
\hline State & $\begin{array}{l}\text { Electric Utility } \\
\text { (Holding Company) }\end{array}$ & State & $\begin{array}{l}\text { Electric Utility } \\
\text { (Holding Company) }\end{array}$ \\
\hline Alabama & $\begin{array}{l}\text { Alabama Electric Coop Inc } \\
\text { Alabama Power Co } \\
\text { Tennessee Valley Authority } \\
\text { Anchorage City of } \\
\text { Chugach Electric Assn }\end{array}$ & & $\begin{array}{l}\text { Cedar Falls City of } \\
\text { Central lowa Power Coop } \\
\text { Interstate Power Co } \\
\text { lowa Electric Light \& Power Co } \\
\text { lowa Southern Utilities Co } \\
\text { lowa-llinois Gas \& Electric Co } \\
\text { Midwest Power }\end{array}$ \\
\hline Arizona & $\begin{array}{l}\text { Arizona Electric Pwr Coop Inc } \\
\text { Arizona Public Service Co } \\
\text { Century Power Cooperative } \\
\text { Salt Piver Proj Ag } 1 \text { \& P Dist } \\
\text { Tucson Electric Power Co }\end{array}$ & Kansas & $\begin{array}{l}\text { Muscatine City of } \\
\text { Coffeyville City of } \\
\text { Empire District Electric Co } \\
\text { Kansas City City of } \\
\text { Kansas City Power \& Light Co } \\
\text { Kansas Gas \& Electric Co }\end{array}$ \\
\hline Arkansas & $\begin{array}{l}\text { Arkansas Power \& Light Co (MSU) } \\
\text { Southwestern Electric Power Co (CSW) }\end{array}$ & & $\begin{array}{l}\text { Kansas Power \& Light Co } \\
\text { Sunflower Electric Coop Inc } \\
\text { West Plains Energy }\end{array}$ \\
\hline California & $\begin{array}{l}\text { Burbank City of } \\
\text { Glendale City of } \\
\text { Imperial Irrigation District } \\
\text { Los Angeles City of } \\
\text { Pacific Gas \& Electric Company } \\
\text { Pasadena City of } \\
\text { San Diego Gas \& Electric Co } \\
\text { Southern California Edison Co }\end{array}$ & Kentucky & $\begin{array}{l}\text { Big Pivers Electric Corp } \\
\text { Cincinnati Gas \& Electric Co } \\
\text { East Kentucky Power Coop Inc } \\
\text { Kentucky Power Co (AEP) } \\
\text { Kentucky Utilities Co } \\
\text { Louisville Gas \& Eleciric Co } \\
\text { Owensboro City of } \\
\text { Tennessee Valley Authority }\end{array}$ \\
\hline Colorado & $\begin{array}{l}\text { Colorado Springs City of } \\
\text { Platte River Power Authority } \\
\text { Public Service Co of Colorado } \\
\text { Tri-State G \& T Assn inc }\end{array}$ & Louisiana & $\begin{array}{l}\text { Alexandria City of } \\
\text { Cajun Electric Power Coop Inc } \\
\text { Central Louisiana Elec Co Inc } \\
\text { Gulf States Utilities Co }\end{array}$ \\
\hline Connecticut & $\begin{array}{l}\text { Connecticut Light \& Power Co } \\
\text { United Illuminating Co }\end{array}$ & & $\begin{array}{l}\text { Lafayette City of } \\
\text { Louisiana Power \& Light Co (MSU) } \\
\text { Morgan City City of }\end{array}$ \\
\hline District of Columbia & $\begin{array}{l}\text { Delmarva Power \& Light Co } \\
\text { Dover City of } \\
\text { Potomac Electric Power Co }\end{array}$ & & $\begin{array}{l}\text { New Orleans Public Service Inc (MSU) } \\
\text { Ruston City of } \\
\text { Southwestern Electric Power Co (CSW) } \\
\text { Terribonne Parish Consolidated Govt }\end{array}$ \\
\hline Florida & $\begin{array}{l}\text { Florida Power \& Light Co } \\
\text { Florida Power Corp } \\
\text { City of Fort Pierce }\end{array}$ & Maine & $\begin{array}{l}\text { Bangor Hydro-Electric Co } \\
\text { Central Maine Power Co }\end{array}$ \\
\hline & $\begin{array}{l}\text { Gainesville Regional Utilities } \\
\text { Gulf Power Co } \\
\text { Jacksonville Electric Auth } \\
\text { Lake Worth City of } \\
\text { Lakeland City of }\end{array}$ & Maryland & $\begin{array}{l}\text { Baltimore Gas \& Electric Co } \\
\text { Delmarva Power \& Light Co Inc } \\
\text { Potomac Edison Co (APS) } \\
\text { Potomac Electric Power Co }\end{array}$ \\
\hline & $\begin{array}{l}\text { Orlando Utilities Comm } \\
\text { Seminole Electric Coop Inc } \\
\text { Tallahassee City of } \\
\text { Tampa Electric Co } \\
\text { Vero Beach City of }\end{array}$ & Massachusetts & $\begin{array}{l}\text { Boston Edison Co } \\
\text { Braintree City of } \\
\text { Cambridge Electric Light Co (NEGA) } \\
\text { Canal Electric Co } \\
\text { Commonwealth Electric Co (NEGA) } \\
\text { Holyoke Water Power Co (NU) }\end{array}$ \\
\hline Georgia & $\begin{array}{l}\text { Georgia Power Co (SC) } \\
\text { Savannah Electric \& Power Co }\end{array}$ & & $\begin{array}{l}\text { Massachusetts Mun Whis Elec Co } \\
\text { Montaup Electric Co } \\
\text { New England Power Co (NEES) }\end{array}$ \\
\hline Hawaii & Hawaiian Electric Co Inc & & $\begin{array}{l}\text { Taunton City of } \\
\text { Western Massachusetts Elec Co (NU) }\end{array}$ \\
\hline Ullinois & $\begin{array}{l}\text { Central Illinois Light Co } \\
\text { Central Illinois Pub Serv Co } \\
\text { Commonwealth Edison Co } \\
\text { Electric Energy Inc } \\
\text { Illinois Power Co } \\
\text { Southern Illinois Power Coop } \\
\text { Springfield City of } \\
\text { Union Electric Co }\end{array}$ & Michigan & $\begin{array}{l}\text { Consumers Power Co } \\
\text { Detroit Edison Co } \\
\text { Detroit City of } \\
\text { Grand Haven City of } \\
\text { Holland City of } \\
\text { Lansing City of } \\
\text { Marquette City of } \\
\text { Michigan South Central Pwr Agy }\end{array}$ \\
\hline Indiana & $\begin{array}{l}\text { Commonwealth Edison Co } \\
\text { Hoosier Energy R E C inc } \\
\text { Indiana Michigan Power Co (AEP) }\end{array}$ & 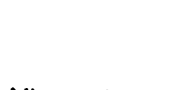 & $\begin{array}{l}\text { Wisconsin Electric Power Co } \\
\text { Wyandotte Municipal Serv Comm }\end{array}$ \\
\hline & $\begin{array}{l}\text { Indiana-Kentucky Electric Corp } \\
\text { Indianapolis Power \& Light Co } \\
\text { Northern Indiana Pub Serv Co } \\
\text { PSI Energy Inc } \\
\text { Richmond City of } \\
\text { Southern Indiana Gas \& Electric Co }\end{array}$ & $x^{2}$ & $\begin{array}{l}\text { Interstate Power Co } \\
\text { Minnesota Power \& Light Co } \\
\text { Northern States Power Co } \\
\text { Otter Tail Power Co } \\
\text { Rochester Public Utilities }\end{array}$ \\
\hline lowa & Ames City of & Mississippi & $\begin{array}{l}\text { Mississippi Power Co (SC) } \\
\text { Mississippi Power \& Light Co (MSU) }\end{array}$ \\
\hline
\end{tabular}




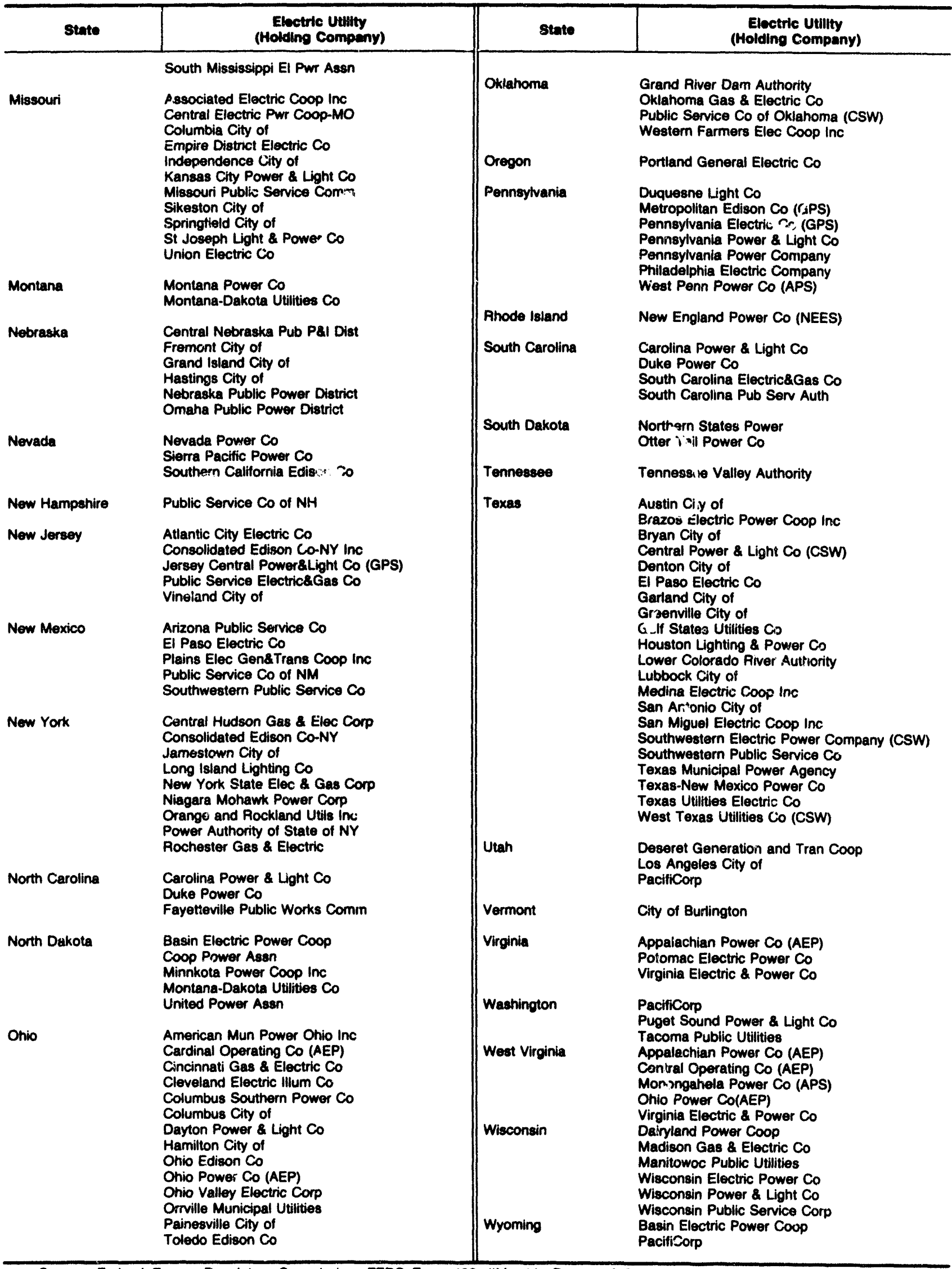

Source: Federal Energy Regulatory Commission, FERC Form 423, "Monthly Report of Cost and Quality of Fuels for Electric Plants." 
Appendix B

References 


\section{References}

1. Energy Information Administration, Office of Coal, Nuclear, Electric and Alternate Fuels, Electric Power Annual, DOE/EIA-0348(91) (Washington DC, 1993).

2. Energy Information Administration, Office of Coal, Nuclear, Electric and Alternate Fuels, Electric Power Monthly, DOE/EIA-0226(93) (Washington DC, 1993).
3. Energy Information Administration, Office of Coal, Nuclear, Electric and Alternate Fuels, Inventory of Power Plants in the United States, DOE/EIA-0095(92) (Washington DC, 1992).

4. Energy Information Administration, Office of Energy Markets and End Use, Monthly Energy Review, DOE/EIA-0035(93) (Washington DC, 1993) 
Appendix C

Technical Notes 


\section{Appendix C}

\section{Technical Notes}

\section{Sources of Data}

The annual report, Cost and Quality of Fuels for Electric Utility Plants, $(C \& Q)$ is prepared by the Survey Management Division; Office of Coal, Nuclear, Electric and Alternate Fuels; Energy Information Administration (EIA); U.S. Department of Energy (DOE). Statistics published in the $C \& Q$ are based on data collected on the Federal Energy Regulatory Commission (FERC) Form 423, "Monthly Report of Cost and Quality of Fuels for Electric Plants".

\section{FERC Form 423}

The FERC Form 423 is a monthly record of receivedfuel purchases, submitted by approximately 230 electric utilities for each fossil-fuel plant whose total steam turbine electric generating capacity and/or combinedcycle (steam and associated gas turbines) generating capacity is 50 or more megawatts.

Instrument and Design History. On July 7, 1972, the Federal Power Commission (FPC) issued Order Number 453 enacting the New Code of Federal Regulations, Section 141.61, legally creating the FPC Form 423. Originally, the form was used to collect data only on fossil-steam plants, but was amended in 1974 to include data on internal combustion and combustion turbine units. The FERC Form 423 replaced the FPC Form 423 in January 1983. The FERC Form 423 eliminated peaking units, which were previously collected on the FPC Form 423. In addition, the generator nameplate capacity threshold was changed by the FERC from 25 megawatts to 50 megawatts. This reduction in coverage eliminated approximately 50 utilities and 250 plants. In 1991, the FERC Form 423 was amended to include combined-cycle generating units. This increase in coverage added 5 electric utilities and approximately 15 additional electric plants. Several plants already reporting on the FERC Form 423 began including fuel receipts for combined-cycle units starting with 1991 data.

Data Processing. A 12-month supply of the FERC Form 423 is mailed to respondents annually by the EIA. Completed forms are due on or before the 45th day following the end of the reporting month. Com- pleted forms are manually logged in and edited before the data are keypunched for automatic data processing. The electric utility companies are telephoned to obtain data in cases of missing reports and to verify data when questions arise during editing.

An edit program checks the data for errors not found during manual editing. Following verification of the data, computer printouts of aggregated data are produced for inclusion in the publication. After the Electric Power Monthly (EPM) is cleared by EIA, the data become available for public use in either custom computer runs, data tapes, or in the publications themselves on a cost-recovery basis. New plants are added to the FERC Form 423 System when respondents indicate the addition of a new plant.

Starting with the January 1993 data, the FERC began collection of the data directly from the respondants. The FERC will process the data through edits and each month provide the EIA with a diskette containing the data. The EIA will review the data for accuracy. Publication schedules will not be effected.

\section{Quality of Data}

The Office of Coal, Nuclear, Electric and Alternate Fuels (CNEAF) is responsible for routine data improvement and quality assurance activities. All operations of this office are done in accordance with formal standards established by the Energy Information Administration (EIA). These standards are the measuring rod necessary for quality statistics. Data improvement efforts include verification of data-keyed input by automatic computerized methods, editing by subject matter specialists, and follow-up on nonrespondents. Completed forms received by the CNEAF are sorted, screened for completeness of reported information, and keyed onto computer tapes for storage and transfer to data bases on random access storage devices for computer processing. The information coded on the computer tapes is manually spot checked against the forms to certify accuracy of the tapes. To ensure the quality standards established by EIA, algorithms have been designed and implemented using the past history of data values in the data base to check data input for errors automatically. This automatically reduces the 
possibility of erroneous entries in the data bases over time as the parameters of the algorithm are updated to reflect new data. Data values rejected by the algorithm are checked with respondents by telephone to correct the problems. Computerized respondent data files are checked to identify those who fail to respond to the survey. By law, nonrespondents may be fined or otherwise penalized for not filing an EIA data form as prescribed in the instructions. Before invoking the law, EIA tries to obtain the required information by encouraging cooperation of nonrespondents.

The CNEAF supports the quality assurance efforts of the data collectors by providing advisory reviews of the structure of information requirements, and of proposed designs for new and revised data collection forms and systems. It also validates the actual performance of working data collection systems, once fielded.

\section{Data Editing System}

Automated systems are used to edit data from the survey on a monthly basis. The edit includes both deterministic checks, in which records are checked for the presence of required fields and their validity, and statistical checks, in which estimation techniques are used to validate data according to its behavior in the past and in comparison to other current fields. When all data have passed the edit process, the system builds monthly master files. These master files are used as input to this report.

\section{Confidentiality of the Data}

The data collected on the forms used for input to this report are not confidential.

\section{Formulas}

Data from the FERC Form 423 are submitted at the plant level. These data are then used in the following formulas to produce aggregates and averages for each fuel type at the State, Census division, and U.S. levels.

For these formulas, let $\Sigma$ represent the summation of all plants in a geographic region. Costs for each fuel type are reported in cents per million Btu. Additionally,

- For coal, receipts (R) are reported in tons, and units for average heat content (A) are in Btu per pound, and the unit conversion (U) is 2,000 pounds per ton;

- For petroleum, receipts (R) are reported in barrels, and units for average heat content (A) are in Btu per gallon; and the unit conversion (U) is 42 gallons per barrel;

- For gas, receipts (R) are reported in thousand cubic feet (Mcf), and units for average heat content
(A) are in Btu per cubic foot, and the unit conversion (U) is 1,000 cubic feet per Mcf.

Total Btu $=\sum_{i}\left(R_{i} \times A_{i} \times U\right)$

Weighted Average Btu $=\frac{\sum_{i}\left(R_{i} \times A_{i}\right)}{\sum_{i} R_{i}}$

Weighted Average Cost $=\frac{\sum_{i}\left(R_{i} \times A_{i} \times C_{i}\right)}{\sum_{i}\left(R_{i} \times A_{i}\right)}$

Weighted Average Cost $=\frac{U \sum_{i}\left(R_{i} \times A_{i} \times C_{i}\right)}{\left(10^{8} \frac{\text { cents }}{\text { dollar }}\right) \sum_{i} R_{i}}$

For these formulas:

$i$ denotes a plant

$R_{i}=$ receipts for plant $i$

$A_{i}=$ average heat content for receipts, plant $i$

$U=$ unit conversion

$C_{i}=$ fuel cost in cents per million Btu, plant $i$

* "Unit" = short ton for coal, barrel for petroleum, and thousand cubic feet for gas.

\section{Rounding Rules for Data}

Given an $\mathbf{n}$ digit number with $\mathbf{r}$ digits to the left of the decimal and $d+t$ digits in the fractional part, with $d$ being the place to which the number is to be rounded and $t$ being the remaining digits which will be truncated, this number is rounded to $r+d$ digits by adding 5 to the $(r+d+1)$ th digit when the number is positive or by subtracting 5 when the number is negative. The $t$ digits are then truncated at the $(r+d+1)$ th digit. The symbol for a rounded number truncated to zero is *.

\section{CNEAF Data Revision Policy}

The Office of Coal, Nuclear, Electric and Alternate Fuels has adopted the following policy with respect to the revision and correction of recurrent data in energy publications:

1. Annual survey data collected by this office are published either as preliminary or final when first appearing in a data report. Data initially released as preliminary will be revised, if necessary, and declared final in the next publication of the data. 
2. All monthly and quarterly survey data collected by this office are published as preliminary. These data are revised only after the completion of the 12-month cycle of the data. No revisions are made to the published data before this.

3. The magnitudes of changes due to revisions experienced in the past will be included in the data reports, so that the reader can assess the accuracy of the data.

4. After data are published as final, corrections will be made only in the event of a greater than one percent difference at the national level. Corrections for differences that are less than the beforementioned threshold are left to the discretion of the Office Director.

A comparison of preliminary data published in the Electric Power Monthly versus final data published in this report is provided in Table C2 of the July 1993 issue of the Electric Power Monthly. The table provides an explanation of the magnitude of the data changes.

\section{Use of the Glossary}

The terms in the glossary have been defined for general use. Restrictions on the definitions as used in these data collection systems are included in each definition when necessary to define the terms as they are used in this report.

\section{Obtaining Copies of Data}

Upon EIA approval of the Electric Power Monthly, the data become available for public use on a cost-recovery basis. Computer listings are obtained by submitting a written request to:

\author{
Energy Information Administration, EI-521 \\ Forrestal Building \\ U. S. Department of Energy \\ Washington, DC 20585
}

These data are also available monthly on machinereadable tapes. Tapes may be purchased by using Visa, MasterCard, or American Express cards as well as money orders or checks payable to the National Technical Information Service (NTIS). Purchasers may also use NTIS and GPO depository accounts. To place an order, contact:

National Technical Information Service (NTIS)

Office of Data Base Services

U.S. Department of Commerce

5285 Port Royal Road

Springfield, Virginia 22161

(703) $487-4650$ 


\section{Glossary}

Anthracite: A hard, black lustrous coal, often referred to as hard coal, containing a high percentage of fixed carbon and a low percentage of volatile matter. Comprises three groups classified according to the following ASTM Specification D388-84, on a dry mineralmatter-free basis:

$\begin{array}{lllrr} & \begin{array}{l}\text { Fixed } \\ \text { Carbon } \\ \text { Limits }\end{array} & \begin{array}{r}\text { Volatile } \\ \text { Matter }\end{array} \\ & \text { GE } & \text { LT } & \text { GT } & \text { LE } \\ \text { Meta-Anthracite } & 98 & - & - & 2 \\ \text { Anthracite } & 92 & 98 & 2 & 8 \\ \text { Semianthracite } & 86 & 92 & 8 & 14\end{array}$

Ash: Impurities consisting of silica, iron, alumina, and other noncombustible matter that are contained in coal. Ash increases the weight of coal, adds to the cost of handling, and can affect its burning characteristics. Ash content is measured as a percent by weight of coal on an "as received" or a "dry" (moisture-free, usually part of a laboratory analysis) basis.

Barrel: A volumetric unit of measure for crude oil and petroleum products equivalent to 42 U.S. gallons.

Bbl: The abbreviation for barrel.

Bcf: The abbreviation for 1 billion cubic feet.

Bituminous Coal: The most common coal. It is dense and black (often with well-defined bands of bright and dull material). Its moisture content usually is less than 20 percent. It is used for generating electricity, making coke, and space heating. Comprises five groups classified according to the following ASTM Specification D388-84, on a dry mineral-matter-free (mmf) basis for fixed-carbon and volatile matter and a moist mmf basis for calorific value.

\begin{tabular}{|c|c|c|c|c|c|c|}
\hline & \multicolumn{2}{|c|}{$\begin{array}{l}\text { Fixed } \\
\text { Carbon } \\
\text { Limits }\end{array}$} & \multicolumn{2}{|c|}{$\begin{array}{l}\text { Volatile } \\
\text { Matter } \\
\text { Limits }\end{array}$} & \multicolumn{2}{|c|}{$\begin{array}{l}\text { Calorific } \\
\text { Value } \\
\text { Limits } \\
\text { Btu/lb }\end{array}$} \\
\hline $\begin{array}{l}\text { LV } \\
\text { MV }\end{array}$ & $\begin{array}{l}\text { GE } \\
78\end{array}$ & $\begin{array}{l}\text { LT } \\
86\end{array}$ & $\begin{array}{l}\text { GT } \\
14\end{array}$ & $\begin{array}{l}\text { LT } \\
22\end{array}$ & GE & LE \\
\hline HVA & - & $\begin{array}{l}18 \\
69\end{array}$ & 31 & $\begin{array}{r}51 \\
-\end{array}$ & $\overline{14000}$ & $\overline{-}$ \\
\hline HVB & - & - & - & - & 13000 & 14000 \\
\hline HVC & - & - & - & - & 10500 & 13000 \\
\hline $\begin{array}{l}\text { LV } \\
\text { MV } \\
\text { HVA } \\
\text { HVB } \\
\text { HVC }\end{array}$ & $\begin{array}{l}=L \\
=M \\
=H \\
=H \\
=H\end{array}$ & -vol & $\begin{array}{l}\text { atil } \\
\text { ile } \\
\text { ile } \\
\text { ille }\end{array}$ & $\begin{array}{l}\text { umir } \\
\text { bitt } \\
\text { bitt } \\
\text { bitt } \\
\text { bitt }\end{array}$ & $\begin{array}{l}\text { s coal } \\
\text { nous } c c \\
\text { nous } c c \\
\text { nous } c c \\
\text { nous } c c\end{array}$ & $\begin{array}{l}\text { oal } \\
\text { oal } \\
\text { oal } \\
\text { oal }\end{array}$ \\
\hline
\end{tabular}

Btu (British Thermal Unit): A standard unit for measuring the quantity of heat energy equal to the quantity of heat required to raise the temperature of 1 pound of water by 1 degree Fahrenheit.

Capacity: The full-load continuous rating of a generator, prime mover, or other electric equipment under specified conditions as designated by the manufacturer. It is usually indicated on a nameplate attached to the equipment.

Capacity (Purchased): The amount of energy and capacity available for purchase from outside the system.

Census Divisions: The nine geographic divisions of the United States established by the Bureau of the Census, U.S. Department of Commerce, for statistical analysis. The boundaries of Census divisions coincide with State boundaries. The Pacific Division is subdivided into the Pacific Contiguous and Pacific Noncontiguous areas.

Coal: A black or brownish-black solid combustible substance formed by the partial decomposition of vegetable matter without access to air. The rank of coal, which includes anthracite, bituminous coal, 
subbituminous coal, and lignite, is based on fixed carbon, volatile matter, and heating value. Coal rank indicates the progressive alteration from lignite to anthracite. Lignite contains approximately 9 to $17 \mathrm{mil}-$ lion Btu per ton. The contents of subbituminous and bituminous coal range from 16 to 24 million Btu per ton and from 19 to 30 million Btu per ton, respectively. Anthracite contains approximately 22 to 28 million Btu per ton.

Code of Federal Regulations: A compilation of the general and permanent rules of the executive departments and agencies of the Federal Government as published in the Federal Register. The Code is divided into 50 titles which represent broad areas subject to Federal regulation. Title 18 contains the FERC's regulations.

Coke (Petroleum): A residue high in carbon content and low in hydrogen that is the final product of thermal decomposition in the condensation process in cracking. This product is reported as marketable coke or catalyst coke. The conversion factor is 5 barrels (42 U.S. gallons each) per short ton.

Combined Cycle: An electric generating technology in which electricity is produced from otherwise lost waste heat exiting from one or more gas (combustion) turbines. The exiting heat is routed to a conventional boiler or to a heat recovery steam generator for utilization by a steam turbine in the production of electricity. This process increases the efficiency of the electric generating unit.

Consumption (Fuel): The amount of fuel used for gross generation, providing standby service, start-up and/or flame stabilization.

Contract Cost: The delivery cost determined when a contract is signed. It may be a fixed cost or a base cost escalated according to a given formula.

Contract Price: Price of fuels marketed on a contract basis covering a period of 1 or more years. Contract prices reflect market conditions at the time the contract was negotiated and therefore remain constant throughout the life of the contract or are adjusted through escalation clauses. Generally, contract prices do not fluctuate widely.
Contract Receipts: Purchases based on a negotiated agreement that generally covers a period of 1 or more years.

Cost: The amount paid to acquire resources, such as plant and equipment, fuel, or labor services.

Delivered Cost: The cost of fuel, free on board (f.o.b.) plant. Included is the invoice price of fuel, transportation charges, taxes, commissions, insurance, and expenses associated with leased or owned equipment used to transport the fuel.

Distillate Fuel Oil: A general classification for one of the petroleum fractions produced in conventional distillation operations. It is used primarily for space heating, on-and-off-highway diesel engine fuel (including railroad engine fuel and fuel for agriculture machin. ery), and electric power generation. Included are Fuel Oils No. 1, No. 2, and No. 4; and Diesel Fuels No. 1, No. 2, and No. 4.

Electric Plant (Physical): A facility containing prime movers, electric generators, and auxiliary equipment for converting mechanical, chemical, and/or fission energy into electric energy.

Electric Utility: An enterprise that is engaged in the generation, transmission, or distribution of electric energy primarily for use by the public and that is the major power supplier within a designated service area. Electric utilities include investor-owned, publicly owned, cooperatively owned, and government-owned (municipals, Federal agencies, State projects, and public power districts) systems.

Energy: The capacity for doing work as measured by the capability of doing work (potential energy) or the conversion of this capability to motion (kinetic energy). Energy has several forms, some of which are easily convertible and can be changed to another form useful for work. Most of the world's convertible energy comes from fossil fuels that are burned to produce heat that is then used as a transfer medium to mechanical or other means in order to accomplish tasks. Electrical energy is usually measured in kilowatthours, while heat energy is usually measured in British thermal units.

Energy Information Administration (EIA): An independent agency within the U.S. Department of Energy 
that develops surveys, collects energy data, and does analytical and modeling analyses of energy issues. The Agency must satisfy the requests of Congress, other elements within the Department of Energy, Federal Energy Regulatory Commission, the Executive Branch, its own independent needs, and assist the general public, or other interest groups, without taking a policy position.

Federal Energy Regulatory Commission (FERC): A quasi-independent regulatory agency within the Department of Energy having jurisdiction over interstate electricity sales, wholesale electric rates, hydroelectric licensing, natural gas pricing, oil pipeline rates, and gas pipeline certification.

Federal Power Commission: The predecessor agency of the Federal Energy Regulatory Commission. The Federal Power Commission (FPC) was created by an Act of Congress under the Federal Water Power Act on June 10, 1920. It was charged originally with regulating the electric power and natural gas industries. The FPC was abolished on September 20, 1977, when the Department of Energy was created. The functions of the FPC were divided between the Department of Energy and the Federal Energy Regulatory Commission.

FERC Guidelines: A compilation of the Federal Energy Regulatory Commission's enabling statutes, procedural and program regulations, and orders, opinions and decisions.

Firm Gas: Gas sold on a continuous and generally long-term contract.

Flue Gas Desulfurization Unit (Scrubber): Equipment used to remove sulfur oxides from the combustion gases of a boiler plant before discharge to the atmosphere. Chemicals, such as lime, are used as the scrubbing media.

Fossil Fuel: Any naturally occurring organic fuel, such as petroleum, coal, and natural gas.

Fossil-Fuel Plant: A plant using coal, petroleum, or gas as its source of energy.
Fuel: Any substance that can be burned to produce heat; also, materials that can be fissioned in a chain reaction to produce heat.

Gas: A fuel burned under boilers and by internal combustion engines for electric generation. These include natural, manufactured and waste gas.

Gas Turbine Plant: A plant in which the prime mover is a gas turbine. A gas turbine consists typically of an axial-flow air compressor, one or more combustion chambers, where liquid or gaseous fuel is burned and the hot gases are passed to the turbine and where the hot gases expand to drive the generator and are then used to run the compressor.

Generator Nameplate Capacity: The full-load continuous rating of a generator, prime mover, or other electric power production equipment under specific conditions as designated by the manufacturer. Installed generator nameplate rating is usually indicated on a nameplate physically attached to the generator.

Heavy Oil: The fuel oils remaining after the lighter oils have been distilled off during the refining process. Except for start-up and flame stabilization, virtually all petroleum used in steam plants is heavy oil.

Holding Company: A company that confines its activities to owning stock in, and supervising management of, other companies. The Securities and Exchange Commission, as administrator of the Public Utility Holding Company Act of 1935, defines a holding company as "a company which directly or indirectly owns, controls or holds 10 percent or more of the outstanding voting securities of a holding company" (15 USC 79b, par. a (7)).

Internal Combustion Plant: A plant in which the prime mover is an internal combustion engine. An internal combustion engine has one or more cylinders in which the process of combustion takes place, converting energy released from the rapid burning of a fuel-air mixture into mechanical energy. Diesel or gasfired engines are the principal types used in electric plants. The plant is usually operated during periods of high demand for electricity.

Interruptible Gas: Gas sold to customers with a provision that permits curtailment or cessation of service at the discretion of the distributing company under 
certain circumstances, as specified in the service contract.

Light Oil: Lighter fuel oils distilled off during the refining process. Virtually all petroleum used in internal combustion and gas-turbine engines is light oil.

Lignite: A brownish-black coal of low rank with high inherent moisture and volatile matter (used almost exclusively for electric power generation). It is also referred to as brown coal. Comprises two groups classified according to the following ASTM Specification D388-84 for calorific values on a moist materialmatter-free basis:

\begin{tabular}{ccc} 
& \multicolumn{2}{c}{ Limits Btu/lb. } \\
& GE & LT \\
Lignite A & 6300 & 8300 \\
Lignite B & - & 6300
\end{tabular}

MMBtu: An abbreviation for 1 million British thermal units, which is an energy or heating value measurement that is normally used for petroleum and gas applications.

Mcf: One thousand cubic feet.

Megawatt (MW): One million watts.

Megawatthour (MWh): One million watthours.

MMcf: One million cubic feet.

Natural Gas: A naturally occurring mixture of hydrocarbon and nonhydrocarbon gases found in porous geological formations beneath the earth's surface, often in association with petroleum. The principal constituent is methane.

Net Summer Capability: The steady hourly output, which generating equipment is expected to supply to system load exclusive of auxiliary power, as demonstrated by tests at the time of summer peak demand.
No. 2 Fuel Oil: A distillate fuel oil for use in atomizingtype burners for domestic heating or for moderate capacity commercial-industrial burner units. ASTM Specification D396 for this grade distillation specifies temperatures at the 90-percent poin $t$ of between 540 degrees and 640 degrees Fahrenheit, and kinematic viscosities between 2.0 and 3.6 centistokes at 100 degrees Fahrenheit.

No. 4 Fuel Oil: A fuel oil for commercial burner installations not equipped with preheating facilities; used extensively in industrial plants. This grade is a blend of distillate fuel oil and residual fuel oil stocks that conform to ASTM Specification D396 or Federal Specification VV-F-815C; its kinematic viscosity is between 5.8 and 26.4 centistokes at 100 degrees Fahrenheit. Also included is No. 4-D, a fuel oil for lowspeed and medium-speed diesel engines that conform to ASTM Specification D975.

Off-Peak Gas: Gas that is to be delivered and taken on demand when demand is not at its peak.

Other Gas: Includes manufactured gas, coke-oven gas, blast-furnace gas, and refinery gas. Manufactured gas is obtained by distillation of coal, by the thermal decomposition of oil, or by the reaction of steam passing through a bed of heated coal or coke.

Percent Difference: The relative change in a quantity over a specified time period. It is calculated as follows: the current value has the previous value subtracted from it; this new number is divided by the absolute value of the previous value; then this new number is multiplied by 100 .

Petroleum: A mixture of hydrocarbons existing in the liquid state found in natural underground reservoirs, often associated with gas. Petroleum includes fuel oil No. 2, No. 4, No. 5, No. 6; topped crude; Kerosene; and jet fuel.

Petroleum Coke: See Coke (Petroleum).

Petroleum (Crude Oil): A naturally occurring, oily, flammable liquid composed principally of hydrocarbons. Crude oil is occasionally found in springs or pools but usually is drilled from wells beneath the earth's surface. 
Plant: A facility at which are located prime movers, electric generators, and auxiliary equipment for converting mechanical, chemical, and/or nuclear energy into electric energy. A plant may contain more than one type of prime mover. Electric utility plants exclude facilities that satisfy the definition of a qualifying facility under the Public Utility Regulatory Policies Act of 1978 .

Price: The amount of money or consideration-in-kind for which a service is bought, sold, or offered for sale.

Prime Mover: The motive force, i.e., steam, engine, turbine, or water that drives an electric generator.

Receipts: Deliveries of fuel to an electric plant.

Residual Fuel Oil: The topped crude of refinery operation, includes No. 5 and No. 6 fuel oils as defined in ASTM Specification D396 and Federal Specification VV-F-815C; Navy Special fuel oil as defined in Military Specification MIL-F-859E including Amendment 2 (NATO Symbol F-77); and Bunker C fuel oil. Residual fuel oil is used for the production of electric power, space heating, vessel bunkering, and various industrial purposes. Imports of residual fuel oil include imported crude oil burned as fuel.

Restricted-Universe Census: This is the complete enumeration of data from a specifically defined subset of entities including, for example, those that exceed a given level of sales or generator nameplate capacity.

Short Ton: A unit of weight equal to 2,000 pounds.

Spot Purchases: A single shipment of fuel or volumes of fuel, purchased for delivery within 1 year. Spot purchases are often made by a user to fulfill a certain portion of energy requirements, to meet unanticipated energy needs, or to take advantage of low-fuel prices.

Steam-Electric Plant (Conventional): A plant in which the prime mover is a steam turbine. The steam used to drive the turbine is produced in a boiler where fossil fuels are burned.

Stocks (Fuel): A supply of fuel accumulated for future use. This includes coal and fuel oil stocks at the plant site, in coal cars, tanks, or barges at the plant site, or at separate storage sites.

Subbituminous Coal: Subbituminous coal, or black lignite, is dull black and generally contains 20 to 30 percent moisture. The heat content of subbituminous coal ranges from 16 to 24 million Btu per ton as received and averages about 18 million Btu per ton. Subbituminous coal, mined in the western coal fields, is used for generating electricity and space heating.

Sulfur: One of the elements present in varying quantities in coal which contributes to environmental degradation when coal is burned. In terms of sulfur content by weight, coal is generally classified as low (less than or equal to 1 percent), medium (greater than 1 percent and less than or equal to 3 percent), and high (greater than 3 percent). Sulfur content is measured as a percent by weight of coal on an "as received" or a "dry" (moisture-free, usually part of a laboratory analysis) basis.

Surface Mine: A coal-producing mine that is usually within a few hundred feet of the surface. Earth above or around the coal (overburden) is removed to expose the coalbed, which is then mined with surface excavation equipment such as draglines, power shovels, bulldozers, loaders, and augers. It may also be known as an area, contour, open-pit, strip, or auger mine.

System (Electric): Physically connected generation, transmission, and distribution facilities operated as an integrated unit under one central management, or operating supervision.

Turbine: A machine for generating rotary mechanical power from the energy of a stream of fluid (such as water, steam, or hot gas). Turbines convert the kinetic energy of fluids to mechanical energy through the principles of impulse and reaction, or a mixture of the two.

Underground Mine: A mine where coal is produced by tunneling into the earth to the coalbed, which is then mined with underground mining equipment such as cutting machines and continuous, longwall, and shortwall mining machines. Underground mines are classified according to the type of opening used to reach the coal, i.e., drift (level tunnel), slope (inclined tunnel), or shaft (vertical tunnel). 
Unit Train: A train consisting of approximately 100 to 110 hundred-ton coal cars that is dedicated solely to transporting coal from a specified loading facility to a specified customer.
Watt: The electrical unit of power. The rate of energy transfer equivalent to 1 ampere flowing under a pressure of 1 volt at unity power factor.

Watthour (Wh): An electrical energy unit of measure equal to 1 watt of power supplied to, or taken from, an electric circuit steadily for 1 hour. 

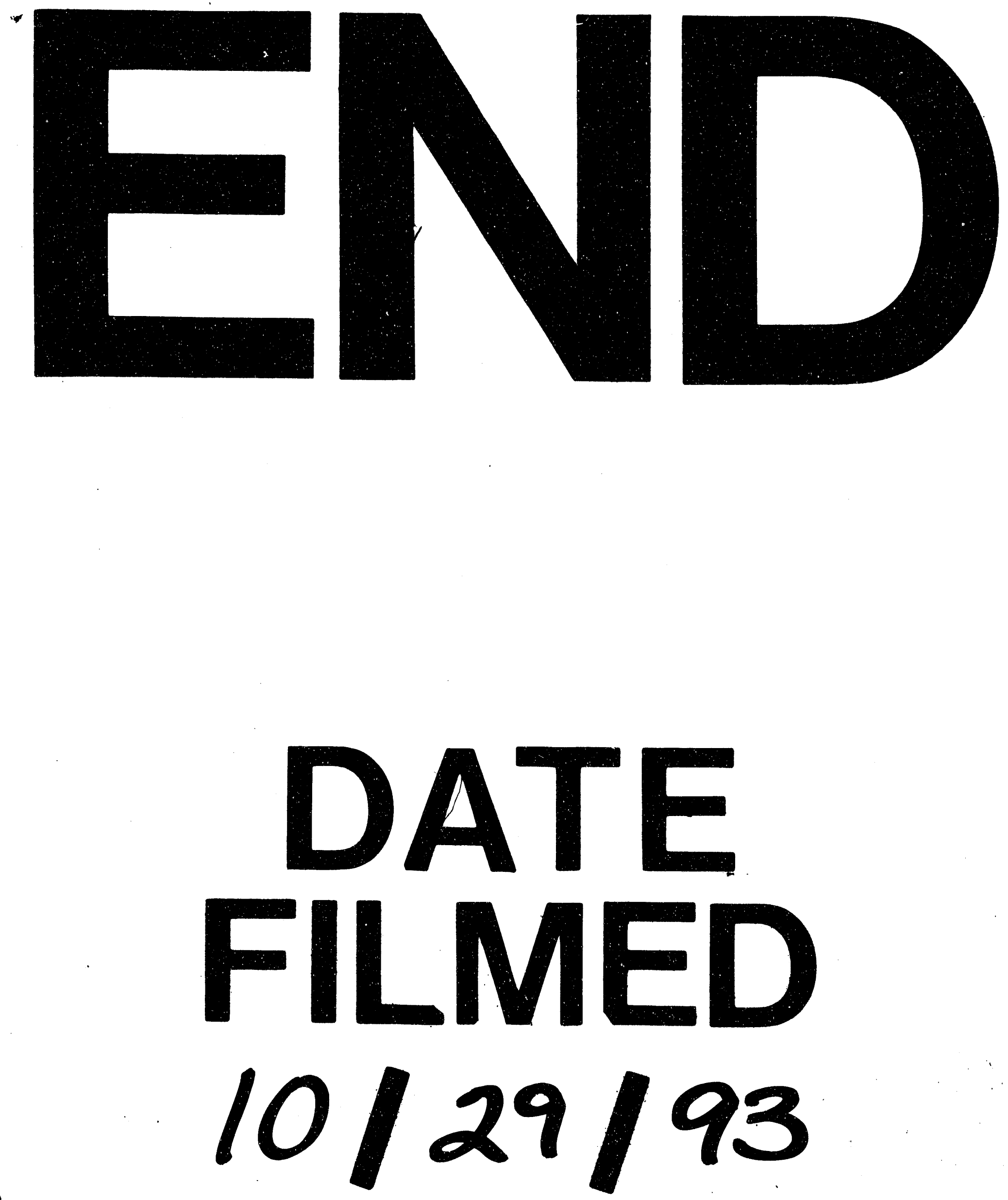